\title{
POSTWAR WOMEN 1945-1960 AND
} THEIR DAUGHTERS 1970-1985

AN ANALYSIS OF CONTINUITY, CONTRADICTION, AND CHANGE

IN TWO GENERATIONS OF PAKEHA WOMEN AS MOTHERS, WIVES, AND WORKERS

\author{
HELEN MAY .
}




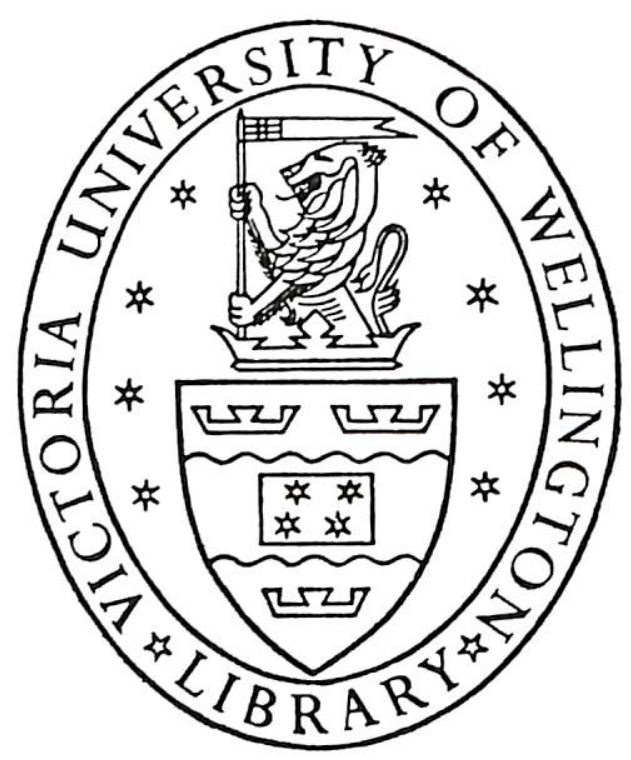




\section{VICTORIA UNIVERSITY OF WELLINGTON}

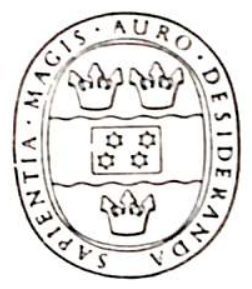

\section{AVAILABILITY OF THESIS}

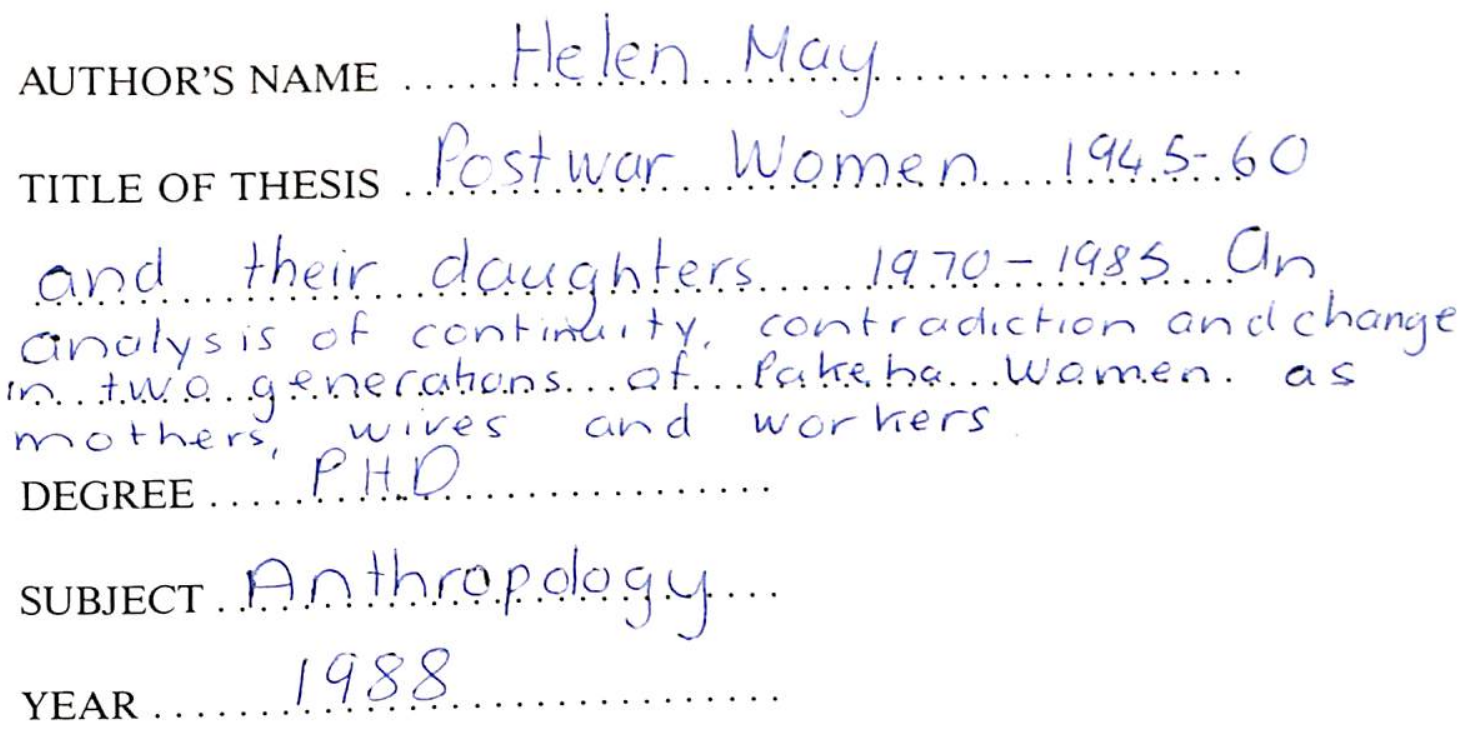

I hereby consent to the above thesis being consulted, borrowed, copied or reproduced in accordance with the provisions of the Library Regulations from time to time made by the Professorial Board.

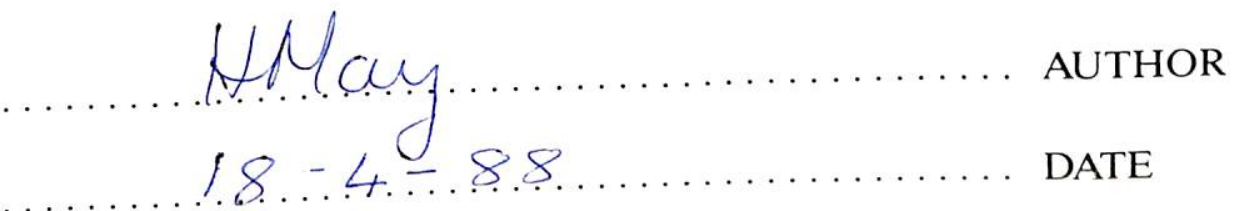



POSTWAR WOMEN 1945-60

AND

THEIR DAUGHTERS 1970-1985 



\title{
POSTWAR WOMEN 1945-1960 \\ $A N D$ \\ THEIR DAUGHTERS 1970-1985
}

\author{
AN ANALYSIS OF CONTINUITY, CONTRADICTION, AND \\ CHANGE \\ IN TWO GENERATIONS OF PAKEHA WOMEN \\ AS MOTHERS, WIVES, AND WORKERS
}

Helen May

A thesis submitted to Victoria University of Wellington

in fulfilment of the requirement for the degree of Doctor of Philosophy in Anthropology

Victoria University of Wellington 1988 


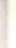




\begin{abstract}
The period of this study covers two generations of New Zealand social history and traces the context of life for two groups of Pakeha women during their childrearing years. It is not a compare and contrast exercise as the changes between generations are cumulative, as well as being variable amongst different groups of women. The women in this study from both generational groups, had much in common, in that they all had the primary responsibility for childrearing and were all economically dependent on their men for periods of time. However, alongside the commonality of experiences between the two groups of women there were differences. Not only were their experiences affected by different economic and political events, but there were identifiable shifts in the ideological frameworks through which the women ascribed meaning to their experiences. It was evident that the frameworks which were so pervasive in defining femininity in the early postwar years were seen as the norm by both groups of women, and the changing perspective of the younger women as a departure from the norm. This retrospective aura of normality surrounding in particular, the decade of the 1950's, is understandable when viewed in its historical context, but it is also misleading. Set between a decade of war and reconstruction and a decade of the 1960's when many values were challenged, it has been tempting for later generations to see the apparent order and consensus of the 1950's as a measure of normality. The years before and after the 1950's have appeared by comparison as more confusing. The argument of this study is that the apparent diversification in lifestyles was not just a post 1960's phenomena but had in fact taken root much earlier and that New Zealand society in the early postwar years operated in such a way to cover up the diversity and the changing social patterns that were already present. In particular this study seeks to show how women have attempted to redefine the boundaries of their responsibilities and spheres of interest during this period: a process which revealed more explicitly the conflict of interest for women between self - in terms of seeking autonomy, and others - in terms of dependence upon their men and their responsibility for children. The context of this redefinition is explored within three interconnected "sites" of the family - motherhood, marriage and work, and over the forty year period of this study it is possible to identify shifts in the construction of what is acceptable and possible, as women individually in the home and collectively outside of it, renegotiated and broadened the boundaries that defined their femininity.
\end{abstract}




\section{ACKNOWLEDGEMENTS}

This work is dedicated to my mother Nola Bradwell and my daughters Sarah Cook aged eleven, and Nell May aged two. We represent three generations of New Zealand Pakcha women and this study began through my reflections on our lives. In particular I have appreciated the many insights which my mother has provided for me of her life before I can remember.

I wish to acknowledge the following people for their support in many different ways:

My son Julian, now thirteen years old, who, as my first child, first caused me to face the joys and difficulties of motherhood in our society.

Crispin Gardiner, for his love and support throughout the years of work on this thesis. For his proof reading and endless technical expertise on our computer. And for Nell, our daughter who was three weeks old when I began writing and twenty months when I finished.

Mrs Nell, and later the staff of the Lintott's baby nursery, who provided my infant Nell with so much love and care while I wrote and worked.

My father Cyril Bradwell's historical interest in the topic, his help with readings, and proof reading.

The twenty-five women who sadly can't be named but who allowed me to talk with them about their past lives. I am indebted to their honesty, insight and friendship that emerged during this work.

My supervisors Professor Ann Chowning and Dr James Urry who were most supportive and tolerant of their long distance student, and whose editorial advice was much appreciated.

Professor Jan Pouwer of Nijmegen University in Holland, but previously from Victoria University, who spent time helping me order the diverse strands of this material.

The James McIntosh Research Scholarship in Education and the Sarah Anne Rhodes Scholarship which supported me financially for three years.

My colleagues in the Education Department of the University of Waikato and more recently in the Hamilton Teachers College who gave me support.

The late Rosemary Seymour who allowed me the use of her valuable collection of cuttings and memorablia of the 1970's, and Dr David Swain who gave me access to his Parenting Files. Both collections are housed at Waikato University.

Many friends who have found the topic interesting, in particular Sue Middleton who always had her eye out for material that might be of use. 
TABLE OF CONTENTS

Chapter

One:

A Personal Prologue

Two:

Introduction

8

Three:

The Childrearing Years

15

Part One: A Shifting Focus

Part Two: A New Zealand Overview

Part Three: The Overseas Connection 28

Four: The Process of the Research 32

Part One: $\quad$ A Life History Approach 33

Part Two: $\quad$ Prescriptive Ideology 38

Part Three: The Empirical and Historical $\quad 42$

\section{Section One \\ A POSTWAR GENERATION OF MOTHERS, WIVES, AND WORKERS: \\ 1945-1960}

Five:

The Forerunners of the "Goodlife"

The Great War

The Depression 49

The Labour Victory 54

World War Two

Six:

The Context of Living 1945-1960: Dreams of a New Order 65

Political Shifts and Establishing Order

Economic Prosperity and the Rewards of Order

The Family as a Symbol of Order and Security

Women as Equal but Different to Men: a Contradictory Order

An Ideology of Childrearing as a Tool Towards Order 84

Seven: Text One: A Paper Dialogue 1945:1960 93

Part One 1945-1950 The Aftermath of War $\quad 95$

Rehabilitating the "Returned Men" 96

The Population Problem 99

Housewife Protests 103

Part Two 1950-1960 Recipes of Harmony 106

$\begin{array}{ll}\text { The "Art" of Marriage as a Career } & 107\end{array}$

"The Lady Juggler" 114

$\begin{array}{ll}\text { Motherhood as a Career } & 124\end{array}$ 
Eight: Text Two: A Personal Reality 1945-1960

Part One "Accomodation and Resistance": Aspiration versus Reality

Part Two Coping With Disorder 142

Marriage For Better or Worse 143

$\begin{array}{ll}\text { Coping Alone and Mothers Take the Blame } & 147\end{array}$

$\begin{array}{ll}\text { The Silent Issues } & 151\end{array}$

$\begin{array}{ll}\text { Part One } \quad \text { The Priorities of Work } & 158\end{array}$

$\begin{array}{ll}\text { A Working Wife } & 159\end{array}$

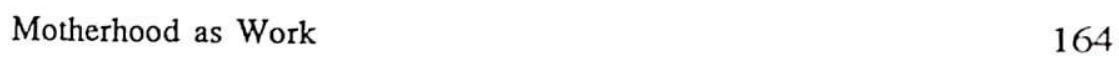

$\begin{array}{ll}\text { Voluntary Work and Working for Change } & 168\end{array}$

Section Two

A POSTWAR Generation OF DAUghters AS MOTHERS, WIVES, AND WORKERS 1970-1985

Nine: The Years Between 1960-1970 175

The Social Face 176

A Youth Culture 176

An Ideology of Equal Opportunity $\quad 179$

A Sexual Revolution $\quad 185$

A "Sick" Society 193

Ten: The Context of Living 1970-1985: New Dreams and Challenges

A Changing Political and Economic Order 202

Changing Families 209

The Challenge of the Women's Movement 214

Children Have Rights Too 220

Conservative Concerns 225

Eleven: Text One: A Paper Dialogue 1970-1985 228

"Libbers" and "Cabbages" 229

Undermining Marriage 232

Challenging Motherhood 242

A Double Load 256

Twelve: Text Two: A Personal Reality 1970-1985 274

$\begin{array}{ll}\text { Part One: } & \text { "Accomodation and Resistance": Aspiration Versus } \\ & \text { Reality }\end{array}$ 
Managing to Stay Married 284

$\begin{array}{ll}\text { Managing Alone } & 290\end{array}$

The Silent Issues $\quad 294$

Part Three: The Changing Perspectives of Work 398

Work - Independence - Fulfilment - and an End in Itself 399

Working at Motherhood 306

Working for Change $\quad 313$

$\begin{array}{ll}\text { Thirteen: A Concluding Overview } & 320\end{array}$

References for Graphics and Cartoons. 332

Bibliography 334 



\section{A PERSONAL PROLOGUE}

Research is a process which occurs through the medium of a person. The researcher is always and inevitably present in the research...To paraphrase a slogan once current in the gay movement, researchers must "come out" in their writings (Stanley and Wise 1981:179).

Liz Stanley and Sue Wise (1981:153) coined the term "hygienic" as a criticism of research which proceeds untainted by the emotions and subjective experiences of the researcher, and they distinguish between "research as it is described" and "research as it is experienced". This study has strong elements of the second variety. My life has helped shape the research topic, but at the same time the research has been dominating the way I organise my life, and been changing what I see and feel. Ann Oakley writes:

A feminist methodology of social science requires that the mythology of "hygienic research"...be replaced by the recognition that personal involvement is more than dangerous bias - it is the condition under which people come to know each other and to admit others into their lives (1981:58).

As a feminist I begin with the maxim "the personal is political" and this is so within my own life and the way I view the lives of the women who are part of this research. The sharing of everyday experiences by women; the locating of politics within the everyday minutiae - and the process of "naming" (Friedan 1963; Rowbotham 1973; Spender 1981) have become the essence of the politics and research of the current women's movement. Previous to the emergence of a feminist critique of research, the subjective data that revealed the contradictions women experienced in their role as wives and mothers were often ignored as valid material. For example, Susan Shipley wrote of the experience which triggered her research on women's unemployment:

I was angry about my own unemployment and that of tens of thousands of other women in New Zealand...I soon established that in New Zealand and overseas women's unemployment was not taken seriously as an issue for social research. The prevailing view in society at large was that it was women's employment which was the problem! (1984:12).

It was not so much anger that triggered this study as a sense of wanting to reflect on the differences between my life as a woman, a mother and a wife in New Zealand and that of my mother's life in the same roles, in the early postwar period. This was the beginning and although the analysis goes beyond the circumstances of both our lives, they are inevitably a part of the pattern that this study shows.

\section{A POSTWAR GENERATION}

Those of us in our thirties belong to a special generation. Labeled as the postwar "bulge" we were born to celebrate the return of family life...and the golden future...Now we've grown up we're no longer the the younger gencration. We are the responsible ones now, who characterize the conventions of the society we live in (Ingham 1981:12). 
Mary Ingham wrote this in her book Now we are Thirty which she began in 1976, when she and her female peers born in 1946 turned thirty. Against the backdrop of British postwar society she wonders how these women had resolved the dilemma of marriage and work, children and independence. Despite the geographic distance from Britain a great deal she said felt familiar to a Pakeha New Zealander, and she stirred memories of childhood in the 1950's alongside the cold war politics; adolescence in the 1960's amidst various sexual and political revolutions; and adulthood and childrearing in the 1970's as an adjunct to the women's movement. When we moved into marriage and childrearing (or if we did), these gave us new frameworks with which to assess our lives that were different from the way our mothers saw their lives, or their expectations of us. Ingham was not seeking explanations, or analysing why, but describing with humour and insight the dilemmas and options of the conflicting ideals she had been raised upon. In 1986 this generation started turning forty and for many of the women the intensity of the childrearing years were passing. Some of the male half of this postwar generation began moving into positions of political and economic power. The female half trail behind but we are more active in these arenas than our mothers were. We are middle aged, and as our parents move towards old age the time seems appropriate to delve deeper in to the female dimension of these forty years in which both of us have lived.

The lives of my mother and myself span from the end of the World War One until the present. Like me she was born at the end of "a war to end all wars". At the time of our births idealism was high and new lives signified a break from old values and hopefully a better life ahead. Unfortunately for my mother things got worse and her family were to suffer in the depression, and then there were the separations and deprivations of another war. These experiences, common to her generation, were to impact on my own. Our mothers' lives had been constrained by economic and political circumstances beyond their control and they determined that in the peace and prosperity of postwar living their children would have more options. We grew up breathing the air of these ideals, but the caution and scars from the depression and war permeated postwar social, economic and political scenarios. It: is only now in the mid 1980's, as this postwar generation of children has begun to move into positions of power within the political and economic system, that our lives are being re-ordered around frameworks in which a 1930's depression and a 1940's war are seen as distant and irrelevant concerns.

\section{POSTWAR CHILDHOOD}

My parents came from working class families. The period of my childhood, however, was a period of slow upward mobility for them as they gradually acquired their own home, car and household appliances. Their marriage was probably a delayed one. They were parted for five years by a war, and married soon after my father was demobilised. Nine months later I was 
conceived, but however unique my birth in 1947 might have been for my parents, they soon realised that they were participants in something bigger. There were not only queues to get beds in maternity hospitals, but pressures on all services for children.

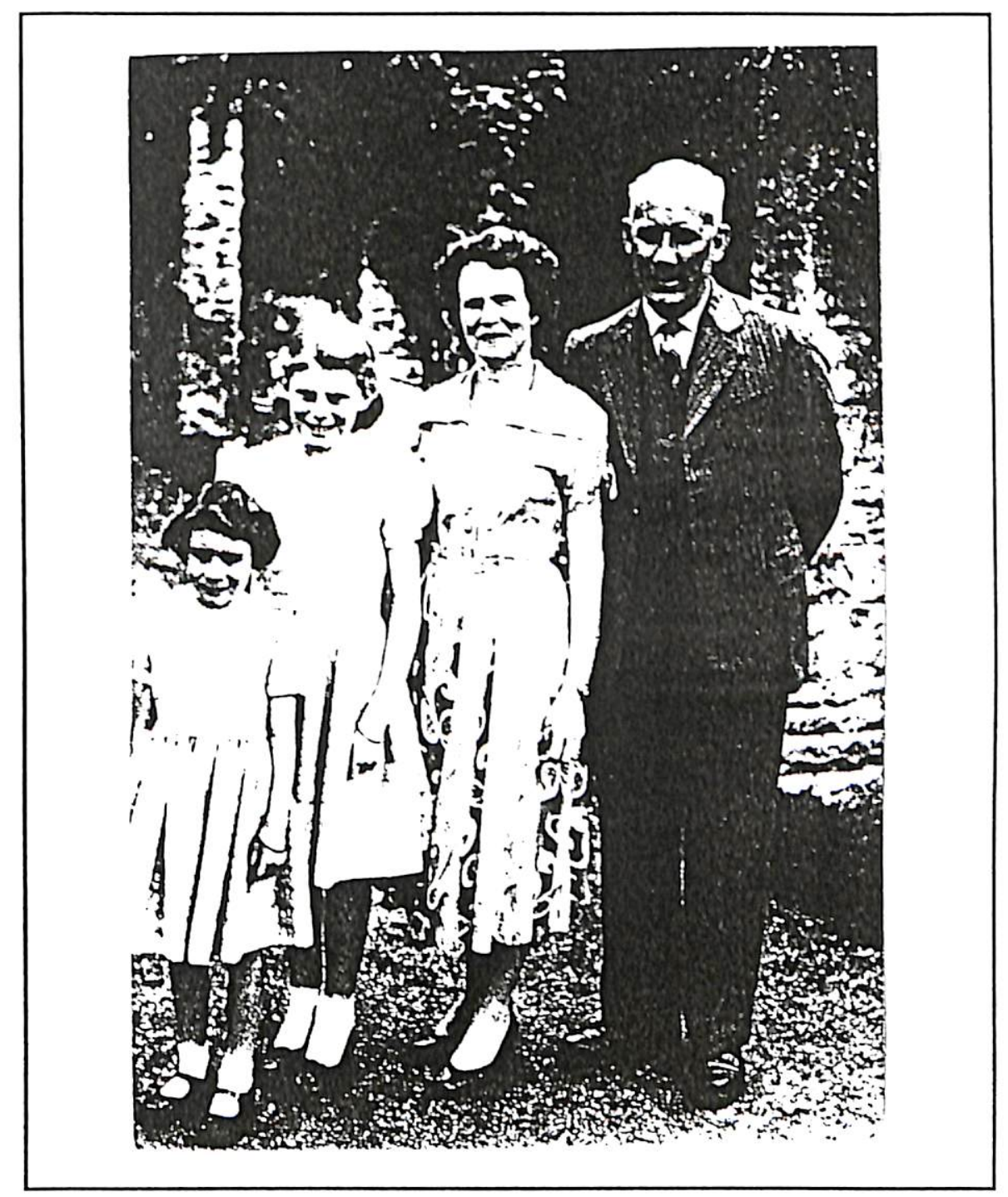

Our births fell along a line that divided an era of privation, separation and disorder, from an era of comparative prosperity, social order and confidence in family life. We were healthier and better educated than any previous generation of New Zealanders. This was made possible by a society which had full employment and put a high political priority on an ordered family life. Policies and services were designed to support the material well-being of families, and also to uphold the ideal of the nuclear family with a full-time mother and a male breadwinner. There were still problems but in the main they were seen as private family issues to be dealt with accordingly. It was not until later that the hidden dysfunctions of family life such as suburban neurosis, matcrnal depression, mid-life crises, and solo mothers, were categorised as social ills demanding collective responsibility and action, rather than private problems bringing family shame and withdrawal. This transformation began in the 1960's. 
In 1960 the 1947 baby boom children swelled into the secondary education system. Many of us moved into schools built amidst new suburbs, which borrowed the trappings and traditions of the old stone and brick city schools. I was part of a generation in which there were new educational opportunitics for girls (Middleton 1985b; Becby 1986), in which a prospering economy needed our labour. Girls dallied with the dilemmas of whether it should be "typing, nursing or teaching", with no worries about unemployment. Officially we were educated as equals with boys and imbued with ideals of independence and carecrs, but the double standard operated and being equal was also being different (Middleton 1985b). There were jobs for girls and jobs for boys. We also carried with us traditional notions of femininity that motherhood as a career was our destiny. Employment was an interim step before motherhood and/or something to return to later. We were educated in the belief that new Zealand was an egalitarian society, but there were some obvious distinctions. For example, some girls got "jobs" when they left school whereas those of us who had passed our School Certificate examinations were suppose to choose "careers", in the sense that there was some kind of vocation implied or training involved. The division was not so neat but was a reflection of a new kind of class division emerging. I eventually chose teaching and unwittingly became part of the "reserve army" of women teachers (Middleton 1985b) who were recruited into teaching in the 1960's, pushed out in the 1970's as school rolls declined, and then wooed again in the 1980's as teacher retention waned.

Our teenage years coincided with the beginnings of the so called sexual revolution, and such shyness we had as teenagers towards our sexuality was hidden beneath a veneer of rather misinformed worldly knowledge. While our parents had grown up with a dearth of sexual knowledge, they thought we should be more informed, but this went only as far as allowing some knowledge of "the facts of life" with the prayer that we would not get pregnant. While our parents used contraception, its commercial availability in the pill form coincided with our own adolescent sexuality. This did not prevent the upsurge in teenage pregnancies of the 1960 's as contraceptives were designated only for married couples. Our friends quietly and tragically left school and town to await their babies alone, then have them adopted. Many followed the long tradition of a quick wedding but for the rest of us our sexual life was a series of decisions as to "how far we should go". While our boyfriends publicly notched up the advances towards the "ultimate plunge", we wondered whether or not to wait for Mr Right. It was suppose to be the time of the sexual revolution yet there was still a division between the ribaldry of late night readings of the Kama Sutra and the wall of silence surrounding back seat passions. Some girls held out in order to be virgins at their wedding. Most, at least among my acquaintances, had sexual relationships that they kept clandestine so that they would not offend parents or friends, before eventually marrying. Open pre-marital sexuality was only for a few. It is difficult to assess the changes in pre-marital sexuality between my mother's generation and my own, although the birth statistics show that pre-marital sex has been quite common all 
this century (Levesque 1986). This issue is addressed later in this study, but using the evidence of my case study material, one could suggest there was less value placed on virginity by the women of my generation than previously. More knowledge, more open attitudes to sexuality and the availability of contraception encouraged more women towards clandestine pre-marital sexual activity during the mid to late 1960's. By the mid 1970's there was a further shift towards more open pre-marital sexuality.

By the late 1960's we had arrived at the same point our parents had after the war. Marriage for me at twenty-one was not much of a change in lifestyle, and unlike my mother, I did not bear a child for another six years. My work as teacher continued and fortunately was transportable as my husband's employment shifted. The household chores were shared, and it was a time of uneasy equality until motherhood tipped the balance of in/dependence. My story is common enough but I did not always fit the trends of my peers. I wish I had been less shy, more permissive, more political, but like many of my friends watched with a certain support and excitement the political and cultural happenings of the late 1960's and early 1970's, but left it to others to forge new life-styles, and to challenge the outdated values. For me it was the experience of childrearing that shook the complacency and stirred the consciousness, forcing me to look at myself, my society and my part in it. This process was set against the backdrop of the 1970's women's movement. The birth of Julian in 1974, and then Sarah in 1977 was to create a new lifestyle for me in trying to balance the roles and responsibilities of being a wife, a woman, a mother and a worker: of managing to fulfil none as well as they ought to be; of coming to know the political, economic, ideological and social contradictions within my roles and relationships; of feeling the inequity of my life as a woman; of wanting change in my life and in society; but also of wanting an emotional stability and being reluctant to rock the boat in all directions - to overturn order I knew for uncertainty. In $1983 \mathrm{I}$ did. I left my marriage and job, shifted town\$ established a new relationship, and in 1986 had another child, thus starting the cycle of uncertainty and dilemma again.

\section{MY MOTHER'S DAUGHTER}

My parents appear so far as the shadowy figures who gave birth to me in 1947. However our lives were lived together in the same house for nineteen years, and the contact is still there. But what do I know about their lives beyond our common connections? Virginia Woolf wrote:

Of our fathers we know always some fact, some distinction They were soldiers; they filled that office or they made that law. But of our mothers, our grandmothers, our great grandmothers what remains? Nothing but a tradition. One was beautiful, one was red haired; one was kissed by the Queen. We know nothing about them except their names and the dates of their marriages and the numbers of children they had (Quoted in Payne 1983:xv).

I was reared by my mother. My father was was either at work as a teacher, or when at home rather remote from the domestic business that I knew as life. Yet I grew up against a 
backdrop of the achievements of my father's life. He was to be the model of academic excellence, physical prowess and musical skills, and "Is she going to be like her father?" was heard by me as a kind of praise. My mother was said by her friends and my father to be a good woman, in the sense of being a hard worker, a good daughter, a good wife, a good mother and above all an exemplary housekecper. But it was my father who was the example presented to me of what hard work could achieve, although it was through my mother's interest and energies that I acquired the skills of reading, writing and conversation. I was to be my father's daughter through my mother's work and energy. However the unspoken expectation was that as well as matching my father's achievement I would also take on board the unsung feminine accomplishments of my mother. The contradictions of this double inheritance were to simmer away for many years to surface into open conflict when career and education were pitted against my childrearing role.

Women of my generation grew up viewing our mothers as unfortunate to have lived through a depression and a war, and were sometimes critical that they had appeared to opt for such a quiet life. They seemed to invest their energy into their husbands and their children and let them take the plaudits. In contrast we did not seem so prepared to put such a heavy personal investment into our men, our homes, and our families, yet were to feel guilty when these responsibilities did not seem to be managed as smoothly as we thought our mother's had done. I grew up believing too, that it was my generation of women who were forging change for women, while my mother's generation had been happy at home after the penalties of depression and war. Olssen and Levesque wrote about this generation of women:

(They) had imbibed the ideals of domesticity and true womanhood with their mothers' milk; they had accepted the separate spheres; but the reality had been two world wars, one major depression of almost ten years, and the uneasy 1920's. Emotionally one suggests these people hungered for a period of quiet suburban life (1978:18).

This is the view we have accepted and perpetuated, but as this study will show my mother was rearing me in a period of change; a time of postwar reconstruction, idealism, new opportunities for women, and a working towards the "good life". It was only in my late thirties I began acknowledging the continuity, rather than the discontinuity, between my mother's life and my own.

This study began as a comparative analysis between two generations of women whose lives seemed to have different priorities, but the neatness of such a comparative story is a distortion. The lives of women in my mother's generation were characterised by missed opportunities and apparent selflessness, but they also had lives the history book never wrote about, and we never heard about. Our mothers' pragmatic idealism, and "make-do" ingenuity, were trivialised by themselves and taken for granted by our fathers. The changes within the community and the family that they forged during the 1940's and 1950's were deemed to be secondary to the "citizenry" endeavours and breadwinning status of our fathers. Our fathers' exploits in war and postwar reconstruction have been remembered and written about but our 
mothers' endeavours, "live" only in the context that "they kept the home fires burning". This study presents evidence of these other lives which exist alongside the public version. It is also an analysis of the lives of women of my generation, although unlike my mothers' generation our lives have received the attention of a growing body of research and writing. This study, while focussing on each generation separately, seeks to give an overview of the changing context of Pakeha women's lives in New Zealand's postwar society. The lives of many Maori women during this time have been lived between two cultural codes, particularly as during the postwar period increasing numbers of Maoris immigrated to urban areas and their children grew up in an urban environment distant from the agrarian rurality of their parents and ancestors. For the first time many Pakehas and Maoris have met and mixed in the workplace, schools, shops and suburbs. This probably had little impact on the majority of Pakeha women except producing a kind of avoidance, or for sone in gaining a deepened awareness of cultural or racial issues. For Maori women however, the impact of this "mixing" has been enormous, but as such deserves an analysis separate from the particular focus of this one. 


\section{INTRODUCTION}

\section{AN ANTHROPOLOGICAL PERSPECTIVE}

My academic life has always been a fringe activity to the business of carning a living. My undergraduate years were squeezed around the demands of a teaching carecr where Headmasters and School Inspectors looked askance at someone who chose to study anthropology rather than education, and who was foolish enough to construct a degree without any "teaching" subjects, and who chose to remain in the early childhood area with academic qualifications. Later I decided to taste the academic version of education and gained a postgraduate degree in education and an M.A. This time my anthropological training was to focus in ways that seemed distant to what was being defined as education. I was a sideline educationalist and the fact that by that time I worked in childcare, the poorest relation in the educational community, brought dubious status. Its children were the smallest, and because they also needed to be fed, changed and rested most saw little "education" in it. "Childcare" however was considered an appropriate topic for an M.A. thesis in education, although it was jointly supervised by the Anthropology Department and partly funded by a scholarship in Women's Studies. As the topic for the doctorate evolved, a debate started in the Education Department as to who could supervise it. The men looked askance at the topic of motherhood which they did not define as a "real educational institution". The only women in the Department were psychologists and I was looking at different things. It was back to Anthropology again: the topic did fit their frameworks and they did have the supervisors, but they were to wonder if I could really give an anthropological focus to the topic. I still straddle the fence. My doctoral research is in anthropology; I work in education. The division is arbitrary as I pull in threads from many disciplines: anthropology, women's studies, history, education, and sociology. Despite this, anthropology is the context for beginning this research. The topic is about women but the process is about how women order and manage everyday life amidst the frameworks of sexgender in New Zealand.

It was Margaret Mead who brought attention to to the diversity of cultural expressions of sex-gender systems. She wrote:

Men may cook or weave or dress dolls or hunt humming birds, but if such activities are appropriate occupations of men, then the whole society, men and women alike, votes them as important; when the same activities are performed by women they are less important (1950:157).

Since the 1970's, and as an adjunct to the growth of women's studies, there has been a growing body of anthropological research analysing gender and sexual inequality (Rosaldo and Lamphere (ed) 1974; Reiter (ed) 1975; MacCormack and Strathern (ed) 1980; Ortner and Whitehead (ed) 1981). The cross cultural ethnographic evidence may suggest to some the universality of male dominance (Rosaldo and Lamphere 1974; Kessler 1976), but there is disagreement over the idea of universal male dominance (Bourguignon 1980), and more so over 
the usefulness of universality itself as a concept for analysis (Novitz 1979). A more recent and perhaps more useful focus has been to analyse the social construction of male-female roles and relationships in different societies (Ortner and Whitehead 1981). It is a focus on process and understanding rather than on the explanation of causality. Ortner and Whitehead wrote:

What gender is, what men and women are, what sorts of relationships do or should obtain between them....are largely products of social and cultural processes (1981:1).

It is the context of this relationship amongst my own peers and parents in my own society that underlies the following analysis.

The specific focus of this study is on how a group of twenty-five Pakeha women have ordered their lives and relationships as mothers, workers and as wives. Twelve of the women were rearing children in the immediate postwar years of the 1940's-50's, and thirteen were rearing their children during the 1970's-80's. Their spoken experiences are the primary data. These are firstly set alongside media representations and analysis from the N.Z. Woman's Weekly and the N.Z. Listener. This material was a part of the "cultural processes" (Ortner and Whitehead 1981) in the sense that it was both a product of particular values and a producer of norms. It showed the changing prescriptions between acceptable and unacceptable social action for women. Secondly, in relation to the social context of relations, the spoken experiences from women are set alongside a general overview of the shifting trends in New Zealand's social, political and economic life in the postwar period. This is an era in which the "good life" of material prosperity was grasped and experienced by more of the population than before, and the Quest for Security (Sutch 1966) as part of the myth of the "good life" has been a powerful and accommodating ideal in New Zealand society (Shuker 1983).

This study uses a life history method which focuses on both social structure and the individual. People are not seen as passive victims but as creative subjects who devise strategies to deal with or resolve the contradictions within the wider structures. As Plummer states:

(The life history method) is particularly suited to discovering the confusions, ambiguities and contradictions that are played as everyday experience (1983:3).

My usage of the concept of contradiction follows that of Anthony Giddens in which he distinguishes between conflict and contradiction. Conflict occurs on "the level of social practices" (1979:131), whereas contradiction relates to the "structural components of social systems" (1979:141). The life histories portray the interpersonal conflict, role conflict and ideological conflict that, in part, arise from deeper structural contradictions. All the women interviewed for this study felt the constraints of gender and economic class, but they were not necessarily passive but struggled to "manage" the conflict they experienced. In her work on gender contradiction, Jean Anyon describes this as a process of "accommodation and resistance". She states: 
The dialectic of accommodation and resistance is manifest in the reaction of women and girls to contradictory situations that face them. Most females neither totally acquiesce in, nor totally aschew, the imperatives of femininity ( 1983:23).

Accommodation and resistance are part of any socially constructed role, and Anyon's study focussed on the particular mechanics of this process by girls and women in relation to the dominant ideology of femininity. This ideology is in itself a social construction reflected in the changing social action of women during the time span of this study. Even in the context of withdrawal Anyon sees the process of accommodation and resistance as active and creative, and she concludes:

Most women...make concessions...They adapt femininity to their own ends, resist it in subtle ways and use it to ward off its consequences (1983:26).

American sociologist Heidi Hartmann offers the concejt of "the family as a locus of struggle...A location where people with different activities and interests come into conflict with one another" (my emphasis 1981:368);..."an embodiment of unity and disunity" (1981:374). She argues firstly, that men and women have different experiences and interests within the Western European family unit, but that while there is conflict there is also mutual dependence. Secondly, she says that the interactions of family life reflect the wider social, economic and political forces. In her analysis of housework within the family, Hartmann shows that women mediate and absorb the conflicts that arise from the wider forces.

The focus on a "location", or site" as something which transforms the realities of the wider society, is a useful concept for an analysis of gender relationships. New Zealand sociologist Steve Maharey (1985) elaborates:

It is within sites that social relations become meaningful to the people involved in them. Within sites peoples' experiences are co-ordinated and limited. They are one thing but not another. By selecting a site within which to study practices, the researcher gains access to meaning, coherence and limits (1985:57).

The "site" or "location" for this study focuses on the lives of women within their families during the years of active motherhood. In New Zealand as in other Western societies this is the time when the contradictions surrounding women's lives are made most apparent, particularly as the activities of these years are set alongside the "myth of motherhood" as being the ultimate fulfilment of women, and deemed as a natural justification to constrain the participation of women in other activities (Kitzinger1978; Phillips 1983). Feminist theorists argue further that the "site" of gender relationships within the family is also an embodiment of patriarchal power relationships, in that the choices for women are effectively limited by the control the context of their sexuality, reproduction and their work (Eisenstein 1981). Anthropologist Gayle Rubin, however, distinguishes between the sex-gender systems around which individual societies organise or deal with sexuality and childrearing and which in theory may be "sexually" egalitarian (1975:168), and the concept of patriarchy which subsumes the 
concept of a sex-gender system within the notion of a social system which is maybe sexually stratified. She wams:

But it is important - even in the face of a depressing history - to maintain a distinction between the human capacity to create a sexual world, and the empirically oppressive ways in which sexual worlds have been organised (1975: 168).

In this sense my study presents some empirical evidence from within family relationships of the ways the "sexual world" in New Zealand has been organised to constrain women and advantage men. The particular arrangement of the sex - gender systems in New Zealand have much in common with other Western industrialised societies, but New Zealand researchers are beginning to analyse the unique characteristics of this arrangement. For example, Jock Phillips' (1987) analysis of male Pakeha culture in New Zealands portrays an image of masculinity that has been articulated through the cultural traditions of rugby, alcohol, and war, but which has a heritage in a colonial culture in which men outnumbered women. Phillips believes that a frontline victim of the particular New Zealand male stereotype has been the New Zealand woman $(1987: 284)$. My own study is not so much an analysis of the New Zealand female stereotype itself, but rather of how a group of women have managed to order their lives in relation to their men whose lives were undoubtably shaped by the New Zealand male stereotype. It is also an analysis of the changing definitions of femininity in relation to a male stereotype that has proved to be more entrenched and less adaptable to change than its feminine version.

My work is also about social change in postwar New Zealand and attempts to account for some aspects of continuity and discontinuity in the changing consciousness and structures surrounding women's lives. This study shows how individuals were able to harness such experiences of contradiction into strategies of resistance to make changes within their own life, and in the way society was ordered. It has to be acknowledged that particular economic, social and ideological conditions affect individuals and families differently, but individuals mediate contradiction according to personal priorities and/or the particular conditions which impinge the most. Apart from women who remain single, women in New Zealand have always mediated the conflicts of family life by ordering their lives to accommodate first, the needs of their husbands and/or children (Novitz 1976; Meade et al 1984; S.R.O.W 1984). The following study shows how some middle class women were able to mediate some of the mismatch between cultural ideology and social reality by using more choice, more resources and more power; to sometimes harness the dominant ideology of femininity towards new directions, or to activate certain changes within it.

Accepting therefore that the lives of women are characterised by both identification (i.c. accommodation) with the dominant ideologies of femininity, and conflict (i.e. resistance) (Anyon 1983) caused by the inherent contradictions within any ideology, I am also concerned with how the women in this study mediated contradiction to construct an appearance of 
identification or harmony, and also with the strategies they used to resist the accepted ideological code. What ideology means is problematic and it is used in different senses by various social sciences. In a general sense one can talk about ideology as referring to the commonly held values and ideas that provide a knowledge of "how things are done" or of "accepted practices". Interpretation differs, however, about the range of phenomena which are perceived as ideological, and the function and the mechanism of ideology. Social scientists seem to agree that ideology includes the legitimation of power by providing a justification for a particular social arrangement and view of reality. Approximating the marxian language of the class context of ideology, feminist theorists (Mitchell 1971; Kuhn and Wolpe 1978) argue that the differential power within gender frame works are a basis for the generation of ideology. For example through the power of the ideology of motherhood (Wearing 1984), men are relieved of the obligation to take the day to day responsibility for childcare and are in a position to legitimate it through the structural ways in which society is organised.

No society is static, and as new forms of consciousness arise ideological structures adapt and change because ideology as an embodiment of the "ground rules" of the society must bear some reflection in people's actual experiences and everyday consciousness. One of the dilemmas of the social sciences is the extent to which consciousness is determined by such hidden structures, or to what extent, and under what conditions consciousness can be be transformational. Ideology is not deterministic but contradictory in that there are competing ideologies which operate at different levels (Althusser 1971), although these levels may be over-determined by class and gender interests (Mitchell 1971). Rather than being a passive actor, the individual can manoeuvre within and against the dominant ideology (Anyon 1983). As Janice Winship says about the ideology of femininity:

It is not merely a passive acceptance by women of patriarchial domination but represents an active subordination (1978:134-5).

There are several interwoven themes that thread though this analysis which shall, at this stage, be briefly introduced. The Second World War highlighted again the issue of equality for women and throughout this postwar period a new ideal of women now being "equal but different" to men was acknowledged In the 1940's and 1950's it was argued that men and women were to have separate but equal spheres. There was to be clear demarcation of roles but they would be seen as being equal. The man was seen as a potential or actual breadwinner and the woman's work was located in the home. The notion of equality arose from the complementarity of these roles in that she was dependent on him economically and often socially, whereas he was dependent on her for raising his children and servicing his physical needs. This analysis will show that the neatness of this arrangement was not so easy to organise amidst the disorder of everyday life, but that it did for while provide a coherent framework within which women ordered their lives. There was however a shift as women sought to gain more economic and social independence. A growing view of individualism was encouraging the individual quest for self-fulfilment by both men and women. This was made 
more possible for women by a society which was moving towards utilizing the economic and social skills of women outside of the home. By the 1970's there was a new interpretation of men and women being "equal but different" which embodied the notion of rights, i.e. equal rights and the right to be different. In this sense some women were acknowledging: their right to economic and sexual independence from men; that their interests were not synonomous or necessarily complementary to mens; and that they wanted to ensure their own security in the workplace as opposed to relying on the security provided by men within the home. This view provided new parameters for ordering the lives of men and women, although it still existed alongside the earlier construction of separate but equal spheres.

Women from both generations in this study have ordered their lives amidst various constructions of the ideal of being "equal but different to men". This has served to impose order on their relationships and to define disorder. In Chapters Seven and Eleven I examine various expressions of this within three separate, yet connected dimensions of women's lives:

women and their relationship to men as wives and sexual partners;

women and their relationship to children as mothers;

women and their relationship to work as housewives and employees.

Ideology creates both order and disorder but ideological frameworks impose order on the diversity of everyday life by defining boundaries between order and disorder, acceptable and unacceptable. Throughout the postwar years there have, at various times, been individuals or categories like working mothers, divorced wives, delinquent children, solo mothers, street kids, lesbian women, and feminist women whose lifetsyles did not fit the images of happy families which the complementarity of separate spheres was suppose to support. Their existence was often labelled as evidence of disorder and/or deviance (Mazengarb Report 1954; Crowther 1957; Manning 1958). Such boundaries are however shifting. This study shows for example how the so called deviance of "working mothers" in the 1950's has had to be accommodated into the category of possibly acceptable in the 1980's, and how the total unacceptability of single motherhood in the 1950's has moved towards acceptance through government sanctions in terms of economic support for single mothers. Such boundaries are not neat and the life history material presented in Chapters Eight and Twelve demonstrates a range of choices and opinions, but in over-viewing this forty year span the boundary shifts become evident.

This study focuses in some detail on two particular time periods: 1945-1960, and 1970-1985. In both periods there is diversity in styles of everyday living, but in the first period the boundaries between order and disorder were more sharply defined and, for example, divorce or illegitimacy which did not fit within the consensus frameworks of the acceptable were signified as possible disorder. Such disorder was both seen and experienced in terms of individual anomalies and failure that were unfortunate but possibly curable. By the 1970's this rationalization could no longer be accommodated or justified by the facts; individual anomalics were not necessarily defined as individual failures but symptomatic of wider social and/or economic trends (Morris 1971; Shadbolt 1971; Ramsay 1975). They were visible rather than 
hidden, and the solution was not necessarily in curing disorder but in accommodating it within new rationales of order and disorder. From the 1970's there were calls for tolerance (McLauchlan 1976; Donnelly 1977; Social Development Council 1977a; 1977b; 1978-9; 1981) and this study shows how there was a tentative acceptance of more diverse life styles in ways that would not have seemed possible in the early postwar years. There were many links between such expressions of diversity and the trend for women towards establishing more sexual and economic independence from men. These issues will be explored in more detail in later chapters. 


\section{THE CHILDREARING YEARS}

This chapter spans the development of a personal theoretical framework towards a wider literature review of the theoretical context of women's lives. Part One traces a ten year personal journey from new motherhood to the writing of my M.A. thesis The Politics of Childcare: an Analysis of Growth and Constraint (1983), and the subsequent publication of my book Mind That Child (1985). The focus of my doctoral research began with the gaps and unanswered questions concerning the lives of New Zealand women that my M.A. thesis had skirted around. Part Two goes beyond the personal to examine the threads and connections to other New Zealand research and writing. Such work is recent, with strong theoretical and personal links into the energies and concerns of the women's movement since the 1970's. Part Three moves outside the context of New Zealand to examine briefly some of the research and writing on women in Western society. This too has been fuelled by the impetus of the women's movement which has helped create a growing body of feminist theory. This section acknowledges these connections.

Part One

\section{A SHIFTING FOCUS}

The condition of women is a seamless web; it is difficult even to unpick the different threads so that they may be examined separately...One quality of their lives is the interdependence of their varying roles and spheres...work and childrearing, marriage and sexuality, family and social life (Wilson 1980:61).

\section{THE POLITICS OF CHILDCARE}

The experience of new motherhood in 1974 brought a tangled mixture of feelings: joy and new love; a loneliness at suddenly being outside the certainties and status of the working world; and the knowledge that it was my life that was being dismantled and reconstructed. The hidden agendas of the politics of childcare which had been following me for some time were starting to surface. This was initially an emotional feeling of, "What is wrong with me?", until gradually it changed towards tentative strategies of action that would help resolve my dilemmas. Returning to teach seemed impossible at the time because childcare for babies was unavailable except in the backyard variety, so I returned to university to complete a degree, and placed a child, then children into a university creche. I also began a new career as an underpaid childcare worker - a small step away from unpaid motherhood. This personal strategy later became part of a collective acknowledgment, within the organisations of the New Zealand Childcare Association and the Early Childhood Workers Union, that childcare provision was a 
political issue for women, and that the political constraint against such provision was a ploy to ensure little change in the balance of power and responsibilities between men and women.

Some years later my M.A. thesis, The Politics of Childcare: An Analysis of Cirowth and Constraint (1983) was to explore these issues by asking why there had been such an orchestrated campaign to constrain the growth of childcare in New Zealand despite the obvious need and demand. This was more than an historical analysis because the childcare debate reflected the unresolved conflict surrounding the relationships between men, women, children, the family and the state. To want, or to need to use childcare had been categorised as deviant and unacceptable because its widespread availability had the potential to create secming disorder. I was to write at the time, that beyond the exhausting politics of lobbying for or against:

Childcare is also political in a much broader sense.

- It challenges the values that mothers should care for their own children for most of the time.

- It challenges the economic structure by enabling more women to be part of the workforce.

- It challenges the power relationships within the home, the community and the state (Cook 1983:14).

The politics of childcare provision were embedded within the contradictory structures surrounding the roles ascribed to women in our society, and over the past hundred years the history of childcare provision had paralleled shifts in the conditions underlying the relationships women have had with their men, their children and their work. There was a complex web of power relationships that were contradictory and changing. It seemed a natural progression to move from a study of the politics surrounding a controversial service which women used despite its placement outside of the boundaries of acceptable childrearing, to a study that facussed on the lives of the women themselves. Understanding individual women's lives could reveal the context of these relationships which were so powerful in defining the acceptable and unacceptable, order and disorder. The knowledge of this was the beginning of this study.

\section{THE CHILDREARING YEARS}

In an early book of papers with a specifically feminist perspective on anthropology (Rosaldo and Lamphere 1974), Rosaldo pointed to the childbearing/rearing role of women as a consistent cross cultural element in identifying the root cause of sexual inequality, because it placed women in the realm of the private as opposed to the public world of men. There was also the view that women's childrearing role limited their involvement in economic activities which were a source of power (Friedl 1975). However O'Brien (1984:68) suggests that in the past anthropologists often ignored women's economic roles in contrast to the emphasis given to womens' roles as mothers. This aspect was being redressed more recently by women anthropologists. There isa evidence that childrearing has little effect on women's econome activities in some societies (Griffin and Griffin 1985). Secking an "explanation" for sexual 
inequality is problematic, in that concepts of power and status may not be so transportable across cultures (Bourgignon 1980). Not only is women's childrearing roles characterised by diversity, but there is also diversity of opinion over the relationship of childrearing to the inequality of women. However, the identification by some anthropologists of the childrearing years as a time that signifies increased dependence is relevant to the context of childrearing in Western society where women usually give up full-time paid employment. They are then economically dependent on men for some period of time. There is in Westem society often an anticipation of this future dependence, which has been demonstrated in early sex-role stereotyping that tracks girls into certain kinds of educational and job opportunities which place them at a disadvantage to boys and men. But it is the onset of the childrearing years where the inequality between the sexes expresses itself most explicitly. As such it is a period of potential conflict, particularly when it exists against an ideological backdrop espousing the equality of women. Sociological focus on the childrearing years is now acknowledging the childrearing years in Western society as a time of tension and stress (Cass 1982; Harper and Richards 1979, 1980; La Rossa and La Rossa 1981; Gilling 1985; Swain 1984). Anne Meade (et al 1984) reports from the Family Network Research Project ${ }^{1}$ in New Zealand that when the first baby arrives, the balancing of activities between men and women becomes more complex, but that women prefer to absorb the tension and act as a buffer against conflict. Meade et al are looking at the conflicts New Zealand families experience when both parents are in paid employment. This propensity by women for "absorbing conflict" occurs in other contexts. For example, the childrearing years for women occur with the crucial years of gaining job experience, promotion, further education or political involvement. That the childrearing years for men also coincide with these experiences has been a non-issue, because fatherhood unlike motherhood has not been synonymous with the everyday care of children, or giving up a job. More recently however, shifting expectations in the involvement of men in childrearing have led to tentative acknowledgement from the workplace that male workers may have children, and for example, domestic leave can be used by male workers, and a few industrial awards do have unpaid paternity leave. Amongst my own generation of women the responsibilities of the childrearing years are being openly acknowledged as conflicting with other endeavours. In the popular press the conflicts of being a mother and, a bricklayer, a student, a fireman, a mayor, or a writer are appraised in detail. Opinions range from the "girls can do anything superwoman" myth, to the "ultimate joy" of motherhood winning over the work experience.

There is not only a reappraisal of the childrearing - work conflict for women, but also the tentative acknowledgement that children are not essential to the fulfilment of a relationship. In the past parenthood has been seen as a compulsory experience, and a public demonstration of the maturity and stability of the marriage. In Why Children? Dowrick and Grundberg state:

\footnotetext{
${ }^{1}$ New Zealand Council for Educational Research (in progress).
} 
In asking this we encourage each other to face a major and often painful confrontation with self, upon a battleficld scarred with family and custom, church and state, mythology, economic reality...even to ask this question is to start a revolution (1980:7).

Going back a generation to that of my mother, this view was hardly a relevant topic and children followed marriage quickly. My mother told me that she felt that she had done very well for those days to manage nine months before you were conceived. The idea of the dual career marriage had not emerged and marricd women gave up work in the expectation of the childrearing years. The apparent lack of conflict between the roles of work and childrearing is however somewhat misleading because many women did work, but mostly in occupations of secondary priority to those of their husbands, which could be quictly fitted in and around childrearing responsibilities.

The time span between the two generations reveal a sufficient shift in both the ideals and realities of women's lives during the childrearing years. During the postwar period the childrearing role was paramount and all other dimensions of women's experiences were carefully wrapped around it to minimise conflict. Anomalies which revealed the contradiction, such as mothers who used childcare, were categorised as individual misfortune, deviance or incompetence. By the 1970's the childrearing years could be controlled more by contraception, and for a few, children were an option to be decided against. There had been a sufficient shift in the ideological, social, and economic infrastructures to encourage wider options and expectations for women beyond childrearing. The structural relationships in which contradiction had been minimised had now become unbalanced. The rights of women to choose e.g. to work or not to work, to delay or not to have children, or to opt for relationships and children without marriage, created expectations which conflicted with childrearing. Similarly a changing economy which needed the labour of women, in which a dual income was more necessary to maintain family living (Easton 1979), in which a new consumerism needed the buying power of women, all served to undermine the neater alignment of roles and responsibilities from the early postwar years. The anomalies during the 1940's and 1950's which were categorised as disorders were later accommodated by acknowledging them as options representing diverse choices. The fact that by the 1970 's-80's women were freer to make such choices did not necessarily make life easier as women felt they had to do more as well as rear children.

Operative alongside the context of childrearing are the powerful myths of motherhood. Ann Oakley defines three dimensions to the myth:

The first is the most influential: that children need mothers. The second is the absence of this: that mothers need children. The third assertion is a generalisation which holds that motherhood represents the greatest achievement of a woman's life, the sole true means of self realisation. Women in other words need to be mothers (1979:88).

These belicfs circumscribe the lives of all women by limiting to some degree their options and consciousness. Some women may be able to modify the ideology but this requires mediation 
of the contradictions perhaps through economic capital, and/or by making choices which may be painful like choosing not to have children. The life history material presented later illustrates the dilemmas of these choices. The juxtaposition of relating to children as a mother, to a man as a wife/sexual partner, and to work as a housewife and/or female employee, can cause tensions that do not affect in the same way the the lives of men during their early childrearing years. The contradictions between being a father, a husband and a worker have been mediated more successfully because women have assumed the major responsibility for childcare and childrearing.

\section{Part Two}

\section{A NEW ZEALAND OVERVIEW}

\section{$1945-1970$}

Until the 1970's the lives of New Zealand women had received scant documentation in history texts, and even less attention in academic research. This thesis straddles a period of famine and one of plenty. There were however some rich resources from which to begin the construction. Firstly the magazine material, which will be described in Chapter Four, yields plenty of anecdote revealing the current concerns and issues. The lives of New Zealand women were put under a media microscope revealing the covert and overt messages that provide rich data for the researcher in cultural studies. Secondly, women writers like Mary Scott, Grace Phipps, and Jillian Squires were penning a local version of romance and family life. They espoused in a lighthearted way the ideals of happy families and the coming of the "good life". As one dust jacket described the characters, "They are the kind of family you see in every street in every suburb". The women are capable, sensible, hard working wives and mothers, and the men are dependable breadwinners. Variations on this model exist but only to tell the tale of what befalls those who do not strive towards the ideal. The seamier and/or grimmer side was not the focus: all is well with the New Zealand family was the resounding chorus, on paper if not in real life. Accepting that this writing ignored the unpleasant, it still gave illuminating glimpses of the ideological frameworks defining family roles. The following extracts from Marriage with Eve (1955) by Grace Phipps are examples:

Eve about herself:

"Sam you don't think I am one of those managing sorts of females do you?" "Well as long as you're married to a strong character like me, who can keep you in your place, you can't do much harm," said Sam (1955:17).

Eve about her career girl friend:

Gail's life sounded so vital and full of important interests. And yet Gail had been no cleverer than Eve when they were at college together. It was just that Gail had seen her opportunities and grabbed them with both hands, and all she had done, Eve told herself with an inward chuckle was 
to grab Sam. Well she wouldn't like to be without Sam would she? (1955:25).

Sam's view of Eve as a wife and mother:

One of Sam's shrewd grey eyes appeared around the edge of the paper. "You've done plenty" he said. "Four strapping young boys to help populate the country - good future citizens. What more do you want?" (1955:29).

Eve eventually agrees with Sam:

"Mmmm I suppose making a success of marriage and bringing up a family to be a credit to the community is just about as important a job as becoming famous. Gail can have her career..."(1955:30).

Eve's advice to her married sister who works:

"I think you'd be better off staying at home. It can't be much fun doing your household shopping in the lunch hour and rushing home at night to cook meals on a mad scramble" (1955:71).

Sam's views about a working wife:

"What I think is this. Bill (her husband) was overseas fighting a war. When he came home he was living in not too comfortable lodgings for a year or two. What he wants more than anything, I presume is a cheerful loving wife, whose first thought is his comfort...And what does he get? A wife who goes to work and comes home the same time he does; who when at home, has to dash about doing the household chores feeling tired and therefore irritable, and not the best of companions" (1955:73).

A contrast is found in two plays: The Trap (1951) by Kathleen Ross, and The Tree

(1959) by Stella Jones. Helen White's (1985) review of these forgotten works notes that:

The few true to life characterization of married women in New Zealand plays reveal their hopeless imprisonment in a domestic role - what might be called New Zealand womanhood's "drab domestic" past (1985:261).

Neither play was able to provide a realistic solution to the "drab" situation. In The Trap the main character was completely trapped by her circumstances as a solo mother of seven children who had "had to get married" in the first place because she was pregnant. She seemed unable to avoid becoming as frustrated and domineering a mother as her own mother had also been. In The Tree the main character escapes with unrealistic ease to a life of independence travel and a career from the domestic "trap"encircling her own mother. The heroine escapes by purposely breaking the cycle of her mother's entrapment by avoiding the possiblity of conceiving a child (White 1985). The trap for women was perceived as childrearing and the dependence that this entailed.

A growing source of information has been in women's reflections and writing. When the impetus for women's studies in New Zealand gathered momentum in the 1970's, the "here and now" was the primary focus. This was part of a generalized political strategy to reveal the ills and redress the wrongs as a forerunner to greater change.It was not until later that women historians (Roth 1980; Hughes 1981; Bunkle 1980; Brookes et al 1986) began to delve back in time to build a Pakeha herstory of New Zealand, but to date this has not reached the 1950's 
although interest has grown in the earlier lives of women who are still alive (Locke 1981; Davies 1984; Clark (ed) 1986). Eve Ebbett's pictorial history books, Victoria's Daughters:

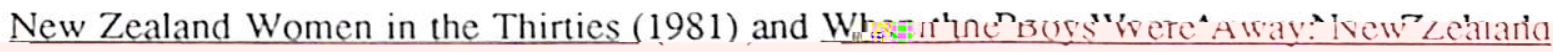
Women in World War Two (1984) began to close the gap. Ebbett presents no deep analysis but gives a "trip down memory lane" as well as recording the details of much "forgotten" history. Her work counters the remembered images of the men in the dole queue, or the men marching to war, by portraying that women too were part of this picture, albeit as the hidden cogs which permitted the male visibility we remember as history. And so did Lauris Edmond's oral history of Women in Wartime (1986).

The overseas picture amongst our European cultural relatives has been similar with historians and writers inching towards the postwar era with an increasing interest in the herstory of Second World War (Anderson 1981). As part of a series on American Women in the Twentieth Century, Twayne publishers have produced two books: The Home Front and Beyond: American Women in the 1940's (1982) by Susan Hartmann, and American Women in the 1950's: Mothers and More (1984) by Eugenia Kaledin. These books give a political and cultural overview of the context of women's lives during these decades. There are similarities but the details still seemed somewhat remote from the lives of New Zealand women. In Britain, Elizabeth Wilson's Only Halfway to Paradise: Women in Postwar Britain 1945-68 (1980) stands out. Wilson sets the story of postwar women's quest for equality against the changing political and economic scene of the welfare state ${ }^{2}$. She tries to account for the submergence of women's inequality within the quest for political consensus, and then its emergence during the 1970's as a visible political strategy. She asks the question, how did the contemporary women's liberation movement grow so suddenly out of the silence that went before it? As part of her construction she gathers together strands from the diverse sources of, philosophy, psychology, literature, and art. Wilson was concerned to show how these disparate areas operated both independently and in unison in the construction of the ideological picture we like to remember. She states:

The orchestration of consensus on the position of women in postwar Britain was the achievement of a deceptive harmony out of a variety of noisy voices; and perhaps that false harmony says something about what ideology might partly be. The orchestration was harmonious - in a peculiar way - in covering up what was really a silence; what was not said...(1980:3).

My work reveals a similar "silence". The twelve women who have related their life stories have surprised me with their knowledge of back street abortion and domestic dispute that were behind the veneers of family respectability. Likewise their clandestine support of the Communist Party in the 1940's; or their involvement in the water front strike in the 1950's; and of learning and teaching about natural childbirth as a protest against ether drugged births.

${ }^{2}$ Sec also Wilson, E. (1977). 
These are realities which were either "invisible" at the time or have lapsed into forgotten history, but these fragments piece together an image of women that is layered, richer and more realistic than that which is "known" about them by my generation.

In our contemporary herstories of the 1970's women's movement the years before provide the contrast, but it is as if the conditions towards change were created by ourselves. In a series in Broadsheet on "The History of the Women's Movement" (Sept, Oct, Nov, Dec 1979, Jan/Feb 1980) Phyllida Bunkle traces the various political and ideological strands from overseas which fused into the women's movement. The forerunners of the 1970's women's movement are located primarily in the civil rights and anti-war movements of the 1960's. These movements taught strategies and were a training ground for activists, but the focus of my study was on the particular conditions of women's lives in the early postwar period which acted as a fuse for the women's movement to grow. As the cracks in the consensus values of the 1950's and the 1960's widened, educated women in particular were having increasing difficulty in resolving the contradiction in their own lives, and these experiences were essential forerunners to the success of the women's movement and the changes it has generated in the lives of my generation.

A reappraisal of the early postwar years is slowly beginning. Sonja Davies' autobiography Bread and Roses (1984) details the pain of illegitimacy, war, illness, and then a life of political activism in the 1950's and 1960's. Janet Frame $(1983,1984)$ was no political activist, but her autobiographical series gives an insight into the life of a women misfit in the1950's. The lives of both Davies and Frame were for periods of time outside the boundaries of acceptable codes of femininity (Matthews 1984). Few women of this generation are however reflecting back on their lives for publication. Interest comes more from women of my generation who are beginning to examine the conditions of their upbringing. In a glimpse of a forthcoming book on being reared in the 1950's, Anne Else states:

...very little about the 1950's turns out to be what it seems on the surface. I was drawn to write about that decade for two reasons: first, in order to look at some of the social factors that helped to shape me and my generation; and secondly, to bring a little more depth and reality to recollections of that time, so as to counteract the vague image of a postwar golden age...(1986: 71-2).

Sue Middleton's thesis Feminism and Education in Postwar New Zealand: A Sociological Analysis (1985b) has been an inspiration in several ways. Middleton traces the lives of twelve feminist educators reared through the postwar period. She wanted to account for their "conversion" to feminism and she grounds this in the contradiction and marginality experienced in their upbringing. Middleton describes the construction of the ideological frameworks within which these women were reared and from which they had to escape, and identifies in particular the contradiction between their sexual and intellectual lives during their upbringing in the early postwar years, along with a later contact with feminist ideas. 
Middleton was to acknowledge the importance of continuity between ourselves and the lives of our mothers:

In studying the educational success and career aspirations of women, the mother's experiences and attitudes towards education are especially important. This is perhaps of particular importance in coming to understand the experience of postwar babies...Trying not to be like one's mother was a major influence on many of the women's working and sexual lives (1985b:11).

This thread is an important connection into my work. These women often saw their mothers as trapped by domesticity and too self sacrificing to the interests of the family even though the focus of the investment of their mother's energy was themselves.

\section{0 's - 1980's}

By the mid 1960's the changes happening to women became a topic for academic consideration and, "The Changing Role of Women" became a popular topic at lectures and seminars ${ }^{3}$. An important watershed was in 1966 when the Society for Research on Women (S.R.O.W.) was formed $^{4}$. The Society realised that there was no research on New Zealand women, and during 1967-8 carried out interviews with 5,400 women. The results were published in 1972 as Urban Women which was a landmark as the foundation of Women's Studies in New Zealand ${ }^{5}$. It was alongside the impetus of the activities and organisations associated with the women's movement, and early feminist writings from abroad, that women's studies as a discipline began to grow. The Women's Studies Association (W.S.A.) as a feminist organisation had been formed in 1977 and the writing and research sponsored through the W.S.A. and the S.R.O.W. have been crucial in bringing a new understanding of women's lives in New Zealand from a feminist perspective.

Linking in with this growth in women focussed research, has been the growth of family studies in New Zealand. Swain (1984) dates its birth, like the women's movement to 1970, with its infancy stretching through the decade (Houston 1970; Ritchie and Ritchie 1970; Ramsay 1975; Koopman-Boyden 1978; O'Rourke and Clough 1978). The studies in these collections acknowledged that the New Zealand family had its own unique variations and did not necessarily replicate the frameworks and norms in the imported texts ${ }^{6}$. This early work also stimulated moves by Government to sponsor research. Government Departments started

\footnotetext{
${ }^{3}$ Linden Playcentre (1967), The Changing Role of Women Auckland University Extension (1968) The Changing Role of Women; (1969) Women's Position in the World Today.

${ }^{4}$ This was following a series of lectures organised by the Linden Playcentre and later published. (see footnote above). Bibliography of S.R.O.W. Publications 1966-1983 (1985).

${ }^{5}$ The popularity of this work caused it to be sold out and reprinted in its first year, and in 1981 it was re-issued as a revised version.

${ }^{6}$ Family sociologist David Swain (1984) argues that when overseas research has been replicated in New Zealand, results have not followed the British or American patterns even though there were similarities.
} 
collecting and collating statistics ${ }^{7}$. A series of papers challenging old values was produced by the Social Development Council. These highlighted the diversity of New Zealand family life styles, portrayed "ills" which had previously been hidden, and analysed the relationships between the family and state politics ${ }^{8}$. All this work has been invaluable in constructing the 1970 's-80's scenario, particularly as it contrasts with the absence of rescarch on the earlier period. Amidst its variety there are several pieces of work that thread more explicitly into my study.

One can begin with Jane and James Ritchie's work on childrearing: Childrearing Patterns in New Zealand (1970) and Growing UD in New Zealand (1978). These books provided a unique overview of the way New Zealanders viewed their children and the values underlying the way they were reared. In their first study the Ritchies showed that:

Methods of control are the key to the mother-child relationship and it is here that the New Zealand pattern is sharply defined. Control by smacking is its chief characteristic (1970:157).

The Ritchies work focused on women insofar as it is the mothers who are the most intimatcly involved in childrearing, but they explode the myth of the happy relaxed New Zealand mother. They reported:

The bleakness of motherhood is a real cause for concern...(1970:156) New Zealand mothers seem chaotic, overwhelmed by the sheer necessity of coping - barely managing...(1970:154).

Their work portrayed women continually constructing order from children's disorder. It was this process that underlay the relationship of women to their children:

The life of the New Zealand family turns around the mother's timetable and if the children disrupt it they must look out..... One is sympathetic to their needs to have a peaceful quiet house but it is no wonder they fail to achieve it (1970:157).

The Ritchies foreshadowed the concerns that were later voiced regarding the negative experience of mothering for women:

They pay a price for this. They are confined within their roles; their social world is limited by house and garden. Their social interaction is with children rather than adults. And the effects are intellectually deadening and emotionally wearing (1973:156).

The field work for this study had been conducted during the mid 1960's and their later book Growing up in New Zealand (1978) portrayed the growing diversity in family life by acknowledging working motherhood, solo motherhood, fatherhood. Although they recorded that childrearing practices were still quite repressive, many more women were finding more

7 Department of Statistics $(1977,1978,1986)$.

Department of Labour (1980).

8 Bringing Up Children in New Zealand 1977a

Housework and Caring Work: Can Men Do Better? 1977b

Families in Special Circumstances 1978-9

Families and Violence 1980

Families First 1981 
enjoyment in their role as mothers. In a comparative paper of the two surveys Jane Ritchie (1979) reports:

$\begin{array}{lll}1963 & 28 \% & \text { whole-heartedly accepted the motherhood role } \\ 1977 & 65 \% & \text { whole-heartedly accepted the motherhood role } \\ 1963 & 27 \% & \text { severely dissatisfied with the role } \\ 1977 & 3 \% & \text { severely dissatisfied with the role }\end{array}$

This seems a large shift in opinion, but Ritchie points out that there had been many changes during the period. For example the average family size of the sample group was one child smaller ${ }^{9}$. Similarly in the earlier sample there were no women in regular employment whereas in the 1977 sample a third were. One could suggest that by the 1970's the lives of women were less constrained by the motherhood role than during the 1960's. This shift is something to address later but it is sufficient to note that the Ritchies' work lifted the shrouds hiding the facts that some women were dissatisfied with the roles ascribed to them. Prior to the 1970's there were fewer options available to redress this dissatisfaction. By the 1970's however there were ideological shifts that were encouraging women to widen their horizons. For example the increased acceptability and possibility of employment provided more options to the full-time motherhood role. This process however revealed new contradictions surrounding the ability of women to balance their roles and responsibilities both inside and outside the home. These contradictions have been the focus of several pieces of research.

Rosemary Novitz's thesis on The Priority of the Mother Role (1976) examined the moves of women into the workforce and the conflict this generated in managing both roles. She concluded that conflict was avoided by women giving priority to the motherhood role, although the weighting of such priorities was interpreted differently. This conflict was the focus of a later study by the Society for Research called Women, Jobs, Children and Chores (1984). Margaret Hayman and Betty Roberts wrote in a preliminary paper:

When a woman with dependent children decides to take up paid work she experiences a number of tensions arising from internalised values about motherhood which may conflict with this decision, and a number of opposing demands on her as a mother and a paid worker. These tensions are of two kinds...(1983:1).

Hayman and Roberts differentiate between tension in values: i.e. questions such as "Will I be a good mother?", or "What will my mother say?" etc., and structural tensions concerning the lack of childcare, or types of jobs available.

The Smith Women (1981) by Rosemary Barrington and Alison Gray was a unique look at the lives and views of 100 New Zealand women. For the first time women were asked about their own lives. The stories are varied but a common theme was the extent to which women arranged their lives to fit around their men or their children. Barrington wrote later:

9 The 1962 sample was 3.2 children, whereas the 1977 sample was 2.1 . 
Women are continually involved in the process of adaptation in combining their occupational and domestic roles. Women adapt their occupational aspirations, actual job choices, acquiring of skills, and hours of work to their more traditional female roles even before they become wives and mothers. They anticipate these roles (1982:30. My emphasis)

Mothers Matter Too by Jenny Phillips was another landmark in acknowledging the conflicts in womens' lives. Max Abbott and Hillary Haines from the Mental Health Foundation wrote in the Introduction:

(The book) shows clearly that the mother-housewife occupation as it is organised, is a particularly difficult one. It is a high stress occupation with built-in conflicts, frustrations...People in this job are highly at risk of developing health problems (1983:viii).

Phillips exhorts women to stop blaming themselves for their malaise. She moves the blame beyond individual women's inability to cope, into the wider context of how society defines and orders women's role in the childrearing process. At the same time she acknowledges the constraints against structural changes and provides a "self help" manual for women to not only combat the effects of these structural ills, but also to generate a new strength and power towards change:

Talking honestly about our reality may well be the most "political" thing we can do. My hope is that by changing ourselves and helping one another, women will stop being victims and become a great deal more powerful (1983:204).

Similarly Jenny Phillips' follow-on publication The Mother Manual (1986) proposes a collection of strategies to help women as mothers manage, cope and/or re-order their lives. Women are absolved from blame and these works reflect the postwar shift in attribution from individual to collective causes of social ills. Phillips however is not going to wait around for the collective revolution and gives self help remedies as an interim.

Anthropologist Julie Park's (1982) research Doing Well: An Ethnology of Coping, focusses on the middle class suburb of Pakuranga. This gives a useful insight into the lives of families who were in the midst of their childrearing years, and in particular the women who were the main inhabitants of the suburbs by day. Park's material illustrated a variety of styles of coping with the conflict and stress of a suburban lifestyle predominantly constructed around the role of the male breadwinner and the female childrearer at home.

Robin McKinlay's doctoral research, Where Would We Be Without Them: Motherhood and Self Definition in New Zealand (1983), was the first major work on motherhood in this country. McKinlay identified three styles of motherhood, and traced the changing historical and ideological threads which have created and defined them. McKinlay too, acknowledges the contradiction surrounding this role and provides insights into the mechanisms by which women organised and rationalised their lives according to the ideology of their particular style of motherhood. Her description of the divcrse "choices" now facing women in their role as mothers, and her conclusion that "this is a heavy responsibility to live 
with" (1983:537), provides a glimpse of the dilemmas of the seeming diversity in choice of the the 1970's-80's. McKinlay's sample does not include the experiences of mothers outside the mainstream, like lesbian mothers, or working mothers using childcare, whose experiences however are part of the process of categorising the good and the bad, order and disorder. McKinlay's mothers fit into the category of the "acceptable". They do not challenge the dominant value system although they do demonstrate various styles of accommodation (Anyon 1983) to this ideology. They portray a group who are "caretakers" (Wearing 1984) of the dominant ideology.

There has been less work done on those who actively resist the dominant ideology (Matthews 1984), although Alison Jones's (1985) study of working class school girls in Auckland who resist the school culture is a beginning. These "resisters" who are outside the mainstream are important forerunners of social change and Sue Middleton's work on feminist educators pursues this hypothesis. These women all experienced a marginality in their lives as they "resisted" the dominant ideology, although in contrast to Alison Jones's working class school girls the feminist women were equipped to use their economic and "cultural capital" (Bourdieu 1974) to transcend some of the structural constraints. In my study I have tried to cover both marginal and mainstream experiences of women as they both demonstrate essential elements in the process of change.

Women writers have also explored in fictional form the particular contradictions experienced by women during the 1970's-80's, and in New Zealand there have been a number of books describing family life behind the windows of the family home in candid detail. Examples include Sue McCauley's Other Halves (1982), a story of a love affair between a thirty-four year old Pakeha woman and a Maori boy of sixteen; Alison Gray's The Marriage Maze (1979), about the entrapment and escape from the suburban dream of marriage and home; Fiona Kidman's A Breed of Women (1979), the story of Harriet's journey towards self awareness in postwar New Zealand; Marilyn Duckworth's Disorderly Conduct (1984), about the dramatic trials of a forty year old solo mother with four children by different husbands; and Helen Brown's satirical sketches of middle class family life, Don't Let Me Put You Off (1981) and Confessions of a Bride Doll (1983). In her inimitable style Helen Brown summed up her own dilemmas:

So I have tried to be good mother as well. I don't think I've been so successful in that area. I could never tie a nappy that stayed up when they walked.

Most mothers wanted to be career women, too. You know - fulfilled as a person. It isn't easy. Bosses still tend to look at women over their spectacles and say, "But shouldn't you be at home with the children?"

And a woman must also work to keep her husband. She must stay attractive, interesting and never too tired for position 103. Otherwise who knows?

You can't blame people for waking up in the dead of night guiltily wishing, ever so faintly, there was some sort of comfortable mould to 
fall back into. A mould of a woman who cares what sort of polish she uses on the kitchen floor (1983:vii).

The writing by women of this period provided invaluable insights into the lives of women beyond the life histories of my interviews.

Part Three

\section{THE OVERSEAS CONNECTION}

Intellectually and culturally New Zealand is part of a wide social and political order. Ideological frameworks in America, Britain and Australia reflect similar patterns that can be found transported and adapted to the New Zealand scene. It is impossible to identify all the strands which have added to the mosaic of my theoretical framework, although I am indebted to feminist theoretical writings on the politics of motherhood (Friedan 1963; Mitchell 1971; Bernard 1975; Rich 1977; Chodorow 1978; Oakley 1979; Dally 1982; Boulton 1983) etc. These works located the oppression of women within the institutions defining the motherhood experience. Adrienne Rich may sum it up:

The institution of motherhood is not identical with bearing and caring for children...Both create the prescriptions and conditions in which choices are made or blocked; they are not "reality" but they have shaped the circumstances of our lives...(1977:42).

There has also been a boom in popular writing on motherhood (Lazarre 1976; Rubin 1982, 1984), as women have detailed the difficulties of modern motherhood. Questioning motherhood suddenly was an acceptable topic for publishers and writers, as it became "safe" and profitable to release such feelings of frustration in public. However I wanted to go beyond motherhood itself, even though motherhood was the crucial experience in determining the priorities of how women ordered their lives. At the time of beginning this research there were three books that gave clues towards the direction I might be heading in the analysis of my material, and I will make the connections more explicit.

Betsy Wearing in The Ideology of Motherhood (1984) bases her study on three groups of mothers in Australia. Like McKinlay (1983) she identifies three styles or ideologies of mothering, but Wearing's range moves beyond the middle class sample of McKinlay. She gives a marxist analysis making explicit links between the various ideologies of motherhood and the economic class of the mothers. Of particular interest is her concept of utopian motherhood as an ideal which she identifies as an essential component towards social change. Wearing defines the radical utopian mother as one who:

Rejects the present structure of society and seeks instead a new breed of men and women, a new vision of the future, a future in which family, community and play are valued on a par with politics and paid employment for both sexes. Such a mother believes that motherhood in its present form is neither necessary for women's fulfilment, nor should it be inevitable, but one of a number of choices for women (1984:80). 
Although Wearing found no mothers in her sample whose life style approximated this kind of utopia, it was an ideal that the mothers in her feminist sample worked towards. Following on from Mannheim's belief that, "Utopias can only challenge the existing order when they embody currents already present in society which are appropriate to the changing conditions" (1936:187, quoted in Wearing 1984:190), Wearing found two essential conditions for challenging and transcending the traditional ideology of motherhood that mothers have the individual responsibility for their children all of the time. Firstly, it was only those women who had access to the material resources, like a car, housing, technology, childcare, who were able to overcome some of the limitations to pursue their own interests. Secondly, in addition to material resources it was only those women who had contact with feminist utopian ideas who were able to de-mystify the ideology to any extent in order to construct an alternative life style. She states:

The role of ideas aligned with material resources has been shown in this research to be of crucial importance for change, even though access to these ideas and networks generally required middle class material resources (1984:204).

There are connections to the work of Sue Middleton (1985b) whose feminist educator's experience of marginality was an essential part of the process of demystification and reconstruction of ideological frameworks. To both, feminist ideals acted as a utopian vision although in Middleton's study the emphasis is on the material rewards of education as "cultural capital". For Wearing the material resources are aligned to the economic wealth of the middle classes.

I interviewed women from a range of economic and educational backgrounds and specifically sought out women who could be labeled as radical. Following on from Wearing and Middleton I was interested in the lives of the women who were activists - changing their own lives, and being part of wider movements of change. Like Wearing I also interviewed women who were the "caretakers of the ideology" (1984:186). Some of these women felt threatened by change and actively worked towards maintaining the status quo. On the other hand, many women acknowledged the changes and maybe supported the new ideals but "actively" chose to accommodate the constraints so as not to "rock the boat". The style and process of accommodation to the dominant ideology by these women are just as much a part of the process of reproduction and change, as those of the radical activists.

Elizabeth Badinter in Mother Love: Myth or Reality (1980), presents a structuralist analysis of the changing relationship between men, women, children and the State, in eighteenth century France. She sets out to demonstrate that mother love and maternal instinct are not immutable, but are socially conditioned sentiments which have been expressed with varying emphasis throughout history. Badinter portrays a society in which these sentiments are absent and her analysis reveals firstly, the conditions which made it acceptable for babies to 
be abandoned at birth, and secondly the changes which created the new idealised expression of mother love in the nineteenth century.

The historical and cultural epoch seems somewhat distant from postwar New Zealand, but Badinter's theoretical perspective challenged my own approach to my material. Like Elizabeth Wilson in Halfway To Paradise (1980) she transcends traditional disciplines, by creating a picture that draws upon a wide range of cultural images.

Badinter also shows how the context of childrearing in relation to women is connected into wide matrix of relationships. Badinter begins by stating:

The mother...is a person who is relative and three dimensional: relative because she is thought of only in relation to the father and to the child; three dimensional because in additional to this two fold relationship, the mother is also a woman - that is to say a unique being with her own assumptions, which often have nothing in common with her hu-band's hopes or her child's desires....the triangular relationship is not only a psychological fact but also a social reality (1980:3).

Badinter explores the various ways in which this contradiction has been mediated, with the balance of power shifting between the rights of the child, the rights of men, and the rights of women. She concludes:

In this conflict between men and women the child plays an essential role. Whoever controls the child and has him in his camp can expect to win out when ever society's interests are identified with the child...Depending on the historical period and the social class, the women either suffered from her role or used it to escape from her obligation as mother and free herself from the husband's yoke (1980:4).

This "dimensional" and "relative" view of the lives of women underpins my study, and like Badinter I am trying to show the changing context of these relationships. Badinter portrays women as prisoners of ideology as she traces the changing position of women alongside the shifting ideological structures vested in male power. Yet her analysis reveals how certain groups of women break out of the cage by harnessing the dominant ideology for their own ends. She provides the example of the middle class women in the late eighteenth century who reversed the practice of child abandonment. Like middle class women of today these were women who placed a value on education for their daughters, but this was an education to enhance their future role and status as a wife and mother and was not linked to the possibility of economic independence or self fulfilment.

It is not an accident that the women who first heeded the male arguments for motherhood were of the middle class... (they) saw in this role an increase in social status and an emancipation that the aristocratic women were not seeking. By accepting responsibility for her children's upbringing the middle class woman improved her personal status
$(1980: 189)$.

Badinter's analysis related these shifting views to the changing economic conditions at the end of the eighteenth century and a new interest of the State in preserving the population. 
The final book is by anthropologist Maxine Margolis, Mothers and Such: Views of American Women and Why They Have Changed (1984). Margolis describes herself as a cultural materialist and seeks to determine why women's roles changed and how these changes were reflected in contemporary media perspectives of the images of women. Like Badinter, Margolis pulls her analysis through several epochs, beginning in colonial America, and moving through to the present time. Her analysis focuses on middle class women, is rich in detail, and the data comes from the advice found in the magazines and writing of the period. She maintains that this literature is powerful in prescribing ideal roles for women.

Part of the value of Maxine Margolis's work is in the arrangement of her analysis. She separates out the various roles of women's lives: i.e. women as mothers, women as housewives and women as workers. She shows how these separate histories mesh together in unity and contradiction to create the dominant images that have become so powerful in defining correct behaviour. Margolis shows how the widening mismatch between the ideological structures and the reality of women's lives was crucial to the conditions which created the women's movement in the 1970's. She states:

The very disjuncture... led to the feminist revival. Viewed from this perspective, the women's movement is ultimately a result rather than a cause of women's discontent (1984:271).

This is an hypothesis that underlies my analysis. Following on from Margolis I move beyond a study of "roles" to one of relationships, and my arranging of women's lives into separate dimensions has a different weighting:

Women in relation to men as wives and sexual partners

Women in relation to children as mothers

Women in relation to work as housewives and paid employees.

There have since been other works whose insight has been incorporated into this work, but at the time of beginning these were important. 


\section{THE PROCESS OF THE RESEARCH}

This chapter describes the three strands of fieldwork and research in this study - the subjective. the ideological and the structural. These strands combine as corresponding yet contradictory parts. Part One discusses the value of life history as data, and describes the collection and analysis of these narratives as they were related by twenty five women. Part Two describes the ideological dimension of cultural images in the context of "prescriptive literature", and the collection and analysis of my own material. Part Three makes the connections between these strands and the empirical and historical material that reveal the wider economic, political and social relationships surrounding everyday life.

\section{Part One}

\section{A LIFE HISTORY APPROACH}

The collection and analysis of life history narratives is an established, albeit fringe form in anthropological and sociological research (Langness and Frank 1981; Sedgewick 1983). As a method though it has sometimes been overshadowed by the view that, "The final goal of human sciences is not to constitute man but to dissolve him" (Lévi-Strauss 1968. See also Althusser 1969). Plummer states:

This rejection of the human subject highlights one of society's core contradictions: an interminable tension between the subjectively creative individual human acting upon the world and the objectively given social structure constraining him or her (1983:3).

The increasing popularity of the life history analysis is part of a movement to recapture and understand the context of the individual, the personal, and the subjective in social theory. C. Wright Mills argues for the "sociological imagination" which:

enables its possessor to understand the larger historical scene in terms of its meaning for the inner life and the external variety of individuals
$(1959: 5)$.

Mills emphasizes the dialectical relationship of the individual to society, and believed that by "living out a biography he contributes to the shaping of this society and to the course of history" (1959:6). The individual is viewed as a creative subject and life history narratives reveal the strategies individuals develop to manage everyday life. Plummer argues that not only is the life history particularly suited to revealing "confusion, ambiguity and contradiction" (1983:68), but that it reveals mechanisms of change in society in the sense that: "Such a focus is a dual one, moving between the changing biographical history of a person and the social history of his or her life span...a life history cannot be told without a constant reference to historical change" (1983:3). 
Balancing life history in relation to the historical - structural context is not easy. Studies have ranged from lightly edited transcripts (Salmond1976, 1980; Heron 1985, Edmond 1986), to the presentation of fragmented selections of "text" arranged around a theme (Simpson 1974; Barrington and Gray 1981; Gray 1984). There is criticism that the life history is often presented with little interpretation and that the detail of the descriptive data hides the collective connections (Langness and Frank 1981:87ff; Young 1983:478-80). On the other hand Mary Sheridan writes in the Introduction to Lives :

Life histories can illustrate the operation of the social order because through them we are able to observe how people adapt to the goals of society. They give access to "the subjective springs of action" (1984:12).

Life histories have had an appeal for some anthropologists, who have looked to personal accounts as a means of locating women in the social formation (Andreski 1970; Carlson 1974; Shostak 1981). For example Marjorie Shostak's life history of Nisa a !Kung woman presents a moving narrative of a woman's life in the Kalahari desert. Amongst the privation and tragedy of Nisa's life, which Shostak admits may have been extraordinary, she is shown to be a creative strategist, coping with the complex relationships amidst her various marriages and love affairs, and managing to carve a place amidst the changing economic conditions as "civilisation" encroaches into the desert. The narrative of Nisa's life gives a unique insight into the changing balance of relationships between men, women and children in !Kung society throughout a lifetime.

Alongside anthropological ventures, the method has been co-opted by feminist researchers of other disciplines.

- For example, to give women voices in history, as Sherna Gluck writes:

(Women are)...refusing to be rendered historically voiceless any longer, women are creating a new history...using our own voices and experiences. Challenging the traditional concepts of history of what is "historically important"..we are reaffirming that our everyday lives are history (1977:3).

- Or, to make "the personal political". Sociologist Rosemary Novitz writes:

It involves looking at the life of an individual both as unique history and the outcome of the economic, historic, political and ideological context within which the person has lived (1982:299).

Life histories have also been used to make collective political statements. From Britain an early example is Margery Spring Rice's account of women's lives in the 1930's published as Working Class Wives $(1939$, repub 1970, 1981). It was said that, "This book stripped off the veil of indifference and ignorance which concealed the hardship of millions of women from their more prosperous sisters" (1981:iii). A more recent New Zealand version of this kind of analysis comes from Lauris Edmond's Women in Wartime (1986). The collective narratives make powerful statements. Individual lives are shown to be caught up in something much larger than themselves, but the individuals are not necessarily passive. 
Feminist theorists (Bowles and Klein 1983; Stanley and Wise 1983) conceptualise research as a social process, in which there is a two sided contribution of mcaning. Oakley (1981) noted from her interviews for Becoming a Mother (1979) that three-quarters of the women said that the interviewing had affected them. It led them to reflect on their experiences and Oakley found herself in the context of a "therapeutic listencr" (1981:51). In intervicws of feminist educators Middleton called her research an "intervention" (1985b:173) in people's lives. She provides a moving case study of "Geraldine" who, in the process of discussion about her childhood, revealed for the first time that she had been an incest victim, thus triggering off a series of changes affecting "Geraldine", her family and the researcher. The life history interview inevitably is one of intimacy that leads to reflection which some individuals may translate into change. This is the context of my research.

\section{SELECTION}

The selection and interviewing of women extended over two years and alongside other aspects of the research the interviewing was part of an on-going dialectic of delving decper. Each dimension guided the other, and shifted perspectives according to the "finds" of the other. At no stage did I feel ready to "do all the interviewing". I just began, and the momentum gathered and the focus sharpened. Twenty-five women took part and the criterion was that they were rearing children in New Zealand at some time between 1945-60 or 1970-85. Women were chosen by a "snowball" method. I began with someone and they might know somebody else and so it would grow. To avoid a "snowball" of too much uniformity I would begin somewhere else in another town, or through a new contact, when the "story" sounded familiar. After a few interviews I got selective and would tick off in my mind kinds of varicty, like rural, city, educated, working class, religious, in paid employment or voluntary work.

The original intention was to include women from varied situations but without extremes But as I began to reflect more on the experiences of women who did not fit the order of the mainstream, their experiences challenged this order (Mathews 1984). This can be seen for example in single motherhood which was unacceptable in the early postwar years but was to gain a reluctant acceptance by the 1970's. I began to talk more with women who felt outside of the mainstream. This experience was usually only for a period of time, as most women tended to move in and out of the categories of order and disorder, acceptance and nonacceptance. The other move away from the mainstream came with the understanding that the study was about continuity and discontinuity rather than comparison. I needed to demonstrate this process at both the personal level and within a wider structural dimension, and decided to interview a few women who were involved in political/radical activity. These women represent a tiny minority of women but were a powerful force in the social processes. In both generations these women had access to education, economic independence and/or ideas that were not always available to their sisters. They were to harness these matcrial advantages and 
theoretical frameworks into strategies towards change, which alongside other forces were part of the process of creating new options for ordering everyday life. Although interested in this scenario at the structural level, I was also interested in how these women mediated contradiction in their personal lives, how they sometimes purposely created conflict, and what made them different from the main group of women interviewed. These were not questions I had in mind initially.

\section{INTER VIEWING}

The first interviews began in February 1984. When first approached most of the women declared that their life was not interesting and that they knew somebody who had a more extraordinary life. It took some reassurance that their "ordinariness" was interesting. The research was explained in the following way: that I was writing about the lives of women in the postwar period in New Zealand and was interested in the changes that had happened, and that I was interested in the time when they had their children, but also wanted to know about their own childhood and growing up years. I was interested in the "everyday" and "ordinary" lives of women as this had been excluded from the history books.

Talking about my research was how I built up trust and the topic was viewed sympathetically. This was important with the older women who were shy and self-effacing to begin with, although the more political women were eager for their story to be told in the sense of "wanting to put history right". Feminist researchers have criticised the "rape" model of research and interviewing in which the researcher will "take, hit and run" (Reinharz 1979:95), and Ann Oakley has stated that:

...the goal of finding out about people through interviewing is best achieved when the relationship of interviewer and interviewee is non hierarchical and when the interviewer is prepared to invest his or her own personal identity in the relationship (1981:41).

Most of the twenty five women interviewed have become friends whom I may sometimes write or talk to about my work. A few could be termed colleagues as we have argued and analysed the context of their own life history narrative.

Each interview was at the home of the interviewee. I often went for half a day, or sometimes stayed overnight. There would be a lot of talking besides what was eventually caught on the tape recorder. The interview would begin when we felt comfortable with each other, in the sense that they felt comfortable with my tape recorder, with me and my research, and I felt I knew something about them and we could identify our connections. As a preliminary to the first series of interviews I wrote a list of topics of interest which would act as a guide sheet, and this grew in length as the interviews proceeded because new topics would arise out of each interview. However as the interviews began their own dialogue, the guide sheet became less of a crutch. Amidst the narrative sequence I would feed material from one interview to the next to get comment and opinion which became an essential process in the 
construction of the scenario. Thus the later interviews were different from the carlier ones; there was more discussion and argument; I gained skills in listening and eliciting information. became less bashful at asking why, became less worried about covering all the ground, and began to discover what I might be looking for.

The first interview was with a friend with whom I had some experiences in common. I then interviewed her mother and although the parts of the interview that connected with her daughter's life were good, there were blocks in communication. I needed more insights and cues particularly in relation to the older women, and so decided to interview my mother as a step towards bridging the gap. This was a revelation to me about my mother's life, and about what she thought of me and my generation. I was to sometimes use this as an anchor for the interviews with older women and dialogues could often begin with the phrase "My mother told me about...." , which brought the connection I needed. The lesson learnt was that interviewing was a two-way, cumulative dialogue between researcher and interviewee.

\section{ANALYSIS}

In life history analysis it has to be accepted that information maybe left out, added or distorted but the concern of this thesis is not the actual events, but how women constructed them at the time and/or reflected on them at the time of the interview. The analysis began with the interview itself. In some cases analysis could begen during the interview as some women would analyse their own lives and the interview would move into discussion of issues rather than stick to the sequential narrative. Or sometimes the analysis began when the tape recorder was turned off. For example, one woman told me about the unhappy marriage she had made on the rebound when her fiance had been killed at the war. I had known this and had held back from probing during the "real" interview. This information was important to the analysis but I also knew that I had been told it as a kind of confidence. I do not quote or report the details of such "off the record" confidences although the confidence inevitably becomes part of the analysis. This was to happen several times.

Each taped interview was transcribed onto the computer giving me a "text" approaching some 1000 pages. While I typed I pondered and the process of transcribing and reflection became an integral part of the analysis. There was an ideal of collaborative research, in which the researcher and subject together constructed the analysis (Westcott 1979; Oakley 1981; Klein 1983), but I was to realise that this worked with only a few of the women. The rest were interested in the general progress of the research, although more often in the progress of my pregnancy or baby. After each interview was transcribed a copy would be sent with the option of deleting, correcting or adding information. In most cases the narrative was left intact although often more information was sent The original intention had been to interview the women again but this became unnecessary when the interview sequence turned 
into more of a dialogue, and the continuing relationships with the women brought opportunities for further updates or discussion over specific issues.

Confidentiality was crucial and it took various forms, including not telling anybody whom I interviewed, changing names at all times, and leaving out material that could identify the person. In one sensitive interview I excluded certain tracts in the typed transcript but kept the tapes intact. It was agreed that the tapes would eventually be lodged in the Turnbull Library. For most of the women the issue of confidentiality however focussed on finding a safe hiding place for their transcript away from the eyes of their family. The interviews carried personal information on husbands, children, and parents that could cause upset. One woman was fearful of even owning a transcript, while most hid them away. For several of the women an edited transcript was provided so that they could pass it on to their children as a record of their life. The women seemed pleased that there was some record of how they felt about their life. Three of the older women told me that they read the transcript to their husbands. The response varied from anger at breaching family confidentiality, to a degree of reconciliation over past events.

Once the narratives were turned into computer texts my own analysis took over. The computerisation was born partly from the practicality of gaining multiple copies, but originally the idea was to break the material apart into subject areas like the war, finance, childbirth etc. A computer programme was written in which the material could be shuffled around and reconstituted whilst retaining the name of the subject and the place in the interview. I then reappraised my undergraduate structuralist skills in myth analysis ${ }^{1}$, in the sense that Lévi-Strauss argues that at a certain level of abstraction the structures of myth are the same: i.e. "constitute a set of variations on a common theme" (Leach 1967b:xvii). In collecting a number of life history narratives I followed Lévi-Strauss's maxim that a logical order can be found amidst "textual" variance. The question is what kind of order, and at what level of abstraction can everyday life be reduced to? Liz Heron who collected narratives from women growing up during the 1950's, states:

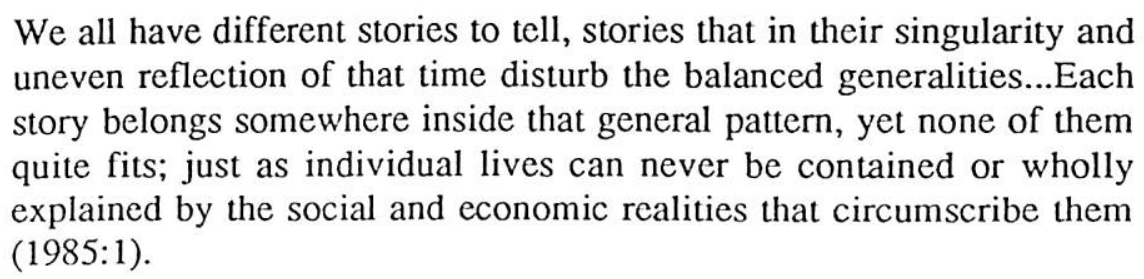

The abstraction that a structuralist textual analysis could yield was not the aim, and I was to see that the crux of my analysis would be in the ordering and selection of material within its own context and without shuffling it too far away from its origins. The aim was to reveal how individuals resolved contradiction in their everyday lives. The contrast and variance could be shown with a series of small case study insights rather than a collective abstraction and the

\footnotetext{
${ }^{1}$ For an assignment I had spent many hours dismantling and reconstructing the novel Sons and Lovers by D.H. Lawrence.
} 
case studies would illustrate and validate the theoretical frameworks being developed, thus complementing the topic orientated focus of the ordering of the magazine material.

Roland Barthes wrote:

A text's unity lies not in its origin but in its delineation... The birth of the reader must be at the cost of the death of the author (1967:148).

The women acknowledged that the intimacy of our words would have their own life, but despite the abstraction of tape recorder, computer, mind and pen the subjective beginnings are an integral part of the end. Plummer criticises Foucault's (1978) use of life history because the individual is only a means to an end in an analysis of power (1983:132). I feel unease at such criticism as I too seem to be scanning the text to reveal the dynamics of the power relations surrounding the lives of my women subjects. Foucault himself says in relation to life histories:

They give us the key to the relations of power, domination and conflict....and hence provide material for a potential analysis of discourse... which may be both tactical and therefore strategic.(1978:xixii).

But in contrast to Foucault, and in response to Plummer's criticism and feminist concerns (Oakley 1981; Reinharz 1983), I have endeavoured to integrate the theoretical abstraction and individual meaning in the structure of this research. Both dimensions are important and as Marilyn Strathern wrote:

In principle, however, interesting a life history is little different from the exercise of interpreting much of what anthropologists call their data. These products are generally the result of collaborative efforts on the part of ethnographer and informant (1981:480).

\section{Part Two}

\section{PRESCRIPTIVE IDEOLOGY}

The analysis of cultural images is one means of identifying and understanding the process and power of ideology. By dismantling such representations we can glimpse some of the mechanisms of ideological contradiction embedded in our society. Barthes wrote in the introduction to Mythologies:

The starting point of these reflections was usually a feeling of impatience at the sight of the "naturalness" with which newspapers, art and common sense constantly dress up a reality which even though it is the one we live in, is undoubtably determined by history. In short...I wanted to track down the in the decorative display of what-goes-withoutsaying the ideological abuse which, in my view, is hidden there (1967:11).

The essays in this volume heralded a new twist in cultural studies, as the underlying messages in everyday imagery were revealed beneath their outer cultural wrappings. This focus is pursued in the research publications from the Centre for Contemporary Cultural Studies Birmingham, or the writings in the N.Z. Cultural Studies Working Groun Journal (now called 
Sites). One dimension of this interest has been in the analysis of what has been termed "prescriptive" history - books, magazines, and popular writings that have defined roles, relationships and behaviour through their advice. For example, in Dream Babies: Childcare from Locke to Spock. Christina Hardyment analyses the changing context of advice to mothers over the past two hundred years. She notes with caution however, that:

They were written by and for the comfortably off, for people who could afford to sit back and consider how their children ought to grow (1983:xv).

Maxine Margolis, whose book Mothers and Such (1984) is based on such prescriptive material also acknowledges their middle class focus, but she argues that in the U.S.A. middle class ideas and prescriptions were powerful and filtered downwards to the working class and immigrant groups. These ideas were to define the acceptable and non-acceptable norms of behaviour, although Margolis notes that it is a moot point as to whether these prescriptions were actually followed.

Historian Carol Beth Norton (1979) talks about the "prescriptive pitfall" and criticises such material for emphasizing the passivity of women, as women have never acquiesced in everything they have been told or advised to do. The value of such prescriptive literature is not whether it was being followed but as an indication of shifting ideological infrastructures. For example the N.Z.Woman's Weekly ran articles encouraging women: to work for war and rehabilitation during the 1940 's; to stay at home in the 1950 's; to work part time in the 1960's; and by the 1970's and 1980's to work full time in the name of equality. These shifts are part of a wider network of political, economic and social relationships which shape the options of individual.

Family sociologist David Swain, advises students of family sociology in New Zealand to collect such cultural materials as "advertisements, cartoons... pamphlets, broadsheets, newspaper and magazine articles..."(1984 37), because of the lack of formal publications. He likens such material to:

...raw data to be processed in as much the same way as the reports of a key informant in an anthropological study rather than as authoritative material per se(1984:37).

Women's magazines have become a particular focus for feminist researchers of cultural studies (Harworth 1975; Winship 1978; 1981). These magazines have strong prescriptive messages in that they advertise certain constructions of femininity as being ideal. They also provide messages in the sense that they interpret news and events as they were seen or experienced at the time, and letters from readers offer alternative opinion and commenteveryday views and happenings. R.M. Harworth (1975) contrasted the images of the feminine role in three popular women's magazines of the the early 1970's, the N.Z. Womans Weekly, Thursday, and Eve. Haworth saw the effect on readers as one of reinforcement in helping to perform the roles associated with the middle class traditional role, and the difference between the magazines representing small shifts to accommodate the changing life styles of a middle class readership. 
Janice Winship $(1978,1981)$ from the Centre of Contemporary Cultural Studies Birmingham, provides some useful insights into the ideological power of women's magazines as a consumer commodity. She identifies three major contradictions in their portrayal of the ideology of femininity: between motherhood and domesticity, between the femininity of the sexually available single woman and the sexually owned married women; and between the "wifehood" of mother-housewife and that of the sexually attractive bed partner for her husband. Alongside such conflicting images of women in magazines, "real" women live contradictory existences - trying to match their lives against the dictates of the "ideal" images of the magazines. Winship argues however that, unlike most women however, the magazines can "manage" such contradiction by:

$$
\begin{aligned}
& \text {...operating within a representation schema of fantasy/reality or } \\
& \text { practicality...where into fantasy are displaced both the ideals and } \\
& \text { resolutions which the reality does not deliver (1978:139-40). }
\end{aligned}
$$

For example, family life as supposedly lived by the Royal Family and the film stars is juxtaposed with the mundane and ordinary life of Mrs Smith in Taihape. In this way the magazines can both reveal and transcend the ideological contradiction in ways not possible for "real" women.

\section{COLLECTION AND ANALYSIS}

My collection of magazine material was partly dictated by the lack of historical studies on women in the immediate postwar period. But I also wanted an alternative framework to position the life history material alongside, and to view the process of "accommodation and resistance" (Anyon 1983) between individuals and collective cultural meaning. The N.Z. Woman's Weekly and the N.Z. Listener with their wide national circulations, and continuity through both time periods were obvious choices, presenting contrasting styles from the intellectualism and analysis in the Listener to the fantasy/reality of femininity in the Woman's Weekly. There were not many articles in the Listener explicitly about women, but there was on-going comment on New Zealand's social, economic and political life, and there was continual feedback from women readers. These sometimes criticised the gencrally male viewpoint of the Listener. The Woman's Weekly had a remarkable editorial consistency throughout the period. Jean Wishart became Editor in 1948 and remained so until 1985. The Woman's Weekly has always covered the range of recipes, non-fiction, readers views and letters, personal advice columns, handy hints, celebrity gossip, consumer advice, news and issues. It has also been skilful in adjusting its messages so that, while never being at the forefront of opinion, the Woman's Weekly has kept apace with shifts in mainstream opinion.

I delved sporadically into a few short run magazines because of the particular perspective they presented at the time. From the 1940's-1950's, the N.Z. Journal of Agriculture. Here and Now - a magazine of short stories and comment, Parent's Centre Bulletin - news and views on childrearing, Landfall, a literary journal. From the 1970's- 
1980's, Thursday - a short lived rival woman's magazine to the Women's Weekly, Broadsheet a feminist magazine, Above Rubies - a conservative religious magazine for women of the New Right, and again the Parents Centre Bulletin.

I "read" every issue of the Woman's Weekly and the Listener from the 1940's through to the present, except for the decade of the 1960's, where I wanted to identify the impact of a decades change. Taking notes was too laborious, and required selection too early, and the visual image was lost. Both the General Assembly and Turnbull libraries, where the collections were housed, allowed me to photo-copy material and I collected it on the basis of intuitive interest, while reading very little. Meantime, to broaden the material for the period 1970-1980's I examined two collections held at Waikato University. Firstly, there was the late Rosemary Seymour's collection of newspaper clippings, cartoon, reports and pamphlets of the 1970's. I was fortunate to be given access to this huge, somewhat chaotic but priceless material before her death in 1984 ${ }^{1}$. Secondly, there were the Parenting Files set up by David Swain as a collection of mainly unpublished material on New Zealand families.

I then took myself and all this material overseas where I had the opportunity to sort, reflect and write away from the cultural images so taken for granted around me, and apart from the women whose "lives" were becoming so entwined with my own. Prior to going however, I delved into the material that focussed on the immediate postwar reconstruction period and wrote a paper for the 1984 Women's Studies Association Conference ${ }^{2}$. There was feedback and positive support particularly from women of that generation. At a crucial stage this brought the confidence to proceed overseas and begin the next stage of the work. For the next eight months sitting in the loneliness of various kinds of rented accommodation in Germany, Britain and Los Angeles, U.S.A. I eventually read the material and thus began the the process of selecting and ordering. I wrote four papers on the lives of women during the 1950's based on the advice and comment from the magazines of the time. These have subsequently been presented at conferences, published (Cook 1985a; 1985b; 1986; May 1988) and for awhile versions even became part of the ladies' luncheon circuit. This exposure provided essential feedback which has assisted in their re-ordering into the framework of this thesis. There was not sufficient time to write a similar series on the 1970-1980's and this thesis will be a first version.

\footnotetext{
1 The Rosemary Seymour Collection is now housed in the Waikato University library.

${ }^{2}$ Cook 1985c.
} 


\section{Part Three}

\section{THE EMPIRICAL AND HISTORICAL}

Beyond the dimension of the personal life history and prescriptive literature I needed another anchor. One which was the collective embodiment of both, and through which the interplay between the individual reality and the wider social formation was apparent. I was mindful of Bourdieu's (1977) concept of the habitus as the negotiating interface between the collective and individual structures, and also of C. Wright Mills view that it is not a "fruitful assumption" to assume society is "nothing but a great scatter of individuals" (1959:163).

Firstly, I needed more insight into New Zealand postwar social history and set about gaining an understanding and overview of the political, economic and social issues of this period. The Listener was very useful, although its analysis was usually of the "here and no . " variety. Historical (Nash 1943; Sinclair 1959; Sutch 1966, 1973; Bassett 1972; Simpson 1974, 1976; Oliver 1981), economic (Easton 1980; N.Z. Planning Council 1977 et al) and sociological works (Koopman-Boyden 1978; Spoonley et al 1982) have contributed to this deeper understanding, along with reflective, political or humorous writing about the New Zealand social scene (Mitchell 1969; Shadbolt 1971; McLauchlan 1976; Scott 1977; McLeod 1976; Brown 1981, 1983).

Secondly, there was the question of balancing and integrating the strands. I was fortunate to spend some time at the Catholic University of Nijmegen in Holland with Professor Jan Pouwer, who had taught me when he was the Professor of Anthropology at Victoria University. At the time of meeting with him my dossier of separate strands was complete, and although I could "see" and "feel" the connections, I had no overall framework or rationale within which to proceed. For several days, on several occasions, I talked through the connections while Jan "looked" at my material and listened to the words. We then talked at a personal level as we tried to make the connections using the data of our own lives. The relationships of our separate lives went under the microscope. What became evident was that alongside the ideological prescriptions and particular economic, political or social structures that helped shape or constrain our lives, we had periodically attempted to redefine and reorder our roles and responsibilities. This had inevitably created conflict within our respective family situations as the process of redefinition was to challenge assumptions that helped define the existing order, although it was apparent that over a span of time there were long periods of apparent calm in which the contradictions underlying this order were either minimal or reconciled. A year later I came across Jean Anyon's (1983) work and her description of the dialectical process of "accommodation and resistance" by women to the dominant ideology of femininity. There were many links to my earlier discussions with Jan. This gave more direction to the analysis of the life histories in the sense that the focus was on the mechanics and process of each woman's negotiation with the social world in which she 
lived, i.e.other family members, ideological codes, economic constraints. It also clarified more the relationship of the life history material to the cultural codes of the magazine material and the social reality of the economic, political and social structures.

I did not wish to lose any of the strands in some kind of high abstraction, although abstraction was essential in making the connections. The framework for two Sections in this analysis eventually emerged with the dialectic of context $<--->$ text. Section One focusses on the years 1945-1960 and Section Two on the years 1970-1985. The corresponding life histories and prescriptive material are separate texts which exist within the context of the political, social and economic institutions. The relationship is dialectical: just as the texts are part of the construction of the context, so too the context is transformed through the paper dialogue of the magazines- (Text 1), and/or the individual case studies - (Text 2). This arrangement may be problematic in the sense of a tendency towards repetitiveness, and/or unnecessary separation between strands which are not separate in everday life. Marcus and Cushman have reflected on the increasing diversity of presentation and perception of anthropological ethnographies. They state:

Of all the social sciences, anthropology has been the most enthusiastically interdisciplinary in exploring relevant avenues of inquiry for any problem. Where the conventional ethnography is limited, such scholars jump over, so to speak, the ethnographic text tied to field work and define problems to themselves that require a much different kind of textual expression (1982: 63). 


\section{SECTION ONE}

\section{A POSTWAR GENERATION OF MOTHERS, WORKERS, AND WIVES: 1945-1960}

The women of this generation have moved towards retirement and old age and their children approach middle age. Except for one born in 1909, the women in this study were born in the aftermath of World War One, were children through the great depression of the 1930's, and were young adults during World War Two. These situations channelled their options, and then fuelled their ideals when they moved towards marriage and childrearing during the postwar years. Section One presents an analysis of these years as they were experienced by women, based on the fieldwork and data collected. 


\begin{tabular}{|c|c|c|c|c|c|c|c|}
\hline Name & Education & $\begin{array}{l}\text { Work Before } \\
\text { Marriage }\end{array}$ & $\begin{array}{c}\text { Year of } \\
\text { Marriage }\end{array}$ & $\begin{array}{l}\text { Number of } \\
\text { Children }\end{array}$ & $\begin{array}{l}\text { Occupation of } \\
\text { Husband } \\
\text { before } 1960\end{array}$ & $\begin{array}{c}\text { Paid Work } \\
\text { after Marriage } \\
\text { before } 1960\end{array}$ & $\begin{array}{c}\text { Unpaid Community } \\
\text { Work } \\
\text { before } 1960\end{array}$ \\
\hline $\begin{array}{c}\text { Nell } \\
\text { b. } 1918\end{array}$ & 1 Year Secondary & $\begin{array}{c}\text { Tailoring } \\
\text { Waitressing }\end{array}$ & 1945 & 2 & Teacher & $\begin{array}{l}\text { Housework } \\
\text { Tailoring }\end{array}$ & $\begin{array}{l}\text { Church } \\
\text { Guides }\end{array}$ \\
\hline $\begin{array}{l}\text { Brenda } \\
\text { b. } 1926\end{array}$ & $\begin{array}{l}\text { University } \\
\text { Degree }\end{array}$ & Teacher & 1948 & 4 & Teacher & Teacher & $\begin{array}{c}\text { Plunket } \\
\text { Kindergarten Mothers' } \\
\text { Club, Playcentre }\end{array}$ \\
\hline $\begin{array}{l}\text { Irene } \\
\text { b. } 1922\end{array}$ & 2 Years Secondary & $\begin{array}{l}\text { Shop Assistant } \\
\text { Manpowered into } \\
\text { Factory Work }\end{array}$ & 1944 & 7 & $\begin{array}{c}\text { Carpenter } \\
\text { Draughtsman }\end{array}$ & $\begin{array}{l}\text { Shop Assistant } \\
\text { Social Work }\end{array}$ & $\begin{array}{c}\text { Playcentre } \\
\text { School Committee }\end{array}$ \\
\hline $\begin{array}{l}\text { Meg } \\
\text { b. } 1921\end{array}$ & $\begin{array}{c}\text { Matriculation } \\
\text { (University Degree } \\
\text { After Marriage) } \\
\end{array}$ & Business & 1946 & 4 & Public Servant & - & $\begin{array}{l}\text { Playcentre } \\
\text { Writing }\end{array}$ \\
\hline $\begin{array}{l}\text { Audrey } \\
\text { b. } 1918\end{array}$ & Proficiency & $\begin{array}{l}\text { Domestic } \\
\text { Servant }\end{array}$ & 1942 & 4 & $\begin{array}{c}\text { Farmhand } \\
\text { Church Social } \\
\text { Worker }\end{array}$ & - & Church \\
\hline $\begin{array}{l}\text { Winifred } \\
\text { b. } 1909\end{array}$ & 2 Years Secondary & $\begin{array}{l}\text { Helped on parents' } \\
\text { farm-an } \\
\text { allowance paid }\end{array}$ & 1942 & 2 & Farmer & - & $\begin{array}{c}\text { Plunket } \\
\text { Women's div of } \\
\text { Fed. Farmers }\end{array}$ \\
\hline $\begin{array}{l}\text { Jane } \\
\text { b. } 1922\end{array}$ & $\begin{array}{l}\text { University } \\
\text { Degree }\end{array}$ & Teacher & 1944 & 4 & Teacher & Teacher & Playcentre \\
\hline $\begin{array}{l}\text { Gladys } \\
\text { b. } 1928\end{array}$ & 2 YearsSecondary & $\begin{array}{l}\text { Student } \\
\text { Nurse }\end{array}$ & 1949 & 4 & Plumber & Nurse-Aid & - \\
\hline $\begin{array}{l}\text { Edna } \\
\text { b. } 1921\end{array}$ & 2 Years Secondary & $\begin{array}{l}\text { Office Worker } \\
\text { Student Nurse }\end{array}$ & 1946 & 4 & Farmer & Writer & $\begin{array}{l}\text { Country Women's } \\
\text { Institute }\end{array}$ \\
\hline $\begin{array}{l}\text { Dulcie } \\
\text { b. } 1919\end{array}$ & Primary & Family Shop & 1945 & 1 & $\begin{array}{c}\text { Family Bakery } \\
\text { Factory Labourer }\end{array}$ & $\begin{array}{l}\text { Family Shop } \\
\text { Factory Worker }\end{array}$ & - \\
\hline $\begin{array}{l}\text { Beryl } \\
\text { b? }\end{array}$ & 2 Years Secondary & Nurse & 1946 & 10 & $\begin{array}{c}\text { Farmhand } \\
\text { Public Servant }\end{array}$ & - & Church \\
\hline $\begin{array}{l}\text { Stella } \\
\text { b. } 1919\end{array}$ & Matriculation & Teacher & 1943 & 3 & $\begin{array}{c}\text { Gardener } \\
\text { Unemployed }\end{array}$ & Factory Worker & - \\
\hline
\end{tabular}




\section{CHAPTER FIVE}

\section{THE FOREUNNERS OF THE "GOOD LIFE"}

Somewhere at the back of the outlook of the New Zealander is a dream, a dream of security in equality...The special quality of the New Zealander's version is that the evil is to disagree or to be different. The chaos of existence is to be legislated into shape (Pearson 1952:218).

The search for the dream of "security in equality" has been ingrained in our national mythology since Wakefield's vision of the colonial society (Sinclair 1959; Sutch 1966; Simpson 1976; Cleveland 1979; Shuker 1985). The myth has been powerful and accommodating, and each generation has activated it according to the priorities and ideals of the time. During this century the myth has embraced the vision of creating a "land fit for heroes" after World War One; the "quest for security" (Sutch 1966) after the depression; the pursuit of the "good life" and a "material utopia" (Dunstall 1981) after World War Two; the rise of the "counter culture" in the 1960's and 1970's; and various movements seeking new kinds of equality for women These dreams have straddled the good and bad times, and myth is sustained by such contradiction. In this way for example:

The "land fit for heroes" existed amid the pain and deprivation of families coping with the death and mutilation of their fathers, brothers, sons, husbands and lovers.

The "quest for security" was sustained by insecurity.

The "material utopia" existed amidst scarcity and alienation.

The "counter culture" moved alongside conformity.

The movement for equal rights for women operated alongside an ideal of separate spheres.

The myth of utopia transforms feelings of social change and disorder into stability by appearing timeless and accommodating, even though the various constructions of the myth are contradictory. Thus the myth can be interpreted in different ways by different people or political parties. This chapter traces the changing expressions of this myth up until the end of World War Two. The personal experiences of the women who contributed to this study are placed within the historical conditions that have fuelled the myth. The intention is to reveal the power these myths have generated, as they have filtered through our separate family histories and been connected into the national versions of our history-mythology. 


\section{THE "GREAT WAR"}

These women were born in the aftermath of a war that took a heavy toll on human life in New Zealand ${ }^{1}$. Robyn Hyde wrote of the hidden pain that continued to affect family life in her "boom and bust" novel Nor the Years Condemn:

Sister Collins' brother Nevil had died on Gallipoli. An assortment of more distant relatives...grey moustached uncles, cousins...vanished at different moments of its narrative...If Sister Collins cried for them it was at the pictures (1938:17).

Easy enough to say that one was done with the war; not so casy to keep away from its aftermath. The sick people, the nervous and the futile, were always drifting in and out of her range...Even the mothers, turning over on their sides to feed the new babies, wondered in their vacant way if there would be another war (1938:113).

Several of the women in this study saw the effects of the war through the eyes of their mothers as they shielded and nursed their shattered husbands. But as children they suffered too.

Irene:

My father had been gassed in the First World War and he had terrible headaches and when he got those headaches he had a terrible temper. There was no treatment - the doctors probably didn't understand it. But as a child growing up I used to dread it when my father had tempers. I look back and see my mother had a hard time coping keeping us children rlother.t.n. everything. I decided that when I had a family I would never give them the hidings we were brought up with.

To Brenda and her mother the war generated guilt which became a powerful tool in defining the context of male - female relationships in the home (Chetwynd and Fenwick 1977). This sense of guilt by women after both world wars is a recurring theme in this study:

You have to go back to the World War One. My father was wounded...IIe was shot in the lung. He got pleurisy in the winter and being a farmer it was very bad. It had an effect on me. The women took the guilt because the men suffered. He was sick throughout all my life. It was very much - he had fought for King and Empire. I felt very upset when I didn't believe any of that when I was older. It was all this guilt of my father being in the war. (My emphasis)

Seven of the fathers of these women were "on the land" as New Zealand moved into the 1920 's. A burgeoning transport system opened up the country, and tracts of land were given to returned soldiers. But in the 1920's the high prices for agricultural exports collapsed, and farming life was not the dream that the myth promised. Many farmers were to walk off their land $^{2}$.

To Meg, World War One conjured up images of sexless spinsters whose fiancés had died. Many of these women had gone on to make carecrs in teaching and nursing, but as Meg said, they didn't have much fun and they were often supporting a mother or something. If the

1

124,211 New Zealanders served overseas out of a population of 1,103,022
18,500 killed

50,000 wounded

6,716 died from influenza in New Zealand in 1918
2 Geoff Chapple (1980) describes Rewi Alley's experience on a Taranaki farm. 
personal and political pain of World War One did ease for some, the ideal of "the land fit for heroes" was not to last long, because by 1929 New Zealand was in the grip of a world depression. This was to leave few New Zealanders unscarred.

\section{THE DEPRESSION}

In New Zealand the depression has become The Depression. The state of society is no longer seen in terms of certain consequences flowing from certain events, that is depression conditions. Instead the Depression becomes the justification for the state of society (Simpson 1974:9).

The experience of women in the depression years is a story just starting to emerge (Simpson 1974, chapter 6; Findlay 1974; Ebbett 1981; Coney 1986). For the women in this study the depression had an impact well beyond the hardship of its years. To protect themselves against future adversity these women spent their lives building safety nets by: seeking the stability of government employment; finding a good breadwinner to marry; possessing a "mend and make do" philosophy; "putting by" for the future; having a fear of hire purchase; saving the offcuts. That these women were very young during the depression years, has not lessened the fear:

Brenda It was after the effects of the depression that we had this tremendous fear about unemployment... and this tremendous need to be educated. My mother said, "If you have a good education you will get a good job and you will be all right if there is another depression".

Such feelings did not diminish with time and Brenda remembers feeling the threat even during the comparative stability of the 1950's.

We had this fear of the depression...We talked a lot about what would happen if $S$ _lost his job...We had this fear of unemployment because we had four children.

Tony Simpson wrote:

To say that the Depression is a great sustaining myth is not to say that it never happened; it is simply to say that we have forced ourselves to continue to live out for 40 years certain fantasies forged in its furnace (1974:9).

An analysis of New Zealand political history shows that governments have won or lost at the polls according to the strength of the safety nets they have since constructed. The 1984 Labour Government, with a 42 year old Prime Minister, was the first not to have its roots and policies bound by memories of depression and war. The realities of the depression however were stark. By 1932 there were 100,000 unemployed men out of a population of one and half million. The statistics for unemployed women were not collected ${ }^{3}$. The relief system, which operated on the philosophy of the "deserving poor" (Simpson 1974), broke down and the new relief schemes were often un-productive. For example, the Public Works Department sacked its workers to re-employ them for less on the minimal relief rates (Simpson 1974). Women were not eligible for relief and were expected to seek the protection of a husband or father, and

3 The Auckland Women's Emergency Unemployment Committee estimated that there were 10,000 women unemployed in 1931 (Coney 1986). 
in 1931 the Minister of Health was to reassure the concerned members of a deputation that charitable organisations were "coping excellently" with the problem (Concy 1986) ${ }^{4}$.

The depression affected some of the women in this study adversely:

Nell: $\quad$ I just had to learn that I couldn't have the things that others had whose fathers were working. When I was 15 he was on the dole, but my brother was working and he got a pound $a$ week and he gave it all to Mum...Mum would get the dole money and I know she got a dole ration but she would not use it at the local grocer. She sent us over to the other side of town to my aunty's grocer to get it...It was only flour, sugar and butter, and that pound of my brother's gave us our other food. Our breakfasts came from the Seventh Day Adventists who gave us a sugar bag of broken Weetbix and we had that with water.

Irene: $\quad$ I grew up with my father on what was called relief work schemes three days a week. I can remember my father talking about Mabel Howard ${ }^{5}$ with the Labourers' Union. She would come around on pay days when they were on relief and get $6 d$ off them .

Audrey: $\quad$ Mum and Dad couldn't afford to keep me. He was on relief work - helping to make roads. He had to get off the farm because he couldn't afford to make the payments.

Helen: How did that affect your family?

We were scattered far and wide. My brothers had to go to work on farms. My other sister had to got to work because Dad could only afford to keep me. It caused a lot of stress and then I got a job doing housework and I could live in.

Others experienced no direct hardship but the imprint was still deep:

Meg:

I think the impact was one of class. My mother used to say that if it wasn't for the depression we wouldn't have gone to a state school.

Something I do have a clear memory of is the unemployment riot in Auckland. It was dramatic in our household because my father was a special constable. He had a baton and an arm band. This was dramatic because he was such a gentle man. My mother was telling me about it in a hushed voice.

I was conscious of the poverty of the depression, apart from my mother saying she had to 'manage', by the poverty stricken young women who came as domestic servants. Also my father was a member of the City Mission. We were the sort who bestowed!

Beryl:

We were fortunate because Dad was in the Defence Department. We had plenty but he took a wage cut. My mother was very active in the St. Vincent de Paul Society. One of my memories was going along and chopping up celery and onion and cooking it in the big copper. I remember pestering my mother with questions as to why they were cooking the soup.

Irrespective of the degree of hardship experienced it ultimately fell to women to cope and clothe and feed the family as best as they could. Eve Ebbett described New Zealand women of the 1930's as experts in "making do":

4

In 1932 the Government was to acknowledge that there was a problem and set up training schools for unemployed girls who would receive $7 / 6$ a week. These were run by organisations like the Y.W.C.A but barely dealt with the problem.

5 Mabel Howard later became a Labour Party politician. 
Everybody made do including the well-to-do, those who could afford to purchase what they needed -- Waste not, want not!. There was a moral obligation not to waste anything in those bad days (1981:1).

This ethic was ingrained into the women of this study during their depression childhoodadolescence, put to good use during a war of shortages, and even demonstrated to my generation in the 1950's. But the later temptations of ready-mades, disposables, and packaged foods, accompanied by a lifestyle with other priorities, caused such skills as turning sheets, making soap, cobbling shoes, unravelling jerseys, and unpicking old clothes to be unnecessary and thus forgotten.

Women had little power to change the economic conditions and they expressed such powerlessness in such terms as: "we managed", "we survived", "I just accepted it", "I never blamed my parents or blamed anybody". But amidst this powerlessness women were creative "managers". Nell remembers her mother's efforts:

Well she managed because she was extra efficient. She sewed and she baked. There was nothing bought and Dad was a good gardener. She sewed for us and always out of old material.

Irene: $\quad$ It was a case of surviving although we always went off to school neat and tidy. I used to go to my maternal grandmother's with a case of clothes that my mother had given to her and my grandmother would alter them.

Edna's father had left her mother for another woman and they were taken in by an uncle, but her mother managed by making sacrifices:

My father would only pay up spasmodically so she did people's washing and she would bike miles to look after a family. She sold the piano to buy a coat. My mother was always in a summer dress all the winter, but we had our winter uniforms.

With the exception of the three youngest women, the rest were moving through their education and then into the workforce during the 1930's. A lack of money and opportunity constrained their educational and work options, but there was a pragmatic acceptance of the situation, not necessarily to be confused with passivity. In the families of Nell, Winifred, Beryl and Irene, daughters were of more use at home than at school:

Irene: I I was runner-up to the dux at primary school. I didn't get the dux because I was away too much. My mother had her last child that year. I was home quite a bit looking after the children. You just accepted it but I really hated it when my mother said that she wasn't well and had to stay in bed. I was really torn. (My empasis)

Nell: $\quad$ Well there was no encouragement to stay on at school and I was the most useful person I suppose being the oldest daughter. And so when Mum was sick I stayed at home for about a year.

Helen: How did you feel about that? Was it something you wanted to do?

No it was something you just accepted and I never got a penny. I did things methodically just like Mum did. The chairs up on the table and sweep out and wash out. Kids' lunches to do. I can't remember if Dad helped but I used to bake the cakes for the weekend. I followed her routine. It was the way I was trained. (My emphasis)

Beryl: $\quad$ I left school after standard 6. I did well in English and writing. At twelve I went and helped my stepmother. I had an apprenticeship in bringing up a 
baby. I felt a bit deprived when all the girls went on to college but I did accept it. You accepted things whatever the situation was. (My emphasis)

By the time I was seventeen I was getting concerned. I could see that it was a disadvantage not to have had an education. I had to actually pack my bag and leave home when my stepmother wasn't around. She was a domineering person.

Alongside this "acceptance" there was also a determination to make the best of the situation and to grab the fleeting opportunities that came along.

Education was a privilege not a right, and girls had less chance of access when there were brothers (Fry 1985). Education for girls, however, still provided the "cultural capital" (Bourdieu 1974; Middleton 1985b) necessary to transcend social class or to protect against future adversity. The women who did get a secondary education paid tribute to the efforts and sacrifice of others on their behalf.

Audrey:

My grandmother said I had to go to high school. I resented the fact because I had no desire to go, but I enjoyed it.

Irene:

My grandmother paid for me to go to secondary school. I can remember the arguments at home over that because Dad said I should be out at work. It was the depression time. But my mother said that as long as Grandma was prepared to keep me I could stay. I can remember sobbing my heart out when I thought I would have to leave.

Nell:

I went to the School of Art because it was the cheapest and it was only at the last minute I was allowed to go, because Auntie made my blazer and Mum made me a summer frock and I never had a winter uniform.

Meg came from a family in which education was a priority and was to receive an education that would provide her with "cultural capital" necessary for marriage into privileged circles. She recalled the snobbery:

I can hear my mother's voice on the telephone saying. "We are sending her to Epsom Grammar because if she goes there she will meet the daughters of lawyers". My mother used to claim that if it hadn't been for the snort and say that of course gone to a state school, but my father used to For most of the women sur

snort and say that of course we would.

chance to move ber wane education gave the My parents hadn't the class background.

was concerned that the vaguest notion what university was but my father they couldn't afford get a good education. I hoped to do Home Science but enabled me to buy to keep me. I then won a scholarship at school which extra year.

When I got to Teachers' College they said why don't you go to university?

I didn't think university was for people like me. It was a bit of a
revelation to me that I could manage it. In the aftermath of the depression yana it.

not necessarily dampen constrained educational opportunities did girls were not career aspirations of the women although working conditions for girls were not easy. Mary Findlay's autobiographical novel Tooth and Nail: the Story of a Daughter of the Depression (1974) described the exploitation of working girls during those 
years. Nell recalled the feeling of gratitude for having a job and for the skills it taught, but also being powerless against exploitation:

When I went to work I got $17 / 6$ a week. I was there for three weeks and he heard that a new award was coming out. So he called Mum in and Mum was dead scared I had been naughty. He said that he would put me off and then he would take me on again. I started for 10/- a week with $6 d$ taken off for tax.

Helen: How did you feel about that?

I had feelings but I was glad to get a job. The union later discovered that I should never have had that $6 d$ tax. I was given the $6 d$ but never any back pay.

After two years the head machinist left and he gave me the chance of taking on the job with full wages. I had the whole responsibility and worked day and night. I used to take my brothers along to sit in the workroom with me because I was scared of the rats.

In Edna's family having a job meant one less mouth to feed, and Edna was determined to get a good job to escape the family's poverty:

My father said that the day we turned fourteen he would cut off money to us and we would have to get a job. I was 11 but got three years of secondary education. At school I knew that I had to go like hell so I would get a job and I did not want a factory job. I got a job straight away doing office work. I went to night school straight away and I passed my Government exams.

Matching the dreams with the realities was not always easy. Audrey had little education and was still dreaming of the career she would have liked:

I was very interested in cooking, I always have been. Had there been the opportunity I would have loved to have done the Home Science course at Dunedin. But there was no way of doing it. I would have given anything for that and look how it would have helped me

Helen: So what did you do?

Housework, there was nothing else in a little town like Opunake. So I learnt to sew, learnt to iron and learnt to cook. It was a good education for what was to come. I got $5 /$ - a week.

For Winifred impoverishment was not the problem, but her sex was:

I had wanted to be an engineer. I had wanted to be able to take machinery apart. I told my family I would love to do this. My father almost had a fit. Helen: That would have been an unusual request for then.

Oh most unusual. But every time I went into the garage I used to hang over watching them fiddle with the car until my father said I had to stop that nonsense. So I had to stop.

Winifred lived on a remote farm and had no paid employment before her marriage in her late thirties.

Helen: What if you had suggested a career in nursing or teaching?

Well nursing, definitely yes, but engineering was quite out. The only thing I wanted to do was to pull things to bits. I always used to pull lawn mowers to bits if they broke, and put them together again. 
Most of the women felt that they had climbed the economic ladder if they got jobs in nursing. teaching or clerical work, but it was only Meg who moved beyond the realms of "women's work" and found a career in business. She modestly asserted that it was not through any brilliant talent but because my father knew the manager. I made out OK but they were falling back on women as a last resort because of the war. Meg was one of a new "breed" of women who were to argue for new equalities for women, and she had dreams of combining marriage, family and a career.

\section{THE LABOUR VICTORY}

The Labour Party victory in 1935 was a watershed and has taken on its own mythical dimension as the magical end to the depression. Labour had come to power with a mandate to get things right. Their manifesto captured the mythic drean and was entitled: Labour has a Plan. The way out of Chaos to a Land fit for Heroes. It was not so simple, but in the minds of many New Zealanders the Prime Minister Michael Savage was to be remembered for introducing security for the working man. In a tribute that was typical by many New Zealanders of their class and generation, the picture of this mystery face was to smile benignly from the wall in my grandparents' house. (I was a teenager before I discovered he was not a relative.)

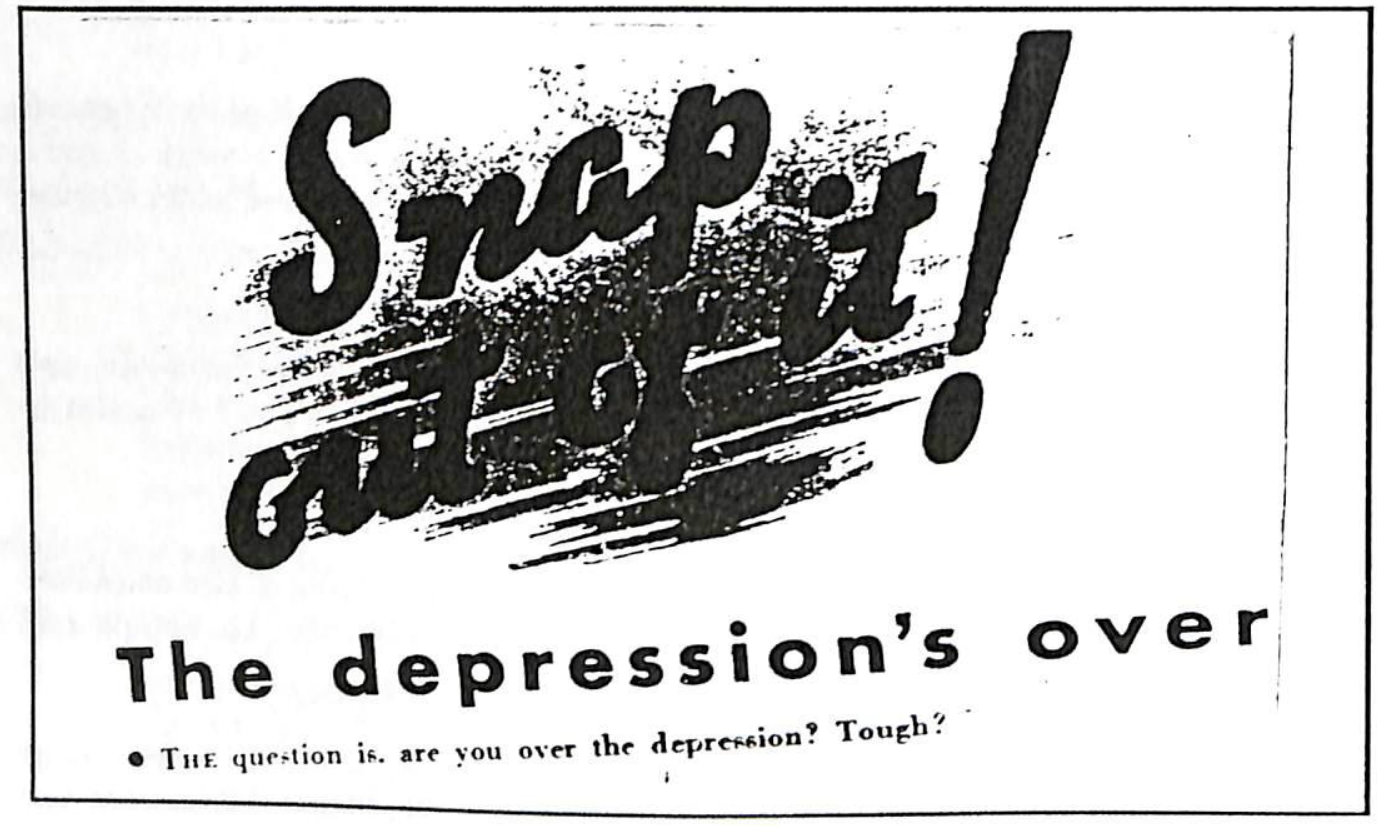

Tony Simpson was to state:

Every government in a democratic political system is faced with the task of reconciling reality and mythology...The first Labour Government was a triumph because it succeeded in doing that (1976:107).

New Zealanders experienced the myth in a tangible way and the women in this study were no exception. The childhood memories of the depression were deeply implanted, and still active, but so were memories of recovery. The 1936 Industrial Conciliation and Arbitration Act 
endorsed the basic male wage as being "sufficient to enable a man...to maintain a wife and three children in fair and reasonable comfort" 6 .

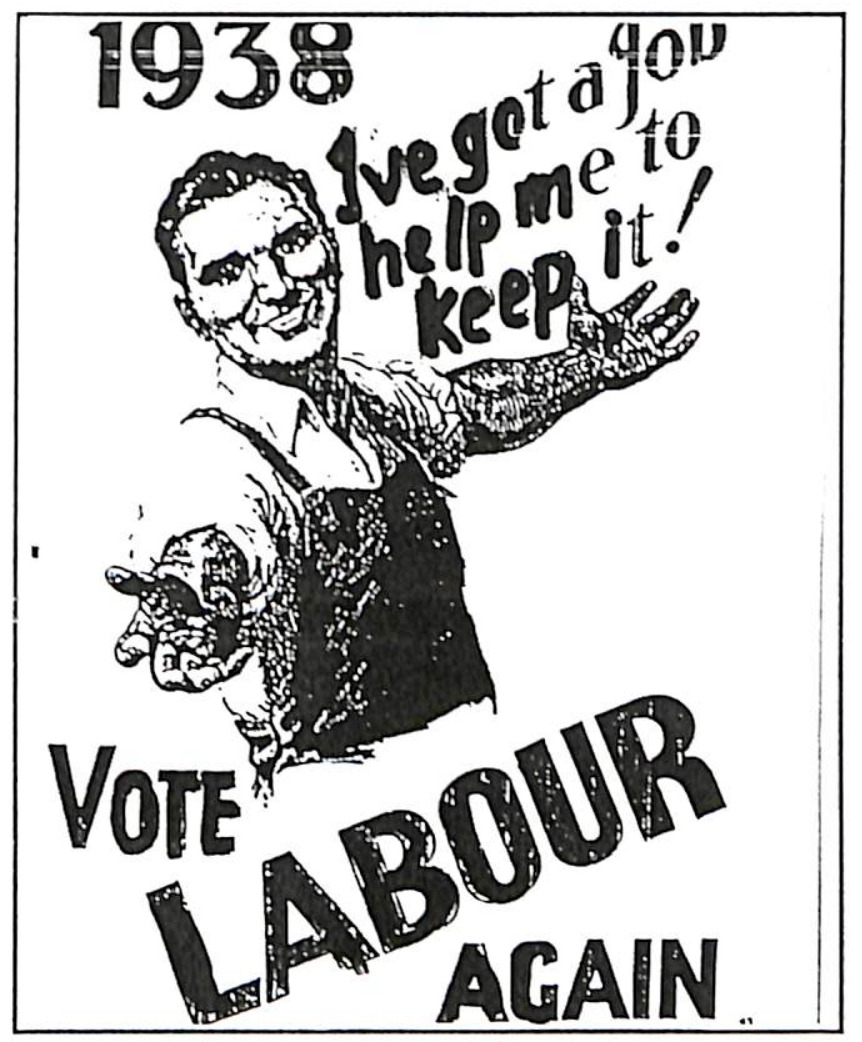

This was hailed as progressive legislation and the ideal still lingers into the 1980's. At the time it was to consolidate into law separate spheres for men and women, and to negate the Labour Party's earlier support of equal pay ${ }^{7}$. Women were to be assured security as wives and mothers, as opposed to their exploitation in the workforce (Kane 1972). Similarly the 1938 Social Security Act and its aftermath of welfare legislation became the comerstone of expectation which successive governments have been unable to retreat from. Peter Fraser as the Minister of Education and the Director General of Education, C.E. Beeby, were architects of a view of education which would pave the way to an egalitarian society through equality of educational opportunity (Beeby 1986). In this way the depression and the recovery became powerful symbols of security versus insecurity.

Brenda: $\quad$ I believed in the welfare state. We really thought it was marvellous and that comes from 1935...The free dental treatment, free hospital. When I had the miscarriage and my wages went on and everything was free I thought it was marvellous. The free education was marvellous. The whole welfare state was great.

We still feel it. I joined an Insurance Scheme the other day but I came home and said that I felt I was selling out after all those years.

\footnotetext{
${ }^{6}$ Book of Awards xxxvi. P.715. Cited M.A. Kane (1972).

7 The equal pay remit that had been won in 1927 was lost at the 1935 Labour Party Conference (Kane 1972).
} 
Brenda's statements were echoed by the other women and it showed an attitude towards government benevolence that is part of understanding the women of this generation. The fact that governments could bestow tangible benefits made it difficult for women to organise collectively and confront government power and priorites in the way the women of a later generation did.

\section{THE WAR}

Despite the aftermath of pain that lingered from the First World War there was little real criticism of the decision to go to war in 1939 (McLeod 1986). There were 59,644 volunteers but disappointed by the lack of response, the Government introduced conscription in mid 1940. Involvement came by cajoling and legislation rather than through any spontaneous enthusiasm. Brenda recalled:

Brenda: $\quad$ That war came so soon after the First World War. The contradiction of my father's patriotism and pride and my mother's cynicism affected me. My father was ill but his two sons in uniform and his RSA badge on. He would say "It is the proudest day of my life". I remember my mother saying, "Poor silly bugger".

Such cynicism was not the official viewpoint and Walter Nash was to proclaim:

The war has the first call on every man and every woman, on every pound and every penny - every form of activity. (1943:43)

War was to be the division between austerity and prosperity, and it came when the women in this study were moving into their adult years. The war generated swift action ${ }^{8}$ and adaptable values, bringing new austerities and new resolve, while heightening expectations for a better society in the future.

My generation grew up amidst stories of "the war", but it was mainly a male version of the war. My father spoke little of his experiences, but as a child I perused his photographs, and played with his medals. He was a bandsman, and later a medical orderly with the 2nd N.Z.E.F. My memories of my mother's war was that it was centred around my father: saying goodbye at Burnham Military Camp, getting engaged by mail, the return of his troopship in 1945 and the march of the soldiers through the streets of Christchurch; their marriage in 1945 which got embroiled in a close down of services as the war with Japan ended. What my mother actually did during the war years was something I did not seem to know, or maybe hadn't remembered, until I began this study.

8

Out of a population of $1,630,000$ :

700,000 in the total workforce

150,000 men were sent overseas

124,000 in the Home Guard

75,000 women in the Women's War Service Auxiliary

37,000 people manpowered into essential industries

11,625 killed

17,000 wounded

21,600 ex-servicemen were receiving disability pensions in 1955 (Sutch 1966:285). 
The women's war in New Zealand, like that of the depression, is only starting to be known, collected and recognized as the herstory it is (Ebbett 1984; Edmond 1986). Edmond has stated:

The stories of men at war have been told and retold. They have become the heroes of Hollywood movies and their deeds have become venerated myths to be remembered at dawn parades. Yet till recently women's experiences have all but been ignored. Nobody thought what women had done mattered (N.Z. Sunday Times September 21 1986).

The final volume of New Zealands official war history, The People at War: The Home Front (1986) by Nan Taylor redresses some of the imbalance, but it took 41 years to be written. In the meantime, the myths we were reared on were powerful: for example, the view that the war was good for women because they gained new equalities and opportunities in the workforce, and that after the war women were forced back into the home. Elements of this are true but the reality is not so simple. Women did gain new options and wider horizons as Lilian Barnard told Eve Ebbett :

I really feel that it was the beginning of women's liberation, the war, because we had something different to do.(1984:11)

Edmond (1986) however, found little evidence of liberation politics in her collection of women's oral war stories. She acknowledged that it was "an expanding time" for women, but they were doing it out of a "massive loyalty" to their men and the nation. "There was never any talk of new found equality" (N.Z Sunday Times September 21 1986). The work, too, was hard and long, and many women were relieved when the men returned to take on jobs women felt they should not have to do.

Jane: $\quad$ Women had been doing this for 4-5 years. You can imagine the relief in handing over the job...Some of those women had the potential for better jobs and didn't want to be mucking out pigsties. They were doing it because it was a service for the war. Women are so damned conscientious that they would be doing these jobs even if they hated them.

War work caused more women to leave home but Eve Ebbett wrote that there was a certain irony in gaining new independence during the war.

Better wages did mot necessarily mean material prosperity. After growing up in poverty, many women reached working age to find that what they could now afford was not to be had and must be done without. (1984:15)

Once the impact of war began to be felt in families, a "spirit of organisation" (Guy 1943) was awakened amongst voluntary women's societies who found new needs and new causes. The booklet Women on the Home Front (1943) by C. K. Guy, described the voluntary schemes that were started to give domestic and childcare assistance to women. This arose from the new demand for women's labour but was also a reflection of the 70\% drop in domestic staff between 1936 and 1945 (Fletcher 1949). That domestic assistance was being arranged voluntarily fuelled the demand that the state should be providing it. In August 1943 the Minister of Health, A. H. Nordmeyer, convened a conference which was significant in the sense that it was the first time there was such a public focus on the role of women in the 
home 9 . A Government scheme of domestic help was called for that would extend beyond the war. There was a call for raising the status of household workers and a wholchcartcd approval for the expansion of kindergartens, nursery and creche facilitics. Issues like communal laundries, electrification and labour saving devices were also discussed. Although little of this eventuated, women's experiences during the war generated a new political consciousness of the working mother and the needs of her family, and of the nature of women's work in the home. This created an expectation that governments would become involved in the problems of the home (Kane 1972), which would not have been possible without the event of the war.

During the war years traditional codes and responsibilities cut across new work experiences and new kinds of independence. Old divisions between men and women broke down, but the war still accentuated the separation of the male and female world. The male world was symbolically centred around military service overseas while the female world was to "keep the home fires burning" at home and in the workplace until the "boys came home". For women this was a double load. Nell expressed it this way:

Well you did the men's job, you carried on. That was your thing to carry until they came back and hand over their jobs to them. I can remember Dad writing from the war about when he came back someone would be doing his job. But the people that were doing his jobs were holding them for him. You were keeping the machinery going until they came back.

Helen: Were women reluctant to give things back?

Well that might have happened in some cases where a job had previously been occupied by a man. It didn't happen in any work that I did. But in those days you would sort of say "She works and she's a married woman" I can remember it being said.

Traditional codes may have been strong, but women learnt that these codes were not intransigent if harnessed to the right cause.

During the war and its aftermath guilt became a powerful tool.Your lives were very much affected but you felt you weren't really doing anything (Brenda). This coloured women's consciousness of the worth of their work. In comparison to the men overseas in the real war the work of the women's war was experienced as secondary as if you were doing nothing, despite official applause for the contribution of women. Feelings of guilt and self effacement not only acted as subtle pressures on women (Chetwynd and Fenwick 1977), but were powerful in assuring that the women's war was trivialised or forgotten, or that women's work during the war was seen as extraordinary and out of character.

Beyond the common experiences of shortages and extra work, the effects of the war on the women in this study varied. Some were still finishing their education:

Brenda: It really messed up our education. All the male teachers went away. We were a very badly behaved class and were completely out of control. I

9

There were approximately forty people invited to the conference and representatives from organisations like Women's Division of the Farmer's Union, War Women's Service Auxiliary, Wellington's Mothers' Helpers, Plunket Society, Townswomen's Guilds, Women's Institutes, Home Service Association (Guy 1943). 
think that was due to the war years. It was an imbalanced education and it took a long time to make it up.

There was an excitement. Every time an old boy was killed there was a special assembly. We would all try to faint - this little girl sort of thing.

Gladys: I went to Grammar but didn't make friends as they came from all parts of Auckland. I felt isolated and there was a war on. Dad was in the Home Guard and Mum was going out to see that all the lights were off. She had her gas mask. But it meant that I was on my own a terrific amount. There were so many changes going on. I decided to leave.

Amidst the disruption Jane saw positive things for girls:

At Teachers' College all the men were called up and that included a man I was having an affectionate relationship with. In terms of our ability to know what men were like we found this rather difficult. But I think we began to assume responsibility for various things that we wouldn't have otherwise.

All the women had relatives, boyfriends or husbands overseas, and some did not return. Stella lost her fiance and she rushed into a marriage which was unhappy. Her life was hard although she stayed in the marriage until her children had gone through school. Winifred lost a brother:

My youngest brother went overseas in the tank corps. He was one of the youngest New Zealanders to leave and he was killed. He was killed in the desert, shot by the Germans when he was out on tank duty. We didn't know for a long time that he had actually been killed. We thought he had been taken prisoner.

Irene: $\quad$ The letters came and then didn't come and the terrible time when the police came and asked where Aunty and Uncle were and told me to go and put the jug on. My cousin was missing believed killed. He was in the airforce. The heartache of it. We found out later that he had come down and had been hidden by some people. They were all shot. My aunty has been over to visit his grave.

Edna: He was captured in Greece. I found out how to go about and get information to him. He was there for five years.

Helen: How did he survive it?

Not very well. He is still a bit of a wreck. He had colitis from having got dysentery on the march out of Germany. The Germans tried to keep them ahead of the Russians. A lot died on the road.

The examples could continue, but a later chapter will show that some of these women are still supporting husbands whose lives were scarred from the effects of war wounds or deprivation.

The war was to disrupt the usual progression of courtship, engagement and marriage. This meant a delayed marriage for some, but for Jane an engagement, marriage and embarkation were squeezed into a three week whirl. It was pretty grim, it was bad. And I went home to live with my parents. I was twenty then. Irene met her husband at a welcome home dance for the first furlough draft in 1943. He had fallen down a cliff getting off Crete and was 
graded as unfit. ${ }^{10}$ She was to have a war time wedding hastened somewhat by the chance of accommodation:

I wore my friend's sister's wedding frock. It was a beautiful prewar
magnolia chiffon velvet. We actually got married at three week's notice.

The war brought new codes of behaviour for women. Although the veneer of pre-marital virginity was the official ideology (Middleton 1985b), it was inevitable that women would seek new relationships amidst the enforced separations. The divorce rate doubled and there was a rise in the illegitimate births ${ }^{11}$. Women were encouraged to entertain the troops particularly when the Americans arrived as the war shifted into the Pacific and closer to home ${ }^{12}$. But there was a double standard as women were expected to both be faithful to the men overseas and be charming hostesses to soldiers at home. The Y.W.C A tried to create a haven for respectable mixing between women and soldiers (Coney 1986).

Irene:

We used to go into town to the Union Jack Club and the Welcome Club. You were effectively vetted to see that you were a nice respectable girl. You were not suppose to meet a returned serviceman outside. I never had any problems of men going too far. Amongst your selves you would say Edna saw a different view:

"Watch him, he belongs to the W.H.B". (wandering hands brigade).

The tragic thing was that the plainer girls would lie under the bush with anybody. The girls who had professional daddies would immediately have the officers, and the ordinary rank and file fellows would have the ordinary rank and file girls like us. Some wouldn't be seen with anyone unless they
had pips on.

The American soldiers dazzled New Zealand women (Kidman 1982; Drummond 1984) and despite strict codes of sexual conduct, girls had to be protected. Schools took no chances against the friendly "enemy". Gladys remembers being escorted daily in crocodile form to the bus, past the waiting American soldiers But the inevitable happened:

Gladys:

I took this American negro home and well you can just imagine it. Mum word was there tight lipped, The problem got worse because every second mother. It was dreadful. My father saw the funny side of it, but not my

Beyond the hardship, bereavement and disruption, the war years did provide some opportunities that the women in this study might not have had. Several were able to leave small rural towns and go nursing in the city, which was hard work but gave a taste of

10 This draft of 6012 men returned

remaining for medical reasons, mant from the Middle East on furlough. Although many were court martialled (McLeod 1986). 11

In 1944 illegitimacy rose from 4\% to 6\%. This was the year in which the most Americans were here and the New Zealand men were absent in their largest numbers. 12

There were some 42,000 American soldiers in New Zealand undergoing training, recreation or medical treatment at the peak of the war. 
independence. Jane and Stella who were teachers got promotion rapidly, although conditions were grim.

Stella: At $\quad$ I had 67 children and two classes. They had been without a teacher for six weeks. The noise when I went into that room. I said "Good morning" and they held their lids and let them slam down. I went to the headmaster and said it was quite impossible. He said "I'll fix them". So he came in and said "Shut up". That first week we went through exercise books and exercise books, anything to keep them writing.

Irene was manpowered ${ }^{13}$ out of her genteel job in the elegant department store of Ballantynes of Christchurch to work in a shoe factory:

We made clogs for Indians because evidently they were giving our men tea. We had lots of fun because the side fence of the factory back yard was a back fence of a private hotel where the airforce was billeted.

We had very strict timekeeping at the factory. They would dock your pay half an hour if you were only a minute late and you had to work the half hour as well.

We used to sit at the machines wearing overcoats and I had an old coat of my father's over my knees and there would be water dripping down the bricks inside the building.You can see why there was a need for unions.

When war ended though women did not generally turn the opportunities gained into an issue of establishing new equalities. Jane summed up the feeling:

There was the feeling "Oh thank God, Oh the relief". Now we can go back and the men can do the things that we found so stressful. Also the psychological relief of knowing where everybody was and that people would come back. Most of the women I knew were quite happy to assume the maternal role. We never assumed otherwise.

The question which underpins this study is the extent to which the experiences of women during the war affected their lives later on. Beyond the more direct changes that have been described, the impact was more subtle because families wanted to erase the war years and to move towards (backwards) to an ideal of normality. The mechanics of this process is addressed in the next three chapters but it is relevant to foreshadow its beginnings. That women would be different after the war was officially acknowledged in the N.Z. Army Current Affairs Bulletin. In an issue on "Women and the War" (Vol.1 No.15. 1943) "for soldiers to read and discuss", they were warned:

The new capabilities developed in wartime...will probably create among women a new awareness of what is possible for them (P.10). It will be no "man made" world which emerges from this conflict (P. 12).

The Bulletin outlined the issues concerning equal pay, childcare, the declining birth rate and married women who worked, and asked, "Will this injure the home?" (P.10). The official prediction was that:

The desire for a home though often postponed and thwarted seems indestructible...It is unlikely New Zealand women would lose their affection for homes or children even after years in the factory or the uniform (Pp. 10-11).

13 Unless single women were working in what was deemed to be an essential industry, they could be directed into war work. 
And it was right.

Beyond the "liberating" potential of the war experience in allowing new codes, it was generally acknowledged that war was a temporary situation from which significant changes were not wanted (Anderson 1981).Even the appeals used to mobilise women towards the war effort did not challenge basic beliefs about women's role. Women's work in the home and the workplace was justified as a patriotic duty to the country and to their family. Women could help end the war, bring back the men and thus bring security to family life (Hartmann 1982). Women's work was still in the realm of home and family as the home extended to the home front.
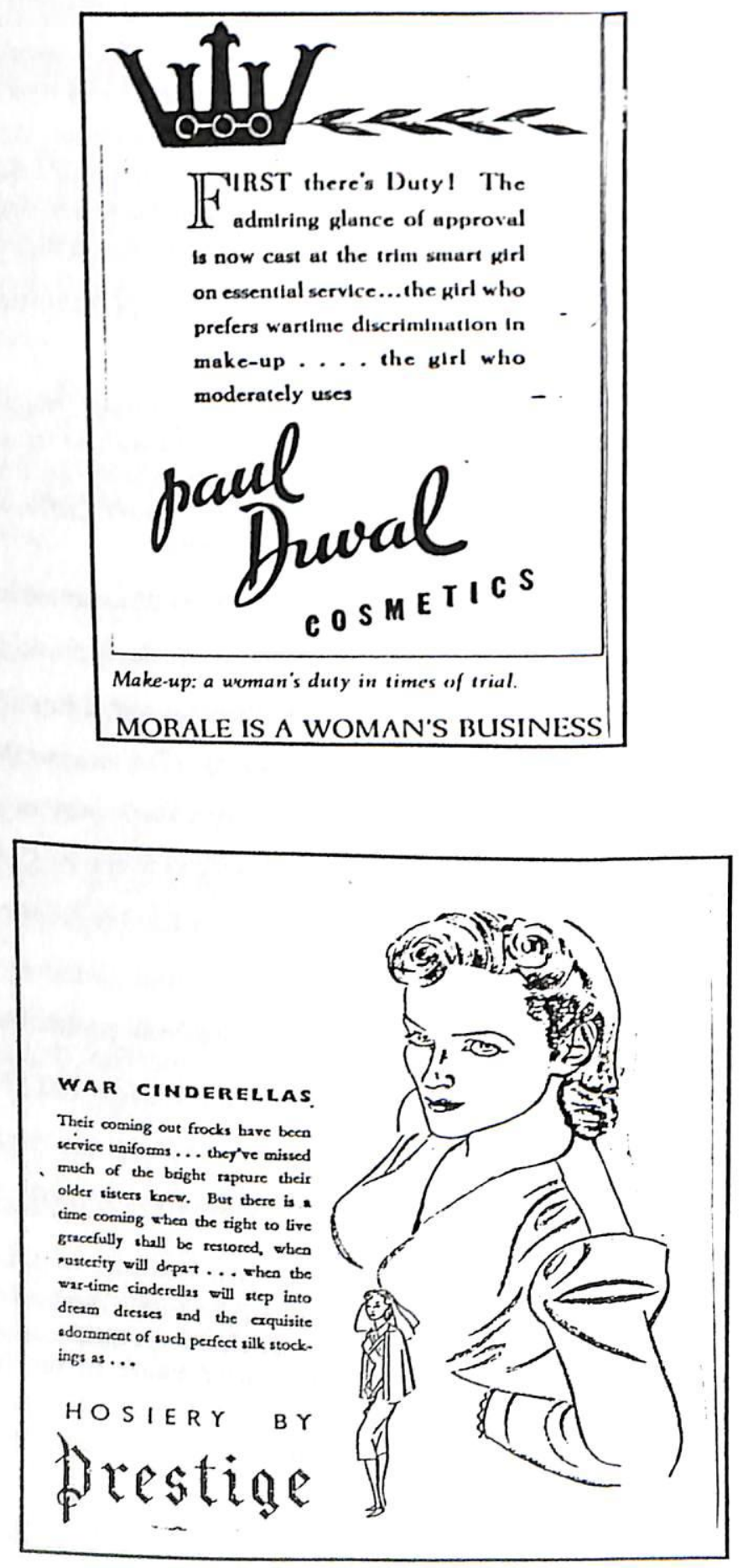
The war showed that values were transportable. Mend, make-do and thrifty homemaking previously associated with the depression were exalted as a patriotic task. It was now a virtue as well as a necessity. The Woman's Weekly ran a column entitled "War Economy Hints" and as the war ended it was retitled "Economy Hints". By the 1950's the same column became "Surer Shopping" with advice on purchasing new home appliances. In the span of a few years the economic circumstances had changed, but in each context women were serving the nation by serving their family, whether it was for the war machinery or big business. The sex role prescription remained intact, but unlike the war years when women's work was regarded as real work, in the postwar period women's work, paid or unpaid, again became "non-work". The focus shifted to the real work of the "returned men" as breadwinners and protectors (Anderson 1981), while women's work in the home was portrayed as a feminine leisure activity (Winship 1981).

The war encouraged a double standard of femininity. It bolstered the imagery of the independent patriotic woman. Women were to demonstrate strength and initiative during the day but there was a concern that traditional femininity and family responsibility not be undermined, and women assumed their traditional roles out of "work" hours. The war generated a heightened consciousness of romantic love and conventional family roles (Anderson 1981; Middleton 1985b). The exaggerated emphasis on family life in the postwar period is a legacy of these contradictory experiences. Yet the next chapters show that a new political and personal consciousness of women's abilities generated by the war existed alongside the support for separate spheres for men and women. These did not mesh together easily at the political level, or in the personal politics of family life, and this was to set up the conditions for the collapse of the "feminine mystique" (Friedan 1963). 


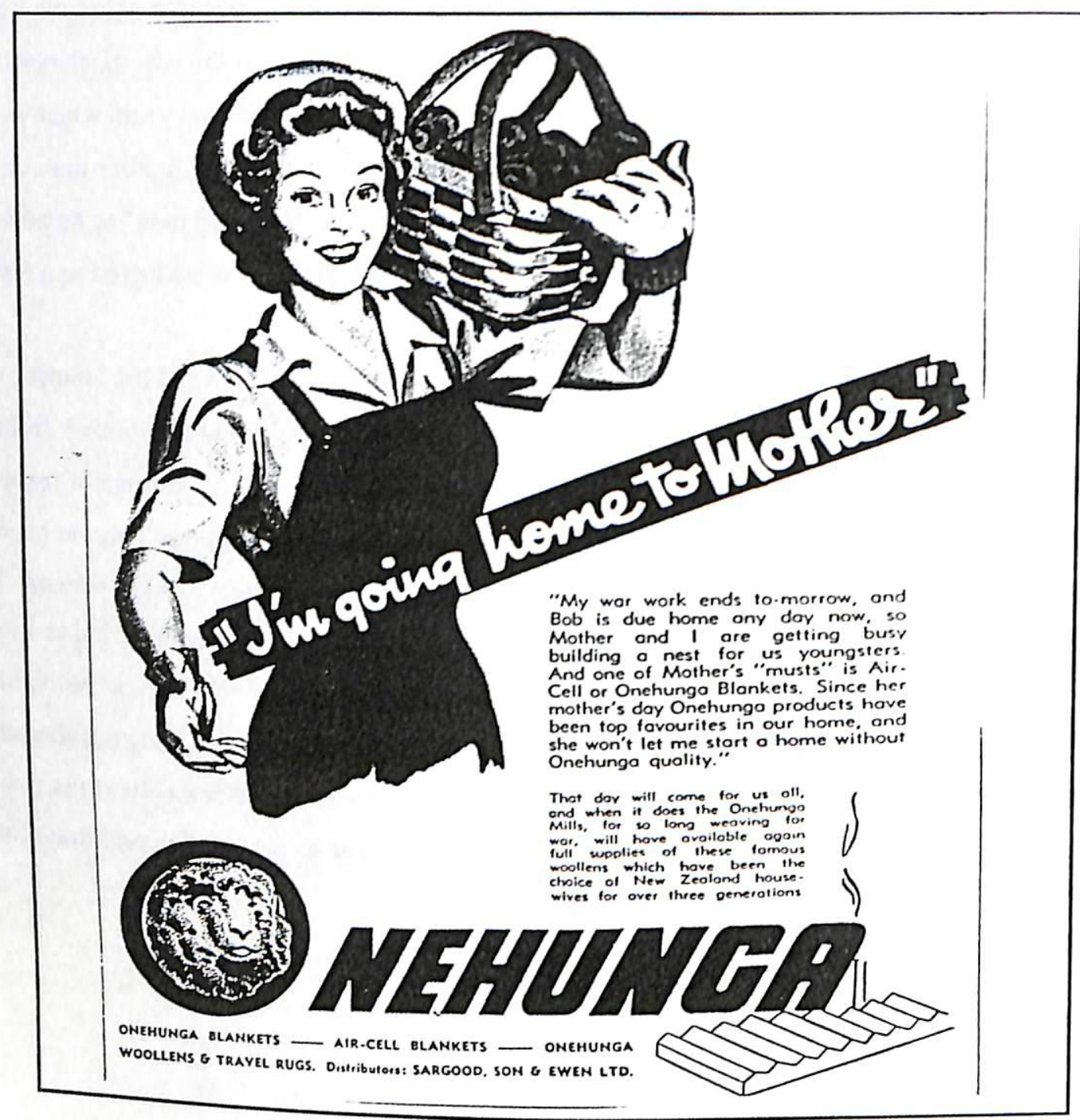




\title{
THE CONTEXT OF LIVING 1945 -1960: DREAMS OF A NEW ORDER
}

\begin{abstract}
The way had been prepared earlier, but the breakthrough came with the end of the Second World War. In less than twenty years the whole society had passed through a series of awakening experiences - depression, recovery, mobilization, the prospect of invasion, victory, peace, and the brief surge of hope it brought. These crowded years transformed a colonial society into an independent one...they underlay the more diverse developments of later years (Oliver 1981:430).
\end{abstract}

In industrial societies after World War Two there was an increasing ordering of social life, to be justified as improving the welfare of the individual. In New Zealand this was to operate as a "quest for security" (Sutch 1966) against the economic and social disruption of past years. Walter Nash ${ }^{1}$ wrote in his wartime blueprint for the future, New Zealand: A Working Democracy:

Whether the conclusion of war will mark the end of one era and the beginning of another, the end of imperialism and the beginning of a century of the common man, will depend very largely upon our capacity so to organize our affairs to guarantee to all men greater security, greater opportunity, a fuller and happier life than heretofore. (1943:157) (My emphasis)

The ideals of security and opportunity were part of New Zealand's egalitarian myth, but they had an uneasy co-existence as successive Governments tried to deal with the ambiguity of simultaneously guaranteeing, yet tempering the excesses of both.

The ideal of security was pervasive in many dimensions of life and this required a consensus view of society that was orchestrated more thoroughly than was possible before 1945 (Pearson 1952), or later in the 1960's. There was a more united vision of the future (Shuker 1985) centred around the welfare state, which for a while embodied both the right and left wing versions of the "good life". This kind of unanimity was demonstrated in the 1949 referendum for compulsory military training in peacetime. To persuade a population who were tired of war, all householders received a booklet with supporting statements from both the Labour Prime Minister, Peter Fraser ${ }^{2}$, and the National Party Leader of the Opposition, Sid Holland ${ }^{3}$. As communism replaced fascism as the enemy, the Leaders' messages were steeped in an emotional rhetoric of the imminence of a closer danger, and a warning that the long awaited social and economic security at home was under threat, unless military and political security was also guaranteed:

Fraser: While forms of dictatorship threaten, New Zealand must be capable of defending itself...peace is precarious, we cannot neglect to take elementary commonsense precautions.

\footnotetext{
1 Minister of Finance in Labour Government 1935 - 1949. Prime Minister of the second Labour Government 1957 - 1960.

2 Prime Minister of the Labour Government during the years 1940 - 1949.

3 Prime Minister of the National Government $1949-1957$.
} 
Holland: $\quad 320,000,000$ people in subjugated countries have been enslaved because they were unprepared to defend their freedom...it is manly to defend onc's country. 4

Both Parties were united against the potential threat of communism and thus began a campaign of persuasion that Russia, a former ally, was now a major enemy ${ }^{5}$. If New Zealanders were somewhat uninterested in the growth of Communism there was more awareness that military training was good toughening up discipline for young men whose lives were easier than those men who had already "served their country". The referendum was won ${ }^{6}$ despite opposition from certain sectors of the Labour Party, the Communist Party and peace groups, who saw it as a threat to civil liberties and an intolerance towards minority views $^{7}$. Historian Keith Sinclair was to write that, "The whole business smelt strongly of the plebiscite of dictators; but few people seemed to have sensitive noses" (1959:286).

There is little critical analysis of New Zealand society during this period. Historians, economists and sociologists have been more energetic in their analysis of later decades, but the 1950's have been remembered and recorded as "golden years" (Shuker 1985:21) of "unsurpassed prosperity and social tranquillity" (Dunstall 1981:347). And from a global overview of industrialised societies, Ernest Gellner (1987:111) termed the era as the "belle époque" in the sense of a "striving towards social justice and liberty all at once". In New Zealand this "good life" of the postwar period was reaffirmed in contrast with the earlier years of rationing and economic controls, but also from the distance of time when later problems appeared greater, and life in the 1950's seemed sweeter. This has become the myth that was powerful even then, but myths are sustained by contradiction. Jean Wishart the Editor of the Woman's Weekly noted:

It is time we asked ourselves why, in a time of great material prosperity, when the standard of living is undoubtably higher than it has been, there should be so much bickering and quarelling, so many murders and divorces, so much obvious frustration and unhappiness (N.Z.W.W. December 3 1949).

There was a growing prosperity (Sutch 1966; Chapman 1981) but it existed alongside the hard times families had in matching the ideal, and this is demonstrated in the lives of the women in

4

Statements by the Prime Minister and the Leader of the Opposition on Compulsory Military Training, Government Printer Wellington.

5

In any reading of the magazines and newspaper articles it is easy to notice the quick shift in attitude during the late 1940's towards Russia, and a little later towards China.

6

With a $57 \%$ poll there were 535,816 votes to 152,573 . The Labour Government abolished
conscription in 1958 but Nations was employed. 7

Frank Langstone M.P. Why I Oppose Conscription Forward Press, Auckland (no date).

Auckland District Committee of the New Zealand Communist Party For Peace Against Conscription: Must Our Children Die? (no date).

Fergussen, J. Why Conscription? N.Z. Peace and Anti Conscription Federation (no date). 
this study. There was however a difference from the earlier years of hardship, as there was optimism that things would continue to get better. For most they did.

Jane: $\quad$ The depression was behind us. Housing was being put up for everyone. Education was being raised and you couldn't leave school until later. There was an optimistic note. For New Zealand its overseas contacts for its markets were reopened again with the war finished. There was an optimism and it was quite clear where we were going.

The general feeling was that our creative feelings could go into better food and better clothing and better family arrangements. It was creativity through the family.

It was also a time of new ideas, seen by W.H. Oliver as the beginnings of a "Small but real intellectual revolution" (1981:430).

Brenda: $\quad$ What influenced me was the wave of new immigrants after the war and the total change in values. Immigrants from Europe threw our value system upside down. They were left wing and Jewish and quite old for their age. It was an exciting time with literature, the Penguin New Writing - all those books! The Chamber Music Society started up at this time and we started to get overseas artists. It was the time the Unity Theatre started. Lili Kraus came to Teachers' College. She had black slacks and a black jersey and a long black pigtail and she played Mozart ${ }^{8}$. It was marvellous. Susan Isaacs was our textbook ${ }^{9}$.

Such innovation and energy however, had to be contained within a consensus rationale. This was bound up in a clear demarcation between acceptable and unacceptable, adjustment and maladjustment, and in such a small population as New Zealand there were few comfortable niches for alternative views or life styles. Sylvia Ashton-Warner's ideas on the education of Maori children during the 1950's were seen as a challenge to established views on education, childrearing and race relations, and were thus unacceptable to the Department of Education and New Zealand publishers. The Department "lost" her Maori Readers ${ }^{10}$, and her book Teacher (1963) languished for seven years until it was published in the U.S.A. Obstetrician Dr. Diana Mason, wife of playwright Bruce Mason recalled the awkwardness of their reversed roles during the 1950's as she earned the family living:

Nor perhaps did we fully appreciate the flac the children had to ward off from their peers. Bruce may well have been one of New Zealand's first house husbands. The term was then unknown. All the children knew that it was regarded as weird that their mother went out to work and their father stayed home and scribbled (1986:31).

Normality however was guided by prescriptions that were often difficult to achieve. For example, to live in a "normal family" with mother as a homemaker and father as a

8 Hungarian born concert pianist Lili Kraus and her Austrian born husband had been issued New Zealand passports before the war, however en route New Zealand they were imprisoned by the Japanese and did not arrive until 1946. Lili Kraus died in 1986.

9 Susan Isaacs was promoting new ideas in early childhood education. She had visited New Zealand earlier in 1937 on behalf of the New Education Foundation, a British organisation that promoted progressive education.

10 Sylvia Ashton-Warner had illustrated these herself drawing on the experiences and words used by Maori children. 
breadwinner; to set up the ideal home that had more material goods than ever before; to raise "normal children" according to criteria that were more exacting than in earlier years, required a high earning capacity from men and a selfless dedication from women. The abnormal was characterised by labels such as "weird", or "deviant", and was ascribed to anything which did not fit the consensus prescriptions governing family life, political viewpoint or cultural perspective. This was part of the process of "marking the boundaries" of order (Wilson 1980) and what was within the boundaries was conceived in terms of normality: "normal family life", "normal children", "normal development". There was however a mood of optimism that education, science, psychology and new economic and social policies could turn the abnormal into normal, the unacceptable into acceptable. What was needed was expertise and individual will power.

R.D. Laing, the psychiatrist guru of various 1960's rebellions against conformity, was to write savagely about the 1950 's preoccupation with the "normal man" and his consequent alienation from society:

What we call normal is a product of repression, denial...Society highly values its normal man. It educates children to lose themselves and to become absurd, and this is to be normal. (1967:27-8)

Laing later characterised this kind of society as a madness which destroyed the individual potential by dragging people towards conformity:

By the time the new human being is fifteen or so we are left with a being like ourselves, a half crazed creature more or less adjusted to a mad world. This is normality in our present age (1967:58).

This paradigm of order in which "normality" would be the outcome, permeated many facets of everyday life. It was operative within the wider political and economic spheres in terms of collective security and material prosperity, family relationships in terms of stability and social order, and the individual through psychological management. This chapter examines various ways in which the paradigm was constructed. The following sections present five scenarios, which in themselves represent small slices of everyday life, but as a collective statement are as part of a fabric that made up the context of living.

\section{POLITICAL SHIFTS AND ESTABLISHING ORDER}

Peace when it finally came was a glorious relief - but we soon discovered it was only an interlude. World War Two had been the major conflagration, but there were other fires of hate and discord still burning. Are we racing headlong to self destruction in this so called atomic age? Is our democratic way of life more secure...is that "new world" any nearer to being a reality? (Jean Wishart. N.Z.W.W. August 26, 1954).

Throughout the period there was a growing fatalism that there would be a World War Three with new allies and enemies, and that it could be atomic. The United States was successful in unifying political thought in the West, and New Zealand's political leaders promoted these ideas at home and, "Though New Zealand still developed some independent minds...the 
majority found (these ideas) acceptable" (Sutch 1966:337). Peace groups ${ }^{11}$ gained a small momentum but in the main the backdrop of political warmongering and the politics for peace did not touch the lives of most New Zealanders whose concern was with politics at home and in the home.

The Labour Government emerged from the war somewhat tired but they were elected to carry on. They had set in place a comprehensive rehabilitation scheme for returned soldiers, and they espoused an egalitarian vision of postwar reconstruction and the "new society". There were lurking fears of a postwar depression as the economy shifted from its wartime schedule and the electors wanted to be safe.

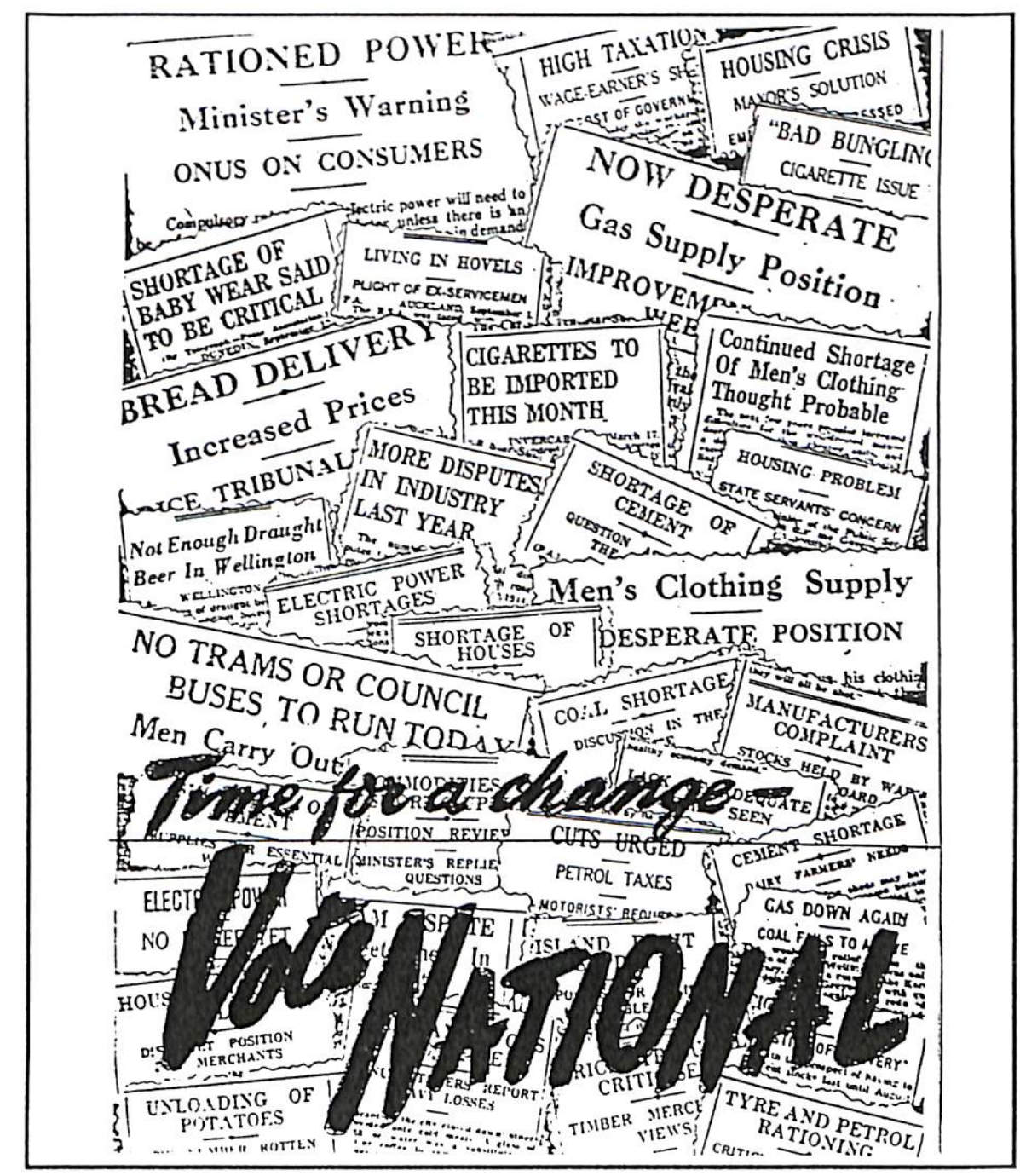

The depression did not eventuate, the rehabilitation schemes worked but household austerities and economic regulation continued. Labour saw these as necessary to facilitate the reconstruction programmes but they frustrated the ideals of individual opportunity. Simpson voiced the resounding view:

11 Campaign for Nuclear Disarmament (C.N.D.), Peace Pledge Union, National Peace Council, Christian Pacifist Society. A rallying point was a Hiroshima March and rally in the main centres (Grant 1986). The conscription legislation of 1949 also generated activism within these groups. 
They were sick of rationed butter, petrol, tea, clothing and meat. Rehabilitation was the final success. After it was completed the party rolled over and died (1976:130).

Historian Robert Chapman's view was that:

New Zealanders themselves had changed because of the war and the opportunities opened up by economic and social security. There was a drive to enjoy the peace, to take Labours' achievements for granted as the basis for getting on with private life (1981:354).

The voter's dreams of a peaceful prosperity were out of step with the Government's attempts to provide it. Labour was unable to balance the need for security and equity with individual opportunity, and thus the National Government under Sid Holland came to power. Since being ousted from power in 1935 the National Party had astutely accommodated the depression fears of insecurity and promised a commitment to the welfare state. But more than that, they harnessed the frustrations of constraints, scarcity and regulation and promised a material utopia and the individual freedom to pursue it.

During the next eight years the philosophy of the welfare state shifted from the primacy of individual security to opportunity. Security instead was promoted as a national concern for protection against enemies at home and abroad. The National Government took on board the United States' definition of democracy as free enterprise, and socialism as a form of totalitarianism $^{12}$; the threat of communism provided a powerful weapon for promoting a consensus view of living. Underlying the consensus politics were conflicting views, and by 1951 these had erupted into an open confrontation.

The Communist Party had been recruiting more members, particularly within a small group of urban intellectuals and among some sections of the trade unions (Simpson 1976). Brenda:

I came to Training College in 1946. This was the great period of the young being interested in communism. A tremendous wave that began when Russia was in the war and all was well.

My husband believed in the socialist ideal and didn't even join the superannuation as he thought there would be a revolution. My age group was a little younger and we didn't fall for it in the same way. I didn't have that awareness that $P$ had of the depression. He remembers the Queen Street riots ${ }^{13}$...his family were so poor.

Jane: $\quad$ What we were getting from Russia was that women were being engineers and we were getting from Russia was that women were being engineers it. We assumed that that would be a good model. That women were going to get things. Although I don't think that I thought about it for me personally.

The appeal of communism in New Zealand was not widespread but it was sufficient to fuel a political campaign against "reds" at home. Cold war politics had been simmering since the end

12

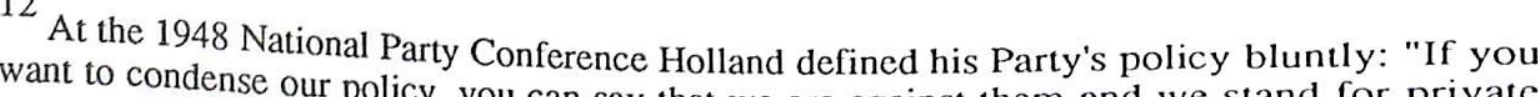
want to condense our policy, you can say that we are against them and we stand for private enterprise" (Quoted in Sutch in 1966:365).

13 On the 14th of April 1982 a union march down Auckland's Qucen Street was joined by thousands of unemployed workers who also wanted to get into the meeting in the Town Hall. A riot erupted (Simpson 1976:84). 
of World War Two (Sutch 1966) but the Korcan War beginning in 1950 officially triggered a hardening of attitudes in New Zealand. President Truman of the U.S.A. and Prime Minister Attlee of Britain both proclaimed the Korean war as sufficient to justify World War Three and called on allies to fight in the name of democracy. In the weekly magazines women were exhorted to protect their homes and families by supporting a new war effort. This time however the enemy could not be pinpointed with such accuracy, or combatted with such unity as Nazism or the Japanese, as the enemy might be active within New Zealand. The "domino theory" was accepted as inevitable:

In South-East Asia communism is trying hard to gain control of Burma, Siam and Vietnam, which produces the rice which feed millions of people. The programme is clear. With control of those countries, Malaya would be next and Indonesia. Thus the biggest part of the communist bridge to Australia and N.Z. would be built. Yes, Potentially we are close to the storm (Roy Theodore N.Z.W.W. February 1950).

The arc is slowly but slowly extending...The infiltration of communism throughout the Far East cannot but have repercussions here, and at the present rate of progress, in the event of a flare up, we stand to fight alone - an unpleasant thought. At all costs further penetration must be halted...The Government need have no fear that New Zealanders will shirk their duty once they fully understand where their duty lies (Jean Wishart, N.Z.W.W. June 29 1950).

New Zealanders did answer the call to Malaya, to Korea and later to Vietnam, although the tiny forces sent were a token commitment to shield the apathy for any large war effort. The fight against communism was also at home. New Zealand's allies had begun their own "red" hunts, but in New Zealand it was the 1951 waterfront strike that whipped up a local paranoia, as F.M.H. wrote:

The whole world today is in the midst of strife, not merely the actual battle in Korea, but all the little undeclared wars where men are striving by devious means to institute communism throughout the world. Here in New Zealand the strife is manifested in the waterfront strike (N.Z.W.W. October 4, 1951).

This bitter strike, or lockout - depending on your viewpoint ${ }^{14}$ was ostensibly about arbitration procedures, but deeper issues came to the fore. The stage was set for a long awaited confrontation by Government towards militant unions, and particularly the watersider's union with their links to the Communist Party which was publicly opposed to the Korean war. Calling for the protection of democracy the Government invoked old regulations ${ }^{15}$ that gave sweeping powers, making it illegal even to give food to striking watersider's families. The strike collapsed and the Government seen as the victor over unionism and communism.

\footnotetext{
14 Michael Bassett (1972) provides the most authoritative work on this dispute.

151913 Labour Disputes Involvement Act

1932 Public Safety Act

1939 Strike and Lockout Emergency Regulation Act
}

Afterwards the National Government attempted to consolidate this power in the 1951 Police Amendment Bill. There was intense opposition to this, and the Bill was amended and then repealed in 1960. 
This backdrop of moral and political unease created an atmosphere for the promotion of social consensus, and there was a carefully orchestrated campaign to the effect that, the dangers of communism could be kept at bay, provided that there was harmony at home. Consensus views and accepted codes of behaviour gained credence too because there was also an optimism that the remaining ills at home could be cured. For socialists in New Zcaland. the 1950 's was a period of believing the unacceptable and the gradual disillusionment with a dream. The "enemy within" ${ }^{16}$ became the new catchphrase and as W.B. Sutch wrote:

New Zealand, as with other countries, went through this turmoil of isolating and denouncing "the left" and of associating sceptics, dissenters, and free speakers as fellow travellers with "Communism" and, by that token, as qualifying for suppression (1966:336).

This was to affect Brenda's husband who had affiliations with the Communist Party:

He did suffer in promotion. It was no question all of them did. They were in mainstream jobs but they were a bit of a bad smell. He left the and went teaching but when a new headmaster came they had to get out as fast as they could. It was dreadful and we had four children. Hungary was the disillusionment and Khruschev's revelations of Stalin. I had never been a member of the Party. I was interested but it wasn't the same disillusionment for me.

For the 1954 election both political parties were to use the compelling appeal of a material security at home against political insecurity abroad. But there was no change of Government until 1957 when Nash, in his old age, was to rekindle again the more collective view of security. The demands for prosperity, and the attempts to deliver it through private enterprise had brought the instability of inflation and high interest rates. This fuelled support for Labour's promises of a new redistribution ${ }^{17}$, but the optimism of a new utopia soon faded and the 1958 "black budget" 18 provoked the reaction that the country had no wish to return to a planned austerity (Chapman 1981). So in 1960 New Zealand returned to the known securities of individual opportunity offered by the National Party under Prime Minister Keith Holyoake.

\footnotetext{
${ }^{16}$ See"How to spot a Communist" by Arnold Kay (N.Z.W.W.September 14 1950). The family benefit was raised. Capitalising of the family benefit for the first family home was introduced. 18

The "black budget" is part of New Zealand's political mythology and despite the years that have passed is still powerful as an insult by the National Party to the Labour Party.
} 


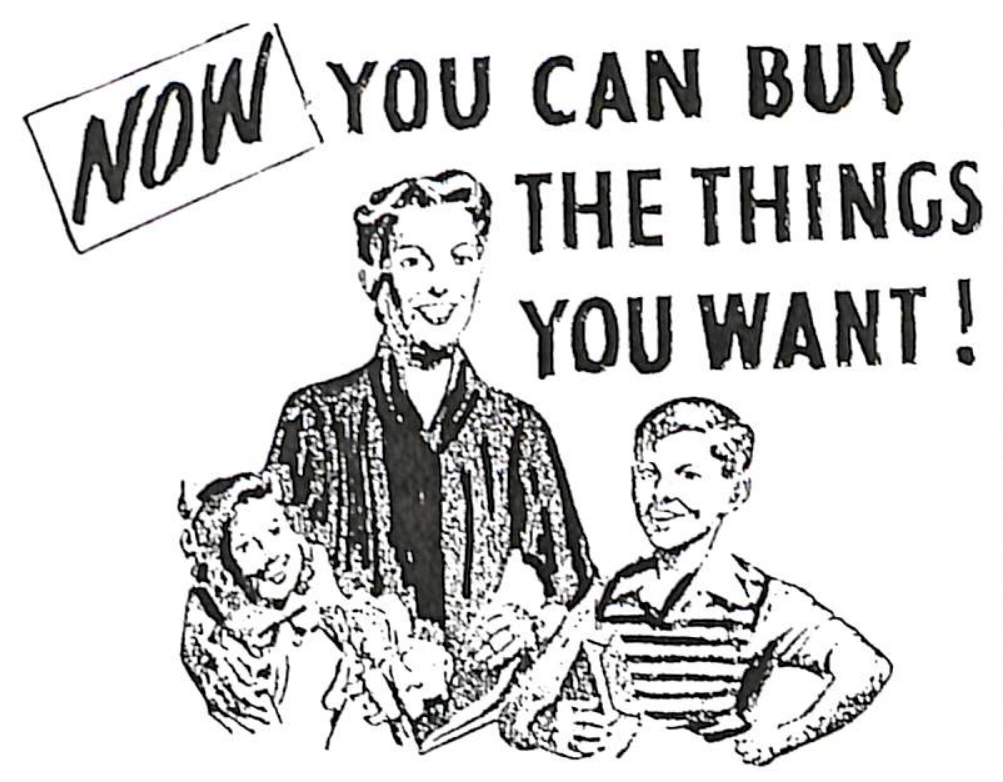

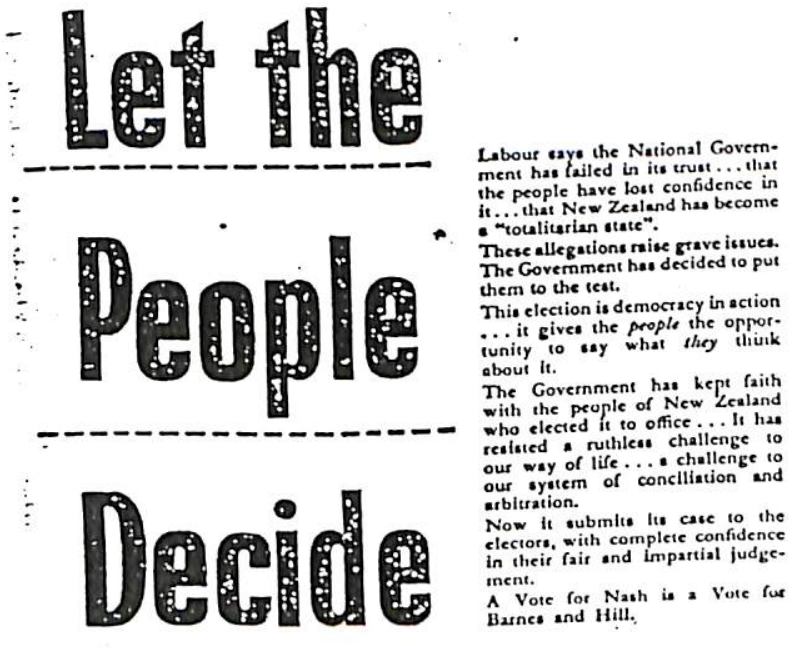

The Issue is -

THE PEOPLE versUS. THE WRECKERS

Vote MATIONALLagain
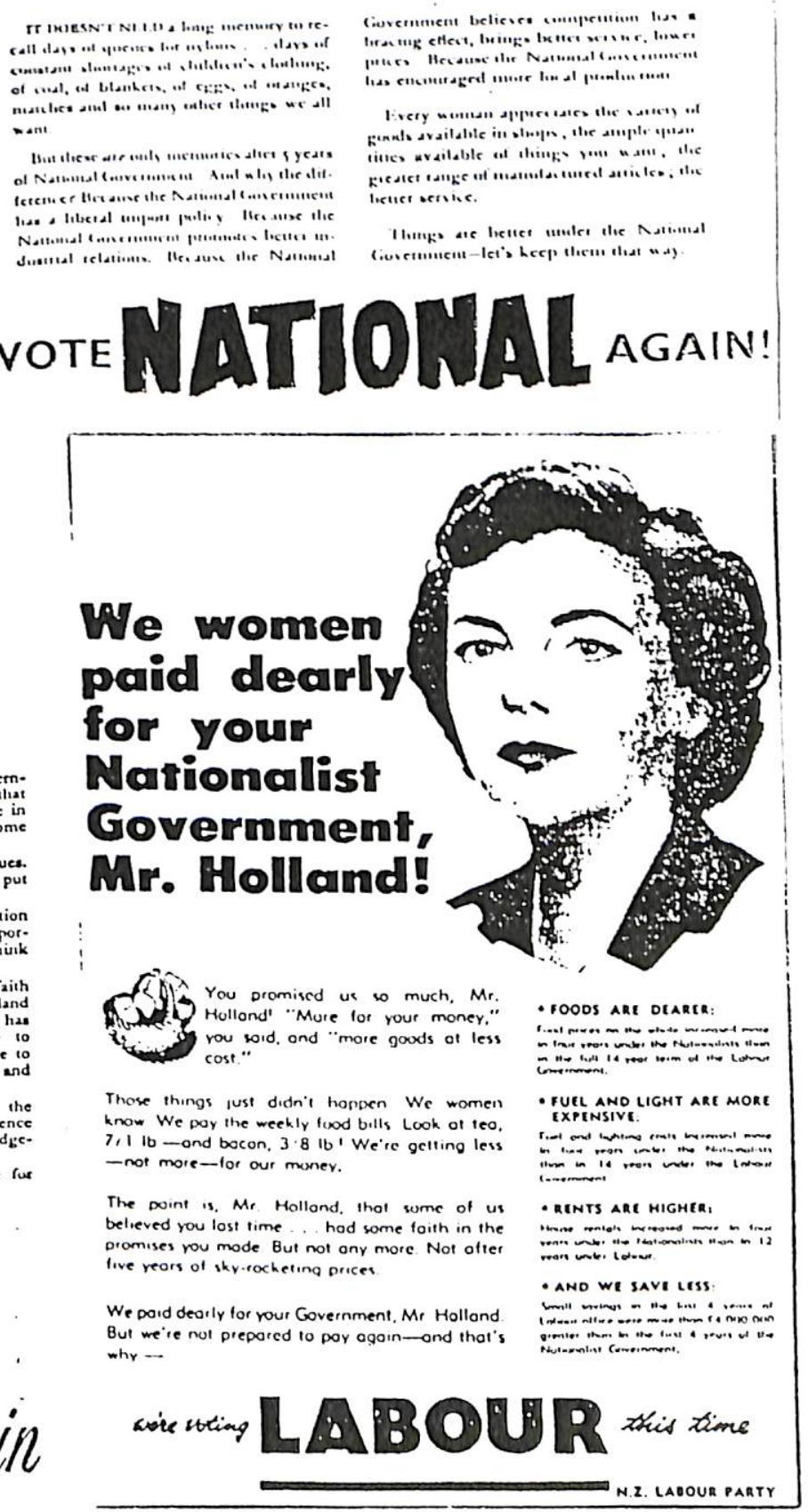


\section{ECONOMIC PROSPERITY AND THE REWARDS OF ORIER}

In this most sustained period of prosperity of the twentieth century, the state took on new dimensions - maintaining affluence, tempering inequality, ensuring security and helping to maintain the high degree of uniformity in New Zealand life (Dunstall 1981:398).

After the war the government assumed responsibility for providing the fabric to support family life, and governments moved in and out of power according to their ability to do so. The two political parties had different views on the construction of the fabric but were in accord that full employment and housing were essential prerequisites. For the National Party

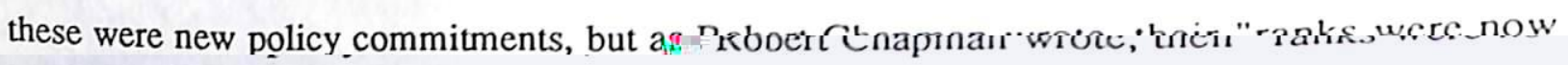
full of people whose life chances Labour had restored or launched" (1981:356). By the time that the National Party came to power in 1949, there had been fourteen years of " $\mathrm{full}$ employmentand any shift in direction was politically unacceptanie. Fortunately the 1950's were years of expansion in terms of farm prices and industrialization, but more specifically from a rising population through immigration and an increase in the birth rate. This change from decay during the 1930's to growth in the late 1940's and 1950's generated an expansion in all services across the public and private sectors, guaranteeing full employment through until the late 1960 's ${ }^{19}$.

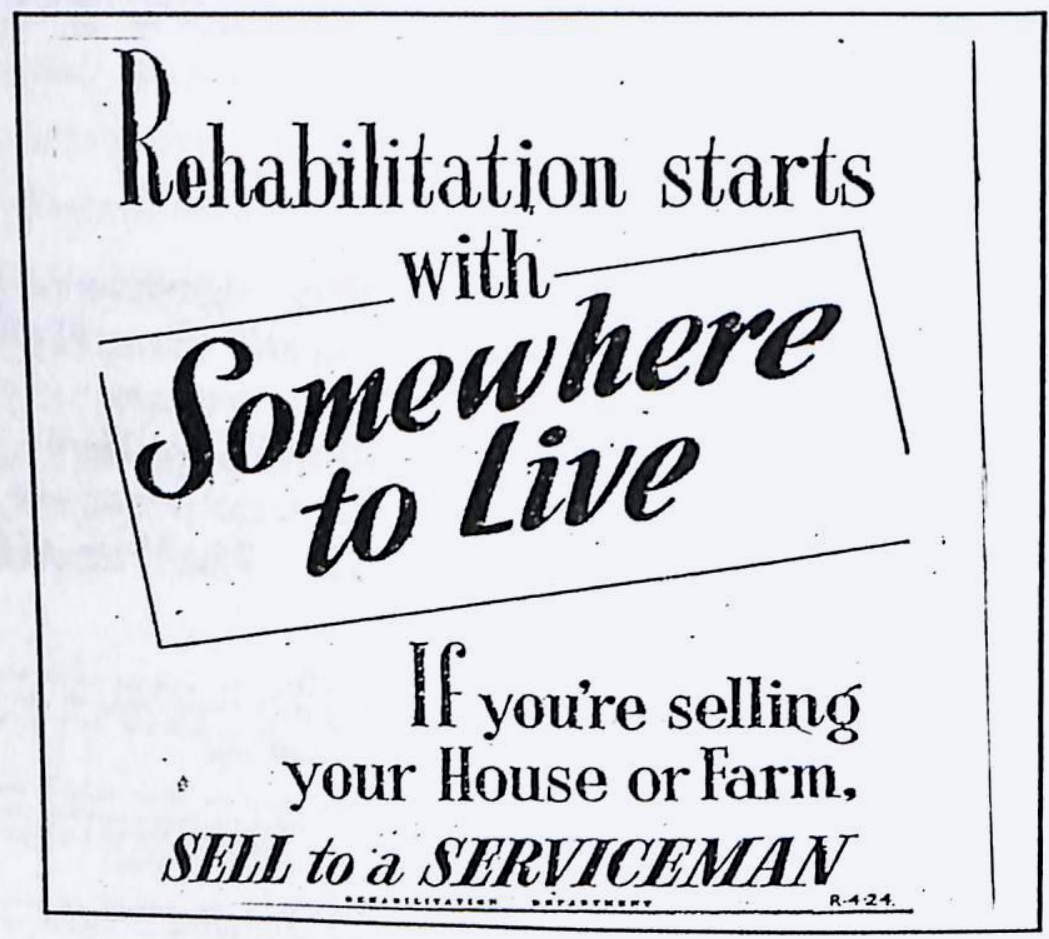

The problem that did not ease throughout the period was housing. While Labour put a priority on state housing and National on private building, neither effort was enough to cope with the shortage (Mahar 1984).The concern had begun well before the war's end, as there was a legacy of insufficient house building going back to the depression years. The unexpected

19 In the worst postwar year in 1959 when the prices fell the registered unemployed was 1656 but usually it was below 500 . 
increase in population after the war was to exacerbate the problem further. By 1949 there were 47,000 unsatisfied applicants for state houses alone (Dunstall 1981). 10,000 houses a year were needed to just keep pace with the population increase, but the most optimistic building rate was only 16,000 a year (Lee 1949). The overflow crowded in with relatives, and filled transit and caravan camps (Gamble 1952), and the housing problem continued as a political football:

In Auckland alone 4250 servicemen are waiting for a roof over their heads. Adults as well as young children and babies are living on verandahs carelessly canvassed in. Many young couples have to live with their in laws (N.Z.W.W. July 15 1945).

A typical story was:.

We have one child and are expecting another one about October. My wife and child are sleeping in a wash-house and we are unable to get even one room to live together. I have had an application for a state house for two years and am a returned serviceman. My wife's health is rapidly failing. It is h__ of a life. (N.Z.W.W April 24 1946).

In the 1950's the headlines were still saying that, "Housing is our Biggest Headache" (Here and Now September 3 1953), but part of the problem was facilitating the purchasing ability of families (Mahar 1984). New suburbs did appear drawn up from plans begun in the 1940's. In 1946 the Listener (June 21) outlined, "The ten year plans for new roads, railways, bridges, pipe lines, aerodromes, reservoirs, and entire extra suburbs (not to mention tunnels)...for Auckland and Wellington". This was part of the new planned environment for postwar living, but one critic noted:

What is wrong with your town planners? They have designed a whole town complete with shops, schools factories, and railroads - and left out a community centre. Don't they read the women's magazines? (N.Z.L. July 19 1946).

It took many years before the traditional amenities of the cities caught up with these new suburbs as Celia and Cecil Manson wrote:

Lower Hutt until now has been drab, dowdy, and higgledy piggledy; a town to be hurried through...Now the magic wand has been waved. With the recent opening of the magnificent War Memorial Library and Cultural Centre, Lower Hutt shows signs of becoming the belle of New Zealand cities (N.Z.W.W. April 5 1956).

House ownership became not only the fulfilment of a dream, but it was also a measure of adult maturity. A Ministry of Housing booklet stated:

New Zealanders are firm believers in the worth and value of home ownership. It proves a secure basis for the welfare and happiness of the family. It develops initiative, thrift, self reliance, and other good qualities which go to make up the moral strength of the individual, of the family and of the nation (1957:2).

In the pursuit of this ideal a Listener editorial stated that New Zealand had become a "Weatherboard Culture":

Home building has become a national preoccupation. An observer who loiters on Sunday near a city could not fail to notice how keenly the 
motorists and their passengers inspect housing settlements... House watching has become a national pastime (N.Z. September 26 1958)

New towns and houses were symbolic of order, albeit the state or privately owned versions of it.

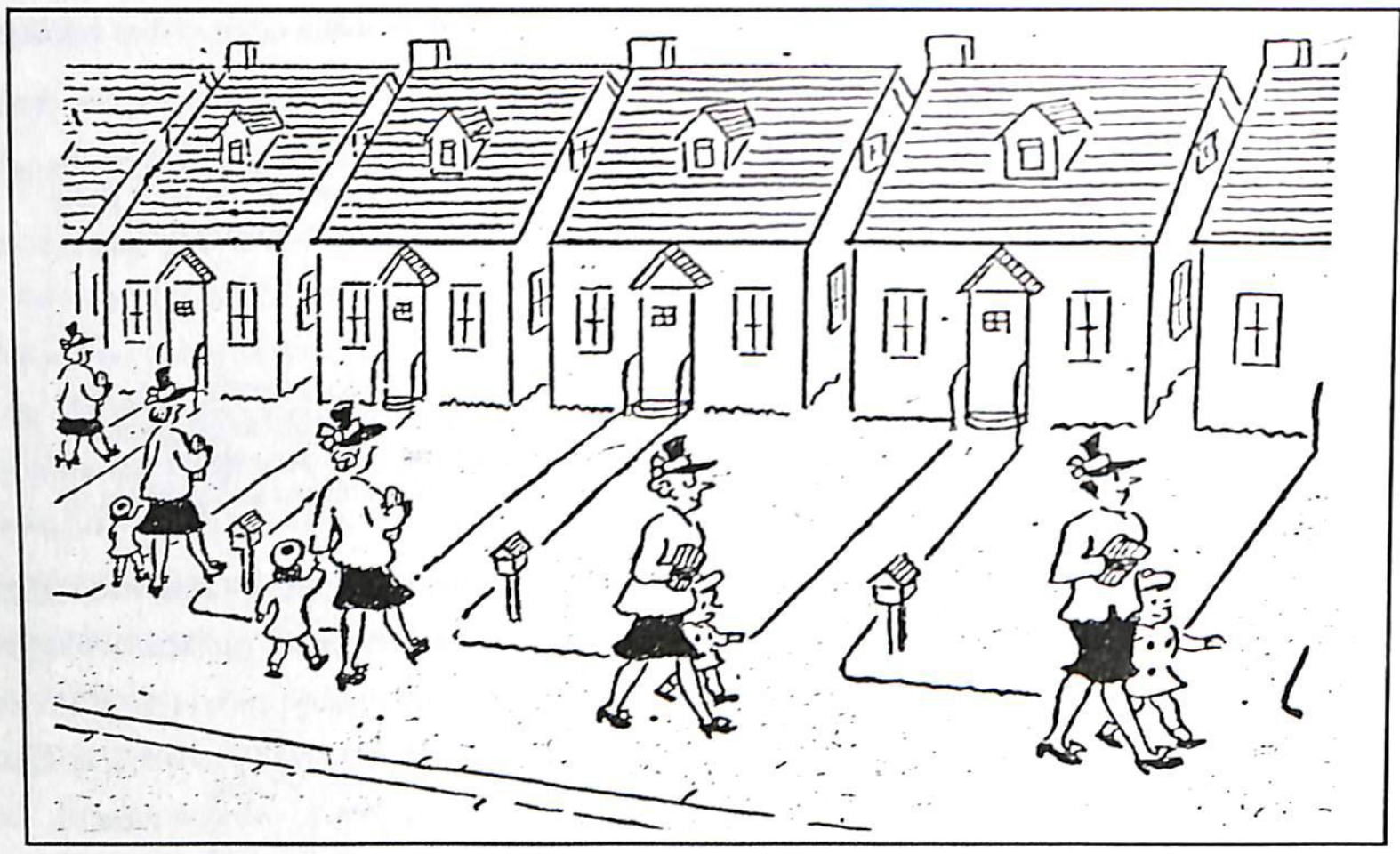

The sameness of the new suburbs gave a uniformity to the culture, although new housing was evidence of a society that was moving towards consumerism more rapidly. Cars, electrical appliances and gadgetry were being acquired and displayed across a much broader range of society than ever before. The period was characterised by a levelling out of class distinction."Inequalities were perceived as removable and the egalitarian myth was maintained" (Dunstall 1981:423). But as the 1950's moved into the 1960's and 1970's the consumer trappings brought their own kind of class distinction, and politicians were unable to meet the material demands promised in the egalitarian myth. This also altered the construction of the definition of the feminine ideal for married women, as Beryl recalled:

A good woman during the 1940's was one who managed and made ends
meet - made the income stretch. This changed. A good woman was
someone who had a beautiful house. But she had to go out to work to
earn the extras to get it. This was the inevitable contradiction underlying the ideal.

\section{THE FAMILY AS A SYMBOL OF ORDER AND SECURITY.}

The symbol of the family as an antidote to political, economic or social stress is a powerful catchphrase, as Lyn Segal writes, "It symbolizes our deepest dreams and fears. These are dreams of love, intimacy, stability, safety, security, privacy, fears of abandonment, chaos and failure" (1983:1). Politicians were to harness both the yearnings for security, and the fears of 
insecurity.Walter Nash was to identify the family as the "foundation" of his plans for the new socicty:

I am a conservative in the sense that I look upon the family as the foundation of the nation....No nation or race can prosper or progress who lack the conditions necessary for a home or home-life in the best and fullest meaning of those words...it is by the toil of their hands that men live, and by the strength of the family that the race will continue (1943:211).

Beyond this kind of rhetoric, postwar policies of employment, taxation, wages, housing and benefits were implicit family policies inasmuch as they were constructed around an ideal of certain normal family arrangements: that a married woman and her children would be provided with security by her husband, and that the woman would assume the day to day responsibility for the care of the children and the home. As a functional unit this arrangement was described as "the keystone of the New Zealand community" (Fletcher 1949). Later in the 1970's the welfare state would have to accommodate to the fact that the ideal was not working, but in the postwar period the ideal and the reality were closer than before or after those years. There was however no perfect fit and those not matching the ideal had no place within the boundaries of normal family life.

Throughout the twentieth century in New Zealand, as well as other industrialised states, the ideal of the family had been taking on the middle class trappings of the "bourgeois family"' and by the postwar period ideas on what constituted a "good family" were becoming the expectation for all classes. For example, the home was to be "nicely" furnished, the children to be "well" behaved, and men and women to be "happily" married and "good" parents. All these were quantifiable in terms of outcomes, and those that did not measure up were dysfunctional. American sociologist Talcott Parsons (1955) espoused a powerful paradigm of the nuclear family with its clearly differentiated functions for men and women, as the most appropriate form for western industrialised society. This paradigm was validated by research and taken to be normative as evidenced by political policies to uphold the separate but unequal spheres (Bernard 1975). Parsons hypothesised a view of the family in which its traditional functions had been transferred into the care of experts and institutions such as schools and hospitals. The new family provided emotional support for its members and was freer to concentrate on the childrearing function, although much of this was now under the oversight of professionals. This view of the family was increasingly child centred. As far as the state was concerned the family was being subsidised through a range of policies to carry out certain functions, and families that did not function according to the prescriptions were a problem.

Family life was changing and the period was characterised by an increasing labour force participation of married women and mothers 20 , and a gradual increase in divorce 21 . 
While social and economic changes were affecting the way families worked from within, the outward face of the family however was of unity and harmony. For New Zealand children the new Janet and John school readers ${ }^{22}$ became the model to measure behaviour and possessions against (Else 1986). Sylvia Ashton-Warner was to write in criticism of these:

I can't belive that Janet and John never fall down and scratch a knec and run crying to Mummy...Doesn't John ever disobey? Why is it always fine in primer books?...I see the respectable happy reading book placed like a lid...ignoring, hiding and suppressing...(1963:69).

The supreme symbol of the family was the Royal family. Alongside the untidiness and failings of real families, royalty symbolised mythical order. The geographic distance of royalty did not dim its image in New Zealand, and it was a fortunate coincidence that during this period of intensified ideological and material support for family life, royalty had a prince and princess ready to fall in love, marry and rear royal children as well. The present Queen married her prince in 1947 in the rush of postwar marriages and in a time of austerity, her wedding was to have the glitter and romance that were the dream of other women. When the Queen became a mother she was the crowned representative of new motherhood despite her duties and rank. "After all it is what we are made for", she was reported to have told her governess (N.Z.W.W. August 17 1950). Although the Queen had none of the everyday responsibility for her children, her subjects were reassured that she was a mother just like them and magazines provided glimpses of happy royal domesticity.

Her ideas on motherhood and family life are sane and healthy...she goes about and makes no secret of the fact that her ideas on having babies do not coincide with advice given to expectant mothers a few generations back (N.Z.W.W. August 17 1950).

The Royal family provided exalted examples of ordinary family life:

Prince Charles and Princess Anne run about the suite in daytime hours. Their toys are on the carpet and chairs, along with the jigsaw the Queen is currently doing, and the latest record the Duke likes to play. Susan and Sugar, the corgi terriers lie on the rug companionably. It's cheerful and happy and slightly untidy like any other home (N.Z.W.W. November 18

Prince Charles and Princess Anne became models for how boys and girls ought to be reared and sex role segregation was the basis of order. At the age of seven Prince Charles was described as having reached the stage when "everything concerned with girls is scorned":

$\begin{array}{ll}1951 & 24 \% \\ 1956 & 29 \% \\ 1966 & 37 \%\end{array}$

21

The number of divorces almost doubled between the years 1943 - 1946 and remained high 2,363 petitions, 1949 . It then stabilised until the late sixties. $1939-1,243$ petitions, 1946 22

These were in fact American readers and were introduced in the postwar years as the basis of the New Zealand reading scheme. It was not until the 1960's that New Zealand produced its own Ready to Read scheme. 
His hair is never allowed to grow very long, since both the Queen and the Duke of Edinburgh hold that a boy should have a proper manly appearance (N.Z.W.W. November 19 1956).

In contrast,

Princess Anne is what her father proudly describes as a "regular young lady", who already seems to show an appreciation of pretty frocks (N.Z.W.W. October 3 1953).

The Duke too was presented as the ideal modern father who would provide some mild discipline:

He doesn't follow the modern fetish of carrying nursery psychology to extremes. When Charles repeatedly flung his slippers down a stairwell to the danger of people below, the Duke duly administered a good tempered spanking (N.Z.W.W. January 23 1954).

Unlike the increasing number of marriages that were ending in divorce, the Queen's marriage was to be enduring, and her wedding anniversaries to become a national celebration. The marriage was to symbolise the ideal of men and women as equal but different even though the Queen had to be beyond equality. In the intimacy of her married life the Queen was portrayed as the subservient wife while Prince Philip was the masterful husband.

Whatever her rank it is always the wife who must make a happy home background essential for a successful marriage...The Queen arranges flowers in the vases herself and often in the evening she will cook dinner in the little kitchen..There are two high stools on one of which the Duke often perches to superintend the cook! (N.Z.W.W. November 18 1957).

She was seen to bow to his knowledge on certain matters and the order of this relationship was presented as a recipe for a successful marriage. This new style of relationship required men to become more involved in domestic issues as long as there was no confusion over masculine and feminine roles.

Princess Margaret was more awkward to place within the ideal. As a single woman until 1960 she reflected the ambivalence society felt about women who did not marry, but did not fit the spinsterish image. Princess Margaret portrayed an image of sexuality, independence, and competence that was in contrast to the image of a married woman of her age. For a while she was promoted as the Royal career girl:

Appearing in public is her career and everyone agrees that as a "career girl" she is a glowing success...She is by no means the over-sophisticated, pleasure mad girl...she is also a sensitive, kind little person who goes out of her way to perform her public duties with dignity (N.Z.W.W. July 22 1954).

This was against the backdrop of her choice of husband. No marriage was better than marriage with a divorced man and there was relief when she publicly renounced the divorced Peter Townsend as a husband. She was applauded for her duty in upholding the sanctity of marriage as a life long institution. Divorce might have been tolerated among movie-land notables or amidst the disorder of working class relationships, but not in the respected echelons of society. Despite her efforts to match the ideal, Princess Margaret was to retain this black sheep image providing comfort to the "ordinary" that even the ideal family had its own problems. 


\section{WOMEN AS EQUAL BUT DIFFERENT TO MEN: A CONTRADICTORY ORDER.}

Indeed, since 1945, the labour shortage, cupidity, and the rising cost of living, interest in work and domestic routine, have brought far more women, both single and married, out of their homes than even before in history. On the whole too, they have come out with men's blessing...In other words, far more New Zealand women have been financially independent, with general approval, for a longer time than in any previous generation (Hall 1958:48).

In the postwar period New Zealand's egalitarian myth was to cautiously embrace again the ideal of equality between the sexes. This created a new paradigm of independence for women to fit alongside a contradictory paradigm of dependence in which men would provide economic security. The latter was the dominant paradigm but during this period there is evidence of a chalienge. This was not a head-on challenge that erupted with a later women's movement but more of an attempt to manoeuvre within the contradiction of two paradigms. The learning of new skills, and the increased independence many women had achieved during the war, had helped create a new ideal of equality. Equality however was not sameness and did not imply that women had to strive to be like men. Instead women had their own unique role in the family, and because their role was essential for the team to function adequately, their status must be equal to that of men. The belief was that women had, in the main, achieved equality, and it was up to individual women to negotiate the degree of equality desired. So for example, a woman now had a choice whether she had a career or not. This contradictory image of the "new woman" provided endless scenarios for women's magazines. How were women to retain their femininity yet be equal partners of men? The media responded with images of a modern femininity that would still attract but not threaten men:

Her whole future happiness will be largely determined by this ability to respect herself as a woman, instead of feeling that she is in the race against men, and handicapped at that. True femininity does not compete with men but prefers to co-operate, or better yet to enlist his cooperation - - charmingly (N.Z.W.W. June 18 1948). (Emphasis in text)

There was difficulty combining the image of the intelligent women with notions of traditional femininity. Edna Harris wrote:

If a woman is really clever, she will use her intelligence subtly. Men on the whole do not like to feel that a woman knows more than they. But at the same time, a woman should not subjugate herself entircly to being a non-entity. She should be herself in all circumstances. When a woman does get married her home should come first. If she can run the two, so much the better, but her career should not cut across the companionable atmosphere of the home (N.Z.W.W. October 5 1959).

The construction of sexuality emphasised the polarity of masculinity and femininity. Men and women had different spheres and each was essential for the other to function. This division had its origins in the physical and mental differences of the male/female makeup but the spheres 
were incomplete unless joined. Dr David Mace, "The world authority on love and marriage", 23 described it from his male perspective:

The average healthy normal man who wants a wife who by her full and vigorous response will meet and satisfy the deep needs of his masculine nature...she completes his nature and makes him a whole man (N.Z.W.W. September 9 1957).

On a visit to New Zealand in 1951, anthropologist Margaret Mead discussed the difficulties of the new idea of equality. She labelled equality as a male idea and suggested that "comparability" was more appropriate ${ }^{24}$. Women would be equal to men but they would not take on board male aggressiveness, and feminine qualities were needed to mediate the excesses of the man made world. The editor of the Woman's Weekly wrote:

This male civilization of the west is just about ready to destroy itself. The wheel has fully turned and has reached the final point of aggression in every field...As a result we may see at last that women exhausted by the sacrifice of her children, generation after generation will take a hand in affairs...A man controlled world is "ipso facto" a world of combat, and no matter in what field will destroy not only our civilization but perhaps the great majority of all human races living on this earth (N.Z.W.W. August 7 1947).

Women were saying with more unanimity than previously that the vote was not enough and that their views should be represented at the political level:.

We need two eyes for perfect physical vision. We need two points, the woman's as well as the man's, if we are to see present day social and political problems in their right perspective ("Yorkie" N.Z.W.W.June 14 1945).

In the spirit of the times it was conceded that women's views should be represented, but at the same time women were not to shirk their domestic responsibilities.Those women that did achieve a political voice were regarded as unusual, and not like "real" women. The assumption was that women had a choice, but the reality was that activism was only possible or acceptable for single, widowed or older women, none of whom were seen to be abnegating their domestic responsibilities. The two most newsworthy women of the period speaking on behalf of women were Mabel Howard and Dame Hilda Ross as the only women Members of Parliament for the Labour and National Parties respectively. Mabel Howard, as M.P. for Sydenham from 1943-1969, was the first woman in the Cabinet when she became the Minister of Health in 1947. She was given the responsibility for over-seeing the interests of women and children in Government policies. Mabel Howard however was remembered more for her newsworthy antics and her blunt "unladylike" language. These were, in part, tactics to counter the trivialization of women's concerns by male politicians who found it uncomfortable that

23 Dr. David Mace had several long running series on modern marriage in the Woman's Weekly during the 1950's.

24 "Of Myths and Men," by Margaret Mead (N.Z.L. August 31 1951). 
topics like the poor quality of female underwear were on the political agenda. ${ }^{25}$ Mabel Howard was to concede that her position as a woman was ambiguous, saying, "I have never lived the life of a woman. I have been treated like a man all my life. People in Parliament treat me like a man" (Gee 1977:97). Dame Hilda Ross, the M.P for Hamilton, presented a more ladylike version of the female politician, and in a similar acknowledgment of the female vote, she was made a Cabinet Minister for the Welfare of Women and Children (without portfolio). Both of these women had a difficult time being a lonely political voice for women they had litule in common with. Hilda Ross said "You have to face the menfolk, and that's difficult, but then you have to face the womenfolk and that's worse. They say, "What can she do in Parliament that I couldn't do better myself? Why doesn't she stay at home?" (N.Z.W.W.March 23 1959).

The movement towards equal pay was illustrative of the clash between two paradigms of independence and dependence for women. This began to make headway in the postwar years when the blurring of work roles during the war and its aftermath had heightened consciousness over the disparity in male and female wages (Kane 1972), and there were new occupations for women in the clerical and administrative areas (Fletcher 1949). The battle was won for Government employees in 1960 but it was not until 1972 that the victory was extended throughout the private sector. The battle was spearheaded in the first instance by the Women's Division of the Public Service Association, but the quest for equal pay embodied an ideal of equality that ran counter to entrenched attitudes and public policy that upheld the male as a breadwinner. This argument against equal pay was based on the potential breadwinning responsibilities of all men, as illustrated in R.J. S. Kinder's letter to the Woman's Weekly :
Increased wages for women would put up men's cost of living. Industries will be forced to increase their costs, but, unlike other cost increases these added prices will fall on all, after only some have benefited. However are they (single women) that badly off today? A large number of them seem to clutch at that jet propelled ship of fashion as it hurries its way through each season, changing rapidly all the while. How about the young men in the group? There are a great many who are living to the limits of their means at the moment and are building careers (September 25 1952).

The reality however did not match the myth, and W.B. Sutch was to argue that in 1951, quite apart from single men, $46 \%$ of married men and widowers had no dependent children ${ }^{26}$. Both political parties nudged tentatively towards the idea of equal pay during the 1950's. By 1954 the Labour Party was promising to narrow the margin towards equal pay, and in 1957 the National Government put it on their election agenda. The Government Service Equal Pay Act

\footnotetext{
25 There was a famous occasion when Mabel Howard held up a pair of women's bloomers in Parliament to prove her argument in her campaign for standardization. Mabel Howard was a strong champion of women as consumers.

${ }^{26}$ Cited in Kane (1972), from unpublished W. B. Sutch speech on the Economic Effects of Equal Pay in New Zealand 1955. (P.S. A. files).
} 
was finally passed in 1960 by the Labour Government. This was the first step towards an ideal of equality for women in the workforce, and was symptomatic of shifting social and political attitudes towards women. Govemment policy on wages and taxation, however, all focussed on the ideal of the breadwinner, and it was not until the 1970's that Government began to cautiously acknowledge that many women and children were disadvantaged by such an uneven distribution of state interest.

Alongside the shifting attitudes towards women, the position of men was ambivalent. They were to recognize their wives as equal rather than subservient partners in marriage, yet their breadwinning status as head of the family was upheld. While there was a growing consciousness of the possibility and desirability of equality for women, there was little accommodation towards this in the role of men. The case studies presented in Chapter Eight illustrate the difficulties individual women faced in negotiating some kind of independence from their husbands. There is little written about the lives of New Zealand men in relation to women in the family; the evidence of the interviews for this research showed men to be somewhat overburdened with the responsibilities of providing for their families. In an analysis of New Zealand literature Robert Chapman was to criticise the sexual polarization of New Zealand society where "the construction of social institutions...provide a refuge for the husband outside the home" (1953:50). Jock Phillips also described these "different worlds" and saw that the male culture, moulded by the mythology of rugby and war was to: "limit the hopes of women and poison their relationships with men" (1980:241).

Using the pseudonym "Leslie M Hall", Phoebie Meikle wrote an angry article in Landfall about the antagonism between the sexes in New Zealand. Referring in particular to educated women, she arges that women were becoming increasingly dissatisfied with their marriages to the "kind of educated men who abound in New Zealand" (1958:47), who appeared threatened by women's quest for equality. Hall believed that factors which contributed to this "disharmony" were the changing economic position and the new educational opportunities for women. Of particular interest was her belief that New Zealand's "special kind of egalitarianism" (1958:47) was also a cause. Hall, along with many other New Zealanders, saw New Zealand as egalitarian in the sense that, "No class exists to which men are legally or socially inferior; there is none to which they must look up; none to humble them" (1958:50). She saw this as a further reason why New Zealand men needed to reason to feel superior in relation to women:

Any women's refusal to be managed and patronized constitutes so grave a threat to these men's emotional security, therefore, that she muct be adjudged "unwomanly", severest of condemnations (1958:50).

Barbara Ehrenreich has written about American men's postwar "flight from commitment" to their families. During the 1950's the ideal of male responsibility for wives and children reached a peak of supportby Government policy, sociology (Parsons 1955) and psychology (Erikson 1950; Havighurst 1953). Ehrenreich claims that the publication of 
Playboy in 1953 was symptomatic of the turnaround in this commitment. "Playboy loved women...and hated wives" (1983:42). Playboy was not advocating an alternative lifestyle and it still believed that men should make money but: "It did not suggest that they share it...the issue was money: Men made it; women wanted it" (1983:46). It is difficult to pinpoint a similar revolt in the New Zealand setting. The magazine was available and popular, and, as in America, was probably symptomatic of the quiet revolt that took time to become visible as news.

The postwar suburban dream and its illusion of family stability centred on the ideal of separate spheres, but the material achievement of this dream sent more wives and mothers into the paid workforce. This inevitably fostered an ideal of independence and equality while providing men with some relief from total responsibility. The dominant paradigm however was one of separate spheres, and Betty Friedan (1963) was to label the primacy of women's roles as a wife and mother as the "feminine mystique". The assumption was that women's equality was vested in her unique role as a wife and mother, and although women could take advantage of new opportunities for women, these activities must be fitted around the traditional feminine role. Friedan saw that the "mystique" crushed women's individual potential and the power of the mystique explained why the "women question" became, "The problem that has no name" (1963:13).The gradual shift in the balance of the economic and work arrangements of families had repercussions on the personal power politics of family life, and the messages hitting men and women were confusing and contradictory. In the main the confusions simmered within each family home as personal problems. It was not until the late 1960 's that individual problems were to start becoming collective social issues that required collective as well as personal changes.

\section{AN IDEOLOGY OF CHILDREARING AS A TOOL TOWARDS ORDER.}

After the war the conditions for rearing children necessitated the financial security of men as breadwinners, and the persuasion of women to be good mothers. Successful childrearing was a symbol of adult maturity for men in the sense that they could emotionally and financially support a family, and for women in the sense that they could nourish and nurture a family. The focus was on the children, and their needs were given a priority that would in effect override many of the new ideals of equality for women. Children were to be the beneficiaries of peace and security through an expansion in education, health services and material goods. There was a darker side to this, and an editorial in Parent and Child magazine (May-June 1958) reflected that:

To be young in our country today is to be suspect... You might be tainted by special germs which may evolve into the dreaded diseases of Delinquency, Bodgieism, Antisocialism, Irresponsibility. Or, if you are 
even younger than that, a worse disease may already be devouring your body and soul - you might be "playway educated".

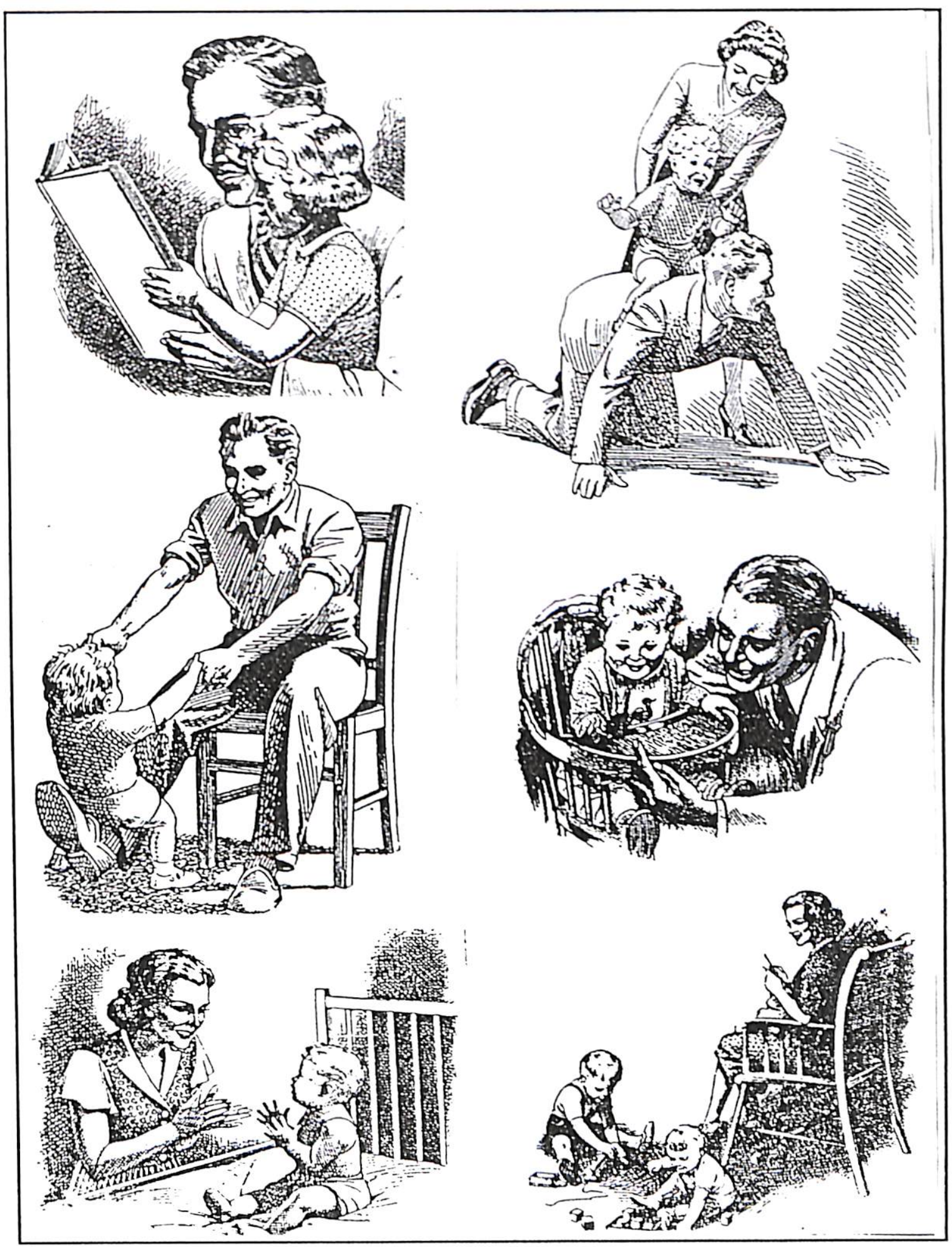


The postwar period saw a clash between two styles of childrearing (McDonald 1978; McKinlay 1983). On the one hand there was a need to re-establish control over children and childrearing:

Jane: $\quad Y o u$ didn't have control during the war. You have got to have control so you make a good job of these kids you are putting into this wonderful new world.

At the same time the children were to be participants in an approach to childrearing that recognized the child as a "psychological being" (McDonald 1978). By 1958 Parent and Child (May/June) was to reveal that there were 12,000 New Zealand children who were emotionally unstable: $9.6 \%$ of girls and $5.6 \%$ of boys. The belief was that adult adjustment was related to the quality of the early childhood experience, and as Helen Brew wrote, "We parents are concerned with bringing up children able to contribute to the building of a happier saner world than the one we live in" (1954:7). This world was to be a planned environment with psychology as a tool to assist personal adjustment. However, the efforts of families en masse trying to establish normality made its own disorder, as the subsequent baby boom continued to create shortages in the housing, consumer goods, education and medical services.

The planned environment began with the advice about babies and toddlers by Plunket. This organisation, which had the oversight was of most Pakeha New Zealand babies, was however caught between the heritage of its founder, Truby King's regimens, and the challenges of new permissive styles of childrearing. Robin McKinlay (1983) described the efforts the Plunket Society made in its new 1945 and 1953 manuals $^{27}$ to tone down its rhetoric of discipline and nationalism, and to allow mother's instincts a little more rein. Following on from the supervision of babyhood, the 1947 Bailey Report ${ }^{28}$ heralded a new commitment by the state to support the kindergarten as a preschool service. These would give psychological and educational benefits to children in a structured learning environment, although early childhood education was not designed to enable women to work. The Bailey Report firmly rejected any support of the new nursery schools which combined full day care with progressive educational ideas 29 , and concluded that:

Young children spending the whole day from Monday to Friday in a nursery school are deprived of the vital experiences that only a normal home can provide (1947:11).

As an alternative to the more formal environment of the kindergarten there was the new playcentre movement which in fact adapted progressive educational ideas into a more

27 Helen Deem, and Nora P. Fitzgibben, Modern Mothercraft Dunedin Royal New Zealand Society for the Health of Women and Children (Inc.).

28

Consultative Committee on Preschool Education.

29

During the late 1930's and early 1940's several nursery schools had been set up (Cook 1985d). These were influenced by progressive ideas on education which embodied a commitment to co-education, individuality, self expression, co-operation rather than competition, and an avoidance of punishment. 
acceptable form for New Zealand society. ${ }^{30}$ Playcentre upheld the emotional bond between the mother and child and recognized mothers as experts concerning their children; it promoted "free play" as the basis of learning. (sometimes referred to as the "playway"), and advocated a more permissive view of children's behaviour. It defined motherhood as a career, and for many women playcentre was to become an unpaid career. ${ }^{31}$ Not everyone in New Zealand approved of the movement towards early childhood education. M.L.D. wrote:

The mistake of the kindergarten movement in New Zealand is in providing a service that takes the child out of his home and encouraging mothers to believe that this is good for him (Here and Now June 1952).

M.L.D. gave support to a "Mrs La Lone", a visiting American Fulbright Scholar who was apparently "disturbed" to find:

New Zealand is moving in the direction of an earlier break between mother and child through the establ:shment of creches and day nurseries whose only purpose is to encourage mothers to enter industry, and by the opening of kindergarten doors to three and four year olds whose needs are best answered in their own home play groups (ibid).

Such disapproval was always an undercurrent but the reality was that long waiting lists, and Government funding for kindergartens and later playcentres, proved their acceptability to a considerable number. In contrast the growth of full day childcare was portrayed as evidence of "social problems" like working mothers, "broken" families and illegitimacy. The childcare centre did not provide the right balance of educational expertise and mother love that the funding and structures of the kindergarten and the playcentre allowed. With no Govemment support childcare provision became the domain of unco-ordinated small scale private enterprise, along with a few charitable/church institutions, but despite its low status it too had long waiting lists. In 1955 the Mother Superior of the Order of the Good Shepherd was reported as saying, "hundreds of children are turned away each year" (N.Z. Herald September 30). The Canterbury Housewives Union "discovered that scores of toddlers are sent to backyard nurseries" and announced plans to sponsor a day nursery ${ }^{32}$ (Here and Now August 1952). While the kindergarten and playcentre basked in a general acceptance, childcare became a concern of Government only through a scandal. In 1958 police, welfare and medical officers removed children from an Auckland centre and when it was debated in the House of Representatives the Labour Minister in charge of Child Welfare, Mabel Howard, declared that the case was:

Too shocking to give details...Mrs Fulham did not know the surnames of most of the children nor their own addresses. When the children were

30 This began during the war as a parenting co-operative among some Wellington women. It initially offered full day care but it soon became half day with the mothers present as staff. See Ailsa Densom (1980).

31 Four of the women I interviewed had an involvement at some stage in the playcentre movement. I am grateful for the insights they gave me into the early years of this movement. Some of their experiences as playcentre mothers will be related in a Chapter Eight.

32

There is no record that this eventuated. 
examined by a doctor one child was found to have a fracture of the leg which he had had for three days...Most of the children had skin disease,or scabies, and one baby was in a very poor physical state. ${ }^{33}$

Child abuse was a powerful image, but more specifically the opposition to childcare came from separation of mother and child which was contrary to the new views on child development. The research of Britain's John Bowlby (1952), and the writing of America's Benjamin Spock (1946) came to dominate the professional views of childrearing. They both represented a departure from earlier authoritarian views of child rearing. Attention, love, and stimulation by the mother were the tools of succesful childrearing, to be tempered with self discipline and control that could be taught, not with the "rod" but, through new psychological techniques of child management. ${ }^{34}$ This was a more positive approach to childrearing than in earlier years and was in accord with the new child centred focus of family living. Not that this view was accepted by all. Nonetheless the new ideal was that motherhood was to be a joyful experience, but this contained a disturbing message. Mothers were the key to rearing well adjusted children and the future of the country depended on her success. Conversely, the implication was that mothers were to blame for the maladjusted child that would later become the adult misfit. Following on from Bowlby's research on institutionalised children, psychologists warned of the ills of maternal deprivation if the mother and child were separated.This message was so powerful that a working mother was seen to be causing psychological damage similar to that of death, war, or famine (Bowlby 1951; Phillipson 1982). Geraldine McDonald (Set 1977, Item 3) was to write with concern about the impact of Bowlby's ideas on New Zealand:

Bowlby's ideas were accepted in New Zealand, as elsewhere, by Government Departments and other Bodies having to do with the health of children and with the provision of care and welfare. The net result was that whether or not women knew of Bowlby's ideas they were likely to be affected by them .

Planning and providing the correct environment in the home and in the preschool for the early childhood years, was set alongside a growing concern over delinquency in the adolescent years. Delinquency may have been a new term, but it was not necessarily a new problem. Concern over vandalism, hooliganism and larrikinism stretched back to early colonial days (Sutch 1966), but in a postwar society that hoped jobs, housing, health care and education would cure social ills, the blame for delinquency had to be found elsewhere. Sandra Coney suggests that it was a, "moral rebellion more than anything else, generated not by the unemployed but by the sons and daughters of stolid suburbia" (1986:251). The search for the origins of this rebellion shifted to parenting. The Director of Education, Dr. Becby stated:

\footnotetext{
33 N. Z. Parliamentary Debates Vol. 316. PP. 1-836. Friday 18th July 1958.

34 The childrearing literature in New Zealand followed these ideas closely. For example:

Current Methods of Child Control Association for the Study of Childhood 1958.

Troublesome Children: The Environment or Hereditary National Education August 1949.
} 
The way to improve the conduct of children is to improve our own, and no matter how wise the guidance of teachers it is no substitute for the good example set in a child's home (N.Z.W.W. September 30 1955).

Dr. Paul Popenoc, an American "expert", who wrote for the Women's Weekly warned:

Delinquency doesn't just happen. It is produced by parents. If we want to reduce juvenile delinquency we should begin with parents, not with the children themselves. Everyone knows that the way to reduce juvenile delinquent is to produce better homes (N.Z.W.W. May 12 1958).

Working mothers were again the front line of concern and the pleas came from leading figures for women to give up their quest for economic independence and shoulder their responsibilities. The Women's Weekly reported the views of Dame Hilda Ross:

Married women worked because they wanted to have independent incomes...There is no necessity for this. The country is today enjoying so much prosperity that married women with children should wake up to their responsibilities in the home and stay at home.

Dr. Mazengarb Q.C. in agreeing with Dame Hilda's views went a step further with an emotional appeal to women. He called for a deeper sense of the joys of parenthood, for more emphasis on spiritual and emotional values and less on material things (N.Z.W.W. June 7 1956).

The specific focus of this concern came from a much publicised sex scandal which lead to the Mazengarb Report on Moral Delinquency in Children and Adolescents (1954). The scandal involved sixty-five school children in the Hutt Valley who were using their parents' home for "organised sex" and "orgies" after school. The Editor of the Woman's Weekly wrote, without being too explicit about the details:

The past few weeks our mail has shown us that there is one particular topic uppermost in the minds of women in this country - juvenile delinquency... Now that it has come to our doorstep, no social issue has aroused greater concern in New Zealand for many years...the Government's appointment of a committee to investigate adolescent immorality was regarded by most people as a constructive step...People have been shocked by recent events (August 19 1954).

The report listed the possible causes for the moral decay: co-education, playway education, new housing developments, contraceptives, broadening of the divorce laws, high wages for adolescents, self expression in children, new views on morality, materialism and parental neglect (as one third of the mothers of the sixty-five children worked for wages). The problem was that some of these possible causes were an integral part of the new society New Zealanders had dreamed of.

D.H. Munroe seemed a lonely voice when he wrote in the safety of Landfall (Vol. 9, No. 1) against the Report, and saw its only value as "anthropological" in the sense that it revealed the prejudices of New Zealanders in "public positions" (1955:80):

Opponents of comics, the new education, the welfare state, working mothers, supporters of community centres, corporal punishment, sex instruction, God, were all apparently certain that they knew exactly what had happened and what must be done about it (1955:76).

Concern spread beyond the delinquency and sexuality of the young to the general state of New Zealand adolescence. The "good life" was making life too easy for them: 
School teachers tell of $10 /-$ and 1 pound notes found in the playground which pupils never bother to claim; of expensive bicycles bought on time payment (N.Z.W.W. March 8 1956).

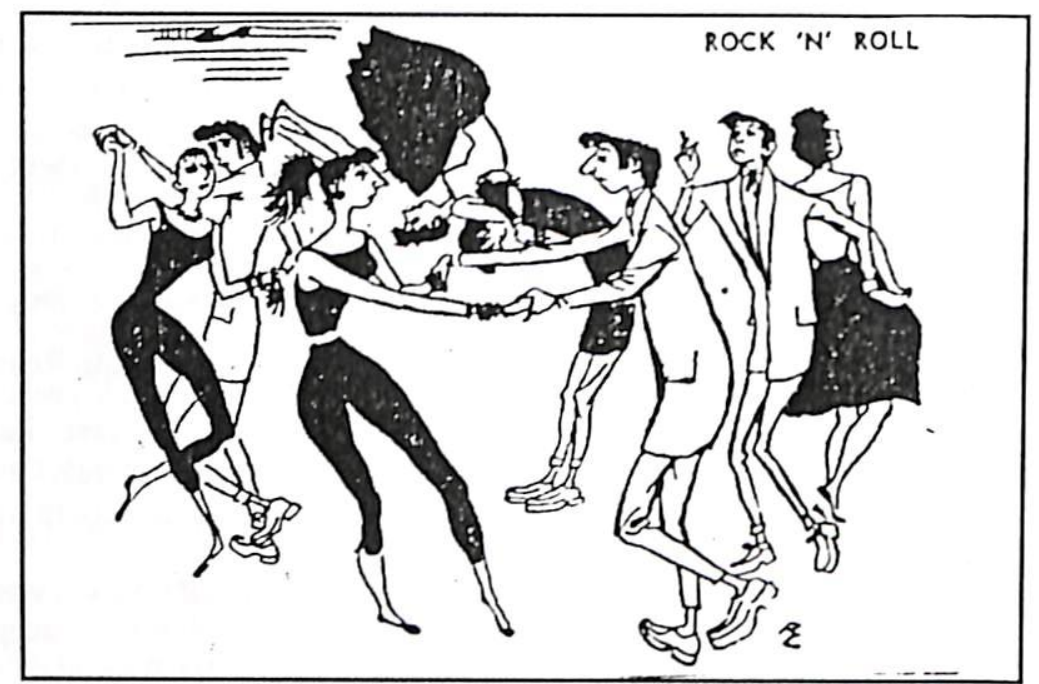

Dame Hilda Ross was to announce that, "Many young girls are behaving badly because of poor home backgrounds and too much money to spend" (Christchurch Press June 6 1956).

The concern about girls specifically arose from statements in the Mazengarb Report that it was the girls who had enticed and led the boys on. The law as it stood was unable to prosecute the girls for "carnal knowledge".

"Youth Without Purpose" was the title of a radio series. Teenagers were called "idle", "aimless", "boy-girl crazy", and the appearance of "bodgies", "widgies", "teddy boys", and "milk bar cowboys", provided another rich field for the new psychological expertise ${ }^{35}$.

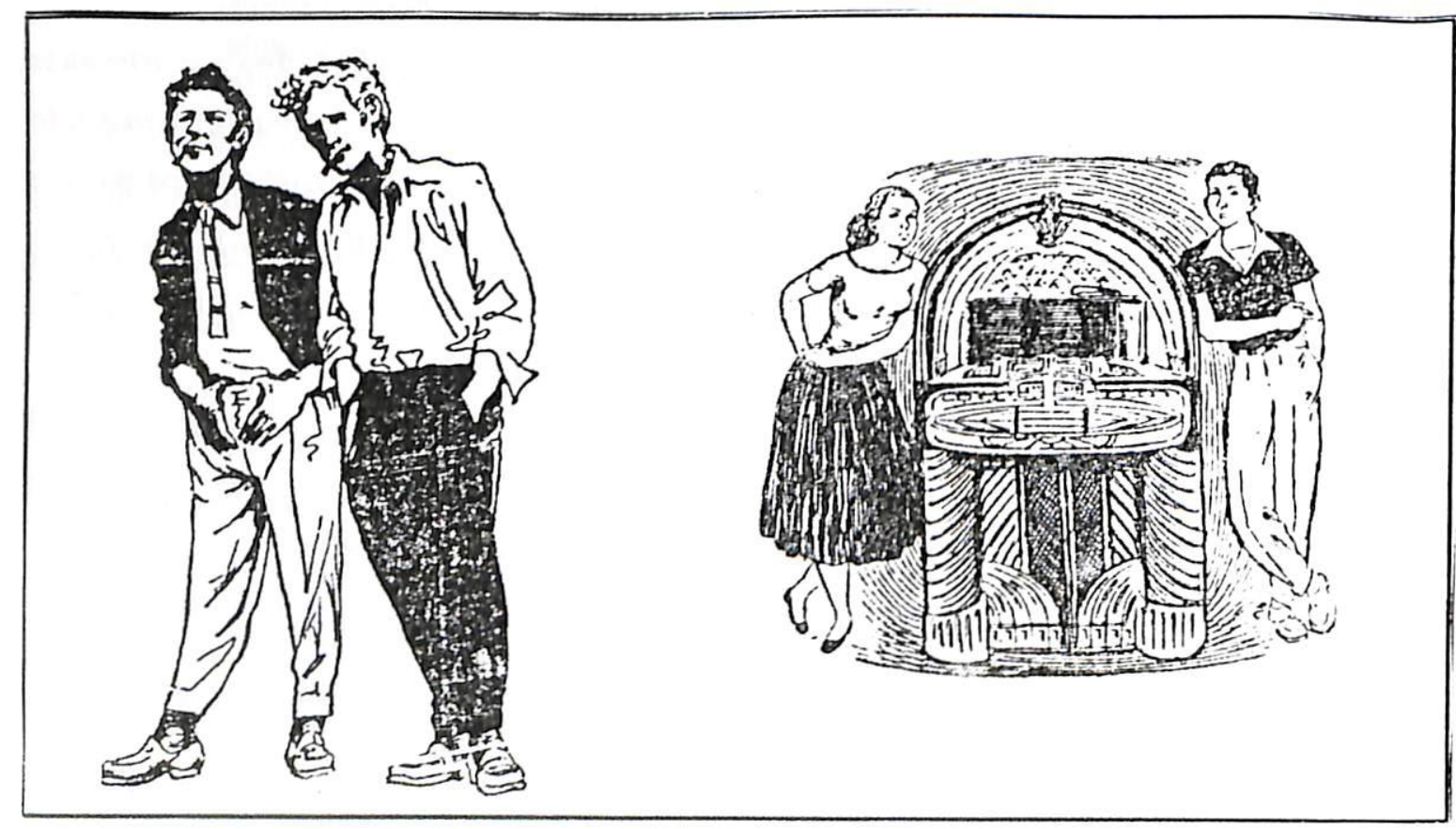

35 D.M. Crowther (ed) (1957); A.E. Manning (1958). 
Being a good mother and charting the correct course between control and permissiveness was now a complex yob, and women were to become the anxious scapegoats when something went wrong. "Gunlty Mother" explained:

All those lectures and articles about the mistakes made by mothers have had me worrying about whether I've done the right thing with my children. I've been so afraid l've given them complexes or hurt them too deeply for them ever to forget. Tonight's the first time I've heard one of these experts say it's all right for parents to behave like human beings, not angels or something ( N.Z.W.W. June 29 1950).

The public rhetoric may have supported this child-centred focus, but direct assistance for mothers in the lask was minimal and came mainly from women supporting each other. The logistics of motherhood was difficult because the planned environment that was part of the ideal plan for postwar society, lagged behind these prescriptions. Letters to magazines had a recurring theme, of questioning the priorities of those in power, and this female rhetoric was just as strident as any later feminist writings on the subject:

If babies are worthwhile, why put so many obstacles in the way of their transport on trams, trains and buses..No shops offer an easy parking space for prams, or a playroom where children can be left under supervision while the mother makes her purchases in peace..And the foot weary mother in search of a quiet place to put her feet up, change and feed her baby, is grateful for the privacy of a bench in a public lavatory (Mary Dobbie, Here and Now October 1949).

This period is characterised by consensus values on the role of the family in society, and the sexual division of roles and responsibilities within the family. Alongside this ideal of normality were newer paradigms of expectations for men, women and children that were to begin to challenge the old order, but the new was very tentatively accommodated within the old. The political front moved backwards and forwards between National and Labour versions of opportunity and security. For women, new glimmerings of opportunity (independence) were set against the quest for security (dependence) within separate spheres and the breadwinner's wage. Men were caught between an increasing institutionalising of their breadwinning responsibilities amidst a growing inability to provide what the "good life" required, and inklings of their own entrapment. Children were reared amidst vacillitating prescriptions of control and permissiveness, and the defects in their behaviour were blamed on both. At the interface of these contradictions, however, it was not a balanced war and the older order of the dominant paradigms provided the boundaries and became the myths that are remembered. 
CHAPTER SEVEN

TEXT ONE: A PAPER DIALOGUE 1945 -1960

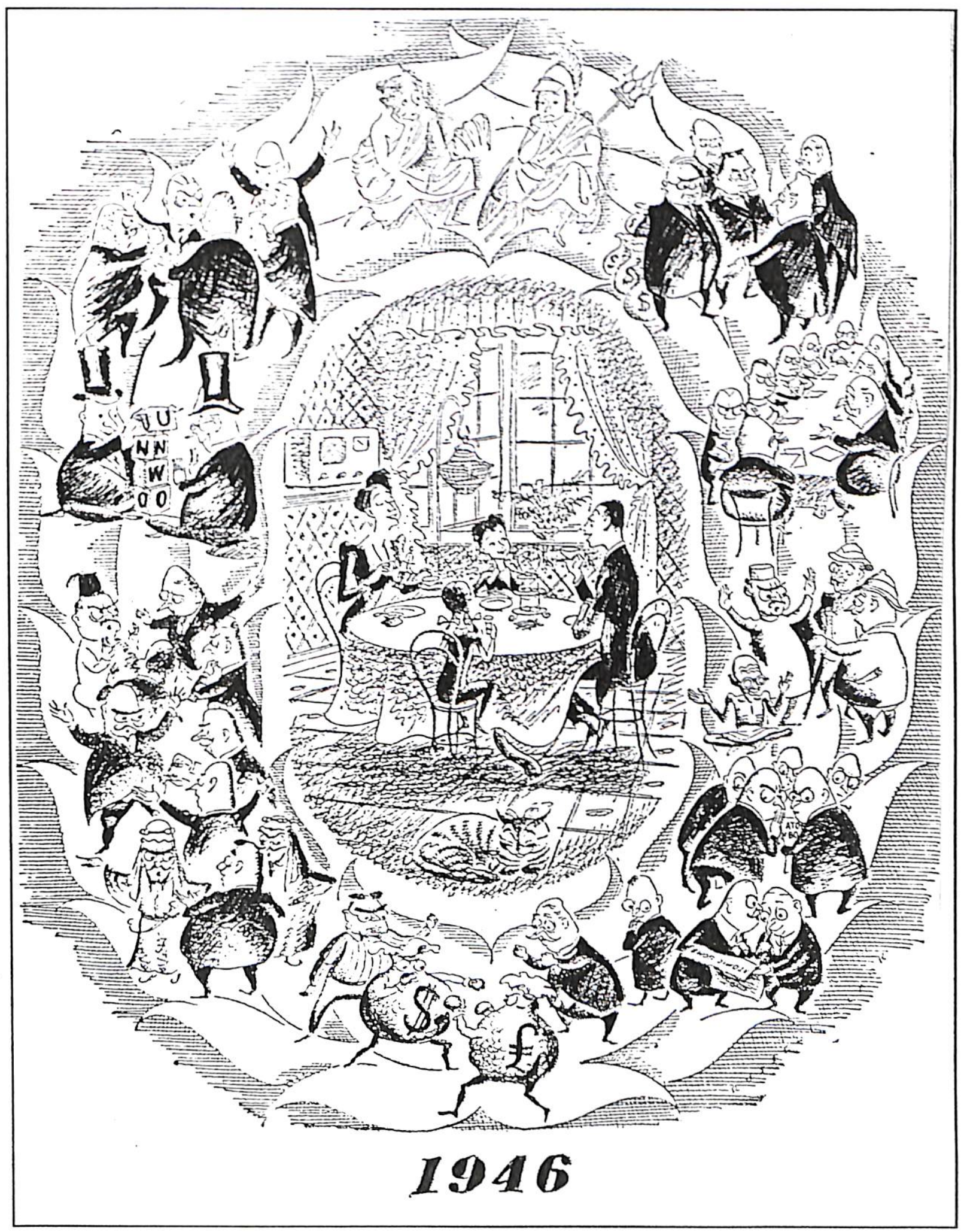


The printed version of life does not reflect reality, and part of the function of the media is to create an image of another world, whether it be the homely fantasies of the N.Z. Woman's Weekly or the intellectual idealism of the N.Z. Listener. Media words and images define responsibilities, foreshadow new ideas, and judge old ones, and become part of the dialogue between the individual reader and the wider society. The magazines have a dual function in this analysis. Firstly, they provide a glimpse of the ideological messages that were powerful in defining cultural codes. These messages had certain strands of uniformity but were also confusing and contradictory to anyone who wanted to believe it all. Secondly they present a factual record of aspects of New Zealand life, although there were also other versions that were not recorded, as life had more moral, cultural and class diversity than the magazine representations of it.

1945 - 1950 was a period of reconstruction. Russell Clark's ${ }^{1}$ grapinic for the 1946 Christmas issue of the Listener portrayed the duality of the wider chaos of a war torn world amidst the yearnings for peaceful family life. But the aftermath of war brought new disruptions and it took some years before the envisaged order was defined as the norm. The problems of "returning to normal" led to protests that were not characteristic of the war years when people determined to put up with things. There was now frustration at the shortages and restrictions which continued to complicate life, and the Government was charged with righting wrongs and realising the dream. However the dream for women was constructed around two themes that proved difficult to realise in unison. The first was that the family would be restored as a haven of security and comfort, and the second that reconstruction would bring new opportunities and services. For the generation in this study the reconstruction experience was different for men and women. Men returning from the war had readjustments to new employment and family life, while the women were moving into new roles as mothers and wives. The process of both of these readjustments was newsworthy with stories of reunions and romance, amidst the hardships families faced in settling down and the fading of the dream. Part One of this chapter presents three such media scenarios: "Rehabilitating the Returned Men". "The Population Problem", and the "Housewives' Protests". Each was a part of the process of adjustment towards normality amidst continuing disorder.

1950 - 1960 were years in which there was little mention of the war. It was as if it had never happened, yet the interviews with women showed that the war had a long term affect on their men. In the media there was optimism that normality prevailed, and the mood was less accepting of the misfortune it reported; the message being that it was up to individuals to take a hold on themselves. The "site" for political negotiation shifted to the family as men and women tried to adjust to the prescribed roles and responsibilities of their sex. The tension of new opportunities versus family responsibilities provided endless copy for the magazines'

${ }^{1}$ Russell Clark was the cartoonist and illustrator for the Listener. 
prescriptions on how women ought to order their priorities in marriage, in work, and in motherhood. The separate images of women as wives, homemakers, workers and mothers contained contradictory codes of femininty, which did not match the reality of women's lives, where all were combined into the rush and routines of living. Part Two presents these as three scenarios of what the media prescribed as acceptable and unacceptable.

Par One

\section{THE AFTERMATH OF WAR}

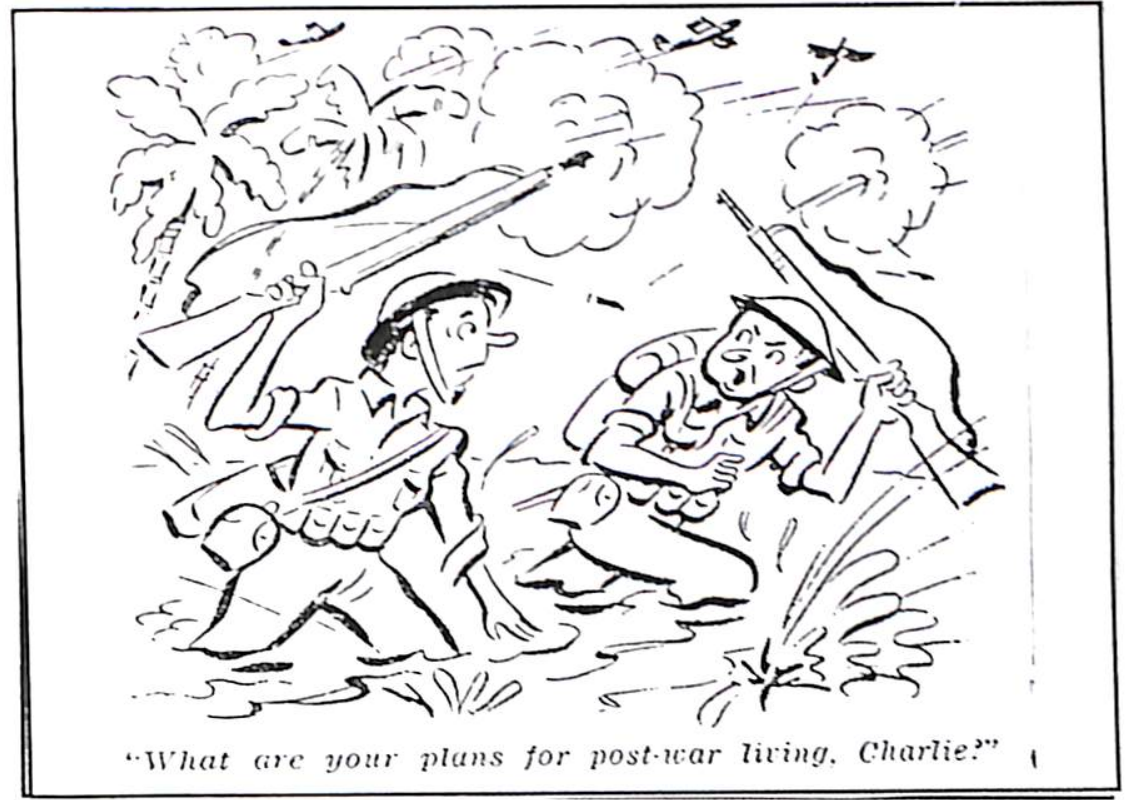

Plans for reconstruction were being blueprinted soon after the war began. As early as 1941 an organisation was set up to, "stimulate the study of postwar reconstruction". Its early organiser Miss Noeline Baker was to say:

Victory in the last war did not give a lasting peace because we did not understand what was necessary to secure it. That is where we women of New Zealand can play a very important part. Many of us are unburdened as far as military work goes but we can give our minds to the problems of peace (N.Z.W.W. July 18 1941).

By 1944 the readers of National Education were being told that, "The world is full of blueprints for a brighter tomorrow. There are plans for better business, more productive farming, happier housing and perhaps most interesting of all...a better system of care and education for the young" (August 1). Early in the war the Government had got plans underway for the reconstruction of industry and the rehabilitation of soldiers (Nash 1943; Second N.Z.E.F. Education Rehabilitation Service 1944; N.Z. Organisation of National Development 1944; N.Z. Rehabilitation Dept. 1945). There was however an ambivalence towards the place of women in postwar reconstruction. It was acknowledged that the role and expectations of women had changed, that the voice of women must be listened to, that women wanted better 
opportunities as well as better support in their roles as mothers and housewives (N.Z. Army 1943b). On the other hand the reconstruction and rehabilitation programmes were focussed towards the men and assumed that the lives of women would continue as they had before the war (Nash 1943; Cook 1945). The aspirations of women combined desires for relief from overwork, a tranquil domesticity and new opportunitics:

After the war we seek more labour on the dairy farm and the wherewithal
to pay the wages, for we crave a little leisure... How heartbreaking for
mothers to see their children toiling fourteen hours a day, losing their
intelligence ("Kowhai", Mangatainoka).
The universal prayer of all we women in the postwar days is to have the
man we love home again with us. We ask for a happy home with fresh
looking curtains blowing at the window, our kiddics running around a
garden with roses (Joy Bell, Ashburton).

What we want after the war is a little fierce feminist action. With women at least sharing an equal place in affairs (Jean Small, Auckland).

(N.Z. Magazine January - February 1945)

These were not necessarily exclusive, and throughout the 1940's magazines provided a forum for the debate on how to realise them. There was however no united women's voice to transform the somewhat contradictory dreams into acceptable political strategies. And the priority on government resources was to meet the immediate needs of the men.

\section{REHABILITITATING THE MEN: women <---> men}

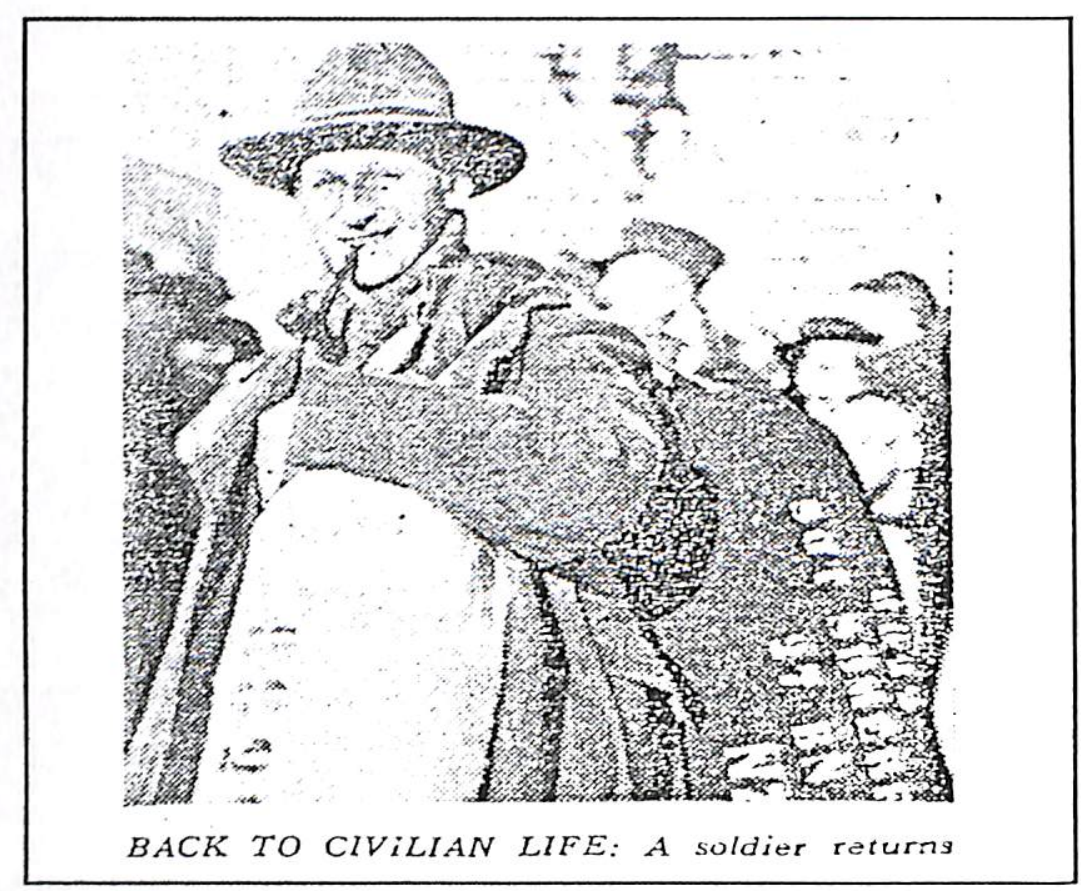

New Zealand provided a comprehensive rehabilitation scheme for returning soldiers which not only gave immediate assistance in terms of retraining and employment, but gave continued 
support throughout the $1950 \mathrm{~s}^{2}$. The success of these schemes in easing the "returned men" into the workforce has been widely acknowledged, and women too were to benefit, in that the programmes assisted the male breadwinner's security. The rehabilitation process was assisted also by personal networks and the Returned Servicemen's Associations; thus a new class of New Zealander was created who had preferential treatment, accelerated upward mobility and privileged avenues of political power. The "rehabilitating" of men into family life has however been a hidden story which this study can only glimpse through interviews with wives and daughters of men who were restless, ill, or found it hard to cope with all the responsibilities of family $\mathrm{men}^{3}$. Lauris Edmond suggests that:

Because women had to take so much responsibility and decided everything for themselves, they matured tremendously. And although the lives of the men were difficult and dangerous, in the emotional maturing sense they just stood still (N.Z.W.W. October 13 1986). ${ }^{4}$

The war had brought a temporary redress in the status of women, but the rehabilitation schemes were to offer educational and work preferences to men that were not available to women. This corrected any short term imbalance in the male/female career achievements caused by the war, and then further increased the gap between men and women of that generation. Geraldine McDonald ${ }^{5}$ recalled her education at university during those years:

What I didn't know at the time was that men coming from the war overseas were being given priority in the courses, in the grades that were given, and in the jobs (Broadsheet January - February 1987:18).

Servicewomen ${ }^{6}$ were entitled to some rehabilitation consideration but they were a small minority compared to the men, and the rehabilitation schemes did not apply to those women who had been manpowered, or who had worked voluntarily within the Women's War Service Auxiliary ${ }^{7}$. While the Government assumed responsibility for the economic and medical well-being of returned soldiers, women were told that the real work of rehabilitation lay in their hands. There was an outpouring of advice on how to adapt their own needs to

${ }^{2}$ For example, Irene's husband wanted to move out of the butchery trade because of a recurring war injury. He was given assistance to buy carpentry tools and he set up his own business. This work was also too heavy and a desk job was arranged for him at the Ministry of Works. Later in the early 1950's he was again given assistance to train as an architect at university. Like many men of his generation he expressed gratitude at the opportunities the rehabilitation schemes provided.

3 Fiona Kidman's book Mandarin Summer (1981) is about a family whose life was made precarious as a "returned" husband tried to take over the role of breadwinner again.

${ }^{4}$ Lauris Edmond was talking to the Woman's Weekly about her book Women in Wartime (1986).

${ }^{5}$ Geraldine McDonald is currently the Assistant Director of the N.Z. Council for Educational Research.

6 There were over 9000 women in the Services at the peak in 1943 (Ebbett 1984).

7 This involved 78,000 women from a number of organisations (Ebbett 1984). 
those of their men, as Dr. Reeve ${ }^{8}$ wrote in the Woman's Weckly: "Wives are perhaps the pivot upon which the happiness and well-being of a family turns. On their judgement, consideration and sympathy depends so much" (November 22 1945). Yet women were not part of the decision making processes of the rehabilitation schemes, and earlier in the war "Juanita" of Morrinsville had written to the Listener:

Do the authorities assume that all these women will display meck gratitude at being permitted to return to their former spheres usually all too narrow until they slide into the "proper" status of wife and mother? (December 1943).

A request from the 1945 Conference of the Women's Division of Federated Farmers to have country women represented on the local rehabilitation committees was met with the reply, "We don't want women on rehabilitation committees". Yet as "Yorkie" wrote:

As least as many women as men will be affected by the work of these committees, for besides the servicewomen to be rehabilitated, practically every serviceman will have a wife who surely deserves some consideration (N.Z.W.W.June 14 1945).

Men were warned that they could not expect women to go back to the prewar situation:

Even their husbands will find that to try and put them back where they were, at the beginning of the war will be as futile a task as to try to prevent the sun from rising. They should not be asked to go back to petty social restriction, domestic slavery and financial dependence on their husbands or fathers. Both their families and the country must realise this and realise what is owing to them (N.Z.W.W. September 20 1945).

At war's end, however, the immediate needs of the returning men were the priority, and women were schooled in the psychological techniques to assist their return to civilian and family life. Mary Wrigley wrote:

Her job will be an extremely delicate and self abnegating one to be sure, but when it seems to her that she is doing all the work, bearing all the blame, she will remember those who never came back, and will throw herself into the trying tasks that confront her with renewed effort that springs from a thankful heart! (N.Z.W.W. September 20 1945).

"Don't fuss over your men and don't organise them" said Dr Walter Reeve:

Remember that for years your men have lived too close to many people, and that their companionship has been entirely male. They find it difficult at first to adjust themselves to the opposite sex and have their freedom curtailed...Don't try to hold your men too close - let them savour their freedom (N.Z.W.W. November 22 1945).

Advice on sex was offered by Dr. Elizabeth Cole, who reported that:

Husbands have found themselves impotent...It may be a mistake for some couples to rush the physical act in the first few hours of reunion...Your husband may find it necessary to woo you his wife as he did in the early days of marriage, leading you step by step day after day until he feels that the physical desire has been re-awakened and that you are ready for the moment of surrender (N.Z.W.W. January 10 1946).

Enid Cook's Booklet Towards Re-Adjustment: the Woman's Part advised women on how to restore to men, "The years the locusts have eaten" (1945:1). She warned that:

${ }^{8}$ The Superintendent of the Services Hospital in Rotorua. 
We may not like the prospect but someone has to be stable and able to suffer and endure...It is probably better for the woman to defer her own claims and cheerfully to make up her mind to get her man right first (19.45:5).

The image of the independent woman which had been built up during the war years suddenly changed as the traditional feminine ideals of nurturing were re-asserted. Women were to be submissive and self abnegating and the responsibility for creating a happy home was theirs. The message was powerful but not necessarily accepted. Hedda Dyson, the editor of the Woman's Weckly complained:

Those young wives have missed the best years of their lives. Men too, are in the same boat, but at least their war years have been crowded with action, whilst tedium in the extreme has been the lot of all too many wives (December 27 1945).

The N.Z. National Review:

We suspect that the rehabilitation people are frigitening thousands of girls with these warnings and unfitting them to be the wives of the returning soldiers. A husband would rather be caught in the beam of an enemy searchlight than in the awful glare of an understanding woman (July 15 1945).

Privately, women may have felt some injustice, but more often women accepted their responsibilities (Edmond 1986); were grateful to the rehabilitation assistance for their men; and were keen to do all they could to get things back to normal. This was to take priority over other dreams, and women were ready to invest extra effort into rebuilding relationships after the separations and hard work of the war years. More than that, the women I interviewed felt they owed this to the men who had had their lives and careers interrupted, and the next chapter will show that this sense of indebtedness to the men was to justify the priorities of these women for many years

\section{THE POPULATION PROBLEM: women $<--$ - children}

Underlying reconstruction plans was a concern over the declining birth rate ${ }^{9}$, and women were also being exhorted to bear more children. As in other industrial countries during the 1930's and 1940's, the population problem had become a Government concern; the cry was "populate or perish" 10 . The strength of a nation was seen in the numbers of able bodied men available for war, and an increasing population was a potential industrial market. The perspective that women brought to the population question focussed more on the quality of the childrearing experience rather than quantity, and the declining birthrate reflected the hard years of the depression and a greater reluctance of women to have large families. During the 1920's and 1930 's contraceptive devices and knowledge had been filtering through to more women, and in 1936 the Sex Hygiene and Birth Regulation Society had been formed. This organisation

9 The 1887 birth rate was 42 births per 1000 people, but by 1936 it had declined to 16 births per 100() .

${ }^{10}$ Quoted by Elsic Locke in an interview with the Woman's Weekly October 61986. 
generated considerable controversy by advocating state supported birth control clinics. But to avoid a head on clash with the nationalistic and eugenicist ideas supported by the Health Department (Mein Smith 1986) there was a change of name to the Family Planning Association in 1939, and a shift in its public focus to the idea of family welfare enhanced by the proper spacing of children. The argument was that women would have larger families if their bodies were not overworked. In private however, Association members were strongly committed to the ideal of women having control over their own fertility (Fenwick 1977).

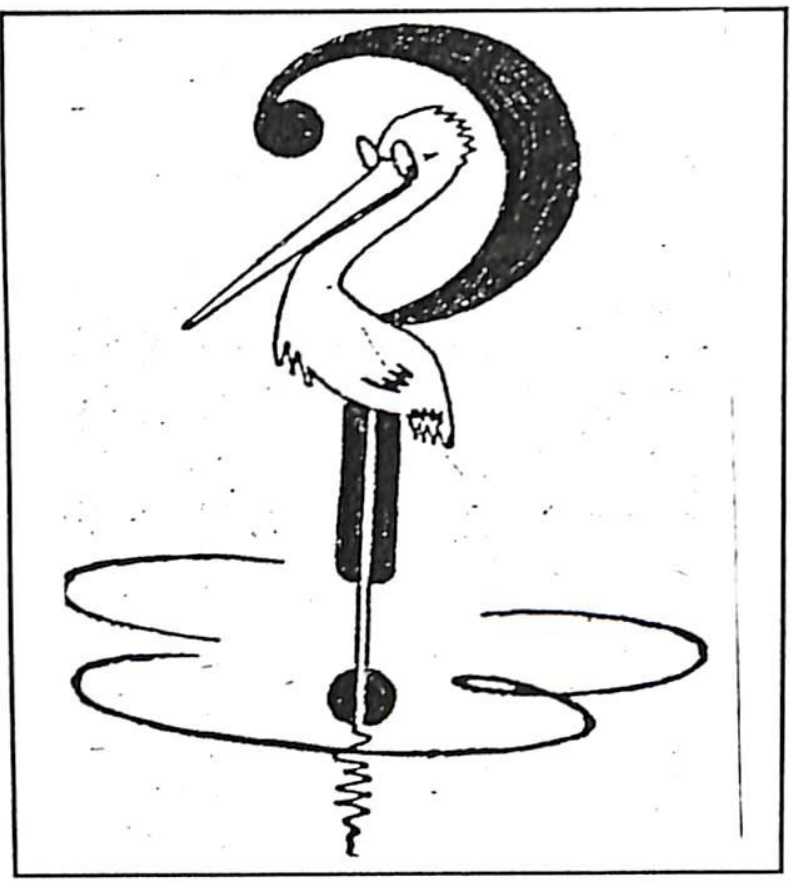

The question of population control was cause enough for conservative and progressive views on the family to clash. One view linked the population decline with deteriorating moral standards, and a report called New Zealand's Doom identified the "deadly enemies for family life", listing criminal abortion, contraception, venereal disease, shortage of homes, increase of flatting life, uncontrolled liquor traffic, pleasure-seeking parents and easy divorce (N.Z.W.W. August 22 1946). C.E. Hercus ${ }^{11}$ in the 1940 Wilding lecture ${ }^{12}$ at Canterbury University College, saw the "problem" as comparable to the war and advocated a Population Cabinet similar to the newly formed War Cabinet (1940:24). He suggested marriage allowances, housing schemes and kindergartens to support and encourage families, and called for radical changes in the education system to "create a sense of values as to what is really worthwhile in life, both for the individual and for the country" (1940:20). The N.Z. Army Current Affairs Bulletin (1943a) devoted a whole issue to the "problem", and platoon leaders were issued with questions for discussion amongst soldiers. The Bulletin did not address the decline as a moral

\footnotetext{
11 Dean of the Medical Faculty at the Otago University College.

12 An annual lecture series on a topic relating to women and education.
} 
problem but lunked the reluctance of women to have babies to medical and social causes. Dr Turbott the radio doctor ${ }^{13}$ joined the debate and observed realistically that:

War marriages may have brought war babies and the birth rate is up; will it stay up after the war? Marriages will not lessen but contraception and abortion are being used more and more to prevent and limit the family...the reasons may not be selfish. Society should step in to try to tip the scales in favour of a family N.Z.L June 22 1945).

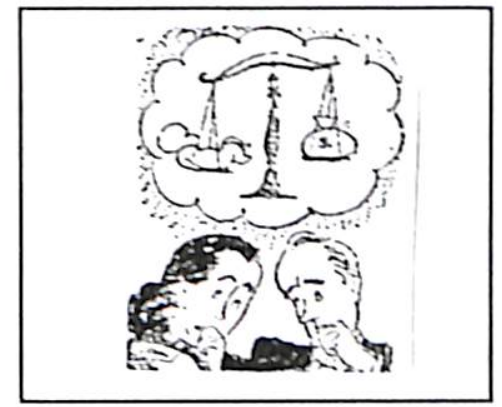

The Labour Government had already introduced a free maternity system with pain relief freely available for all childbirths, and two weeks hospital care for all (Mein Smith 1986), as well as extended family benefits. In 1946 universal family benefits payable to mothers were introduced $^{14}$, and at $10 /$ - for one child were close to $9 \%$ of the average weekly wage. The Listener had already canvassed opinion, and the connections between support for mothers and the population decline were not missed. "Butcher" replied:

If an increase in population is what they are after, family benefits alone won't do it. What they want to do first is to remove the threat of war. How many women want to go on having children just to feed them to war? (October 26 1945).

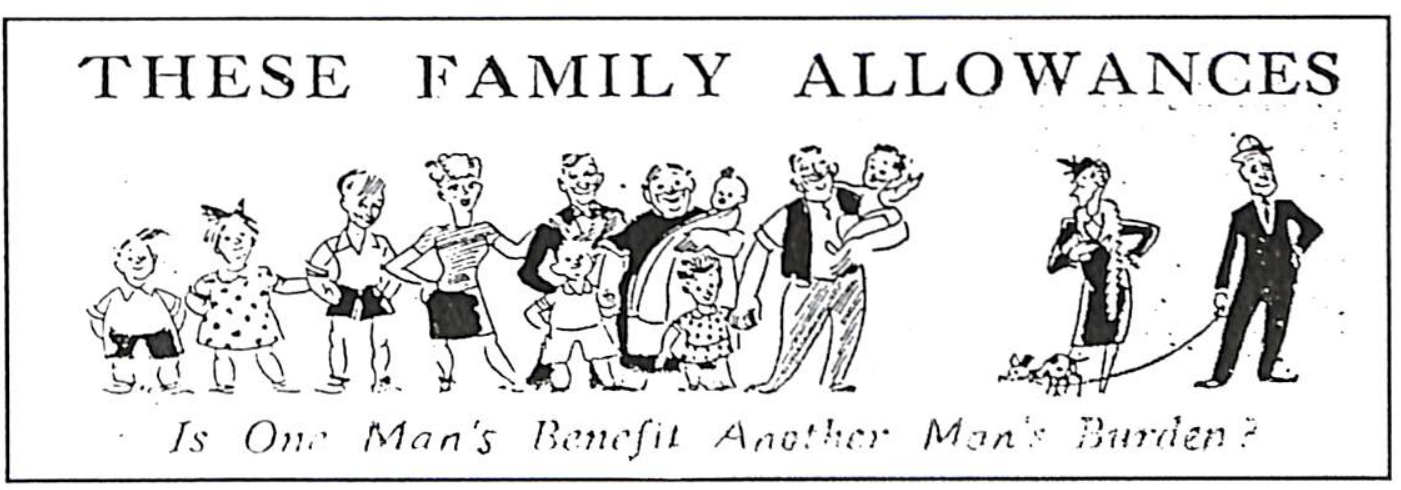

The population problem produced official concern in the Parliamentary Committee on Dominion Population in 1946. The Family Planning Association's submission promoted such

\footnotetext{
13 Dr Turbott is remembered for his down to earth weckly radio broadcasts on family health which were reprinted in the Listener.

14 Since 1941 all children in a family received the family benefit but it was means tested until 1946. In 1944 it had been increased to 10/- for every child. Motherhood allowances had been Labour Party policy since the 1920's, and had found favour again during the McMillan Inquiry into Abortion, which was established amidst concern over fertility decline (Mein Smith 1986).
} 
matters as family allowances, housing, kindergartens and nurserics, painless labour techniques, and help for mothers with small children. They argued that New Zealand women would have more children if the difficulties associated with childrearing could be reduced (Fenwick 1977). The Woman's Weekly reported that the Family Planning Association had sent out a questionnaire to "thousands of women" to gather opinion for its submission as to the "hindrances of having bigger families", and quoted "American sociological rescarch" which said:

The children of larger families are more mature and better poised than only children. It is realised that larger families give the parents greater satisfaction and that childless couples were much more liable to grow apart and become neurotic and disgruntled (December 6 1945).

Events started to overtake the mounting debate and by the time of the Select Committee Hearings, the Editor of the Woman's Weekly was stating:

If we believe the evidence of our ears and eyes it seems that the stork is working overtime just now. Nursing homes are booked up months ahead and many of our young women are worried to death by the failure to book in a place where they can bring new life into the world...It seems a little strange that just now almost hysterical reports are appearing pointing to the dangers of a falling birthrate (August 22 1946).

Immediately war ended the birthrate started an upward trend that was to stay constant until $1961 .^{15}$ The birth increase had little to do with nationalist population concerns and women were not having larger families. The immediate baby boom was caused by marriages and births delayed during the war, occurring alongside what would have been the normal births and pregnancies. Of more lasting impact was the popularity of marriage, with couples marrying at a younger age, and more people marrying that ever before (Vosborough 1978; O' Neill 1979).

The Government had extensive plans to alleviate the housing shortages, but had not anticipated the shortage of maternity beds. In 1945 in Christchurch, 300 patients had not obtained accommodation and the, "Medical Officer of Health felt the position would become worse instead of improving" (N.Z.W.W. August 2 1945). It was reported that the number of babies born in taxis increased as women in labour could not find a hospital to accept them, or more often women were admitted to hospital illegally (Gordon 1957). As the rush became more acute the headline read, "War Workers Tackle Peacetime Emergency" (N.Z.W.W. September 13 1946). Nursing shortages were assisted in some areas by stopgap voluntecrs from the Women's War Service Auxiliary until Red Cross and and St John's volunteers could be trained. In 1946 Dr. Doris Gordon was appointed by the Government as the Director of Maternity Services with a brief to sort out the chaos and plan for the future. She was

\footnotetext{
15 From a low of 16 births per 1000 in $1935-6$ the European birthrate rose to over 26 births per 1000 by the late 1940's. (European and Maori figures were kept separately.)
} 
outspoken in her crutucism of Government priorities. ${ }^{16}$ In Christchurch she addressed a special mecting of the Natronal Council of Women:

It was a situation that called for action as swift and decisive as that when the Japanese invasion threatened New Zealand...Contrary to any masculine belief, the real primary industry in the country is that of infant life. Only a shortsighted male could put the building of a shirt factory before a baby hospital (N.Z.W.W. June 27 1946).

Few women made the connections so explicitly, and in the order of priorities the reconstruction of industry, and the rehabilitation of the men were judged more important than the needs of women and children. Most women accepted the order of priorities, but it was difficult to accept the shortages that affected their children. There were extra coupons and rations for mothers, but they did not match what women believed they should have. The media reported the difficulties women had in "making do". Betsy Burton stated:

In the last few months I have been going each week to an antenatal clinic and have learned the importance of wool. So began my viyella, clydella hunt. Big shops, little shops, in and out, week after week and always the same answer. "I'm sorry madam"...So here I am with two months to wait, weary of shopping for my illusive layette, childishly I feel like shouting, "It isn't fair, it isn't fair" (N.Z.W.W. February 12 1948).

These early shortages were just the beginning of something the mothers of the first echelon of the baby boom learnt to cope with. During the next two decades the baby boom brought a continual pressure on Plunket and medical services, early childhood education and schools. All were stretched to meet the need. There was a heightened consciousness of children's needs but there was an inevitable mismatch between the dream and reality and the shortfall had to come from those mothers who had the time and resources to invest.

\section{HOUSEWIFE PROTESTS: women <---> work}

Women had little choice but to accept the extra work and shortages that the war caused, and their encrgy in the workplace and the home were accorded status as part of the war effort. To continue doing so as part of national reconstruction after the war had less appeal. There was little war debris, so New Zealanders wanted an immediate return to normal, and were impatient for evidence of the "better things to come" dreamed of during the war. For the men there were new economic and educational opportunities, and the job market for women also remained buoyant. For women who were housewives, however, the period of reconstruction became so frustrating that as a new kind of protest, Housewives Associations were formed to lobby Government. The argument was that houscwives were carrying the brunt of a restructuring that would benefit men. It was particularly hard for women with young children. Beatrice Wilson wrote:

Picking up a paper the other day I came upon a letter to the editor from "another tired housewife". I didn't bother to read it. So many tired

16 Doris Gordon (1957) described her years as the Director of Maternity Services in a book published posthumously. 
mothers had told the same pitiful story of shortages, and the trouble it entailed to think out substitutes. So many told of standing in queues in all sorts of weather - in rain, in cutting winds and even snow. The shopping itself...its packhorse aspect, coming home laden with parcels...had found its concern in chronicles of these weary overworked women (N.Z.W.W. July 8 1948).

To express frustration publicly was unacceptable during the war years but in the postwar years it began to spill over. Some wanted the time just to be mothers, as Penny Wise wrote:

What do mothers want? In the first place they want to be mothers. At present that is the last thing they are. They are washerwoman, cleaners (dirt money please?) gardeners (dirt money please?) cooks, polishers, nurses, teachers, moralist, dressmaker etc. - How can they be mothers in all this? (N.Z.W.W. May 4 1948).

Others saw childcare as the priority:

Have we creches which can relieve the mother's troubles? There is much talk about the need for increased population, but years have passed and the young mother in this country is still an absolute captive of her babies. If she is conscientious she will be tied down for many years (N.Z.W.W. April 26 1945).

During the war there had been much debate about a system of home and domestic help to assist mothers. This concern had arisen from the special needs mothers faced during the war, but women's organisations promoted the idea as a long term solution to halt the declining birth rate (Guy 1943). Aunt Daisy ${ }^{17}$ had returned from a wartime visit to the United States with enthusiastic reports about childcare for working mothers. Mabel Howard supported the idea although she was to state that the scheme: "Should not support those who want to go out playing bridge or golf. Many of those women who do that would be better off doing their own housework" (Quoted in Gee 1977:96). In 1945 the Government set up the Home Aid Scheme but it was only to provide home help in emergencies. It was a step forward but far short of the dream of a system of home help for all women.

During the war there had been shortages but women had become accustomed to extra home deliveries and extended shopping hours. The unions had agreed to such changes to encourage increased war production, but the Labour Government had a commitment to reestablish the conditions of earlier industrial awards. The establishment of a forty hour week after the war was to affect the housewife adversely:

Chores have to be done, someone has to work when another enjoys a week of leisure. It seems to us that the new unpaid servant class, who seem to have no redress, no let up from enervating toil and stupid restrictions are the New Zealand women as housewives and mothers. Life has not become easier for them as it has for the male worker (N.Z.W.W November 6 1946).

Home delivery services, which many housewives depended on were curtailed:

There have been endless protests from the housewives side, through their Associations and organisations against the non delivery of meat, and against Friday shopping, which to many housewives meant a nightmarish experience. Against no fresh bread over the weekend, which

17 "Aunt Daisy" was a well known radio personality. 
agann to many, meant carrying large parcels, when they are overburdened and now the milk question (N.Z.W.W. July 10 1948).

The forty hour week was however only the symptom of the deeper issues surrounding the workload of women. Mary Dobbic wrote:

If the press and the vocal public is genuinely concerned for the harassed housewife, it would employ itself more profitably hammering at housing and houschold services, than by fogging over these real ills with gusts of politically expedient hot air belched up from a bad spleen over the bakers' forty hour week (Here and Now October 1949).

The immediate difficulties caused by the forty hour week led to the formation of Housewives' Associations which co-ordinated a protest campaign at both the national and regional level. The common concern within the Housewives' Associations harnessed together a lot of the dissaffection women felt:

In it many women pin their faith, hoping that the day will come when through sheer weight of numbers the Association will be able to force issues which are of prime importance to daily family life. It is a good sign that women are realising the value of banding together and that by working as a single unit they should be in a position to enforce legislation (N.Z.W.W. September 7 1946).

Such unity was tenuous and there was an anti-government, anti-union tenor to the protest. In Britain a similar disaffection amongst housewives led to the establishment of The British Housewives League, but this was an openly right wing organisation that was effective at harnessing the discontent in an attack on socialism (Wilson 1980). I have found no evidence of such explicit connections in New Zealand, although the activities of the British organisation were reported in New Zealand and undoubtedly provided some inspiration. In both cases the organisations represented a groundswell of discontent about the hardship women were facing. The New Zealand Labour Government was not sympathetic and was unable to transform the deeper dissatisfactions that the protests touched into any real policy of support. The Woman's Weekly reported at a "well attended" protest meeting in Auckland, women were told:

That despite strongly worded protests through many organisations representing thousands of women, the Acting Minister had the effrontery to state in the House that the protests of the public and particularly women against the closing of shops on Saturdays had been negligible (N.Z.W.W. March 14 1946).

At the national political level the specific needs of women were trivialised and placed low on the schedule of priorities. Women for their part continued to "manage" and "make do", but there was a growing consciousness that New Zealand politics needed the perspective of women. The editor of the Woman's Weckly wrote angrily:

At present we live through an age in which modern devices and modern organisations should make the lot of women as housewives easier. The contrary is the fact: the weight of regulation, union demands, lack of services, short supplies, all these factors tend to drive the great proportion of women back to the kitchen sink...Some time ago I was in Wellington interviewing M.P.'s of both parties and even a few Ministers. They, no matter what they pretend to be, feel lost in the labyrinth of their own creation, and provided their vanity can be saved, they are as willing to 
consult women as they were ready to run to mother when they hurt themselves as little boys (N.Z.W.W. Febraury 28 1947).

In 1947 there was a National Women's Rally held in Christchurch that tried to provide a national forum to promote the views of women and: "To encourage younger women into taking an intelligent interest in the social, educational and national affairs and to help her realise her responsibilities as a citizen" (N.Z.W.W. April 3 1947). The Women's Weekly which had advertised the Rally wrote:

This was a truly pioneering effort and was the first rally of this nature with a dominion wide coverage ever staged in New Zealand...The outcome surpassed the expectation. It was a furore.

A committee was established to hold further rallies but there is no record of any more. By 1949 there was a change of Government; rationing and restrictions were lifted and the tenor of protest penned in the magazines softened. This easing of restrictions was to quieten the brief appearance of a strident women's political voice. In the years that followed women were not passive but they organised in smaller groups around specific issues like new childbirth techniques and the right to visit children in hospital; or local efforts to get playgrounds, kindergartens, restrooms and community centres. This kind of activism was more subtle but a forerunner of the collective analysis of the ills of women and children which the later women's movement was to address.

Part Two: 1950 -1960

\title{
RECIPES OF HARMONY
}

\begin{abstract}
present
Theanostalgia for a decade in which traditional family values appeared certain is perhaps understandable from a generation which saw their values challenged. Such challenges however had their roots in family life of the 1950's. Thus, little about this era is as it appears on the surface - particularly the nostalgic view of it. The Woman's Weekly and the Listener gave their readers endless recipes for ensuring family harmony, which would not have occurred if family harmony had matched the nostalgia of memories. The media message was that maintaining a happy family was an art to be learnt and negotiated according to principles governing the roles and responsibilities of its members. At the same time the family was the arena where individual women negotiated their growing desire for more independence. The official argument was that women had achieved equality and it was up to individual women to choose. In the absence of any collective analysis private negotiation was delicate. The next three scenarios reflect the dilemmas women experienced as they accepted the primacy of their roles of wifehood, homemaker and motherhood amidst the growing ideal of independence. But even in the acceptance of these roles women were to find that they were contradictory. To be both an exciting sexual partner and a sensible wife; to be both a creative homemaker and a thrifty housewife; and to be a loving mother as well as have "good" children were impossible prescriptions for anyone to balance.
\end{abstract}




\section{THE "ART" (OF MARRIAGE AS A CAREER: women <--->men}

New Zealand demographe studies have shown that in the postwar period there was a trend towards younger and more universal marriage (O'Neill 1979). This was encouraged by economic security, but also new psychological prescriptions were promoting marriage as the only way to adult happmess. Maturity was the key word and the American developmental psychologist Erikson (1950) identified a progression of stages leading towards adult maturity, and there were tasks and responsibilities required of each stage (Havighurst's 1953). To marry was a proof of adult maturity, and a successful marriage demonstrated emotional maturity, but it was an art that had to be worked at. Maturity was demonstrated by responsibility and conformity to adult sex roles, and conversely immaturity was the label for all behaviour that did not conform to the norm. The criterion for measuring adult maturity was different for men and women. If a man did not marry, or did not become a good breadwinner, he was deemed to be neither fully adult nor fully masculine (Ehrenreich 1983). Women who did not want children, did not demonstrate an enjoyment in homemaking, or put their own needs before those of their family were not demonstrating adult maturity. New Zealand magazines popularised and promoted American ideas of psychiatry which offered to assist individuals towards maturity and emotional well being.

A rational explanation for marriage conflict and divorce was sought by the Listener. Representatives from the proliferating agencies dealing with marriage ${ }^{18}$ and "experts" from the University Colleges' new Social Science Departments aired their views. For the Listener, however, marriage was an occasional interest topic, whereas the Woman's Weekly devoted most of its space to explore the emotional conflicts of the "marrieds", "about to be marrieds", the "never marrieds" and the "were marrieds". Marriage was the essential adult experience around which all other strands of life were linked, and the Woman's Weekly offered varieties of "expert" advice. These are a guide to the boundaries between the acceptable and unacceptable behaviour at the time. In the 1940's readers had begun writing to Lou Lockhart, revealing that conflict within marriage, adultery and premarital sex were not uncommon in New Zealand society. In the 1950's Lou Lockhart was changed into Mary Millar who, with a sensible name and a high moral tone wrote a weckly advice column based on the letters she received. Overseas experts got more space. England's Dr David Mace, "the world authority on love and marriage" compiled many serics of the "Marriage Guidance Casebook" as well as making a visit to New Zealand. There was also Dr Paul Popenoe, "the noted American authority on family problems", Bernard L. Calmus in "The Psychologists Consulting Room", and Barbara Cartland's "Marriage School".

18 Marriage Guidance Council, Family Discussion Burcau, Family Guidance Centre. 
The message from these experts was consistent. Successful marriage was not casy, it required men to shoulder responsibility and women to show sacrifice, and the ability to do this was labelled as maturity. It was believed that except for the occasional bad husband women could have a successful marriage if they followed the rules. But women had the major task of smoothing over the cracks because they were more adaptable than men, and they did not have to earn the living. There is however a difference between prescription and practice and not all the advice was accepted unquestioningly."A.C.A". grumbled:

From what one reads, it seems that a man marries a woman to have, firstly, an unpaid housekecper, After that, she is supposed to possess all the beauty of a film star, the brain of a university graduate, the poise of a mannequin, and the patience of the worm that never turned. She must never be disgruntled, never answer back, never put herself first and always admire the "master" (N.Z.W.W. September 5 1952).

The art of making marriages work could be a career that would not only benefit the family but also the nation, as M.L.C wrote, "(Marriage)...certainly is the most important carecr of all, as the nation depends on the stability of the home for the future generations" (N.Z.W.W. July 16 1956). Newsworthy engagements such as that of Louise Rose to Sir Edmund Hillary in 1953, set the ideal of the educated, talented and seemingly independent woman who put a higher priority on being a supportive wife. Louise Rose had been studying music as the Sydney Music Conservatory and, "Marriage was to cut short her plans for a career in the National Orchestra" (N.Z.W.W. September 3 1953). Women were applauded who could demonstrate that they had achieved equality but who valued home, marriage and family more. "Lady Hillary, will share, for better or for worse, the future of a young man who has already written his name in history" (ibid).

Husband and wife both had careers even if they were different in kind and reward. It was an equitable pooling of talents for the husband to work outside the home for money while the wife managed the home. In its ideal (middle class) form there would also be childcare and housework assistance that would alleviate the drudgery of home life. This would make marriage an attractive career, so that women could be supportive companions to their husbands and could give priority to the rewarding aspects of childcare and homemaking. Such assistance did not materialise, but new consumer products such as tinned foods, electrical appliances, gadgetry and new cleaning formulas were heralded as the genies which would lighten the burden and enhance the marriage relationship. The career wife who managed the home was supported by a new ideology of consumption (Winship 1981), as the chore of purchasing and using these commodities became more than just a duty to be performed. These skills were elevated to an art to be acquired by the new wife, and purchasing them, a leisure activity that would fill the hours presumably saved from drudgery.

The image of the independent career wife who had purchasing power was not based on the assumption that wives had their own money. Instead women would have the skills to manage 
their husbands wage packets carefully. The Bank of New South Wales began encouraging housewives to put their housekeeping money into a cheque account.

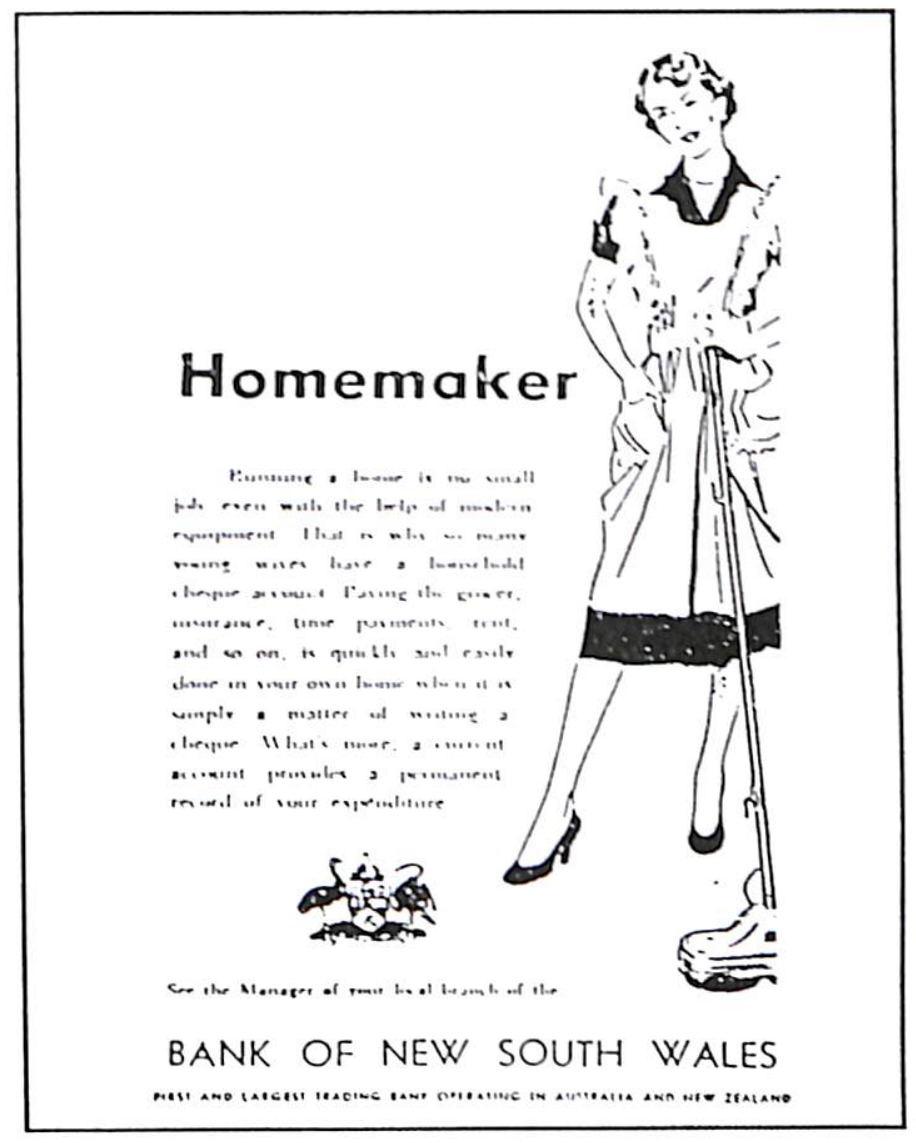

Training courses for prospective brides on, "Home decorating and the buying of furniture; marketing for two; meal planning, cooking, kitchen efficiency and economy; bed making and cleaning" were promoted through the Woman's Weekly (January 5 1950). Dr Paul Popenoe however was concerned that the idea of marriage as a career should not be taken too far, otherwise, "She may look on the job as something taking up regular hours, with the rest of the time for fun...to be a good homemaker requires very different ideas" (N.Z.W.W. July 9 1959).

Mary Millar's weekly advice column revealed the tightrope of managing a relationship which was based upon being equal, but different. The idcal of marriage as a career for women depended on the subtle difference in the rhetoric of equality for husband and wife. It was acknowledged that marriage was a joint partnership and there was a rejection of the notion of a wife dutifully submitting to her husband in the Victorian sense, but as Mary Millar reasoned, "The home should be headed by husband and wife, with the husband as the slightly senior partner" (N.Z.W.W. February 24 1955). In practice this was to mean that each had their own sphere but that decisions could no longer be a unilateral male preserve. Mary Millar reminded her readers that the male must have the final say because of his legal responsibility to support his home and family. In the situation where women were forced temporarily into the 
breadwinner's role, Mary Millar warned women to hold back as "masculine pride is casily hurt and if any woman values her marriage happiness she'll take care not to do anything to hurt that pride" (N.Z.W.W. August 11 1955). This double standard of equality inevitably required women rather than men to make the adjustments. To "Agnes" whose husband would not allow her to choose her own clothes, Mary Millar suggested:

She should always flatter her husband...probably he had an unhappy childhood...to strip off his protective facade at this stage might be worse than useless...it might even ruin the marriage...Agnes must face the fact that she married her husband and she took him for better or worse (N.Z.W.W. March 3 1955).

A shortfall or excess in any of the responsibilities and tasks of a wife found little sympathy. Mary Millar commiserated with "Ted" whose wife had got so "bored with housework and restless" that she had got a temporary job. "Ted" was advised to give a "show of firmness". He was to tell her "that she was to give up her job" (N.Z.W.W. October 14 1954). "Chris", whose wife was becoming too involved in charitable interests, was to, "Protest firmly if the family were left alone at meal times, not able to go out together, or bothered by vacuuming, cleaning and the like, late in the evening". Mary Millar warned that, "Such things constitute neglect. They aren't as bad as doing no cooking and cleaning but they are a form of neglect just the same" (N.Z.W.W. August 5 1954). Yet when "Anna" complained about her husband's hobby of making models in the middle of the living-room floor she was told that her attitude was at fault and that, "She wanted to possess her husband body and soul" (N.Z.W.W. April 28 1955). The unequal equality of the marriage partnership was justified by the husband's breadwinning responsibilities. The concept of the male breadwinner's wage for all classes had emerged alongside the nineteenth century "cult of domesticity" for women (Olssen and Levesque 1978). Throughout the twentieth century the the breadwinner's wage had been edging towards equivalence with the working class pay packet, and by the 1950's it was becoming closer to being a reality. The notions of masculinity and being a good breadwinner became closely entwined, although Ehrenreich (1983) suggests that the resulting pressures forced men to begin their "flight from commitment" towards new definitions of masculinity and a larger slice of their breadwinning cake. During the 1950 's, however, the breadwinner was central to the marriage relationship, and the debate was on the mechanics of accommodating the notion of marriage as an equal partnership.

Men were to be more involved in domestic issues, but women were warned that there must be carefully drawn lines, so as not to confuse the essence of masculinity and femininity:

In principle I feel that a husband should take an interest in all that goes on in his house, except for cooking, mending and ironing... No wife expects her husband to come home from work and don an apron... That is not the idea at all (N.Z.W.W. December 16 1954).

Barbara Cartland who became the most artful advocate of the double standard advised women to, "Let HIM be boss (in theory)" 
There was a double standard of sexuality as well as equality. Married sexuality, which had been a taboo subject, was being tentatively discussed in the mainstream media. The Kinsey Repor (1948, 1953) created a greater awareness of sexuality and the "art" of sexual fulfilment; birth control was becoming acceptable and available, and marriage manuals were stressing the desirability of pleasurable sex within marriage for women as well as men. Opinion was, that female pleasure was a male responsibility, and that a man should control his stronger sex drive in deference to his wife's weaker urges. The media messages were however confusing: sex was strictly confined to marriage - but this was alongside the glorification of the extra-marital sexuality of filmstars like Marilyn Monroe and Diana Dors. They were temptresses to men in contrast to the sex manuals which gave the initiative to men. The fashion scene however, with its feminine "new look", was an encouragement to women to dress with a kittenish sexuality. The message was that a wife could also be a Marilyn Monroe for her husband and then he would have no need to go "astray".

Sex education too was carefully promoted. In 1948 the Woman's Weekly had responded to the obvious ignorance on sexuality that its own letter column revealed with the publication of a book 1001 Problems Answered by Lou Lockart. This covered hitherto delicate subjects such as "How far can I let a boy go?", "The first night of marriage", "Why must men philander?" The editor of the the Woman's Weekly strongly chastised mothers whose daughters were left in ignorance, otherwise, "Sex may take on the significance of something brutal and abhorrent, as many a young bride can testify" (N.Z.W.W. January 29). The 1942 Thomas Report, which was the blueprint of postwar education, had argued that "every adolescent should know the facts of reproduction" (1942:53). This was not to encourage an expression of sexuality amongst adolescent, but a concern to instil codes of correct behaviour (Middleton 1985b). The 1955 Department of Health pamphlets on Sex and the Adolescent Boy and $\underline{\text { Sex }}$ and the Adolescent Girl gave factual information but the morality of sexuality was directed only at girls, who were told that their sexual feelings were weaker than boys' and that it was up to them to control boys' stronger impulses. Boys could not help themselves, but girls were told that boys only respected girls who had control (Middleton 1985b). The tenor of these pamphlets came from the 1954 Mazengarb Report which had recommended that all girls under sixteen who permitted a boy to have "carnal knowledge" or to "handle her indecently", should be liable to be charged with an offence. Although Freudian notions of healthy sexuality were being popularised, sex education had little to do with sexual pleasure, but was more a process of civilising the instincts. "It helps us to know what we are fighting, to protect one another until we can mate in a civilised sense - through marriage", said Bernard Camus in "The Psychologist's Consulting Room" (N.Z.W.W. May 18 1957). Pre-marital sex was unacceptable. An appeal from "M.K", who did not want to marry too young, but was reading that, "A regular and creative sex life was essential to one's maturity and personal development" received the firm answer from Lou Lockhart that, "A creative sex life means a 
controlled sex life". "M.K". was assured that he would not become a "frizzled up unemotional fossil" because he was not yet married (N.Z.W.W. July 6 1950). This advice was not always convincing, and Mary Millar wondered, "What are the standards of "nice" girls these days?". She expressed concern that "girls who have maintained a very strict standard of conduct have still got left on the shelf" (N.Z.W.W. August 27 1953). To Barbara Cartland sex was the supreme art, but again to be learnt only in marriage. She warned that, "sexual love must colour every action everyday. Ignore sex - and a bitter, unforgivable hatred is born " (N.Z.W.W. January 27 1955).

For women who never married, moral codes forced them into a life of visible celibacy and sometimes spinsterish activities. The situation of single women in a society where women have been accorded status through their roles as wives and mothers has never been easy. The decline in numbers of marriageable men after two world wars brought some re-evaluation of the worth of these "unclaimed treasures":

Unable to devote themselves to husband and children, they put their qualities and desire to serve at the disposal of the community; they became deaconnesses, district nurses, kindergarten teachers, missionaries, welfare workers...Goodness knows what the world would do without them. They don't dignify their work with the name of "career", and they probably grieve more over lack of children than lack of husband (N.Z.W.W. December 30 1954).

Society had a place for spinster women who had missed out on getting a man, but it was more difficult to categorise women who were apparently choosing to have careers rather than marry. At one level women were being told that they had a choice now whether they married or had a career, but there were subtle messages of disapproval against women who chose the latter. A sole article on lesbianism entitled "Rejectors of their Sex" (which does not mention the word lesbianism) expressed concern about, "Women who display mannish traits. They wear collars and ties. Their jackets have a masculine cut, and as often as not the hairdo also has a suggestion of masculinity" (N.Z.W.W. January 8 1948). The author (male) attributed such behaviour to feelings of inferiority before men and suggested that such women were apt to join the career race against men. There was tolerance of the new "career girl" only so long as she remained in traditional areas of women's work. Even so her independence was still a threat to an order which was unused to the economic independence of women. One mother wrote:

I am worried about my daughter who is single and shows no inclination to get married. You see she is one of those carecr girls. She is proud of her money and her position and so won't want to give up either or sacrifice anything to making a home or rearing children. I can't help feeling that this would be better for her than having a life all her own way (N.Z.W.W. March 4 1947).

With the marriage age dropping, this independence was usually short lived, and for most women success was equated with making the right marriage and accumulating the trappings of a good family. Those who did not achieve these wondered what was wrong with them, and it 
was only a tew women who were able to feel assurance in choosing to remain single. There were many sad letters from single women:

I long above all things to be married as all my friends are now. I am slum with good features and I do understand clothes and make-up. I'm keen on sports and 1 go where there are men. Yet I also seem to miss the proposal. My romances seem to fade out...Should I change my job? There aren't many single men where I work. I do so want a home and babies.

Mary Millar's reply was not sympathetic:

She thinks only of herself and of "wanting" marriage, home and babies...Does she ever think of a man except as a home-baby-prestige provider? (N.Z.W.W. May 25 1959).

The messages in this sad communication were confusing. On the one hand, marriage and family were upheld as the ultimate fulfilment for women, yet custom demanded a modest stance. Women were not to appear too eager. The art of getting a man was subtle and confusing and for all but the popular few could be fraught with unhappiness.

Alongside the emphasis on a happy home and family life there was a growing concem about an increase in the divorce rate. This was an anomaly in the mythology of the "good life", that was difficult to accommodate ${ }^{19}$. In 1953 there were the first changes to the divorce legislation for over thirty years (Phillips 1981), ${ }^{20}$ but the issue was more than an individual solution for ending an unhappy relationship, and debate focused on the threat it posed to the moral and structural fabric of the family. Divorce was a "sore", and as divorce became easier a spate of agencies appeared to promote "responsible marriage" and provide services to assist families to stay together. Like the advice columns of the Woman's Weekly, these agencies were an acknowledgement that "normal" family life was difficult to attain, and maintaining a successful marriage was now an art with skills to be learnt. In 1948 the Marriage Guidance Council was formed and not only counselled couples with problems, but soon moved into prevention by offering classes on personal adjustment, sex and parenting. Academics found a fruitful research topic in the cause of marriage failure. The suggested reasons ranged from housing problems, confusion of roles, being an only child, emotional immaturity (J.H. Robb $^{21}$ in the Listener March 10 1950), to the theory that divorce was most common amongst watersiders, scamen, barmen and taxi drivers, and was more common in the North Island (A.J. Nixon ${ }^{22}$ in the Listener July 6 1956).

19 This had risen from 3.64 petitions per 1000 marriages in 1939 to 6.12 per 1000 in 1946. The war had been mainly responsible for the rise and the rate had dropped to 4.53 per thousand by 1950 . Throughout the decade there was a gradual but not a dramatic rise (Phillips 1981).

20 21 22 A new ground for divoree was added which allowed it after a seven year separation.

1 Lecturer in Sociology at Victoria University College, and later Professor.

22 Lecturer in Law at Auckland University College. See also, Divoree in New Zealand: A Preliminary Survey. Bullecin No. 46. Sociology No. 1. 
The anxiety surrounding divorce epitomised a struggle between conservative and progressive forces that has been repcated in various scenarios in postwar socicty (the most recent being the Homosexual Law Reform Bill in 1985-6). In the divorce debate both sides upheld the importance of marriage and family. The conscrvative vicw was that divorce created broken homes which were breeding grounds for delinquency, social disorder and even communism. The more progressive view was to switch the argument around and blame these social ills on inadequate divorce laws, inadequate marriage preparation and a lack of support services. This era which strongly reaffirmed the tradition of marriage and family, also created the trend towards divorce as an option. Happiness in marriage was the new ideal, and when this collapsed or was not the reality, it was inevitable that divorce became a possibility. What threatened the order of society was at the same time liberating to some members of it, although it was not until the 1970-80's that divorce became easier to obtain, more acceptable and more equitable for women. In the meantime the effects of the slowly rising divorce rate were to reveal more clearly how marriage and divorce for women were based on dependence and inequality. The concept of equal but different had been formulated into the marriage partnership, but the anomalies this duality uncovered became important as a forerunner to a fresh consciousness of the insecurity of women as wives and mothers. Women in the 1940's embraced the ideal of equal but different as a means of awarding status to the married role. The hard realities eventually showed that such shadowy equality, negotiated within the privacy of each family home, was not always sufficient.

\section{"THE LADY JUGGLER": women <----> work}

The well poised juggler, managing all her responsibilities, was an ideal image of women, but as jugglers know, the appearance of ease disguises the skill required in keeping it all rolling around. "Kitts" warned that:

It takes consummate skill and a deft touch to hold a fine balance between your duties as a wife, mother, employee and custodian of the cat. In short you have to be a lady juggler to keep all the balls going simultaneously, with exactly the right relationship of one to the other. When the crisis comes, unfortunately, some women make the mistake of dropping the husband instead of the job or the cat...Remember man waltzes to the altar because he wants a wife, not a business associate (N.Z.W.W. May 17 1951).

Such a warning was part of the ideological pressure to shift the focus of women's work back towards the home after the war, despite the continuing employment opportunities after the war. Women's work was to become non-work and trivialised as a leisure activity (homemaking and shopping), as an educational process (childrearing), and as the acquisition of "pin money" (paid work). Men as breadwinners were the real workers. There was however a mismatch between the ideological separation of male and female work and the actuality. The process of transforming real work to non-work was never complete and irregularities kept 


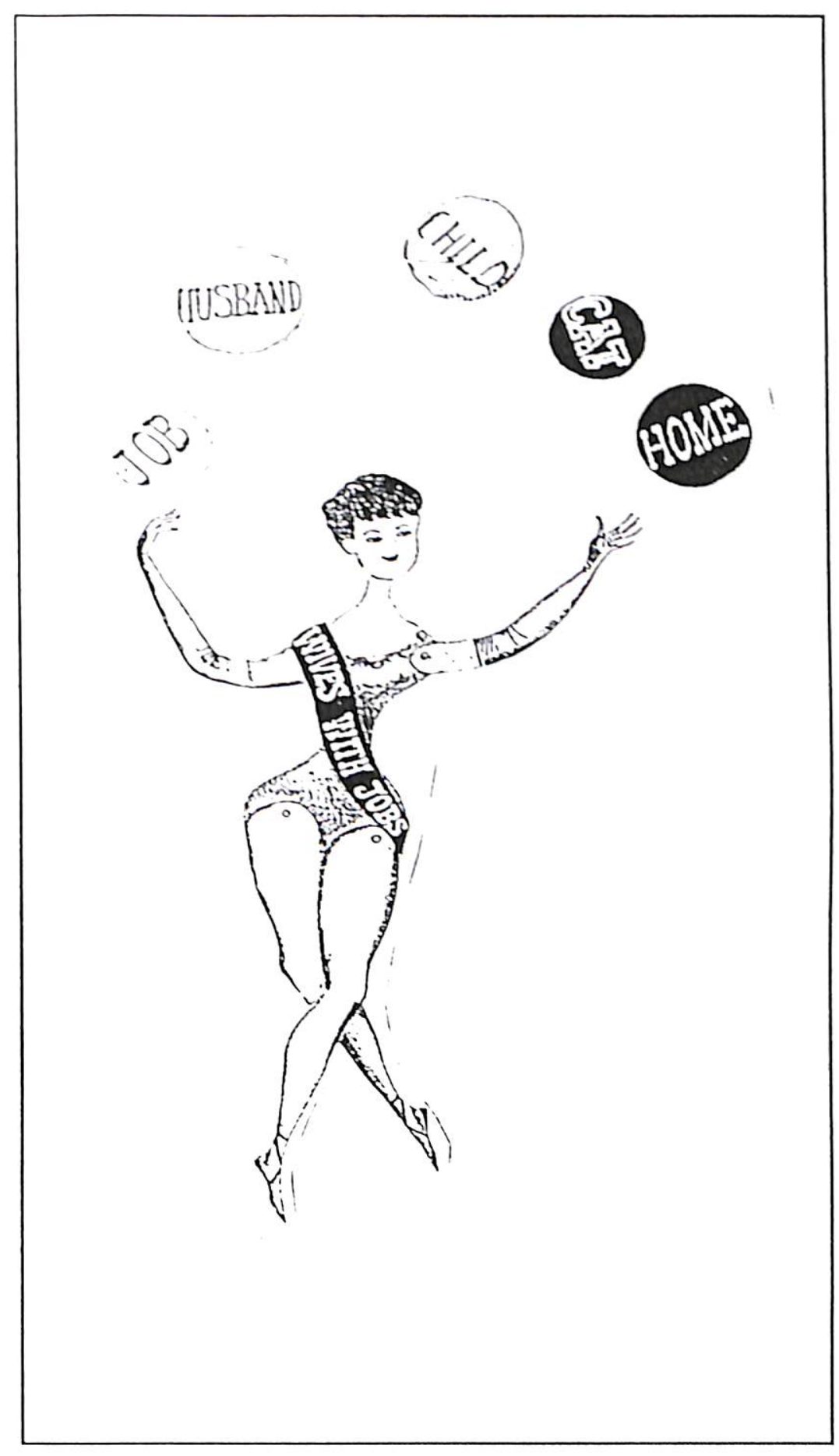

erupting through the outward acceptance and order of separate working roles for men and women.

The media image of women as workers in the 1950's was confusing, as femininity had different faces; from the married woman as a sensible housewife to the single working "girl" available for marriage. The latter, idealised as the glamorous "career girl", held an ambivalent position amidst the separate spheres. She portrayed an image of independence, competence and equality, but of kind that would still find her a husband. For many single women, however, their career was a mundane job which they were anxious not to have to stay in for too long. "Careers for Girls" was a popular catchphrase in schools and the media, but careers were gender 
specific, or if appearing to cross the gender boundaires were rationalised in the context of adding to a woman's worth in marriage. For example:

If a girl accountant gets married, she is far better equipped to budget her weekly expenses and to understand her husband's financial projects, and if the need arises has her job to fall back on (N.Z.W.W. November 5 1948).

Career "girls" were tolerated and as the age of marriage dropped the time span of being a career girl was not long. Women were expected to make an carly commitment to a career in the workplace or at home.

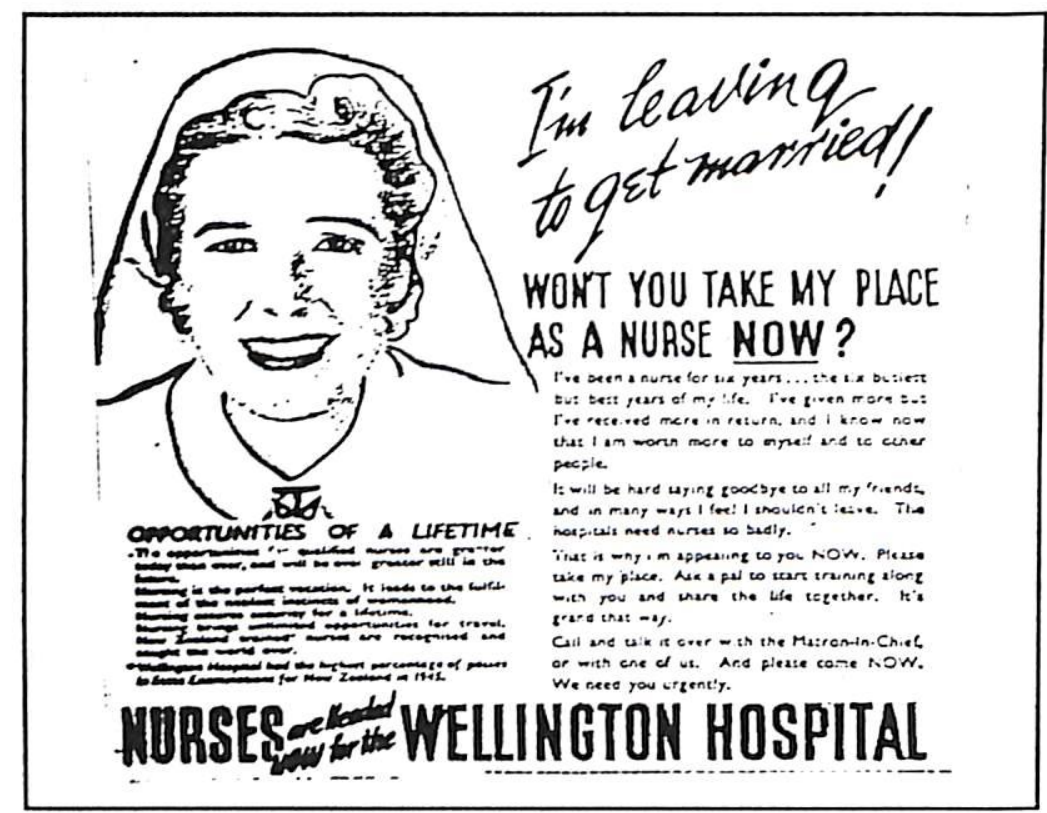

Dr Paul Popenoe published a "Test" that would help. A score of 16 out of 20 indicated that, "It would be doubtful if marriage would satisfy you", and a score of less than 10 indicated that, "You are not a career woman at heart". The assumptions were that being a wife was a passport to move out of the workforce; that the husband's wage was sufficient for two; that a wife would be too busy looking after her house, family and husband to want to work. The ideal was not always achieved. In the first instance, many men did not earn enough to support a wife and family. As expectations rose in relation to housing and houschold goods, the dual income family became an advantage, if only to get the minimum requirements for a houschold to be established. Secondly, some women enjoyed their work and the independence it brought, as domestic life was not always as romantic or fulfilling as they had hoped or had been led to believe.

The debate over women's work outside the home was argued at two levels, and the judgement for the working mother was harsher. Not only was she placing her marriage, if she had one, under threat, but the emotional, physical and moral well-being of her children were in jeopardy. The attitudes towards the working wife were more ambivalent, reflecting again the contradiction inherent in the concept of women being equal but different. Women had a right to 
work even as waves, but thetr work was different from men's work because they were not going to be breadwinners, and their work must allow them time and energy for their real work in marriage - caring for therr husband, home and children:

A man looks for the companionship of a woman when he returns at night and he likes to find her there, fresh and ready to welcome him, not tired out after rushing for the five thirty train in an endeavour to run two jobs. A man likes to feel he is needed even if a woman does earn a salary of her own (N.Z.W.W. March 20 1952).

All opinion along the spectrum, however, from cautious support to concern, acknowledged that a wife's work was secondary and temporary. Mary Millar cautioned working wives to, "Make it a rule that you will never reveal what you earn to any one, and to treat your husband as head of the house. Don't wield the power of the purse".(N.Z.W.W. August 4 1958). There were limits for career wives, and to one husband who complained that his wife had been posted out of town in her job, Mary Millar was firm:

In society, even today, the husband is recognized as the head of the household, and just makes himself ridiculous if he lets his wife drag him from job and home. Let the husband give way and he's resigned himself to being his wife's slave for life. Is that what he wants? I don't think he does, and I don't think that in the end she will want to sacrifice her marriage to a wonderful career (N.Z.W.W. August 4 1958).

It was also a matter of careful apportionment of the budget so that the husband felt he was the breadwinner and:

If a wife supplements her husband's income it doesn't generally disturb him -- unless she uses the situation...Let the husband take responsibility for the larger regular expenses, like rent and food, while the wife's contribution goes for clothing or luxuries N.Z.W.W. October 29 1953).

The message was that wives could work as long as they did not challenge male working status, and according to Elizabeth Thorpe it was all a matter of "subtlety". "Your husband's attitude towards your job will depend largely on your attitude to him. If the house is run down, dinners burned, you can't blame your husband for harbouring resentment against your working" (N.Z.W.W. June 19 1956).

The issue of working wives was in the main regarded as a family concern to be negotiated at that level. In contrast working mothers were of national concern and blamed as threatening the stability of postwar life. Scandals of delinquency and promiscuity figured prominently in the media; and as the milk bars thronged with "restless" teenagers it was felt that something ought to be done. Parents were exhorted to be more conscientious in rearing their children and to control their teenagers. The Government felt it had done its job by providing housing, jobs, and better health and education services, thus the blame must be within the home. Dr Mazengarb in his Report on Moral Delinquency and Adolescents (1954) maintained that one third of all cases of juvenile delinquency came from homes where mothers went to work, although E. Burke's subsequent research to test this hypothesis concluded that, "No significant differences were found in the behaviour of children of employed mothers as 
compared with children of non employed mothers" (1958:36). In this debate there was little acknowledgement that there might be economic motivation for women to work. The editor of the Woman's Weckly, Jean Wishart, seemed a lonely voice against the condemnation of working mothers:

In defense, some women declare that their husbands do not carn sufficient to provide more than food and regular houschold expenses. If their children are to be clothed properly they must supplement the income. Others argue that by working they can give their children the advantages which they themselves never had (N.Z.W.W. Junc 5, 1956).

The accepted explanation for why married women were working was that, apart from a few women who "had to work" because there was no breadwinner, women were working for pin money. This trivialisation of women's paid work became an attitude that has been difficult to change. Many of the things that women were working for were an integral part of the "good life" to which all New Zealanders were suppose to be aspiring. The Woman's Weckly (September 2 1954) surveyed working women and found they were spending their earnings on such things as: dancing and music lesson for children, household appliances and furniture. These arguments were easier to justify, but it was not the only reason women were working. As "Waimea" wrote:

The average woman of today receives a wide and varied education, involving so many interests that she frequently rebels against leading a life narrowed to domesticity after marriage (N.Z.W.W. July 30 1953).

It was also convenient to blame the war years for encouraging working mothers, as "Lundis" explained:

Most of the working wives were themselves teenagers during the war. They were trained to early independence so that their mothers could do war work outside their homes. A mother with leisure was practically a disloyalist. All this time girls were maturing and forming their concepts of married life; their models were their mothers and the working mothers around them. Their mothers, their early models were lauded for the same conduct (N.Z.W.W. April 6 1959).

Few critics however were willing to acknowledge the contradiction that the national economy needed the labour of the same women who were being accused of undermining the stability of the nation. An exception again was Jean Wishart who argued that, "Industrialists say that if married women, who comprise a large percentage of their employees, are discouraged from working, industry - and prosperity - would suffer" (N.Z.W.W. Junc 7 1956).

During the 1950's the arguments began to shift as it became apparent that emotional pleas were not successful in keeping wives at home. The concept of a woman's dual role was discussed. Women would primarily be mothers and wives but they would also move in and out of the workforce according to family needs. They would work up until the children arrived but not while the children were at school; but then as the children grew older women could become part of the workforce again, although preferably part-time. This was in preparation for when the children left the nest altogether. The small part-time job was the solution because it would 
balance the limitations of the breadwinner's wage without disturbing the breadwinner's head of the household status; it would give a new fulfilment to women who felt "restless"; it would not alter the primary role of women as mothers and wives; it would allow men and women to manage their separate spheres: it would support the standards of the "good life" without disturbing the values and assumptions of family life; and it would permit the labour of women which the economy needed. Everyday life was not so neat, particularly as families' economic needs were usually their greatest during the years when women were suppose to be at home. Time has shown that the effects of women's dual working role were to snowball and reverberate into many levels of social, political and economic life during the following decades. This movement of married women into paid employment was connected to the growth of postwar consumer society. During the depression and war years women had been at the forefront of a "make do, mend and conserve" philosophy. In New Zealand this did not disappear. Women were enticed with images of consumer goods that would enhance further the quality of their home made goods. The housewife's image of "making do" and improvisation was overlaid by the skill of selection. The Woman's Weekly "Economy Hints" page was retitled "Surer Shopping" and readers were introduced to the new range of goods coming onto the market ${ }^{23}$. Consumer goods brought a new power to women, and although they did not always earn the money, women spent it. They became "individuals" through consumption (Winship 1981), as they had to acquire the skills and knowledge of successful shopping for the house, the table, the family and for their personal appearance. Women's magazines became the housewives' handy advice book, constructing the possibility of success as long as you "worked" hard at it.

The home was symbolic of women's individuality. "Judy and John" became the Woman's Weekly version of the school's "Janet and John". Judy and John were an engaged couple building a house, and week after week every detail of their purchase was appraised. Judy and John had a joint interest in the home but there was a clear demarcation in the interest and responsibilities of spheres. Judy was to be the expert on "the kitchen, the laundry, the decorating and the cleaning, and she pestered the architect to show her the detailed drawings of the kitchen cupboards...there was a sliding towel rack...a sliding chopping board, magnetic catches" (December 16, 1954). Judy was told that she didn't need to bother her head about the garden, the exterior, the lighting, or the roof, as John would take care of them. Judy was going to work for two years after they married, "So they can buy extras like a refrigerator, washing machine, floor polisher, good radiogram and vacuum cleaner, in that order...In her mind's eye she saw a completed kitchen, and herself bustling about preparing a meal for the hungry John

\footnotetext{
23 Some of the items discussed during the early 1950's were labour saving devices such as, electric cleaners, knitting machines, automatic washing machines, steam irons, plastic plates, rotary lines, plastic table cloths, plastic pegs, vacuum cleaners, floor polishers, plastic sponge mops, ready made clothing. New lifestyle goods included coloured baths, household heating, louvre windows, coffee makers, tape recorders, portable radios, electric razors, bed settees, clockwork vs.electric toys, plastic coats, motor scooters.
} 
returning from a long day's work". Judy's image was of an independent woman with expertise and choice, but in areas that did not challenge John's expertise.

The image of women being responsible spenders of their husbands' wages "for the good of the family" subtly changed as it became apparent that the husband's wage was not sufficient. Working women were still wives and mothers, but their wages from part-time work were to be spent on the commodities that every "good" family home needed. The transition from spending her husband's money to spending her own was relatively smooth because the focus of the spending was the same. Whether one was "at home" spending or "going out to work" spending, it was all subsumed within the framework of enhancing family life. Advertisers ignored the contradiction that women were quietly going into the workforce to uphold the ideal of being at home.

American magazines presented a picture of a houscwives' idyll. Bcatricc Ashby, a Ncw Zealand housewife returned from America, wrote a series on "The American Way of Life" for the Listener. She bemoaned the lot of the New Zealand housewife:

I burn my hands on metal pot handles and long for plastics; have no idea what to do with the stains without my standard washing equipment, a liquid bleach; have forgotten how to pile the dishes without a rubber covered dish rack; and struggle with can openers that stick or cut jagged edges (October 10 1947).

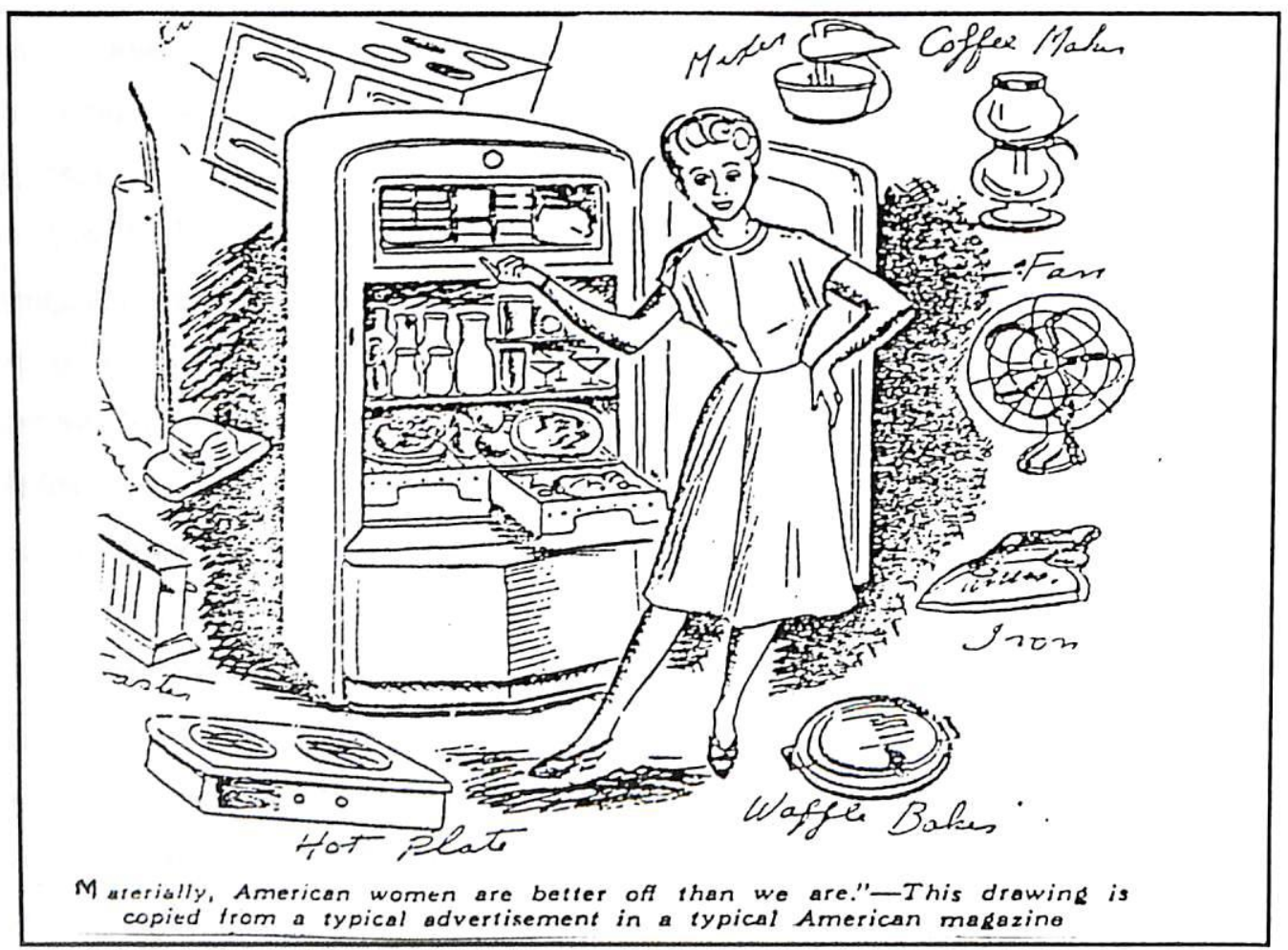

A 1950 survey of 100 homes in Dunedin by Norah Holland for her M.A. thesis on Some Aspects of Homemaking, showed that $100 \%$ owned an electric iron, $50 \%$ an electric jug, $72 \%$ had a vacuum cleaner, but only $7 \%$ had a refrigerator and $16 \%$ a washing machine, while $32 \%$ 
were still cooking on a coal range. In an analysis of the work of women, R.M. Fletcher (1949) maintained, however, that New Zealanders were purchasing cars, telephones and radios before such home aids as refrigerators and washing machines. This was a reflection of the priorities of spending from male carnings. Things did start to change in New Zealand and by 1955 "Surer Shopping" was stating that, "Many a young housewife now considers a refrigerator as essential in her kitchen as her stove. Together with a washing machine, it is becoming quite common for both to go on the mortgage when the home is built." (N.Z.W.W. January 6 1955). Such domestic apparatus shortened some household tasks for women, but not the time spent on houshold task. Rather, it altered the structure of domestic work. The washing took less time, and the oven needed less cleaning, but there were more clothes to wash, and the time involved in basic cooking became more complex, and home decorating became a feminine art. Bett Duncan expressed the ideal of the fulfilling career at home:

The rewards of being a housewife are in your own achievements and contributions...payday comes everyday as you see your children developing, your husband contented after a good dinner, and your home a comfortable background for them...Though you serve for love instead of money, by your work you can raise the standard of living for your family just as surely as if you were a typist. Wise purchasing, sewing, baking, and keeping things in good condition, all make your money go further (N.Z.W.W. July 13 1950).

In her memoir of growing up in the 1950's, Anne Else made the judgement that:

I soon understood that these activities were far more appropriate outlets than Art itself. Yet they were in no way to be taken seriously, nor was their value to be recognised by men; far from being of benefit to men, they were understood to be a burden on them, the topic of innumerable jokes and jibes (1986:75).

Consumer goods had been heralded as easing the heavy workload of housewives, but as women still complained of "malaise" or tiredness, efficiency experts began to apply the time and motion studies of industry to the home. If women were tired it must be because they were inefficient. Dr. Turbott in his weekly radio programme told women to, "Study your housework techniques. I never understand why you have to stand throughout that tedious job of preparing vegetables or ironing. Is there something about a high stool that repels womenfolk?" (N.Z.L. February 18 1955). To run a home was a highly skilled art and women were advised on the techniques of drawing up a daily, weekly, monthly and seasonal workplan so that, "Time is being used economically, working time will be shorter, and there will be more time for recreation and those little things that make life more enjoyable N.Z.Journal of Agriculture October 5 1953). Jean Wishart told of, "An actual case where it was proved that by placing her coffee grinder nearer the kitchen stove, a housewife saved herself an annual walk of 90 miles" (N.Z.W.W. October 21, 1954). The Plunket handbook Modern Motherhood (1948, 1953) gave daily timetables for toddlers and babies, but these schedules were not constructed on the probability that there might be a toddler and a baby, or that there was housework to do as well. In this reappraisal of the efficiency of women's work in the home the sexual division of 
labour was not addressed, and the fact that housework was combined with childrearing was ignored, as one reader commented, "bring children onto the scene and your method is mincemeat" (Here and Now April 1952).

Homemaking was the euphemism to acknowledge the new skills in the occupation of housewife. There was continuing debate whether there should be a wage over and above the family benefit paid to women. "Wages for wives" would give value to the work of women in the home now that marriage, homemaking and motherhood was idcalised as a career. The editor of the Listener, however, lamented that, "Perhaps it is another symptom of our times that some women should be active in support of wages for wives. The wider employment of women, before and after marriage, was bound to have awkward social results" (November 21 1958). Mary Millar was firmly against the idea:

The sanctity of marriage would collapse if we were to regard marriage in the light of a man hiring or employing a woman to do housework for him.Surely when a woman marries a man she realises that marriage is not a business bargain. The husband agrees to clothe and shelter his wife and he is legally responsible for this while the wife agrees to minister to the wants of her husband (N.Z.W.W. May 5 1952).

Later she was to concede that:

The job of running a home is worthy of some consideration which enables a woman to feel that the pocket money business is not all one sided...Tell him that you too, want to feel that you have something in your purse that is yours, and has been given to you not as wages for a hire servant or a domestic worker, but as a consideration a little consideration for a job well done (N.Z.W.W. January 19 1959).

"Pocket money" was less threatening than a wage, particularly if it was incorporated into the housekeeping allowance. There was much discussion in the Woman's Weckly on how much money a wife should get, and what it should be spent on. The consensus was that if a wife was thrifty she should be able to retain some pocket money for her own needs. This was a far cry from a wage, but it was the beginning of a movement to break down the monopoly that men had held on household spending. If women were to be partners in marriage then they should also have a say in the budgeting priorities, although it was not necessarily intended that women were to be equal partners. W.B. Johns advised that:

A husband as wage earner is entitled to guide the spending, and his wife will have to avoid giving the impression that she is suspicious, interfering or treading into territory where she does not belong (N.Z.W.W. March 23 1950).

Doris Kirby gave a more feminine analysis of the balance:

The moral would then appear to be...Let the wife hold the purse strings, but let the husband occasionally feel the weight of the purse. Give him the credit (N.Z.W.W. June 24 1954).

This paradigm of power enabled women to quietly manoeuvre changes in family responsibilities and roles. Women quietly went to work, joined community groups, learnt how to handle money, learnt new skills, without necessarily challenging the "breadwinner - head of 
the houschold" status of the husband. These women have been termed the "quiet generation" because they did not explicitly challenge men. Yet as these women negotiated over housekecping, family budgeting, household purchasing, and part time work, they were generating a "quiet revolution" in family life. Subsuming their role in the workforce within the framework of a homemaker was to create the tension in social and economic life necessary for a collective analysis of women's non-work. But it was not necessarily a new analysis. Margot Roth, who was to later acknowledge that she was always ahead of her time ${ }^{24}$, wrote an angry analysis in the Listener (November 20 1959) of the situation of housewives:

Over the years I believe we have been busily cultivating a myth of the overworked housewife. Like most myths it has a definite basis in fact...If we are honest though, we must admit that housework, or homemaking as some advertisers prefer to call it, produces nothing that is directly useful to society. It opens no doors to the future. Domestic chores should take their proper place as background necessity, like brushing the teeth... True creative work implies a steady development. And you can't tell me anybody's developing if all she ever thinks about is food for the family and her resentment at their lack of appreciation for her often self imposed drudgery.

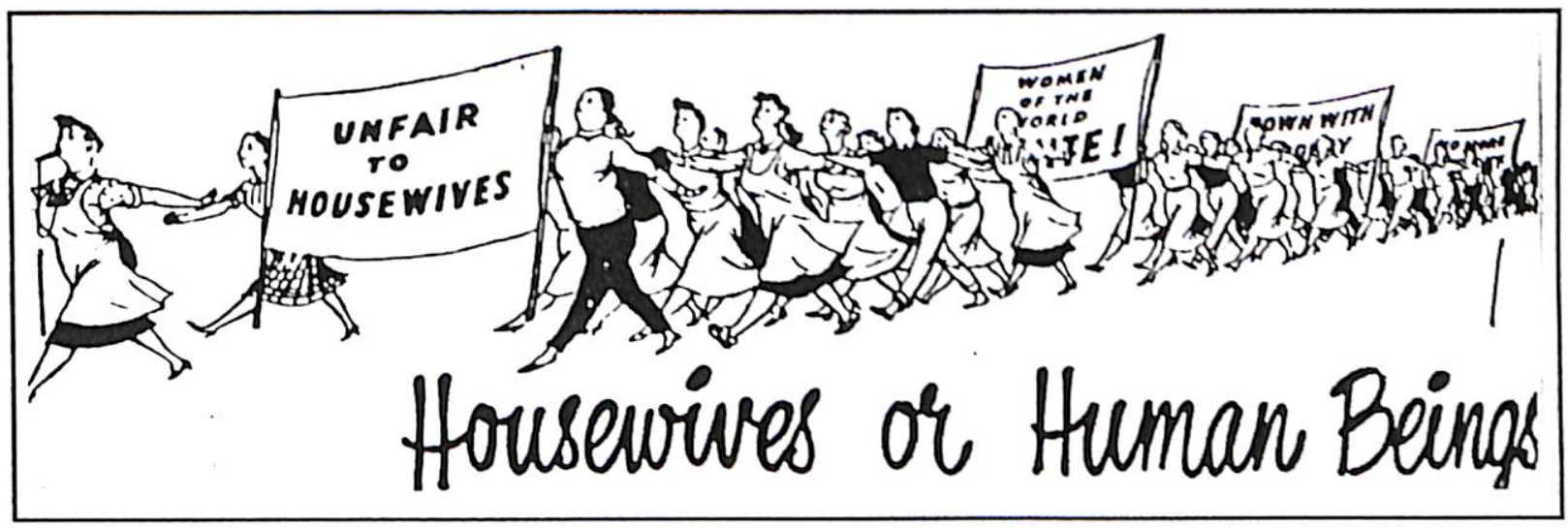

It was not only the occupation of housewife that Margot Roth felt so strongly about, but also the triviality of women's lives as they tried to organise everything around their home and family:

So they go in hordes to learn about flower arranging, or cooking or sewing, or child development...Such studies too quickly become an end in themselves...We're so conditioned to the idea that domesticity comes first, last and all the time...Our false commercial picture of the little homemaker hasn't led to wide social or political reform. What it has led to is a woman's organisation at every lamp post... You devote your time organising and battling with rival associations for prestige. For instance there are several women's working organisations catering for mothers and children, but generally they are slaving so hard to organise a ball...or arranging lectures to tell us where we are going wrong in bringing up our children, that they've overlooked the basic need of many

24 Personal intervicw. 
mothers and babies...I mean relief from the social isolation and the physical strain caused by a 24 hour day.

New Zealand did not have to wait for Betty Friedan to explode the "feminine mystique", and the reaction was overwhelming. It took the Listener wecks to clear the letters of support and hurt confusion, which came mainly from women and mainly agreed with Roth's arguments.

\section{MOTHERHOOD AS CAREER: women<----> children}

The assumption was that women had chosen between a career in the workforce or marriage. But once married, motherhood was more than an inevitable duty: it was the crucial experience needed to cement a marriage. As "Mother" wrote:

Nothing is more precious and more fascinating than a baby, and the couple without one is the poorer for it. One really only starts to live ones married life when the baby arrives (N.Z.W.W. August 3 1951).

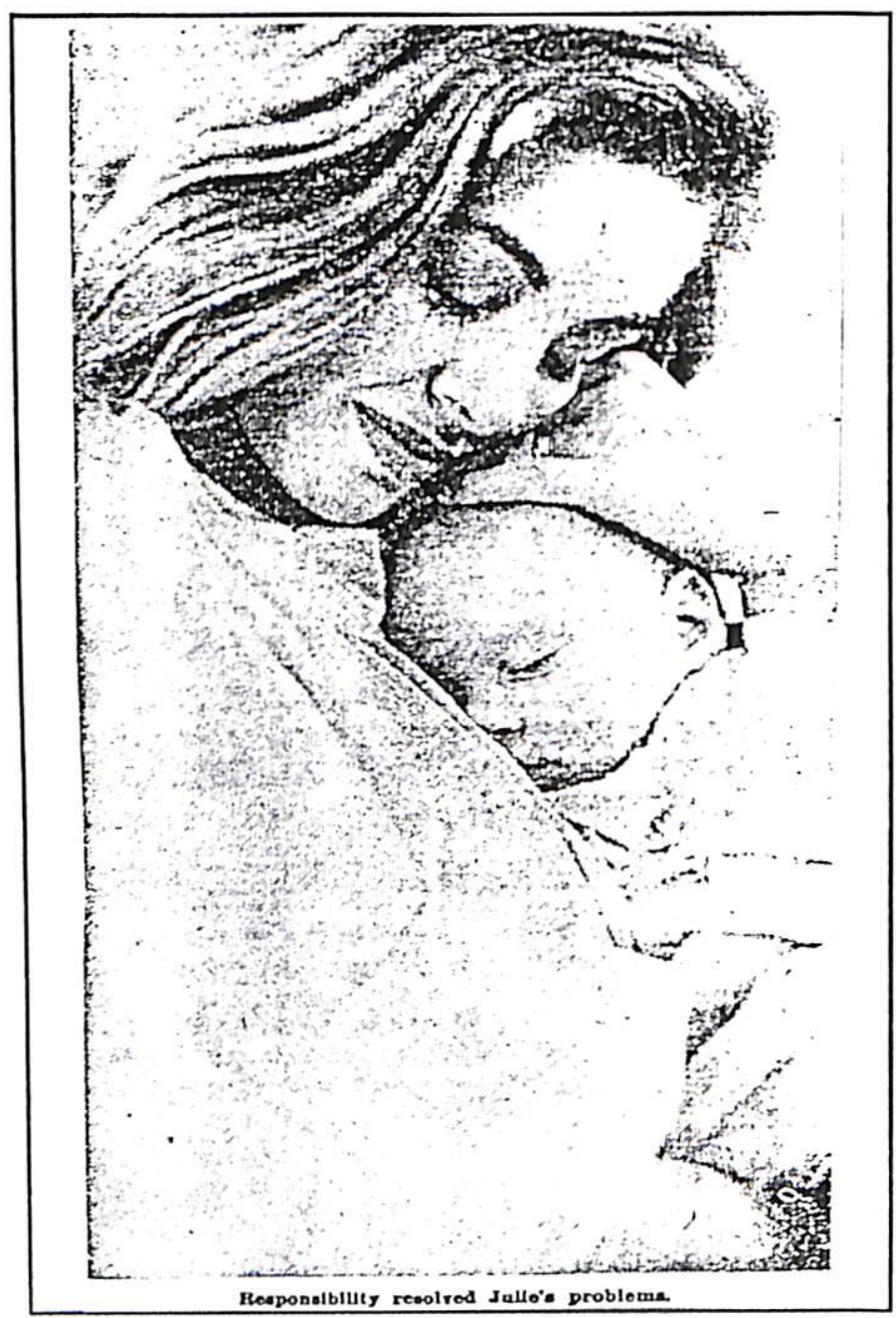

Motherhood would bring women ultimate joy and fulfilment. The case of "Julie" received extensive "treatment" by Dr. Mace in "Marriage Guidance Cascbook" (N.Z.W.W. February 16 1959). She did not feel ready to start a baby even though she had been married to David for more than a year, - Julie was unhappy because she had not had a career. In his analysis of the 
case, Dr. Mace said, "Julie thought that independence would make her happy. This would be frustrated by a baby". Dr. Mace persuaded her that the "responsibility of a baby would help to resolve this conflict". The full page picture showed Julie peacefully and joyfully cuddling her baby. Whether the analysis was correct is not as important as the outcome, which showed Julie's serenity in motherhood and Dr Mace's conclusion that there was less tension in her marriage. This exaggeration of the joy in motherhood also created guilt as women tried to match the ideal. During the 1950's discontent was deemed a personal failure, and it was not until the 1970's and 1980's that the frustrations of motherhood became the focus of collective analysis and acknowledgement (Gribben 1979; Phillips 1983, 1986).

Motherhood was not only the path to personal fulfilment, but women were seen as providing a service to the nation as "teachers and moralists, else what is to become of the next generation, and the homes of the future? Motherhood is the finest career" ("Green Light" N.Z.W.W.August 17 1950). Women were conscious of the mismatch between the political rhetoric which praised the worth of mothers, and the actual support mothers felt. Penning one's frustrations was one of the outlets available, and A.E. Irvine sums up a common theme:

I seem to recall an astute politician clamour..."the farmer is the backbone of the country"...I merely wish to retort "utter foolishness". The mothers are the backbone of the nation. Upon them rests the great duty of bearing children and nurturing them to adulthood, a vocation fraught with some danger, discomfort, no little sacrifice and not very much money. We build fine hotels, elaborate Government buildings...We construct grand highways for motorcars. Councillors, Board members and Ministers may lounge in well appointed offices...Search the cities and larger towns and see how many rest rooms and nurseries you will find...but the mother has no such privilege when she finds a visit to the city inescapable (N.Z.W.W. February 18 1950).

While there was little move by women into national or local politics to counter such priorities women were active in changing the conditions of childrearing. This political activism was of a different kind. The growth in early childhood health and education services, the increasing power and involvement of parents in those services and the growing popularity of behavioural and Freudian child development theories created a climate in which increasing numbers of women felt able to challenge "experts" and institutions over their attitudes to the care and rearing of children. Several campaigns were started in the 1950's which were to benefit a later generation of women.

The baby boom years placed considcrable strain on maternity and child health services. Medical knowledge had reduced the mortality rate, and the Labour Government had introduced free maternity services, but more and more women were unhappy about the practices and attitudes of the medical institutions. Armed with both psychological theories and the commonsense knowledge of practicality and intuition, there were various campaigns with an aim to restructure and humanise the the birth experience for women: to allow mothers more contact with their babies in the hospital, and to promote more relaxed schedules for the care of the young baby at home. These were a challenge to hospitals' routines such as: rigid four 
hourly feeding of babies and swabbing of mothers, anaesthetised births, communal labour wards, restriction to bed for 10 days, enforced separation of the mother and baby, the exclusion of families, and denial of knowledge about birth to women. Outside the hospital, the Plunket Society, which had had a major impact on infant health in new Zealand, was also challenged to shift away from the regimentation of baby routines prescribed by its founder Truby King (McKinlay 1983). The underlying concern about all these challenges was about rights and autonomy over women's bodies and women's children, but the challenge was "acceptable" in that it focussed on the interruption to the natural mother - child relationship, rather than the deeper issue. So the arguments were presented as follows:

- Women's instinct was an essential part of childrearing and women were not just a body giving birth. As Jean Wishart wrote, "We have neglected that essential ingredient of family living, the mothering instinct. We have stepped in between the mother and her baby and taken a responsibility that does not belong to us" (N.Z.W.W. August 4 1955).

- Babies should be kept near their mothers after birth."Why then, whisk away this most precious thing for the duration of my stay in hospital, often to be fed and cared for by others? At the end of a fortnight my baby is presented to me like a new car off the production line, and I take a little stranger home" (N.Z.L. September 8 1950).

- Babies should not be turned into automatons to be fed and comforted by the clock. "She establishes her own rhythm instead of having one forced on her. If she cries for attention she gets it and we are both happy. I feel a baby has as much right to attention when it wants it and when it needs it" (Mother of Three N.Z.L. December 3 1948).

- Mothers know best as they have maternal instincts whereas the "experts" have only had theoretical knowledge. "J.B." of Opotoki argued that, "Conditions have been governed by men and single women, who however good their intentions, have no point of contact with the patient...each (maternity) Home should have attached to it a group of actual mothers, whose recommendations should be given at least serious consideration" ( N.Z.L. June 20 1953).

It was thought that maternal femininity was imbued with special knowledge that was essential for the development and well-being of the child. The assumption was however that all women were innately "Ordinary devoted mothers" (Winnicott 1949) ${ }^{25}$.McKinlay's (1983) later analysis of the Plunket Society concluded that by the 1950's:

The mother herself is seen as less dangerously ignorant...Though she needs guidance in correct mothercraft, she is also able to learn by experience (1983: 153).

Mothers were still warned about the problems resulting from spoilt babies but routines could now be tempered with "commonsense and elasticity" (Decm 1953:59).

25

Zear Winnicott gave a series of talks on the B.B.C.radio which were also broadcast over New spirit of the mother child relationship. A book was published which became available in New Zealand and I was fortunate to be given a copy. 
There was a growing interest in natural childbirth which followed on the tail of a long campaign to ensure that all women had access to painkillers in childbirth (Gordon 1955; Tennant 1985 ${ }^{26}$ ). In a booklet The Psychology of Childbirth (1946) Dr Enid Cook argued against the removal of responsibility from women during childbirth and she rebuked the typical attitude of the medical profession to women as being, "we will look after you and you will never know about it until it is all over" (1946:1). Grantley Dick-Read's book Revelations of Natural Childbirth (1947) was very popular and came with a preface from the Queen Mother. This book challenged the tradition of anaesthetised births and promoted knowledge and autonomy as the the key to removing pain and fear. The Parents Centre movement was founded in 1954 from a Wellington lobby group which aimed to change the "management of childbirth through the education of parents, the public and the medical profession". An article in the first issue of the Parents Centre Bulletin (No.1, July 1954:3) explained that, "Having a baby should be one of the great maturing experiences of life". For this to happen the Bulletin claimed that women needed, not only knowledge about childbirth but "care and support during confinement which gives her full support as a feeling thinking person". Support grew and at the opening of the Parents Centre Conference in 1957, Dame Hilda Ross was to applaud the Parents Centre classes for pregnant women which "dispel the fear of childbirth". She went on to reaffirm that, "Mother love is the most enduring of all. No matter what mistakes are made a mother's love can over-ride it all" (Parents Centre Bulletin No.9, July. 1957:4) The rhetoric of mother love was not politically threatening even though the arguments it was supporting were forerunners of the later women's liberation rhetoric about women's rights over their bodies. The demand at this stage was that the hospitals recognize woman as individuals with emotions rather than just bodies. As the argument gathered momentum Evelyn Lovegrove argued:
A large increase in the birthrate following the war years made childrearing look easy, and the emergency measures adopted depreciated its significance...Large scale hospitalisation has had a strong tendency to reduce childbirth to a purely physical thing. New Zealand will soon build a large Obstetrics Hospital. What recommendations have our present mothers to make? What are their preferences? Have they been asked? (N.Z.W.W.July 25 1952).

In 1959 a Consultative Committee on Infant and Preschool Health was established, although in 1960 journalist Christine Cole was to report, "It is rare to hear any mention of mothers' views in any official discussion of our maternity services", she claimed that most hospitals were still following the rigid adherence to four hourly feeding and swabbing (N. Z. Parent and Child January - February 1960:12). It took some years before the recommendation from this Committee had an impact but the Report did incorporate the new ideas that had been so vigorously argued.

26 Elizabeth Tennant's research into the maternity care of unmarried mothers in New Zealand showed that working class women and unmarried women had difficulty getting pain killing relief and that for the latter it was often denied by hospital staff as a kind of punishment. 
Besides the experience of mothers in hospital, there was also the question of hospital visiting for children which had traditionally been kept to one weckly visit. The research of John Bowlby (1952) into the "maternal deprivation" of children in institutionalised care was used to support the rights of children and mothers to have closer contact. The medical profession were cautious, ostensibly for fear of infection and disordiliness, and the merits and problems of this were often to be seen in magazines and journals of the time. The Listener collected medical opinion on the topic which was consistently negative:

I have never heard parents complain about not being able to visit their children daily and don't feel they would welcome daily visiting. I do not feel that a child's personality suffers if he is only visited once a week (Matron-in-chief. Wellington Public Hospital N.Z.L. June 5 1953).

One of our problems is the stupid mother who excites her child and gives unsuitable food under the impression that she is helping its recovery...and so muciı depends on the amount of understanding the parent shows in handling the child so that it settles down in hospital (A Senior Pediatrician N.Z.L. June 5 1953).

Ranged on the other side were the mothers, but with the powerful backing of psychologists and educationalists, the Parents Centre, and the Nursery Playcentre Federation. They lobbied for the emotional needs of the child, and that the rights and expertise of the mother be acknowledged. Again the sacredness of the mother - child relationship was argued. Psychologist Quentin Brew reported that:.

Many follow up studies of children discharged from hospital show that personality damage is greatest and most lasting the younger the child, and the longer and more complete his separation from his family. especially his mother...a disproportionate emphasis is placed upon the physiological and administrative aspects of hospital services (Q.H. Brew, Psychologist N.Z.L. June 5 1953).

It took many years to change the attitudes and structures in the hospitals but the latter argument eventually won out, and the slow moves to accommodate the presence of mothers in hospital wards began (Mc Kinlay 1983).

Such campaigns were to show the effectiveness of a collective voice with psychology as a weapon. Staying under the umbrella of parental concern and motherhood as a career, rather than any explicit political rhetoric, this "voice" was acquiring the techniques of nudging institutions towards change. Elsie Locke, writing with a certain irony, captured the new spirit of alliance between the experts and mothers:

The psychologists at the moment are very kind to us mothers. Self effacing creatures that we are, mere Jills- of-all-trades...we have been so accustomed to laying our own judgement aside in defence of those who know better. Who are we to ask questions of Sir this or Dr. that M.B.,Ch.B., M.R.C.P., or whatever?...It is a glorious time for mothers. All the things we wanted in our hearts to do, turn out to be the right things...mothers go up the social scale. She puts her shoulders back and lifts her head and looks the experts straighter in the eye. They may have letters to their names, but SHE has instincts! (N.Z.L. September 11 1953). 
However the investment of the mother - child relationship with such potent emotions had a darker side. The status of motherhood may have been raised, but it labeled woman as "bad mothers" if they did not embrace the idcals of motherhood as a career, or if their children erred from the path. Such a child centred focus was a white middle class paradigm, which assumed that

- The values and realities of the "good life" embraced all families.

- The family was a haven of security and comfort.

- Mothers could always be with their children or even wanted to.

- Men could eam a breadwinner's wage and that they were willing to help in the home.

The new appreciation of child development and the power of maternal instincts may have encouraged activism towards better services for mothers and children, but the other side of the joy of maternal instinct was transformed into the ills of maternal deprivation when children were not always with their mothers. In this case psychology worked to the disadvantage of women, and particularly working class women, labelling them as "bad mothers" if they worked. The spectre of maternal deprivation (McDonald 1977) would not affect middle class women to the same extent until the 1970's when they started to continue careers or seek other options to full time mothering, and by then the potency of the myth had waned. In the 1950's, however, the awareness of maternal deprivation was on the ascendancy and this fitted neatly with the mood, if not with the practical realities of everyday family life. Those who did not match the ideal, who did not want or could not have such a child-centred life style, were seen as problem parents. Sustaining the ideal of motherhood as a career needed "bad mothers" to reinforce the boundary between normality and abnormality. The job of being a mother had become more complex with any "problem" reflecting on her ability. Psychology provided support for women in the recognition of maternal instinct, but the flip side of this partnership was a sense of guilt, as "Guilty Mother" wrote:

All those lectures and articles about the mistakes made by mothers have had me worrying about whether I've done the right thing with my children. I've been so afraid I've given them complexes or hurt them too deeply for them ever to forget. Tonight's the first time I've heard one of these experts say it's all right for parents to behave like human beings, not angels or something (N.Z.W.W. June 29 1954).

As the "art" of childrearing became more complex the role of men as fathers was reassessed. The image shifted from the remote disciplinarian to a person who was a playful buddy to sons and a grown up sweetheart to daughters. The position of men in the postwar family was ambivalent. They should recognize their wives as equal rather than subservient partners in marriage, yet their breadwinning status as head of the family was upheld. While the psychological ideals of motherhood heralded a new joyful relationship between mothers and children, fathers seemed to have little input apart from housing, furnishing and feeding the nest. New Zealander Brian Knight wrote a six month series on fatherhood for the Woman's Weekly. He portrayed a sad end for men if the current trend continued: 
Father is placed in a situation where he has to hold the position of head of the house with what dignity he can muster... I see a grim picture of the male of the household in another 100 generations assuming the role of the praying mantis male. He is used by the female and then eaten (N.Z.W.W. December 11 1952).

A new role would be created for fathers who had a contribution women were unable to make:

The busy housewife is not always sufficiently aware of the very important part which a child's father plays in shaping its personality. While the mother stands for home, and security, the father symbolises the great world beyond, and a child's future attitude towards other people, his career and the world in general is inclined to follow the pattern of his early relationship with his father (N.Z.W.W. December 4 1952).

This image slotted neatly above the instinctual mothering of the carly years. At this time the father was to be "sensitive" and "understanding" because the mother was seen as incapable of dealing with the outside world. Dr Winnicott suggested that the father could, "Provide a space in which the mother has elbow room, (and then), properly protected by her man the mother is saved from having to turn outward" (1949: 8). Brian Knight agreed that, "Mother and child are relatively helpless during this period", but added, "Fortunately today's child psychology is redeeming itself and placing a new weapon in the hand of the father" (N.Z.W.W. December 11 1952) - This was male rationality and worldly machismo. Men were to be mediators in the case of over-indulgence from maternal instincts because, "The over mothered child is effeminate, lacks confidence, and may even become physically underdeveloped" (ibid). This was a veiled allusion to the fear of homosexuality.

In contrast to the high expectations placed on mothers there was little censure of fathers if they did not meet the new ideal. Mary Millar replied to "Mrs D.F" whose husband stayed at the office late and never saw his children:

It is often a pity that these men ever married or become fathers...but the fault is not always entirely with them, inasmuch I've found wives make the return home so unattractive. They don't take the little extra trouble to get tidy and look pleasant when father arrives home (N.Z.W.W. April 15 1953).

The code was that it was nice if you got help but do not expect it, and do not rely on it, and if you don't get it the fault could be yours. Brian Knight was to suggest that fathers lend a hand with the domestic chores, but there was a careful line of demarcation between helping and responsibility. Debating the issue of "Whether Father Should Help with the Dishes?" he warned:

We will find that father is actually succeeding not in helping but in proving quite conclusively that his wife is as inefficient and as inadequate as she fears she might be. Thus the more the father does the more inadequate the mother feels...Even in our culture the home is happier where each partner is successful primarily in his own role, while at the same time being prepared to assist the other where necessary...so that it is not so much a matter of whether father washes the dishes or not, but rather the spirit in which it is done (N.Z.W.W. January 29 1953). 


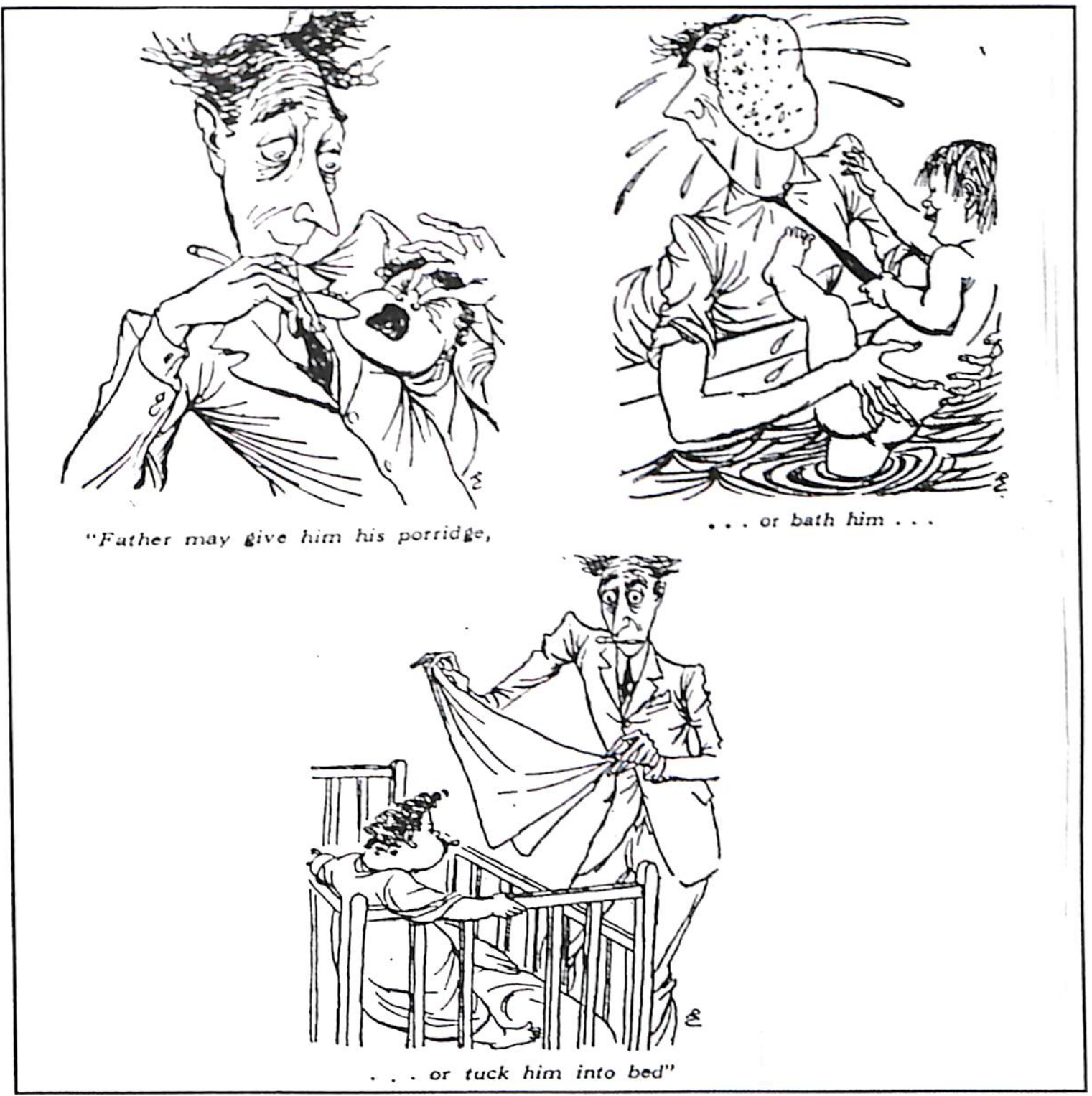

Jean Wishart went further and suggested that schools should provide cooking classes and social classes for boys. There was, however, a clear demarcation between women's work and men's work, and cooking for boys would not mean that men would take over the kitchen. She reasoned, "How much more appreciative of his wife's meals a man is going to be if he knows how much work has gone into their preparation; how much more understanding he will be of failure" (N.Z.W.W. July 15 1957).

These prescriptions for male involvement in childrearing and housework brought no dramatic shifts in responsibility. It was the beginning of a trend that continues. In the 1950's it grew as a support to the values surrounding motherhood as a career. The new expectations for both mothers and fathers were part of a re-affirmation of the family unit and the emotional ties which bound it together. This idealistic belief in the goodness of the family existed alongside evidence that many homes were not a haven of security and love. The paradigm of motherhood as a career was a powerful tool in supporting this idealistic view of the family although there 
was the acknowledgement that there were "bad mothers". The paradigm however also provided an acceptable umbrella for political activism for women. This was the forerunner of a more radical analysis of women's lives which would directly challenge the primacy of motherhood as an experience for women. 


\section{TEXT TWO: A PERSONAL REALITY 1945 - 1960}

The lives of the twelve women interviewed for this study are part of a mosaic created by particular historical forces and bound by common values. Yet the uniqueness of each story shows that none of them quite fits the common pattern of social history. The women however were apologetic for their ordinariness and wondered why their lives could be of interest and would point to someone else who appeared extraordinary. Ordinariness was of interest, particularly the extent to which they identified with the common pattern. But in each ordinary story was the extraordinary: firstly in the sense that their lives did not always conform to the pattern; circumstances prevented them, or in some cases they challenged it. Secondly in the sense that the construction of social history for that period has been selective in what it includes. The mythical and historical versions show a consensus, order and morality that does not match with the life histories. The construction of social reality (Berger and Luckman 1966) is a process of categorising the ordinary and extraordinary, the normal and abnormal, but the process of making history squeezes the diversity of everyday life into generalities.

This chapter presents a slice of the diversity of individual experience for the mosaic. The arrangement of material has its own rationale however, and must fit within the framework of this study: that is, to see how women have identified with, or challenged the dominant and contradictory codes of femininity for women as mothers. It is also to see how these women "managed" the extraordinary and contradictory in their lives. Their choices may have been constrained by social, economic and political circumstances, but the strategies to make life manageable were individual. Thus within the broad generality that makes social history are a series of case studies which show how individual women have ordered their lives. These are a concern of anthropology. Carolyn Steedman wrote:

Case study presents the ebb and flow of memory, the structure of dreams, the stories that people tell to explain themselves to others...We need to search backwards from the vantage point of the present in order to appraise things in the past and attribute meaning to them. When events and entities in the past have been given their meaning in this way, then we can trace forward what we have already traced backwards...(1986:21).

Part One

\section{"ACCOMMODATION" AND "RESISTANCE": ASPIRATIONS VERSUS REALITY}

The women in this study were rearing children during the ycars $1945-1960$. The first child of each woman was born between 1945 and 1950 and some were still having children in the early 1960's. Apart from Winifred who waited four ycars for her first child, and Brenda whose 
husband went to the war three wecks after they marricd, all the women had their first child within 18 months of marriage ${ }^{1}$. Motherhood was synonymous with marriage. In more recent years it has been acknowledged that having children is an option (Dowrick and Grundberg 1980); that the childrearing years create tensions in familics (Cass 1982; Gilling 1985; Swain 1985); and that women absorb and mediate the tensions (Mcade ct al 1984). These changes are said to have arisen from changing aspirations, and opportunities for women (Harper and Richards 1982; La Rossa and La Rossa 1981). It would be easy to assume that this was not the case for postwar women in that there were fewer options that would conflict with the responsibilities of motherhood. The women viewed motherhood as their most important career, but this did not remove the conflict that they experienced during their childrearing years as they balanced motherhood with other kinds of work, responsibilities, and aspirations. The ideology of motherhood was powerful and although ihe options were fewer, women had to make compromises that caused sacrifice and guilt. In the later period, 1970 - 1985, women still made compromises but the conditions of compromise were to shift. Jean Anyon's (1983) description of the process of "accommodation" and "resistance" through which girls and women come to terms with the conflicts in being female, underlies the compromises women made. Anyon argues that the process is not one of passive acceptance but that women "make concessions", and "resist subtly" in "daily (conscious as well as unconscious)" attempts to come to terms with the contradictory ideology of femininity (1983:21). The case studies of Meg, Dulcie and Edna show the process of negotiation and compromise between their own aspirations, and the realities they were faced with. They provide an understanding that moves beyond the bald circumstances that differentiated their lives, e.g. that Meg and Dulcic lived in the city while Edna lived in the country; or that Edna and Meg were full-time mothers while Dulcie was in full-time employment; or that Meg came from an educated middle class background whereas Edna and Dulcie had had a limited education in their working class backgrounds.

\section{MEG}

I put this investment into my children, the same that my mother put into me, but I tried to do it in a way that didn't smother them. My daughter made a throwaway comment recently that shocked me... about the way she was brought up to be independent and leave home as soon as possible. She said that was the impression. Now I look back on all those years of childrearing as wasted.

Meg came from a family that put a high value on education, although there were confusing messages about its purpose. My mother thought that marriage was the only thing for women. Education was more of a thing in that you needed a badge. In this sense education was a qualification. It was also the place where you met fellas who were going to be professional men, and so it was a good thing. But alongside this rationale was another

1 During these early postwar years three-quarters of all babies were on the way inside fifteen months of marriage (N.Z. Official Year Book 1950:61). 
message. Educatton was to be a buffer against whatever. After all our parents had gone through the depression and so had our teachers. Education was the key to getting women out of all that.

The war brought opportunities and Meg got a job in business which she believed was due to the shortage of men, and because they hadn't had time to dream up a separate award I always had equal pay. Meg developed a consciousness of being a career woman, although the only career women that she had known had been spinster school teachers. She had respect for them as educators but they didn't have much fun and as far as we knew, I don't think they did. We didn't want to be like them. They often had mothers to support or had lost their men in World War One. We didn't want that. Meg also assumed that she would get married and have children:

I think it is right. I had it in my head of going on with my career, and I was reading a lot about the equality of women. I had it clearly in my head that I would leave children in daycare

Helen: You must have been quite unusual to think that you would have a career and leave them in daycare.

I don't know how weird I was, but I was clear in my own mind. I didn't of course but I must have had this on my mind a lot before I married, because my sister in law told me that she wouldn't dream of putting her children in daycare and I had thought what a silly woman.

In the 1940's there was little daycare available (Cook 1985d) but Meg had heard of a highly regarded centre in Wellington ${ }^{2}$. Such a centre was unusual but its existence had allowed a dream to seem possible. Meg's aspirations of equality and opportunities for women were feminist, and a "resistance" against both her upbringing and education, as she wanted a sexual life and children as well as a career. Meg saw her career as not only for her own benefit, but as providing the means to support a man when he got back from the war:

Helen: Was this a debt to the men who fought in the war?

It was a particular man. This is an accurate thing about women who had got careers and then they could support a man. I was good at my job and I saw it as my thing to do as well as I possibly could. When this chap came back from the war, I could pick and choose what I could do because I knew that there would be competition in the job. I saw myself keeping or helping to support a chap. I joked that I put him down on my income tax. He could only pay the rent and we were living on what I earned. It only occurred to me recently that I was actually keeping him and I think that happened to a great many women who didn't see it as being the breadwinner.

However within the space of a few years Meg's life had taken on the outward appearance of the "feminine mystique" (Friedan 1963). She was married with four children, and a house in the outer suburbs, and felt trapped at home and sometimes depressed. Meg's view of her early idealism is now cynical but her insight into what generated it, is important to this analysis:

2 Evidence of this centre has come mainly from women who knew about it or used it. Childcare centres were not required to register until 1961. It is said to have begun during the war by Amos Softgoods, and it had trained staff who ran kindergarten programmes. 
It was part of the whole war thing. like it makes any relationship between male and female seem sweeter when you are all the time saying goodbye. There was this heightened view of romance like I was going to pursue my career and I was going to have a male partner.

Women were to have a crucial role to play in the social and psychological rehabilitation of their men on the return from the war. But there was also a sense of sharing gains because "returning men" had missed out on establishing carecrs whereas women like Meg had moved ahead. Like a number of women in this study, Meg spent the early years of her married life facilitating her husband's career so that he could become a good breadwinner. Although Meg had aspirations to be a career woman and was able to support her husband she did not see herself as the breadwinner. Equality and opportunity for women was not conceived of in terms of usurping or challenging the traditional role of men. There was more security in supporting it because it was important that he got a good career and promotion and there was this fear of unemployment because of the Depression. The employment situation remained buoyant but the priorities of the men and the continuing wartime austerities dimmed the dreams the war had helped to generate. For Meg, the idea of a continuing career collapsed when faced with the realities of rearing children.

There must have been disillusionment. But then there was the housing. it was diabolical. I had two kids in an upstairs flat and you couldn't open a window in case they fell out. The physical environment that you were placed in was not a bit what you hoped for or what you filled your glory boxfor.

My own personal situation made it impossible. I had no support whatsoever. I suffered acutely from post-natal depression. I had awkward children. They were all allergic to everything. At that stage I had two with asthma and at that stage too, mother was held to be at fault - overanxious. My husband was disapproving and I had no encouragement. I had the two things in my head and then didn't do it but I don't remember when the break came. I was swamped by the physical. I had bad pregnancies, childbirth and post-natal depression - a constant state.

There were other reasons like geographic ones. The mechanics of it were so hard. There was a good bus service but there was one bus driver who was so awful we would miss the bus with our push chairs and wait for the next one. These sorts of things made difficulties for women who wanted to work as a lot of women didn't have cars.

It was more than the visible constraints that made the dream impossible; the attitudes to working wives and mothers also shifted:

The whole Bowlby thing got translated to New Zealand. It was even stronger than Plunket. I remember too the Mazengarb Report. When that came out I was pregnant. I was trailing up the hill and I was exhausted. I had been reading about it. A motor bike stopped beside me and this guy said, "Would you like a lift?". I was so thrilled as I had been feeling so bolshie and awful.

Meg did not work in paid employment during her childrearing years, although she had friends who did part-time teaching, but this was more acceptable because of the teacher shortage (Middleton 1985b). 
Meg's accommodation to the role of wife and mother was determined by the economic and social circumstances of postwar life, but it could not be said to be a passive acceptance and her earlier aspirations remained strong. This took a toll on her marriage which was years later to end in divorce. During the childrearing years however Meg invested her education and aspirations in her children:

\section{I took motherhood very seriously. I tried very hard. I also wanted to have six children. There were all kinds of things about protecting one's children. It may have been something about the war where a lot of women nurses and teachers had seen the diabolical condition of institutions. This may have motivated them to oversee their children and give them a good start.}

An involvement in the early years of the playcentre movement becamed substitute career for awhile:

Like a lot of women we saw it as a way forward...something new and progressive. It was very much a haven for the liberal educated woman. The women that thought kindergarten was too regimented. It was a way to acquiring a career. And one wanted to do one's best for one's children especially with the makeshift in schools.

Later she went to university as a mature student, some years before this became a popular option for women. Paid employment would have been difficult to organise and going to university was again the career that she could not have. It was also a resistance against being submerged by the duties of wife, mother, and housewife.

Within the compromise and constraint of her life Meg did challenge the accepted, and her early aspirations remained strong. Meg was one of a group of educated middle class women whose lives were caught between two codes that were difficult to combine into the realities of postwar life. Firstly, there was the ideal of new opportunities and equalities for women, which included the possibility of career, marriage and children. The men however did not share their aspirations, and the economic and social conditions still rested on the security of the male breadwinner's wage. Secondly, women were influenced by progressive educational ideas on childrearing that were not to be found in the overcrowded mainstream education system. Mothers would provide the shortfall and enhance the quality Thus there was a full-time commitment to childrearing, and "motherhood as a career" became a fact and a compromise.

\section{DULCIE}

I always worked hard. I liked hard work and didn't like staying at home all day.

Dulcie came from a working class family. Leaving school was the best day in my life. I always look back and know that I would do the same again. I didn't like school. Unlike Meg's family who viewed education as an insurance policy, Dulcie's family sought security in owning a small bakery. Their German origins kept them apart and their lifestyle was constructed around hard work and being inconspicuous. During the First World War, before 
Dulcie was born, they experienced harassment. This stopped when it was discovered that Dulcie's mother was in fact English.

Leaving school meant starting work in the family bakery and Dulcie worked without wages. There had been several attempts to manpower her during the war but these had been fought successfully. I didn't want to be a land girl or go into the army. Asked about her life at this stage Dulcie replied that work was the most important thing: not in the sense of having a career or economic independence like Meg, but work brought a sense of identity in the family. You were respected for it. But she also wanted to find a nice man and marry him. Dulcie found her "nice man" when he returned from six years at the war. She had known him before the war. He was a bit older than me but the ages had evened up.

When Dulcie married, her husband came to work in the family shop. He got a wage and supported her, and she continued to work as before. Unlike Meg, Dulcie had littic contact with new ideas of equality, and she did not question this arrangement as this was the way things were and I just accepted it. D was very good to me. Dulcie accepted her husband's role as the breadwinner, and indeed expected it. She had a child within a year of marriage. At this stage her parents died, and Dulcie and her husband bought a small shop:

We had a home above and so $S$ was brought up where I worked. I
could still do the house and a woman came in for a bit to look after
$S \quad$ and to help with the cooking. I wouldn't have liked to have been
at home all day.

Working and having a family were natural and possible in these circumstances, and the fact that she was not actually going out to work made it acceptable. Although they both worked in the shop the appearance of separate spheres was maintained in that her husband took a wage, whereas she had responsibility for the home and the baby, even though someone was employed to help. I asked Dulcie why she had only had one child and her answer revealed the key to her resistance against the prescriptions of a "career" and fulfilment in the home as a wife and mother:

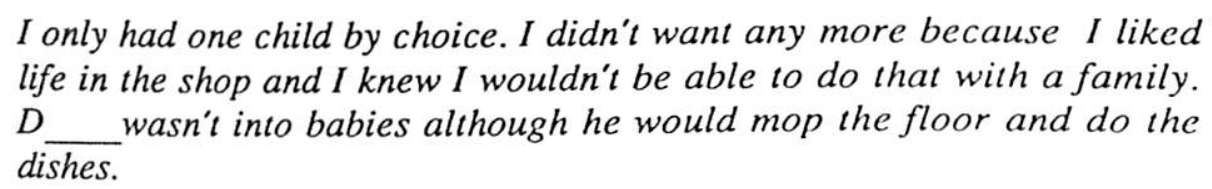

By controlling her fertility Dulcie knew she would always be able to work. Economic independence was not the issue but the right to work was and she was not prepared to sce this threatened by children. $D$ would have liked more but I said no. It would have been too difficult. This arrangement worked until her husband sold the business. She had expected him to buy another shop but instead he bought a house in a new suburb in the middle of a field and he got a job as a labourer in a factory. Dulcie found herself at home with a child, feeling depressed and isolated, and D thought she should have another child:

I was at home. S had gone to school. I was by mysclf and I didn't know anyone and one day I sat down and wept. I didn't tell $D$ __ but I went to the factory where he worked and asked for a job. They said they 
would telegraph if they had one. When I got home there was a telegram waiting and I worked there for wenty years.

Dulcie did not seem to think that D minded her working and in fact she felt that they needed the two wages to manage. But D was still to be the breadwinner and Dulcie never saw her wages:

I was to get my first pay packet. I was very excited as I had never had any money of my own before. When I got it I said that I was going to keep my own money, but somehow it disappeared. I never saw it again.

The old arrangement which began in the shop continued. Dulcie could work as long as her husband was seen to be the breadwinner. She was to accept this although with more reluctance this time.

Unlike Meg, Dulcie had no contact with new ideas of childrearing, nor did she feel particularly constrained by hardening attitudes towards working mothers. It was now 1957 and there was increasing concern expressed about the detrimental effects working mothers were having on the moral well being of children. When she went to work in the factory, however, Dulcie gave her daughter the key and decided that at age 11 years she was old enough to look after herself. Dulcie worried sometimes and acknowledged that the situation was not as ideal as working at the shop.She saw it as a case of having little choice, and did not consider a parttime job for herself was really working. Dulcie made some good friends at the factory, loved the work and life was happy. A postscript to this occurred not long before the interview with Dulcie. When she retired from the factory her National Superannuation was paid into her own bank account. This time she kept it for herself and she negotiated her contribution to household expenses. She was to comment that even though her husband had not been mean with money, it had taken all her working life to get money of her own.

Dulcie's aspirations for herself were not part of a framework of equality and opportunity for women. Her wish to work was never threatening as her husband always retained the rights and appearance of the breadwinner. Controlling her fertility so that work remained possible was an option Meg had not considered as a way of achieving her career. Meg believed that both should be possible, and felt angry at the injustice which she later turned towards a political involvement in feminism. Dulcie's working class realism was a more accurate assessment of what was possible and her life has been one of outward acceptance. Her resistance was personal and not part of any collective strategy.

\section{EDNA}

Edna grew up in a small country town and spent her childrearing years on a farm. The rhythm and isolation of farm life has limited the options of rural women in different ways to urban women. New Zealand's rural mythology is imbued with images of men and women cultivating the land together, and during the war rural women were heralded as managers and minders while the men were away. Edna's story tells of the hard work of rural women but it also reveals the contradiction experienced in trying to manage it all: 
I found it very difficult to be working with the children and seeing to their education. Then how can I be a good wife in bed..a good woman in the cow shed.. a good mother. And how can I be a good person in the community, a bit like doing my Christian responsibility. It took a tremendous toll on me and I felt nothing of myself.

Life had been hard for Edna, particularly during the depression years. For some years she had yearnings for the adventure of life as a missionary, but she had to support her mother and the war years intervened. Edna persevered at school and got work in an office, but during the War she escaped the small town life by requesting tope manpowered into nursing. This devastated the family and I really got it in the neck. During the war she corresponded with a man who was a prisoner of war and when he returned to New Zealand they met again:

He was very unsure of himself. They were completely tongue tied with women. They couldn't mix well. I had no real thought of marrying him. but after a fortnight of being together socially, and I had just been kicked out of nursing thinking I was no good, although it was really because l had to leave because of illness. I was on a low and he was just always there and we sort of latched on.

Edna was to say that marriage gave her a feeling of direction in her life she that had not had before. It was a challenge and a purpose. It also brought stability and fulfilment. Yet Edna was to feel constrained:

Ifelt a restrictiveness I hadn't dreamed would be there in my pre-marriage days. The commitment had its cost. One was almost a total loss of independence except to decide on mundane things like shall I wash, it's Monday. Perhaps I won't, but not for things like being free to come and go as I would have liked. Or to take up interests.

These were thoughts that were not shared, and Edna's life had the outward appearance of a fulfilled mother and wife. Privately she was to think that there must be something wrong with her. Married life had begun on a rather unproductive farm. Economic survival was hard but more so because of the long term physical and psychological effects the war was having on her husband. The extent to which women like Edna propped up "returned men" into an appearance of being good breadwinners has been a hidden and unwritten story in New Zealand social history ${ }^{3}$ :

He never really settled down and I copped it in a way. He had buttoned it all in and he wouldn't discuss anything with me. He keeps it to himself.

Money was tight and so Edna worked as the farm hand as well as rearing four children, but her husband's ill health was a continual worry:

For a time I milked but I had to spend all day propping him up. It was excruciatingly difficult to be a good mother and to divide myself up among them. He was so demanding. I remember crying around the cowshed sometimes as he was so nervy and tense. Ile could be very hard and never ever let me off a the farm chores.

\footnotetext{
${ }^{3}$ The suggestion so far has come from male fiction writers telling of the return from the male uniarderie' of war to the obligations of family life.
} 
Edna was to admit that taking on a hcavy workload on the farm was her own decision, but that she had not anticipated her husband's health would deteriorate so much. I guess I was trapped once I started to help on the farm. She began work in the cowshed at $4.45 \mathrm{am}$, and was there again at $3 \mathrm{pm}$ for the second milking. This was not uncommon among dairy wives, but Edna found it difficult to cope with the expectation that the house, the cooking and the children would be perfectly ordered. The outward appearance of separate spheres was important:

It was his farm and I was helping. When we eventually started to make some more money he said that there should be money set aside as my wages. But it was just a book keeping thing and I never saw it.

Helen: Did you feel that you ought to be working so hard?

I wanted to help my husband because I thought that he deserved a better deal because of the war. I was imbued with the Protestant work ethic. Work is honourable. Jesus first, others second and yourself last....

Edna did find something for herself. She wrote a magazine story about family life on a farm, although the inspiration, based on her own life, presented an image of rural harmony that did not match with Edna's confused feelings. She had never written before but it was published, and more were asked for. Thus began a small paid job that brought immense satisfaction although it was a job that she hid from her neighbours by using a pseudonym. My mother-inlaw was appalled. She thought I was neglecting my kids and my husband. But I had it neatly packaged. It could be done when the children were in bed. In this sense Edna's job was acceptable because it was hidden. She was not going out to work and work and family responsibilities on the farm did not change. Despite this hidden acceptance, Edna felt guilty:

Even when I was writing stories I felt guilty about it. I thought it was
presumptuous of me to be doing it. I felt embarrassed that it wasn't my
role as a woman...preserving, cooking and sewing for kids and being as
economical as I could, and setting a moral standard of behaviour.

Edna gave up her writing when she gave birth to a sickly handicapped child, and her husband's illness got worse. I just frizzled up. I was too busy and my writing connections were broken. For some years Edna "quietly" suffered from feclings of inadequacy and occasional depression. I remember feeling so low about my inability to cope with farm, children, husband, home, take responsibility for their school activities, other adolescent traumas and $M_{\text {_ }}$ 's additional demands. Later when her handicapped ch.ld got a place in a kindergarten in town, Edna again found a "neatly packaged job". She worked in an office while M_ was at the kindergarten every morning. To all appearances she was being a good mother taking her child into town to kindergarten. When her children were at secondary school and leaving home Edna made some changes. She gave up working on the farm and went to work full-time in an office in a nearby town. This was a shock to her children as they had never "seen" her work and had always known her in gumboots, but they were to change their opinion. She saved and purchased her own car, and felt relieved of the guilt of borrowing the family car. Her husband retired early from farming, they shifted into town, and Edna continued at work until her retirement while her husband stayed at home. 
Meg and Dulcie and Edna came from different class, educational and geographic backgrounds which helped shape their options. Meg had access to the educational and economic resources that encouraged her to resist the traditional codes of femininity. Dulcic's challenge was to control her fertility. Edna tried to balance all her roles but found it was not possible. She was however, able to package her work sometimes so that there was no appearance of the conflict she felt. Their aspirations had to be adapted to avoid conflict and were secondary to supporting the breadwinner, but the aspirations of the women were able to surface and survive. Edna managed this very neatly but such invisibility could never last long. Dulcie had childcare assistance and only one child to manage. Meg had dreams but saw the futility and found a partial solace in the playcentre movement. All the women manoeuvered small concessions within the accepted coundaries, and made changes as they grew older that would not have been possible for them in the 1940's - 50's. There was, however, little expectation that their husbands should make any accommodation. It was important that their husbands be able to be good providers, and for each woman this was an investment that brought the security necessary for rearing a family.

\section{Part Two}

\section{COPING WITH DISORDER: "We Managed"}

During the years of this study there was a pre-occupation with stretching the breadwinner's wage in order to finance and furnish a home, and by 1960 nine of the families lived in their own home. Achieving this was not easy, and amidst rearing children these women had their share of makeshift homes which brought its own kind of stress. The skills of adversity learnt from the years of depression and war were still in use throughout the 1950's.

Irene: $\quad$ Life was fairly hard financially. My first little girls' overalls were made out of a pair of her father's old trousers. I was lucky in one respect that I grew up during the depression and through the war. I still don't waste things. We paid five pound for a treadle sewing machine and I would sit and sew and sew at night time and sew and sew until I fell asleep. Until the girls went to Intermediate they never had a bought thing. I remember that my girls both had a Fairisle jersey and I was airing them on a fire guard. A spark came out and put a hole in one. I can remember sitting crying my eyes out trying to mend that hole so that people wouldn't see it.

Audrey: Things were so expensive you just couldn't buy new things. You unpicked and you made. I have a photograph taken of $A \_$in a silk suit made from the lining of an old coat that I had found. I smocked the top. You went to all this trouble because if it wasn't new you wanted it to look extra nice.

Managing, however, was more than coping with adversity, and the postwar years were a time in which families were acquiring consumer goods hitherto not previously available. Women continued to "make do" so that these new goods could be acquired. They recounted with pride 
how and when they had been able to manage to purchase these things. Nell's description of her home appliances around 1950 was typical:

$$
\begin{aligned}
& \text { Well we had an electric jug. a toaster and an iron. The stove was wood } \\
& \text { and later gas. I washed all the clothes by hand until } R \text { was eight. } \\
& \text { You only washed weekly except your baby washing once a day. You } \\
& \text { never changed your clothes so much. We never got a fridge until } \\
& R \quad \text { was at High School in } 1960 \text {, although we had bought a washing } \\
& \text { machine and carpets before then. }
\end{aligned}
$$

There was variation in the order of such purchases. Stella never owned a fridge or a washing machine, while Winifred had most of the modern appliances possible on a remote farm by the late 1940's. The women saw this gradual acquisition of the trappings of the good life as part of managing, although most were to acknowledge that by the late 1950's life was getting easier. Irene recalled how they began to occasionally go out to some kind of entertainment.

During the interviews there were reminders of the differences these women saw between their lives and those of their daughters: We managed - we had to; we knew how to make do; we accepted things more; we didn't give up as easily as you; we never blamed the Government all the time; we didn't get the help from our husbands that you girls do; we had no option; we put up with things; we didn't have the things in the home that there is today. The criteria for being a good wife and mother was in being seen to cope in all circumstances with as little help as possible. Coping was the outward face of normality that masked the disorders which kept disrupting the ideal. Yet in coping with the difficulties of bad housing, a sick child, poor contraception, depression, an unreliable husband, the need for two incomes, women expressed feelings of guilt when it might appear as if they were not managing. But managing had many dimensions that straddled across the economic, the personal and the political. Part Two explores some scenarios around this theme. Firstly they "managed" with husbands who were not always able to earn a breadwinning wage. Secondly they "managed" children who needed extra time and attention. Thirdly they "managed" with the complicated codes of silence surrounding sexuality, contraception and childbirth, which the women were supposed to know, and/or not to know.

\section{MARRIAGE FOR BETTER OR WORSE}

Women were dependent on their husband as a breadwinner for economic security. When this arrangement faltered the security of women became tenuous, and so women were prepared to invest their husbands' breadwinning potential with a lot of their own encrgy. Boys were reared in the knowledge that they would eventually need to be able to support a wife and family on their wages. But the reality was that this was often not possible even though the family wage was an economic priority. A man $w$ judged on his ability to be a "good provider" but a good wife was someone who could facilitate this by minimising his home responsibilities,by being thrifty and efficient, or being able to prop up her husband when he faltered from the breadwinner ideal. Despite the ideal of separate spheres it was apparent that the women of this 
study were often moving into the men's sphere but there was little of the reverse. Apart from Stella's husband, this was not because of any reluctance of the men to be breadwinners (Ehrenreich 1983), but resulted from a mismatch between the idcological and economic realties of the breadwinning wage. These case studies illustrate three common disruptions to the ideal.

\section{GLADYS: "He never got up for twelve months"}

Gladys and her husband, who was a plumber, decided to shift to Christchurch in the mid 1950's because of the opportunities in the building industry. Gladys had two children at that stage and took work in an old people's home at night. This was seen as a short-term arrangement that would enable them to save for their own house. They eventually paid a deposit on a section and to speed up the saving process shifted into a caravan on the section. Glady's husband was going to do a lot of the work himself. At this stage the dream collapsed when he became seriously ill. They took him to hospital and there was I left with two children in a caravan for twelve months.

Helen: How did you manage financially?

God knows. There wasn't the same Social Security. I could only just afford the rent on the caravan. When winter came the condensation used to drip down and I would put the children on the dry bed while I slept on the wet bed. I used to put everything into one pot and stew it. It was nightmare but I managed.

Helen: Did you have friends to support you?

No I didn't have the same support network in Christchurch and I wouldn't have asked for help anyway. I couldn't keep working for the simple reason I had to get to the hospital each day. I put in for a State house then and when he came out of hospital we went into it. But he was home for a long time and it was terrible. Even when he started back at work he used to get tired and would have to have days off. He had used up all his sick leave so any time he had off he got short pay.

The State house was in a large new estate. On the first night in the house the police knocked on the door at 11 o'clock wanting to know if they had heard anything because all the letter boxes in the street had been knocked down. Gladys found that she made good friends but she felt unhappy about raising the children in that area as there was a lot of crime. At this stage Gladys decided to go night cleaning so that they could once again try to get a deposit for a house.

I was tired, very tired. I would come home and sweep the floor and make the beds and then go to bed. Providing the kids in the next door unit were quiet I would get some sleep until the children came home from school.

After marrying in 1949, it was not until the 1960's that they got their own modest house. Two more children made it difficult for Gladys to work but she often put things aside and arranged things somehow to go out to work for short stretches so that they got their house, and later the extras their growing family needed. 
STELLA: "I was the one who had to keen,things going"

The war blighted Stella's life when her fiance was killed, and she rushed into a hasty marriage. She was to admit that it was a mistake and the marriage ended in divorce in the 1960's. Things began badly when her husband bought a market garden in 1945 when the prices were way up. which he sold at the wrong time just before the National Government came to power in 1949.He didn't ask me he just went and did it. His lawyer told him not to. Stella had invested a lot of energy in this venture but felt as a wife she had no right to intervene. For the rest of their marriage her husband went through many jobs as well as long periods of unemployment. There was work around but he didn't enjoy work because he had to do it. He wasn't prepared to work at things. Stella had three children between 1946 and 1950 and providing them with the best she could, dominated her life. Their immediate housing problem was solved by getting a State house, but it was not the house she had dreamed of:

I hated the thought of a State house. The planning of it was absolutely dreadful. From the kitchen to the wash house was a mile long. It must have been a man who designed it. They didn't even have the roads done when we shifted in and the kids dragged in the tar. If you didn't take the place they offered, you went down to the bottom of the list. I thought however that we wouldn't be there that long but we were there far too long.

Stella stayed in that home for twenty years and she felt trapped:

What I found difficult was the fact that when my husband lost a job the first week off we didn't get any Social Security for it so anything that I had managed to save was gone in that week. It went on food. The Social Security didn't really go far enough but my husband's sister used to send a couple of pound or something. But I couldn't go out and do anything because that money was subtracted from the Social Security and then I was working for nothing.

Stella tried working part-time in a biscuit factory to bring some stability to their finances, but her husband disapproved and after two years she gave it up. Eventually he committed himself to a psychiatric hospital:

They rang me up and I went into a state of shock. I managed to ring a neighbour and she wrapped me up. I got the children home from school. That happened several times and then one day he walked out and I asked $S$ _Where is your father?", and he said that he had gone.

Stella was still bitter about the inability of her husband to be an adequate breadwinner, and the difficulties of a Social Security system that trapped her in a State house. She never recovered from the shame of being a deserted wife, and for many years would not divorce her husband. She remained on Social Security and was to feel apart from "respectable society". Stella had dreams for a comfortable family life after the war, but she saw her tragedy in marrying the wrong person to achieve it. Beryl summed up the attitude towards divorce, which would justify Stella's ostracism:

I remember that word failure of marriage. It was a terrible thing for your marriage to fail. That is why women stayed in appalling situations rather than admit it had failed. I saw divorce as a modern evil and as a 
result of people's selfishness. There was the Hollywood thing of divorce. I think that if I accepted divorce marriage wouldn't be necessary. I changed my views.

\section{NELL: "I was prepared to do do it - we did discuss it"}

Many women felt they owed a debt to the men who had gone to the war because they had missed out "on the best years of their life". During the war the code had been that a woman could not refuse the first dance with a serviceman (Coney 1986). After the war the feeling of debt affected the priorities of women of that generation. The assumption was that the men needed to catch up the lost years, so that they could become good breadwinners. Several of the women supported their men financially, or were to "manage" while their husbands retrained. This put additional pressure on family life and the family budget at a time when they had young children and were trying to acquire homes and furniture. Nell's husband went to Teachers' College and studied part-time for a degree over a period of years. This meant that Nell got little help and little company in the first years of marriage:

I was prepared to do it and we did discuss it. To get him through because he had been at the war. He had been deprived of those years that were very precious years, and the openings were there to get, and to study.

This second chance at education was valuable to a generation of men who had left school early because of the depression or the war, but this was a sacrifice for Nell who had received only a minimal education herself:

So my first years of my married life I look back now and wonder why I put up with it. He would come home at night, have tea and then study again. I put up with that for years but you supported your husband.

In 1948 Nell's husband was offered a scholarship overseas. This had not been in the original plan and it was soon realised that it would not be feasible for Nell and their young baby to accompany him. He had not long been back from a five year separation during the war.

Helen: How did you feel about that?

Well I didn't want to stand in his way because it was made very clear to me by his mother that he should be given the chance to go.

Helen: You had only just got him back after the war.

I know but I wouldn't have been able to finance it. He was very adamant that he should go and I didn't want to stop him. It drained our finances....

Helen: How did you manage?

Well the 10/-family allowance had come in and the Government gave me an extra 10/- which was kindness when you think of it today. And my four brothers gave 216 each so $30 /$ - was all I had to live on.

Nell sublet their flat, lived with family and took in scwing in order to keep herself and the baby. She saw this sacrifice however as a positive contribution to her husband's career and thus for the good of the family. Later Nell again took in sewing and cleaned people's houses while her husband worked in school holidays and at night. This all helped to stretch his salary and to make up for lost time. 
Brenda supported her husband in a similar way upon his return from the war, but was more cynical about her investment. Unlike Nell, Brenda makes her hindsight analysis from a feminist perspective and the knowledge that she came to the marriage with a good education and a career:

There was this tremendous responsibility that the men felt as breadwinners. $S$ has said that it was easy enough for me to opt in and out but that he had a wife and four kids to support. I told you before how ambitious I had been but this is how it went. He went and did a degree and I helped him do it. He had come back from the war very very unsettled and here was me worrying about the degree he would get without me finishing mine. I saw his promotion as very important. You could say now that this was the "sell" that we were given but it was really necessary with the conditions. I had been brought up to think that education was very important and obviously what I did when I thought of having children was to transfer my education to him and his job and all the things he got involved in with his work. I serviced them. In that way we were effaced - a faceless crowd-but what else in the conditions. We had no choice.

Brenda's analysis accounts for the investment by women in their husband's work. But Brenda's education and Nell's lack of it constituted a difference in their perception of this investment. Nell saw her investment as a sacrifice and a duty as a wife, but saw that it paid off because she had enjoyed higher status and fulfilment through her husband's job. To Brenda it was not so much a sacrifice but a pragmatic transfer of resources, and she was to measure the growing distance between herself and her husband with cynicism and regret as she remained at home rearing children.

The three case studies show different ways in which women managed with the disruption to the ideal marriage which presupposed the existence of a ready-made competent breadwinner. There could be many variations around this theme, but the women saw it as their job to invest in their husband's future career so that he could provide long term security. When this failed there was the State, and Stella and Gladys found a further safety net in Social Security which again allowed their husbands to keep up the appearance of being the breadwinner. The women may have felt powerless to change the circumstances their husband's placed them in, but being seen to manage no matter what was important. The private sacrifice of this managing was not what socicty saw, and Nell, Stella, and Gladys felt pride in managing alone.

\section{COPING ALONE AND MOTHERS TAKE THE BLAME}

You were expected to cope. There wasn't the support services there are now and you were just expected to cope. This meant that you were too busy to have suburban neurosis (Irene).

Several of the women had children that demanded more than the "ordinary" expectation of mothering. This created additional stress and compromise. Edna's fourth child had Downs 
Syndrome; Brenda's child had severe physical and intellectual handicaps and was to eventually die. Nell had a child who was sickly and slow to develop, while Gladys and Winifred each had a child born with a hip displacement which had to live in traction. Meg and Audrey had children with asthma, and Stella and Edna had children who "got into trouble" as teenagers. It may have been coincidental that the twelve women had so many "problem" children or it may be that such problems were normal, but these women were to talk at length about: the strain they felt as they tried to protect their family from disruption; about their own sacrifice; and about how alone and unsupported they felt. A recent New Zcaland study of 91 families of intellectually handicapped children reported:

...the abysmal "quality of life" experienced by many of these mothers because of the lack of resources, understanding or support. The concept of rugged individualism may be heroic, but its practical execution, in terms of childcare, is all too often left to highly competent heroines who are too busy, exhausted, trapped and guilty to call for help (Chetwynd et al 1985:4).

These observations fit the description of life that the women gave, although not all the children were intellectually handicapped. In the 1950's there was even less assistance from the medical, welfare or educational services, and there was often frustration in trying to find out what was wrong with their children in an era when there were rising expectations that something ought to be done.

Nell's baby failed to thrive and was slow at doing things. Nell knew that there was something wrong with the child but could get no help until the child was thirteen. By then it was 1963 and the child was tested by the Department of Education's Psychological Services. 4 At that stage the child's IQ was assessed well bclow average and she was found to be deaf. Throughout these thirteen years, and particularly during the early childhood years, Nell had felt alone. She knew there was a problem but did not know where to get help:

I suppose I coped but I felt that the Plunket nurse should have taken the baby. She wouldn't make that final step and send it to the Karitane. They more or less said that it was an over-anxious mother, but she had the charts there and she wasn't gaining weight.

It is not possible to assess why the baby was not sent to Karitanc ${ }^{5}$. Audrey, Edna, Stella all had babies that went to the Karitane hospital because they were sickly but Nell was not so fortunate. She managed alone. The children were her responsibility and her husband was preoccupied with his own study and teaching.

Helen: Did you ever seck help?

He left it to the school and it wasn't recommended that we do anything. I did ask the Primer teacher but she didn't really get any help. It broke my

\footnotetext{
4 4 Psychological Services had been established in 1946 but were stretched to meet the demand for their services.

${ }^{5}$ These were hospitals run by the Plunket socicty for sick babies.
} 
heart but I never really had the courage to go and have it out. But it got my back up but what can you do if your husband is a teacher, you are suppose to understand.

During the 1950's the schools were overburdened with the numbers of children and the area of special needs was only beginning to be addressed (Beeby 1986). Nell felt she could do little more than warn the teachers of the child's slowness and beg them to be patient. Nell saw that she had to provide the shortfall herself and the child was thirteen before there was any support through the school. It was hard for Nell to assess how different her life would have been without the worries and work of D She may have got a full-time job earlier, but the main thing was the stress of coping alone and Nell knows that she carried it all while protecting her husband from it.

With Edna's Downs Syndrome child, it was uncertain for some months as to whether the baby would live. After she gave birth nobody would tell her there was anything wrong and she was not allowed to see the baby. Later when she was told, the Plunket nurse advised her not to even take the baby home because of the effect it would have on her family. Her neighbours and family kept away. This lack of support and avoidance by everyone was to leave Edna coping alone.

Nobody came near me and offered help. Nobody sought me out. The doctor was quite good and said give lots of love and affection but he was no use on the practical things. I longed for some professional back up but it wasn't there.

Edna learnt how to cope and how to be assertive and she was to get her child into a kindergarten amidst considerable prejudice. This was the beginning of a battle to get her daughter an education.

Brenda's fourth child was severely retarded. For some months she tried to manage things but looking after the baby was a full time task and unless her husband was there she couldn't cope with the other children. She felt no option but to put her baby into an institution:

It was a terrible decision to put him into a Home and it was the wrong decision for me. We had the greatest difficulty getting him there. But we had got totally desperate. The two year old had reacted badly and was running away. It would take over an hour to feed this baby because he couldn't suck. Up until that time I had really enjoyed everything and coped.There were no hassles and tensions. I did it for my other children.

It would have been better if we could have put him in some kind of daycare which they do now. We made the right decision for them but not for me. I had nightmares for years. I still get them. Part of the collective guilt.

It became very important to Brenda to have another child, to prove to herself and her family that everything could be normal again. 
Gladys's problem initially was to get doctors to accept that there was something wrong with her one year old who cried and cried as he got tired and then would start to limp. The attitude was that she was a neurotic mother:

The last time the doctor got very angry and said. "Is he an only child?" and I said that he wasn't and that I know that there is something wrong. It took six months pushing them.

He had a dislocated hip and at that time all such children were hospitalised in traction for up to two years. Gladys was to fight to keep her child out of the hospital system because once a week visiting would isolate him from the family. She had some nursing experience and wished to care for the child at home but found resistance to the idea that an untrained mother could manage. With the support of her husband who was able to build a special frame in which the child could be transported, the doctors relented. The task was not easy with two other children, and she was pregnant with another.

I spent the first six months when his hip joint was still breaking down just standing by his bed at night holding his hand. You couldn't dope him all the time and that was all you could do. I was so tired it drained you, it really did. You had no married life and you were completely numb.

But Gladys always knew that despite the cost it was for the best:

I felt proud of myself. When he came off the frame I took him to the Crippled Children's Society and they said that he needed no psychological help like the others, who had been in hospital. We gave them the plan of the frames and they started letting others go home to be nursed.

Gladys had set a precedent.

There was strain for all these women in apportioning time. They felt that the "others" missed out because of their preoccupation with the "one" which was their burden. Husbands were of limited help because of their work priorities, but for the women there was guilt if you neglected the "others", the "one" or the husband. There was a feeling of helplessness but there was also a consciousness that something more ought to be done about the lack of support or understanding from the educational or medical authorities. Society's reaction was one of avoidance and the women felt guilty that they were not doing enough.

If an apparently normal child started to "go off the rails" mothers were judged harshly. Being too permissive or too strict, or being a working mother, were all justifiable causes for behavioural problems. The concern about delinquency and morality in tcenagers expressed in the Mazengarb Report (1954) had been an official judgement against mothers and this backdrop created guilt and anxiety as children grew older:

Edna: I often reacted badly. My eldest came home with something obscene. A description of sexual intercourse that I found in her blazer. I nearly had a blue fit. I tackled her about it but I was far too self righteous. I was scared that she might get herself pregnant. She had a boy that she was seeing on the bus. 
Jane: The children who were born in 1947-8 were coming towards adolescence so what did you have but a wide range of teenagers all at once. They started Youth Groups. I went down one night at about 7 o'clock and was absolutely scared stiff of passing through all those bodgie - widgie types and my daughter was in there somewhere. Then my daughter was looking to do the coffee bars as the excitement of the week and we had to let her go at fourteen into town by train. I was a permissive mother but I wondered what am I letting my daughter do. I trusted her and I am glad I did but people were worried.

For Stella, the anxiety moved beyond worries of what might happen because "the worst" did happen. They were living in a new state housing suburb and her son got in with the wrong crowd, and joined a motor bike gang. This led to a series of convictions for disorderly behaviour.

I could ride through my daughter's teenage years although there were a few problems because of the area. The boys didn't value a girl as I would have liked her to be valued when she was taken out. The most terrible time was when $B$ went into the motor bike gang and that terrible sense of failure.

Helen: You saw it as a personal thing?

Oh yes I felt shame. You would never know the things we had to put up with. Our house was broken into, beds slept in. I could never tell anybody. Dad would close up so it was so difficult. Men just close off and I couldn't get through. But you just can't have your children through the good times, you have to see them through the bad times as well. I knew that if you kept thinking you were a failure you will be a failure. So I just held on and held on. It seemed so long it was so awful at the time....I had this fear that often the brothers in gangs get their younger ones to go in. It was a terrible terrible feeling that we might have to go through it all again. But it didn't happen. I couldn't think where I had gone wrong that he could have had a different upbringing to the rest.

Stella blamed herself and the area they lived in. She felt ostracised and a failure, despite the evidence of her other children who were a credit in every way.

Motherhood was not only a career in itself but an investment to give their children the educational benefits and opportunities that had not previously been available. There was disillusionment when their children sometimes scorned these things. Coming to terms in the 1960 's with children who dropped out of school or university; or who went on the dole; a daughter who got pregnant; a son who joined a new style religious sect, all had to be coped with. But by the 1960's the judgement wasn't quite so harsh and mothers weren't totally to blame because socicty might be "sick". But during the 1950's these women carried the guilt and the load personally, because as Stella found she could not communicate with her husband anyway. Managing was creating an outward appearance of an untroubled and successful family life.

\section{THE SILENT ISSUES}

Throughout the century feminists have tricd to empower women with knowledge about their bodies but there have been strict codes about what was acceptable "to know", and there have 
been double standards between what women could be told and what they knew through unofficial networks. Subjects like sex, contraception, abortion, depression, or childbirth were treated coyly by the media or not at all. For the women in this study getting access to such knowledge was hit and miss and, because of the silences surrounding such topics, the women would manage their problems very much alone and often believed that it was happening to them alone. For example, several of the women had never before talked about their childbirth experience and did not see themselves as part of any common experiences of the women of that generation. There was considerable variation amongst the women in terms of access to knowledge in its official and unofficial versions. The educated women had such access more easily, although women would sometimes avoid information that was there, because they did not want to know or could not cope with it. These interviews were not constructed to elicit information on these issues, so what was told was sporadic, but the women gave glimpses of the attitudes and experiences of sex and reproduction. .

The ideal of virginity before marriage was strictly upheld even through the war years. Social clubs for mixing with soldiers like the Y.W.C.A. had strict rules and carefully vetted girls to ensure respectability (Middleton 1985). Yet the rising number of adoptions (Else 1986) showed that the moral code was not working. Jane was to admit that she and her fiance and herself did not wait to have sex until they were married. He was due to go to the war but even then they only had three weeks sexual life together before he departed. Such transgressions were for most hidden behind a veneer of correct behaviour. Gladys was to step outside the moral code and felt that she was not forgiven by her family until she was safely married with children:

Helen: At what stage did you start thinking about marriage?

At no stage because I wasn't going to get married. I met this boy and went to Nelson with him. Well that really put the kybosh on things. Mum was furious. We went fruit picking. We were on a sort of mutual high for awhile and then we came back and he took me to $A_{\text {_t to see }}$ Mum and Dad. It was terrible they were so stiff and formal ...you have no idea. I knew that I wouldn't be able to face them by myself. The thought in those days was that even if you just travelled alone with a boy it was absolutely sinful. They did accept me back but there was always this reserve because I had done something wrong.

Helen: How did you manage?

It was very restrictive and very difficult to be open. I started to close up and didn't discuss things because our values were so different. I had crossed over the boundary of what was acceptable. ( $\mathrm{my}$ emphasis)

Gladys described what happened to her friend who not only "crossed over the boundary of what was acceptable" but got pregnant ${ }^{6}$ :

I can remember my girlfriend who was teaching out on the Canterbury plains. She was going with this boy and having a baby with him. Well

\footnotetext{
${ }^{6}$ The illegitimacy rate averaged $4 \%$ of live births during the early postwar years although there had been a rise in 1944 to $6 \%$.
} 


\begin{abstract}
I have never heard such an outcry. But I could understand it as I could just see and the narrowness just got to me. I have never seen a girl so persecuted in my life. She took to her bed completely and the whole of A knew about it. Everybody was up in arms about it. Nowadays they wouldn't be. I used to feel so sorry for her. She was so lonely out on this country job and he was her companion.
\end{abstract}

New Zealand had a string of charitable and religious maternity homes that would provide a discreet hideaway and arrange an adoption for unmarried mothers, but they were also a kind of punishment for transgressing (Tennant 1985). For those who couldn't face these there was the option of an abortion. In 1937 the MacMillan Committee of Inquiry had been established to investigate the rise in deaths from septic abortion. $80 \%$ of deaths from abortion were married women, and it was estimated conservatively that $13 \%$ of all pregnancies ended in criminal abortion (Brookes 1986) ${ }^{7}$. Throughout the 1940's and 1950's the effects of makeshift abortion continued to be a concern but was a taboo subject in the media sources used for this study. The only references were the warnings printed by the Health Department.

After a grim experience in a Maternity Home in 1949 Edna detailed the common abortion recipes:

Out of the five in the ward of the rather unkempt nursing home I seemed to be the only one there according to plan. I remember hearing with horror then how the other four had all tried to abort their babies. Having lost my son at birth I was mortified to learn that people not only didn't want their babies but here was I talking to people who had tried, as I saw it then, to murder them. One told me how she had tried jumping off the table. Another had tried a whole bottle of laxative pills popular at the time. It shifted something she said but it wasn't the bloody kid. Another tried the gin and hot bath treatment. Someone else had tried jabbing the uterus but none of it had worked. They joked about it but they were wounded by the trauma. One was only 21 and had had four babies in four years and her husband didn't even come to see her.

Hospitals were on the look-out for suspected abortions and Brenda recounted a mortifying experience when she had a miscarriage:

I hadn't been to the doctor even though I knew I was pregnant. There was this trendy thing not to. But something went wrong and I was very distressed when I did go but the doctor thought I had had an abortion. That was a shock to me to think that they thought I was hiding an abortion. Next time I got pregnant I went to the doctor early.

Brenda was particularly sensitive because her Aunty was a backstreet abortionist:

She was a nurse. All these things were talked about by the women in my family and I had always known that Aunty $L$ did the job from my earliest years. When I came to Wellington and was going to visit relatives my mother told me that it wouldn't be wise to call on Aunty $L \quad$. I can see why now but it was a contradiction at the time because there was all this talk. I had known ladies who had had an abortion or who had tried to have an abortion.

7 Phillipa Mein Smith gives the Department of Health's calculation for this Committee of 20\% (1986: 102). 


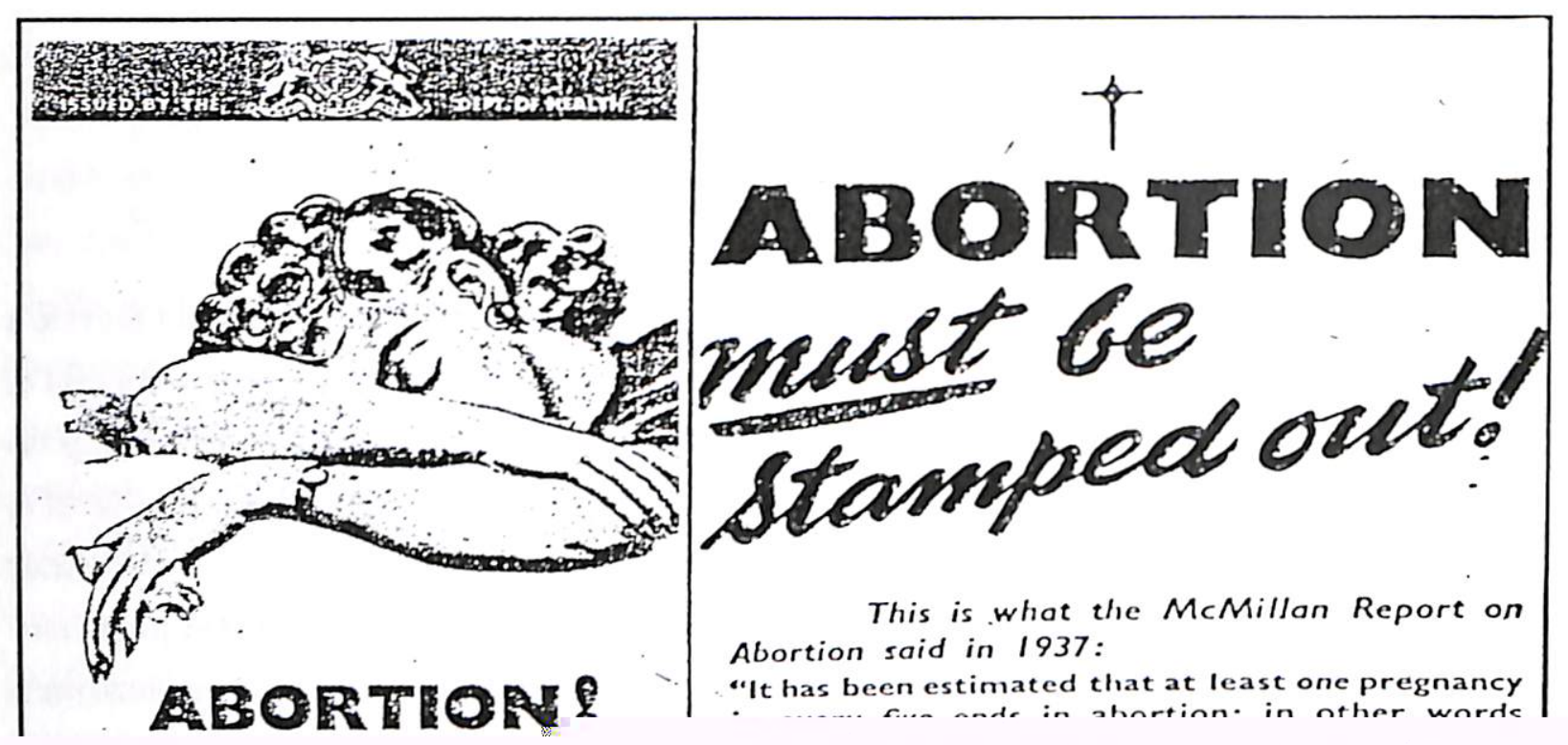


Institutes, the Working Women's Council, the National Council of Women, and the Women's Division of the Farmers Institute, the 1937 Commission of Inquiry into Abortion had been negative towards freely available birth control. The Catholic and pro-natalist lobby was strong. Women were warned of the "race suicide" involved in abortion and birth control, and selfdiscipline was advocated (Brookes 1986). The women of this study had grown up amidst such official disapproval of contraception but all of them were to attempt to limit the size and spacing of their families. In the intervening years there had been the war years when all soldiers had been issued with condoms as a protection against venereal disease. However several of the women said that their husbands' felt it was "not nice to use those things on the wife" and therefore arranging other contraception was left to the women. Attitudes towards contraception mellowed but access was difficult (Chapman 1953). The quest for information was evident in the 2,317 letters that the Family Planning Association received between 1941 and 1946 (Fenwick 1980). Later in 1953 when the Association placed its first discreet advertisement in the Women's Weckly, "hundreds of letters" were received. It was not possible to talk about the specifics of contraception with all the women interviewed, but those who offered information found contraception harassing and embarrassing to organise in the years before doctors were particularly sympathetic, or informed, when sex itself was such a taboo subject.

Finding the right doctor was daunting, although Brenda was to assert that during the 1940's the women amongst the "varsity crowd" knew the right doctors.

There were some special women doctors and I went before I was married. My sister in law had been to her local doctor who was a Catholic and had been pretty upset. It was the fashion then to have your babies in the spring. There was this thing about showing how clever you were about your contraception. The dutch cap and the diaphragm were the types and were pretty reliable. But there was a lot of uncertainty really about contraception. There was that silver diaphragm which caused a lot of cancer.

Other women did not find it so straightforward. Edna lived in the country:

There was not much information on birth control. It was the accepted idea that the first baby was a hit and miss thing. I got a bit of help by pooling ideas with the other young wives. Later I was fortunate to meet one of my mother's boarders who had married a doctor. She had a university education and she told me about the diaphragm. I tootled off to my doctor and asked for a diaphragm and he said, "What's that?". He eventually found a kind of dutch cap but my friend said that it wasn't so good. The doctor said that my husband should use the sheath but I said that he wasn't very keen on the idea. It was like shaking hands with a rubber glove on he said. It was made very clear that it was my responsibility.

Getting contraception before marriage was especially difficult. Meg was asked by the doctor not to tell anyone she had been fitted with a diaphragm as the doctor did not want to get a reputation that she might do abortions. Brenda recalled the negative attitude in 1944 towards the idea of women being able to control their fertility and their lives: 
We had to go to very special efforts to get family planning. I had to go almost illicitly to the doctor. It was quite difficult to pursue the idea that I was not going to have a child until I wanted one. Not easy at all. It was the mechanics of getting information. A few people I knew had ideas and they passed me on pamphlets and things. That was the first glimmerings of my later feelings that women were having a bad deal. Up until then I had never felt inadequate.

Not that contraception was always successful. Irene had seven children and, although they were all welcome, most were the result of contraception failure:

We didn't find a satisfactory method of birth control until the pill came. When I asked after the first baby my doctor told me that if you had your second baby soon it would be an easier birth ...Women were women and you had babies as the natural thing was his view. I had to go to a woman doctor.

Beryl was a Catholic and had ten children. She was to admit that she did not mean to have so many but that she too always made them welcorne. Beryl tried the rhythm method of contraception but found that she was always cribbing days by having sex on days when she could possibly be fertile:
Now I had sussed out my cycle very well but $J$ 's work had a lot of tension and a lot of us in those days were geared to meeting our husband's needs, particularly with the Catholic Church. I knew there was a certain release of tension for men through sex and so I would crib a day or two.

While these women found preventing pregnancy a great worry, the reality was that pregnancy and birth dominated their lives for some years. The experiences of these women reinforce the documented arguments surrounding the maternity services in the postwar years (Gordon 1955, 1957; Parents Centre Bulletins). Some were to benefit from changing practices and attitudes, some took control of things themselves by pre-empting officially sanctioned change, while for others it was a case of not wanting to know and of putting up with things. In the 1940's there was little information around on the process of birth and women learnt to cope through experience, although some hospitals and some Plunket Socicties were running ante-natal classes. Nell knew little about the process of childbirth. She had heard about classes, but felt too shy to go and preferred not to know. Irene asked her doctor about going to classes but was told good heavens no!, all she needed to do was to eat her meals properly and take a walk every day.

I knew absolutely nothing in spite of my mother having had six daughters after me and all being born at home. I had got pregnant on my honeymoon and I didn't even know that was possible. I knew nothing about the birth process. You just put up with it and then a baby was produced for you.

Irene had very difficult births, and throughout her seven childbirths attitudes and practices changed very little. The small private hospital she used was bought by a group of doctors who 
did not approve of changes. On the other hand she appreciated the midwives' efforts to get breastfeeding established, and the fourteen days bed rest was nice 8 .

For her first child in 1947 Jane knew nothing, apart from her mother saying, "It was terrible" and she wouldn't give me any more details. Jane's attitude was that, Oh well I am a very obedient girl. I was head prefect and I did what I was told I had to do. However during the second birth they were late giving the anaesthetic and she felt the baby coming. She reached down to help pull it out but was strongly reprimanded and promptly anaesthetised:

\section{I never forget that feeling of being imprisoned in those stirrups with my legs up in the air, wanting to help and wanting to be conscious and doing something and not being allowed. Totally out of control.}

For her third child in 1951 Jane had read Grantley Dick-Read's (1946) book on natural childbirth. She knew the Matron of the hospital and took the book to her and asked not to be andesthetised. The Matron was interested to try it out and arranged to be called to supervise the birth. It was not quite as easy as Grantley Dick-Read stated, but Jane was able to remain conscious all the time and the Matron helped her breathe. It was the young male doctor who was rather disconcerted to be asked questions and receive instructions. Later Jane made contact with Helen Brew who was pioneering natural childbirth.

I had had no contact with other people doing it and Helen Brew was getting such bad press and such bad vibes from the doctors that it was a bit tricky even to be known to be interested. But things were starting to move fast in terms of better communication and we were getting stuff from America. Up until then we had felt really cut off because of the war. We didn't know what other people were doing.

Beryl also stumbled onto natural childbirth but it was not until some years later that she heard of Grantley Dick-Read's book which confirmed for her what she had intuitively found out. After a getting a bad reaction to anacsthetics for the first baby she refused to have any more anaesthetic. This was not easy to do and for all her other nine children she was to have a running battle with people who would always try to make me. Beryl found that she was able to control the pain eventually, and she was fortunate to have a doctor who would let her lie on her side to deliver and not make her use the stirrups.

The pressure on numbers and the concern about cross infection in the maternity services (Gordon 1955, 1957) encouraged regimentation and docility, but several of the women spoke of the low standards and intimidation. Edna was given injections to stop the labour because there were too many in labour when she went into labour in a small country hospital in 1947. Her baby subsequently died, and she is still pained by the insensitive attitude attitude of the staff. She never saw the baby, and for two days was told nothing. Next time Edna tried another hospital but found little improvement:

8 Some of the hospitals were moving towards a shorter period of bed rest although it was many years before women were encouraged to get up immediately. In 1947 the practice was that you did not put your feet to the ground for at least ten days. 
There was this ghastly woman who ran this hospital and she had this big dog who ran around with her. When she was prepping me she told me that she had been up every night and that I wasn't to disturb her. "Do not ring for me," and there I was left. Some hours later when it came to the actual birth she had a couple of young sixteen year olds there and my baby was delivered by them because she was busy. No doctor and I was ripped around. It was horrific. These kids gave me chloroform.

Docility by the mother was essential to hospital routine:

We were not allowed to go anywhere near the babies and in a small hospital you get to hear your own baby. After having lost one I wanted to be near it, but they never came on duty until seven in the morning and the babies had to wait until then. You just didn't dare help yourself to the baby. You were forbidden.

Audrey and Gladys both had four children but also had numerous miscarriages. The silence that surrounding these was stricter than birth. They were never discussed which made it so difficult when you were so ill. You had to pretend there was nothing wrong. Even Mum didn't really say much although she would visit me, said Gladys. For both women the outward appearance of marriage and family life was a matter of coping with a never ending cycle of pregnancy, and miscarriage. Audrey said that I just learned to live with it. Her husband helped as much as he could but the reality was that he needed her to help him in his job. He worked for a church organisation that ran an old people's home.

I had to work and work hard. I still had to cook for the men and do the rest of the things we were doing in the home...the washing and all the rest.And there were the children...If you went down you knew that everyone else went down. I learnt many years ago to laugh at things. If I hadn't done that I don't know where I would be-down the drain...And I was trying to keep $B$ (husband) happy.

\section{Part Three}

\section{THE PRIORITIES OF WORK}

The women found an identity in the roles of wife and as mother, but they were creative in adapting their skills and interests to minimise any conflict of interest. In this sense their paid and unpaid work was often seen as supporting their husband or as a part of motherhood. Paid work was often a matter of necessity but it sometimes created opportunitics for change and new independence. The possibilities of pursuing paid work or interests outside of this framework were short term or difficult. For example, Edna's magazine stories were possible as long as they fitted in and around the real work of family and farm. When writing was about to conflict with the responsibilities of a wife and mother, Edna gave up writing. It was only in hindsight that Edna was conscious that things could have been arranged differently. Similarly, Irene became involved in kindergarten and school committee work. This was acceptable and her husband saw himself as a progressive husband in supporting her in this. She was then offered the chance to train as a teacher which was the opportunity for the career that the depression had prevented. Her husband objected and Irene did not argue: 


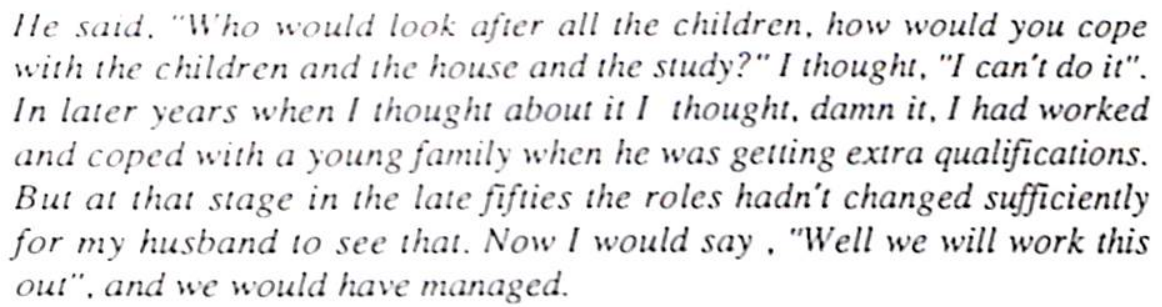

On the other hand Irene had been seen as a good wife when she encouraged her husband to leave the family to further his education in another city for a year. She had two preschoolers but by juggling around kindergarten times she worked as a tea lady in a factory. It was a matter of survival. To work on behalf of her husband was acceptable but it was selfish to train as a teacher.

The paradigm of new opportunities and equalities for women in the postwar was difficult to extend into marriage, except insofar as it was accepted that a wife could have outside interests as long as they did not conflict with her chosen career of marriage and family. The two paradigms of opportunity and security for women co-existed as long as women kept to a correct order of priorities or could compartmentalize their responsibilities and interests neatly. Part three examines various contexts in which these women were able to work whilst still keeping their identity as a wife and mother in the foreground.

\section{A WORKING WIFE.}

Mary Millar of the Woman's Weekly, would remind readers that although husbands and wives were now equal the breadwinning responsibilities of the husband justified his head of household status. While there was a shift in attitudes about choice, opportunities and rights for women, there was little shift in the attitudes and structures that upheld the breadwinners' roles and rights.

The structures upholding the breadwinning wage were, however, changing. This was a period of transition from the Labour Party's 1936 commitment that the basic award wage for men be sufficient to support a wife and three children, towards tax adjustments for men with families (Kane 1972). But the sufficiency of the breadwinner's wage, whether it was upheld through awards or tax, was a myth. Families relied also on overtime (Wilson 1980) or a wife's earning. Working wives did not directly challenge the concept of the breadwinning wage at this stage but were to gradually undermine it. A more direct challenge to the breadwinner's wage was coming from the growing demand for equal pay. This was part of the inclusion of women in New Zealand's egalitarian ideal, but it was also a recognition of the faulty security for women dependent on their husband's earnings.

The messages that women received were contradictory: that women could be independent, and that they should develop their own interests, although a good wife and mother must service the needs of her husband and children. A later comparison between the two generations of women will show that these two paradigms of femininity have come more and more into direct conflict. During the first era the case studies will show that "self" was served 
when there was no obvious conflict with the needs of husband and children. The hicrarchy of priorities was defined more clearly in the postwar period than later, but as the following case studies will show, women were gaining a consciousness of their right to something of their own.

Janet Finch's book Married to the Job analyses the extent to which women have been incorporated into supporting their husband's job. She states:

When a woman marries, she marries not only a man but also his job, and from that point onward will live out her life in the context of the job which she has married (1983:1).

Finch examines the cultural and structural mechanisms which have made it difficult to alter the existing order of priorities because many male breadwinning jobs are structured around the incorporation of women's services. The later generation of women in this study were beginning to resist such incorporation, and some were challenging their husbands to service their own work by demanding more childcare and housework assistance. There was little evidence of this amongst the older women although an exception was when Jane's husband offered to shift to another city so that she might be able to return to work. This did not eventuate as she got a job in the same city. This was 1960 and even Jane admits her husband's attitudewould have been most unusual.

The following case studies show the kinds of ways women were part of the workforce but were also seen to be supporting their husbands. Minimizing conflict was important. It was possible to find a personal fulfilment as well but for some this would have caused conflict and was not considered a priority. Economic security was often the over-riding concern.

\section{NELL: "I bought the carpets and I got the fridge"}

Nell was a skilled tailor and also sewed for friends. In 1958 when both the children were at school she decided to work on a more regular basis. She got a job with a clothing firm to do tailoring repairs which would be collected and delivered to her home. This could be fitted in with her other responsibilities. Nell justified her job because they could not build up savings and they wanted their own home.

Helen: Why did you want to work?

I wanted the money. I didn't handle our money, Dad handled it. It took me years to cotton on that he really wasn't saving. He paid every account and no one was owed anything but he wasn't really saving sufficient to cover the cost of a new house and new furnishings.

Helen: What did you want the money for?

To build up a balance and to buy some things for the house. And that is how it has been. Almost everything that has been bought for the house, has been bought with money I earned.

Helen: Did you want your own money?

Well I had always had my own Post Office account and always kept something in it but I didn't really have money to put in it. When I started work I could let it build up and then get something. 
For some years Nell worked at home and then later started doing housework for several families. Nell was proud of her contribution and became more involved in controlling the finances. Her earnings were quite small but she determined what they were to be spent on, and the house became filled with items that she identified as having been purchased with her money. This gave her a sense of financial independence, and she would say, Dad could not have managed without me. When her children were at secondary school she went to work full-time in a tailoring firm. Throughout this shift from being at home full-time to working full-time Nell continued to maintain all the responsibility for the children and the house. She got up earlier and went to bed later to complete all her tasks. There was a wide gap between Nell's and her husband's full-time wages and a disparity of status in their full-time jobs, and he kept the outward appearances and responsibilities of the breadwinner. Nell received a housekeeping allowance as before and she saw her money as "buying the extras", even though they were now the necessities of the "good life".

WINIFRED: "Everything had to run like clockwork"

Winifred never worked for real wages. She was reared on a farm and stayed with her parents until she married another farmer in her mid thirties.She had her own lambing beat on the farm and worked in the garden. She helped her mother do the cooking for the men, and helped care for the other children on the farm. As she got older her father paid her an allowance in recognition of the work she did. Winifred still had time for her own leisure activities that were part of farming life: riding, bridge, golf and tennis. After she married, life continued much the same except that she took full responsibility for organising the household and later the children. Winifred was an essential $\operatorname{cog}$ in the work of the farm:

$I$ had to organise the men's meals and very punctually too. Everything had to be run to a timetable. I would also help in the yards. (Her daughter recalled in another interview the image of her mother with her baby on her back down in the yards each day.) I would also drive my husband around each day. I was very very busy. You had your jobs to do. You had to have everything organised right to the minute.

Winifred was also a teacher to her children through the Correspondence School for several years:

I had been dreading it and even tried to find a governess but couldn't find anyone. We acted like school. We rang the bell at ten to nine and she would come in and brush her teeth, comb her hair and wash her hands. We would co-operate as much as possible with the radio lessons. But the stock and station agents that came in would all help. One used to come in and give $V$. some reading arithmetic on Monday and another would give her

Winifred saw this work as part of her role as a wife and mother but there was time for other things. She was involved in community activities like Plunket and the Women's Division of Federated Farmers. She kept up her own leisure interests which were often shared with her husband too. A sense of financial independence was fostered because her husband gave her money of her own as apart from any housckecping: 
When I married my husband arranged for money to be paid directly into my account. I always felt that I didn't have to ask him for ten pounds to do this or that with. It was like a wage for working on the farm. I suppose.

Winifred's "wage" was in contrast to Edna whose real wages for milking the cows were only a bookkeeping transaction. Edna and Winifred however came from different rural economic classes. Winifred's family was well off financially and it was customary to give daughters and wives some independent allowance.

\section{GLADYS: "I could never follow a career through"}

Gladys had yearnings for an interesting job but could never fit this around the needs of her family. When the children were small Gladys worked as a cleaner at night on several occasions of financial crisis. These were short term stop-gap measures that left her exhausted by day. Her husband's earnings were low and Gladys began to work more regularly once thu four children were in school.:

Helen: What sort of work did you do?

I went cashiering at a shop, but really I did all sorts of things.

Helen: Was the work primarily for the money?

Well we needed the money but I thoroughly enjoyed it all the time. But I could only work for so long and something would make me stay at home.

Helen: What sort of things?

Well the children or something like that, or it might get too much with everything else. But the real cause was, if there was anything wrong it always had to be me staying at home. I could never follow a career through. Never have been able to.

Helen: Did this upset you?

Yes very much. I would get interested in something and then I would have to give it up. It would break my heart. Or I would join something and $S$ _s night class would change and I would have to give it up.

Helen: What sorts of things did you do?

Oh bowls and things like that, going out with friends. I started a hair dressing class and had to stop that.

Glady's work and leisure activities were a low priority on the family agenda even though her bouts of paid work were essential for the family to survive. They were always curbed if they moved beyond a short term financial injection to support her husband in his breadwinning role.

JANE: "Schools needed teachers"

Jane was exceptional. She had a strong concept of equality for women and was supported by a husband who had similar views. Both Jane and her husband had been influenced politically by socialist views on the equality of women. Jane admits also to being very careful about her selection of a husband and was to state that she turned down others who showed no signs of respecting my rights. Yet Jane was to admit that she saw her life as part of the "feminine mystique" and identified strongly with Betty Friedan's book when it became available in New Zealand in the early 1960's. Jane had trained as a primary teacher during the early years of the war and continued to teach until the birth of her first child in 1947 . In the 
meantime her husband had returned from the war and was re-establishing himself in his career. Jane had a general idealism about the new postwar society and a better future. Raising children was an important part of this:

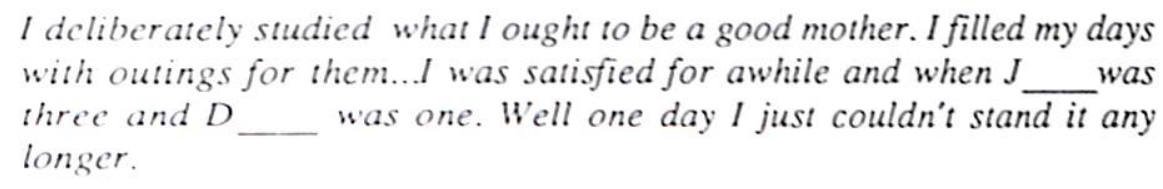

Jane decided to return to teaching and was to stress that it wasn't for the money as they could manage on her husband's salary. She arranged childcare for her two children:

Helen: How did people feel about you teaching?

Nobody had a negative word to say. They knew that I was a good teacher and that schools needed teachers. There was a shortage and so it seemed quite right that I went back. Perhaps if it had been a different type of job it would ha"e been different. Teaching was acceptable for a woman to do. If I had gone into a factory or something like that there might have been something to say.

However the ideal of managing a job and rearing two young children was constrained by the difficulty of finding substitute childcare that could match the quality of life she wanted for her children:

\begin{abstract}
$I$ had a series of people come in and mind them but I wasn't very happy about it.Then one day as I was just getting my class into good shape the woman who was minding my kids came with her kids too, past the school at lunch time. Here were my two in scrappy clothes with their food plastered around their mouths and $L$ being dragged along. I thought "No I can't stand it", and I stopped teaching. It was a good job and right beside where I was living.
\end{abstract}

Jane was unusual because she had support from her husband to have a career and he would help with the domestic chores. There was also a kind of support from society which saw the teacher shortage as akin to women's work during the war (Middleton 1985b). But Jane was to admit that her children always came first with her and good quality childcare was the issue. It was not until the 1960's that Jane moved back into paid work. She was to work hard at containing the feelings of malaise and worthlessness that would still erupt despite the satisfaction she was to find working in the playcentre movement.

\title{
AUDREY: "I just walked out one day"
}

Audrey's husband worked in various institutions run by a church. These were Homes for old people or children. There was an expectation that Audrey too would help on a regular basis and in emergencies. They were always understaffed and Audrey usually found herself involved in the kitchen as she had worked as a domestic servant before her marriage:

I was doing the cooking for the men and some of the cleaning. It wasn't a very big place as we only had seventeen men. But also did the preserving and the making jam and looking after my own baby.

Audrey had four children but her health was poor. There was stress in trying to manage her own family responsibilities as well as working with her husband. The institution provided a 
community that could be supportive but there were few opportunities for time off as such institutions operated around the clock. It took many years before Audrey felt able to organise time off for herself. It was also a matter of balancing time alone with her own family and time in the institution. She was to fecl that her children missed out because they always got the grumpy side of her. There was always a feeling of guilt because somebody had to do the work and her work was regarded as part of her Christian duty. When you worked for the Lord it was harder to clock out. Her "resistance" began when she walked out one day and said that she had to get away and went to town. Afterwards she arranged for Thursday afternoons to be her own time and went to a women's church group. This time was highly valued by Audrey and she later extended her time away by teaching scripture in school. She loved it and felt that this kind of "time out" could be justified as part of her Christian duties. She had found a good compromise.

These case studies show different ways women contributed to the myth of the breadwinner's sufficiency, yet were able to manocuvre changes without challenging directly. For Winifred on the farm and for Audrey in the institution the conflict was minimal in that they were essentially working for their husbands. Nell and Gladys moved in and out according to financial need but the appearance of separate spheres was strictly maintained. Jane's attempt to combine a career and childrearing was the exception but even in a supportive environment did not continue for long. Her sense of responsibility and concern for her children was to override other aspirations.

\section{MOTHERHOOD AS WORK}

When attitudes are overcome the real constraint upon women's options of paid work and leisure was, and still is, a responsibility for children. Women have had to balance the needs of their children for reasonable care against the needs of the family for extra resources, or their own needs to do something for themselves. This chapter has shown how women avoided clashes as much as possible, but this created strain. While women acknowledged the work involved in bringing up children, and the fact that their responsibility for the children structured the other options available to them, there were different views about the work of motherhood itself. Meg noted the difference:

My next door neighbour used to say to her children, "Go outside while I do my work". This may have been a class thing because I saw my children as my work, whereas she saw housework as her work. I made a distinction in my head as to what was my primary work, although my husband saw it as the housework.

This comparison illustrates two different views of motherhood. McKinlay (1983) suggests that the playcentre and Parents' Centre philosophies were indicative of a new style of motherhood, in which women saw their primary role as servicing the individual needs of their children in a more intense and comprehensive way than before. An earlier stylc of motherhood, but one that 
was still dominant during this period was one in which women sought to control and train their children to conform to the priority needs of the household and society. This new paradigm of "motherhood as service" (McKinlay 1983) was linked to the new consciousness of the child as a psychological being (McDonald 1978) and the idea that women followed their intuitive maternal instincts (Winicott 1949). There are variations within any paradigm, but the women in this study could be placed in these categories. Meg's suggestion that there was a class difference in childrearing priorities is substantiated but was one of educational rather than economic difference. Meg, Jane and Brenda who had an education beyond secondary school saw themselves as permissive mothers, and came to view motherhood as the career they could not manage themselves. They were to study the art of motherhood and childrearing but were to admit that it did not alleviate the day to day stresses and strain. For the other women extending the work of motherhood as an art or a substitute career was not the issue, instead, they fitted the work of motherhood in amidst all their other responsibilities. This was managed with varying competence, enjoyment and interest. Two case studies show different experiences of the work of motherhood. For both motherhood was a career. For Beryl this has been a life-time occupation that has only recently ended, whereas for Brenda motherhood was an investment of her own career and education in her children which became less fulfilling as the years passed.

BERYL: "I felt responsible for bringing them all up":

Beryl was to have ten children over a period of eighteen years with the first arriving in 1948. She had been nursing before she married and as was the requirement then, left nursing when she married:

\section{We didn't question that then. It was what happened if you married and you just made your choice. I missed it terribly but my ideal was that when I married I would have a family so my first baby was born a day under nine months}

As a Catholic she always expected to have a large family and the art of motherhood was in managing so many, and coping with frequent arrivals. Beryl found a deep fulfilment in her family although was to admit that having good health and good organising ability were the key to managing:

I would get up very early in the morning and get the washing underway. Then I would fix the baby first and bring the baby out in the pram. Then I would get the breakfasts and do all the lunches and get the children off to school. Then I would give some time to the toddlers and listen to the radio stories. I wouldn't touch the beds and dishes until that was over. When they were satisfied that they had had something of me then I would do all my housework.

With so many children Bery'l was very conscious that people might see them as neglected and so would ensure that their clothes were always well ironed, often staying up to midnight to do it. Looking back she says that she kept an impossible standard, whereas nowadays I hardly do any. I wish I had had that attitude then. It was difficult managing on her husband's wages and she had no way of supplementing them, but again Beryl managed through her skills of 
thriftiness and making do. The purchase of a sewing machine in the early 1950's was crucial. Beryl saved up for it out of the family benefit although twice it got spent on something else:

I could get a child's pyjamas out of old men's pyjamas by using the strong parts and the same with a shirt. Then the three yards of cloth in an old dress would make up into all kinds of things

They grew lots of vegetables, and never went to hairdressers, but managing was still hard:

We never had money to spare and it was a matter of deciding whose shoes needed mending the most and I remember not wanting to go to communion because of the cardboard in my sole.

Beryl felt that she had the total responsibility for bringing up the children and felt that it was her duty to shield her husband from them because of the pressure of his work. The Christian thing encouraged it. I wouldn't do that again. Beryl was not a supporter or permissive childrearing and saw her role as teaching them manners, morals and a good attitude. We did not have this idea that a child knows what he is. However Beryl did not believe in hitting her children and in this area she feels that she was permissive. Her other priority was to ensure her children got a better education than she had got, although she did not send any of them to kindergarten. Beryl had a strong consciousness of her duty as a mother to train her children and did not want them leaving home too soon.

Having more children than her friends and neighbours, Beryl was to feel the changes as more and more women took up jobs.

When we first went there everyone was busy getting their garden in and there was always someone to have a cup of tea with. Mothers were at home. Gradually they started to go out to work. One woman across the road went to work because she wanted a washing machine and she went out cleaning early in the morning. She knocked off when she got her washing machine. Another neighbour got a job at Woolworths at night because she couldn't manage financially. Her husband hit the roof. "Nobody is going to say that I can't provide for my family". He comes across with another two pounds a week which was quite a lot really. So she didn't go out for another year. He would then buy things on hire purchase and pay the deposit and leave her to pay off the instalments. One by one I saw my neighbours go out to work and they all got cars and it became a matter of waving to them as they went off in their cars and I saw less and less of them. It was rather sad really as I was still having children.

Beryl's youngest child only recently left home and motherhood was a career in every sense. For a few years before her retirement, though, Beryl used her experience in her first paid job since she had left nursing to get married: looking after other people's babies, which she saw as an appropriate ending to her career of motherhood.

BRENDA: "I felt I was at home for years and should have been moving out"

Brenda married soon after the war ended and she was concerned that her husband get himself qualified as a teacher before she gave up work to start a family. Brenda admitted to being very ambitious for herself as a teacher but that when she marricd she transferred this ambition to her husband because he was going to be the breadwinner. As compensation she 
invested heavily in childrearing. Like Beryl she saw a clcar choice between marriage or a career at that stage:

I felt that I was giving up a tremendous amount to have children and so I wanted to have enough children to make it worthwhile. We all had this idea of a big family and this idea that you gave up to have children and so just having one was not worth what you gave up for. Four was the idea. Two boys and two girls. So once we were into having children we were into it in a big way.

For some time Brenda enjoyed being at home with the children and the whole domestic scene of sewing and cooking. She taught night classes which kept her hand in at teaching and brought in some extra money, but saw herself primarily as a mother at home. Brenda became involved in the playcentre:

Now permissiveness was the big thing and I was into all of that. Whether yu sent your children to kindergarten or playcentre was very important at the time. Playcentre was a lot more free and we were focussing on a new educational philosophy with our children.

Brenda felt that her generation of mothers carried the brunt of permissiveness. They had been brought up in an authoritarian way and were caught in between two lots of expectations. We had to kowtow to our parents as well as our children.

Brenda described her generation as child-centred in the sense too that they saw any marriage break up as a disaster for the children:

It was for the sake of the children that we must keep married at any cost. We would take each other's children when marriages were rocky. Lots of times I would have kids to stay here a week - someone whose husband was having an affair. We would let them go for a holiday. We didn't think that we had the right to break up a family.

By the late 1950's Brenda was feeling disillusioned. I was getting old and what had I done with my life. I was tired and we were still hard up. I had been home for years by now and should have been moving out . Brenda had a child who would not let her out of his sight, at a time when her friends were getting back to work. This caused strain because the strong message she received through playcentre was to accept it and stay at home with him. There was no relief and some kind of childcare would have been the salvation for me with him. We all needed it as it was a strain on all of us. Throughout her years of childrearing playcentre had however filled a hole :

I was a Liason Officer but I was restless and wanted to be in a real job and I didn't consider playcentre a real job. I had moved a lot since I got married.

Doing some extra-mural courses through Massey University was a compromise but also a fulfilment as it gave privacy. I was very busy with the family at that time. P.T.A. and music lessons and the study was for me. When Brenda's youngest child was settled into school in the 1960's Brenda then felt that she could think about teaching again and moved into the workforce full-time. 
The experience of motherhood is different for women despite the common chores of childrearing. Economic circumstances alter the conditions (Wearing 1984). Educational and philosophical heritage influence the style (McKinlay 1983). However the lives of these women show that there were common values and particular economic and social circumstance that were to underpin the separate experiences of all the women in this study. These case studies show too that personal commitment varies. Various philosophical, economic or educational continua could be drawn and the women placed along accordingly, but life is is not so orderly and the lines cross.

\section{VOLUNTARY WORK AND WORKING FOR CHANGE}

Three of the women did not belong to any voluntary organisation or club during their childrearing years. A husband's opposition, a lack of time and a lack of interest, were the reasons given. For the other women their involvement included: the political - the peace movement; the educational - playcentre, Plunket, kindergarten and school committces, Plunket, Parents' Centre; religious - church women's groups; the rural - Country Women's Institute and the Women's Division of Federated Farmers. These activities were important but were also the first to be dropped under pressure, and inevitably came second to their husband's work or out of work activities. Elizabeth Wilson referred to the British women's organisations in the postwar years as serving the cause of "reasonable feminism" (1980:162), and the view was that tact and gentle persuasion would get women further than stridency. This was also the case in New Zealand. There was no explicit challenge to the structure of family life or to the ideal of separate spheres. The concern was to achieve security for women within the family rather than to challenge its structures in any way. Michelle Dominy argues in her analysis of older Pakeha women's involvement in the National Council of Women ${ }^{9}$, that the women were often motivated by an ideology of motherhood:

While traditionalist Pakeha women believed that their activities in the domestic sphere should be valued equally with those of men in the public sphere, they also believed that these activities should be maintained as separate and female (1985: 50).

This argument applies to the majority of women's organisation's during the 1950's and it is probable that the women who were the focus of Dominy's analysis were of the same generation that this study focusses on. While these women had become involved in work on behalf of women outside of the home, the major strategy was designed to protect the domestic primacy of women (1985: 58).

While there was lip service to the ideal of women's vicwpoint in political life, the reality was that women were expected to do this without lcaving the family. This can be seen, for example, in Brenda's involvement in the peace movement in the late 1940's and early

\footnotetext{
9 The National Council of Women (NCW) is an umbrella organisation for many women's community organisations.
} 
1950's. There were many strands of the peace movement (Grant 1986) but Brenda and her husband were part of the Campaign for Nuclear Disarmament (C.N.D.). Every year the various peace groups would merge their philosophical differences for a Hiroshima Day march. It was a day out for the family, but when it came to the real politics, only the men would march while the women would walk alongside with the children, or meet the men at the rally. The women and children went home alone while the men remained to plot politics in the pub. On hindsight Brenda was amused at the sexual politics of her activism, but at the time such a division of labour was not questioned. There was a contrast between this kind of supportive activism and the direct involvement of women in organisations that were specifically directed towards the well-being of mothers and children. Two case studies highlight the work of such organisations in effecting positive changes within an umbrella that did not appear to challenge the status quo.

\section{A Rural Lobby}

Winifred had had a life-time involvement with the Women's Division of Federated Farmers. She had been enrolled by her mother before she was married although her mother was a member of the Country Women's Institute, which was the rival rural organisation for women. It was intended that the family be represented in both. The Women's Division has been an effective lobby for women both within Federated Farmers and on its own behalf. It has a tradition of being more political than the Country Women's Institute's. The Women's Division has consistently lobbied governments for better educational and health services for rural families. It also had a realistic "do it yourself" philosophy and for example had set up its own housekeeper scheme for rural women who needed help ${ }^{10}$. Winifred talked about two projects that her Branch fought for during the 1950's which made a difference to local families. The school buses which collected children from the farms would not pick up children at more than half mile intervals. During the 1940's and 1950's lots of "rehab" farms 11 opened up in the high country valley where Winifred lived. Soon there were more children than the district had ever had. Through the efforts of the local Women's Division of Federated Farmers the Education Department was persuaded to alter its policy so that every child would be picked up at their gate and the route would be extended. This was not a fast procedure:

Your local branch had to send a petition to the provincial conference and then it would have to go to the annual conference and then you would go in a delegation to Parliament - but that wasn't me.

Success meant that Winifred did not have to give correspondence school lessons ${ }^{12}$ to her son who could catch a bus to school. Another endeavour was getting a District Nurse in the area. The baby boom in the valley created the need and gave the impetus. This time it needed more

10 In 1942 there had been approximately 100 housckeepers who had some 580 monthly engagements (Guy 1943).

11 Given to returning soldiers through the Rehabilitation Scheme.

12 These lessons were sent by the Correspondence School in Wellington to remote areas where children could not attend school. 
than the efforts of Federated Farmers and it finished up as a district appeal to the local Member of Parliament. They got their District Nursc.

Winifred did not see her work within Federated Farmers as political but nor was it "good works". It was a matter of fairness in getting services for rural women that city women took for granted. Encompassed within the conservative male politics of the Federated Farmers, the Women's Division has never been known for radicalism or stridency. They have always upheld traditional family values but within this framework have been active and astute in persuading governments to improve the education, health and welfare services for rural families.

\section{The Playcentre Way}

Jane became involved in playcentre in the early 1950's. Having been a teacher, and involved in a kindergarten mother's club and a Plunket mother's club she had experience and confidence in things educational. Her first child was raised with lashings of Truby King and four hourly feedings as I felt that it was the way to cultivate good habits. By the time the next child came I thought, this is stupid, I shall feed him when he is hungry. It was a relief to Jane when Dr. Spock's book arrived in New Zealand because it gave the go-ahead for her to be permissive. She felt some guilt about permissiveness particularly in areas like toilet training which were so different from her mother's or her neighbour's vicws. But the idea of playcentre which encouraged free expression and recognized individual differences in children coincided with Jane's own views which she had developed through experience. Jane was to start a playcentre in a working class urban area which already had a well established kindergarten.

There was this conflict and you had to really sell it to parents that they could run their own preschool. They believed that they should hand their child over to a teacher. We were something new. It was very rarely known and people didn't really understand at all what it was about. It was fairly difficult and there was a lot of unacceptance from kindergarten - why should we try and put up something else?

The focus of playcentre was ostensibly on the child, but it was also on women because mothers were empowered with knowing the most about their own child. Playcentre also empowered women with skills to run their own playcentres, and to train their own staff. In retrospect Jane sees the playcentre as feminist. Geraldine McDonald was to write that playcentre:

...represents in an institutionalized form the efforts of mothers to invest their role with value and to provide themselves with an activity which fits in with the desire of women to be employed in some worthwhile enterprise (1974:163).

Playcentre became a career for Jane in every sense:

I knew I was using my capabilities and it was an alternative, although if I had felt that I had needed to work to add to the budget I would have had no qualms. But I was getting the satisfaction. But I was bloody lucky because $D \_$allowed me. We could afford my voluntary activities and we must have spent pounds on petrol and my time - quick meals and 
quack clothng and all those things which meant that I wasn't being such a good householding mother.

At home Jane and her hushand shared domestic chores and childrearing in a way she knew was uncommon. Jane still saw the domestic sphere as her responsibility but saw herself as fortunate that she had married a man who helped. She would even go away for the weekend on playcentre work:

I still put my children first. Even when I went away for the weekend. I made sure that $D \quad k n e w$ what to have by the way of food and what their day would be like, and my concern as soon as I got home was "How did it go?" I didn't think that I had a right for them to let me go. That came a lot later.

Jane was aware that in relation to most women she was very lucky with her husband:

We would get a bit of a backlash at playcentre when women would say that they couldn't come any more because their husbands wouldn't let them. There was a lot of that. The same with taking office in the playcentre. "My husband wouldn't like me going out at nights". A lot of the women I had in training started to get ahead of their husbands in comprehension and that started to break marriages up. Although a lot of women held on because they didn't know how to get divorced. You didn't talk about broken marriages then.

Jane was living in a large state housing suburb without amenities and was involved in a number of community activities to get social amenities. She did not see her work as feminist at the time but had a strong feeling that while the men had their R.S.A. ${ }^{13}$ Clubs the women had nothing. Her work was to do something for the women and children. Jane saw and experienced disillusionment:
I think it was because we were in a State housing area. The people had been teenagers during the war and they expected good things to come from being a mother and having a good family and it didn't eventuate. There was still sheer slog - baking and sewing. We had to do it but they kept saying is this all there is in life. In their minds anyway. Even for me I remember once walking in a distracted way around the house under the pear tree thinking is this what I really wanted. I think that mentally I was really disarrayed. I suppose I pulled things together and I went on.

It was Betty Friedan who was to publicly pose the question "Is this all?" with the publication of The Feminine Mystique:

The problem lay buried, unspoken...It was a strange stirring, a sense of dissatisfaction, a yearning that women suffered...Each suburban wife struggled with it alonc. As she made the beds, shopped for groceries, matched the slip cover material, ate peanut butter sandwiches with her children, chauffeured Cub Scouts and Brownies, lay beside her husband at night, she was afraid to ask even of herself the silent question...(1963:13).

Not all the women came to see things this way. Betty Friedan was challenging values that enshrined a lifestyle these women had invested heavily in. But throughout the childrearing

13 Returned Servicemen's Association. 
years all of the women were making changes that brought increasing independence even though it was constrained within the primary roles of motherhood and marriage. For example getting a job, learning to drive a car, finding out what their husband earned, having some money of their own, arranging time to go out to an evening class, or assuming responsibility in a club, were important issues to these women These experiences created a consciousness of competence. The "do it yourself" ethic was turned into a consciousness of "I can do it". The growing independence began to create a climate in which the imbalance in inequality was gradually felt more acutely by women. This was to undermine the demarcation of power vested in the breadwinner within the family home, and the faulty security of the breadwinner was made more visible but not necessarily challenged. In the workforce however women's paid work was not so threatening. There was no equal pay and in an expanding workforce men and women were not competing for the same jobs or promotions. But as women began to assume the dual role of homemaker and worker the imbalance between the idyll of domestic imagery and the realities of the burden created the tension necessary for a more collective analysis of women's non-work. Amidst the consensus that women's place was in the home, the new ideological construction of women as "equal individuals" who could "choose freely" whether they married or had a career, or whether or not they worked, was a cautious bridge towards the later concepts of "freedom" and "rights" which were articulated in the political demands of the women's movement during the seventies.

Brenda summed up her generation of women with the statement We were aware that we were happy families as long as we played the game. That is what we talked about a lot. Brenda did "play the game" and still does but with some cynicism now. To Nell however "the game" is still valued, despite the acknowledgement that you women are able to live your own lives. For Nell the cost of women living their own lives and all the breakups was not worth altering the rules of the game she valued:

You have to get a balance of motherhood because they are females, between home life and bringing up children and work. Men can help this to work but there still has to be a balance of motherhood. There are too many choices now and this can cause failure. It is all right for the wife to have her job and I am all for that interest, but the mother must still maintain her role. For us it was clear cut roles. It is hard to dovetail now.

For women like Nell there had been security and fulfilment in "clear cut roles", but for some others "the game" had not worked according to the accepted rules. 


\section{SECTION TWO}

\section{A POSTWAR GENERATION OF DAUGHTERS AS MOTHERS, WORKERS AND WIVES \\ 1970-1985}

By 1970 the "daughters" of the postwar women had completed their education although several were to move back into the education system later. They were all in the workforce, were forming more permanent relationships and moving towards the childrearing years. Two women had already had a child by 1970 and for the rest the first child arrived during the 1970's. For these women there was no happening like a war to create an artificial baby "famine" or "boom", and in this sense the common experiences of these women through their childrearing years were less cohesive than for the postwar generation. The childhood setting of this second generation of women has been documented in the previous section, but Section Two shifts to the postwar daughters themselves who carried these childhood codes through to adulthood. These codes would be upheld, adapted, redefined or rejected amidst the changing economic, social and political circumstances from the 1960's onwards. 


\begin{tabular}{|c|c|c|c|c|c|c|}
\hline Name & Education & $\begin{array}{l}\text { Work Before } \\
\text { Children }\end{array}$ & $\begin{array}{l}\text { Number of } \\
\text { Children }\end{array}$ & $\begin{array}{c}\text { Occupation of } \\
\text { Husband }\end{array}$ & $\begin{array}{l}\text { Paid Work } \\
\text { while } \\
\text { Childrearing }\end{array}$ & $\begin{array}{c}\text { Unpaid } \\
\text { Community } \\
\text { Work }\end{array}$ \\
\hline $\begin{array}{l}\text { Adrienne } \\
\text { b. } 1948\end{array}$ & B.A & Social Worker & 3 & Mechanic & $\begin{array}{c}\text { Craft } \\
\text { Catering } \\
\text { Childcare } \\
\end{array}$ & $\begin{array}{l}\text { Pi.jocentre } \\
\text { Plunket }\end{array}$ \\
\hline $\begin{array}{l}\text { Delwyn } \\
\text { b. } 1950\end{array}$ & $\begin{array}{l}\text { 6th form } \\
\text { (later B.A.) }\end{array}$ & Nurse & 2 & Business & $\begin{array}{l}\text { Nurse } \\
\text { Teaching } \\
\text { Tutor }\end{array}$ & $\begin{array}{l}\text { Parents Centre } \\
\text { Playcentre }\end{array}$ \\
\hline $\begin{array}{l}\text { Penny } \\
\text { b. } 1946\end{array}$ & U.E. & $\begin{array}{l}\text { Waitress } \\
\text { Domestic } \\
\text { Factory }\end{array}$ & 3 & Electrician & $\begin{array}{c}\text { Factory } \\
\text { Community Work }\end{array}$ & $\begin{array}{c}\text { Playcentre } \\
\text { Political and } \\
\text { Community Groups }\end{array}$ \\
\hline $\begin{array}{l}\text { Carolyn } \\
\text { b. } 1947\end{array}$ & U.E. & Library & 1 & - & Library & $\begin{array}{c}\text { Union Work } \\
\text { Community Work }\end{array}$ \\
\hline $\begin{array}{l}\text { Beverly } \\
\text { b.1948 }\end{array}$ & 5th Form & $\begin{array}{l}\text { Office } \\
\text { Worker }\end{array}$ & 3 & Labourer & - & $\begin{array}{l}\text { Playcentre } \\
\text { Church }\end{array}$ \\
\hline $\begin{array}{l}\text { Pauline } \\
\text { b. } 1945\end{array}$ & School Certificate & $\begin{array}{l}\text { Office } \\
\text { Worker }\end{array}$ & 2 & $\begin{array}{l}\text { Own sales } \\
\text { business }\end{array}$ & $\begin{array}{l}\text { Husband's } \\
\text { Business }\end{array}$ & - \\
\hline $\begin{array}{l}\text { Sharon } \\
\text { b. } 1947\end{array}$ & U.E. & $\begin{array}{c}\text { Reception } \\
\text { Shop assistant }\end{array}$ & 2 & $\begin{array}{l}\text { Fitter and } \\
\text { Turner }\end{array}$ & $\begin{array}{c}\text { Spot welder } \\
\text { Barmaid } \\
\text { Library }\end{array}$ & Playcentre \\
\hline $\begin{array}{l}\text { Sheila } \\
\text { b. } 1958\end{array}$ & 5th Form & Reception & 3 & $\begin{array}{c}\text { Car } \\
\text { painter }\end{array}$ & $\begin{array}{l}\text { Childminder } \\
\text { Office }\end{array}$ & - \\
\hline $\begin{array}{l}\text { Denise } \\
\text { b. } 1946\end{array}$ & 4th Form & $\begin{array}{l}\text { Office } \\
\text { Worker }\end{array}$ & 3 & $\begin{array}{l}\text { Retail } \\
\text { manager }\end{array}$ & - & - \\
\hline $\begin{array}{l}\text { Elizabeth } \\
\text { b. } 1953\end{array}$ & 6th Form & Teacher & 3 & Teacher & Teaching & - \\
\hline $\begin{array}{l}\text { Racwyn } \\
\text { b. } 1948\end{array}$ & 4th Form & Factory & 5 & Sharemilker & Craft & - \\
\hline $\begin{array}{l}\text { Annette } \\
\text { b. } 1945\end{array}$ & $\begin{array}{c}\text { 4th Form } \\
\text { (Later B.A.) }\end{array}$ & $\begin{array}{c}\text { Factory } \\
\text { Office } \\
\text { Social Work }\end{array}$ & 2 & Research & - & Playcentre \\
\hline
\end{tabular}




\section{THE YEARS BETWEEN: $1960-1970$}

In the struggle between the old and the new, traditional and modern, virtue and vice, the 1960's appear as the key moment of transition, the decisive meeting place of conflicting values (Weeks 1985:18).

Popular opinion labels the 1960's as permissive in contrast with the earlier postwar years. In 1970, however, James Ritchie, Professor of Psychology at Waikato University, reflected back to declare that, "The sixties were about as permissive as the nineties were naughty. Something started in the sixties but I'm going to wait until the seventies to see how real the search for real experience really was" (Listener January 16 1970: 6). What did start in New Zealand were shifts in the perception of race, culture and class; more openness towards sexuality with more freely available contraceptives; a powerful and imported teen-age culture; a small "counter culture" that existed outside mainstream social and cultural traditions; and the brief expression of an ideal of a new utopia through liberation politics. These shifts which have since characterised the 1960's as radical, were identifiable and newsworthy because they were on the fringe and the older order which these shifts appeared to threaten, was still entrenched. James Ritchie suggested that, "The young in this sixties decade, as in others, have simply failed to realise the intrinsic inertia of the thing against which they are pushing" (Ibid 1970:6). Only one of the

$\therefore$ women in my sample lived a permissive life style and was active in radical politics during the 1960's. The lives of the other women appeared more mundane by comparison, but the impact of these protests against moral and political codes was still important. In some cases there was a rejection of the new, and an attempt to protect the older order. For most, however, the legacy of the 1960's was a gradual distancing from the old and a tentative accommodation to the new, but the mechanics and extent of this process was different for each woman.

By the time these women reached adulthood there had been a more generous economic investment in their childhood years in comparison to their mothers' lives, and they had broader options and opportunities available than their mothers would have dreamed of. Mary Ingham (1981) labeled British women born in the early postwar years as the "breakthrough generation" in that they were growing up in the forefront of the rapid social changes of the postwar period. During the 1960's there was more acknowledgement of the impact of these changes on New Zealand society, and a fresh analysis of the ills of society which had not disappeared despite increasing affluence and new social policies. 


\section{THE SOCIAL FACE}

New Zealand's population in the 1960 's grew from $2,300,000$ to $2,800,000$, but the birth rate began to fall after a steady upward climb from $1945^{1}$. The Government Statistician during this period blamed the advent of television in 1960 as the reason for the drop (Cumberland 1970), but the popularity of the contraceptive pill was probably more effective. A further factor that stemmed the population growth was a shift in the balance of immigration. As the baby boom children reached maturity the "brain drain" ${ }^{2}$ began and, as the immigration rate also dropped suddenly, by 1967 more people were leaving New Zealand than arriving. The drop in immigration was accompanied by a shift in the traditional pattern of immigration which had previously come from the European "home countries", and during the 1960's there were increasing numbers of migrants from the Pacific Islands. The influx of Pacific Islanders into the North Island urban areas coincided with the continuing move of rural Maoris into ihe cities. This generated a deeper consciousness of racial division in New Zealand society that would contradict the previous assumptions of harmonious race relations.

The growing awareness of racial division was accompanied by a new consciousness of class division (Dunstall 1981). Given the strength of New Zealand's egalitarian ethos the acknowledgement of class was a sensitive matter. Equal educational opportunity was still regarded as the key mechanism of breaking down class divisions, but a decade of National Government in the 1960's also encouraged a version of egalitarianism in which social mobility was to be achieved through economic opportunity and individual initiative. This was in contrast to the Labour Party's version of egalitarianism through collective safeguards of security. Regardless of Party perspective the decade saw a continuing growth of a middle class lifestyle, with increasing mobility, and rising expectations of standard of living. The fact that racial and class divisions were probably becoming more and not less evident was being tentatively acknowledged in the 1960's, but there were no official attempts to rethink the social pattern or to explore new solutions. In a reflective overview of the social policies of the decade Professor John Roberts of Victoria University stated that, "The years since 1960 could be characterised by strategies of more of the same" (Listener January 30th 1970:8). The fact that full employment continued throughout most of this period meant that there was little economic impetus to question the status quo.

\section{A YOUTH CULTURE}

When the 1960's ended they were labeled as the "the decade of the teenager", in that the 10-24 age group made up one third of the population in New Zealand (Cumberland 1970). This bulge,

\footnotetext{
1

There was a sharp decline in the annual population growth from $2.2 \%$ in 1960 to $0.8 \%$ by 1969. The birth rate had dropped from 27 to 22 per thousand for Pakehas and from 47 to 37 per thousand for Maoris.

2 This was encouraged also by the increasing popularity of travel to Australia, America and Europe by young people.
} 
which had been created by the postwar baby boom, followed on from the emergence of "the teenager" as a new social category in postwar society. The teenager was both more dependent and more independent than before. Increasing educational opportunities had extended the years of dependency of the young on parents, but the increasing affluence allowed them more economic independence. Full employment and increasing standards of living meant that, unlike the earlier generation, these teenagers were not so often forced to give up school to help support the family by either working at home or outside of it. At the same time, however, full employment often offered the more enticing option of economic independence, in contrast to staying on to gain qualifications at school.

The distinctiveness of a teenage culture had become evident in the 1950's with the girl "widgie", the boy "bodgie" and the "teddy boy" and his girl. The defiance and and strangeness of these cults haci already become the focus of analysis and disapproval (Crowther 1957; Manning 1958), but a consumer market in clothing and entertainment was awaiting the spending power of the large population of "teenyboppers" of the 1960's. These sub-cultures, fed via the media from America and Britain into every home, had their own kind of music, meeting places and idols - mostly male. A failure to conform to the dictates of the culture brought the label of being "square", like everyone over the age of twenty. For girls what you actually did was less important than what you looked like, who you went with, and where you went. Thus presenting the right image was the crucial but painful task. Sandra Coney wrote in recollection:

Never before had women endured an image that required such a resource to artifice. The desired effect was to look as nearly as possible like a Barbie doll. Her hair was dyed, teased and lacquered into something approximating the nylon tresses of a doll...Each night a whole generation of teenagers lowered on their pillows heads bristling with hair rollers (1986:253).

Such artificiality in women's appearance was in fact not uncommon if examined historically and cross culturally, but coming after the "austerity" look of the 1940's and the more "natural" look of the 1950's, the 1960's new lacquered and polished look was a contrast. Teenage femininity was centred around the acquisition of glamour and charm, "making the best of your assets", all of which would attract and keep men (Johnson n.d; Coney 1986). Charm courses for girls were popular club activities ${ }^{3}$. Even the schools joined the bandwagon and as Denise recalled, the distinctiveness of the boys' masculine culture and the girls' feminine culture was reinforced.

While the boys did Cadet training at school they had to find something for the girls to do so every year we had two weeks when they taught us how to put on make up, do our hair, what colours to wear and jobs that girls could do. We were told to be natural but there seemed a lot to learn. We also did a lot of talking about sex and boys. Some of this was very useful information because nobody else told me much.

${ }^{3}$ For example the Y.W.C.A. ran "charm" courses and "elegance" courses.These are described by Sandra Coney (1986). 
Women's magazines shifted their image to appeal to a younger generation but the ideal of glamour and charm in their pages reinforced the traditional role of women even though it was promoted in an idiom of freedom and choice (Winship 1981). Autonomy was constructed around being able to choose but was akin to conformity as there were limited variations on the right image. Magazine pages gave prescriptions for clothing, hair and make-up that were a rejection of adult conformity and that would accentuate a girls appearance as a "dolly-bird chick", but amidst all the fun of exercising this new freedom the end was still to catch a man. The Woman's Weekly was slower to respond to this new market but American magazines like Seventeen and Britain's Honey filled the gap.

There was however a cost involved in constructing the right image of femininity, and Raewyn's experiences showed that wages for working class girls were hardly sufficient for the life of independence, charm and glamour that the magazines idealised.
My first job was at Woolworths. The pay wasn't that good and at that age you were looking in windows at all the things you wanted to buy and you are thinking that you can't afford them. I left Woolworths and went to work in a factory doing speakers and coils and wiring T.V.'s. It wasn't much better.

The teenage years for girls were contradictory because the model of growing up was a masculine one (Johnson n.d). Adolescence was defined as a time in which children moved away from dependence on their parents towards adult independence, yet the ideology of the teenage femininity led directly towards marriage and dependence. For girls, evidence of a successful transition towards adulthood was thus measured in their ability to attract men. For example, Barrington and Gray (1981) did not anticipate the large number of "Smith Women" in this generation who had no opportunity to experience any kind of autonomy between dependence on their parents and dependence in marriage. The task of attracting men was to dominate the teenage years of many of the women in this study. The first step was to be "going out with boys", then the task was to gain a "steady", where for the women anyway, there was ideally some kind of ownership commitment which excluded other relationships. The next step was hopefully for the "steady" to become a "fiance". However, keeping a steady boyfriend could be a time consuming activity which, as Denise describes, left little time for anything else:

Well I had all my boyfriends and besides going to work they took up all my time. You went to work and you came home and at weekends you went out with your boyfriend. If he played soccer you went out and watched him. Washing your hair and doing your make-up took up a lot of time and you might see him during the week too.

Young women like Pauline felt the pressure of keeping a "steady" boyfriend. There was the dilemma of being available and being seen to be attractive to men, but not being seen as "over used" before settling down:

I had lots and lots of boyfriends in fact I was never without one. But I never had a steady boyfriend for any length of time. I would get sick of them. But I thought there was something wrong with me because I could never find a boy who suited me. You would go out with him for a time and you would think he was dreadful and not what I wanted. But then you 
were left out if you didn't have a boyfriend. At 20 I was already being told that I was going to be an old maid and would be on the shelf because I had no steady boyfriend.

Helen: How did you feel about that?

Well I remember at 20 taking out an insurance policy in case I never married. I took it out just in case I had to fend for myself. I thought it was better to do that than to accept any person just to get married.

The dominant concern for many girls/women like Pauline, was to ensure their future security by their ability to attract men, even if alongside this quest they were continuing education and/or establishing economic independence in the workplace. Indeed the latter quest could be an asset in attracting men, or a fallback position if the women failed. However, these years were particularly painful for girls and women who did not feel they could attract boyfriends, and who did not perceive any satisfactory identity in being a single woman. Sharon felt herself to be unattractive, with no identity as a wuman until she got a boyfriend:

I always remember that I never felt myself as attractive and the boys in our class had a poll of who were the great girls and I was near the bottom of the list. I remember one boy who used to hang around me. He put me on his list very low too and I thought, "You hang around me but I am not on the list". I remember that really hurt. I would have liked to have gone out with boys, but I didn't. It even took me much longer to have a bra than anybody else. When I was seventeen I started to go out with boys and that became the most important thing to me than anything else. More important than study and so I left Teachers' College to work in a shop which made it easier.

This pattern in which women gave a priority to their relationships with men was also seen amongst the "Smith Women" and was evidence of women's early adaptation to their future role as wives and mothers (Barrington 1982). For example the "Smith Women's" early job choices during the teenage years were often affected by dating patterns and the women gave a priority to fostering relationships with men before promotion or extra training opportunities at work. The early establishment of this pattern undoubtably made it easier for the priority that women in the workforce gave later to being a mother. Rosemary Novitz's (1976) research showed that there was a consistent tendency for women in employment to see the demands of their role as mother as the most important determinant of their employment behaviour in relation to the kind of work chosen, the hours worked and the promotion sought. Thus by the motherhood years the pattern of adaptation was well established.

\section{AN IDEOLOGY OF EQUAL OPPORTUNITY}

The way we bring up girls - the goals set for them are contradictory...For fifteen years she is officially encouraged to compete with boys in the school room...and then our curious system insists that she fall in love with a potential husband (Bettelheim 1962:121).

The women in this study may have been participants of the "breakthrough generation" (Ingham 1981) but they had been reared amidst two codes of expectations: that women had a right to equality, opportunity and independence, and that women must attract men to ensure their future economic security. Previous chapters have shown how the lives of the older women were 
situated within a similar contradiction, but in their case the balance was heavily tipped towards a dependence on men rather than independence. During the 1960's there was a gradual shift towards the latter. The mechanisms of dependence, however, did not necessarily lessen but as in the teenage culture the quest for security in men was hidden behind a veneer of freedom and opportunity. In her book Living Contradictions (1982), Joanne Michael described the mixed messages that American women of this generation received as they grew up: that they would be independent and have a career, and that they would follow also the traditional pattern and marry, have a home and family. But Michael argued that few girls were given the necessary confidence, resources and support systems to combine both, and that the mechanisms for managing both were hazy and unrealistic.

Sue Middleton believes that New Zealand's postwar education system also embodied these contradictory prescriptions for girls:

The postwar woman then, was to experience in her schooling a set of cultural practices which were based on the assumptions of both a liberal ideology of equality of opportunity and at the same time an ideology of domestic femininity (in which) women's true role economically was a biological and social reproducer...(1985a:3).

C.E. Beeby $(1986)^{4}$, who was a key person in shaping the postwar education policy, explained later that the postwar expression of the ideology of equal educational opportunities arose from the depression years. The blueprint had been outlined in the Thomas Report (1943) and equal educational opportunity rekindled again the possibilities of realising New Zealand's egalitarian ideal. The school curriculum was ostensibly the same for boys and girls, but girls were still tracked along a separate pathway (Middleton 1985b; Fry 1986). Girls got more education than ever before, but more boys went to university; there were considerable differences in the subjects taken, qualifications gained, access to resources, and even at the new postwar coeducational schools that the Thomas Report had recommended, the sexes were kept firmly apart both in class and at play (Fry 1986) ${ }^{5}$. In reflecting on this postwar education policy, which later came under attack from feminist critique (Deem 1978; Spender and Sarah 1980), and New Zealand research (Abigail 1983), C.E. Beeby was to state:

In our call for equality of opportunity we too readily assumed that nearly everybody who was given the opportunity would take advantage of it...We did not even realise, for instance, that the average girl did not have the same opportunities as the average boy simply because less was expected of girls both at school and at work (N.Z.L. November 8 1986:54).

${ }^{4}$ C.E. Beeby was the Director General of Education 1940 - 1960.

5

In A Study of the Education of Girls in New Zealand (National Advisory Council on the Employment of Women, Wellington, 1969 ) it was reported that in 1965, 2,321 girls stayed for a fifth year at secondary school compared with 4,374 boys. This Report also noted that girls were taking more subjects for School Certificate which could not be advanced to University Entrance, and that there were significant differences in the numbers of boys and girls taking mathematics and sciences (cited Fry 1986). 
Subsequent New Zealand research (Abigail 1983) was to show that these lesser expectations for girls came from both within and outside of the school system, and was reinforced strongly through peer pressure (Jones 1985). Yet the myth of equal opportunity through education was still powerful because it was seen to work for some. More women were able to move beyond their working class background and the gap between the achievements of boys and girls at school did begin to narrow. For example Penny's access to education provided an escape from a family that was under emotional and financial stress.

\section{My education had a dramatic impact on me. It was the one thing I really liked.The first year I never said a word at school just in case I said the wrong thing...I will never forget the day I realized that I was good at school work. We were being put into queues for going into Standard One. This boy said, "Oh this must be the A stream because Penny's there". and I started to realise.}

Penny remembered her primary school as being rough, and there being insufficient teachers or furniture to cope with the numbers of children, but she then won a scholarship that sent her to a prestigous private girls' secondary school.This environment was competitive, but Penny found that she also was competitive and enjoyed it. Nevertheless the transition was not always easy and Penny experienced a clash in expectations. Those set for her by the school were much higher than those of her working class background. For example, she wanted to be a kindergarten teacher:

\section{$I$ was rubbished when I raised that at school. I was sent off to Vocational Guidance who decided I could be in the diplomatic service or I could be a lawyer.}

Penny saw these as too extraordinary and distant from her home background and her own view of herself. She entered neither of these careers, but her story typified a new confidence at the time that "girls can do anything" and that class origins should be no barrier in the education system. As Beeby had stated, the belief was that opportunity was the key to equality.

A more typical and traditional opening for educated girls was teaching. By the 1960's the Department of Education was hoping to ease the teacher shortage by recruiting the first echelons of the baby boom children. The Currie Commission recommended a recruitment target of "one sixth former in two" (1962:.585) and Sharon was one of them:

I didn't know what I wanted. I didn't know what I was good at. Everyone else went to Teachers College and so I went to Teachers' College. It would have been better if I hadn't.

In Sharon's 1963 sixth form class, the Department went above its target as nearly all the sixth form girls went to Teachers' College leaving a few swots and most of the boys who stayed on to the seventh form because they were going to university.

In a way we were forced. There was little option and I was so much younger. I was only fifteen when I went for the interview.

Whil hitanueargacatiactadcantin was a crucial factor in opening up opportunities for girls, not all girls benefited, and for the thirteen younger women in this study, upward mobility through marriage and their husband's career still provided a much faster track than the 
acquisition of educational qualifications for themselves. Despite the high value being placed on education for all, school for some girls was something you suffered and left as soon as possible ${ }^{6}$. This showed a shift in attitude from the older women in this study who more often felt that adverse circumstances had deprived them of getting more education. Several of the younger women felt alienated, or did not cope and were to leave as soon as they turned fifteen. Education was an end in itself, and was not seen as providing self-fulfilment or as a means towards further opportunities.

Denise: I never tried hard at school. I don't think a lot of people did. There were always such a lot of pupils in the class when we were at school and I always felt that we never got the individual attention. You were just one of a huge number and it was survival of the fittest.

Raewyn: School didn't really appeal to me that much. When I was younger my only thoughts were to get married and have kids and bring up a family. I should have looked at something else first.Well I was only there, for eight months. I was a bit behind in school. I thought I might be a Karitane nurse but that meant staying on at school and that was no good.

Annette: I Ifell behind. That started a strong inferiority complex as far as my educational ability. I never really felt that I could cope with the work...By the time I got into the fifth form I felt that I had completely come to the end of coping with the school system and begged to leave school.

With full employment the lack of school qualifications was no barrier to getting a job, and five of the women in this study left school without qualifications. Jobs were plentiful but none of the women found any long term satisfaction, and like the "Smith Women", changing jobs each year became a way of breaking the boredom and filling in the time before marriage and children broke the cycle. There was disillusionment, as Annette recalled.

\begin{abstract}
I hated work because it didn't offer the glamour that I hoped it would. I went into a flat with some other girls but could barely manage it financially so it was a life of drifting from one accommodation to another and one job to another. Most of the wages went into staying alive: food clothing and accommodation...I wanted a male companion. Someone to go out in the evening with and I was very conscious of the fact that most girls of my age had men. But I just didn't want to go with anyone.
\end{abstract}

Annette was not only caught in a gender trap of working in low paid servicing jobs done exclusively by women, but also in the age trap of being paid youth rates, which in many occupations affected both male and female workers under the age of twenty-one.

There were opportunities in the workforce for girls but not equal opportunities. Public servants had equal pay but this was not the case in the private sector. The imbalance in opportunities between men and women in the workforce was noted but during these years was not a priority issue. However there was an increasing consciousness of the idea of careers for girls as opposed to a just getting a job. The notion of a career was partly influenced by such vocational jobs as teaching or nursing that had a sense of "calling" about them or involved some kind of specialised training, but there was also the idea that a career had some long term

\footnotetext{
${ }^{6}$ The school leaving age was fifteen years, only one year later than when the older women were at school.
} 
prospect to it more akin to men's role in the workplace. It was only the educated women in this sample who defined their work as a career, and although in each case their "career" was shortlived there was a view that it was a career rather than a job because the vocation could be picked up again later. So, for example, a girl who chose teaching as a job would regard herself as a teacher even when she was at home as a full-time mother. By comparison the girls who went into shop, factory or cleaning work did not appear to carry the identity beyond their time in the job. Careers for girls were offered more options, in comparison to the limited options that their mothers had had. The variety of jobs had increased but the gender segregation of such work was still strong. Jobs or careers for girls were seen in the main,as short term experiences before the transistion to motherhood (NACEW 1969), and the promises of security within marriage. Girls entered the workforce with few long term strategies although careers that involved some training were viewed as an investment and something to return to when the children were older. The work expectations of boys had their own sexual tracking, but as Mary Ingham noted in the English education system, there was a difference in expectation:

(The boys) knew from the start that they would have to shape their own lives...The pressure on them was to make positive, decisive choices, whereas we (girls) could cushion ourselves with the hope that the future would take care of itself (1981:80).

The traditional sexual division of labour in the workplace placed most women in domestic, servicing, educational and clerical occupations. The women in this study who left school without qualifications went into factory, domestic or retail work. Those that stayed on to get their school certificate went into nursing or secretarial work, and those who completed the 6th form went teaching. Penny and Adrienne went on to university, although Penny later left to work as a waitress. Outside of this pattern, there were Sharon who had a brief experience working as a spot welder and Raewyn who worked on the farm alongside her husband. Educational backgecund would also sort the boys out in a range of possible occupations, but the key to understanding women's work experiences was the narrow range of occupations that women moved in by comparison with men, and where there was mixing within an occupation like teaching or the public service, the obvious hierarchial divisions which very soon separated men from women (Whitcombe 1980; Holt 1982).

\section{PAULINE - from office girl to receptionist}

Pauline came from a working class family and admitted that she did not have high aspirations when she left school, although getting a job was important and so was doing the best I could. The boredom of her first experience as an office junior as a fetch and carry person was sufficient impetus to make sure that she did not stay there too long.

I applied for a job for a typist in a warehouse and I was pleased to get that and I enjoyed it. I must have been there about three years and they asked me if I would do the book keeping machine in the main office.I was really the top girl then. Later I applied for a job at Broadcasting which was a big achievement in those days as fifty people applied. It 
was considered a plum job at the time. It was reception work and I was thrilled to get that job. I really enjoyed it.

At this stage Pauline's aspirations were side-tracked by the possibility of marriage:

I really felt I had achieved a lot by getting that position. I would have gone further if at that stage I had not met $D$ . I felt he was the man I would marry and the idea of a career went out the door.

Upon marriage Pauline gave up her job to go into business with her husband. This became a profitable business but it also became her husband's business which she helped to build rather than her own career. The reason underlying this shift was that she saw her future security better insured by investing in her husband than herself. This was a view reminiscent of the older women in this study, but still strong in the 1960's as opposed to the newer view of women maintaining an investment in themselves. By the 1960's women did not give up work when they married, but the responsibilities of marriage, along with an assurance of future finan rial security dampened the drive for long term job prospects or career satisfaction (Barrington 1982).

\section{DELWYN - student nurse to nursing sister}

Delwyn grew up with an image of her mother as an independent career woman. Her mother was divorced and supported the family with a small business.

She combined motherhood and a career...She ran the place like clockwork and the only things she didn't do really was run off to schools and join committees. She didn't do the traditional motherly things.

These "traditional motherly things" outside of the home which Delwyn linked to the role of a "real mother" were unpaid voluntary work, the mainstay of many New Zealand institutions. That Delwyn's mother had a full-time career made her different, but unlike married women who worked full-time, Delwyn's mother was still regarded as a good mother even though she did not do the traditional things. In the face of adversity she was seen to be combining both a mother's and father's responsibilities:

Other people would say, "You have a good mother. She provides for you and works long hours". Especially as I got older I felt obliged as soon as I could in a practical sense to become upwardly mobile and nursing was one way of doing it.

Delwyn would have liked to have been a vetinarian but at the time it seemed impossible as her mother was nearing retirement, and I thought it was time I made my own contribution. Nursing was also an acceptable way to leave the home background she felt stifled in.

It provided me with shelter and gave me that bridge. I didn't want to go flatting ${ }^{7}$ - being in the mid sixties it was the flower power and hippies and all that and I wasn't at all impressed with that. I wasn't sure as one could get a rotten name.

Helen: At that stage of your life did you have any visions of where you were going?

7 Flatting in shared houscholds was seen as an intermediate step between living at home with parents and marriage. In the 1960's these households would generally have been sexually segregated, but by the early 1970's mixed flatting was becoming more common. 


\begin{abstract}
I was going to climb the skies and go as far as I could in nursing. I was going to become a Sister. I wasn't going in there to become half baked and by twenty-one I was a Sister which was a very young age in which to have quite a lot of responsibility
\end{abstract}

In an unusual move for a twenty-one year old woman, Delwyn bought a section as an investment in her future in case she did not marry, but soon afterwards she met her husband. They built a house on her section, got married, and she decided to start a family immediately. Delwyn had achicved her ambition to be a Nursing Sister, albeit briefly, and she saw motherhood as the new challenge. For both Pauline and Delwyn, marriage curtailed and ended their carcers in which they had been successful, and neither of the women again achieved the same level of responsibility or independence. It was not only the belief in the security cushion of marriage that caused women to opt out of opportunities, or the reluctance of women to appear more successful than their men, but there were still codes for women that prevented the mixing of sexuality and careers. Student nurses or teachers were expelled from training if they married, and as Delwyn described, if student nurses wanted to succeed they had to choose between the job or boys:

It was well known that if you became engaged in your final year you were failed so you didn't announce having designs on any boy. I cut off all social life. In fact there was no social life. If you were really ambitious as a nurse your social life went by the board. You didn't have boyfriends and you didn't go out.

Those women who had boyfriends or were married were seen not to be serious about their work. Young married teachers were often asked by the school inspectors who graded their work about their motherhood plans as if it was not worth giving an intending mother a good grading. There was, as Sue Middleton (1985b) described a conflict between "intellectuality and sexuality" and this worked against the belief of equal opportunity. Middleton's study showed that this conflict often led to the abandonment of education or career training in favour of an early marriage or explicit sexuality, because the women often sought to establish "sexual and emotional security" before they could went on to further study or careers. The effect of this double life did not necessarily end in a commitment to marriage and family, and several of these women attempted to come back to their careers or to get more education.

\title{
A SEXUAL REVOLUTION
}

For women the sexual "liberation" of the 1960's was more apparent than real...It is therefore not surprising that by the end of the sixties strong feminist criticism of the so called sexual liberation of the decade were beginning to appear (Dann 1985a:83).

The 1960's brought vivid displays of sexuality in commercial advertising, dress and in the entertainment world of the pop star. This new visibility of sex was evidence of a newer code of sexual freedom. The women in this study were at the cutting edge of this shift and had to accommodate the dictates of an older code which preached sexual control. The prescription of sexuality dictated by the church, the medical and education professions followed the traditional 
code of virginity until marriage, with girls/women having the responsibility to ensure that boys/men did not "go too far" (Dept of Health 1955a). This had been sternly reinforced only a few years earlier in the recommendations from the Mazengarb Report (1954). This code had always been transgressed but the so called sexual revolution was to challenge such repression and to acknowledge the "transgression" as as act of freedom. The new code of sexuality was divorced from marriage and reproduction, and sex without commitment was in order. The maxim was based on the pleasure principle that, "if it feels good it's all right". This was in accord with a growing view that repression was out of fashion (Dann 1985a). But women found themselves without security (Firestone 1971; Game and Pringle 1979), and new expectations of sexual performance and availability had their own kind of entrapment to play the role of a "dolly-bird chick" as a cute and playful off-sider of men. Theoretically the new codes of sexuality represented a shift from the view that it was necessary to control sexuality to a doctrine of sexual freedom, and the works of Wilhelm Reich (1962) and Herbert Marcuse (1961) became the popular texts for those seeking intellectual justification. Reich believed that the "authoritarian family" was the main mechanism of sexual repression, thus sexual freedom was a political act because sexual repression created adults who were passive supporters of authoritarianism. Marcuse turned around an older belief that sexual repression was necessary to control society to argue that in a time of prosperity, happiness and sexual freedom were possible.

By the 1960's there was evidence that attitudes towards divorce, birth control, unmarried pregnancy, homosexuality, extra-marital and pre-marital sex were slowly relaxing. The media began addressing these issues with less coyness and less moral censure than in earlier years. Trends towards acceptance had begun earlier, but the 1960's hastened the process and highlighted the issues so that during the 1970's successive governments had to devise legislation to deal with liberalisation. At a practical level the sexual revolution for women was more to do with technology as the contraceptive pill became available. Contraceptive technology had already begun to change the lives of the older women in relation to their work, marriage and childrearing, but the ease and security of the pill was to make a more dramatic impact on their "daughter's" lives. Mary O'Brien took a global view of the new contracepitve technology and likened this new freedom for women as "a world historical event" in the sense that it "creates a transformation in human consciousness of human relations with the natural world which must as it were be renegotiated or...mediated" (1981:22). This "renegotiation" was to confront the younger women as it coincided in time with their own teenage years of awakening sexuality. The messages were contradictory in that there was still an official code of virginity until marriage, yet the sexual revolution called for their sexual availability. Mary Ingham (1981) described the tension of this double standard amongst a group of British women - of keeping up appearances of pre-marital virginity to parents but being seen as sexually active and available by one's friends. Virginity was both an embarrassment and a prize, and 
determining how far to go, how fast and with whom was a process that required a combination of skill and force. Official school, church and parental guide-lines about sex said "don't", but the real dilemmas of this process were not addressed. Few girls/women were prepared to commit themselves wholly to permissiveness or prudery as the label of both "whore" and "virgin" were derogatory. For most of the women in this study the strategy of these years was one of surreptitious heterosexual activity that was hidden from parents and indeed sometimes from friends, because "having a reputation" or being seen as "too readily available" were seen for most of the women, as possibly decreasing rather than increasing their marriage opportunities. For example Delwyn told how she avoided flatting in case she got a rotten name. There was often a sense of relief when marriage allowed the subterfuge to end and one's sexuality, albeit restricted, was sanctioned in marriage. The women in this study accommodated to this double standard and although the experiences of the women are selective the following case studies show some strategies of managing.

\section{PENNY - a Dermissive lifestyle}

During her early teenage years Penny became aware that there were different attitudes to sexuality between home and school. At the upper class girls' private school she had won a scholarship to the girl boarders had little access to boys, and sex was a subject which produced giggling and twittering. Out of school Penny went around in a group that went to country dances with boys from the freezing works. Here there was a distinction between the good girls and the bad girls:

Those that went into individual relationships were those who were into heavy sex.

"Heavy sex", as opposed to just having sex presupposed some kind of regularity and maybe commitment and was consequently dangerous if you wanted to avoid responsibility, but as Penny stated:

We knew that some went away to have babies and to have abortions so we were aware of the dangers of getting heavily involved.

When Penny went to university in 1963 she became involved in the Student Christian Movement (S.C.M.) and the New Left Club. The liberal ideals of these organisations encouraged sexual freedom but it was not sexual license.

If you were involved with someone it became a sexual relationship and there was some attempt at contraception. I got into some heavy relationships but I tended to fall in and out of love according to my politics of the time.

Penny kept this life apart from her family, and would rarely take her partners home, so that her parents had no idea that she was sexually active. Contraception was available but haphazardly used. And for any of Penny's friends who got pregnant a wedding was hastily arranged, and as Penny recalled outside pressure from families would come in to make things respectable. When Penny left home she became aware of a more bohemian fringe: 
The Art School set and the overlanders 8 and they did really sleep around.

I started going around in that scene and I had a few guys who I really

liked but I felt a bit on the outside really.

It was amongst this small bohemian fringe that the sexual revolution in New Zealand found real expression. Women were sexually available and there was no expectation of commitment from men with marriage or with the advent of pregnancy. This attitude has been attacked in feminist critique (Firestone 1971; Dann 1985a) as a sexual revolution which was male oriented and which subordinated women. Conversely, Penny believed that this lack of commitment by men began to generate a new collective consciousness amongst women.

There was a strong strand of women sticking together and it was acknowledged that a woman had a right to say no.

The difference between the liberal and bohemian versions of the sexual revolution represented different views of the male-fcmale relationships. In the first, men still had a responsibility to provide security for women if they got pregnant, and for women the hidden agenda of premarital sex was to get a future partner. In the bohemian version, women who got pregnant "got rid of it" through adoption or abortion or kept the child themselves with no expectation of support. In this framework there was, ideally, no agenda of using sex to get a man but rather that sex was only $O K$ if you didn't have an agenda - if it feels good you do it.

\section{ADRIENNE - Sexual subterfuge}

Adrienne was brought up on a farm and went to boarding school for her secondary education. There was a strong belief in virginity, and the one girl who was known to have slept with a boy was viewed with disgust by the other girls. The dangers of losing one's virginity were demonstrated by one girl who was expelled when she got pregnant but after much debate at the school was allowed discreetly back to school to sit her University Entrance exams. It may not have been acceptable to be sexually active while still at school, but this was not necessarily a code they expected to adhere to for long. Adrienne and her friends did not intend to remain virgins. The code however between morality or immorality was whether sex was with a steady boyfriend; "sleeping around", in the sense of having a number of partners at once or too many in succession, was not condoned. The ideal of sex and committment were entwined.

The school encouraged the girls to have careers and Adrienne and her friends expected to establish their careers and travel before they married. At eighteen Adrienne went to live in a university hostel:

I lived a million years and had a $360^{\circ}$ turnaround in attitudes. There was lots of talk and talk and talk, and we had not been allowed to think before. It had been all suppressed. I discovered that I was a Liberal and that everyone had rights. I discovered that there was another Party apart from the National Party...I grew my hair long. It was the time of

\footnotetext{
8 These were people who had traveled back overland from Europe through Asia and India. This was possible until about 1972 when the border was closed between India and Pakistan.
} 
Vietnam and I went on demos and marches. We would go and listen to Tim Shadbolt. 9

Adrienne went on the pill. She went to Dr. Erich Geiringer ${ }^{10}$ who would prescribe the pill without charge to women students. Adrienne and her friends had what she described as steady sexual relationships which often ended in marriage - there was no real sleeping around. Adrienne had a long term boyfriend but contraception was crucial, and twice Adrienne used a "morning after" pill as a further protection against pregnancy. It was not the bad girls who got pregnant but the stupid ones, was what we used to say. After a year in the hostel Adrienne went flatting with a group of women friends whose sexual lifestyle was similar:

If anyone wanted to have a guy stay over you had to let the others know. None of our parents knew although they would often visit. There were discreet codes used if your parents rang up and you were away for the night and we always knew how to get hold of one another. This code was not broken.

Living amongst other women during these early years of sexual experience had a positive spin off as the women began to talk to each other about the problems they might be having:

We came to know more about our own bodies. For example we found out by accident that we all got cystitis and it was a tremendous relief to talk about it. We had all suffered in silence before and felt embarrassed. I look back and see that as an undercurrent of what later became the women's movement.

This kind of communication may account in part for the more open attitude towards sexuality and health by the younger women. In comparison the older women's first sexual experiences were either as married women, or kept too discreet to talk with girl friends about. Eventually Adrienne went to live with the man she was going to marry but still her parents did not know. Even at the time of this interview twenty years later, Adrienne was most concerned that her mother should never realise this. To Adrienne there was a double standard of active sexuality existing alongside the appearance of virginity. Pre-marital sex was acceptable to Adrienne as long as it was carefully controlled by contraception, there were assurances of security, and parents were not upset. As with her friends this subterfuge ended with all the trappings of the church white wedding.

\section{BEVERLY AND ANNETTE - security in virginity}

Beverly and Annette were both virgins when they married. Both were wary of the excesses that they saw in the more explicit sexuality of the 1960's. They held the view that they would not marry a man who did not respect their virginity. Remaining a virgin was both a test of his worthiness as a man and a reward for waiting.

Beverly's parents saw themselves as her keeper until she married and thus marriage was the reason that you left home. The whole family was deeply involved in church activities and

\footnotetext{
9 Tim Shadbolt was a student radical leader.

10 Dr Geiringer was known at the time for being more liberal than most most doctors.
} 
any suggestion of pre-marital sex was taboo. At the age of eighteen her parents had to shift to another town but her parents would not allow Beverly to remain in Auckland where she had a boyfriend and a job:

Well in those days you didn't go flatting. There was no thought of it in my family. I felt rebellious about having to move at eighteen because I was madly in love with someone. I had lots of boyfriends. I was always very much for boyfriends.

Beverly went with her parents and she soon met another man, fell in love again, and was to marry him when she was twenty. During her engagement Beverly's parents continued to monitor the relationship carefully. She was not allowed to go away with her fiance, even to stay overnight at her sister's house. Beverly felt that she was treated harshly in comparison with her younger brother who was allowed a good deal more freedom. Remaining a virgin was her own choice, but Beverly felt irritated at her parents' policing Marriage was an escape:

\begin{abstract}
We were completely green when we got married which was very nice. We had fun learning and that is quite good. But it was hard in the first year getting used to each other and understanding each other, but there was obviously a very deep bond from the beginning.
\end{abstract}

Annette did not marry until her early thirties. In the early years Annette was a virgin because she had no boyfriends and she saw herself as unattractive to men. She left home at eighteen hoping to widen her horizons but this was not easy. In her late twenties she started to meet more men. Her decision still to remain celibate was partly affected by her religious values, but more specifically it stemmed from fears of insecurity if she gave in to men. She had seen several friends get into trouble:

I had a number of friends who were going through the whole thing of wanting to be married. They were having all sorts of relationships with all sorts of men. All sorts of things that I thought were completely unwise. Even though I could understand their feelings as I was going through the same...Because I had seen some of the unhappiness of my friends getting into such situations I determined to be strong and steer clear of it as much as possible.

Sticking to traditional values of sexuality and waiting for Mr Right to come was a long and lonely wait, as Annette had an image of herself as a wife and mother. But for Annette, sex went hand in hand with the security of marriage. These were attitudes reinforced by the church environment which provided a lot of her social life. Marriage at aged thirty was a long awaited relief, and for Annette did combine the sexual, emotional and economic security she had believed to be worth waiting for.

Beverly and Annette were representative of women who adhered to the official moral codes of sexuality confined to marriage. For Beverly an early marriage was the solution and it allowed her to leave home. For Annette virginity was a conscious choice between a moral code that dictated a life of celibacy and the risks and insecurity that Annette saw in pre-marital sex.

SHARON - it's not the bad girls but the stupid ones 
Sharon got pregnant at cighteen. Unmarried pregnancy was not a new phenomena but during the 1960 's the illegitimacy rate crept up as pre-marital sex increased. Unmarried pregnancy was however still strongly condemned and to be hidden ${ }^{11}$. The women in this study could tick off numbers of friends who tragically left school, left work, and secretly left town to have their babies, then returned and tried to act as if it had never happened. The new sexual code, however, assumed that everybody used contraception and that it was available. Subsequent research (Cameron 1984) has shown the knowledge of contraception amongst teenagers to be inaccurate, confused, and reliant on the erroneous ideas of the peer group. During the 1960's the pill undoubtably encouraged pre-marital sexuality, but it was not available to everyone. The Family Planning Association which was still battling for recognition would not issue the pill to the unmarried (Fenwick 1977). The Association would want to know the date of the wedding before they would give the pill and would allow the minimum time for it to settle down. Prospective brides would be given the courtesy title of their new married name. Unmarried women had to find doctors who would give them the pill or had to pretend to be married, although as Penny and Adrienne found women students could get contraceptives more easily by knowing the right doctors. Sharon was not on the pill. She believed that getting it would have been difficult and moreover saw going on the pill as an acknowledgement of being sexually active which was not an image that Sharon had of herself. Her sexual relationships with men involved heavy petting but not full intercourse. Fear of pregnancy, or of being seen as, "too easy to get" prevented this final step. Again there was the dilemma of determining when sexual availability was enhancing or diminishing one's prospects with men. And in Sharon's case she deemed full penetration to risk her reputation because she thought that men liked to marry virgins. On one occasion Sharon let a man ejaculate near her vagina without penetration and she became pregnant. At the time Sharon was well conditioned into believing that the woman was responsibile for sexual control, and that men could not help themselves if a girl gave encouragement. She took the responsibility for the pregnancy to the extent of not even telling the father. She felt foolish and did not think he would believe her:

I didn't tell anyone for eight months. I actually told mum because she said to me one day, "What about doing some exercises with me". I just burst into tears and said that it wasn't that I was putting on weight but I was pregnant. I just don't know the actual stress that must have caused me to go eight months without telling anyone...I also felt, well here again I have bombed out and I have let the family down. The only one in the whole family to get pregnant. (Sharon had four older sisters.)

Sharon went in secret to Dunedin to stay with a friend and to book into a discreet private maternity hospital. Not even all her family were told, and during the remaining weeks of her pregnancy Sharon rarely went out for fear of meeting the only person she knew in Dunedin who might report her condition back to Christchurch.

11 In $19503.99 \%$ of babies were born out of wedlock. By 1960 this had increased to $5.25 \%$, but by 1970 increased to $13.34 \%$. 
The public censure surrounding unmarried mothers was strong and even heightened by fears of new sexual morality. Most women left town and went to maternity homes attached to church and charitable institutions which provided a hideaway for several months before the confinement and afterwards until the adoption was arranged (Tennant 1985). Those women that went to public or private hospitals were carefully segregated from married mothers. The birth experience for Sharon was traumatic and the baby was born dead. When the baby did not breathe the Matron accused Sharon of doing something to it, but the exact cause of death was never known. Sharon could only feel relief, as the Department of Social Welfare had told her that if her baby had any deformities, nobody would adopt it and she would have to keep it.

Helen: How do you feel about the pregnancy now - it must be about eighteen years?

It has taken a long time to come but now I really see myself is not a bad person. I am quite a nice person. It has taken me a long time to come to terms with everything. It was something that I couldn't talk about. It was something that was bottled up inside me. When I came back home there was nobody I could actually talk to. Mum felt uncomfortable. I just thought that it was my little thing where I had gone wrong, and that the best thing I could do was to be quiet about it... When I married $T$ __ he knew about the baby and had been supportive to me. I was very grateful for this as he needn't have been. But he really didn't want to know about it and I had to act like a virgin with him. He seemed to want it like that and it made me feel pure but it was uncomfortable. I always had to say, "No further". We didn't make love until we were married.

Again it was a matter of Sharon being responsible for defining the boundaries that determined whether she was seen as a whore or a virgin. Her family, and later her husband, coped by pretending her "slip" had not happened, but Sharon had to face the antagonism and censure behind the silence when she tried to get her old job back :
$I$ remember going back to $B$ where they said I could have my old job back again. It was a bit naive to think I could but anyway I went back there and they took me into the manager's office. They bought in all the big guns and I had the third degree gestapo interrogation which ended with me almost going into a fit. I started to go into hysteria and they told me not to be so silly and to pull myself together.
Helen: What were they saying?
Asking me if I took money from this man, and they thought that I must have had an abortion because I was back so soon and I hadn't looked pregnant. Anyway at the end they offered me my job back, but I couldn't. I said I didn't want it and they said that I was being ungrateful. But I just walked out and didn't go back. I still can't go into that department store without being upset.

Sharon's story was typical of something that happened to thousands of New Zealand women just a few years before it was possible, almost acceptable and indeed expected, that an unmarried mother would keep her baby and rear it as a solo mother. Two other women in this study had children outside marriage, but their children were born in late 1969 and 1970 and their lives will be discussed in a later chapter. Both of these women battled to keep their babies but unlike 
Sharon refused to hide away, and did not want the options of adoption or abortion. For one of these women pregnancy was, as it was for Sharon, an unfortunate accident but for Penny pregnancy was an expression of independence as a woman. Having a child alone became an extension of a political philosophy to be sexual and independent:

\section{I used to actually dislike living with a guy because I used to feel it drained me. It drained my potential - it cramped my style...A few times there had been someone I had got on well with but if you actually set up home together they expected you to sit around with them quite a bit. I much preferred to live with couples or other women and have relationships outside of the home. I could sustain a relationship like that over a period of time.}

Penny was fleeing from the security that was traditionally idealised in relationships with men and saw herself as part of a wider community of people who gave her emotional and economic security. In comparison to the other women in this study Penny was exceptional, and the more common compromises women made were an early marriage like Beverly's, or by Adrienne there was carefully controlled pre-marital sexuality on a pathway that hopefully led towards the securities of marriage.

\section{A "SICK" SOCIETY}

The paradox of consensus in the fifties was that the very attempts to create a homogeneous society seemed to bring with it its own opposition. Out of the very heart of the family that was the organizing centre of the new welfare society came the new dissidents: the young, the alienated, the mad (Wilson 1980:193).

During the 1960's there was the beginning of a more radical critique of family ills. In the early postwar years such things as divorce, delinquency, illegitimacy, working mothers were problems but were believed to be curable through social policy and individual will-power. The new criticism gave a new economic and social appraisal of the problems of family life, and delved deeper into the psychological ills of the family itself. Much of this critique came from abroad and was to herald a slow shift in personal and political attitudes towards the family in Western society. There was for, example, a shift from the earlier view that the family was a haven of security and love. In a Reith Lecture, British anthropologist Edmund Leach labeled postwar society as a "Runaway World" and argued that in contrast to the past:

The modern family looks inwards upon itself; there is an intensification of stress between husband and wife, parents and children. The strain is greater than most of us can bear. Far from being the basis of the good society, the family, with all its narrow privacy and tawdry secrets, is the source of all our discontents (1967a:44).

In this view the family was "sick" and so was society. In the early postwar years anything that did not fit the criteria of "normal" family life was labeled as deviant, but in the new critique the problem was not so much the deviance but the criteria of normality itself. The best selling writings of R.D. Laing $(1964,1967)$ were a stimulus to this radical view. Laing was suggesting that madness was the only sane response to an irrational world and that the 
repression within the family destroyed children. The rhetoric of his writing was extreme but was in accord with a growing mood of disaffection about "normal" family life. The expressions of such disaffection were not always explicit, but were revealed in the letter columns of magazines, and in New Zealand poetry and literature of the time (Alcock 1970). For example, New Zealand poet James K. Baxter caught the mood in the domestic imagery of The Ballad of Calgary Street (1960) where "National Mum and Labour Dad" go mad in a sick society as "two birds that peck in a fowled nest". Again the origin of this sickness came from within the family itself where they "hag and grumble and growl and fight" and "two old souls go slowly mad". In America, Betty Friedan's book The Feminine Mystique (1963) captured the disaffection with the traditional family roles. She labeled the pro-family stance of earlier years as a "cult of domesticity" that entrapped women and caused depression. Friedan's message did not influence the younger women until later when they too were moving into childrearing anci by then there were many others in public accord, but two of the older women recalled the impact that reading Friedan's book had on them. For Brenda and Jane, two educated women whose life stories were told in Section One, Friedan sparked off a process of adjustment and reordering of their family life. Friedan's challenge to the family as it was structured was potent, and both women told of friends whose marriages broke up because their husbands would make no accommodation to their wives' need for more independence.

Brenda: I had read Simone de Beauvoir but it was Betty Friedan's book that affected me. It was real hammer blows. It was terrific but it was also very private for me. It was the first sharing and the first realisation that everybody else felt that same as I did. It was the privatisation of always adapting. You knew it wasn't your own personal relationships you were adapting... and for the sake of the children you must keep married at all costs.

Jane: $\quad$ Well I told you that I had this gnawing feeling inside me that something was missing for me. Is this what life is about.? At that stage with four children I couldn't see what my future might be. When Betty Friedan's book came out it grabbed me tremendously. When I read it I realised that I had been lucky in filling my life with that playcentre work, but for other people it was still a hole, and they were saying. "I must be able to do better than this and the children are not my whole life". I don't think even when I read the book that I stopped being a self sacrificing mother.

Despite the popularity of this book both in New Zealand and America, this kind of critique was a minority view. Still, it was to feed into a variety of cultural, social and political protests which generated a small counter culture. In New Zealand the various versions of the counter culture only skimmed the surface against established values and behaviour, but was again a new variation of the egalitarian ideal; a reaffirmation of the individual; a reaction against the increasing conformity of postwar life; and a rejection of the growing affluence of middle class life. The spirit of this was evident in Tim Shadbolt's Bullshit and Jellybeans which documented aspects of the New Zealand protest movement of the late 1960's. Shadbolt saw the small, but vocal, protest by the young as the forerunners a larger revolution. He described how, "Young kiwis, dropping out, forming communes, smoking pot, protesting 
(were) smashing the complacency" and were the "new pioneers of New Zealand society" (1971:199) It was also the view of Theodore Rosak (1972), in his analysis of the counter culture in American society, that the alienated young - "technocracy's children" - were creating a vision to save an endangered civilization. In New Zealand however, protest had its own distinctiveness, particularly in the "No Maoris No Tour"12 rugby protest, but sustenance also came from the example of American civil rights movement, the student protests in Europe and America, and in particular the protests against the Vietnam war.

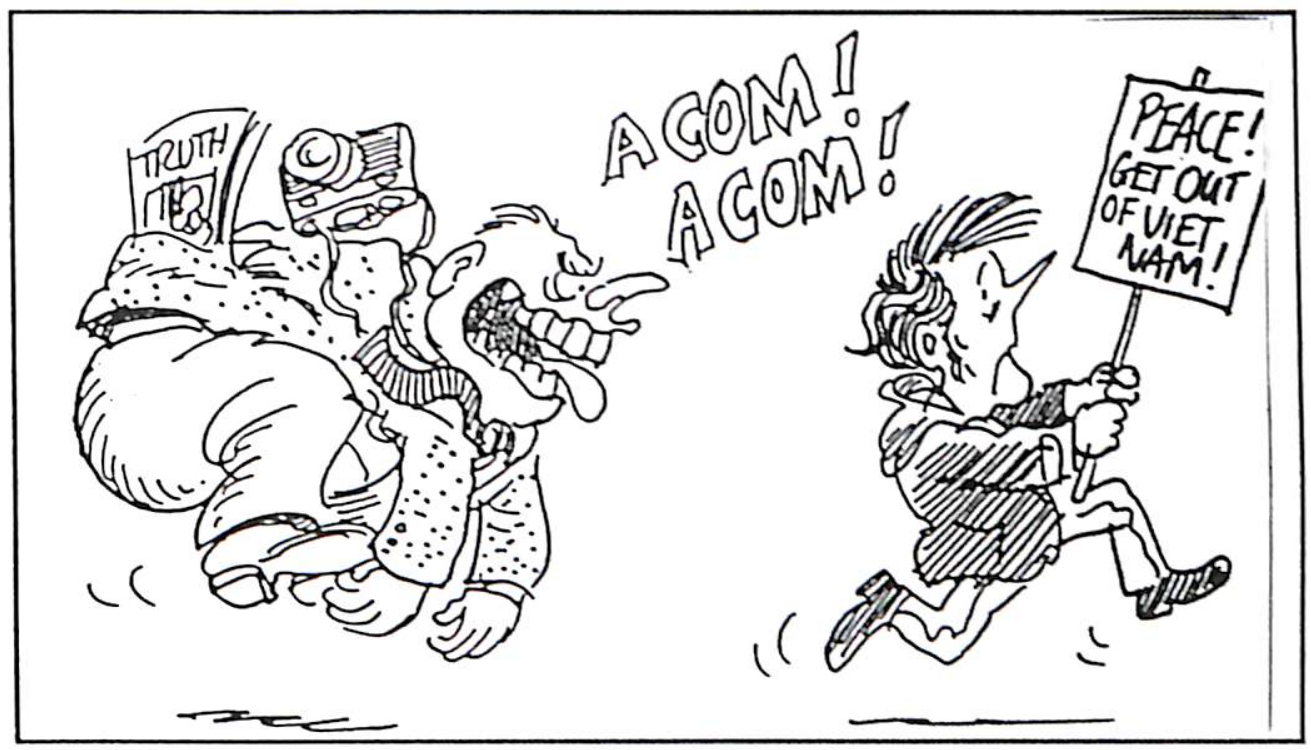

It was not only the horror of the war but the protest was against the moral and political values that allowed it. A new world was needed to demonstrate that society could be organised around other values. There was also the example of the American hippy movement's lifestyle of communal idealism, flowers, and peace, as Lynn Segal wrote:

Sections of the anti-war and hippie movement were united in their search for a new way of life, a new co-operative society. America was to become one big happy family, instead of violated, sexually frustrated, fragmented families at war with each other and the world (1983:41).

Of the women in this study, some were uninterested in these happenings in New Zealand and abroad; some like Delwyn were very conscious but purposefully distanced themselves from any association; or there was Adrienne who was sympathetic and occasionally went to demonstrations, but to all appearances led a "conforming" lifestyle. It was only Penny who identified strongly with this kind of idealism. In 1965 she left university to work in manual jobs more akin to her working class background:

I used to work just enough to give me money to get by with. Like I would work as a waitress for a few days, a few weeks and then get involved in some cause, or involved with people. I had a few real heavy relationships-well I did an awful lot of growing up.

12 In 1970 the All Black rugby team was to tour South Africa. 
Penny studied Marxist theory, was deeply involved in the anti-apartheid movement, and the Vietnam war protests, but Penny also saw herself as part of the cultural and social revolution in New Zealand that made up the counter culture:

The other strand of my life was that I was really involved with this fringe...outside of society for three or four years...I was close to most of the really heavy people in the drug scene and the music and the art side of it. The people I was attracted to were people who did not accept things the way they were and put themselves at risk. Women were very vulnerable then.

This world was exhilarating - it was "The Age of Aquarius"13 - and its creativity and chaos were distant from the conformity of established family life. Again in the world of pop culture the Beatle's album "Sgt Pepper's Lonely Hearts Club Band" (1967) reflected a new alternative society of psychedelic colours, long hair, peace, flower power and drugs. America's Dr Timothy Leary urged the young to "Turn on, Tune in and Drop out". But there was also pain and danger. News of suicide and drug overdoses became more common as the drug culture grew. The commune and for some the drug culture itself, became the outward symbol of the counter culture. The commune was a practical expression of escape from the nuclear family and demonstrated an optimism that society could change from the grassroots. James K. Baxter set up a commune at Boyle Street in Auckland, and then in the romantic remoteness of Jerusalem up the Wanganui River. Baxter's mission originally was to rescue the young from the drug scene but it was also a demonstration of a new society organised around the principle of aroha "the love of many". Throughout New Zealand there was a brief flourishing of various kinds of urban and rural communes (Jones 1975). It was the city communal lifestyle in which Penny felt comfortable for awhile.

The political and personal revolutions of the 1960's were an expression of the theoretical critique of the "new left"' politics. There were many political and theoretical strands, drawing in particular on the Marxian concept of alienation and its later interpretations through Sartre's existentialism and the writings of Marcuse and Fromm. There was also the psychology of Jung and Laing. All were essential reading of students of the Left. The common theme was that of a society in which the individual had become a passive object and revolution was needed. There was little agreement on the origins, the mechanics or the goals of such a revolution, but an acknowledgement that it would come from those "outside" the mainstream the unemployed, the students, the racially oppressed - those who Marcuse believed were the only ones who could make the "great refusal". In New Zealand Tim Shadbolt saw his role in protest to "Wake up this apathetic, overfed cabbage society" (N.Z.L. May 10 1970).

13

This came from the rock musical Hair. It did not get to New Zealand until the 1970's but the music was well known. 


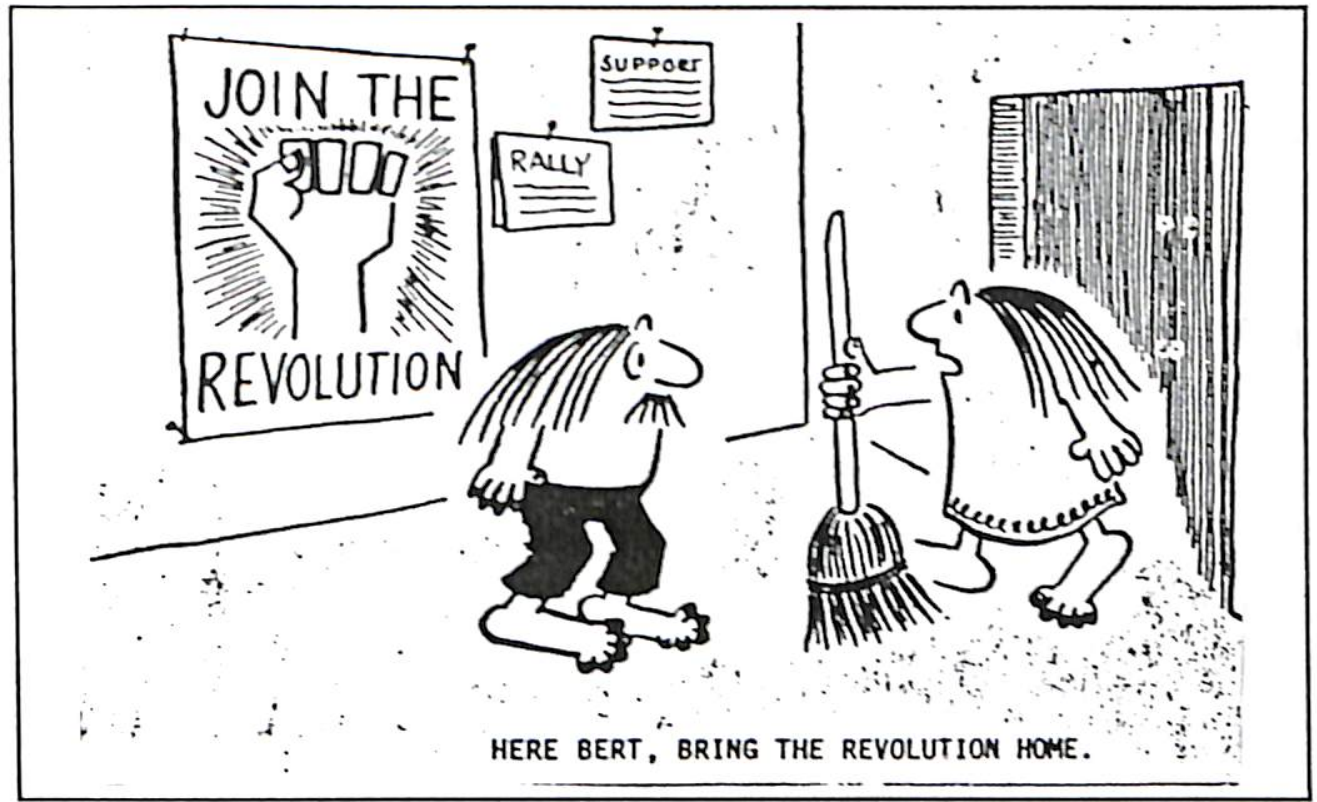

During this period of new idealism the women's movement had its beginnings. The political analysis of the 1960's produced a new consciousness of the mechanics of power relationships, which women were to use to reveal more explicitly their own inequality with men. The conditions that brought disaffection had arisen during the postwar years from the rising expectations of women for more independence and life outside of the family. The example of a counter culture and lessons learned from the protest movement provided some of the early tools and rhetoric of liberation for the few women in the forefront. However such things as communal living, political protest and a sexual revolution, had little impact on the ways in which women's everyday lives were organised. Involvement in such activities or adherence to newer moral and political codes did not alter the sexual division of labour. Nor were the fears of insecurity necessarily alleviated for those women who were involved. Women had not been leaders or voices in the cultural or political movements of the 1960's (Segal 1983), but as Penny recalled, there were strong connections with the early stirrings of feminism:

We used to spend a lot of time talking about things. Why there were so many good women and not so many good men. We developed this strong notion about women and so we were obvious candidates for a women's consciousness. None of the friends I had were into this thing about needing a man, although we were into having relationships with guys.

The women's liberation groups did not emerge in New Zealand until 1970 (Dann 1985b), but before then there was a growing consciousness about the impact of social and economic change on women's lives. For example the Wellington Branch of the Federation of University Women (1968) published a booklet of advice for women returning to the workforce. The tone was one of moderation with advice on how to manage work and family without stress. Women were advised against shift work or "on call" work, and were cautioned about the impact of full time work on the children or a husband. This was some years before the more 
radical critiques of the inequality of women in employment or work at home. Predating the women's liberation groups were organisations like the New Zealand Association of Childcare Centres which was established by Sonja Davies in 1963 as a lobby group to promote good quality childcare for the children of parents in paid employment. Similarly the Society for Research on Women was formed in 1966 when it was realised that there was no research on New Zealand women (S.R.O.W. 1985). These were not radical organisations but they were identifying the gap between the reality of women's lives and the idealised prescriptions. "The Changing Role of Women" 14 became a popular topic at lectures and seminars. Magazines like the Woman's Weekly gave advice on how women could reorder their priorities so that the family would not suffer if they worked. The new magazine Thursday which appeared in $19688^{15}$ was instantly popular as it was to address many of the issues causing conflict in the lives of women (Harworth 1975). Thus the decade ended as the women's movement began, and in hindsight it has been argued that the women's movement has had a greater impact on family life than the specific cultural and political protests of the 1960's. They were, however, entwined as the women's movement followed on to widen the definition of what had been deemed to be political during the 1960 .

14 For example: Linden Playcentre (1967) The Changing Role of Women ; Auckland University Extension (1968) The Changing Role of Women; (1969) Women's Position in the World Today.

15 This stayed in the bookshops until 1974 and was to challenge the editorial style of the Woman's Weekly. 


\section{THE CONTEXT OF LIVING 1970 - 1985: NEW IDREAMS AND NEW CHALLENGES}

The habit of protest lasted in to the 1970's, a decade in which the problems have intensilied and taken on every appearance of being permanent and without solution. The tide has turned towards reaction (Oliver 1981:458).

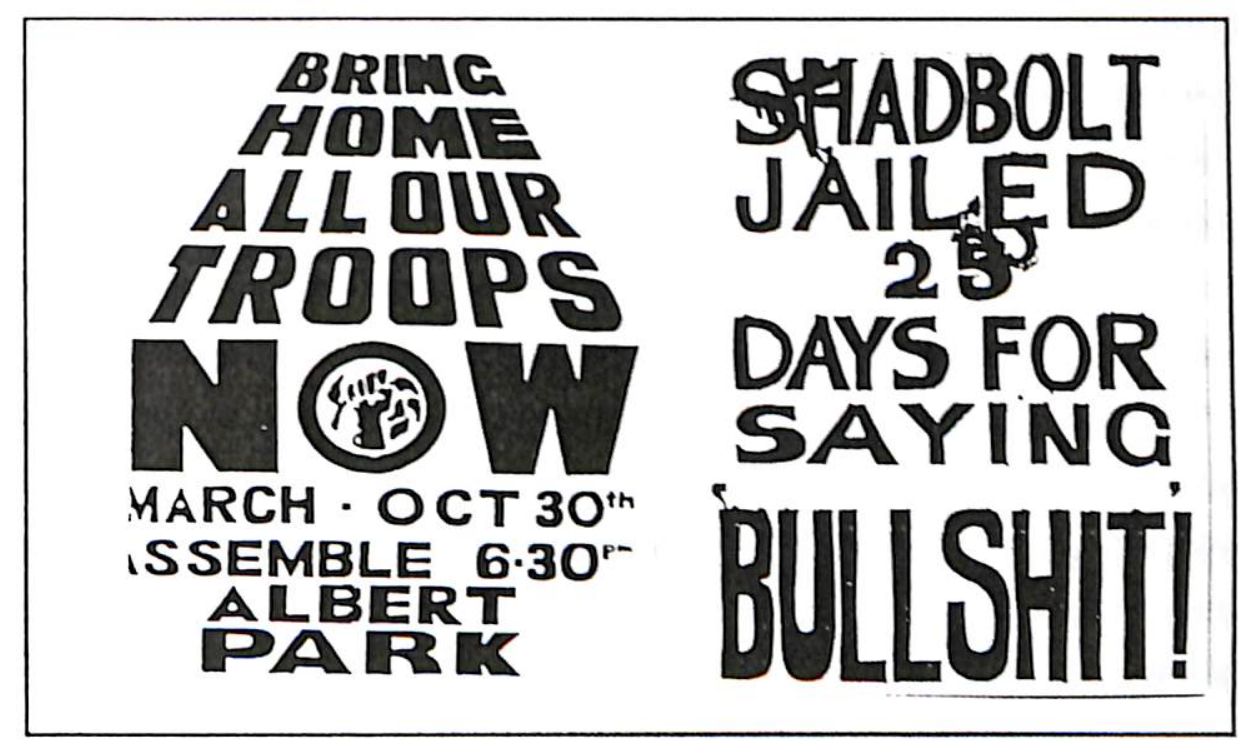

During 1970 the protest movement was at its most active. The aim was to challenge existing values and reveal injustice, but the tactics were designed to shock the complacent and to undermine authority. A part from a few large marches of up to 30,000 protesters, the numbers involved were small. Nevertheless, the impact on New Zealand was not so much a measure of who did or did not take part, but in the extent to which such activities created an awareness of new and conflicting vicws. The specific focus of contention centred on South African apartheid policies and the continuing presence of New Zealand troops in Vietnam. 1970 was a crucial year for both issues, as the All Blacks were scheduled to visit South Africa, and the United States wanted more troops for Victnam (McGraw 1981). Protest did not succeed in keeping the All Blacks from touring South Africa, although the fact that two of their players refused to go was some consolation to the protest movement. The visit of the United States Vice President Spiro Agnew sparked off the most violent anti-Victnam war demonstrations New Zealand had witnessed. This became a turning point in commitment and within a year Auckland was able to mobilise over $30,()(0)$ for an anti-war march ${ }^{1}$. Tim Shadbolt later wrote, "You could feel it brewing - cveryone everywhere was just getting that lecling that it was all on" (1971:145). As the momentum of protest grew the focus widened, and the criticism of the 1970 Royal Tour showed a society that was becoming more divided about traditional political ties. The Listener

${ }^{1}$ The MOBE march, July 3()h in Auckland 1971. 
(March 6 1970) headline read - "The Qucen is coming HOORAH! HOORAY?" and although there were no protests on the strects there was for the first time open hostility expressed through the media, and compared with the press reporting of the 1953 and 1963 Royal tours the adulation was muted. 1970 was also the year in which the first women's liberation groups were formed.The Woman's Weekly (October 26 1970) warned its reader to expect a "revolt". Quoting American opinion, the Woman's Weckly reasoned that because, "Hysteria was used during the 1960 's to bring about change, women and women's groups may have to resort to similar tactics during this decade". Thus, while equal pay and the changing role of women were crucial issues, women's liberation captured the media focus with a series of pub ${ }^{2}$ liberations. Women went into public bars from which they had been banned, and demanded servicc. Such tactics brought attention in a new way to the inequality of women, and as Joan Rolt of Hamilton reasoned, "This country's younger women have learnt that their mothers made little impact by their less dramatic protests" (N.Z.L October 5 1970). Such "liberations" probably made lite affect on the majority of women and writer Sue McCauley summed up the year by saying that, despite the street protests and the birth of women's liberation, "The real issue of 1970, the cliff hanger, was the mini-midi hooha" (N.Z.L. December 28 1970). This happened when the mini-dress reached its shortest length and had nowhere else to go except back down. The fashion houses responded with the midi-dress and were waiting to see whether women would buy.

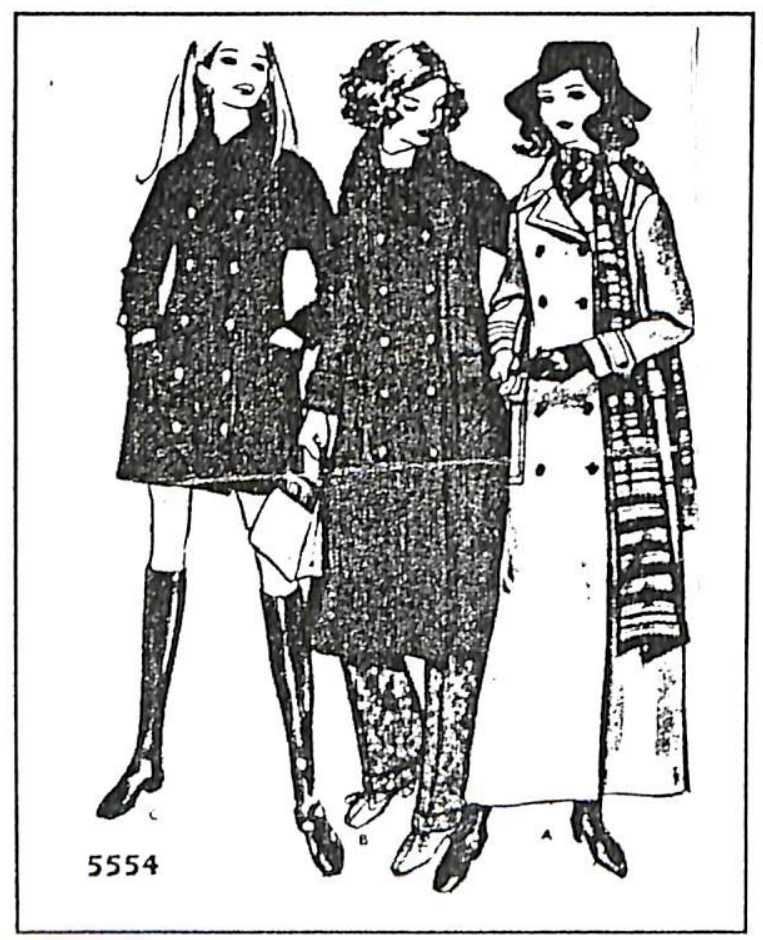

Once New Zealand's involvement in the Vietnam war ended in 1971, protest moved off the streets to be transformed into a broader critique of the institutions of New Zealand society. From personal relationships within the family to the preservation of the environment;

2 A Pub is an abbreviated term for a public house, a bar or or a hotel where alcohol is sold or consumed. 
the strategies of big business to the ills of the education system; a new consciousness of racism to the workings of government - little was left untouched. Earlier there had been optimism that postwar reconstruction policies and the political system could deliver the "good life" (Roberts 1987). Now there was a growing acknowledgement that the postwar dreams of the "good life" had not been realised by all (Gifford 1980); that the wrongs of postwar planning needed righting (Morris 1971; Task Force 1976; N.Z.Planning.Council. 1977, 1979); and that conformity was no longer acceptable or possible (Mitchell 1972; Shadbolt 1971). During the early 1970's a new version of the "good life" (Shuker 1983) was briefly rekindled. Gordon McLauchlan (1976:2) described this as a society imbued with a, "Vision of love and beauty, a sense of variety of lifestyles, of alternative viewpoints and philosophies through which we may fulfil ourselves in different ways". The earlier ideal of consensus through conformity was replaced for some by irieals of tolerance, diversity and difference. There was a belief that individuals could shed their materialist desires and conformist attitudes, and that it was possible to change the very institutions that in the past had constrained and alienated. But this was no massive turnaround. Not all individuals were so motivated, institutions not so adaptable, nor were problems so surmountable, and by the 1980's the impetus of change had faltered. What began in the late 1960's as an ideal of revolution through protest (Shadbolt 1971) became by the mid 1970's, an exercise of softening the hard image of a Government looking towards technocratic solutions (Shuker 1983). This process did bring a tentative tolerance of difference and diversity (Social Development Council 1977a, 1977b, 1978-9), as the increasing visibility of alternative life styles appeared at odds with older codes which had seen the "different" and the "deviant" (Gidlow 1982) as symptoms of social disorder. The N.Z. Planning Council in its advice to government on social policy reflected the new view:

The adherence to a notion of normality in fact undermines the effectiveness of social policies. It is misleading to see each of us fitting into the mould of a "normal" citizen. Yet it is very difficult to cater for diversity within an administrative or bureaucratic system (1979:26).

This tolerance did not mean total acceptance and in the mid 1970's a new kind of protest emerged vested not in the politics of the Left but in the New Right. Defenders of older values regrouped around causes such as abortion, childcare, sex education in schools, and homosexuality. As McLauchlan predicted,"Diversity frightens the chunders ${ }^{3}$ out of New Zealanders" (1976:44).

Neither the questioning of valucs, the softening of authority, nor the flowering of alternatives cased the problems. By 1974 the postwar economic boom had ended. Throughout the period there appeared to be a worsening of violence and disaffection, and there was increasing disillusionment in the ability of the political system to deal with the problems. By the late 1970's the arrival of a more cquitable, more peaceful and less materialistic society appeared to have been postponed again. By the mid 1980's the effectiveness of tolerance was

3 An antipodean colloquial term for vomiting. 
being questioned and the Roper Committec of Inquiry into Violence (1987) blamed the past decades of permissiveness - "The public now has the violent society it deserves," was the new official view.

Amidst these changing and somewhat confusing currents and counter currents the women in this study were, in Lydia O'Donnell's (1985:11) terms, a "pivotal generation". They came to motherhood during a period which brought a more explicit challenge to the assumptions held by the previous generation surrounding the role of men and women in relation to each other, their children and their work. This rethinking had several origins: the impetus of the women's movement, a wider consciousness of the rights of individual, as well as the changing social, political and economic climate. This chapter traces some of the ideological currents which gave an appearance of diversity of opportunity and choice, but also the counter currents which revealed entrenched attitudes anci an inability of institutions to keep pace with the realities of diversity. There was a growing mismatch between the idealism of what should be possible in society and the reality of what was possible. This mismatch is later shown to be of significance in the lives of the women in this study, and is apparent in each of the dimensions of New Zealand society discussed in this chapter. A common thread too is the continuing "quest for security" whether it be political, economic or personal, amidst changing definitions of order.

\section{A CHANGING POLITICAL AND ECONOMIC ORDER}

New Zealand's size and isolation, its dependence and vulnerability particularly in economic terms, point up the fact that the country is "expendable" as far as the power centres of the outside world are concerned. This places a responsibility on New Zealand to make an independent judgement on the strategy it wishes to follow (Task Force 1976: xx-xxi).

Political and economic policies at home and abroad faced new challenges as the traditional assumptions and established securities shifted. New Zealand's postwar political and economic policies had been based upon preferential tics with Britain and the United States. Throughout the 1950's and 1960's New Zealanders continued to see themselves as feeding Britain, the main export market, and under various alliances sent troops to join the fight against communism in Korea and Malaya in the 1950's, and Victnam in the 1960' $\mathrm{s}^{4}$. The economic and political securities of this older order based on colonial ties, old war alliances and a fear of the spread of communism, started to decline during the 1970s - 80's, and New Zealand had to look for new trading markets and more friends. The economic security of safe markets for New Zealand's produce was shattered when Britain joined the European Economic Community in 1971. Soon afterwards the oil crisis further rocked the foundations of the world economy and New Zealand

4 David McGraw (1981) argues that by the time of the Victnam War New Zealand was a "reluctant ally" who stalled at being incorporated into the war in comparison to Australia who was an eager ally. 
was left to ponder its isolation and economic dependence on others. The main turnaround was in New Zealand's relationship with the United States. The ANZUS Treaty had been the cornerstone of New Zealand's postwar foreign policy, but as the "domino theory" of communist expansion in Asia and the Pacific became less plausible and less acceptable, support for American policies among younger New Zealanders waned ${ }^{5}$. This coincided with a strong antinuclear groundswell of opinion in New Zealand, and under the 1984 Labour Government the break finally occurred. Visiting rights for United States nuclear powered and armed ships were withdrawn, and to the Americans the ANZUS treaty had been violated. As the Treaty lay in disarray and New Zealander's argued about the implications, the United States demoted New Zealand from being an "ally" to a "friend".

Politics at home had fewer turnarounds and in one sense followed a pattern established in the earlier postwar years with the National Party continuing to be the dominant party (Clements 1981). Political parties, however, faced a challenge to fulfil new kinds of dreams whilst still protecting older securities. After twelve years of National Government, the 197275 Labour Government tried to acknowledge shifting values. They attempted to harness the mood of optimism that society must change, and believed moreover that they were the party to do it. They forbade a proposed rugby tour from South Africa; they sent a frigate into the French nuclear testing zone; they gave out remote land to people who yearned for the communal lifestyle; and a new array of social inititatives cautiously acknowledged the inevitability of change ${ }^{6}$. At the end of this whirlwind term the new leader of the National Party, R.D. Muldoon addressed the fears of people who thought that the country was being changed too fast $^{7}$, and Labour lost the the election in a landslide defeat just as dramatic as their landslide victory. The brief change of political direction illustrated the lack of consensus for change. Some voters wished to grapple with the new realities and to look for new solutions whereas other parts of the community felt threatened and wished to reaffirm older certainties.

One acute problem was the rising number of unemployed ${ }^{8}$. The long period of security in full employment which had existed since since World War Two had ended. Memories and fears of the depression years were revived but the real impact of unemployment on New Zealand socicty has been difficult to assess. Susan Shipley's (1983) study on unemployment amongst women showed that many of the ill effects were hidden from public view. Successive Governments responded with various kinds of work schemes to remove the

5 The 1984 Labour Government was the first postwar government in which the majority of members had no personal experience of the depression or World War Two.

${ }^{6}$ Accident Compensation, the first support for childcare scrvices, the introduction of the Domestic Purposes Benefit, establishing the Parliamentary Sclect Committee on the Role of Women in Socicty.

7 The National Party's clcction campaign cartoons of dancing Cossacks suggested that the Labour Party was leading the country towards socialism.

81970 1985

1,600 registered unemployed 62,830 
unemployed from the streets and retrain the young but again, as Shipley's study showed, the majority of women who lost their jobs were rarely counted in the statistics yet their loss of earnings had a considerable impact on family life.

As in the early postwar years housing continued as a problem. It was not appropriate still to blame the war years for all the shortcomings, but throughout the period, homelessness, overcrowding, high rents, and high interest on mortgages were problems that neither of the political parties could solve. The 1971 Commission of Inquiry into Housing reported that a housing shortage was still part of the problem. The National Government encouraged financial assistance for home owners, while the Labour Government increased the building programme of State houses, but it was apparent that ncither Party's policics were able to sustain the expectation that families had a right to home ownership. Vernon Wright summed up this failure:

Time was when home ownership was accepted as the traditional cornerstone of family security and stability in the New Zealand way of doing things. But that was yesterday (N.Z.L. May 13 1978).

It was not only the problem of the mismatch between expectation and realities of home ownership, but that the mistakes of earlier planners who designed the large low cost dormitory suburbs were still being repeated. One of the effectrivas, as B. Richardson reported:

Thousands of young mothers, many of them immigrants trapped in a suburban landscape of appalling monotony. There are no nearby shops or social services and they are without the transport to get them to the facilities they need (N.Z.L. October 30 1976).

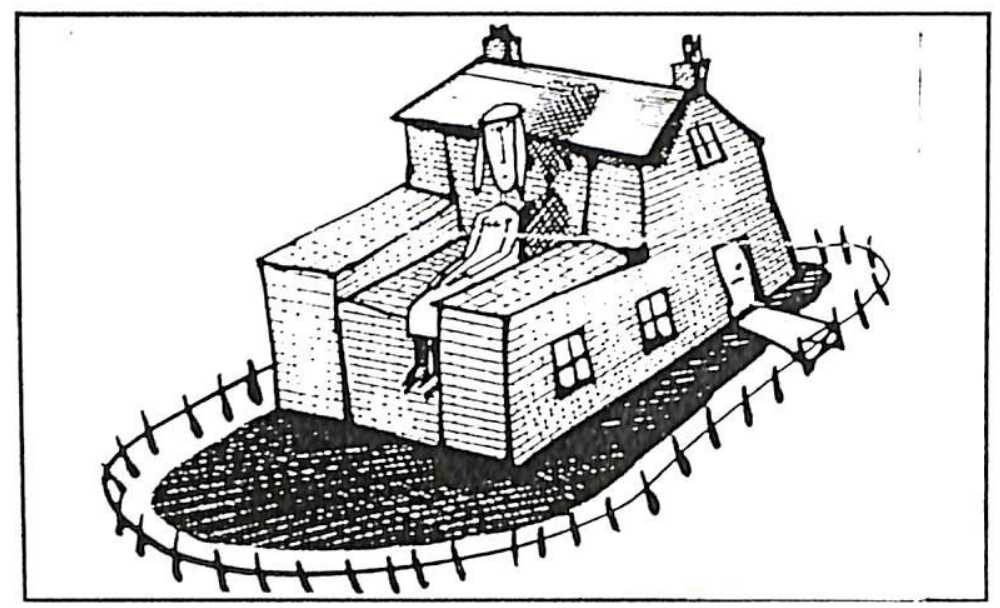

A policy of inner city renovation as an altcrnative to building new suburbs was no solution because as middle class people bought city houses to renovate, the original poorer occupants were thrust out into the distant suburbs. Planners, too, found it impossible to allow for the diversity of family life styles in terms of age, children and culture, and the three bedroom home design continued to dominate the market.

A heightened social concern during the 1970's saw the problems of unemployment, homelessness, drug abuse and violence, as by-products of uncaring cconomic and social policies 
(Oliver 1981), although many New Zcalanders still thought that personal misfortunes were the result of personal incompetence. Throughout the period there were attempts by individuals, groups and Government itself, to create a more "caring society" (N.Z.Planning Council 1979; National Party Manifesto 1978). For some the trigger to change began with the individual. "Keith" told the Listener:

You have to start with yourself and live the way you want to live. Then you can set a living example to those around you. You can't say that the whole world should live differently if you're not going to do it yourself (May 7 1973).

During the early 1970's, the energy and ideas from the counter culture and protest movements pushed more people towards alternative lifestyles, (Taylor 1972; List and Taylor 1975; Mushroom 1974--) and the intimacy and separatism of the commune where there was a common quest for self reliance, open relationships, a communal sharing of resources and a concern for the environment (Jones 1975). Tim Shadbolt's withdrawal from tactics of street protest to his Huia commune (Jones 1975), was symbolic of this "do it yourself" "setting a good example" ethic. By 1975 it was estimated that there were up to two hundred urban and rural communes (Jones 1975) ${ }^{9}$. The Labour Government's ohu ${ }^{10}$ scheme was an attempt to resurrect the ideal of pioneering self-sufficiency, and blocks of remote land were given at a minimal rent for groups wishing to set up communities. The Ohu Advisory Committee believed that the ohu would, "Give the opportunity to experience the earth, the country and each other in a new fraternal unity" (1975:4), although Prime Minister Norman Kirk had seen other benefits in perhaps getting the "discontented youth" off the streets:

For the past few years we have had a lot of young people telling us that the establishment has gone soft, its lost its idea, it's lost its drive... The thought about developing this type of settlement is simply to say to a lot of young people who have been offering criticism...well, here is an opportunity. Let's sec if you can do what you say we ought to do (Press Statement, October 9 1973).

The Minister of Lands, Matiu Rata, later denied that the ohu was the "Government's answer to dissident urban left or right wingers...or a cheap method of developing marginal lands", and described the ohu as the Government's response to an, "Over emphasis on the gross national product, perpetual greed and the cult of individualism". He hoped that it would, "Soften the harsher aspects of much of New Zealand's life" (Ohu Advisory Committee 1975:4). While only a small number of people actually opted for a remote communal lifestyle, there was an interest in the ideal, and in the cities groups set up food co-operatives, recycled waste products of consumer society or experimented with solar heating and wind power. The magazine Mushroom preached the ideals of a psychological and environmental renewal. The First Whole

${ }^{9}$ Several communes like Riverside in Nelson and Beeville near Hamilton had been established as early as the 1930s.

${ }^{10}$ Ohu is a Maori word meaning a communal or volunteer group (Ohu Advisory Committee 1975). 
Earth Catalogue (1972) sold some 20,000 copies in Ncw Zealand (Jones 1975), followed by the even bigger Second Whole Earth Catalogue (1975). "This is a handbook of social change" the Second Catalogue stated, but it contained an abundance of advice on the skills of selfsufficiency for a world that was seen to be running out of resources and secmed particularly appropriate to an economy that was recling from the oil crisis. Whether the choice was living on a commune and practicing some kind of self-sufficiency, or living in the city and re-cycling waste, both lifestyles involved expressions of disquict at the directions of the new technological society in which individualism as opposed to the co-operative was the priority. However, while some New Zealanders may have wanted to diversify their lifestyle few were intending radical changes. Practical gestures of disquiet were in the main fringe occurrences.

It was a period characterised by opposites. As the quest towards individualism, in the sense of striving for what one could get for oneself, was becoming more persuasive, there were new kinds of community activism by groups endeavouring to see benefits from small scale change. More women stood for Local Body Councils (Sarr 1981; Ritchie 1982); community centres, women's refuges and creches were established under a " D.I.Y. do it yourself - be paid later" philosophy; (O'Rourke 1981), arts and crafts thrived (Oliver 1981); and lobby groups manipulated the political system to get new causes and concerns included on the agenda for support and funding (Cleveland 1972).

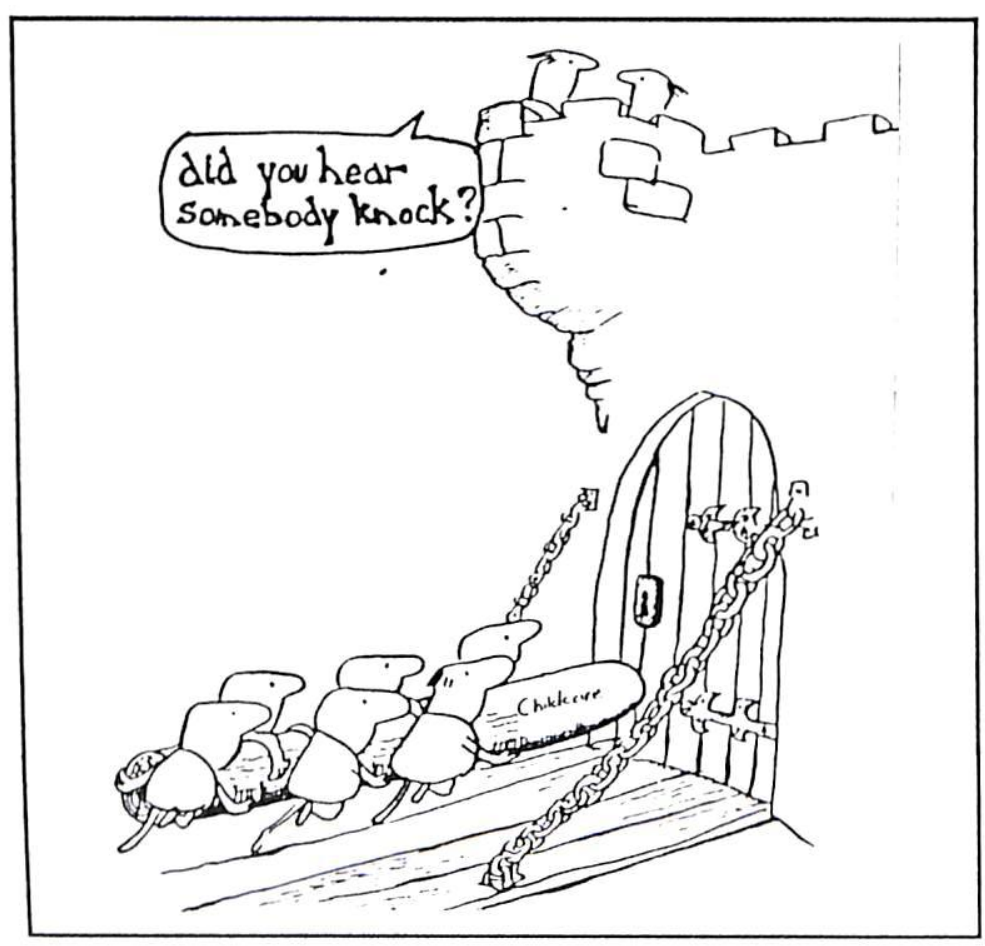

The problem however, as the cartoon suggests, was that the new community activists were looking towards funding support at a time of economic retrenchment. Duilia Rendall recalled how blind optimism was combined with willpower to set up a parent's co-operative childeare centre: 
We knew you just had to keep on battering and it felt like battering. There was a sub layer at which you knew it wasn't going to work. But if you thought about it too much you would have stopped. There was something about small returns boosting you up (Personal interview 1985).

Such groups as this were also preaching a new style of participatory politics, and alternative kinds of delivery for social and welfare scrvices (Task Force 1976; N.Z.Planning.Council 1979; Rendall 1987). Governments saw too that it was cheaper to fund voluntary community organisations to provide services than to expand the burden of the welfare state (N.Z.P.C 1979). Thus the idea of "community development" and "community support systems" became favoured in Government rhetoric. The New Zealand Planning Council wrote that:

The Welfare State would remain, but the future improvements would come less and less from Wellington and more from collective and individual efforts of New Zealanders concerned for the well being of their families and their fellow citizens (1981:22).

The style of delivery may have been more caring and less judgemental but the reality was a tremendous burden on voluntary community services which were always kept on a shoestring budget (Driver and Robinson 1986).

Some of this community activism surfaced in the Values Party. Values adopted much of the philosophy implicit in the commune movement but there was no intention of opting out of the urban lifestyle which their main supporters followed. The Party addressed the questions of womens' issues, race, open government and the environment in a much more direct way than before (Values Party Manifesto 1972, 1975, 1978) Values offered "an alternative future" (Values Party 1972) and was an intellectual urban attempt to create a more caring "goodlife". Values used the rhetoric of the young, the Left and the disaffected, and their Blueprint for New Zealand was to wam that:

New Zealand is in the grip of a new depression...It is a depression in human values, a downturn not in the national economy but in the national spirit (1972:1).

They accused government of:

Perpetuating New Zealand's problems (and of) spoon feeding its citizens with affluence in order to keep them quiet instead of reshaping society and industry (ibid).

Other political parties saw Values supporters as the "trendy lefties", brentom volues santured some $7 \%$ of the electoral vote in 1975 the other Parties began to adapt some of the rhetoric and idealism to their own political platforms. Values was regarded in the main as a soft option for middle class romantics, and although their opposition to large scale economic growth received some kind of intellectual support the reality was different. Most New Zealanders wanted to see their standard of living rise, not drop for the sake of conservation 11 . Faced with economic decline, worsening unemployment, and the new insecuritics of overseas trade and oil, most

11 For example Value's call for sharing of home appliances as a conservation measure was not a measure that manufacturers wanted to hear. 
voters opted for the known idea of security in growth espoused by the main political parties (Task Force 1976).

By 1975 there was some consensus that Ncw Zcaland needed new economic directions and thus began the quest for a technocratic utopia (Shuker 1983). This would be achieved through a planned strategy of economic growth. In the New Zealand Planning Council's first publication, A Moment of Truth, New Zealanders were advised that they were in a "hole" and that they must not "underestimate the seriousness of the present problems" (1977:1). Later publications (N.Z.Planning Council 1978, 1979, 1981) looked towards growth through "economic restructuring", "economic management", "a co-ordinated strategy". New Zealanders were warned however that, "The solution can't be painless" (1977). The welfare state philosophy which had been upheld during the postwar years by both political parties was seen as too burdensome and too expensive to expand anymore. Geographer Harvey Franklin (1978) argued that it was time New Zealander's relied less on the welfare state to solve their problems: "The State will realise it hasn't the capacity to do it anymore...It's healthier if people do things themselves" 12 .

The solution was the production of wealth, rather than the redistribution of resources and the National Government introduced the Think Big strategy involving the construction of a series of large industrial projects ${ }^{13}$ that would assure NewZealanders again of "safeguards for our future security" and "provide opportunities" (National Party Manifesto 1981). The problem was to convince an electorate to Think Big but National promised full employment and the funding of welfare, health, and education services out of the profits. The National Development Strategy, as it was officially called, was always controversial, and was known by its opponent as "Sink Big". The dream was again short lived, and by the mid 1980's the Labour Government was blaming the projects as the cause of their massive debt burden. Patricia Sarr (1981) had earlier analysed its effects on women to argue that women would gain few jobs and the costs of implementing it would remove the hard won small gains in childcare, medical scrvices and education. The Labour Government came to power in 1984 with a commitment to end Think Big and put its own free market economic restructuring into place. Again New Zealanders were being asked to bear with the "pain" of another economic strategy. By 1985 none of the political parties had been able to develop effective policies to deal with the perceived problems. The gap between the rich and poor continued to widen (Sarr 1981; Davey and Koopman-Boyden 1983), and the achievement of an egalitarian society was still as unrealistic as it had always been. The possibility of achieving some kind of rural utopia though an alternative lifestyle had long since disappeared, although by the 1980 's the Centrepoint commune was preaching a new style of

12 Interview with Harvey Franklin. National Radio July 281978.

13 Methanol Plant - Taranaki, Mobil's synthetic gasolene project, third pipeline at the Comalco Smelter,synthetic petrol plant, pulp mills for Nelson and Northland, plus a crash construction programme with the proposed dam on the Clutha river and at Huntly and strip mining of Southland lignite (Sarr 1981). 
urban utopia. As an experiment in psychotherapy Centrepoint sought to give its members the psychological tools to cope with the "social decay" of New Zealand society (Oakes 1986). Although it aimed at a kind of collective self sufficiency for its several hundred members, the focus was not so much to change society, but was a quest for individual self fulfilment through spirituality, open sexuality, and expressing emotion. Individualism was deemed to be the inevitable product of the technocratic society.

\section{CHANGING FAMILIES}

Modern society is characterised by diversity and the family, like other social institutions, reflects this trend...However the image of the "typical" New Zealand family is so widespread that people tend to see this sort of family as the ideal, and to regard variations on it as intrinsically undesirable (Social Advisory Council 1981:13).

During the 1970-80's the changing structure and function of the family appeared for some as a crisis in which the days of the "normal", "traditional" family were numbered, and "saving the family" became popular political rhetoric. Moreover, the family came under the critique of the women's movement, which in its more radical analysis saw the family as a place of oppression for women (Mitchell 1971; Greer 1972).

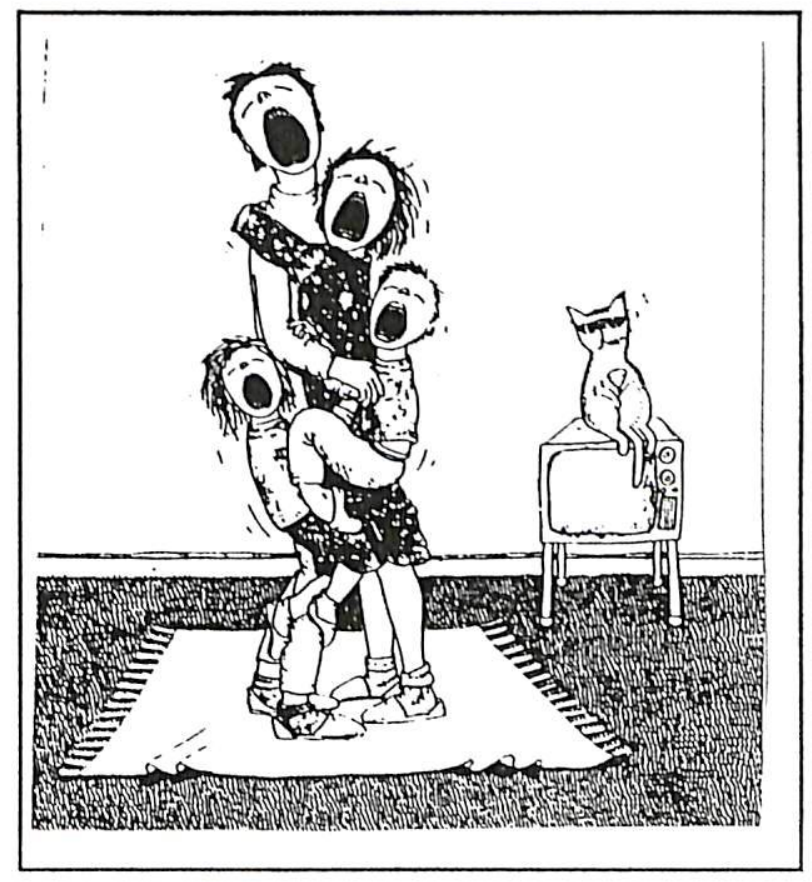

This encouraged the view that perhaps the family was no longer the haven of security and love it had been portrayed as. Early in the decade Dr Fraser McDonald, Superintendent of Kingseat Psychiatric Hospital, was to suggest, amidst considerable media coverage, that the "sick society" was not just imported theoretical jargon, but that'one in every five New Zealander's had some mental illness. "We have healthy cows but crazy people" (Listener May 10 1971). Dr 
McDonald was particularly concerned about the "battlefield in the kitchen", because mental illness was affecting four times as many marricd women as married men. "The only way that (women) can remove themselves from the situation is to go mad and they can be put away in hospital" (ibid). "Suburban Neurosis" was the diagnosis which Beverly Morris ${ }^{14}$ defined as a "disease or uneasiness" resulting from the "isolation of young women who have given up jobs which gave intellectual stimulation or at least social interaction" (N.Z.L February 6 1971). There was also a realisation that the family was sometimes a place of abuse and violence for women and children (Church 1978; Social Development Council 1980; Ritchie and Ritchie 1981; Saphira 1981), and rape crisis centres and women's refuges were opened in many towns. One viewpoint linked the apparent increase in mental illness and violence within the family to a breakdown of the traditional family and its values (Above Rubies magazine 1978--); others saw such family ills as symptomatic of deeper issues reflecting the changing roles between men and women (Dworkin 1983); while the view was also held that such ills had always been part of family life but had been hidden behind a code of silence (Ritchie and Ritchie 1981).

Besides questions about the well-being of the family it was apparent that the family was changing its appearance, and was characterised by more diversity (Swain 1983). The intercensus period from 1976 to 1981 showed a $31.7 \%$ increase in one parent families. For example, the 1981 Census showed that only $34.9 \%$ of households were made up of couples with children. Another $20.4 \%$ were defined as couples, with the other $44.7 \%$ were defined as "incomplete families" ${ }^{15}$. The increasing visibility of diversity led to a gradual shift in the conceptualisation of the family by policy makers. The Cabinet Committee on Family Affairs which sought to clarify the confusion defined the family as:

A group of people including the very young and elderly, who live in a close association which produces interdependence and a moral obligation to support one another (1976).

This definition, however, was criticised for being too wide as it could apply to religious orders, but worse, to "bikie" or Maori gangs (Social Development Council 1981). That the appearance of the family was changing was also seen in the growing demographic evidence (Waikato University Centre for Population Studies; Department of Statistics), although many of these trends had roots in the early postwar years and did not just happen as a result of changing lifestyles and attitudes in the 1970-80's. Families continued to get smaller with the fertility rate dropping to the average of 1.92 children per childbearing woman by 1986 . During the depression and war years there had been concern about the declining population, but by 1970 this concern had reversed as a world population explosion seemed imminent. Zero population

\footnotetext{
${ }^{14}$ Lecturer in Human Relations and Family Development at Victoria University of Wellington.

15

$10.6 \%$ a mother or father of child absent

$9.5 \%$ extended houscholds

$18.5 \%$ single person households

$6.1 \%$ non family households

(Dept of Statistics)
} 
growth became the goal for some, even in such a seemingly under-populated country as New Zealand. Professor Jim Rowe ${ }^{16}$ attacked the old view that New Zealand needed a bigger population and assured New Zealanders that:

You don't need a population growth to keep a buoyant economy. It's quite possible to achicve buoyancy by using monetary policy (N.Z.L. September 4 1972).

The Values Party, for example, called for more sex education, freely available contraceptive advice and liberal abortion laws to further hasten the population decline (Values Party Manifesto 1972), Dr Erich Geiringer ${ }^{17}$ indicated that half of the babies born were unplanned and that if only planned babies were born zero population growth would be achieved. Guilt and moral pressure were also recommended as tools of control, and Dr. Henry Heald ${ }^{18}$ told radio listeners:

Every time you come across someone who says "I'm going to have more than two children", you tell them they're socially irresponsible (N.Z.L. September 4 1972).

Such arguments however were probably not the reason for the falling birth rate. The cost of rearing children (Easton 1979) was becoming something to be offset against maintaining standards of living. The changing aspiration of women who wanted a life apart from motherhood was also a cause. Marriage and motherhood was being delayed for a growing number of women ${ }^{19}$, and spanned fewer years (Swain 1983) than in the previous generation. Changing economic circumstances meant that women were reluctant to take too many years away from the workforce. Living on one income was difficult for both working class and middle class families to sustain for long. Except for a few women entering highly skilled areas of work, women who were trying to pursue careers or find a job, still found it difficult to reenter the workforce after a break for childrearing and invariably re-entered into a job of lower status (SROW 1974: Vocational Training Council 1977; Beauchamp 1978)

The nature of marriage too was changing. Marriage and remarriage remained popular, despite the increasing popularity of de facto marriages, and despite the predictions linking the rising divorce rate to the collapse of marriage as an institution (Domestic Purpose Review Committee 1977). Swain (1983) suggests that marriage as an institution was changing rather than "collapsing". O'Neill identified a continuing trend towards the separation of marriage and fertility, particularly with the stigma of ex-nuptial birth declining and the increase of

16 Department of Economics, Massey University.

17 Secretary of the New Zealand Medical Association at the time, and a supporter of the Values Party.

18 Department of Sociology, University of Auckland.

${ }^{19}$ In 1971 the average age for a first marriage for women was 23.4 whereas by 1984 this had risen to 27.3 (Department of Statistics 1986). This rise however was in fact approaching the marriage age of the immediate postwar years when it had been 26.18 in 1946. From this date it had steadily decreased until reaching the 1971 figure which was its lowest in the postwar period. 
childlessness within marriage:

Sex and companionship are essentially available without the commitment implied by marriagc...(and) one of the remaining sociological rationales for marriage...the bearing and rearing of children...seems shaky (1981:13-14).

Pregnancy was becoming a less important reason for marriage as more women chose to rear their babies in de facto relationships or alone, and by the mid 1980's the ex-nuptial birthrate rose to one in four from one in ten in the early 1960's. However, in a Christchurch study of the 1977 birth population it was shown that $48 \%$ of the ex-nuptial births were to parents who were living together and furthermore that $19.6 \%$ were planned births (Koopman-Boyden \& Scott 1984). This indicated that the old criteria of linking social stability with legal marriage was on the wane.

Marital breakdown too was more visible, with the evidence of more women rearing children alone, and more reconstituted families through remarriage. The rate of marriage breakdown was labeled as a major problem with social agencies trying to stem the tide, or ease the stress of the process. By the mid 1970's politicians used the figure of one marriage in three breaking up (Domestic Purposes Review Committee 1977), but this was shown to be a misleading calculation based on the marriages versus divorces in any one year without taking account of the fact that these figures represented two different age cohorts (O'Neill 1980; Swain 1983). Swain (1983) estimated, for example, that the 1978 marriage cohort would have between a $15 \%$ and $35 \%$ rate of divorce in the long term. Amidst the evidence of changes in the structure of the family, was the reality of the growing independence of women who, even if they had children, had more chance now of surviving outside the older securities of marriage. This enabled a lot more flexibility in relationships, but for some this was indicative of instability bècause stability was equated with marriage (Above Rubies magazine).

Alongside these changes there was a cautious shift in government attitudes regarding the family. The Social Development Council's ${ }^{20}$ report Families First summed up the dilemma:

Government needs to decide whether its resources should be concentrated on the traditional nuclear family or allocated so as to support the many different sorts of families now in socicty (1981:5).

Government was being called upon to direct its policy towards strengthening family life. For many people this still meant that policy should discourage the increasing diversity, but there was a growing view that strengthening the family also meant providing policy that could accommodate diversity as opposed to "outlawing it" (Social Development Council 1978-9, 1981). For example, the 1980 Marriage Proceedings Act was to provide a no fault divorce after two years separation. This signified the acceptance by policy makers that the break-up of marriages was inevitable, and that tough legislation would not halt the process but rather make

20 The Social Development Council was set up as in independent body within the Department of Social Welfare. 
it disruptive to family life. The divorce legislation did not cause marriage breakup although immediately after the 1980 Act the divorce rate took a sharp upward turn but by 1984 this slowed as the backlog cleared ${ }^{21}$. The tug of war between the conservative and liberal views on family policy had also been seen after the Labour Government's introduction of the Domestic Purposes Benefit (DPB) to support single and separated mothers (and later fathers) who needed to care for children. The DPB represented a considerable shift in attitude as there had previously been no support for women who had children out of wedlock ${ }^{22}$. From its inception the DPB was controversial, particularly as there was a rapid increase in use ${ }^{23}$. Women now had the assurance of regular financial support as opposed to precarious alimony and maintenance support from fathers ${ }^{24}$. The Government had originally argued that the benefit was to prevent children being reared in poverty (Report of the Royal Commission of Inquiry into Social Security 1972), but the DPB was soon accused of encouraging the birth of children out of wedlock and causing marriage breakups. In an early attempt to stem the tide, the government reduced the benefit during the first six months of separation (Report of the Domestic Purposes Review Committee 1977), but this had little effect on the numbrs claiming the DPB.

While it is possible to trace the shifts in government attitude and policy there was also reluctance by government to proceed too far down a track which acknowledged the possible independence of married women apart from their husbands. For example the unemployment benefit could not be obtained by women who were in a de jure or de facto marriage. In terms of social policy, evidence of a sexual relationship was justification of a man's responsibility to support a woman financially. This philosophy applied also to the DPB. Entitlement to the benefit meant that there there could be no sexual relationship that might appear to be in the nature of a marriage. Thus, while the government made concessions to accommodate "problems" arising from changing values and family structures, there was little shift in the assumption that women were financially supported by men and would/should be at home rearing children while men were in full time employment (Koopman Boyden \& Scott 1984).

21

19715.15 per 1000 marriages

19809.1 per 1000 marriages

$1982 \quad 17.2$ per 1000 marriages

198412.6 per 1000 marriages

(Dept of Statistics)

22 Pregnant women had been eligible for the sickness benefit and this had been extended for as long as they were breastfeeding the baby. There had been a further system of emergency domestic purposes benefits for some but they were difficult to get.

23 In 1970 there were 3092 women receiving a domestic purposes benefit but there was no right to have it and it was difficult to get.

$1975 \quad 17,231$

$1977 \quad 28,401$

$1980 \quad 27,040$

$1985 \quad 56,548 \quad$ (Dept of Social Welfare)

24 Women had to obtain a maintenance order or to enter into a maintenance agreement to be eligible. Maintenance was paid directly to the Department of Social Welfare who guaranteed the full benefit to the wife. (Later men too could receive the benefit and the reverse procedure applicd.) 
The key to government initiative was in promoting the desirability of stable families as a means of fostering acceptable behaviour and values (Ryan 1984). Diversity was tolerated and supported if it was seen to enhance stability; otherwise government policy was cautious.

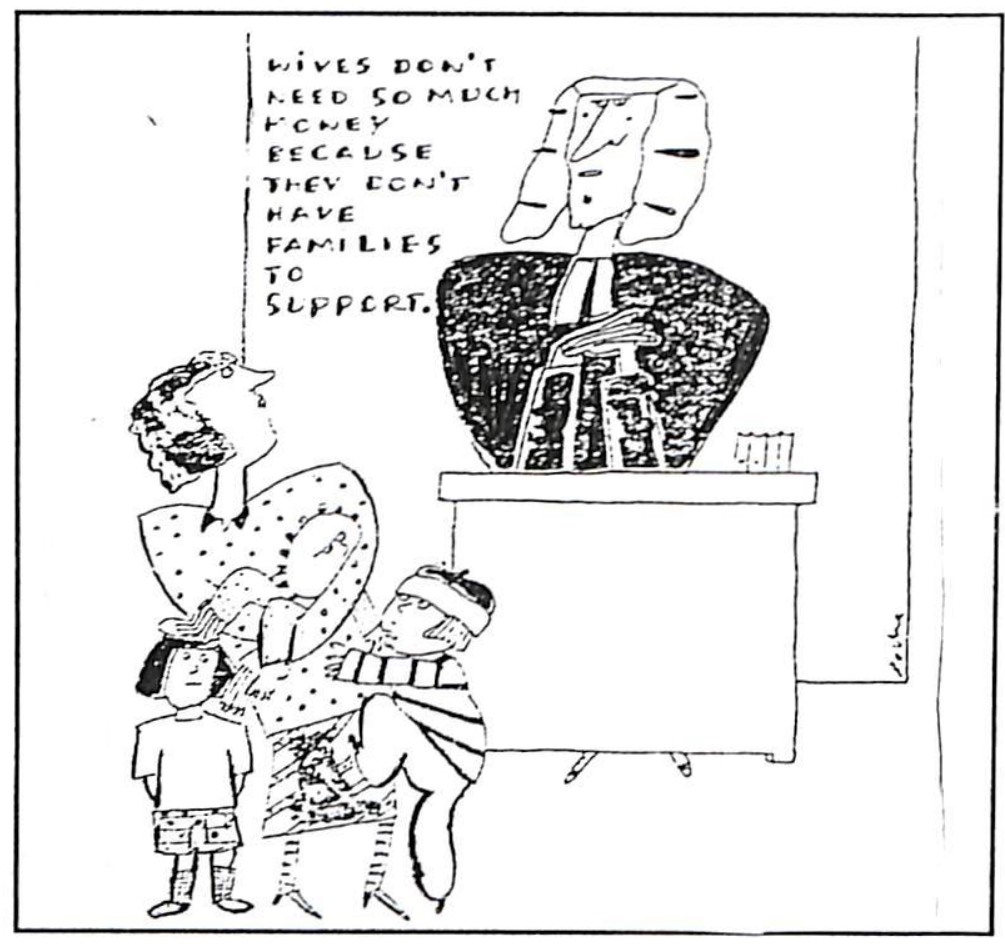

\section{THE CHALLENGE OF THE WOMEN'S MOVEMENT}

Women's liberation is an extraordinary cause. In an age of minority assertiveness it makes claims for half the population (N.Z.L. October 15 1973).

The visit of Dr. Germaine Greer to New Zealand in 1972, and her subsequent arrest for using the word "bullshit" brought full media attention to the new ideas of women's liberation. The fact that her book The Female Eunuch (1971) sold 8000 copies in six weeks of its release (N.Z.L. March 27 1972) was evidence of the intense interest. It was not only the new ideas which were a challenge, but many New Zealanders were uncomfortable with Germaine Greer's image of liberated womanhood. She was educated and articulate in the language of the gutter and of academia, independent and sexually liberated, bra-less and even knicker-less. Her image and tactics reinforced the militant style of the women's movement. The Listener (March 27 1972) reported:

The message of Dr Greer carried to New Zealand women was one of defiance and activism. She showed how women have been deprived or castrated of a basic energy. Women can regain this energy by becoming aware of themselves through sexual and economic autonomy.

A milder home grown challenge came in Sue Kedgley and Sharon Cederman's book The Sexist Society which set out to show a society saturated with sexism. The message was:

Women's liberation is not just removing the obvious discrimination against women...liberalising abortion laws, frce contraception, childcare 
centres. All these things assist women in gaining control over their lives...but they are only partial measures. The real liberation takes place within you. It affects your whole life style. It is a way of life (1972:7).

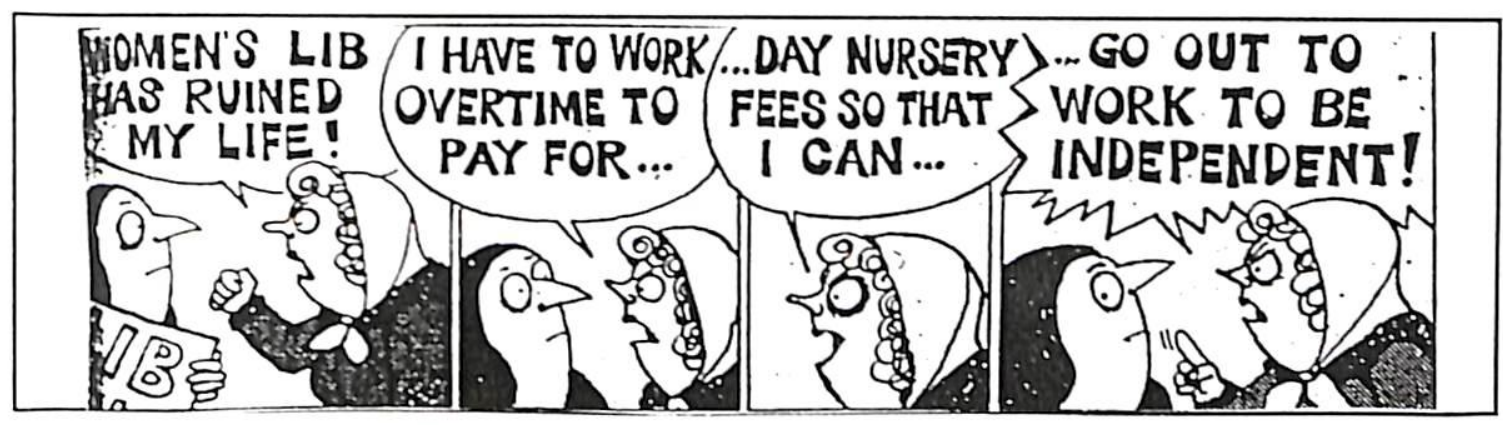

These messages challenged the earlier maxim that there was already equality between the sexes and that it was up to women to negotiate or pursue equality individually. The new politics of women's liberation embraced the concept of women's rights. The argument now was that marriage and childrearing should not preclude a woman's right to sexual and economic independence. This challenged the view that equality between men and women was vested in their different roles and responsibilities towards each other. The tension between these views is evident in the analysis of the life histories of the women in the this study, who express confusion and uncertainty about their efforts for example to balance their responsibilities of motherhood with employment. It was also evident in the confusion of policy makers who tried to make provision for equal rights legislation in the public sphere while continuing to assume that the protection and security for women lay within the private sphere of the family. These embodicd contradictory concepts of equality.

An important maxim of women's liberation was that the "personal is political". There was a new analysis from both overseas and within New Zealand, of the "taken for granted"and "private" aspects of women's lives. This was to reveal the depth of discrimination against women: in health (Boston Women's Health Collective 1979; Calvert 1982), sexuality (Greer 1971; Dann 1985a), mothering (Oakley 1979; Phillips 1983), houscwork (Oakley 1974), education (Spender and Sarah 1980, Middleton 1985b), work (Novitz 1976; Shipley 1983), childcare (McDonald 1978; Cook 1983). Femalc anthropologists (Rosaldo and Lamphere 1974; Friedl 1975; Kessler 1976; MacCormack and Strathern 1980) demonstrated the breadth, pervasiveness and diversity of inequality cross culturally. A frequent theme was the links between the childrearing role of women and the lower status ascribed to them.

There were many dimensions, strategies and kinds of happenings within the loose framework of the women's movement: consciousness raising at home and in the workplace, new kinds of writing and research, campaigns over equal pay, abortion, pornography, sexual harassment and childeare; new kinds of community services that aimed not only to redress wrongs but to empower women to make choices for themselves; new endeavours by women to seck power in the establishment institutions; a series of United Women's Conventions (1973, 
1975, 1977, 1979); and a huge growth in organisations and groups providing workshops, courses, seminars, discussion groups, advisory groups reappraising the situation of women in society (Sissons 1982). While there were shared belicfs that women were missing out on opportunities and that women needed more support in their traditional roles of childrearing caring and servicing, the Convention cry of "United We Stand" was too optimistic. The women's movement could be broadly divided into two camps based around liberal and radical ideological frameworks (Jagger and Struhl 1978), and an analysis of the activitics of the womens' movement reveals the differences between these two versions of liberation (Eisenstein 1981). Although there was often agreement amongst feminist groups over issues like childcare, abortion, anti discrimination legislation, organisations and individuals had different agendas concerning the "ends" of womens' liberation. A liberal ideology generally supported the political and economic status quo, but argued that women were discriminated against and lacked opportunity to succeed (Women's Electoral Lobby 1978; National Council of Women 1974). A radical view stressed that women were oppressed and that this oppression was rooted in the capitalist and patriarchal institutions of our society (Goodger 1974). These versions of liberation could not always be separated so neatly and for many women pragmatic politics dictated that the liberal concerns about discrimination be the focus. Amongst early supporters of both ideologies there was sometimes a euphoric optimism that they could create rapid and/or radical changes. As Sue Kedgley recalled the early 1970's:

In those day I felt quite messianic about changing the world. Nowadays I don't have the same zeal...I think it is more important to change yourself...To me being a feminist is living life by your own rules (N.Z.W.W. April 13 1987).

Pragmatism also affected the kinds of activism surrounding the issues feminists deemed important, as Helen Wilson ${ }^{25}$ stated in a letter to Broadsheet (December 1982):

Now the impetus seems to be in self help and therapy groups and the basic demands like childcare, sex education, fertility control and abortion are obscured.

Wilson followed Zillah Eisenstein's (1981) maxim that such liberal endeavours had radical potential because the process of reform could reveal the depth of discrimination.

In the early days "women's libbers" were regarded with derision or scepticism. While some of the "liberation" activities did focus on the outragcous, the media found it difficult not to trivialise and ignore the real issues that women's libcration was addressing (Kedgley 1972; Dann 1985b) ${ }^{26}$. However, as the the depth of support for change became apparent, the attitudes

25 Organiser and activist in in the radical women's group Women's Organisation for National Abortion Action Committee (WONAAC).

26

This concern turned into outrage at the 1973 United Women's Convention, held in

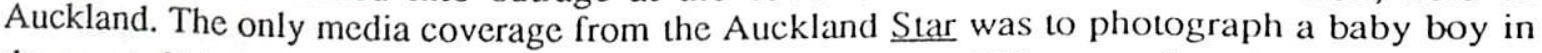
the arms of his mother, with a caption stating that the boy would have preferred to have been at a Rugby Test which was held in Auckland on the same day (Reported in Scott, N.Z.L. October 8 1973). 
of those in power began to shift. In 1973 the Labour Government established a Parliamentary Select Committee to investigate the extent of discrimination against women and "to recommend policies for its elimination". The issues addressed were wide-ranging and the publication of the report, The Role of Women in New Zealand Society coincided with the publicity of United Nations International Women's Year (I.W.Y.) in 1975. The Committee believed that the inequalities of women stemmed mainly from the "traditional acceptance of the assumption that men and women have essentially different roles". They believed too that a "comprehensive approach" would be needed (1975:103). The focus of recommendations however was much narrower and concerned with the role of government. This role was contradictory because the Government was still voicing its commitment to uphold and protect the traditional family unit and assumed that women would service and nurture its members ${ }^{27}$. However the fact that many feminist women with children were living in the traditional family unit and had responsibility for rearing children, meant there was no groundswell for any economic or domestic policy which might undermine this. Government did give new legislative protection (i.e. Equal Pay Act 1972, Maternity Leave and Protection Act 1976, Matrimonial Property Act 1976, Domicile Act 1976; Human Rights Commission Act 1978), but there was, by contrast, a minimal allocation of financial resources in terms of services and support to women to release them from their childrearing and domestic responsibilities. Despite some early optimism, Marilyn Waring's report What's Been Done (1978) showed the extent of government inaction. Government was in fact selective. For example, on the issue of women's rights in the workforce, government moved with reasonable speed towards the implementation of equal pay for men and women doing the same job; was slow in implementing policies of equal opportunity through training and recruitment; and avoided and often opposed the issue of childcare provision as a support to women in the workforce with children.

Government gave support to International Women's Year in 1975, although Christine Dann wrote later of the scepticism felt about this:

Women's liberationists greeted it with mixed feelings. They welcome government support for feminist activities, but they did not want government control. Government was top heavy with men, hierarchial and bureaucratic as well. These characteristics of government assistance were unwelcome to the women's liberation movement for they contradicted the movement's aim of empowering women (1985:18).

After IWY there was a series of initiatives between women's groups and government departments to examine the inequality of women. They included: the Conference on Education and the Equality of the Sexes (1975), Women in Social and Economic Development

27 For example, this can be seen in the Government statements opposing any expansion of childcare services:

Minister of Social Welfare. Press Statement January 191974.

Department of Social Welfare statement to the Women in Social and Economic Development Conference 1976, Wellington.

Department of Social Welfare statement to the International Labour Organisation 1977. 
Conference (1976), Women and Health Conference (1977).These were a first attempt to mesh feminist demands for women's rights, with the more cautious moves which government departments were prepared to take. For example, after the Conference on Education and the Equality of the Sexes, the Department of Education set up a National Advisory Council on Women's Education (NACWE) and appointed a Women's Education Officer ${ }^{28}$. There was an acknowledgement that structural barriers were denying opportunities to women and girls (Whitcombe 1980; Middleton 1985b), and thus began a reappraisal of the extent of sexism in the school curriculum. The process of identifying sexism and of challenging the political power of men was not something all male politicians were comfortable about, and in reply to the Women's Electoral Lobby (WEL), who wanted more women placed on statutory boards, the Prime Minister Mr Muldoon was to retort that he would only have, "Well balanced women" and "not beady eyed women who shouted slogans" (Star March 14 1978). Even so, from the mid-1970's there were efforts by successive governments and political parties to reflect some kind of women's viewpoint. In 1984 under the new Labour Government the Ministry of Women's Affairs was established, although amidst some controversy. Radical women saw it as a further exercise in taming the voice and activism of women (Broadsheet May 1986), while conservative women's groups set out to take over the Women's Forums set up by the Ministry to hear the concerns of women (Pryor 1985).

In 1985 there were attempts at a celebration for the end of a decade after IWY. Women who had been involved in the women's movement for some years were able to identify changes but saw the road ahead as just as long and hard and not the transformation they had hoped for (Broadsheet July, August 1985). There was evidence of a heightened consciousness by some about the disadvantages women experienced but the evidence suggested a gap between the new idealism of what was now possible and the reality of what women actually did. The National Council of Women (NCW) stated in relation to their end of the decade survey, that they had assumed that there would be:

Seemingly more confidence and assertiveness...In fact the survey showed that for some women there had been little change. Many women did not know a lot about changed laws...Change was not scen as positive by some women. There was nervousness that change might make things worse (1985:150-1).

In its challenge to the values and institutions of New Zcaland society the women's movement has been perceived by many men and women as threatening rather than liberating. Feminist ideas challenged the traditional assumptions about how society should be ordered in relation to the roles and responsibilities between men, women in the home, the workplace and towards children.

Some men were to attempt to deal with the challenges by taking on more

28 These were both lost under the 1982 "Cuts" campaign by the National Government, but then re-established in a different form by the 1984 Labour Government. 
responsibility for domestic and childrearing tasks. A few tried to explore the idea of male liberation or a men's movement (Donnelly 1977). In the earlier postwar years the quest by women for independence and equality did not question the role of men as breadwinners, but this time men were being challenged to change their attitudes, and to exchange some of their economic and political power. While there were men who were supportive of the ideals of the women's movement, many felt uncomfortable and threatened when the challenge was personal.

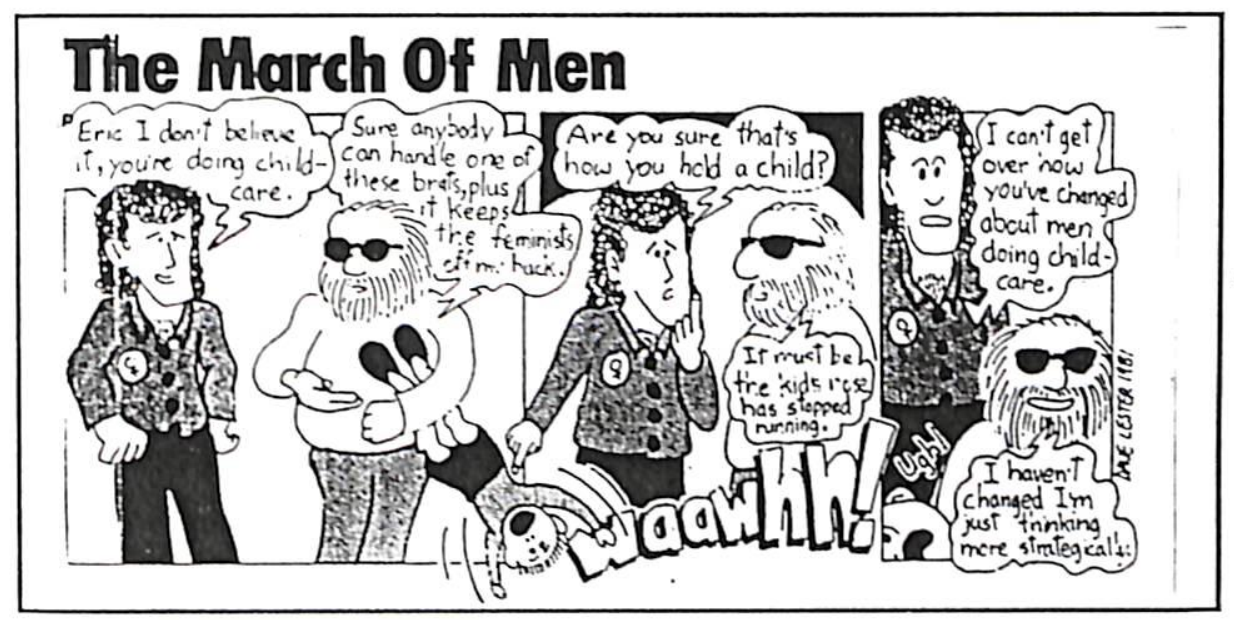

When demands from women forced changes to men's lives, or needed a reallocation of resources, or a new style of decision making, there was conflict. The NCW (1985) survey found that $53 \%$ of men felt that the women's movement had made life more difficult for them, although $77 \%$ felt that it had had a beneficial affect on men in general. In an appraisal of Pakeha male culture, Jock Phillips (1987) argued that while the women's movement encouraged some men to reorder the older patterns of domestic roles, the extent of response by other men was limited more to giving help with childcare or assistance in the kitchen so that their wives could have a few hours off.

The increasing participation of women in the workforce served to alter the role of the male breadwinner, although the concept of the breadwinner's roles was still strong with few men feeling able to opt into part-time work or to stay at home. In the early postwar years the male breadwinner's role was sacrosanct in the sense that ideally it was supposed to support a family. As early chapter's showed, women worked to uphold and support it, and a married man was judged by his ability to be a "good provider". By the 1980's, the nature of this support had changed. Not only were more married women working, but they did not go to such lengths to give the appearance of being a wife and mother at home. It was being accepted that while a breadwinner's wage might still be the mainstay of a family's income it needed extra support. Paid work reinforced the independence and self sufficiency of women, particularly in the sense of weakening male control over spending decisions in the family. (Barbara Ehrenreich (1983) argued too, that as the possibilities of economic independence for women increased, there was a "flight from commitment" by American men to provide the economic security for women and 
children that they had previously felt bound to as part of their masculine role.)

The old divisions between men's work and women's work were still strong. It was, in the main, educated women moving into skilled jobs who were were able to achieve some kind of equality, but one that they often saw as tenuous, and which placed them at the lower end of the promotion - wage scale (Wilson 1986).These shifts are caught amidst an imbalance between the ideas of equality and independence for women which some did achieve, the realities of the home in which women continued to have the major responsibilities for childrearing, and a workplace in which women only earned $75 \%$ of the male wage, and where there was still strong gender divisions .

\section{CHILDREN HAVE RIGHTS TOO}

The childrens' rights movement springs from a belief that children born in God's Own Country, are a deprived minority. It supporters are out to challenge the reassuring old myth that New Zealand is a paradise for the young (du Fresne 1979:11).

By the 1970's the permissive style of childrearing that had begun in the early postwar years was more accepted (Hardyment 1983). In the 1940-50's parents were expected to "control" their children in the interests of an ordered society - although not too harshly. By the 1970-80's parents were expected to be tolerant towards their children and not necessarily to blame themselves for what went wrong.Child management was, in the words of Kate Birch (1984:2):

To help children become "their own people"; it is not for ...controlling children...but for developing potential in both parents and child.

Such expectations, however, were the messages found in the childrearing literature and do not necessarily reflect what parents actually did with their children. McKinlay (1983) had linked permissiveness with the idea of "motherhood as a service" in which the mother's priority role was to service the needs of the child. For the 1970's McKinlay identified a new style of childrearing in which some mothers tried to service their own work and leisure needs alongside those of their children. The style of childrearing could still be permissive but these women sought to share the role of mothering with others. Childrearing literature reflected a shift from viewing the child as a delicate emotional and physical object that needed the total attention of the mother (Spock 1946; Deem and Fitzgibbon 1948; Bowlby 1952), towards a view of the child as still precious but a problem and a cost to adults (Gribben 1979; Phillips 1983). Parenting, or more specifically motherhood, was something to be survived and parents needed to be taught survival skills. Childrearing also was presented as an option (Maharey and Maharey 1979; Dowrick and Grundberg 1980). This was all in contrast to the child-orientated focus of the early postwar years. Magazines like More and Metro presented images of women whose lifestyles did not include children. There was increasing separation of the childrens' world and the adult world in terms of space and activities (Cook 1985d). For middle class families the family room became the popular addition to get children and their mess out of the lounge. It was argued that children were a luxury and economist Brian Easton calculated the cost of 
children to illustrate the sacrifice families made in their material standards of living to raise children ${ }^{29}$. Easton was concemed that families were becoming poor because they were involved in what he deemed to be New Zealand's most important industry - childrearing.

The postwar support and services for families had been intended to cure society's ills by rearing a generation of children who were healthy, emotionally well adjusted and happy. At the same time there was a new appraisal of the quality of childrens' lives and a challenge to the assumption that all was well. In 1972 the Minister of Social Welfare Lance Adam Schneider had stated that, "It is pleasing to note that...child abuse is not a problem of major social importance in New Zealand" ${ }^{30}$. But by the 1980's there was public acknowledgement that the family was not necessarily a haven of security and kind nurture for children, but that it was often a violent and unhealthy place (Geddis 1979; Saphira 1981). The evidence of physical abuse, sexual abuse, and neglect of children, was at last breaking down the codes of silence around such issues. The health of children continued to cause concern, along with the poverty in which some children were reared (Easton 1979). Continuing revelations of this kind were to dim the belief that New Zealand was a great place for children (Swain 1980), and these views acted as a catalyst to a fresh reappraisal in the rights of children. An image of the child as a victim emerged along with the acknowledgement that the interests of children were not necessarily synonymous with those of their parents (McDonald 1978), or with institutions providing services for children (Cameron et al 1980). 1979 was designated as International Year of the Child (IWC) and became a newsworthy forum to express these concerns. Dr Geddis, the Director of Medical Services for the Plunket Society, stated:

Unlike the rest of society, children are powerless to act themselves. They have no vote, no economic power, no means of asking for themselves and little chance of being heard even if they do. There is currently no effective voice talking solely for children (N.Z.L. June 30 1979).

The Committee for Children ${ }^{31}$ was formed as a result of IYC to act as a childrens' voice, although moves to protect the rights of children had begun earlier. In 1969 the Status of Young Children Act had removed all legal disabilities of children born out of wedlock and the term illegitimacy was removed from the statute books. The 1974 Children and Young Person's Act deemed that "the interests of the child shall be paramount" in any care arrangements. The Act gave children legal protection in the courts as well as giving the Courts the right to remove children from the care of their parents ${ }^{32}$. In 1976 a Steering Committee set up by the

29 The first child caused a $40 \%$ cut in the parents material standard of living. Subsequent children caused cuts from $20 \%$ from the second child to $12 \%$ for the fifth child (Easton 1979).

30 Department of Social Welfare Report on Child Abuse (1972). This report however only documented the 150 child abuse cases uncovered by child welfare officers. A report in 1987 revealed that $80 \%$ of children in the care of social services had been sexually abused at sometime while in care.

31 This acted as a children's "voice" and a lobby group over policy issues before government.

32 There were still many concerns about the practices carried out under this Act and by 1987 
Christchurch City Council considered a Bill of Rights for children. The Sutherland Report, as it was subsequently called, took a view that many parents were neglectful and/or incompetent. They thought, for example, that where possible mothers should not work but stay at home with preschoolers. This view was by then out of step with the economic reality of women's lives and with the aspirations of many women for a release from full-time childrearing. The tenor of the Sutherland Report revealed the inevitable conflict between the view that a child has a right to be cared for in the family and preferably by the mother, and the view by some that for women to gain equality with men they must participate in public life. Throughout the period women-who did work with young children were accused, and most often by other women, of sacrificing the quality of their childrens' lives to meet their own needs (Rendall 1987).

The quality of childrens' life was also being addressed through research.That of Jane and James Ritchie (1970) showed that New Zealand mothers were harsh disciplinarians of their children because they were fearful of spoiling or losing control of them. In a radio interview James Ritchie stated that:

If our data is representative, today one in every five children will be spanked. This week one in 2.5 will be...We don't know how often threats are used the chances are six in ten she will follow through (N.Z.L. August 12 1970).

Throughout the period Jane and James Ritchie were part of a growing number of childrearing professionals calling for the abolition of corporal punishment in the school and in the home. A later book, Spare the Rod (1981), pursued the Ritchies' concern about any kind of violence as a punishment for children, but this was probably not a view the majority of parents shared.

A different kind of challenge to the power wielded by adults over children was seen in the publication of The Little Red School Book (1972). This was a frank reference book for adolescents on questions about school, sex, drugs, teachers, authority. Public interest spiraled as the book was held up by the Indecent Publications Tribunal because of its explicit sexual material. Probably of deeper concern was its incitement to children to question and rebel against schools and authority. In reviewing the book educationalist Jack Shallcrass wrote:

The 15,000 copies around the country may be time bombs of confrontation or a source of co-operative energy and some teachers and principals will fell threatened by the prospect of shared rather than imposed authority (N.Z.L. April 17 1972).

The growth of a small alternative school movement reflected the disaffection by some people with traditional structures and styles of learning. These were established, usually by parents, to redress the balance concerning the rights of children to self determination and participation in the learning process. The seeds of these came in part from the alternative lifestyle movement but also from the growing publications on radical educational alternatives ( Holt 1965; Illich 1971; Reimer 1971; Freire 1972). Such schools flourished for a few years but like the communes most eventually were to close; the effort and dedication to provide education outside

the Children and Young Person's Act was being reviewed. 
of the state system without the endowments or fees of other private schools was too great. Their existence was a challenge that caused some schools and parents to re-examine the values and structures they imposed on children. On the other hand from the mid-1970's there was a growing number of fundamentalist christian schools particularly in the preschool and primary areas which espoused a lifestyle of separate spheres for men and women, conservative views of morality, and taught a curriculum backed by bibilical teachings.

New kinds of early childhood education services grew during the 1970-80's to recognize the changing role of women and new attitudes to childrearing. The Hill Report $(1971)^{33}$ was the first government inquiry into early childhood education since 1947 but it lacked imagination and suggested no great changes in direction despite the growing evidence of changing family needs (Sutch 1973). The Report recommended further funding and support for the kindergarten and playcentre but failed to address the need for childcare support except to recommend that the community should be encouraged to initiate provision. The means for such encouragement were not given and neither did they materialise. Instead childcare services grew of their own accord ${ }^{34}$ as an alternative to the kindergarten or the playcentre. There were several new ideas underpinning the growth of childcare provision:

- That women's childrearing responsibility was a barrier to equal participation in society.

- That children did not necessarily need full-time mothering.

- That the idea of childcare embodied the idea of education.

- That all children were entitled to quality care and education whichever service they attended. This view was given support by a later inquiry into early childhood education The State Services Commission Report on Early Childhood Care and Education (1980).

Childcare centres, which had earlier been viewed as a last resort for those parents who "had to work", were now servicing a growing number of parents who regarded childcare as good for family life and good for their children. Nevertheless Duilia Rendall, a single working mother, recalled the attitude from playcentre and kindergarten people to this idea as being "cool":

Really and truly if we were being proper mothers we would be using kindergarten or playcentre, but given the obvious fact that we weren't "proper mothers" and we were going to use childcare anyway, well they had better do something about childcare too (1987:27).

There was also a challenge to Bowlby's (1952) theory of infant attachment and maternal deprivation. It was now argued that the crucial thing was the quality of the care itself rather than the emphasis on the care always being provided by the mother (Rutter 1972; Clarke and

33 The Report of the Committee of Inquiry into Preschool Education.

34 In 1970 there were 8,437 childcare places. This had increased to 17,671 places by 1985 . Some of these would be in sessional centres where more than one child would be using each place. 
Clarke 1976). Although Bowlby's own work probably was not widely read, his ideas however were widely promulgated in New Zealand (McDonald 1977), and continued to be reflected by the reluctance of government to support any services that appeared to encourage the separation of mothers and children. Geraldine McDonald wrote:

The existence of playcentres and kindergartens has meant that many mothers are not expected to rear their children entirely unaided. (But) if one examines the structure of these preschool institutions however one can see that they are designed to ensure that women are not relieved of any responsibility for their children (NZCER Set 77, No.1).

The 1972 Labour Government had come to power with a commitment to early childhood education and a brief to "do something" about childcare. The government however was not comfortable with the new rhetoric of the women's movement and did not want any moves to be interpreted as directly supporting feminist demands. In 1973 they tentatively brought in the first support for childcare by introducing subsidies to parents who could not afford fees. The Minister of Social Welfare, Mr Norman King, assured the public that despite this "first venture", "normal family life should remain the paramount unit for childcare in the community...we have not and will not design a scheme which will encourage mothers to place their children in care unnecessarily" ${ }^{35}$. This became the basis of the government's commitment to childcare and successive policy statements reflected this attitude:

Successive governments have been very reluctant to see any policy change that would tend to encourage mothers in general towards believing that mothers are "workers" in that they are "key operators" in the most important "industry" in New Zealand's future...The Government has been no more interested in creating conditions suitable for "working mothers" than it has been for creating conditions which would enable mothers to hold down two jobs simultaneously (Dept of Social Welfare 1977).

This particular statement which was prepared for the International Labour Organisation, caused an outcry from feminist groups and had to be withdrawn amidst criticism of its "archaic attitude towards women". "It was to be more diplomatically phrased", conceded the Director General of Social Welfare (National Business Review September 21 1977). Subsequent statements were more "diplomatic" but there was little shift in government's views until 1984 when the Labour Government endorsed the Social Advisory Council's view which stated that, "Childcare services have become an integral part of everyday life for many families...the time has come for a concerted programme of action to encourage their optimum development for the well being of children, parents and society" (1985:32). By 1985 there was more acceptance that the needs and rights of children need not necessarily be pitted against the needs and rights mothers, and it was being argued that government policies towards families and early childhood services should be in the interests of the family as a whole and should not be used as a tool to constrain the options of families by only supporting half day services (Cook 1985d). There was however a

35

Address to the New Zealand Childcare Association's 1974 Conference. 
gap between the rhetoric of political policies and the reality of the actual funding support to childcare services. By the mid-1980's the users of childcare services were mainly middle class parents as they alone could afford the fees. It was therefore easier for middle class women to balance their work aspirations and childrearing duties through the purchase of childcare. This was less of an option for working class women, who tended to use childcare when there was an emergency when maybe they became eligible for a welfare subsidy.

\section{CONSERVATIVE CONCERNS}

There are those who claim ours is a sick society, well maybe they're right...but I am sick of having policemen ridiculed and called "pigs" while cop beaters and rabble rousers are hailed as some kind of folk hero...I am sick of permissiveness. I am sick of the dirty, the foul mouthed, and the unwashed (N.Z.W.W. October 18 1970).

During the street protests of the late 1960's it was evident that many men and women felt affronted at the apparent disruption to order but also to the challenge to established values. Throughout the 1970's as new ideas and values permeated through the social and political institutions, the existence of divisions became more evident. Groups with both conservative and radical concerns became more vocal and organised, and political parties had to steer a safe course through the extremes. When government appeared to be shifting towards more liberal views of morality, groups emerged espousing views that the family would be under threat. Feminism was often proclaimed as the convenient enemy as Neville Rush, founder of the Christchurch Integrity Centre, outlined:

The feminist movement is seeking to undermine the traditional structure of society by encouraging free sex, an irresponsible attitude to parenthood, and the assuming of unnatural roles in the workforce (Neville Rush N.Z.L. May 22 1982).

There has not been a cohesive Moral Majority on New Zealand's political scene, as in the United States, but rather a diverse network of groups ${ }^{36}$, often possessing a strong Christian philosophy, conservative attitudes towards sex, and a traditional view of family life based on feminine submissiveness and separate spheres (Openshaw 1983). These groups, which had strong support by many women, combined over specific issues. The task of group members was not only to live lives that upheld traditional values of family life, but also to be political activists when the status quo appeared threatened. From the mid 1970's there were a series of explosive campaigns as radical and conservative groups fought to sway the public conscience and the politicians vote. In campaigns over abortion and childcare it was apparent that women held differing views over the right of women to have autonomy apart from their born or unborn children. From a conservative perspective, aborting a fetus or placing a child in childcare were similarly condemned except for the most extreme circumstances. In contrast the liberal

36 For example, Concerned Parents Association, Society for the Protection of Community Standards, Feminists for Life, League of Rights, Society for the Protection of the Unborn Child, Family Rights Association, New Zealand Working Women's Council Incorporated. This list came from Above Rubies, a conservative magazine for women. 
perspective saw abortion and childcare as an optional right for women. The depth of division between liberal and conservative views over women's rights was first seen over the issue of abortion.

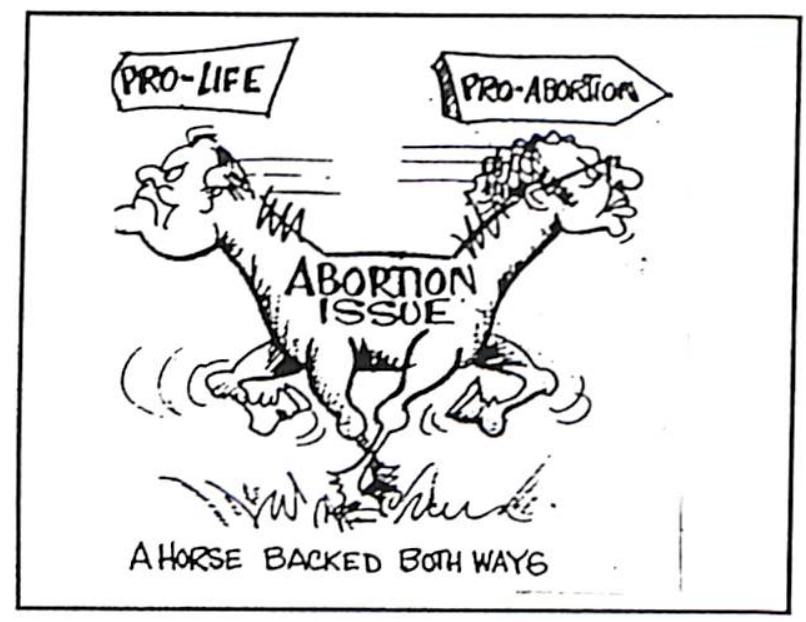

The Society for the Protection of the Unborn Child (SPUC) had been formed in 1970 in response to overseas trends towards liberalising abortion laws. The issue in New Zealand erupted when a clinic was established in Remuera to carry out abortions, using a liberal interpretation of the 1961 Crimes Act ${ }^{37}$. Thus began a series of actions culminating in the controversial Royal Commission of Inquiry into Contraception Sterilization and Abortion, and the eventual cautious government stance taken in the Contraception Sterilization and Abortion Act in 1977. This allowed for abortion clinics but introduced tight criteria and screening procedures and Allanah Ryan was to write that the abortion debate was not:

Simply a moral issue regarding "life" but rather...one involving - competing ideologies about society, sexual relations and most specifically women's role in society (1984:16).

These kinds of divisions also surfaced over the Johnson Report (1977) recommendations for sex education in school, the demand for childcare services outlined in the Working Women's Charter (1978), the proposed ratification of the United Nations Convention on the elimination of all forms of sexual discrimination, and the Homosexual Law Reform Bill. So effective were the campaigns from conservative groups that the respective governments of the time inevitably came down on the side of caution ${ }^{38}$.

Conservative groups made strong links between preserving the traditional values in the

37 The clause on the mental condition of the mothers as being a relevant criteria for assessment for an abortion was interpreted liberally.

38

The Johnson Report was shelved

Childcare funding was delayed until 1982 and then it was only minimal (Cook 1985d).

The National Government was not going to ratify the United Nations Convention, although the 1984 Labour Government did so.

The Homosexual Law Reform Act 1986 narrowly passed a clause decriminalising homosexuality but homosexuals were given no protection under the Human Rights Commission Act. 
home and the well-being of the country as the slogan said "Save Our Homes - Save the Nation" While the campaign strategies coalesced around specific moral issues, magazines like $\underline{\text { Above }}$

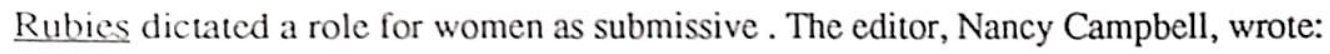

It is still the best way for a husband to love his wife as much as he loves his own body. It is still the best way for a wife to reverence and submit herself to her husband. It is still the best way for children to be disciplined and to obey their parents.(April/May 1983:2).

This view was to challenge the feminist version of a liberated woman who no longer needed to rely on the financial securities of a husband as breadwinner, or to whom childrearing need be no constraint to equality. The feminist version of sexual and economic independence for women was seen by conservative groups as threatening the stability of society by destablising the family. For example, the M.P. R. Talbot ${ }^{39}$, argued that the liberalised abortion and contraception laws would:

Shatter the very foundations of our society...such issues which if allowed to go unchecked would shatter completely family life and community and social standards generally (Hansard 1977, quoted in Ryan 1984:17).

The concern for containing sexuality within the confines of marriage, and the prescription of a primary role for women as wives and mothers at home, were at the core of the conservative ideology. This reaffirmed the provision of security for women within the home, and preached that the confusion, violence and insecurities caused by new values could be controlled. The home was a protection for women. Angela Dworkin wrote:

The Right offers women a simple fixed predetermined social, biological, and sexual order. Form conquers chaos (1983:22).

These ideas vested the protection and security of women in the family, and in the benevolence of men. This was in contrast to feminist ideals which sought new kinds of security for women in the world outside the home and apart from men. The new conservatism was reformulating values that had been relevant and generally supported during the early postwar years, but they were just as new as the radical feminist values. They were complementary. Both were forged in new circumstances, except that one looked forward to a new utopia and one looked back in time to rekindle an ideal of more clearly defined relationships for men and women vested in the attitudesof dominance and submissiveness. These different values underlying the relationship of men and women had been simmering beneath the surface in the 1940-50's, but it took until the $1970-80$ 's for them to be constructed into visible divisions of conflict.

39 Member of Parliament for Ashburton. 


\section{TEXT ONE: A PAPER DIALOGUE 1970-1985}

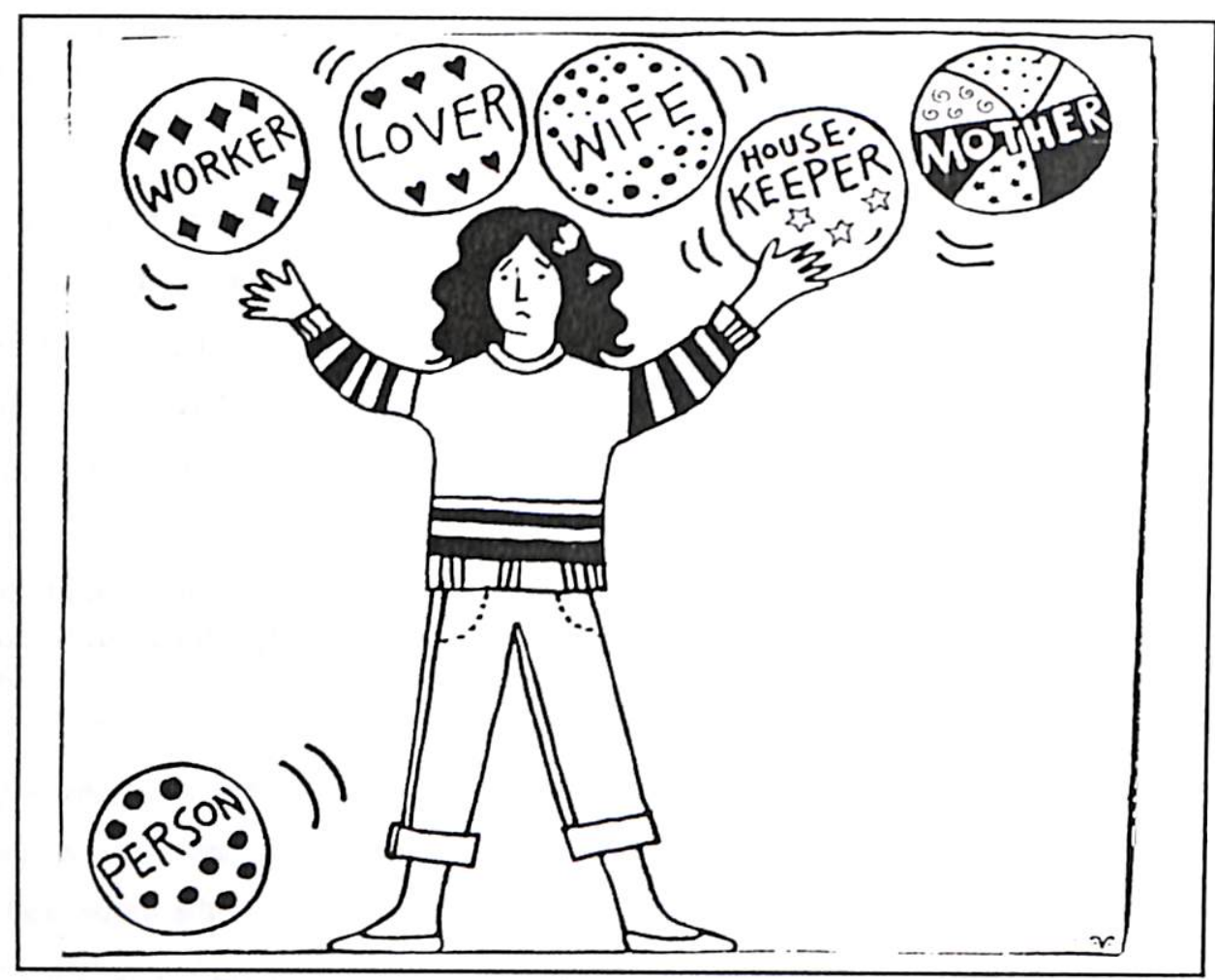

In contrast to the colourless images and staid advertising of the 1950's Woman's Weekly and Listener magazines, the 1970's versions were a kaleidoscope of colour and style. Both magazines were larger and had to contend with more variety and competition in the market. They had, however, remained popular by carefully accommodating to changing attitudes without moving to the extremes of opinion. Both magazines were important forums for debate on social change $^{1}$, and writers found fertile copy in the debate over women's issues. Magazines like Broadsheet $^{2}$ became a forum for feminist women, while at the other end of the spectrum the glossy magazine, $\underline{\text { Above Rubies }}^{3}$ espoused a lifestyle which claimed to support traditional religious values. There were also attempts by magazines like Thursday, Eve and More to target particular groups of women by age or economic status, but none of these other magazines spanned the whole period. The tenor of debate about women in the Woman's Weekly and Listener was not dissimilar to earlier years: how to balance home and outside responsibilities, and how to accommodate personal needs versus those of husbands and children. The emphasis had, however, shifted from focussing on the home and how women could perhaps fit in some

\footnotetext{
${ }^{1}$ Research by the Federation of University Women (1976), showed that 402 out of the 1,000 women interviewed regularly read the Woman's Weekly, and it was noted that such magazines were in many cases the only material women were reading.

${ }^{2}$ Broadsheet was first published in 1974.

${ }^{3}$ Above Rubies was first published in 1978.
} 
outside interests and/or employment, to a focus outside of the home, with suggested strategies to help re-organise the home and family. As for the "Lady Juggler" of earlier years, life was still a balancing act, but now the argument was that personal fulfilment was also important. There were endless guidelines on how to "do your own thing", although it was still considered important to keep the husband and family happy. It was suggested that the family could make some accommodation, because "doing your own thing" deserved an allocation of time that might overlap one's duties as a wife, housewife and mother. In mainstream magazines like the Woman's Weekly and the Listener there were less dogmatism, more subtlety, a greater variety in the codes which defined roles and responsibilities, because opinion was more obviously divided. The messages were still confusing and contradictory because there were now two powerful paradigms: that women with children should have economic and sexual independence, and that women with children needed economic and sexual security. Women were caught between the idealism and insecurity of the first and the reality and dependence of the second. Thus the women in this study felt guilty if they stayed at home with children because they were then "just a housewife" and maybe a "cabbage". They also felt guilty if they were out of the home because the house was in chaos and they were not being seen as proper mothers. "E.R. Blenheim" described the dilemma:

I think that the present time will go down in history as the great mix up...In all sorts of ways we have still one foot in the past and the other foot somewhere reluctantly in the future (N.Z.W.W. Jan 2 1978).

This "mix up" meant more choice for some women, but it also created conflict because everyday reality did not always match the ideals of the new or the traditional values as espoused by competing opinions about what women should do. The choices for women embodied a much wider construction of femininity than in the earlier years of this study but there was conflict as the paradigm of independence appeared to become the dominant ideal if not the reality.

\section{"LIBBERS" AND "CABBAGES"}

By 1970 lacquered hair and mini-skirted fashions had created an image of little-girl-women who were playmates for men. Unlike the dumb kittenish blonde of the 1950's, the new dolly-girl could have brains, but these were to be the surprise beneath the packaging. The Woman's Weckly as usual found a royal figurehead for the new look, and for a short time Princess Anne appeared to fit the image:

The with it Princess Anne would appear to be entirely fancy free...a girl with a string of boyfriends and happy to play the field...She has emerged in recent time as a swinging dolly-girl who is also a professional princess - and clever enough to merge these two seemingly conflicting images without marring either one (May 18 1970).

Women's liberation strongly rejected the dolly-girl image, but created its own stereotype of feminine freedom. Helen Brown (1983:136) wrote: 
Back in the early seventies it was all jeans, singlets, shift dresses with no waists and sandals. It was simple. All you had to do was to dress like a man. And boy it was comfortable. It was after all the beginning of the revolution...We looked back with scorn on those poor creatures of the past. We were women of the future in our unisex waistcoats and zip front jeans. At least, that's what we thought.

Satirist Rosemary McLeod wondered about the meaning of the new look for women:

A feminist doesn't flash her nipples to give people a sexual thrill. She's making a statement about the shape of her body and telling the world they don't point upwards like bras forced them to 10 years ago...When she's not wearing form fitting clothes as a true statement about the true shape of her body, she's likely to wear rather shapeless things also as a statement about the shape of a woman's body (N.Z.L. February 1 1975).

The Woman's Weekly (June 18 1972) expressed relief that Sharon Cederman and Sue Kedgley, the feminist co-authors of Sexist Society (1972), were attractive to men and reported that they, "Were both as attractive and feminine as any girl - even an unliberated one - could hope to be".

Sharon Cederman who has shining dark hair, tranquil dark eyes, smooth skin, sweet expression, low voice and deliciously lissome slim body, seems all softness and gentleness.

Susan Kedgley...how completely feminine she is, with her strikingly pretty face, long blonde hair and slim, narrow backed delicately curved body.

M.E Knightbridge too gave reassurance that, "A large majority of the liberationists I know are just as pretty, fashion conscious and feminine as any other group of women", and rejected the stereotype of feminists being "bra burning - man hating lesbians" (N.Z.W.W. August 15 1971).

Women's liberation encouraged the women's fashion scene towards a more casual image, and while it became acceptable not to dress up as a "lady," an archetype of feminine beauty was still powerful. The Miss New Zealand contest remained popular. The criterion were that competing "girls must have poise, charm and a measure of brains" (N.Z.L. June 1 1970). Despite protests by feminist groups there was little shift in this attitude, except that by the 1980's women were paraded a little less in their bathing suits, personal success was perhaps a marketable asset, and there were attempts to promote the shows as providing training and development for a career. Organiser Johnathon Foley argued:

I've tossed and turned over the question of exploitation, but what we're doing isn't like that. I'll be damned if it is...it is now an opportunity to gain a foothold in the world of modelling... You realise how much confidence they had gained in themselves (Evening Post June 22 1984).

A popular spin-off from the Miss New Zealand show had been the quest for Mrs New Zealand. The 1970 winner described herself as "very average" but to the Woman's Weekly she was:

Very gay and fun loving, with a ready smile, who plays tennis, loves to entertain, and is a member of a creative dance group...She's a natural beauty with rosy hued olive complexion, jet black hair and dark hazel eyes that rarely twinkle as brightly as when she is playing with the children (January 4 1971). 
Mrs New Zealand was a careful mixture of Miss New Zealand's beauty and charm combined with the abilities of a housewife, hostess, and mother, as well as possessing a husband who could afford it all. Women's liberation generated debate about the criteria for selecting a Mrs New Zealand. "Copperknob" wanted reassurance that "despite women's lib, the competition would still be for women who placed their husbands and family ahead of their own interests and desires". She hoped that, "They are looking for a woman who has proved herself capable of being a good wife and mother" (N.Z.W.W. September 11 1972). This kind of prescription was not easy to fill and the Show's popularity waned, but other criteria for judging feminine excellence were tried. In 1980 The Woman's Weekly launched a competition, to find the "most enterprising woman" with the judges stating they were looking for initiative. "She might be the woman who has started her own business, or who has developed a new and worthwhile product for the community" (N.Z.W.W. August 1 1980). In 1982 Media Women's Collective launched the Media Women of the Year Award. The recipient, trade unionist Sonja Davies, was a popular choice but the television "hype" of the event was not something all feminist women were comfortable with, even though the exercise was planned to demonstrate an acceptable alternative to the Miss New Zealand Show.

Women's liberation had helped create an image of women who aspired to financial independence, and by the 1980's the financial institutions were also offering "a way to financial freedom" for women. This demonstrated a considerable shift from the Bank of New South Wales' early efforts to attract custom amongst women during the 1950's with a picture of a woman in an apron sweeping the floor, and a caption suggesting that they use the bank to deposit their housekeeping money in. By the 1970's the idea was that a liberated women could manage alone, although there were several variations on this theme. The media produced the "liberated lady" who had the looks of a "lady", was still attracted to men, but was also educated, financially independent and above all successful. By the 1980's a good woman was no longer a woman who stood in the shadow of her husband, but was a kind of superwoman with her own life aspirations, although she was still a caring mother, an efficient housewife and a glamourous wife. There was also the image of the woman with children who now managed alone. The producer of the television show "Helen - A Woman of Today" believed that Helen, as a separated woman with children, "evolved from Women's Lib, the pill, equal pay and countless other roads to freedom which were coming to make a woman - like Helen who was very much aware of herself as an individual" (N.Z.L. February 21 1976).

As more women were seen to be active outside of the home, and as enterprise and initiative outside of the home became more of a measure of success than one's domestic talents, the lives of women who stayed at home were, by comparison seen as dull, boring and thus unfulfilled. Such women, according to psychiatrist's opinion (Thompson 1977), were most prone to suburban neurosis, and according to popular opinion were in danger of becoming suburban "cabbages". But this was a view based on middle class values which assumed the 
workplace to be fulfilling whereas some women in this study found staying at home with children a refuge from dull and often exploitative employment. The image of the depressed mother - housewife imprisoned at home by husband, housework and children - albeit a real experience for some women, was graphically portrayed as justification for women's liberation, but there was a fine line between reporting the ills of suburban neurosis and demeaning and devaluing the lives of many women at home. Nina was relieved when she found that staying at home was not as bad as she had imagined:

After reading much on the subject of cabbages and housewives I was not looking forward to resigning from my well paid responsible job...In actual fact a whole new world has opened for me. I suddenly have plenty of time to follow new interests, enjoy my friends, read most extensively - most important of all - spend more time with my child (N.Z.W.W. June 6 1971).

The President of the Country Women's Institute, Mrs Wood complained that it was unfair to refer to women who preferred to stay at home as:

Second class citizens and "cabbages"...Both sides of the picture must be painted and at least equal importance given to the role of homemaker as is given to that of working outside of the home (Press July 23 1971).

In the 1980's Jim McLay, the Deputy Prime Minister, was still reassuring the Catholic Women's League that while, "In the not too distant past it was fashionable to suggest that women were little more than suburban vegetables and candidates for all forms of neurosis...the traditional role was a most valuable contribution to the fabric of our community" (Evening Post July 7 1984).

The distance between the caricature images of the "libber", as a woman who did not need men and who abandoned her children to the care of others, and the "cabbage" as a woman whether she be trapped or content with her home, husband and children, emphasized the extremes of a spectrum covering the life options of women. Both of these images were somewhat distorted, and as the next chapter will show there were other versions in real life of women "at home" and "out of the home" who were well adjusted, and that there were indeed many options between the extremes of the spectrum.

\section{UNDERMINING MARRIAGE: women<---> men}

The traditional assumption of women's dependence upon men in the marriage relationship was to be challenged during this period. One of the more obvious expressions of this was the reluctance by some women to assume their husband's name or to use the title of Mrs. Keeping one's own name in marriage or using the title of Ms became an alternative ${ }^{4}$. There were no legal barriers to this, but attitudes were sometimes resistant to the idea as the marital status of women became much harder to identify. This challenge to women's dependence on men in

\footnotetext{
${ }^{4}$ In the 1980's some newspaper editors still would not allow the term Ms to be used as a title for reporting.
} 
marriage had its roots much earlier when women were said to be equal rather than subservient partners in marriage although they still had separate roles. This had been expressed strongly during the earlier postwar years, but this kind of theoretical equality had been difficult to realise because women were made economically dependent by being tied to their domestic and childrearing roles. Women had invested their energy and often their earnings into supporting their men as breadwinners as a means of assuring their own security. This began to change. The new ideal was that women were not only to be equal partners but also independent partners. This had far reaching effects and for example, mountaineer Sir Edmund Hillary now felt that the attitude of wives was making it more difficult to mount expeditions:

Wives are not the same creatures as those of the forties and fifties when I first began going on expeditions. In those days the little woman stayed pluckily and happily at home, caring for small children and generally keeping the home fires burning. But times have changed. Either they refuse to let the husband go or they want to come along too (Waikato Times February 23 1979).

For some a unisex image symbolised the ideal of fusing the roles. Canon Bob Lowe ${ }^{5}$ protested in his Woman's Weekly column (June 1 1970):

I for one wasn't made for a unisex world. I like the old divisions with girly girls (but not boyly boys). Recently I had to perform a marriage in which it was impossible to distinguish one from the other...I had to ask "would one of you kiss the bride".

For most men and women unisex was not appealing, but the suggestion that there be less separation in the roles of men and women meant, for example, that it became less fashionable for women to give up their education so that their man, as a future breadwinner, could pursue his. Some women began to question or resist giving up their job skills during the childrearing years, because childrearing was no longer seen as a life-long task in itself but as a temporary disruption. Women were becoming more conscious that long term security within marriage was less assured and that it might be necessary to have earning capabilities as a fall back position for managing alone. Alongside these ideals, however, the traditional arrangement of separate roles for men and women was predominant and the view that men had a responsibility as a breadwinner and a provider were still strong. So was the view that women were entitled to be dependent within marriage. For some this was in accord with social values, but for many there was little option. Although there was a growing consciousness of independence for women, this was difficult to achieve, given the attitudes of some men, the responsibilities for rearing children, and the difficulties both men and women faced in organising these responsibilities to fit in with the demands of the workplace. There was still a considerable gap between the ideal and the reality of women's financial independence. A study on women's access to money in marriage (SROW 1981) showed that while $77 \%$ of women stated that they had personal money to spend, the remaining $23 \%$ still had no access to money in cheque or savings accounts and no

${ }^{5}$ Canon Bob Lowe was an Anglican minister, well known for his television appearances and writings. 
personal spending money. The report suggested that many women still accepted a"trade off" by settling for substitutes such as trust and security, and Helen Paske told Listener (October 3 1981) readers that, "If women want equal power they will have to give up some of these rewards. They will have to take responsibility for their own financial security".

There was growing confusion and uncertainty about what the respective roles and responsibilities for women and men really were. "Tippy" wrote to the Woman's Weckly (June 14 1971), expressing the hope that women's liberation was here to stay and that it should begin at home:

Many men do not wish to see their wives working. "I am the breadwinner" they loudly declare. However if they have the misfortune to accumulate a few debts guess who goes out to work. If it is not necessary to go out to work who is the one who scrimps and saves to make ends meet.

This was akin to the attitude of the early postwar years when women saw it as their duty to support and uphold the role of breadwinner. But during the 1970's there was for some, a change in opinion. "B.C." wrote:

From the days when husbands resented their wives having an income, we now have some husbands who resent their wives not contributing financially. These women have worked for many years as well as bringing up families. In the present social climate of equal marriage partnership and equal pay, does a woman have any more right to work part time (N.Z.W.W. April 26 1982).

This kind of statement highlighted the growing ambivalence over the independence and/or dependence of women, and was a reflection of the decline of middle class ideals of the single breadwinner. Both of these scenarios reflected either end of the spectrum of possibilities, but there was increasing expectation that women with children would contribute financially, and women often felt guilty when they were not working even though they had young children.

That women were gaining more financial independence took time to be accepted and the assumption that a man was ultimately responsible for his wife's financial transactions was still upheld in the financial world. For example, "Silver Bay" owned a bach ${ }^{6}$ purchased from her own money, but the Power Board said that her husband would have to sign before they would connect the electricity:

I explained that I owned the house, but he said that a woman could not be responsible for Power Board accounts while she was with her husband... Every second month the electricity account has arrived addressed to my husband. I pay the money by my own cheque and the receipt comes back addressed to my husband (N.Z.W.W. September 3 1970).

Eileen Saunders from the Marriage Guidance Council believed that women could not have it both ways:

You can't at the same time say that, "I as a woman have an equal right to education, work opportunities, and my husband should accept this and

${ }^{6}$ A New Zealand holiday home. 
if necessary adjust his role to alter it," and at the same time have a legal concept which roughly speaking gives a married woman a meal ticket for life (N.Z.W.W. July 7 1974).

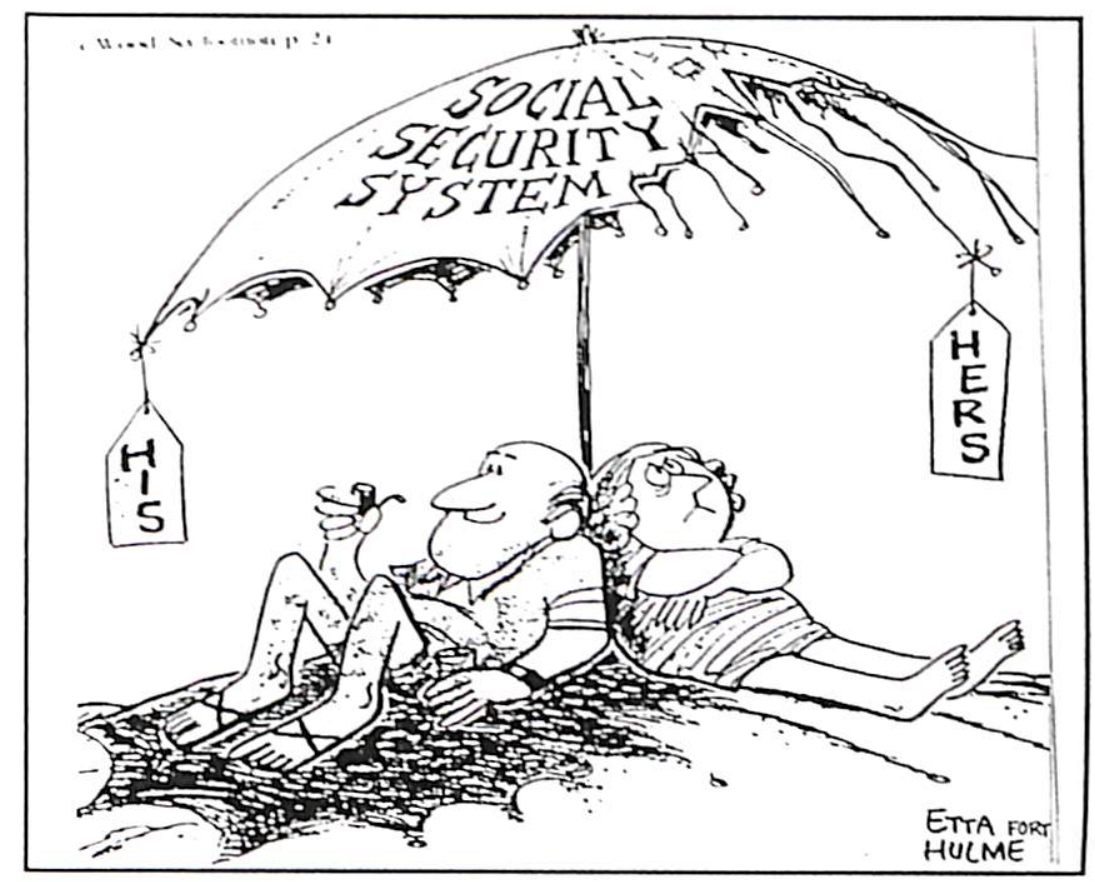

Government was cautious in encouraging increased independence for women at the expense of men. For example the Commission of Inquiry into Equal Pay (1971) expressed concern that the move away from the traditional relationship of husband as breadwinner and wife as dependent, would have far reaching effects which might necessitate a total review of family and domestic law. When the Royal Commission on Social Security (1972) recommended increasing the amount of the family benefit paid to women, with the revenue coming from removing tax exemptions for fathers on children, concern was expressed that this would take money from a man and give more to his wife, which could cause marital problems (ㅂerald March 23 1972). Whether a wife was a dependent or a partner with her husband in marriage was to be clarified somewhat with the passing of the Matrimonial Property Act (1976) which recognized that marriage was a partnership and that if the marriage ended, the women's contribution was seen to be equal and the property to be equally shared between the separating couple ${ }^{7}$. Thus, while a woman may be financially dependent she was still seen as an equal partner in the marriage. "Judy Boyle" wrote to the Woman's Weekly (January 17 1977) supporting the Act because it, "Reinforces the role of homemaker by recognizing the values of contributions, other than financial, made to the marriage".

It was not only the issue of economic independence, but also sexual independence, that was to pose a challenge to the relationship between men and women. Despite a so called sexual

7 The 1963 Matrimonial Property Act had suggested that the property could be divided according to the spouse's contribution, but there was no criteria to measure the worth of the separate contributions. 
revolution established attitudes to female sexuality were still strong. Canon Bob Lowe blamed crumbling marriages on the idea of liberated sexuality. His view was that:

Sexual union has to do with women's need to be mother, wife, lover, sharer of pain with man, and builder of a nest to receive and complete a man's strength and creative virility. There seems to be a great fulfilment for a woman in helping her man when he comes home to take off the armour of sophistication in which he must do battle in the world...The one partner plan of Christian marriage provides great psychological security (N.Z.W.W. May 2 1977).

Women, however, challenged this view of sexuality which made them adjuncts of men. Sue Kedgley was to write in her book The Sexual Wilderness (1985:117):

For the new woman then, the traditional search for a professionally "eligible" man who could support her financially in the style to which she was accustomed throughout her life, has been replaced by a new quest - for an emotionally eligible man, and a relationship in which love gets love in return, and not money or status.

While there was a flurry of explicit books demonstrating the fun and possibilities of heterosexuality (Comfort 1972), there was also a new awareness that women did not necessarily need men for sexual satisfaction. From America, Masters and Johnson (1966) and The Hite Report (1976) affirmed the independence of female sexuality from men by dispelling the myth of the vaginal orgasm for women (Koedt 1973), and by hailing the clitoral orgasm. This was to give support to the feminist perspective of self-sufficient sexuality for women, the view being that the myth of the vaginal orgasm ensured female sexual dependency upon men which in turn was used to enforce economic and domestic dependency (Dann 1985b). Lesbian feminists in turn were to challenge the idea of compulsory heterosexuality for women (Rich 1980), and growing communities of lesbian women sought to establish an accepted identity, a visible culture and a right to live and work without discrimination in a society which was only beginning to accept that lesbianism existed. However, many people felt threatened by homosexuality in any form and by the fact that lesbian women were demonstrating a lifestyle of economic and sexual independence from men. This was an uncomfortable time for some heterosexual feminists who also wanted to be free from the constraints of compulsory heterosexuality and monogamy but felt they had perhaps taken the inferior option to their lesbian sisters. Athina Tsoulis wrote in Broadsheet (November 1986):

Men as a group are labeled as the enemy, hence living with a man somehow feels like collaboration. The man, or men you love, are not seen as individuals but are lumped in with the "normal" male. Instead of having sex with an individual, you are having sex or making love with the rapist, the pornographer, the wife batterer or the child abuser.

Some feminists were to argue that the institution of marriage was outmoded and oppressive to women as it reinforced economic dependence and compulsory monogamy which had been eulogised by society as giving security and love for ever-more. These were deemed to be tools to control women. Thursday magazine (December 11 1975) interviewed feminist women to see whether it was possible to be a feminist and to be married. Connie Purdue stated 
that ,"For a woman who takes up the cause of women's equality the marriage relationship is at risk", but as the article showed there was no consensus except insofar as feminist women believed that a successful relationship with a man depended on his ability to accept their right to independence. Anne Else (1979) identified the necessary conditions for an equitable relationship with a man as economic independence, control by women of their fertility, and real communication. Satirist Rosemary McLeod outlined the difference between old and new attitudes towards marriage:

Marriage was supposed to give security to women and children, since men were suppose to provide for them financially...It was supposed to be a good basis for raising children, since they were generally supposed to need two parents. It was supposed to confer a sex life satisfactory to both parties...Fortunately, we've managed to obliterate this idea. Marriage appalls us. We are disgusted by the very idea of weddings. Such as there are are performed in secret, with some apologies...The idea of staying together indefinitely while quaint, we recognise as impossible. We realise that marriage can only last as long as a more attractive sexual partner for either person doesn't came (N.Z.L. March 29 1980).

Despite the challenge to the institution of marriage there was, according to the statistics, no decline in marriage, but there was evidence of more flexibility in relationships with an increase in delayed marriage, divorce, remarriage, and defacto relationships (Swain 1983).

For some couples living together was an option which could stop short of the traditional responsibilities of marriage. The Woman's Weekly (September 5 1977) reported the view of counsellor Brian Lythe, that living together was no longer an "issue" but an "accepted" thing. However, the editor expressed some scepticism when they found plenty of people willing to talk about their experiences of living together, but none would allow their name or photograph to be printed out of consideration for their families. By 1983 the Woman's Weekly (April 25 1983) reported that 90,000 New Zealanders were now "living together", although it reassured its readers that this still represented "just a drop in the bucket to the 1.3 million Kiwis who are married to their partners". Living together or a de facto relationship was not necessarily liberating for women. While there was often more economic independence in these relationships there was little security and lawyers were to caution against the lack of legal protection for women in de facto relationships.

In the midst of these challenges to marriage a recurring theme in magazines was to detail the lives and views of the wives of important men, and these images of supportive wives were a reassurance that the traditional values of marriage were still alive. The Woman's Weekly caption (May 16 1983) read BEHIND EVERY STRONG MAN and readers were told of the debt the Prime Minister owed his wife:

Thea Muldoon is the vital core of this family. She actively supports her husband by attending functions, making speeches, hostessing important meals, traveling with him and looking after his clothing needs. She takes care of home and family matters. 
When the Labour Government came to power the Woman's Weekly (October 18 1984) said that Naomi Lange, wife of the new Prime Minister, would provide a "striking contrast to other prime minister's wives". Naomi Lange told the Woman's Weekly that "It is his job, not mine...I am really a home person" even though she was "not enthusiastic about housework or ironing". Whether a wife by his side or a wife at home the important thing was that she was enhancing and supporting his position of power. The marriage of Lady Diana to Prince Charles provided the ultimate expression of this sentiment. After their marriage the Woman's Weekly (August 10 1981) wrote:

It was a dream wedding - the sort which fairy tales are made from. She looked pure and downright pretty in ivory, he was dashing in royal navy blue...It was a couple thoroughly in love...It was a televised tonic to lift the hearts.

Rosemary McLeod wrote satirically about Lady Diana as a reaffirmation of the ideal of feminine purity :

She never had a boyfriend before she met Prince Charles. She has held onto her virginity roughly 10 years longer than the average girl, in spite of the fact that she'd been flatting. She's what purity is all about (N.Z.L. April 1982).

The Princess of Wales was to espouse the feminine and wifely traits which had taken such a battering as she announced to the world that she saw her main role to be a good wife and mother to her future kings.

It was ironic that in a generation which was probably the first to question deeply the relevance of the institution of marriage, there should also be such high expectations on the institution. The Reverend Peter Davis told the Woman's Weekly (January 8 1979):

I believe the expectations of young people who are getting married today . are vastly different from those of their parents. No, "for better or worse" times have changed.

And as Valerie Young wrote, it was women's liberation that had unwittingly influenced expectations in marriage:
Women expect a great lover as well as a good husband, kind father, great handyman, conscientious gardener, concrete layer, lawn mower and stimulating companion as well as breadwinner...In other ages many a woman thanked her lucky stars for a kind husband, enough to eat and children she was happy to slave for. Today's woman expects far more (N.Z.W.W. October 4 1982).

There was however a difference between expectation and reality for many women. "Sheryl Cooke" wrote to the Woman's Weekly (September 11 1972) that she wished that she could have had a private look at marriage before she indulged. "Thank God for the psychiatrist and thank God for Women's Lib. They are doing their best to make us start thinking about ourselves, instead of being brainwashed by a lot of romantic nonsense". In an interview with the Woman's Weekly (September 12 1981), authors Barrington and Gray expressed "sadness" that the "Smith Women" (1981) had been prepared to settle for so little in marriage and concluded that New Zealand women were not aware of the choices available in their lives. "Only those who stayed 
at school longer or were better educated seemed aware of greater choice in careers, travel, lifestyle, relationships with men and children". This reflection however could also apply to men, and it should be remembered that feminist ideas were attractive and more possible for middle class women than for working class women.

There was amongst some groups, strong support still for what were considered traditional values surrounding women's relationships with men and the institution of marriage. M.A. Lowrie felt that women were now losing rights, and that the old courtesies of ladies first and a male protective arm would not be offset by the rewards of equality:

For centuries we have held the right and opportunity to be cherished and desired by men...So you now consider this outdated and non-existent you don't know what you are missing...Think it over softly, softly, ladies. Remember your title as lovers, ladies and mothers, all wrapped up in one feminine bundle (N.Z.W.W. November 9 1970).

The feminist argument though was that the rights of being a lady were precarious and a smokescreen for subservience. Rosemary McLeod satirised a lady as someone who:

Knows their place when they're in the presence of men, which means they don't offer any opinions of their own...Ladies have written off their own personalities so efficiently that anyone close to them just has to seem interesting...In return for having a lady a man has to perform certain duties. These are to pay for her when they go out and to open the door when she wants to go through them...Men say that it's the little things that count and that women who don't want such favours bestowed on them are just plain butch as well as not ladies (N.Z.L. June 2 1979).

The Editor of Above Rubies (April/May 1983) however, assured readers that "the old way is the only way that works":

It is obvious, isn't it, that the modern trend and propaganda that is blazoned through feminism today is not working. As more and more women are asserting their rights...It is still the best way for mothers to keep the home fires burning.

The message that appeared in this magazine was that equality meant sameness and that a unisex world rejected the traditional roles embodied in masculinity and femininity. Underlying this was the view that equal rights for women denied women the sexual and economic protection and security from men which was their right in marriage. It was marriage which provided the protection women needed against the economic and sexual exploitation outside of the home. As American writer Angela Dworkin (1983:6) wrote, "In the home their value is recognized and in the workplace it is not". There was a reassertion of these views through the growing conservative New Right groups. These should not be seen as representing a continuation of the more traditonal values about the role of men and women from the early postwar years, but as a reformulation of these ideas into something new. They drew upon and reasserted older values, but the existence of these groups needs to be understood as a reaction against the support for the ideas of sexual and economic independence for women. Such different constructions of the relationship between men and women were expressed as a kind of opposition to each other in a way that had not been apparent in the early postwar years. In America several women made 
millions of dollars for their cause by writing best selling recipes for the successful marriage according to so-called traditional values (Morgan 1973; Bryant 1976; Schlafly 1977). Wives were to submit to their husbands on all matters, but women were told that if they became exciting sexual partners they would keep their marriages intact and their husbands happy, and thus be assured of security. Provoking lust in her man gave a woman power (Dworkin (1983), and as popular American writer and media personality for the Moral Majority, Marabel Morgan found, when she started applying these principles to her own dull marriage, her husband Charlie started bringing her gifts home (N.Z.W.W. September 29 1975). To Morgan " a Total Woman caters to her man's special quirks, whether it be in salads, sex or sports" (1973: 60). Right-wing women saw safety and security within a framework of home and marriage in which wives and mothers were to be cherished and respected (Dworkin 1983), but this was set against growing evidence that some marriages were perhaps unhealthy and that the home was the most unsafe place for women to be (Church 1978; Tapp 1982). In New Zealand concerns about the situation of women in the home had received extensive media coverage from psychiatrist Dr Fraser McDonald's revelations in 1971 about the "alarming plight" of married women. He stated that they were "slave labour" and sufferers of "battle stress". These angry words came from his evidence that there were twice as many women in mental institution as men, four times as many outpatients and three times as many suicide attempts. To Dr McDonald the "phony values and false expectations" of marriage were at the centre of the problem (Press Association April 5 1971). The National Council of Women found such criticism of marriage "sad and dangerous". While admitting that there were genuine cases of stress and strain, they believed that "for every such one, there are hundreds of happily married woman who are rearing children in the best traditions and who regard happily married life as a vocation". Dr McDonald however replied, "If my comments on the matter are dangerous, then marriage must be in a pretty fragile state" (Waikato Times June 6 1971). "Joslyn" wrote to the Woman's Weekly (May 24 1971):

Many of us actually enjoy our status as wives and mothers and regard the "slave labour" Dr McDonald refers to as a labour of love for our families...I think it would be much better if Dr McDonald encouraged those of us who are happy in our work to stay that way, instead of making us feel that we are doing a loveless, depressing task and are regarded as "things" rather than people.

Later in the year Fraser McDonald did just that in a Woman's Weekly article (November 22 1971), but was to warn women that there was no possibility of changing their husband's attitudes. "She has to accept that hoping or wishing, or nagging won't do it". Instead women were advised, to make the changes in their own lives by, "manipulating the environment sending the youngsters to kindergarten...getting a job...by changing her relationship with people".

Marriage was not only seen as being unhealthy for women (Thompson 1977; Calvert 1979), but also there was a shocked and reluctant acknowledgement that for many women the home was also a place of violence. This had been one of the "silent issues" but more and more 
the media became a forum that gradually shifted the blame for violence away from wives who may have "asked for it", to men who were using violence to assert their power and dominance (Tapp 1982). The Listener reprinted a radio documentary "Wife beating the hidden violence" (January 11 1975) which brought together for the first time on air a lawyer, a doctor, psychiatrist, marriage guidance, church and welfare organisations and several women who had been in violent marriages. The Woman's Weekly (October 1978) reported that a questionnaire to their readers on wife beating was "unveiling a shocking secret...and paints an appalling picture of hidden violence behind lace curtains and drawn blinds". There was a gruesome list of the kinds of violence and maltreatment women were experiencing. Miriam Jackson ${ }^{8}$, who had collated the material, expressed concern that these women were so emotionally and financially dependent on the men who were beating them that it was difficult for them to leave the home:

When it comes to the crunch they often fear they would be unable to cope with children on their own. They have also been led to believe that it is woman's responsibility to keep the marriage together. We need to encourage women to be independent and confident.

The establishment of a network of women's refuges in urban areas by feminist women was an important move towards getting public support for the problem. A 1978 report from the Dunedin Refuge stated that women of all ages and from every social class were coming to the refuge, but the problems of providing staffing 24 hours a day on a voluntary roster, and the problems of maintaining financial security from voluntary donations, were "stretching us to the limit". The 1984 Labour Government started to give funding support to Women's Refuges and with a first woman Minister of Police, Ann Hercus, new initiatives for the police handling of domestic violence were beginning. In the past the police had seen their role as mediators and had only laid charges if the woman pressed for them. Police were instead instructed to make automatic arrests that would remove the man from the home and take the onus off the woman? This was only a beginning, and to change attitudes towards women who were victims of violence and rape was still a long way off, as Miriam Jackson stated:

We scapegoat our victims because of our own vulnerability. So the battered wife is accused of being a nagging wife, just as the rape victim is accused of asking for it (N.Z.W.W. October 23 1978).

The ills of violence and depression for women within marriage were not new, but talking about them was. As divorce became easier and less stigmatised. As there was an assurance of financial support, it became possible for more women to leave unsatisfactory marriages. The Woman's Weekly (April 12 1982) wrote that once the initial pain and anger was over, "going it alone" was easier than you might think:

Even if the marriage wasn't a bed of roses, just having someone around is a kind of security...Some of the worst pain comes from the inevitable

8 Miriam Jackson later changed her name to Miriam Saphira. She is an author and a psychologist.

${ }^{9}$ This new policy was originally tried in Hamilton and was then introduced nationally in 1987. 
loneliness...But lone mothers become very enterprising people. They juggle jobs, share baby minding with other mothers, even share jobs.

The rising divorce rate was a recurring theme in the magazines but the emphasis was changing from a reaction of condemnation to one of inevitability. Counseling agencies like Marriage Guidance, who in earlier years had seen it as their mission to keep marriages together, focussed more on honest communication between couples and if the marriage was going to end gave counseling on how to ease the pain and smoothe the process. After the Matrimonial Proceedings Act (1980) there was no such thing as divorce. Instead marriages ended through a no fault dissolution and practical guidelines on ending marriage became the new focus of advice (Davidson 1985). However "J.C." thought that attitudes had taken too swift a turnaround when a "Do It Yourself Divorce Kit" was advertised:

So now we have a do it yourself divorce kit - just as simple as that, with public response quite astonishing and orders flooding in. Instead of "until death do us part" the marriage vow might as well now read "until we choose to part". If, when I married 36 years ago, this popular device had been on the market, I am sure I (with many of my generation) would have rushed to buy one, thereby becoming lesser persons in terms of tolerance, tenacity and self sacrifice (N.Z.W.W. April 4 1983).

Popular psychology was now posing the process of marriage separation and forming new relationships as a growing experience (Sheehy 1976). The amicable separation was the ideal and the new adult challenge was to survive the crisis, to learn from it and to move on with new insight to the next experience. This challenge to the traditional fabric of male-female relationships created both disillusionment as well as higher expectations. There was disillusionment as traditional relationships did not bring the expected security, as well as disillusionment when new style relationships could not match the expectations of equity and sharing (Kedgley 1985). Yet amidst the disillusionment there were heightened expectations in relationships whether they were based on dependency or equity. The problem in both scenarios was a gap between the expectation and reality.

\section{CHALLENGING MOTHERHOOD: women<--->children}

The traditional view of motherhood presented an image of women who demonstrated sacrifice by always putting her children's interests before her own. Betsy Wearing's research on motherhood in Australia identified a "good mother" as someone who was "always available" to her children and was always calm, loving and patient in all circumstances (1984:49). Sue Neal wrote in Broadsheet (December 1981:2), that as good mothers "we never raise our voices to the children, teach our babies to read, play stimulating games with them and be there all the time to listen to them and meet their needs". Soon after the birth of her first child, Rosemary McLeod wrote about her "joy of sacrifice":

So far I know that ...I will not be able to make love. I will not be able to sleep. I will not be able to sustain friendships on my own bchalf. I will not be able to work or pursue my own interests. I certainly won't be able to read. All this happens because of that moment of 
fulfilment....that will turn me into someone who is no longer a human being but a mother (N.Z.L. June 7 1980).

Robin McKinlay likened New Zealand mothers to mythical heroes because "like the heroes, mothers put aside their own personal needs to the greater cause of society" (1981:26). But unlike heroes the rewards for mothers are dubious, and as McKinlay states, "The cultural framework (of motherhood), labels their task as trivial, their sacrifices as fulfilment" (ibid). The acclaim for mothers, like heroes, was somewhat fragile and mothers also took the blame for what went wrong (Margolis 1984). Writing about about postwar America Betty Friedan had argued that, "In every case of a troubled child, alcoholic, suicidal, schizophrenic, pychopathic, neurotic adult, impotent homosexual male, frigid promiscuous female...could be found a mother" (1963:189). This attitude was still strong in Western societies. Childcare experts James and Joyce Robertson visited New Zealand from Britain in 1976 and criticised mothers who were not mothering full-time. The Robertsons were described by the Woman's Weekly (April 22 1976) as "champions of the child away from mother" in the sense that they were championing the child who in their view should not have been away from its mother. Their work and presence in New Zealand was used at the time to support arguments against childcare provision (Rendall 1987). The Robertsons, who had continued the work of John Bowlby on institutionalised childcare and the effects of maternal deprivation, still recommended that all separation should be avoided during the early years. They were to argue that once any child was outside of the family it was "vulnerable" and that mothers ahould be paid to stay at home rather than go to work (Parents Centre Bulletin Spring 78). The Woman's Weekly (ibid) reported:

This has tremendous relevance not only for solo parents but for all parents - warning them to avoid separation from their toddlers wherever possible.

Duilia Rendall (1987:28) was to later record her feelings as solo parent, at one of the Robertson's lectures during this visit:

I can remember making an absolute fool of myself at that seminar. They went on and on and I am still emotional about it ten years later. I perceived their arguments as a personal attack on me, in that I was using childcare, therefore it was proven that I was a bad mother. I was so angry that day. I remember being led off into a little side room to calm down.

There was a mismatch between the ideals of motherhood and the realities of women's lives. Jenny Phillips in her book Mothers Matter Too was to label this ideal as a myth. She stated:

Part and parcel of this myth is the idea that all mothers are loving. Not true. Plenty hit, shout, nag and threaten. Most of us, however loving, have done some of those things on a bad day, and some children are fed a diet of it. Shouting, hitting, threatening mothers are distressed mothers (1983:125).

In many societies this kind of behaviour, however, would have been considered normal for mothers. The fact that many New Zealand women as mothers did not match the mythical image in terms of their availability to their children or in their relationship with them was, however, a 
part of the visible evidence of a much deeper challenge to the role of motherhood. The concerns of feminism were with freeing women from the constraints of their childrearing roles through campaigns for contraception, abortion, childcare, and the recognition of childbearing and childrearing as a legitimate activity for women while still in the workforce. It was inevitable that within this schema motherhood became a burden (Firestone 1971).

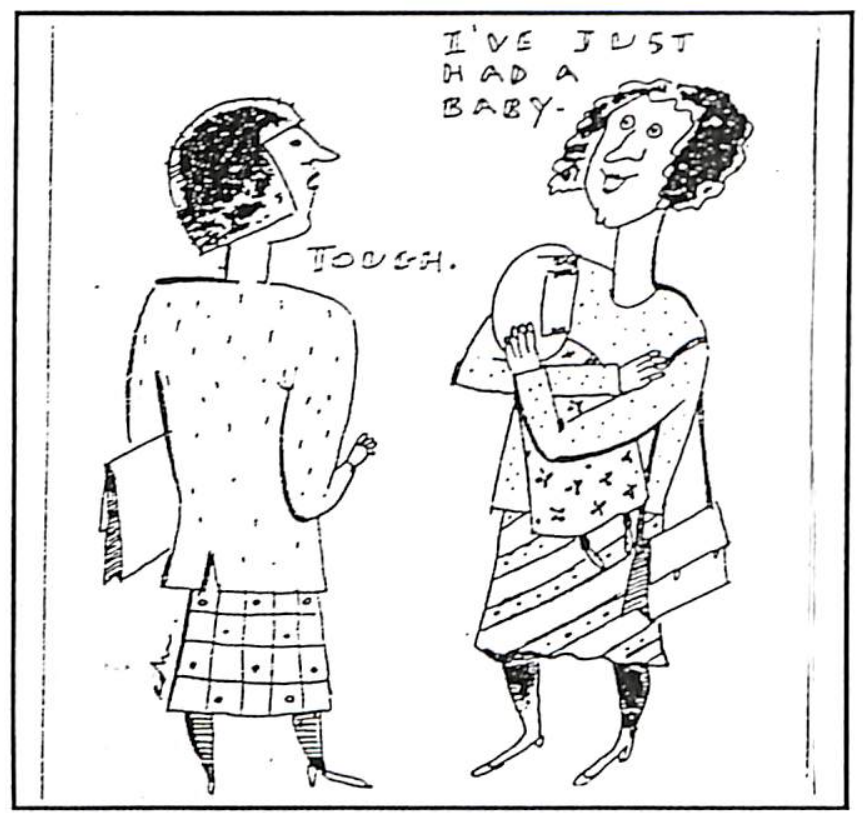

But feminism is not sufficient as an explanation for the challenge to motherhood. The fact that the value of motherhood was being lowered also stemmed from a number of changes. The new technological economy needed women in the workforce while children had become an economic burden rather than an asset (Easton 1979). This point was a key turning point in society. Apart from the emotional investment parents might have in their children, in the space of a century there had been a turnaround from viewing children as a potential capital investment for a family's well-being (McDonald 1978), to one of a financial burden for families. Accompanying this shift, though, there had been a transference of much responsibility for children from parents to the state, and now it was the state rather than parents that was viewing children in terms of an investment for the future (Department of Social Welfare 1977; Easton 1979). This idea of state responsibility was not new but it was evident, for example, in childcare demands. Increasing numbers of parents were seeing it as the state's responsibility to provide and pay for the daytime rearing of their young children. These kinds of shifts in investment responsibility made the role of motherhood more complex. But there was still a double message - that the role of motherhood was both sacred in the sense of duty and worthless in terms of support (Rubin 1982). These changes created difficulties for all mothers trying to make the role meaningful to themselves. Nancy Campbell, the editor of Above Rubies (April 1978), expressed her concern as a supporter of the established ideal:

It is sad today so many women are not really enjoying motherhood. They feel children are a deterrent and a nuisance to stop them doing the 
things they want to do. But God never intended that our children should be a curse or a bondage too us. No, they are given to us as REWARDS.

Campbell believed that the answer lay in the fact that women had not accepted their role, and advised her readers that, "When you accept your motherhood with all your heart, you will begin to enjoy it". At the other end of the spectrum feminist mothers saw motherhood as only one of a number of choices for women (McKinlay 1983), while responsibility for rearing children also rested with men and the broader community. In Australia Betsy Wearing (1984) found a number of variations between these views but again was to show the gap between the ideal and the reality because the women in her research experienced guilt as they were often unable in everyday life to match the ideal of their choice.

At both ends of the spectrum there was contradiction between the ideal state of motherhood, and the existing political, social and economic structures with the effect that the ideal was unattainable for most. For example, the traditional view of motherhood assumed that women were able to "accept" and to "sacrifice"; that they were naturally skilled in childrearing; that they found childrearing fulfilling; and that they had a supportive breadwinning husband who earned enough and would not walk away from his responsibilities. On the other hand the feminist ideal assumed that men and the community were willing to undertake more responsibility for childrearing, and that the workplace was fulfilling for women, did not discriminate against women with children and provided equal opportunities. In both cases most of these assumptions did not match the reality, and thus the role of motherhood for most women was one of ambivalence as they struggled both to endorse certain ideals and to live amidst the compromise of everyday life.

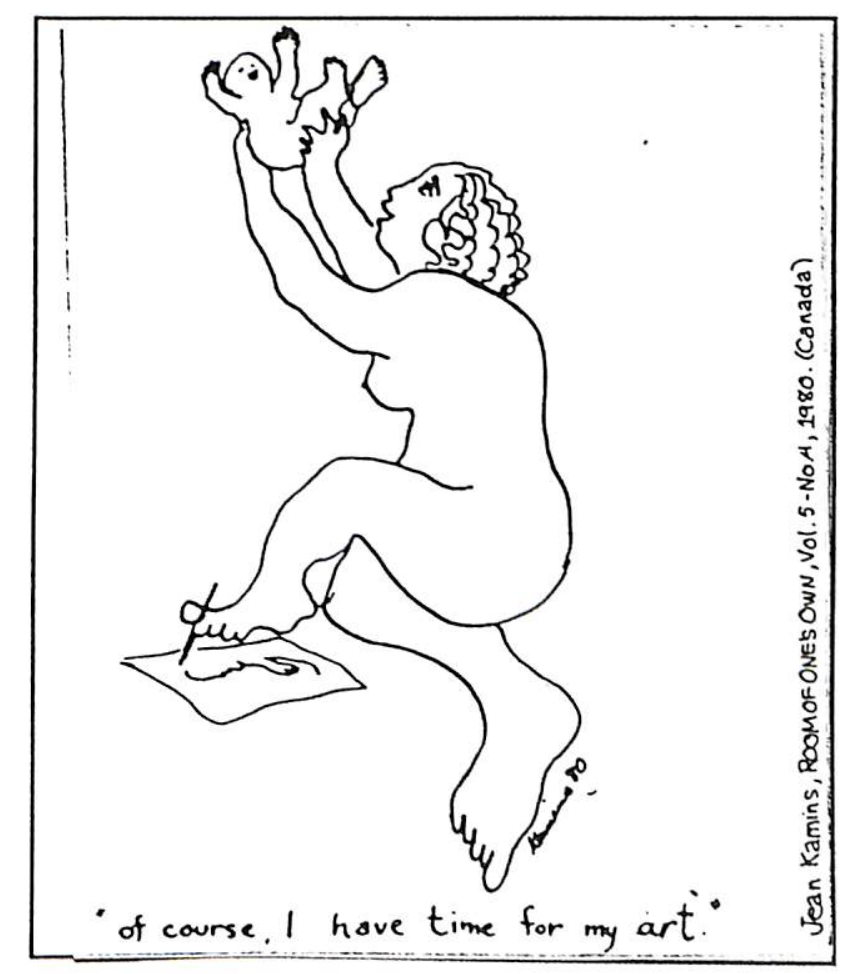


In reply to a Listener article "The Motherhood Myth" ${ }^{10}$, "Josephine Baker" wrote that life for her was much more stimulating as a mother than at work. "Filing was a bore and filling in those registers tedious beyond description... We now find great joy in sharing the lives of our children. Furthermore we actually love our husbands and our homes and find great happiness in them" (N.Z.L. June 14 1975). Life was not so satisfying for all women and the National Council of Women survey (1985) found that one third of the women felt that it was more difficult being a mother to small children than it had been ten years previously. The reasons given reflected the contradiction that on the one hand there was a lower status now ascribed to motherhood but at the same time "women felt pressured to be super-mums" (P.38). "G.M.W". wrote to the Woman's Weekly (September 25 1972) about the conflict she experienced as the birth of her first child approached:

As long as well meaning friends and relatives persist in the idea of "baby first" mothers will never be liberated...Because I was not knitting bootees at three months I was apparently neglecting my child. The majority delight in telling me my busy life must stop. I shall only have enough time for my babies. It is no wonder that some mothers feel guilt at spending time or money on themselves.

But on behalf of mothers whose houses were "constantly invaded by the children of liberated women either out indulging their hobbies or devoting themselves to good works", "Araluen" rebuked "G.M.W.":

No matter how much it irks, one's children do come first and if the mother cannot recognize this she should save the world from further pollution and remain childless (N.Z.W.W.October 30 1972).

Valerie Davies wrote in her Woman's Weekly Family Forum column (March 21 1983):

Sometimes I think I was lucky to have had my children in the early sixties when women's liberation hadn't penetrated the home where there are young children. Although I was committed to feminism even then, it didn't constitute the clash of desires which it often seem to today.

Stories of well known women who were mothers provided a popular formula for magazines like the Woman's Weekly. These women appeared in public, at least, to have resolved the conflicts surrounding the role of motherhood and they generally reasserted the traditional values of motherhood and marriage in the sense of children and husband being the first priority. For example the Woman's Weekly (May 24 1982) headline read that "Marriage and motherhood have changed Tania". Tania Harris came to overnight fame when she led the famous Kiwis Care march $^{11}$, but now with baby Christopher a few weeks old, Tania revealed that she was, "No longer the same girl - I was so impatient - and aggressive...I'm a lot more patient now...I've got a good man, that's what counts". For singer Suzanne Prentice, the Woman's Weckly (January

\footnotetext{
${ }^{10}$ Written by Ruth Beaglehole and Vera Levett (May 24 1975).

${ }^{11}$ In 1981 Tania Harris had been at the front of a 30,000 strong patriotic march down Queen Street in Auckland in reaction against a strike by Air New Zealand engineers. The Prime Minister rewarded her with a place at his dinner party when Prince Charles came on a visit to New Zealand.
} 
25 1982) reported that, "There's no career-versus-home conflict...life in Invercargill as Mrs Steven Dalton - wife of a police constable and mother of 18-month old Blair - has top billing...(Suzanne) would give it all up if she thought that her family life were affected". M.P. Whetu Tirikatene-Sullivan was the first woman to have a baby while she was a sitting Member of Parliament, and was to set an extraordinary standard for aspiring "super-mums". The Woman's Weekly (May 11 1971) reported:

May Ana's MP mother was absent for only six working days. "My husband, Denis, collected me at the end of the day...and May- Ana Maria was born the next day"...Discharged from hospital...Mrs TirikateneSullivan drove straight to Parliament to resume duty.

Readers were however assured that despite Whetu Tirikatene-Sullivan's responsibilities MayAna had not been separated from her mother despite 6000 miles of travel and she was a "bright, happy little person, who appears to lack anxiety completeiy. She seldom cries and sleeps twelve hours at night". The supreme symbol of motherhood in the 1980's would have to be the Princess of Wales and millions followed her through every step from the first hint of morning sickness:

Pregnancy is high fashion at the moment and the Princess of Wales is bringing it right out into the open where everyone can see what she looks like...It is frills, frills and more frills...Far from feeling the need to retire from the public eye, the twenty year old princess has continued to happily draw admiring glances...She shows no sign of having lost interest in her appearance (N.Z.W.W. June 7 1982).

The media images of the Princess of Wales as a wife and mother reasserted the traditional ideals. The Woman's Weekly (May 13 1985) likened her to a "Madonna in a tiara" and reported that "regardless of all the treasures and pleasures that come the way of the Princess of Wales, it is her role as a mother which gives her the most gratification".The Princess was portrayed as having reversed the trend of women to delay childbirth to build careers, by seeing her role as making her man happy, having children and supporting him in his work. The Princess of Wales made motherhood appear more natural and easy than it was for most women. For Frankie McGowan, however, the example of the Princess of Wales had made the decision about when to have a baby harder:

\begin{abstract}
Rather depressing, for some of us though, when the Princess of Wales moved so quickly from marriage to expectant motherhood at 20 . But then she is unlikely to have to cook, clean, shop and juggle an average wage packet ...For the rest of us - do we establish our careers first and continue them after a short break...Or do we give up working after a few years and then try to pick up where we left off...Or what about abandoning work altogether? (N.Z.W.W. April 25 1982).
\end{abstract}

These were choices, barring accidental pregnancies, which had not been issues for women during the early postwar years, but were crucial issues for a generation of women who did not have the same faith in men as breadwinners to provide, and/or who had more confidence in their own earning abilities to support themselves. As Sue Kedgley (1985: 63) wrote: 
Many women I interviewed expressed great difficulty making decisions particularly the agonising decision whether or not to be a mother, and whether or not to combine motherhood with full or part time work.

There were two conflicting messages about the experiences of motherhood. Firstly that it was fulfilling and secondly that it was a hazardous occupation for the mental health of women. Max Abbott, Director of the Mental Health Foundation, believed that between 25-45\% of women showed signs of depression while caring for preschool age children, and he described this kind of depression as primarily a social problem rather than a personal one:

Social forces have isolated the modern mother from the rest of society...There is nothing normal or traditional in this social arrangement whereby mothers are cut off from the rest of society...Solutions to this problem are likely to require a major social transformation, affecting the way we order our lives in love, at work, and at play (N.Z.L. October 23 1982).

For example, post-natal depression was now a recognized experience that affected, in varying degrees, up to $80 \%$ of new mothers ${ }^{12}$. Organisations like Parent Centre, Plunket and New Mother Support Groups were providing active support to women, but they were powerless to change the conditions in which mothers reared children. As a more radical expression of support, the focus of the New Mother Support groups was not so much to address the needs of babies, but to focus on the mothers' feelings in raising consciousness in order to develop strategies of coping with existing conditions ${ }^{13}$.

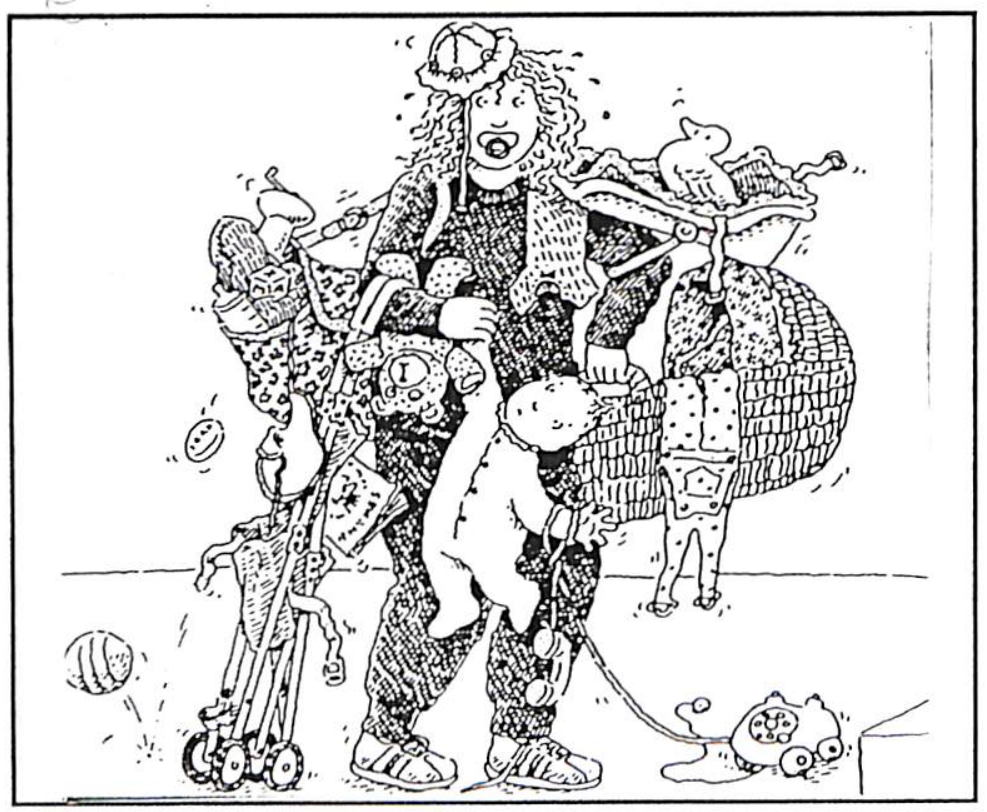

That motherhood was fulfilling was a message not confined to those upholding the traditional view of motherhood. Feminist writers from America and Britain were reasserting the experience of motherhood as one of potential power for women, in contrast to the institutions surrounding motherhood which had oppressed and alienated women (Rich 1977; Oakley 1979).

\footnotetext{
12 Quoted by Max Abbot, director of the Mental Health Foundation (N.Z.L. October 23 1982).

${ }^{13}$ From Peta Joyce and Pat Rosier, Broadsheet December 1985.
} 
There was a continuing endeavour by many women's groups to reclaim aspects of the motherhood experience that women were said to have been alienated from. For example, in New Zealand there was a resurgence in breastfeeding during the 1970's and organisations like La Leche League ${ }^{14}$ criticised the institutions and attitudes that made this difficult (McKinlay 1983). Likewise, the campaign for more involvement by women in the childbirth process that began in the 1950's, gained a new momentum within the framework of the women's movement. Demands for a reappraisal of childbirth institutions and medical practices were addressed in terms of the rights of women over their own body, and as the Listener headline (March 15 1980) read, the pertinent questions were, "Whose body is it? Whose baby is it?". Throughout the period there were considerable shifts in hospital practices so that gradually women were not being drugged, strung up in stirrups, shaved, given an enema, cut and induced, and the baby taken away after birth as automatic processes. By the mid 1980's (when the author too had a child after a nine year gap), the process was one more of consultation in which women determined the strategy for their own birth: who was going to be there, what drugs and when, and what position to labour and deliver in and what happened to the baby after birth. Such changes had resulted from a tug of war process with the medical profession. Pauline Ray wrote:

For women, childbirth is an intimate emotional event, the first step in a life time relationship between mother and child. For doctors it is a medical event (N.Z.L. March 15 1980).

This period signified a turning point in what had been an increasing appropriation of birth as an illness and medical issue throughout the century (Donley 1986; Mein Smith 1986). Part of this concern had been expressed in a tug of war with technology. While more technology became available to hospitals to ensure safe births, some women began to yearn for a return to the assumed simplicity of natural birth processes, in a way that was at times akin to the idealism of the alternative life style commune. The 1974 visit by the famous psychiatrist R.D. Laing and the subsequent film Birth which was produced with psychologist Helen Brew ${ }^{15}$ and screened on television in 1977, generated heated debate. The film portrayed the childbirth practices in New Zealand hospitals as a process of assault and violence towards the mother and the child, and a psychological disaster to both. Letters from women strongly confirmed this view:

As one of the "silent consumers of institutionalised birth services", I welcome the film Birth. I have seen the film three times and each time the words of the mothers in the film ring as true as experiences I have had in hospital...All these things remain in my mind as an assault on my body and a gross indignity (Christine Rowlands N.Z.L. November 12 1977).

At last someone is saying the things women have said for years. It was a truly emotional experience for me and my family (Marian Goldsworthy, ibid ).

14 The La Leche League was an American organisation founded in 1956 to promote breastfeeding. It was established in New Zealand in 1976 (McKinlay 1983).

15 Helen Brew had been an activist from the 1950's over natural childbirth and had been one of the founders of the Parents Centre. 
Feminists for Life ${ }^{16}$, supported by organisations like Parents Centres and La Leche League, proposed a Maternity Patient Bill of Rights, which again challenged hospital routines and the lack of power women had. A more direct challenge came from the growing popularity of home births as women chose to opt out entirely from the hospital structures. Midwife Joan Donley ${ }^{17}$, a foremost activist for home births, saw that women had a fight ahead for both hospital and home births:

If she goes to hospital she has to fight to resist sedation, induction, foetal heart monitoring, oxyocins, separation from infant and husband. If she decides to have her babe at home she has to resist social pressure and intimidation, and even unprincipled scare tactics (N.Z.L. March 15 1980).

Hospital policies did begin to soften and by the time that the Princess of Wales had her first baby and went home after twenty-four hours, the Woman's Weekly (September 9 1982) was writing that she was:

Keeping both trendy and traditional thinkers happy ...early discharge is an excellent compromise.

And readers were told that at the National Women's Hospital:

The once rigid regime of the obstetrics hospital's unending routine has all but disappeared, as administrations all over the country listen to women with a great deal to say about how their babies should be born.

Campaigns over the rights of individual women to choose and to have power over their own bodies was heard on other issues. The dispute over abortion was a major issue but has been addressed in an earlier chapter. A less publicised trend was when women started to talk about childless or childfree lifestyles ${ }^{18}$. Thursday magazine (September 16 1971) was the first to identify what they called "a new phenomena":

- It goes with things like emancipation, careers and the pill. It is in may ways a symbol of the new freedom of women to choose who and what they will be - and when they will be it.

"J.N.K." wrote to the Woman's Weekly (August 15 1977), calling for more support for the childless option as an"alternative lifestyle for women" in a time when the "earth's resources are running dangerously low". "J.N.K." was concerned at the entrenched attitudes which made this difficult for women - "the luxury of choice still makes things complicated". For some women the choice not to have children was a liberation from attitudes that had defined women through motherhood, but for others the choice was more of a painful compromise arising from the fact that it was impossible for them to combine motherhood with a career. In contrast to some women who made the painful decision to "give up a career", there were other women making an equally painful decision to "give up motherhood" (Kedgley 1985). During this period

\footnotetext{
16 This was an anti-abortion organisation who were active in supporting the rights of married women at home.

17 Author of the book Save the Midwife (1986).

18 Between 1966 and 1981 there was a $10 \%$ rise in households without children (Dept of Statistics 1985).
} 
motherhood was being portrayed as both the natural fulfilment for women as well as an alternative for which women could choose when and if to be a mother.

The rights of the solo mother probably received the most attention during this period. The increasing visibility of solo mothers in the community and their financial support by the state forced recognition that unmarried mothers were choosing to keep their children rather than have them adopted ${ }^{19}$; increasing numbers of women were not marrying if they were pregnant ${ }^{20}$; and more marriages were ending, leaving women to rear the children alone. While these were seen as evidence by some of the disintegration of the family, there were also many campaigns to support the rights of women who reared children alone. In 1973 the Woman's Weekly (July 7 1973) started a fortnightly Solo Parent Forum by asking "Who are these solo parents we keep hearing about?" For five years this forum fielded problems and aired issues affecting solo parents. The Council for the Single Mother and Her Child's booklet, Everything a Single Mother Needs to Know (1975), sold 10,000 copies in its first edition alone. Women who were most vulnerable economically and socially began to organise and be political. The 1970's was a period of intense criticism of solo mothers particularly as the numbers of people on the Domestic Purposes Benefit soared upwards. The Woman's Weekly (July 31 1978) reported social workers' and doctors' views that:

The DPB is encouraging irresponsible parenthood. Doctors tell of single girls who depart from their surgeries deliberately to conceive a child who will allow them to give up work and be supported by the State.

In the past unmarried women had their babies adopted and one of the concerns expressed by the Governments Domestic Purposes Review Committee (1977) was that the pool of babies for adoption was drying up. Julie Maddison from the Council for the Single Mother and her Child told the Woman's Weekly (August 26 1978) the "long adoption lists are putting pressure on single mothers".

Being on the DPB as a "bride of the state" (Broadsheet May 1977) was not easy, but as the Council for the Single Mother and her Child argued, "All that stands between any woman being a solo mother is a man" (N.Z.L. August 20 1977). Valerie Davies wrote for the Woman's Weekly Solo Parent Forum (September 1976):

Any parent bringing up her family deserves the support of the State but neither the solo mother struggling on a benefit nor the solo mother working fulltime gets much encouragement from the State.

In 1976 the Minister of Social Welfare, Bert Walker, launched his famous campaign to ascertain whether solo mothers on the DPB were having sexual relationships. The official argument was that if a woman was in a sexual relationship with a man, then he should be

19 During this period the number of babies available for adoption outside their families fell from 2786 in 1970, to 331 babies in 1985 N.Z. Official Year Book $(1972,1986)$.

20 The rate of ex-nuptial births rose from one in seven in 1970 to one in four by 1985 Dept of Statistics Monthly Abstracts. 
supporting her and her child financially and she should not be on a benefit. Feminist women labeled this expectation as being akin to prostitution, but the Mininster determined that in the case of Beth Furmage, unless she signed a statement promising not to sleep with her manfriend more than once a fortnight, or to have meals with him more than three times a week, her benefit would be canceled - and it was.

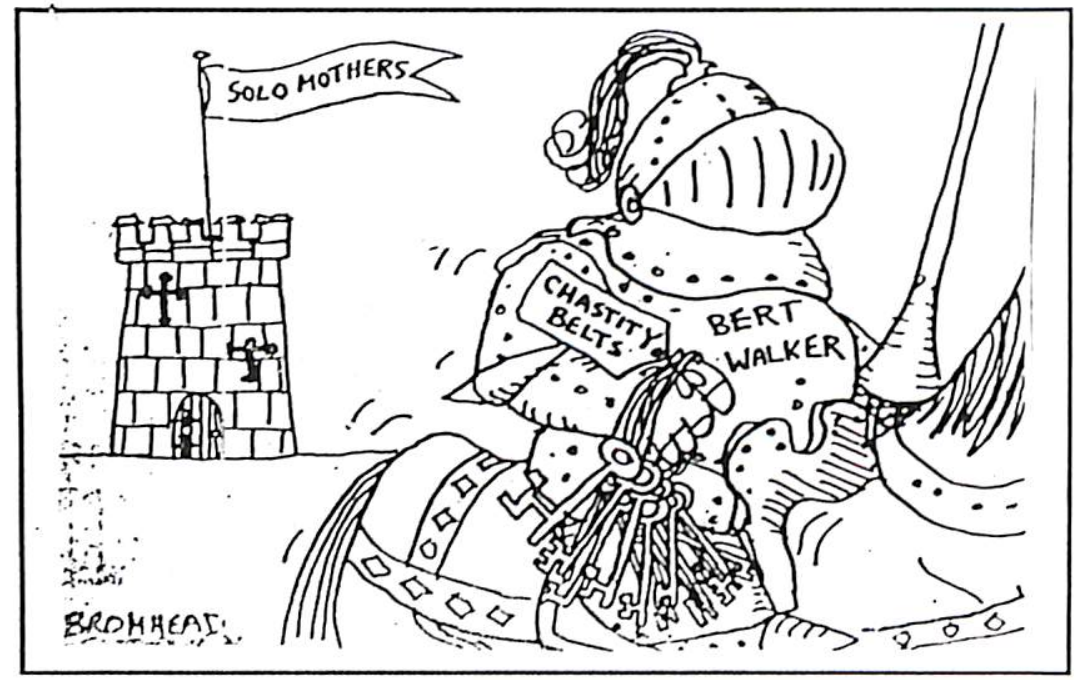

Beth Furmage had to take her case on behalf of the sexual rights of solo mothers to the Supreme Court which ruled in her favour that her relationship with her man-friend was not in the nature of a marriage: he did not live with her, and had never given her any financial assistance. This was a test case which the Government lost, but the issue continued to simmer as again and again solo mothers were accused of "ripping off the system" or "sponging from the State". Valerie Davies wrote (N.Z.W.W. May 9 1977):

Solo parents are under fire this year. 1977 will go down as the year when they were under constant attack from the community after having gained a measure of acceptance and understanding from it ...It is probably the children who will suffer from this unkind attack.

This campaign highlighted the precariousness of the quest of women for the separation of sexuality and economic dependence, particularly when in this case the groom was the State.

The hidden side of this issue was that each solo mother represented an absentee father who was never to receive the same admonition as was heaped upon women rearing children alone (Wylie 1981). The bad effects on children of being reared by a solo mother was often debated, but the fact that all these children also had an absentee father who was putting less effort into childrearing than the mother was rarely addressed. In the United States Ehrenreich (1983) saw this "flight" from the responsibilities of fatherhood as a reaction against the endless financial burdens of being the breadwinner. Ehrenreich argues that this "flight" had in fact begun during the 1950's when the ideal of the male breadwinner was at its height and that was encouraged by the increasing return of married women to the workplace. By the 1970's women with children had more opportunities in the workforce, and it was easier for men to leave their 
families. In New Zealand the establishment of the Domestic Purposes Benefit made the flight almost acceptable as the state then took over the remaining financial support which the men could not or would not afford. But as women were left alone it soon became apparent that there was a new class of the poor - solo mothers who could not easily care for their children as well as work and thus depended on the DPB, or who supported a household on a woman's wages.

Coinciding with the abnegation of financial responsibility by men towards their families was a small trend moving from the opposite direction. This was the increasing involvement of men as fathers in the rearing of young children. The encouragement of men in these tasks had begun earlier in the 1950's, but the suggested role then was one of providing a masculine point of view, and fun and games. As women began to see it as their right to be involved in activities apart from childrearing, more women were successful in involving men in the actual "work" of fatherhood, and similarly more men came to accept such work as part of their responsibility and not demeaning to their masculinity.

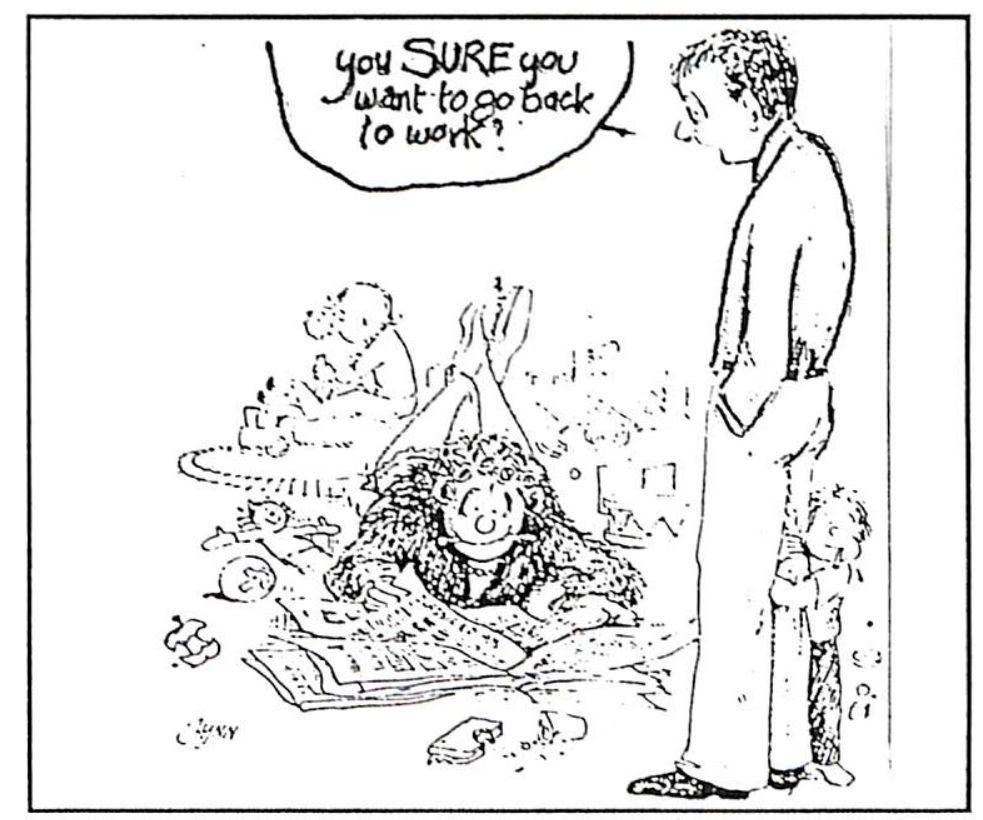

During the 1970's fathers were admitted to the labour wards in maternity hospitals, and as fathers became involved in the birth process it was a natural transition to helping in the early infant care, which had in earlier years been seen as natural only for mothers. Graeme Higgs reported in Parents Centre Bulletin (Winter 1982:10) that:

A quiet revolution is under way (which) is changing our values...More women are now insisting that their partners share greater responsibility for child minding and rearing. As if these changes weren't enough women are now pressing for changes in the traditional male values system by wanting us to express our feelings and become more sensitive! Worse - they want to raise our children as if there were no differences in the sexes... 


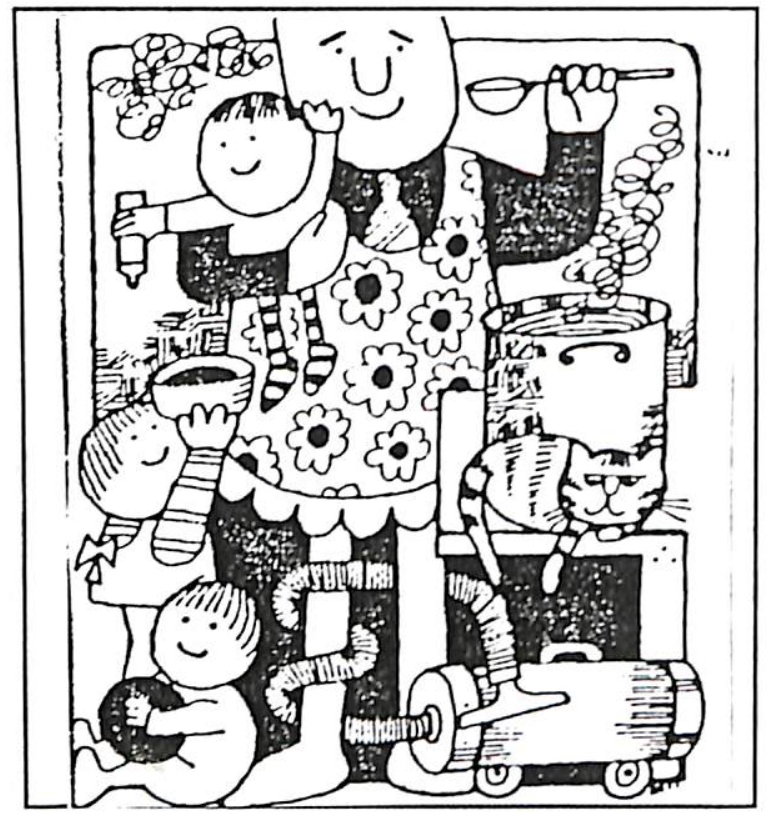

A greater involvement in childrearing, while possible for some men, could, however, only go so far within the constraints of the male workplace, where there was little acknowledgement that male employees had responsibilities to their children (Cook 1985d). So while men did share more in the work of rearing children, it was still women who took the responsibility. There were exceptions as a few capable-care-giving fathers took on the role of househusband, and the Woman's Weekly (April 24 1978) wrote about househusbands who were neither unemployed nor idle, although still noted the fact as extraordinary rather than to be expected:

If a man stays home he's either some sort of hero - or a nutter - but a women can do the same thing all her life with no acclaim whatsoever.

There was also a new trend for some men to assert their requests for custody in divorce cases. This was to begin to challenge the court system which had, for many years, automatically awarded custody to the mother. A group of men formed the Divorce Law Reform Society in response to their bitter experience of Court system, and its orders to pay maintenance. The Society wrote angry pamphlets about "homebreakers" and "adulteresses" who were allowed to get away with house, furniture, children and maintenance. They were to argue that:

The idea that the woman is almost always the better parent is based on outdated psychology which used to produce texts on childrearing where fathers were never mentioned (N.Z.L. July 10 1972).

The views of this society was an expression of the increasing involvement of men with their children, but also the attitudes that men should not be "bled" to support their ex-wives who should be capable of taking care of themselves.

That the worth of mothers should be given more recognition has often been expressed in our social history. During the late $1930^{\prime} \mathrm{s}^{21}$, and again in the $1950{ }^{\prime} \mathrm{s}^{22}$, groups of women had raised the idea of a wage for mothers as a way of addressing the issue. In the mid 1970's the

21 Wages for Wives, by Mary Barklas in Women Today April 1937.

22 See Chapter Seven. 
idea surfaced again with a much wider base of support than in earlier years, yet this was met by a rejection of the idea from some groups of women. Throughout the decade, economist Brian Easton had been arguing two things: firstly that childrearing causes poverty - "families are poor because they are involved in New Zealand's most important industry, the provision of people for our future" (N.Z.L. June 8 1978). And secondly that society should be re-evaluating the economic worth of mothers who were rearing children (N.Z.L. March 17 1979). From an economic and not a feminist perspective, Easton was concerned to redress the financial imbalance between mothers who stayed at home to rear children and those who went out work, and had suggested a "mother's benefit" - later called a wage. It was because. children had become a financial burden to parents, that he argued that the state should give more direct support to families with children. This was seen by many women as an attractive measure to infuse the work of motherhood with more status in an era where women were seeking status outside the home and beyond family interests. The idea was orchestrated by Easton through submissions to the Royal Commission on Social Security (1972) which was to recommend a mother's benefit of $\$ 10$ a week set against an average wage for women of between $\$ 50-60$ (Easton 1972). Easton calculated that it could be funded through the extra taxation generated through the implementation of equal pay, but the new Labour Government did not place it on their political agenda. Support for the idea still grew and it was it again promoted through submissions to the Select Committee on Women's Rights (1975). The Plunket Society was a strong advocate, and in their submission (February 1974) were to emphasise that:

It is not meant as payment for having children but to encourage and help mothers to stay at home.

The Plunket Society was however to concede that:

Social and cultural aspirations, as well as economic reasons may motivate women to return to work and this self - fulfilment is a woman's right, but not to the detriment of her family.

There was, however, feminist opposition to the idea and at a series of seminars held to explore the idea marked differences surfaced. The amount of $\$ 10$ a week was seen as an insult, and the Thursday headline read MUMS RATE - 10 CENTS AN HOUR. Cherry Raymond reported in her Woman's Weekly column (May 6 1974):

At first a "mother's wage" seems the kind of thing that should please people who complain about the denigration of women in our society. More careful thought suggests it could in reality be a token palliative, a short term advantage which could actually set back the cause of women's equality by at least 20 , or more likely 50 years.

By the 1970's the quest for women's security was being sought in the workplace and not in the home as this benefit sought to do, yet in terms of the economic needs of women at home with children, a personal "wage" would have given all women a small amount of economic independence. This issue of economic dependence was important to the women who were interviewed for this study, and all were to express the humiliation they felt during the times when they were earning no money of their own. The idea of a government subsidised mother's 
wage, however, would have been more important in the late 1940's-1950's when status for women was achieved through demonstrating the well-being of one's home and family, and when it was extremely difficult for women with children to survive outside of these confines. Additional financial security in the home would have supported both the ideological and economic realities of women in the home at that time. But by the 1970's, the idea of a mother's wage got caught between two realities. On the one hand, the majority of women were still at home rearing children for periods of time in situations that reflected little change since the carly postwar years, but at the same time there had been an ideological and economic shift in terms of what was possible for women with children to do. The idea of a mother's wage appeared to undermine these ideas. This contradiction between the realities and the possibilities for women who were mothers was an important feature of any analysis of motherhood during these years (McKiniay 1983; Wearing 1984). Women appeared to have choices before them but the reality was that economic and ideological constraints were still powerful in limiting these choices. This led to feelings of dissatisfaction and guilt amongst a lot of women in their role as mothers.

\section{A DOUBLE LOAD: women <---> work}

The percentage of women in the workforce had been rising steadily since the end of the Second World War. In 1971 women represented $29.8 \%$ of the labour force and by $1981,39.1 \%$. The increase was caused, in the main, by the employment of married women. In 1945 only $7.7 \%$ married women were in the workforce, but between the 1971 and 1981 Census alone this increased from $26.1 \%$ to $35.8 \%$. Furthermore, it was apparent that increasing numbers of women were working while they had young children. There has been no explicit analysis of these figures in relation to the class origins of women, although during the early postwar years the view was that the only women with children who should work, were those in financial need or who had exceptional skills that were needed, like teachers and doctors. During the 1970's-80's it became evident that it was more acceptable for middle class women to move back or to remain in the workforce during and/or after childrearing, and they made the idea of employment for married women with children more respectable than it had been earlier. This was reflected in shifts in the meaning of women's paid work. There was paid work that women did as an end in itself and not for the money. This had always been deemed acceptable if a woman had to work for what were recognised as extraordinary circumstances. The case studies of the early postwar years showed that quite a few of the women worked for this reason and that it was in fact, not so extraordinary. But there was a new concept of work - to work for ones own well-being rather than to assist the family or the nation in difficult circumstances. This newer view of work was imbued with the ideals of self-fulfilment and independence which were being more clearly articulated during the 1970 's-80's. However, many married women with children were still working because they needed the money, but in contrast the early postwar years, for reasons that 
were not deemed as extraordinary, but quite normal. The distinction between working for money alone, and working for one's own well-being, was more one of economic value rather than actuality, as women in both situations were inevitably feeding their earnings back into the family.

Alongside this transition of married women's paid work, feminist women were to put considerable efforts into revealing discrimination, and lobbying for more opportunities and rights for women in the workforce. The argument was that unless women were free to work outside the home they would remain apart from the mainstream of social and political life (Gillespie 1980).

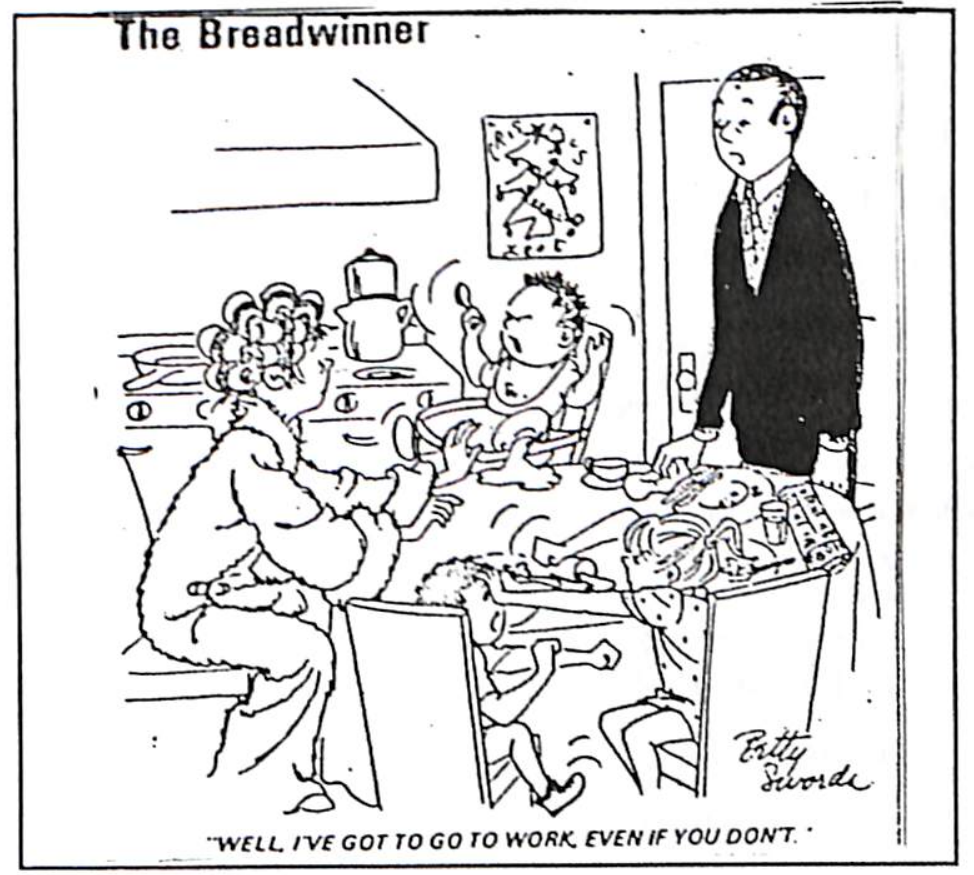

There was also the tacit acknowledgement that marriage did not provide sufficient security and that women, even with dependent children, should be entitled to seek their own economic security in the workplace. Paid employment brought more autonomy to married women within the family (SROW 1981), but also revealed more acutely the discrimination against women who not only had a double load - with responsibilities in the home and in the workplace, but having to face considerable discrimination within the workplace itself (SROW 1973 , 1984). The view that a woman's place was in the home was still strong insofar as home responsibilities took priority over paid employment (Novitz 1976). The Equal Pay Act (1972) was to give equal pay for the same work, and the Human Rights Commission Act (1978) was to prohibit sexual discrimination in the workplace, yet neither of these could alter the fact that there was a women's world and a men's world in terms of occupation, status and wages in the workplace (Elley and Irving 1977); that the lack of support services in terms of domestic leave and childcare provision made it difficult for women to manage the double load (Gillespie 1980; 
Hayman and Roberts 1983) and that women's labour was used as a reserve labour force during times of demand and withdrawn during times of recession (Hill 1979).

At the same time there was a new theoretical analysis of women's unpaid work (Benston 1969; Gardiner 1976), and from British sociologist Ann Oakley (1974) an analysis of the experiences of women as housewives. This highlighted the job's exclusive allocation to women, its association with economic dependence, its status as non-work and its priority for women over other roles. In New Zealand there was still a popular image of a housewife as a:

Busy person happily zooming around house and children, tending to her little ones, devoting time to charitable causes and whipping up sponges for frequent "ladies a plate" occasions ( NZFUW 1976:1).

Media advertising turned this into a more demeaning image of the housewife as someone who was stupid, obsessed with cleanliness and keeping the love of her man. Women were finding new kinds of achievement apart from the arts of housewifery, and Listener columnist Pauline Ray reported that the houswife's numbers were dwindling, her status downgraded, and that "Mrs Housewife is showing signs of strain" (May 22 1976). There were fervent attempts to infuse the role with more value, and the Country Women's Institute's National President, Mrs Barbara Wood, told her members that they should not apologise for being "only a housewife":

To be a success in this most demanding profession needs all the education one can assimilate for it is true that a homemaker, wife and mother needs the wisdom of Solomon, patience of Job and some knowledge of most other professions....Our profession is practised not for 40 hours per week but for 24 hours per day, seven days per week and 365 days per week (N.Z.W.W. September 23 1974).

The study of Women at Home noted that although women were better educated, had equal pay, could control their fertility, and had been freed from much of the household drudgery by home appliances, there was still minimal support for women at home:

Society still depends on her for the welfare of its children and to a large extent for the care of its aged, invalid and handicapped members. It gives her little recognition for doing this and in fact puts her at a financial disadvantage(NZFUW 1976:69).

This argument which emphasized the financial disadvantages of women at home was to gain momentum as comparisons were made between women at home and women in the workforce, and while feminist womens' early concerns were for the rights of women in the workplace, there were'attempts to return the focus to the home. After attending the Wellington Women's Liberation Conference in 1972, Julie Cameron formed a Housewives' Union which was active for several years. Cameron stated:

Women's lib is "too far out" for the average housewife. It is reaching for an ideal state but is not being very practical about it and helping women in their everyday lives (N.Z.W.W. November 27 1972).

Cameron was not seeking a return to a submissive and subservient role for women that was being espoused by conservative religious groups (Above Rubies), and was to criticise the rigid 
sexual division of work in the home and the lack of identity of women at home. Cameron's efforts showed the conflict between reaching for an ideal and managing reality:

Women are in a state of transition changing from being wives and subordinates to being equals...At the moment we are in a state of change between two eras. In other words women are playing an ambiguous part in society (ibid).

As inflation rose during the 1970's there were occasional attempts to combine the purchasing power of the housewife into a boycott movement against rising prices, somewhat akin to the early postwar Housewives Associations. In Christchurch in 1977 a public meeting of 300 women decided to boycott tinned fruit, coffee and chocolate biscuits. The organiser, "Mrs Hemenia", emphasised that the movement was not just a "mother's club", but a "serious organisation whose members were determined to show that they were sick and tired of rising prices" (Star July 11 1977). There were in fact a series of spin off boycotis around New Zealand, but "Asafoetida" felt that housewives could never take effective direct action - "We're too self sacrificing and too considerate of our children and husbands!" N.Z.W.W. July 11 1977). Like the Housewives' Association, family loyalties again made it difficult to maintain the momentum of any brief expressions of unity amongst women at home.

The pages of the Woman's Weekly had been filled for a long time with an array of "make work" activities for women at home. This started to change and in the 1970's the focus shifted to advice on reorganising the housework in order to maximise time for other activities. "Louise Walker's" advice to women like herself returning to the workforce, was to be organised and to allocate work to the family - "My life was one of lists" (N.Z.W.W. May 8 1974). Cookery expert Alison Holst introduced "food without fuss" for busy women - although you needed a freezer, food processer and by the 1980's a microwave to produce it. Holst's name and advice became almost as well known as Aunt Daisy had in earlier years. Holst said that the key to her success was that:

Women could identify with me, they could think to themselves "now here's a woman like me with small children and limited time and money, and the sort of thing she is doing I can manage" (N.Z.L. October 19 1974).

In some families it was a case of redistributing the load of housework so that men and children took more share, but for satirist Rosemary McLeod there were some difficulties:

The husband and I divide up the housework evenly, and the system works brilliantly. It is very emancipated. I do the shopping most of the time. This is because I seem to have the knack for not coming home with a pound of garlic and two eggs....But when it comes to cooking we share...He is the creative one...The thing about being creative though is that the planets have to be lined up properly...That means that I do most of the cooking. This is fair because I am more efficient at it....He also does the dishes when I have cooked the meals. But he has to do those when he feels like it, and it's my problem if I don't like them hanging around...It's not easy being a pioneer (N.Z.L. May 16 1979). 
The major responsibility of housework still rested with women even though men were spending more time with their children (Ritchie 1979), and the husbands of women in paid work were spending slightly more time on housework (Fletcher 1978). This however was not a view supported by Canon Bob Lowe who wrote in his Woman's Weekly column (October 19 1970):

Within the domestic confines of New Zealand suburbia talk of the feminine liberation must sound very strange to the so called man of the house. In fact he is so busy doing the dishes, mending the iron or taking out the rubbish that he is yet quite unaware of the distant thunder.

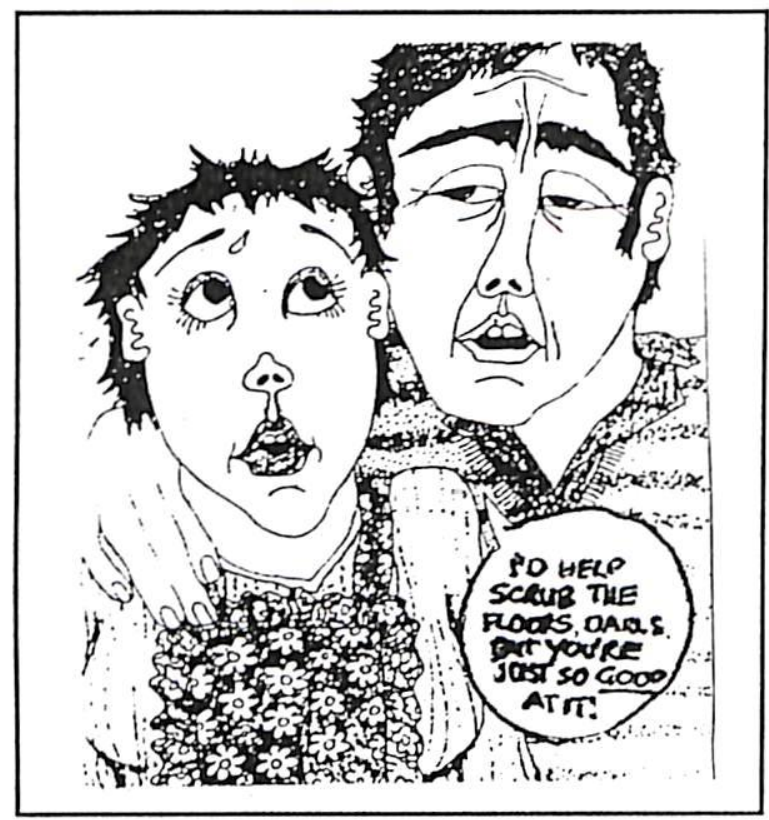

A Federation of University Women (1976) survey showed however that only $42 \%$ of women had any help with housework from $\mathrm{men}^{23}$, and a later National Council of Women (1985) study revealed little change in men's involvement over the decade. "J. C.", who had three children, complained she needed a "wife" to look after her when she returned to work. She had tried to redistribute the chores:

I tried to explain to them that I would need their full co-operation with the chores, otherwise I simply would not be able to cope.

But "J.C." was realistic and blamed her husband's mother:

I think it is hard for a family to change, specially a husband accustomed to being waited on for some years. This is a result of programming in his earlier years when his own mother thought a wife should cope with all the household chores.

And realised that attitudes concerning women's work were deeply ingrained:

He does the ferrying about of the children to various clubs and emptying the rubbish and the vacuuming once a week. He looks on most other

23

of men did not think housework their responsibility gave some help at home shared the work did own work first then would help other 
chores as extras. He is not consistent and will insist on referring to all the chores that he helps with as "your work" - meaning mine (N.Z.W.W. June 11 1976).

Persuading men to share the load was the dream, but for many women an unrealistic one.

"Angela de Carlo" was putting her efforts in training the next generation of men in domestic matters:

Somewhere I like to imagine there are three young girls growing up who will one day be very grateful to me. I visualise three happy young women whenever I watch one of my three school age sons cook his dinner, fold the clothes he just removed from the dryer, or patch the knee of his jeans (N.Z.W.W. July 21 1980).

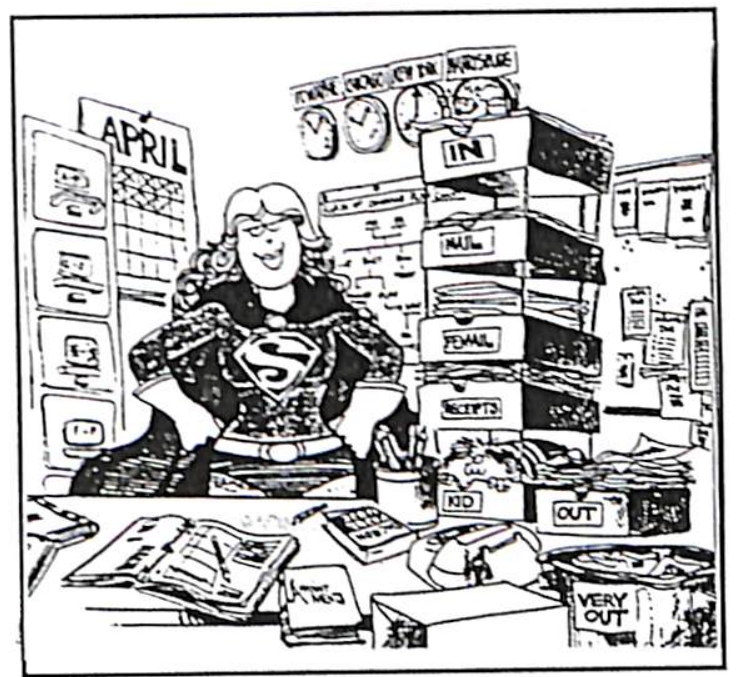

In the meantime Shirley Conran's best selling book Superwoman (1977) was to offer some strategies. Conran declared "Why waste time pushing a vacuum cleaner when you could be writing a best seller or riding a camel across a burning desert" (N.Z.W.W. August 18 1983). Such a view fitted the mood of the time. The woman's movement was encouraging women to move outside the confines of the home, yet there had been no rearrangement of domestic life. Conrad's prescription of housework was that it could be "buttoned up" through efficiency so that women could be super successful somewhere else. Listener columnist Helen Paske listed the book's virtues:

There is advice on how to cut down on housework, how to be your own laundry-maid, great shopper, famous decorator, chef and maintenance person...It tells you how to spend and save money and what on, how to get organised...how to profit from a crisis and what to do with the time you've saved (N.Z.L. January 13 1979).

But Roslyn Grove wrote of her later dissatisfaction :

Strung up, as many of us were in the mid-seventies, Superwoman seemed like manna from heaven. What woman didn't dream that one wave of a feather duster would transform her from a mild mannered housewife into a soaring goddess who would rule the world and rule the roost (N.Z.W.W. April 18 1983). 
Instead of easing the load, Conran's "superwoman" created even higher expectations in women. The assumption was that life for women must incorporate a home and a career if women were not to be destined for mediocrity, and that women were seen to be under achieving unless they were super at every level of their life. This was to take its toll on women and psychologist Jane Firbank hoped that the superwoman era was on the wane:

I think superwoman was a transitional thing. We tried to be the perfect housewife hostess that we'd always meant to be, as well as working outside the home. We were most reluctant to lose territory. When you go out into the world, there is very little exclusively yours that's feminine. That's why we cling to our old special fields (N.Z.W.W. April 18 1983).

The view that women moved out of the workforce to rear children and later returned, is supported in statistics and by sociologists (Bernard 1975). But this kind of schema is too neat and does not reveal the complex ways in which women arranged their childrearing and work experiences. Claire Hadfield's (1981) study showed that $68 \%$ of women had worked at some time while they had a preschooler. Using the data from the Smith Women (1981), Barrington found that many women with children under five years had paid work. Such work tended to be fragmented and thus unable to be represented accurately through census statistics. The 1976 census figures showed that women with children under 15 years made up $43 \%$ of women in the workforce working over 20 hours a week, and $14.7 \%$ of those women had children under five years ${ }^{24}$. It appeared that many more women were having short periods in the workforce and that women's work was characterised not so much by stages, but by a pattern of moving in and out of the workforce during the childrearing years.

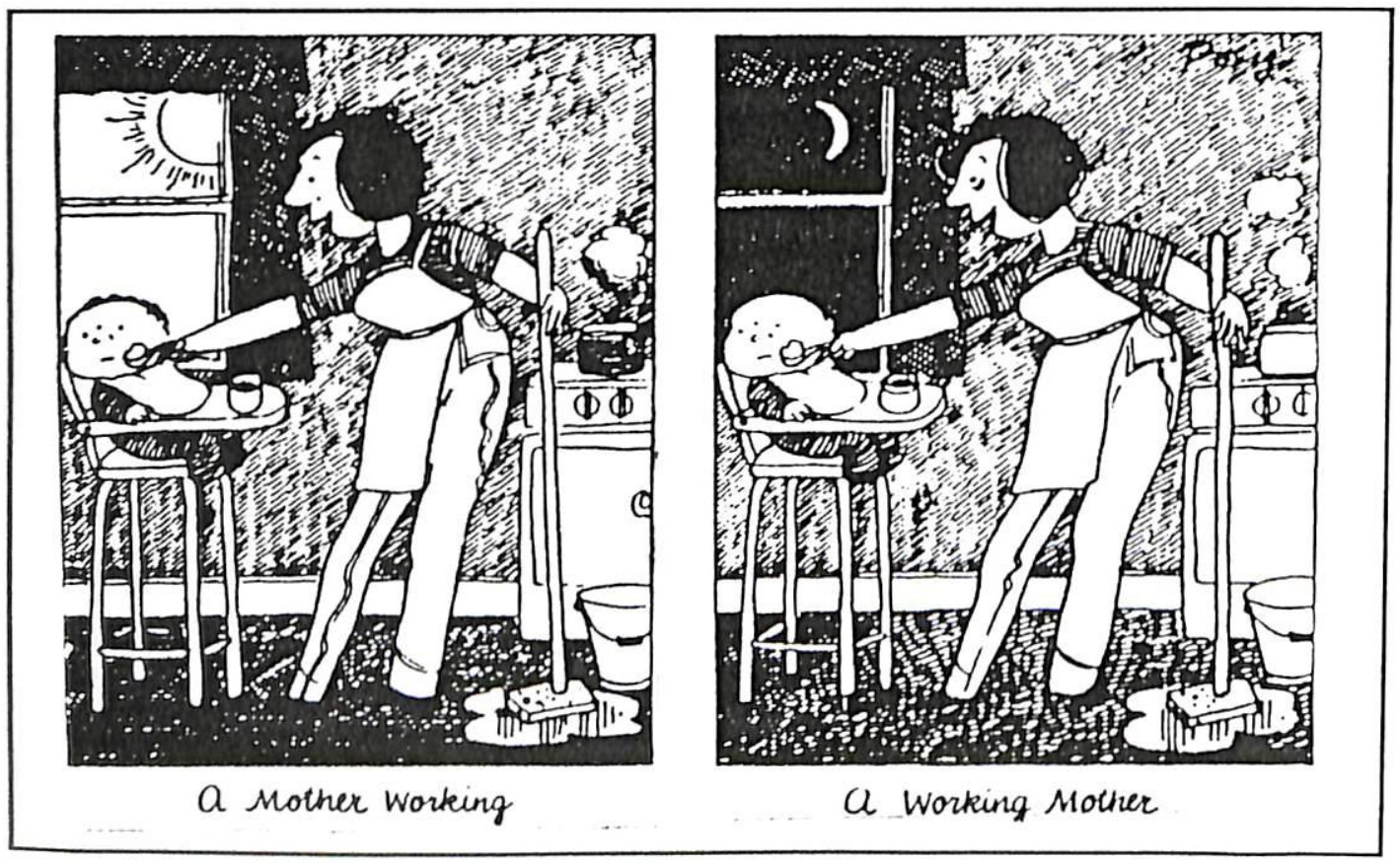

241976 was the first Census in which this kind of statistic was collected. The 1981 Census showed only small upward shifts in these figures. (Mary Mowbray, Dept of Statistics). 
Despite this reality that mothers worked, there was a distinction made between the work of a mother at home and in the workplace which was not the case with a father's work. The mythology of the working mother that grew out of the 1950's was still potent. This asserted the ideology of motherhood as being the primary role, and despite new equalities and opportunities for women in the workforce, a women with children had secondary status (Eisenstein 1981). Feminist women were to argue for the rights of mothers to work and to reveal the difficulties confronting women with children in the workforce. Connie Purdue 25 argued against the wastage of resources:

We cannot afford to do without the talents and skills of half the population. Most women's childbearing now ceases at 26 years of age. A women's years from then, at her choice we hope, can be of meaning to herself and our community if we can gear our services to the needs of the day (N.Z.W.W. June 14 1971).

The balancing act for women was in finding the right prescription which would enable work to be combined with managing children, husband and home. This was a recurring theme in the Woman's Weekly and in research (Moorsom 1976; Novitz 1976; Barnes 1981; Rogers 1982; S.R.O.W. 1984).

Part -time work was often presented as an option which could mediate the contradiction between the ideal of self fulfilment and the reality of other responsibilities in women lives. "Dee Em's" letter won a \$5 prize in the Woman's Weekly:

It seems to me that women's liberation could well direct its attentions towards making employers more aware of the need for part-time jobs for married women, rather than agitating for nursery facilities for full-time workers. During the past two weeks I have been employed as a nurse full-time...Just where does one fit in extra cleaning jobs, sewing knitting, reading, social contact, letter writing, community involvement? (N.Z.W.W. October 15 1977).

But "21 part-time jobs" suggested by the Woman's Weekly (July 13 1970) focussed on the domestic skills of women ${ }^{26}$, thus highlighting the problem that part time work was always on the fringe of the employment (Clarke 1986). Night work was another way of balancing home, family and work. Hazel Barne's (1981) research on night cleaners showed that $90 \%$ of the women were working at night to avoid childcare problems. These women felt strongly that they should be looking after their own children, even though their tiredness and stress was often at the expense of the children.

The balancing act was manageable for women who worked part time but not so easy for full-time workers. This required an offloading of some responsibilities. "L.J. McM" "took the plunge" after fifteen years:

25 Connie Purdue was a trade unionist and in the early 1970's a supporter of women's liberation. She was to move to a conservative stance later in the 1970's over the issues of abortion and childcare.

26 For example: making novelties, motel help, coffee lounge cooking, temporary clericals , ironing and sewing, tea staff, clerical work at home, distribution of circulars, growing flowers for sale, home knitting and crocheting, home dress making, boutique work. 
A friend looked after the children after school. For a while things were lovely with the extra income. Then slowly we realized the children were growing away from us...I started needing more clothes; started to get very tired. I would advise mothers to stay at home, do without the luxuries and start loving their children. We are now a one income family with no money for extras (N.Z.W.W. January 23 1978).

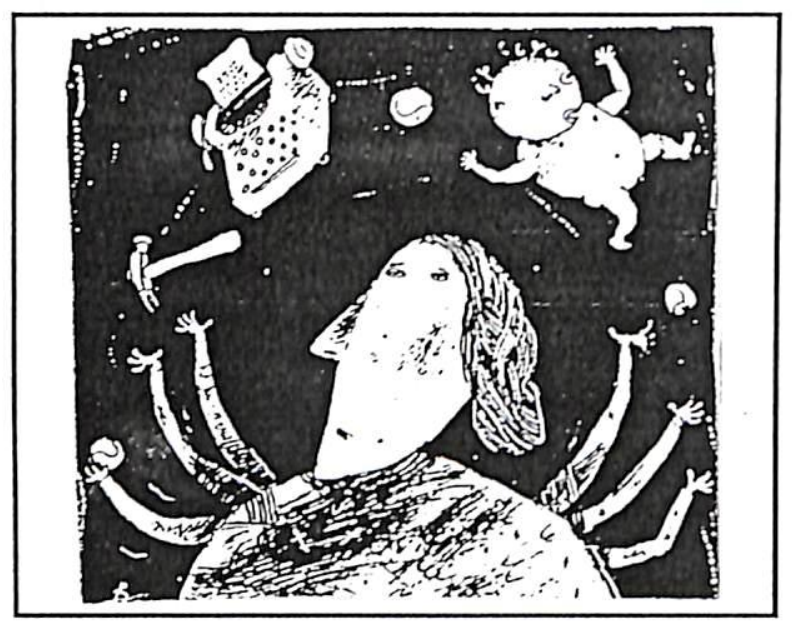

Motherhood, unlike fatherhood, was still deemed to be a twenty-four hour task. But for a fee, "Mrs C.K.S. White" was able to contract out some of the hours and continue work as a secondary teacher because a creche was established at Kawerau College:

I had been conditioned to accept the belief that a university degree and teacher training must be put aside while I applied myself 24-hours-a-day to the care of my own preschoolers...The creche has allowed me to continue my training at a time when I have the energy and interest needed for teaching. I feel that my live contact with adults and pupils during these years of child rearing has added immensely to my family life (N.Z.L. August 16 1971).

"Mrs C.K. White" was fortunate because there was a big gap between the number of childcare places and the number of women in the workforce with preschool children (Cook 1985d). Women with school age children had the school as a caretaker, but the school hours did not match the full-time working hours of women. While a few out of school programmes began in the 1970's it was apparent from Maggie Rogers' (1982) investigation that many children were being left to fend for themselves. A Waikato Times (October 4 1986) investigation into after school care in the Hamilton area, showed a dearth of services and an avoidance of responsibility by government agencies, and this was yet another area in which parents were beginning to look to Government to take on more responsibility.

Participating in the paid workforce gave women more autonomy within the family despite the imbalance of earnings and domestic responsibilities. However, the increasing presence of women with children in the workforce revealed the depth of discrimination against women. The Herald (August 6 1975) reported the fact that:

Despite advances in winning rights for women, pregnant women are often given the sack...The attitude is still prevalent that pregnancy is a 
nuisance...Dr Glass reported that the attitude has less to do with medical reasons than with men not liking to see fat women around.

A dispute over special maternity leave benefits for married women teachers ${ }^{27}$, which was aired for some months through the Listener, highlighted the arguments and counter-arguments surrounding the rights of women with children to work. The argument began when "D.A. Roberts" argued that teachers' maternity leave created instability in the classroom:

While I do not deny that married women make a valuable and vital contribution to the teaching profession. I feel that academic standards will continue to fall and discipline problems will increase until a more stable staffing situation can be obtained.

"D.A. Roberts" felt that the maternity benefits were:

Handouts (given) indiscriminately to young women who may have no real intention of pursuing a career in teaching (N.Z.L. February 5 1975).

Nelson Mackintosh came to the support of women teachers:

Maternity benefits were introduced at a time of critical staff shortages but have proved of such benefit both to the teaching profession, and to enable teachers who are not fulfilled by housework, that they should be retained. With an increase in day-care centres, schools will be well served by women staff who are able to rear a family and still provide at least as continuous a service as other teachers who take some sick leave or attend many in-service courses (N.Z.L. March 5 1973).

The older view that women had to choose whether to have children or a career was still apparent. Ruth Craighead argued:

Surely the point here is that women cannot be employed on an equal footing if they choose to bear children...I see no more reason why special conditions should be made for a woman who has chosen to bear children than for a man who has chosen to take a holiday in the Bahamas (N.Z.L. March 26 1973).

Carol White from Auckland Women's Liberation argued from the feminist perspective that childrearing should not be a barrier to a woman's participation and promotion in the workforce:

Breeding may no longer be a social obligation, but many women teachers, while placing high priority on their profession, also urgently desire their own children. They see no reason why these two priorities should be mutually exclusive. Compressing child bearing into a few years set aside for that purpose and little else may not be the wish of the liberated woman (N.Z.L. April 16 1973).

These kinds of arguments were a forerunner to the later debate surrounding the Maternity Leave Protection Act (1981), which gave pregnant women workers some minimal protection to return to their jobs. The issue was really about the rights of women with children to have the same opportunities in the workforce as men with children, so that women's childbearing function not be used as discrimination. But the deeply held attitudes and the practicalities of bearing and rearing children while in the workforce, offset much of the idealism that equality was possible. Unionist Sonja Davies expressed cynicism about the Maternity Leave Act and told the Woman's

27 Teachers would receive six weeks on full pay before the baby was born and if they returned to teaching within six months of the birth they would receive another six weeks full pay. This provision had been introduced in the early postwar years in order to ease the teaching shortages. 
Weekly (July 8 1983) that "all the Act has really done is acknowledge there should be such a thing as maternity leave".

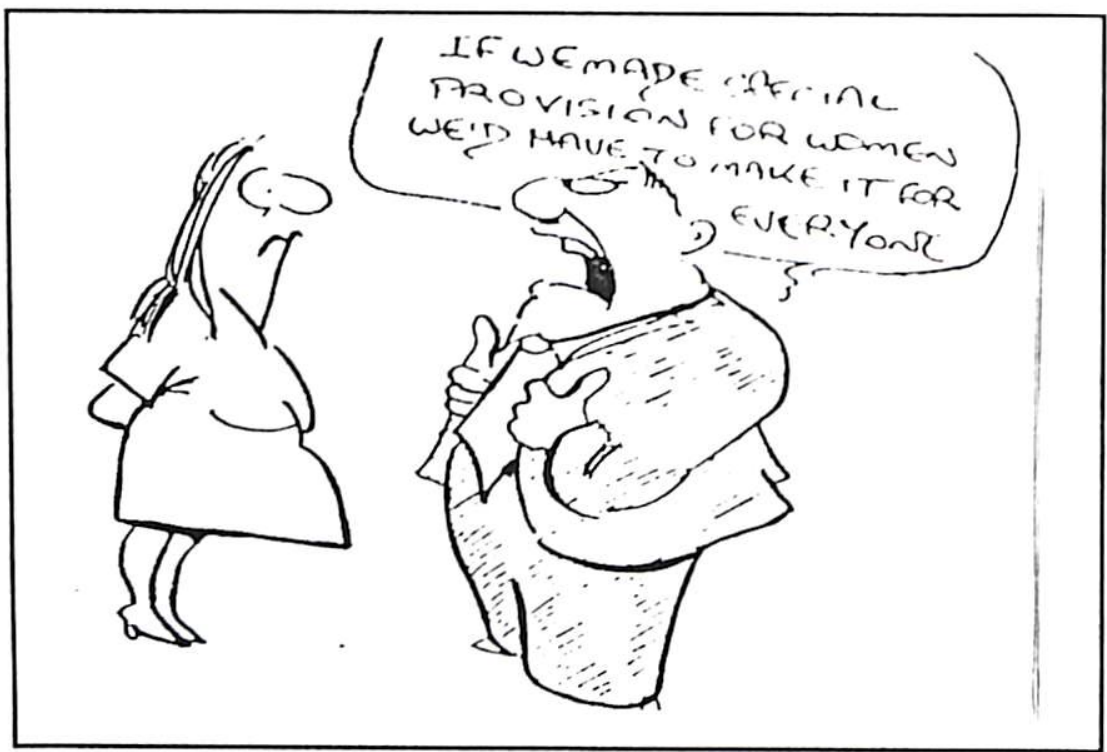

Employers attitudes to women with children was often negative. Studies showed that employers felt obliged to enquire about the domestic arrangements in manner that was not done to men (SROW 1973, 1984). The SROW research on employers' attitudes to women expressed concern at the extent to which women were "used as expendable parts of the workforce", and concluded that:

Until working fathers and working mothers are treated in the same way there can be no equality in employment for women with children (1984:76).

Separate studies by the Society for Research on Women $(1973,1984)$ showed that in the early 1970's employers were more prepared to make favourable arrangements for women with children, but that this was less evident in the 1980's. By then an economic recession had made a deeper impact on employers' attitudes than the preachings of the women's movement. For example in the early 1970's Thursday (October 24 1974) reported that:

Manufacturers, in particular, are prepared to make extraordinary concessions to tempt staff; retraining courses have been set up in many skills. All that is lacking is the takers...

There was an image of employers who were sensitive to the needs of women:

Employers now offer a choice of glide time ${ }^{28}$, shift work and plenty of part-time jobs. And they can be most understanding if a child falls ill and the mother suddenly can't come to work. They need women as they have never done before...

At three o'clock in the afternoon at the House of Raymond, industry grinds to a halt: 95 per cent of $\mathrm{Mr}$ Cohen's productive machine staff walks off the factory floor and goes home to the kids. They take the school holidays off...Mr Cohen is establishing a creche next door...

\footnotetext{
${ }^{28}$ Glide time allowed some workers more flexibility to determine what times they began and ended their days work.
} 
Wellington Hospital reported that they were trying to ease the nursing shortages by recruiting married women. The Woman's Weekly (November 3 1973) reported:

They are offering a more flexible system designed to go halfway towards meeting the needs of a married woman with family commitments. Today's system has a less militant ring about it, and puts out an unashamed invitation to trained women to explain why they are now ex nurses.

On the subject of childcare the hospital was more cautious. Matron Gratton conceded that they would have no problem attracting the young marrieds if they had a creche, but:

While she supports the need for a creche, Matron points out that that the hospital has a moral responsibility not to employ mothers at the expense of their children.

A number of hospitals and factories did open creches during the early 1970's, but as the economic recession deepened the creches closed (Cook 1983).

The more women penetrated the paid workforce, the more the depth of discrimination against them became apparent. Campbell (1982) reported that 27,261 jobs had been added to the workforce between October 1975 and February 1981 and that women took 90\% of them, but he showed that jobs, wages and access to vocational training skills were still segregated by gender. Researcher David Smith, ${ }^{29}$ was to show that, despite the influx of women into the workforce, not only had there been little change in job segregation between the 1956 and 1976 census figures, but also women were in fact losing ground in the higher professions (N.Z.L. May 22 1982). The S.R.O.W (1973) survey of 1000 employers concluded that changes in employment patterns were more likely to come from outside the employment structures. Commenting on the study, Woman's Weekly columnist Cherry Raymond was to state, "Put in less careful language, women will have to fight for opportunities" (March 25 1974). This battle was multifaceted and was to show that the long fought battles for equal pay, maternity leave, equal conditions of employment, equal opportunities in recruitment and promotion, and childcare were in fact just the beginning of trying to address the institutionalised sexism. In 1978 the Working Women's Council formulated the Working Women's Charter as a Bill of Rights which working women needed in order to achieve equality. This document received general support throughout the trade union movement but clashed with conservative groups because it linked women's rights in the workplace to their need for childcare services and the control of their own fertility by abortion if necessary. The outcry against the Charter was loud and orchestrated. It was seen as a threat to traditional family life and as an agent of communism. An extract from one pamphlet by the Working Women's Council (Inc) ${ }^{30}$ stated that the Charter:

\footnotetext{
${ }^{29}$ Lecturer in Business Administration at Victoria University of Wellington.

30 The similarity in names between the two groups was no coincidence and the feminist based Working Women Council was to challenge the conservative Working Women's Council (Inc.) usage of their name.
} 
Denigrates the role of the homemaker and would create a situation which would force women into the workforce. It expresses a contempt for life. It calls for the state to become the principle custodian of children. It aims to bring about a society like China and Russia.

Amidst such opposition, the earlier idealism that the women's movement could bring about real changes for women were to fade as the 1970's moved into the 1980's. Francis Porter wrote:

If feminists now seem to be facing inward perhaps that is a perfectly natural response to years of battering vulnerable egos against the solid walls of male privilege and prejudice...It is simply a matter of selfpreservation (N.Z.L. June 26 1982).

It was not only a battle against conservative attitudes, but also a realisation that discrimination was embedded in economic structures that were difficult to change. The long fought battle for equal pay was an example.

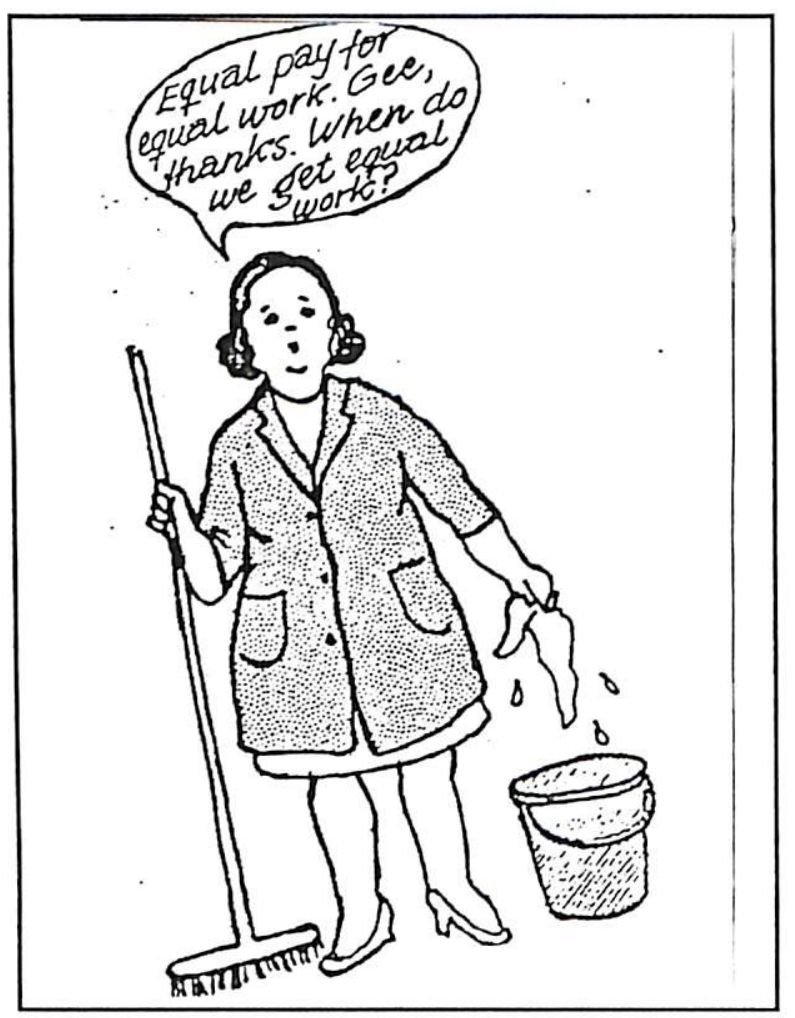

In 1971 there was an optimistic view that the introduction of equal pay would right the wrongs of inequality in the workforce. As Dennis Rose of the Institute of Economic Research said:

An increase in female rates of pay will make paid work more attractive to women and may induce an increase in the supply of women workers...

Equal pay will break down the distinction between men's and women's work, and tend to create one labour market...

Equal pay will reinforce the already strong demands for improved education and retraining facilities for married women, for easier access to part-time work and for assistance with childcare... 
There is a general change in attitude towards the economic role of women. Equal pay will reinforce these tendencies and..give them formal recognition (N.Z.L. July 26 1971).

Equal pay had been available to women public servants since 1960, but women had continued to suffer discrimination in promotion (Malcolm 1978; Holt 1982), and in most parts of the work force job segregation meant that equal pay had a minimal effect on women's wages. By the mid-1980's women were still getting only $70 \%$ of the male wage and a new campaign was underway - equal pay for work of equal value ${ }^{31}$.

Attitudes towards reform had hardened as an economic recession set in, unemployment rose and employment opportunities for women became fewer (SROW 1984). Debbie's story seemed typical. She had two young children but her husband did not earn sufficient to cover their living costs. Debbie delivered circulars but needed a better part-time job, but when she applied for a morning job in factory, "So did 700 other women... when they hear you have kids they just don't want to know" (N.Z.L. April 22 1978). Married women were often the first to become redundant (Shipley 1983), like Mary who lost her job after ten years:

There was a feeling of uselessness She's dropped back in the house, in a role she thought she had shed...she misses the people she used to work with...they were her second family. But most of all she misses the feeling of being part of the world (N.Z.L. April 22 1978).

In times of recession the old argument that married women took jobs from breadwinning men resurfaced. It was also argued that married women were taking jobs from unemployed school leavers. The leader of the Opposition, Mr Rowling, made the suggestion, but accused a Listener staff writer of mis-interpreting his statement:

I pointed out to the New Plymouth Rotary last November that the 1960 's baby boom was coming on the labour market at the same time as increasing numbers of married women remained in the workforce...I pointed out that this combination of circumstances made it very difficult for young people trying to enter the workforce. But at no stage did I criticise married women for wanting to work...

Yet Mr Rowling went on to state that:

Society has got to come to grips with the implications for the labour market of the working mother (N.Z.L. May 13 1978).

Economist Brendan Thompson called married women "Job Stealers" (N.Z.L. July 11 1981), and argued that if married women had had the same pattern of participation in the workforce in 1976 as they had had in 1966 , some 60,000 more jobs would have been available. Society should, he claimed, consider the cost when married women take jobs from school leavers. Reaction through the letter columns of the Listener was swift, voluminous and angry:

Would Mr Thompson completely deny married women the right to any economic and psychological independence... Woman it seems is not a person, but a series of roles: as a school leaver a girl maybe permitted to work....as a wife social sanctions must ensure that she withdraws entirely from the paid labour force (Anne Green N.Z.L. August 8 1981).

31 Hyman and Clark (1987). 
"Susan Wauchop" suggested that there was another way of viewing the situation:

Look at the way that paid work is distributed: men - married men - are holding down (hogging, you might say) the majority of positions. No one says, "Look at all those selfish men refusing to give up their jobs for school leavers and unemployed breadwinners!" (‥Z.L. August 1 1981)

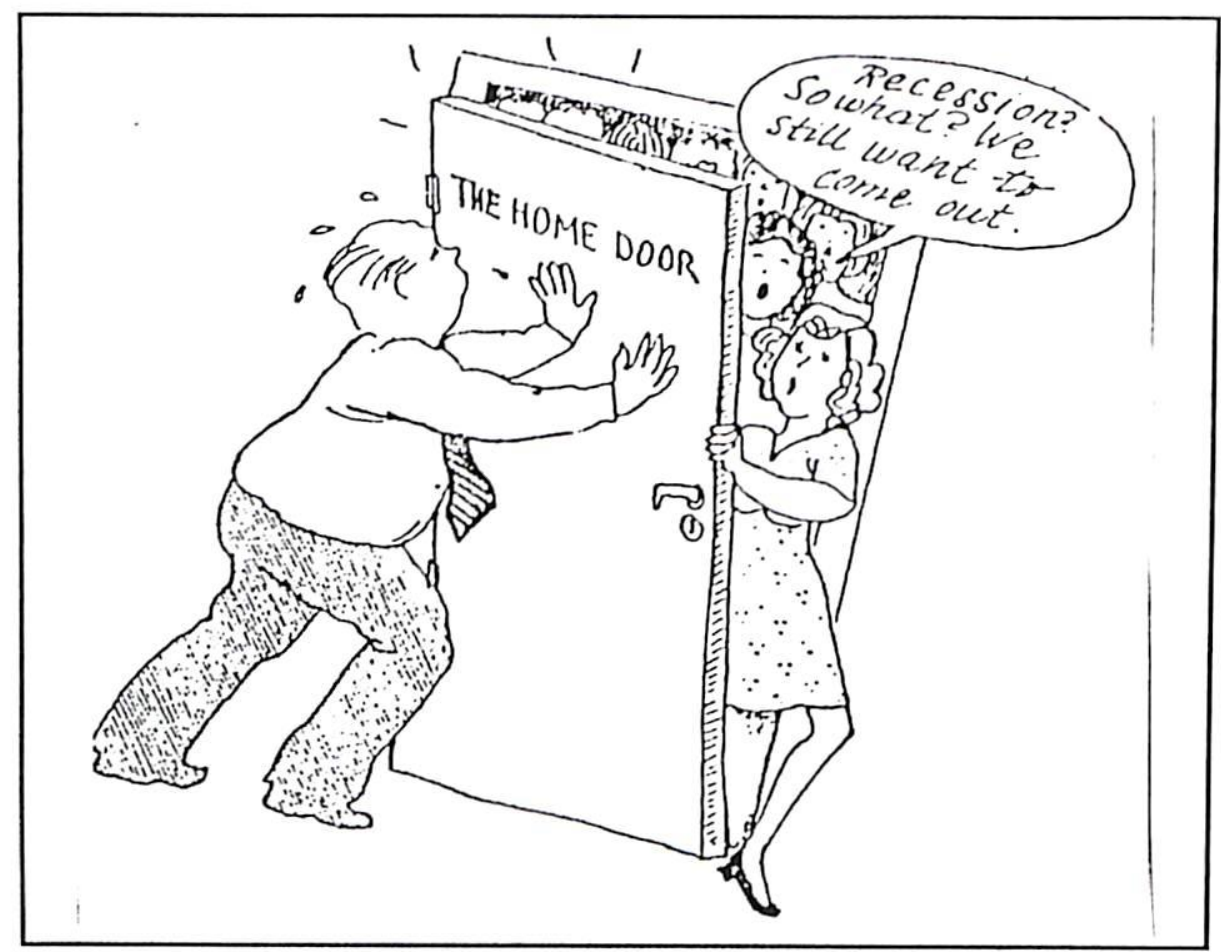

Concern about unemployment focussed on the plight of school leavers and male breadwinners whereas the problem of women's unemployment remained hidden (Paske 1978; Hancock 1981, 1983), and did not appear in the statistics (Shipley 1983). In the Walsh Study ${ }^{32}$ it was estimated that official statistics on unemployment included only $10-11 \%$ of the real figure for females, and that the overall unemployment rate for women was three times that of men. Women's unemployment was not a priority issue amongst politicians and when Cabinet Minister Dr Shearer stated that "unemployment was not a problem for women in the Waikato", senior social worker Lorna Booth replied angrily:

Unemployment may not be affecting women in Dr Shearer's
professional and social circle...I cannot understand where the man's
thinking apparatus is...perhaps he is sitting on it...I would like to take
the M.P. around the electorate to give him an insight into the social
situations caused by the unemployment of women (Waikato Times
November 21 1978). Two studies on women's unemployment began to reveal the depth of the problem and the hidden anguish it caused for women (Hancock 1981 Shipley 1983). Shipley stated:

The loss of a mother's job can often transform the way a family lives... And women, who are dealing with the household's financial difficulties

\footnotetext{
32 Quoted in Women on the Dole by Marie Dwyer Broadsheet June 1980:23. Dr Carl Walsh was an economist from Auckland University.
} 
on a daily basis, bear the brunt of it. It's all taken out on her - planted at her door (N.Z.W.W. June 6 1983).

Hancock (1983:45) reported:

For many of the married women the feelings of depression, loneliness and isolation that were widely expressed related also to their loss of economic independence as women, with their sudden reliance on their husbands for financial support.

Shipley's research endorsed this, and noted that one of the effects of unemployment for women was that it altered the "balance of power" in the marriage. "In many cases it led to an oppressive situation for women" (N.Z.W.W. June 6 1983). The rise of women's unemployment and the efforts to make it visible were to reveal that despite the new achievements of women in the workforce, married women had only conditional rights to work and no rights to receive unemployment benefit ${ }^{33}$, all of which highlighted the precariousness of the new equalities. The government appointed Committee on Women stated:

Society pays lip service to the equal right of men and women to work when times are hard. Women are the last to find jobs and the first to become redundant. Women themselves must believe in their right to join the workforce. Today they accept lower paid jobs with less responsibility and fewer promotion opportunities, and then feel guilty because they are employed in jobs which some say should go to school leavers and breadwinners (Newsletter, April 1978:1).

The media, however, found it more attractive to focus on the penetration by women of traditional male bastions of power. It always made a good story, but these were individual stories and it would be easy to misjudge the extent of such infiltration. There were, however, increasing numbers of women keen to try occupations where they had previously been excluded like the fire service, the navy and trade apprenticeships. And there was the world of political and economic power where it was difficult for women to climb up the rungs of promotion. During this period there were rapid changes in the economy and shifting employment patterns for both men and women. The demand for skilled labour was opening up opportunities and in a few specialised areas breaking down old divisions of labour. Yet it was still the idea of getting women into Parliament which was used as a measure of success of emancipation and only eleven women had made it into Parliament by 1970 when there were four women out of eightyseven members. Sue Kedgley reported on one aspect of the problem

A New Zealand mother could not leave her children with her husband for a week while she shot off to Parliament...A National woman who was a candidate in 1969 when she had young children told me that the attitude of most people in her electorate - particularly women - was one of horror. She concluded it was an asset for a man to project a "family man" image but for a woman it is a tremendous disadvantage (N.Z.L. October 16 1972).

\footnotetext{
33 The unemployment benefit was not payable to anybody whose spouse had an income over a certain limit, so most married women who found themselves unemployed were not eligible for the benefit.
} 
There was a heightened consciousness about getting more women into parliament, particularly as a survey of M.P.'s (N.O.W.1975) revealed "wide spread ignorance of concern on women's issues". $81.5 \%$ of National and $68 \%$ of Labour M.P.'s felt that mothers with preschoolers should be encouraged to stay at home, and there was little support for the view that traditional mother - father roles were interchangeable. The conclusion was that:

Ignorance is no substitute for genuine concern. Women represent $50 \%$ of the votes in New Zealand and we are no longer prepared to tolerate polite indifference to our needs and concerns from parliamentarians (N.Z.L. August 30 1975).

Organisations like the Women's Electoral Lobby (W.E.L.) were formed and by 1981 there were eight women Members of Parliament. The Woman's Weekly (February 8 1982) reported that there would be a:

BREATH OF FRESH AIR IN A WORLD OF MIDDLE AGED MEN: They bring to Parliament a range of experience as women from a divorced grandmother to a separated mother of three young children, experience they see as different from the traditional image of a Member of Parliament as a middle-aged male.

By 1984 there were twelve Labour Party women M.P.'s, two of whom were Cabinet Ministers, aand two National Party women M.P.'s. A similar trend occurred in women's representation on local councils and mayoralties. It was an exercise in breaking down traditional attitudes, getting the concerns of women onto the agenda, as well as balancing childrearing responsibilities. The Woman's Weekly (May 26 1980) reported:

Hamilton City Councillor Margaret Evans knows what it's like to breast feed a five-month-old baby during a national municipal conference or interrupt a toll call to take a toddler to the toilet...Margaret Evans believes she was the first woman to have a baby while serving in local government.

Being a first though was never easy. The Listener (February 14 1976) reported Jenny Goodwin's appointment as the first woman news reader on the national television network with the assurance that she was "no rampant spokeswoman for women's rights". Jenny Goodwin herself said:

I agree with the commonsense objections of the women's movement but not their methods.

Developing strategies to survive in a male world were crucial and Jenny Goodwin was pragmatic:

Chauvinism may exist around the television channel, but I don't choose to notice it. I certainly don't go in for confrontations.

The Evening Post was to report that in most cases "the system has given in gracefully" to the pressure from women, and listed the appointment of women professors, judges, a woman Director General of Radio New Zealand and an industrial mediator. But from Sonya Bank's observation, it was harder to change attitudes than to get a few women into top jobs:

In my job I sometimes travel around the country... I'm always amazed just how few women there are on these planes...On Friday nights rows 
on row of businessmen get off the plane in Wellington or elsewhere to be met by wives. What this means is that when women do travel during working hours - and there are a few - air hostesses tend to say things like "Going on holiday dear?" (N.Z.L. May 9 1979).

Industrial psychologist Helen Place ${ }^{34}$ told the Listener (January 9 1982) that the major problem for women reaching the top was that women did not see themselves as climbing the managerial ladder because everything they "see, hear and read labels that path for men only":

The ideal manager is male...and feminine characteristics are seen as non ideal... There is never any suggestion that female characteristics may be equally well suited to managerial tasks.

The choice for women was a dilemma: to either remain in the comfort of the traditional female occupations with the poorer pay status and conditions or, as Francis Porter wrote:

Attaching herself to the masculine comet and being pulled along with its tail. This tactic may succeed merely in getting a fair rate of pay, and at what price? (N.Z.L. June 26 1982).

By the mid 1980's women were reappraising their role as workers in the workforce. For this second round there was perhaps less idealism and more pragmatic planning towards longer term strategies. There was still banging on doors of male bastions, but there were louder assertions that it was male attitudes and methods which needed to change. There was also more acknowledgement within the union movement of the particular plight and oppression of low paid women workers, and the need for employers to recognize parental responsibilities for both male and female employees. The emphasis was not so much now on achieving equality with men, but on the need for men to change (Kedgley 1985).

34 Published as Women in Management (1982). 


\section{TEXT TWO - A PERSONAL REALITY 1970-1985}

The younger women were rearing children during the 1970's - 1980's. They had all had their first child by 1975 . For some, the early years were past and by the time of their interviews they were embarking on a new phase of parenting young teenagers. For others there were still nappies on the line. Unlike the older women in this study, marriage and motherhood were not so synonymous. One woman never married, three had children before they married, and in contrast to the older women the gap between marriage and children was deliberately longer. But despite improved contraception, three of the married women still had unplanned first pregnancies.

These women had been reared as children during the early postwar years and their lives had been caught between contradictory expectations. They were imbued with ideals of fulfilment and security in marriage and family (Middleton 1985b); but they were also being assured of a certain financial independence during the years they were working, and for women who had educational qualifications there were expectations of perhaps pursuing a career as well as having children.

The childhood years of these women have since been portrayed as the "golden years" of "unsurpassed prosperity" in New Zealand, but this was not the experience of most of them. Two women had childhoods which were economically comfortable, but the rest were reared in families managing on limited resources, and in the cases of Pauline, Sharon, Sheila and Penny, grew up with violence, depression or illness within the home. The childhood memories of these women confirm the view of the older women that managing everyday life during the early postwar years was a struggle. Unlike the older women whose philosophy of mend and make do helped them to survive during times of austerity, the younger women had fewer such skills and less inclination to acquire them. There were more opportunities in the workforce and they had fewer inhibitions about working while they had children.

Expectations of what was necessary for family life rose considerably over the two generations. Ten of the younger women were living in their own homes at the time of the interviews. Four had a personal car. All homes had basic home appliances such as an electric stove, fridge, washing machine, floor cleaners, television and stereo. Unlike the older women, most of whom had spent years saving for such commodities, one by one, the younger women saw these as the minimum requirement for any household. If they could not afford them when they set up home they were generally put on hire purchase (something the older women in this study often disapproved of when they talked about the younger women). For Pauline however, there was a dream house with all the latest things such as a spa pool, video, and microwave, but for most of the other younger women these were extras to be acquired gradually, as the older women had once done. With the exception of Elizabeth, few of the younger women put energy into sewing and knitting for their children. Most had other 
priorities for their time and preferred to purchase ready-mades. Such maxims as "paying one's way", "keeping one's head above water", or "making do and managing" were not as powerful during these years as they had been in the early postwar years. The consumer oriented society was so constructed that the concepts of waiting and saving were a little archaic. The advertisers' ethos was one of instant self-fulfilment: "If you want it you can have it". However, this was not possible for all. During these years there was the reluctant acknowledgment that poverty still existed (Easton 1979), and life for several of these women was a real struggle, even though none were to experience the extremes of homelessness and destitution sometimes portrayed in the media.

This chapter follows a similar format to that of Chapter Eight and again presents a series of case studies constructed from the interviews. The issues are similar in that the case studies reveal the strategies and rationales women used to balance their aspirations and manage their responsibilities to their children, their men, and their work. The case studies of the younger women, however, reflect shifts in the changing economy which allowed increasing economic opportunities for women, alongside new ideologies of self-fulfilment and equal rights for women. The women had the common experience of being mothers, and all but one were married at the time of the interviews, yet their experiences varied. They came from rural, urban and small town backgrounds; they had had good and bad experiences with men. Penny, Beverly, Adrienne and Carolyn had become economically independent while Sheila, Denise and Annette were totally dependent. Yet, while Sheila yearned for more independence and was carefully working towards it, Denise and Annette upheld the view that it was their husband's responsibility to support them and resisted incorporation into the workplace. Their experiences may reflect the lives of other New Zealand Pakeha women, but there are undoubtably many others. However, the aim is not so much to codify the range of experiences but to use these particular case studies as a window towards understanding how women rationalised and ordered their lives amidst the contradictory realities that made up everyday life.

\section{Part One \\ "ACCOMMODATION AND RESISTANCE": ASPIRATION VERSUS REALITY}

Jean Anyon's (1983) description of the process by which women and girls made concessions to the dominant ideology of femininity while also resisting it, was again a useful framework for understanding how women order and reorder their lives. Three case studies in Chapter Eight showed how the older women carefully manoeuvred to obtain some kind of independence but did not expect accommodation from their men, and accepted that these concessions would be shelved if they conflicted with the priority needs of their families. The following case studies of Penny, Raewyn and Elizabeth, appear along with an expectation that men should make 
some accommodation, and a new ideal for some, that women too could be breadwinners. This created new strategies and choices, but also some painful compromises.

\section{RAEWYN}

Gee it's an unfair world. It's a man's world. Gee what do they do. They just do their 9-5 job and go out a number of evenings a week and what do you do. You are slogging from daylight till dusk...Well as I say my husband thinks I should be doing all the gardens, and mow the lawns and if I can find time, help him on the farm, which of course I do. Two weeks before I had my first baby I was picking up 320 lb bales of hay with a tractor and trailer. That was hard and I will never do that again.

Raewyn came from a large family which had struggled to manage financially. The women worked hard, and so did the children. From a young age Raewyn had the responsibility for caring for numerous younger siblings. School and work were not good experiences for he:- She saw her future in being a wife and mother, and was happy to give up her job in a clothing factory to marry a struggling sharemilker ${ }^{1}$. Raewyn often worked alongside her husband on the farm, but for fourteen years of marriage she had had no access to money apart from asking her husband. This was something she accepted, but always felt it to be a denial of her work on the farm:
I have an independent streak and that really bugged me. I felt that asking my husband for money was nothing short of begging. I don't like him asking what I want it for. That really bugs me which is silly because in a way we were in partnership. But he would say that I've put nothing into the farm as they were his cows. But that is very very wrong because I said to him later, "You may have put the money in but there has been a lot of sweat of mine gone into that".

Their goal was to get their own farm, but the likelihood of this appeared distant. Yet for Raewyn, this was a sufficient reason to make sacrifices. At times they were able to afford help on the farm but when this was not possible Raewyn was the "hired help" although without wages or recognition:

When I was working on the farm people would say, "How are you getting on without a boy", and instead of saying. "Oh I have my wife helping me", he would say "I'm doing all right", and they thought he was a jolly martyr which bugs me. I just like to be acknowledged that I am doing the job otherwise a lot of farmers snigger behind their backs saying, "Oh poor old L_ he is working his guts out on the farm and what's his wife doing sitting back at the house watching the soap operas".

Raewyn had five children and while she worked on the farm, her husband gave no assistance with domestic work or with the children:

It had been drummed into him when he was younger that a mother stayed home and looked after her kids and that was her lot until they were off her hands. Quite often his mother has said to me, "You are a married woman with five kids and you should be home looking after them". I was, more often than anybody knew I was. One time when we

\footnotetext{
${ }^{1}$ Sharemilker farmers usually own the animals, but not the land.
} 
had no boy and I was pregnant, but it was a case of getting the cows milked and we had no money. I had to leave three kids at the house and it was very awkward as one was a two year old. I would help him but at night when it came to the dishes he'd just be sitting there watching TV.

Racwyn had accepted that her husband was unlikely to change. Instead she was training her children to help around the house and in particular ensuring that her two boys could cook and clean. Raewyn had recently tried to get some financial independence and short breaks away from the children, but this had created conflict in her marriage. A crisis had occurred two years earlier when she had a breakdown from depression. At her doctor's suggestion Raewyn decided to get off the farm once a week, but this had not been easy. First she tried going to judo:

But his bowls club would start to clash with my night out and I couldn't have the car. He went out to two bowls clubs and a Jersey Cow club. If you miss too many nights you might as well go back to square one...I felt really good and I was getting really fit and felt happier everyday and was taking the kids out more. But he didn't like the thought that I might be able to up end him.

Raewyn then tried yoga which was during the day:

I enjoyed that too. I even took the little one along in the bouncinette. But then there turned out to be car problems too. I started to think that this was a bit of a have that he wanted to go to sales. And so that put the kybosh on that too.

The test came when she decided to go to Housie:

I didn't even play cards. I mean I wasn't a gambler. Well I went the first night and I thoroughly enjoyed it and I was a box of birds the next day.I mean things were going right and even things that were going wrong as far as I was concerned they were going right. I have never looked back since. I go a couple of times a week now.

Helen: So how did you work out the car arrangements?

Well he'd do things like come in late from milking and I'd be running late. So I'd keep his tea in the pot and say, "Your tea's there, the kids are fine. They have all been fed and they're all washed. The baby's in bed", and I'd shoot out the door. One night he hid the keys but I got around that when I told him I would borrow the neighbour's car and all of a sudden he found the keys.

Helen: You sound as if you were becoming a lot more assertive.

Oh boy did I ever, and I never thought I had it in me. I was determined I was going to never end up as I had been. When I thought he might take the keys I had another set cut and I still have one. He tried quite a few tricks. I think it was all in the way that he was brought up but I still thought he was lousy and called him quite a few names. We never came to blows or anything like that but we had quite a few rows. I nearly gave in a couple of times when he said about the baby. He said, "If she cries I will turn the radio up and I won't hear her". But my older son who was about twelve whispered to me as I went out the door "Don't worry mum I will see to her".

Going to Housie had a bonus, because Raewyn had a lucky streak which gave her an independent source of money. She would gamble the family benefit, but would sometimes 
have winnings of up to a hundred dollars. Raewyn had also begun knitting fancy goods for a shop, inititally to raise money for an overdue bill:

My husband said, "That's only chicken feed". But I was quite indignant and said, "At least I'm trying to do something about it and I'm not sitting and moaning".

Raewyn continued her work and started baking for friends. The amount of money she earned was small and invariably went on urgent bills or clothes for the family, but like her Housie winnings, it was money that Raewyn controlled. At the time of her interview Raewyn was feeling she had made her point, and felt a lot more positive about her relationship with her husband. She could get out, she had a little money of her own, her children were helping her around the house and best of all she was not feeling depressed.

For the first time Raewyn had a consciousness of changing her life. The process had also made her aware of the boundaries between upsetting and protecting her marriage which she did value. Raewyn accepted, albeit reluctantly, that her husband would not or could not change much, but she was more confident that she could carefully carve out a life that gave her more independence. She still saw her husband as the breadwinner, but wanted her role in the partnership to be acknowledged more. That her husband now rarely challenged her right to go to Housie was a tangible reminder to her that small changes were possible. Sue Kedgley (1985) identified a growing mismatch in attitudes between New Zealand men and women of the postwar babyboom generation. They had both been reared amidst a framework of separate spheres, but Kedgley believed that while the girls as women were to gain new aspirations the men were slower and often reluctant to change. In the case of Raewyn's husband it was apparent there would be little change except through confrontation.

\section{ELIZABETH}

When we were first married we used to share out the work on a Saturday, and he would do the vacuuming or whatever. But as soon as I gave up work it all became my job. I just wished he would do the dishes at night. When I went back to work it was still my job.

Elizabeth was to find, like Raewyn, that her husband had firm views on the different roles of men and women but these did not affect their lifestyle until they had children. He saw the role of motherhood as synonymous with a wife who stayed at home and took on the domestic responsibilities, just as his mother had. In contrast to Raewyn, Elizabeth was more assertive, better educated and as a school teacher had a marketable job. The pattern of negotiation was therefore different, even if the issues were similar. A contraceptive failure after a year of marriage cut short plans for travel and saving for a house: all the things Elizabeth and $\mathrm{S}$

had intended to happen before they began a family.

It was a shock. It took a bit of a adjustment. I remember coming out of the doctor's surgery and the nurse saying. "Congratulations you are going to have baby", and I thought "Oh crumbs am I?". I was only in my third year of teaching...but in some ways I am an accepting person 
after the initial shock wore off. It just meant that there was going to be a change...It was a shock for $S$ quite pleased. too. After the shock wore off he was

Elizabeth had few illusions about motherhood as she had had a lot of experience helping with her younger brothers, but she found motherhood lonely because none of her friends yet had children and she had no transport:

\section{$I$ decided on my own without consulting $S_{\ldots}$ to get a job. There was an advert in the papers saying relievers ${ }^{2}$ were wanted as at that time there was a teaching shortage. I rang up and was asked what school I would like, and so I chose one near where my mother lived.}

Elizabeth did this mainly because she was bored and lonely, but to her husband and family the emphasis was on the financial necessity. There were financial pressures but they weren't really pressures. We could have managed, but you know we managed better because I had a job. Being pored and lonely would not have been sufficient reason to justify going back to work with a young child, but working as a sacrifice to help get a house was almost acceptable. The childcare problem was resolved when the grandmothers' shared it as a contribution to help Elizabeth and $\mathrm{S}$ get established.

Helen: How did everyone feel? Were they supportive to you?

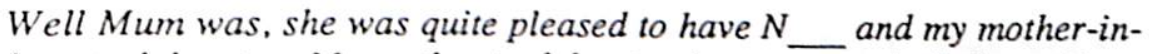
law took her too. My mother took her to playcentre and all these things that I never did. That was good. But $S$ was not at all happy because obviously I was away from $N_{\text {_ }}$ when I should have been with her. He felt I shouldn't be at work if I had a young child.

Elizabeth felt that it would be difficult for her husband to change and saw their different upbringing as part of the cause. She had a mother who had worked all her life, whereas her husband's mother had never worked and never had any need to.

On her return to work Elizabeth enjoyed the stimulation of teaching again and felt that she was keeping her skills in practice:

I had a greater insight into children and it felt good getting back into being with people who were of similar intellect to myself and talking about things other than babies...It was just interesting being able to get right away from the house. It was something I really needed at that stage because you become stagnant in your thinking and you also feel very inadequate being at home all the time...I went back to teaching to prove that I could still do it and run a house.

On the home front, however, it was not so rosy and Elizabeth continued to take the major responsibility for the child, the house and the cooking:

It was always very busy. There were a lot of pressure just to get off in the morning. There were car restrictions and one day a week you weren't supposed to drive your car ${ }^{3}$. Mine was in the middle of the week and it was such a hassle getting someone to come and pick us up. Getting home it was so late. There was always such a lot of organising just to

2 These positions were short term contracts from as little as a day to a year.

3 This was in 1979-80 at the time of a petrol crisis and the Government introduced carless days. 
get everything done. I still did all the cooking and by the end of the week the house was just filthy.

Yet these hassles were worth it, and Elizabeth saw this as a time to prove to herself and her family that she was not just a housewife and mother. I needed that to help my self esteem which was pretty low.

When $\mathrm{N}_{\text {_ }}$ was five, Elizabeth decided to have another child. This meant giving up teaching again. Elizabeth could not see how she could manage to teach as well as care for two children even though one would be at school. Working was also becoming harder to justify because her husband was beginning to earn sufficient to support the family and by then they had bought and furnished a modest house. With a second child Elizabeth now had friends who were having children and this brought new support networks. While she missed the contacts with teaching, Elizabeth found life more relaxed, particularly with her husband as she was now conforming to the role he thought a mother should assume. They had to be careful with money, but Elizabeth made crafts to get extras for herself and the family. To get a break from children Elizabeth worked at her daughter's school library on a voluntary basis and had developed a strong commitment to the work. Childcare was again solved by support from grandmothers.

At the time of the interview Elizabeth was pregnant with her third child, but was hoping to continue her voluntary work in the library. She was again worrying about childcare and wished that there was a creche nearby that offered casual care for babies. Elizabeth now envisaged that she would be home for a few years and was planning strategies to relieve the tensions that resulted from full-time childcare. She did not profess to want to make a "career" out of teaching, but wanted to keep the involvement. Library work was thus a kind of investment for the future. The ideal for Elizabeth had been when she working with one child, but in choosing to have more children, she had to re-order her priorities. Like Raewyn, she was not prepared to cause too much conflict in her marriage and felt that she had gained concessions by demonstrating that she could work and be a mother, and by arranging time for herself. I don't think it will be an issue again. As I said he would prefer I didn't work, but I don't think he would stop me. Fortunately I don't want to get into teaching too heavily.

Elizabeth expressed concern about women like herself who were at home which reflected the views of other women in this study who were at home:

You don't want to be downtrodden. You want to be treated as an equal. I think that the role of mother needs to be looked at. Obviously it is downtrodden because it is unpaid and the images in advertising are bad. This is something I found hard to justify at first when I was home. The fact that I was really important and it was something to be proud of.

At the time of the interview, Elizabeth was however, feeling more comfortable with her role than when she first became a mother, and as she remarked it seemed strange that she had to be superwoman for a while to help that to happen. 


\section{PENNY}

The thing that I found was that it took me years and years to work out the ambivalence I found at being in one relationship and being married. A lot of that was by the way people treated you if you were.

Penny believed that relationships with men should not result in her sexual or economic dependence. When she had her first child she had little to do with the father and managed alone with the support of friends. Penny had always lived with groups of people and did not feel comfortable in a pair relationship. Penny lived first with her future husband after she left the town because she felt that the police and child welfare officers might possibly take her child away from her because of her associations with the fringes of the drug culture. L offered her a refuge from that scene:

I got this letter from $L$ __ He knew my independence and everything else. I remember sitting around with these people including the guy that I was with at the time, a Maori activist. I was startled the effect my decision had on him. He was quite amazed that I could just walk out of the relationship, but I said that, "If I don't go I never will", so I packed and went in the train that night.

Life was stressful because she was on a benefit which would have been cancelled if it had been

- known she was living with someone:

It was a risky thing being on a benefit. I had a friend in Social Welfare who used to check my files regularly to see whether anybody had any suspicions. She would see what was the latest on me.

Penny eventually went off the benefit, placed her baby in childcare and worked as a postie ${ }^{4}$, but there were continuing stresses because of political pressure on L__ and herself. The only way Penny felt she could get release from political demands, and put time into her new relationship, was to marry:

We were married on May Day. We decided to wait for that and we decided to have a baby. I went off the pill as soon as we got married and $T$ was born one year later. So it became the usual sort of thing. I gave up work that Christmas and we shifted to an old house in the suburbs and that was the first time we were really by ourselves.

At the time of the interview Penny and $\mathrm{L}$ were still married, and had two children along with Penny's first child who had never met his own father. Despite Penny's discomfort with the institution of marriage, the relationship had been successful. Her political activities continued, but the focus shifted to the situation of women in the suburbs, as this was where she was too. Penny, however, only ever had brief periods of time at home with her children. With two small children she realised how isolated she was, and noted that people didn't sort of acknowledge me. They were short of money as L___ 's earnings as a factory worker were small, but the decision to return to work was mainly because Penny wished to be economically dependent. Access to money was not the issue as her husband shared everything,

\footnotetext{
${ }^{4}$ The term postman was often abbreviated to postie.
} 
but she felt that it was difficult to be equal partners if one was at work all day while the other was at home:

When $T$ was three months I went to work in a factory. That was very hard on myself physically. I had a real need to earn some money. We decided that if $L \quad$ worked overtime I would see even less of him, and we would share less of the work around the home. I wanted to work the same hours as him even though I got less pay. I got $\$ 25$ a week working in a fireworks factory.

The logistics of this were formidable:

I used to leave home when it was dark at about quarter to seven. I found a childcare centre that took babies. We only had one car and $L_{\text {_ }}$ used to drive the children over to the childcare centre and then he would take me to work for eight o'clock. At the end of the day he would come and collect me at five o'clock and we would go and get the kids and take them home. And then we would have to do the shopping, the washing and everything else. There wasn't much time or energy for anything else or for political things. But it was important to me at the time. It was the only way I could feel all right. I knew that is what I had to do so I did it. But then my health could only sustain that for so long.

Although childcare made working possible with young children, Penny's description demonstrates that this was not always an attractive or easy option. Penny had, however, established an important principle that became a pattern of her life with $\mathrm{L}$ . It was not always possible for Penny to work full-time, she sometimes looked after other people's children, and it was agreed that when she did not work the family benefit became her own money. Later, when Penny had three children, she worked part-time for a community organisation, but she found this stressful in a different way because she found it was too easy to take on the double load of work. Because her hours of work were shorter than L__ 's, she would have all the cooking and cleaning done before he came home. Penny moved again into the fulltime workforce:

Well I am a lot happier working fulltime and the same length of time as $L$ _. Paying someone to come after school is important to that. And when I get home I will now often sit around and wait until $L$ home before we start tea. We leave for work at the same time and we share doing the shopping and things like that. Even buying the kids clothes I will leave until the weekend and we will go together. It is not that I have a thing that we have to share everything it is just that it feels more comfortable to me. This is now a good time for me and I am showing less stress.

While Penny continued her political activities but she also put a lot of energy into ensuring she felt comfortable with the ; way responsibilities were shared at home. The arrangements were not always ideal, but she admits that she was fortunate to have a man who did not feel threatened by her quest for independence. Penny found that the stresses caused by organising childcare relief, and the tiredness of full-time work, were far outweighed by the well-being she felt when she had an equitable partnership with her husband on both the home and work fronts. 
The lives of Raewyn, Elizabeth and Penny are different in terms of class, opportunities, aspirations, and particularly in terms of their husband's attitudes to the role of women. Each of these women made a pragmatic accommodation to prevent, or ease, conflict. Raewyn accepted that her husband would not change; Elizabeth eventually gave up work and stayed at home; Penny got married. At the same time each woman was, at some cost to herself, to resist the expectations of their husband or society by making a stand that not only gave them more independence but enhanced their self esteem. If placed along a scale of independence, these women would be distant from each other. But Raewyn's stand to go to Housie, and Elizabeth's and Penny's stand for the right to work, were strategies that had a considerable momentum in terms of personal politics. Each within the constraints of their relationship and opportunities, had an ideal of independence and self-fulfilment and each was to manoeuvre concessions to facilitate this. A key difference between each woman was the degree of opposition and/or support they received from their husband.

\section{Part Two \\ COPING WITH NEW CHALLENGES}

It has already been stated that the women's movement challenged existing codes of what was acceptable and unacceptable. This challenge occurred during the period when the women of this generation were rearing children. The childrearing years, however, were when the women were most dependent on a partner, and economic independence in the workplace was most constrained and discriminatory. There was therefore, a widening contradiction between the new rhetoric of sexual and economic independence, for women, and the realities of the women's lives. All the women in this study felt something of a dilemma in steering a course through this contradiction. Only Penny professed to be a feminist at the time she became a mother. The other women were more cautious about such an identification, although they would often use femininst rationales as a tool towards making selective changes in their responsibilities. Delwyn, and Adrienne, for example, were attracted to feminist ideas, but felt uncomfortable with some of the feminist stances which they found difficult to live up to themselves, like the acceptance of economic dependency within marriage, or the fact that their husbands had expectations of them as wives and mothers that were contrary to their feminist ideals for women. They were to find that the extent to which they could "be a feminist" in practice depended a great deal on their male partners. The other women professed more scepticism about feminism insofar as it was seen to be "anti-men, or it had "not done much for women at home", or it was "too way out". Several of the women expressed concern that feminist groups had been opposed to a wage for mothers which they felt would have raised their status as mothers and given them some independence as women. Yet among all the women there was a striving for autonomy and self-fulfilment which expressed itself in much 
stronger ways than with the older women. The consensus view was that women should be free to make choices as to whether they stayed home or went to work. The reality was that such choices were painful.

A common theme with the younger women was an attempt to distance themselves from the experiences and constraints of their mother's lives (McKinlay 1983), and this would appear to have been just as strong a motive for making changes as any impetus coming from the women's movement. There was a view by the younger women that their mothers had been too selfless in terms of putting their husband's needs before their own. Even though they themselves faced similar situations, they were aware that they had more independence and choices than their mothers. This section looks at three aspects of women's lives in which there had been noticeable changes between the two generations: being married, being alone, and again the "silent issues", except that now the issues were media news and could at least be talked about.

\section{MANAGING TO STAY MARRIED}

Most marriage services in the 1970's-80's still contained the words for "better or worse "till death do us part". Most of the women in this study still hoped that was true, but in contrast to earlier years, there was more awareness that there were other options if it failed. As a comparison between the two groups of women, the younger women kept addressing the problem of what they would do if their marriage failed. They would often refer to contingency plans. It was as if they felt there was far less certainty that they might reach old age with the same partner, than the older women had. Investing in their husband's careers without safeguarding their own, which had been the pattern with the older women, was entered into more cautiously by the younger women.

\section{DELWYN: "We didn't have a romantic engagement, we had an entire negotiation".}

Delwyn believes that she selected her husband on the basis that he would be a good father for the children she planned to have, and would make a good companion. She was very specific about the kind of man she could live with:

To my mind you have two choices. Either you marry someone who is a career person or you look for a family man. I have looked for a family man. We discussed it before we got married and I said that there was no way that I was going to be prepared to play second fiddle to a man. I am not the socialising sort so if he thinks he is going on the spaghetti soiree set he can forget it. I expect him to be an eight to five guy and to give me a hand around the place. In short I want a father to the children.

Within these contraints of when he could work, Delwyn was still concerned that her husband be a reliable breadwinner as well as someone who would let her develop her own interests. Marriage in fact became an opportunity to do this:

I had no illusions about marriage at all and I must have been one of the few brides who thought, "Well if this doesn't work out I can get a 
divorce". That is how I went into it in a very cold and calculating way and had no illusions about it. No ideals. Now I have changed and would go up the wall if he left.

Delwyn became pregnant immediately after marriage but was to find that playing the wife and mother far from easy. She became ill, suffered from postnatal depression, was isolated and alone in a new housing suburb, and they had very little money:

That first year was just Hell...I was stuck out here doing whatever a
housewife was suppose to do except I wasn't sure at that stage...For the
best part I sat in an empty shell of a house, broke, alone, isolated and
unwell and pregnant. S said "You have got to get out. OK we are
broke but we just have to scrounge up enough money for you go to the
WEA 5 . For goodness sake go and do the course". So once a week I
trailed into town to a mental health course. It was good and it just
whetted my appetite for more. This was before I had children.

This established a pattern which became an important feature of Delwyn's life when she had one then two children. She was to use her years at home to further her education and eventually went to university. Delwyn had given up her career as a nurse when she married and life was organised around the traditional breadwinner - housewife roles. On the other hand her husband invested in Delwyn's education which she saw as an equitable exchange:

\section{$I$ had some freedom. Even though being a wife and mother is suppose to be incarcerating, it isn't, it gave me freedom. I had a husband who said "You go and develop interests of your own". So it was with his support and with his money and his car.}

The cost of this was considerable as it involved continually rising petrol costs of transport to the nearest university, creche fees for two children as well as books and student fees.

Delwyn saw life ahead as a series of dilemmas. She had the qualifications to work in a well paid full-time job and had done so for periods of time although she found full-time work and motherhood difficult to combine without extraordinary stress. Yet this was preferrable to part-time work where she felt exploited. Delwyn still looked towards her husband as having the breadwinning responsibility, but she was careful not to let her skills get rusty as she may have to be financially independent. Although she felt her marriage was secure, she was still taking no chances. During the early years the financial investment from her husband in her education was seen as a fair exchange for her taking the major responsibilities of motherhood. Now that Delwyn was making more forays into the workplace, the nature of the exchange was changing. It was no longer a monetary transaction, but one of labour, as Delwyn needed her husband to take on more domestic and childcare responsibilities. This was proving difficult to arrange within the constraints of his job in a male workplace, along with continuing difficulties of childcare beyond the preschool years and a general lack of support from friends or relatives.

\footnotetext{
5 Workers Education Association.
} 


\title{
SHEILA: "You don't tell a fifteen year old that she is not in love. That was IT for me".
}

Sheila found herself married at the age of sixteen, not because she was pregnant, but because she thought herself to be in love with a man some ten years her senior, and because her father told her husband-to-be $\mathrm{G}$ that if his daughter was good enough to screw she was good enough to marry. Sheila's father was a sickness beneficiary ${ }^{6}$, and her mother was periodically beaten:

He has knocked her up over the years. And when I was a kid growing up I used to hate myself so much because I couldn't get out there and fight him and say, "Leave her alone you big bully". I used to hide in my room and just loathed it.

Sheila wanted her life to be different but as she stated:

Apart from seeing my parents I had no idea. My only idea of love at that stage came from watching TV, love stories, and romances.

At the age of fifteen she was the only one of her girl friends who was still a virgin and when G__ showed an interest in her, she felt that this would be a chance for a new life. But she was soon disillusioned:

\begin{abstract}
I was treated like dirt right from the beginning. My husband was a flirt and that was a threat to me. We had lots of arguments over that. And when he wanted to go out he would go off to the pub and leave me alone at home and that was awful. Sometimes he would say he had been at work but he hadn't. I had to learn to cook and sew. He expected me to service his needs as well as my own. He was looking for the perfect woman. It has taken me years to to realise that at sixteen I was only a girl.
\end{abstract}

Sheila was both economically and socially vulnerable as a sixteen year old. Her wages were low and barely sufficient to live alone on if she had considered leaving her husband. But Sheila had no consciousness that she could leave, and even if she had there was nowhere to go and no support. Her mother was helpless and her father's view was that she had "made her bed and must lie in it". Sheila described herself as a nobody who didn't deserve to be recognized and felt she was at the beck and call of everybody older than herself. Sheila had hoped that becoming a mother would improve her situation. She had her first child at the age of seventeen, her second and third came at two year intervals, but her marriage continued in the violent pattern of her parents'. She was almost a prisoner in her flat and had no access to money apart from what her husband would give her:!

\section{I didn't have the confidence then to get out and be a person. I didn't feel that I was allowed to go out and do things. I felt that I had to account for all the money I spent. It was his money I spent.}

But amidst these constraints Sheila did start making changes in her life. She got a child minding job looking after two children while their mother was at work. This took her out of her small house into a larger home where her own children could also play. It gave her contact

\footnotetext{
${ }^{6} \mathrm{~A}$ person who was unable to work for health reasons and who received a sickness benefit from the Government.
} 
with another person and a small independent source of income, even though it was usually used to purchase basic housckeeping items. This brought a degree of autonomy that she had not had before, but this did not prevent the violent and emotional abuse that Sheila still received from her husband.

$$
\begin{aligned}
& \text { The arguments would lead to physical violence. Every individual can } \\
& \text { only take so much and mine was } 70 \% \text { mental and } 30 \% \text { physical. The } \\
& \text { actual physical was punches, pulling hair, kicks and bruises. But it was } \\
& \text { the mentharassment that went on for hours and hours on end which } \\
& \text { was the more tiring and terrible and the exhaustion. }
\end{aligned}
$$

Child minding had built up Sheila's confidence and on one occasion she ran to a Women's Refuge $^{7}$. Several weeks later she returned to her husband and this became a pattern that is still a part of her life. Sheila described this process however, as a positive one that had given her more control, and in fact was a weapon she had used to get more independence.

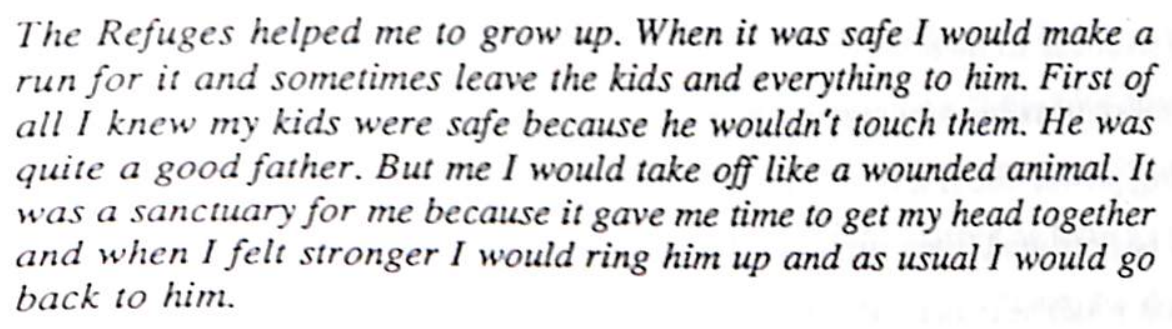

Sometimes Sheila had got as far as having separation papers drawn up, but was to admit she did this as a threat. If you do this to me I can do that to you. It is a bargaining point and it gives me power. But deep down all I want is for him to change.

A year before this interview Sheila had had an affair. Her lover wanted no commitments, but this still gave her a confidence that she had not experienced before. It was when I started to grow up. I changed from a girl to a woman. It opened a whole new door. I got the cuddles and kisses I wanted. Someone to talk to and to listen to me. The affair was however short-lived as Sheila found out that her lover was not faithful:

He was screwing three other women at the same time. That opened my eyes. I was angry at myself. He had been the dream romance, the Prince in shining armour on a white steed. But he was a farce.

Sheila's husband also had an affair, but she saw this again as a learning experience which had given her strength:
I think that $G$ has at last learnt that not every female goes $\mathrm{OOH}$ AAH at the right moment and that everyone is different. He used to place so much emphasis on the bedroom scene. I can be happy without actually having to be sexually satisfied all the time.

At the time of the interview Sheila's life was still difficult, but she felt more in control of things than in the earlier years of her marriage. There was still occasional violence and harassment but Sheila knew she could walk out, and did. The last time she packed her bags

\footnotetext{
7 The first of these was opened in 1974, although there had previously been charitable and church refuges for women.
} 
and left before he became violent. I just thought bugger I am not living with this and walked out. Sheila now saw herself as a much stronger woman who could cope with things.

I can speak my mind openly to anybody and I am not embarrassed now. There is nothing he can do to hurt me any more. If he hurts me physically I hurt him back which I have done. I wouldn't take any of that shit any more.

Sheila's life typifies that of many women who have to live with violence and domination, although she may have been luckier than some in that she had survived and was now coping with the situation - at least at the time of the interview. Feminism had not touched Sheila's life much, except insofar as feminist women ran the refuges, and Sheila was rather sceptical about their hardline views against men. Despite the harshness of her experiences with men as regards to her father, her husband and her lover, Sheila still held the media's romantic images of love as an ideal. Its espousal of the view of men's responsibility for women and women's subissiveness to men was more powerful than any feminist ideas. Realising feminist ideals was more possible amongst middle class women who not only had an education, but whose earning power could also sustain their economic independence from men. In Sheila's working class background, men provided for women as it kept them submissive and her father, who was on a sickness benefit, would not allow her mother to work. Yet Sheila had developed a strong consciousness that she was entitled to some independence in the sense of money to spend and time for herself, and that she did not have to put up with the violence from her husband. Her strategy however was to learn skills to handle her husband and did not extend to managing without him. In contrast to her earlier years of marriage, Sheila knew that she was now a lot more "liberated" than her mother. While Sheila was sceptical of femininsts she had was using femininst ideas and verbal rhetoric as a way towards gaining more control over her life.

ANNETTE: I was very conscious of the fact that most girls of my age were married.

As a single woman in her late twenties Annette felt left out of the scene in which everyone else appeared to be in couples and all her friends were married and having children. They were busy in their domestic life with their own families and therefore didn't have time to be entertaining single friends...Some of them would have been uncomfortable at having $a$ single friend around too often. In an analysis of single women in Australia, Penman and Stolk (1983) argued that the pervasiveness of the role of marriage and motherhood had created an image of singleness as a negative state. Single women were defined by their lack of marital status. Annette had an image of herself as a potential wife and mother, but as she got older and was still single she had been making a painful adjustment to the fact that she might remain single. Annette fitted the category of single women Penman and Stolk call "anxious seekers" (1983:125), but who were moving towards the adaptive stage (1982:122) in the sense of trying to come to terms with a future alone. Annette was not prepared to have sexual relationships outside the security of marriage. She wanted a marriage partner, but by her late 
twenties had sadly decided that marriage did not seem to be her destiny. She decided instead to invest in an education she had missed earlier so that she could at least have an interesting career as a single woman. Up until then she had been working in poorly paid factory, domestic and office jobs. This was a crucial decision:

\section{To me it was not so much a decision that I will never marry because I did want to. but more of a decision that it doesn't appear that I will marry. I have not met any person. There was no one around quite frankly. So again it was a matter of accepting that as the situation. Instead of waiting for something to happen I have to make it happen.}

She went to night school and got her School Certificate and then gained special admission to university ${ }^{8}$. The next three years were a struggle both academically and financially, but Annette succeeded in gaining her B.A. She also met the man she was to manry.

Annette got a job as a social worker, but felt a conflict between the demands of establishing herself in a career and putting energy into her marriage and home. She was determined to try to establish a career, especially after her efforts to get an education. Her husband, who had a well established career, expected her to take over the responsibilities for the domestic side of his life. He was not opposed to Annette having a career as long as this did not impinge on his own career demands, and Annette too was eager to assume the domestic responsibility:

I was delighted to have my own home. I had lived in so many houses of other peoples. I enjoyed the security that I now had and had never had before.

This security was important, and Annette took on the responsibilities of the domestic load even though she was working fulkime. She also handed over her wages to her husband:

That was a rather old fashioned adjustment. We were buying a house and wanted as much money as possible...It meant handing over my wage packet to my husband and never seeing it. To some extent I resented it but it seemed the easiest way to pay for a house. And if I needed anything I just had to ask, "Can I have twenty dollars"? I did find it hard asking him for it.. I did resent him and I remember his mother saying to me to always have your own individual account and to make sure that $I$ had money of my own. I think once or twice I used to make humorous comments about it but it was not worth making a big issue over.

Annette found she was pregnant and this resolved the conflict she felt over managing home and work responsibilities and Annette made her home, husband, and family her priority. At the time of the interview both of Annette's children were at school, but Annette was not anxious to move back into the workforce and felt comfortable with the homemaker - breadwinner demarcation in roles. She took pride in the fact that she provided a stable home and routine for the children, she serviced the children's material and emotional needs, and she enjoyed the security of her husband as a provider. There was some cost in this and Annette expressed resentment at being left with all the domestic responsibilities in relation to the children, and ${ }^{8}$ This was possible for students over the age of twenty-one who did not have the University Entrance certificate, the normal means to university entrance in New Zealand. 
felt her husband could help more, but again she had decided it was not worth making an issue over it. Keeping the status quo gave Annette the security she had always wanted.

Annette had found economic and emotional security in marriage which was something she had never attained as a single woman. Her husband had access to a much higher standard of living than she could have ever commanded, with or without an education. Other aspirations were a secondary consideration to maintaining this. Annette still identified with the ideas of the women's movement particularly in its analysis of women in the workforce. As a poorly paid factory and office worker Annette had experienced some of the worst forms of male exploitation in terms of sexual harrassment. Although she had got further education she had not had time to establish her career, and she felt that marriage had given her more security and improved status than she had before. In many ways Annette's life was in accord with the ideas of conservative groups that upheld a traditonal view of marriage as a haven of security for women from the exploitation of the world. Annette was not linked to any of these groups, but her life demonstrated that the realities of achieving economic and sexual independence for women were not easy. She felt that her switch from a career to marriage was a more secure investment.

There are countless other arrangements by which women manage their relationships with men, but in these three case studies it was apparent that although the women's movement had encouraged an ideal of independence, there was no total acceptance of the idea. Moreover the realities of everyday life made it almost impossible to realise. Annette equated economic and sexual independence with insecurity and opted for the security of a traditional marriage arrangement. Delwyn was more ambivalent and was trying to balance the need for security in a breadwinner against the need to assure her own economic independence if it was needed. Sheila's life did not allow such strategic choices. She had left her marriage on several occasions, but still perceived she had more security when she was married than on the occasions she left home to manage alone in the women's refuge. For each woman there was a consciousness of the ideal of independence in the sense that each women carefully balanced the extent to which they would pursue their independence in relation to independence and/or the security of their husband as a provider. They were wary of the vulnerability of managing alone as well as wary of being too dependent. Each woman had to find a place within these extremes.

\section{MANAGING ALONE}

Several of the women were, through choice or necessity, to manage alone for periods of time by taking full responsibility for rearing the children and sometimes for earning a living. An earlier chapter described the rise in single parent families headed by women, and the reluctant acceptance by government that they should receive support through the Domestic Purposes 
Benefit. Despite this acknowledgment and financial support, women rearing children alone still fitted uncomfortably into a society arranged around the assumption of a male breadwinner.

Penny: "When I had a child it was a statement. I'm a woman but I'm not looking for a Darner".

Major Thelma Smith, who was in charge of the Salvation Army Women's Social Services, was to report on'plight of single mothers in New Zealand in comparison with other European countries she had just retumed from visiting:

In no country was the single mother who kept her baby left without financial support...In no other country was the housing of the unwed mother left so completely to chance as it was in New Zealand (Parents Centre Bulletin March 1970).

It was this kind of situation Penny faced when she had a child in 1970 . Penny had no intention of marrying, nor did she intend seeking support from the child's father. Penny believed that women should be be economically and sexually independent from men. But to achieve this was a struggle and in the end a political battle. Penny was aware that, unlike women who got pregnant through some misfortune, there would be little sympathy for such obvious flouting of convention:

I didn't go to the doctor until I needed to go on a sickness benefit, which they wouldn't give me because they didn't believe that I didn't secretly have a man supporting me. I had to go to the ombudsman. We had to have a sit-in at the Social Welfare office until I went on the benefit.

Penny went to ante-natal classes but found that a difficult experience as a single mother. Most unmarried mothers had their babies at discreet charitable or private hospitals and did not attempt to mix so boldly with married mothers in public hospitals. During childbirth she felt that she was given a hard time by being neglected. There were babies of single mothers born at the hospital but they were mostly for adoption, and this was never Penny's intention:

They used to put all the babies on trolleys to wheel out to you every four hours for feeding. They used to have this bottom row and these were the babies for adoption. The women didn't ever see them after they were born. Women who were quick with feeding their babies could then feed one of these babies on the bottom of the trolley. They would have their bottle beside them. It would have a name: Baby Please Feed Me.

Penny did not act with the expected demeanour expected of an unmarried mother:

They were fascinated by all the visitors I had and they sat observing them all, wondering which one could be the father. Also I got masses of flowers which they found a bit obscene for an unmarried mother to have flowers.

It was a struggle for survival afterwards and a woman choosing to keep her child was viewed as at risk:

I was on a sickness benefit of $\$ 11.75$ a week which even in those days was very little by the time you paid the rent. Very few women in those 
days kept their kids. I suppose that if a welfare officer had looked at the sort of lifestyle I had I would have been thought not to be coping.

Penny realised that her independent stand at that period made her very vulnerable. She was living on the fringes of society and could lose the custody of her child:

I had to shift myself and disassociate myself away from that whole strand of my life. It was one of the hardest things I have ever done...I wasn't going to lose the baby.

Penny's story from this point has been told earlier and she did not envisage that she would be married so soon and living what appeared to be a normal suburban lifestyle.

\section{CAROLYN: "Breastfeeding was crucial because otherwise there was no financial assistance"}

For Carolyn, unlike Penny, getting pregnant was an unfortunate accident. She came from a middle class, religious background in which "good girls" did not get pregnant. There was no support from the father, but Carolyn determined to try and keep the baby and set about finding out how this could be managed:

I went to visit the Social Welfare. They were not interested in me. Their attitude to me was - what was I doing visiting them? I was so obviously middle class. Why should I call on their services. I complained about this and told them I was there to get some facts together. They talked to me about adoption as if that was the only option for me but I abruptly cut them off.

There was a sickness benefit for the last months of pregnancy which was paid until six weeks following the birth. This could be extended as long as the mother was breastfeeding, which therefore became imperative for economic survival. Before the birth Carolyn also investigated childcare possibilities and was directed to a charitable organisation, but did not feel comfortable with what she saw. There were so few adults and so many children. It was all a reeling mass of children. Carolyn was to find that childcare for babies was almost nonexistent.

After the birth Carolyn lived with another unmarried mother, and like Penny, she too realised how vulnerable women alone were. The establishment of quality childcare services she considered essential if women were to be able to keep their babies. She observed the problems faced by the woman she lived with who had to make childcare arrangements. A friend had a baby who was looked after by a childminder:

It was horrific. The baby would come home in the same nappies that she left in in the morning and had the most appalling nappy rash.

Carolyn found it hard to understand why the mother would continue using such an arrangement knowing that the care was less than best and probably damaging. It was a shock to realise that there was no other choice and that women alone could not afford the luxury of defining what was quality childcare. Carolyn felt angry at the attitude of society to childcare, and was scathing about women who had the protection of a man and the luxury to stay at home with their children: 
They shouldn't be so righteous and jolly well ought to know that not cverybody could afford that.

Helen: Was there personal antagonism to you?

I was aware of it. Once when $J$ _ was eighteen months old and for God's sake I had been coping for that long. This woman gave me a lecture on really I ought to give up my child. I sat through this being told what massive harm I was doing my child and how her life opportunities were so stunted and that she would be bound to be criminal at the very least. I can remember being very angry about that. It was brought home to you that you were not doing the right thing by your child.

Carolyn felt particularly vulnerable in that she was unsupported by women from her own middle class background:

These were the people I was akin to. I recognized fairly quickly that I had stepped outside of my class. I was declasse. I now had no class because I had forfeited the right to be seen as part of my middle class background - pure and all that. I demonstrated that I wasn't. By having a child and deciding to keep it I had stepped outside the bounds. That changed my life.

Pauline: "Pcople ring you up and say do you want to come out. They feel sorry for you".

Pauline managed alone, not because she was not married, but because her husband was often away from home. She had been careful in her selection of a prospective husband to find someone with ambition. She had also seen it as a good investment in her own future security to work with him to establish a business. Pauline had now been married for fifteen years and had two children. She lived in a luxurious house and her children attended the most exclusive schools. Her lifestyle was one of elegance and assisted by every convenience. But amidst all this luxury Pauline was managing alone in the sense that her husband worked long hours or travelled extensively on business. Pauline had had to adjust to a change of identity from being a working women running a joint business with her husband to being at home as a mother. She now had the total domestic responsibility:

He used to do quite a lot when they were babies. But now he leaves everything to me. I wouldn't like to say that he is only a fun father and he does like to think that they will give him cuddles. But I wish he would take more responsibility. He really doesn't take on any role with them unless I ask him to. It is just that he is so busy. He is always thinking about something. He will do something if I ask him nicely but only if I ask him nicely.

Pauline looks after all the house and although she knows they could afford help, feels guilty because she is not working herself:

I have very high standards that I set in keeping house. I like everything tidy and that creates problems because the others don't want to keep the house clean. The kids don't see why they should have to pick up toys. The husband doesn't see why he should have to pick up his underpants. I have to do it all myself. I find that I am always working. 
Pauline was ambivalent about her life. They had become affluert, but she was now alone. There had been a cost.

We just carry on because if I thought about it too much it would get me down. We don't go on about Dad being away otherwise the children would notice it more. They would dwell on it.

Pauline had been forced to become more independent and this made it harder for her husband to adjust when he was at home. I wonder how much it is me that has changed since he has been going away? Pauline was caught between two codes. She had a husband and responsibilities as a wife even though he was not there. This meant that her social life was limited and centred around wives of colleagues of her husband's. At the same time she was really a solo parent and as such fitted uncomfortably into the couple's scene.She was starting to realise that she had to have some identity of her own, but was unsure how to organise it in a way that would not threaten the security in the marriage which she had so carefully constructed.

Managing alone was a different experience for each of these women, and had arisen because of different reasons. But the common thread was an experience of being a misfit in a society in which women with children were attached to men. For Penny and Carolyn there was a sense of vulnerability as they tried to maintain economic independence from men. For Penny this did not last long, but could have resulted in losing custody of the child because her friends were seen as the misfits of society. For Carolyn this censure continued because she did not seek the protection of marriage or men. Pauline's identity and status depended upon those of her husband, but being alone so much was making it difficult to keep intact. Pauline was feeling socially, if not financially vulnerable.

\section{THE SILENT ISSUES.}

One of the aims of the women's movement was to increase women's knowledge about their bodies. This was intended to give women more control over their lives. For the older women it was evident that getting access to information about contraception and childbirth had been difficult, and that a "good woman" showed she could cope. The younger women were better informed and more assertive than the older women. In relation to health issues there had been some shifts in medical practices and attitudes, but more important taboo topics were now being more openly discussed. Issues like pre-menstrual tension, post-natal depression, suburban neurosis, domestic violence, bad childbirth experiences, abortion and contraceptive difficulties were publicly debated. But negative attitudes were deeply entrenched and the younger women experienced feelings of guilt when such things happened to them. In this sense the experience was no less traumatic than it was for the older women, but greater access to knowledge and public debate encouraged the younger women to seek explanations that involved less sense of personal blame. 


\section{Pre-menstrual tension: "You can't see it, but other people can sense it".}

Sharon had had a number of adverse experiences which she felt must be her fault. Her father suffered from severe bouts of depression: she had nightmares; she was supposed to wear glasses which she did not do; she had an accidental pregnancy; and had strong feelings of inferiority in relation to a glamorous and popular older sister. But as Sharon recalled, We kept our problems privately. Like I wouldn't have dreamt of going to a teacher to say that I had any problems. You just didn't do it. Sharon remembers her teenage years as a time of worry and tension over things that she can now see were probably trivial when she married she felt depressed and tense about other things. Sharon described herself as:

This nice person who copes with things and this person who can't cope with anything. These highs and lows.

Sharon regularly listened to Sharon Crosbie's session on the radio ${ }^{9}$ and acredited this for her awakening to the ideas of the women's movement. On one occasion she heard a programme on pre-menstrual tension:

$$
\begin{aligned}
& \text { I was really angry. I was hopping mad. I was quite surprised by my } \\
& \text { reaction. The fact that so many women had it and that was exactly how I } \\
& \text { felt too. I didn't know I had it. I just knew that every now and then I } \\
& \text { wasn't very wonderful. There were two me's. I didn't do anything like } \\
& \text { throwing knives or anything like that. It is mental - like glaring at } \\
& \text { people. It can be up two weeks of every month. I had a friend who used } \\
& \text { to confess to the priest and she said that if she had known that she had } \\
& \text { pre-menstrual tension she wouldn't have confessed so much. But I am } \\
& \text { still so angry about it. It was such an eye opener to me. }
\end{aligned}
$$

Sharon's anger arose from having blamed herself for so long for her inability to cope, when there had been a medical cause and she felt there was a conspiracy to prevent women from realising that they were not inadequate. Sharon's new knowledge was to trigger a number of changes. She read all she could find on the subject. She went to her doctor for treatment and decided to start a milk free diet. She took up yoga classes as a kind of relaxation, and talked with her husband so that together they could identify the symptoms and would know when to leave the other alone and when to approach. She became aware of the need to talk to other women and to have women friends. She tried not to smack her children and had been working out other ways to discipline them. And the topic of pre-menstrual tension was discussed around the house and when she went out. I always talk to men about it now. Sharon felt more in control of her life and although she still worried and she still got pre-menstrual tension, she recognized the symptoms and developed strategies to minimise its effects on family life. She was to describe the discovery of this knowledge as her political awakening.

\footnotetext{
${ }^{9}$ Sharon Crosbie's programme was popular amongst women, and ran during the late 1970's until 1984. Her programme became a forum for debate about women's lives.
} 


\section{Post-natal depression: "I acted like a moron".}

As a nurse, Delwyn expected pregnancy, childbirth and babies to be something she would demonstrate competence in. Instead she was sick throughout her pregnancy, and childbirth was not the experience she had imagined:

It was a hard long labour which lasted thirty-six hours and I was quite
shattered at the end of it. That Parent's Centrelo which had said about
this marvellous bonding that happens at birth. Well I looked at my son
when he was born and said, "Thank God it is all over", and fell asleep.
All I remember is my husband crying with absolute joy and I didn't care.

Delwyn was anxious to get home from hospital. The obstetrician allowed this on the assumption that, as a nurse, she would be able to cope. But she had two severe bouts of postnatal depression. Delwyn was aware of what she was suffering from, but had ambivalent feelings about why:

In our lectures as nurses we had been taught by a doctor that it was psychosomatic, but I remember a midwife telling us that studies done in Christchurch showed that it was not psychosomatic and she told us to give those women a fair go. But in the exams you have to put what the doctor says so you know it was drummed in.

Delwyn felt guilty that she should get post-natal depression. There was little help apart from the support of her husband and he was away at work from 6.30 in the morning until 6.30 at night. Worst of all, Delwyn felt humiliated:

I remember the doctor correcting me like a father. I had put the wrong suffix on a word and he corrected it and I felt such a twit. I really felt dehumanised. I had a good brain and had been in a crackerjack position in nursing yet I was like a moron. I felt perpetually tired. In the morning I couldn't get up. I was like a piece of lead which was due to hormonal imbalance.

It was the Plunket nurse who was supportive and gave Delwyn confidence:

I know people decry Plunket nurses but she was my saviour. She would whisk in and really reinforce what I was doing saying, "Tremendous keep it up. It is good to see you". I don't know whether she sensed the guilt I had.

By the time Delwyn had her second child her circumstances had changed. She was less isolated, and was going to university while leaving her child at a creche. She was determined that another pregnancy and another child was not going to alter this pattern. Things again began badly and she was ordered to have bed rest. Fortunately, the rest of the pregnancy went well, and the delivery was straightforward. Delwyn had also talked to the obstetrician about her problem with post-natal depression:

I said I was not prepared to go through what happened last time. It was hell on me, it was unfair on the baby and unfair on my husband. It was plainly unnecessary. He asked me why I had put up with it. I said that I had been to the doctor who hadn't given me anything except a pep talk.

\footnotetext{
${ }^{10}$ The Parent's Centre ran ante-natal and parenting classes for pregnant women.
} 
He said "Next time you come to me and I will give you something". I didn't know that I could have turned to alternative help.

The second time around, motherhood was a better experience. Delwyn had become more assertive about her own needs. She had also worked through the feelings of guilt in which she took the blame so personally. In the event post-natal depression did not occur.

\section{Depression "I felt that if anyone touched me I would spark. It was a horrible feeling".}

Racwyn lived on a farm and perhaps suburban neurosis would not seem an appropriate description for her depression. Yet the rigid expectations about her role by her husband, her isolation from friends, and unrelenting responsibility for childcare were akin to the suggested causes of such neurosis (Phillips 1981). Raewyn had gone to the doctor because she had collapsed, feeling ill. He was to state that her "nerves were shot":

I was to laugh at that. He told me off. He said, "You have been under the weather for quite $a$ bit and this has been coming on for awhile".

Raewyn blamed herself first, and the negative image of neurotic women was powerful in her determination of blame:

I had kept thinking that I was uptight and kept thinking, "Oh you're being silly. Get a hold of yourself". I would give myself a mental shake. I had this thing about these neurotic women - these stupid neurotic women. I thought they were just plain spoilt. I had this picture in my mind that I wasn't going to be like that and I suppose I did suppress it for awhile.The doctor gave me valium for a wee while but I wasn't a pill pusher. I had this thing about pills so I got off them myself.

Raewyn's doctor was supportive about her not wanting to take pills. He asked her what she did for relaxation:

I said "Nothing", because at that stage I was going out and just sitting in the paddock. Just sitting out there like a toadstool. Just take off from the kids and the husband when they were having tea and I'd just sit there until it was time to put the baby to bed. After awhile the doctor asked me if I ever went out and I said that I wasn't going anywhere.

On the doctor's advice Raewyn determined that she had to get out. The story of trying to arrange this has been told earlier in this chapter, but Raewyn was to change from a usually Submissive wife into a person who could be assertive:

Oh boy I never thought I had it in me. I was determined that I was never going to end up again as I was. I know some that are on pills for months and years and they don't bother to help themselves. So I decided that I was going out if that was the only way for me to get better. I had got that way that I started to think I was going insane. I thought I might end up belting the kids.I had this picture that I might take off and leave my kids with nobody in the house.

Developing strategies to get out of the house, and her enjoyment of going to Housie, did appear to be the tonic needed to overcome her depression and Raewyn felt confident that she would never allow herself to get into a position where it could happen again. 
The need to ascribe responsibility is fundamental when so called disorder disturbs the apparent order. Maxine Margolis (1984) argues that an underlying cultural theme in western society is "blaming the victim" for disorder. This preserves the status quo by deflecting attention away from the social, political and economic conditions causing the problems. An alternative view has been to blame "the system" rather than the individual. There are still victims, but responsibility is cast much wider. Nell was to describe what she saw as one of the main differences between the older generation of women and that of the younger women. You go to the Government if things go wrong - we sorted things out ourselves. This turnaround in opinion was not so neat, and it was evident that the younger women still felt a sense of blame. However, a common thread was that at some stage each woman began to look beyond herself and her own failings. The women of the older generation were to always say "I managed - I jist accepted it". However opinion was changing, the issues were less shrouded in secrecy and the younger women were more likely to seek help, to talk about it, and most important to try and make some changes in their lifestyle or relationships. They were to begin acknowledging that some of the causes existed outside of themselves. This discovery and the resulting action, was invariably political and revealed a new consciousness of their lives as women. For example, Sheila found an escape from violence through the Women's Refuges which gave her strength and new strategies to deal with her life. Raewyn was overcoming her depression by negotiating time away from the family to play Housie. The experience made her less submissive. Sharon became angry when she heard about pre-menstrual tension, and she was to use this anger to read and understand more about women's health and her own relationship with her family. Delwyn found that post-natal depression could be controlled, but that it meant shopping around for different medical advice. It also meant arranging a life in which she had interests outside the home and childcare support. These case studies were not presented as stories of miraculous cures, but rather to show how women had become less passive, less willing to blame themselves, more conscious of wider issues, but most of all more assertive in managing to cope.

\section{Part Three CHANGING PERSPECTIVES OF WORK}

Unlike the women of the older generation, few of the younger women felt comfortable with the identity of being just a wife and mother. The older women subsumed their work and leisure interests within the framework of upholding their domestic and childrearing role, but the younger women were not always so successful, or did not wish to subsume their identity. There was more conflict between the work interests and domestic responsibilities of men and women, and mediating the conflict required an accommodation from men that was not so apparent in the older generation. The ideal of opportunity and independence for women was 
now being extended into the realm of marriage in a way that was neither possible, nor acceptable, during the early postwar years. This penetration was not easy as it upset the older belief of the male breadwinner providing economic security for women within marriage (Scymour 1977). For example, the three women who were not employed at the time of the interviews felt guilty as if it might appear to many as if they were either not contributing to the family budget, or that they were cabbages - housewives trapped at home. There was also less acceptance by women that they should be incorporated into their husband's work, in the sense of giving direct help to his job, or taking on extra domestic duties that might have been his in order that he might work overtime or travel (Finch 1984). Such energy as they may have once invested in that direction was more likely to go into an investment in their own future. So for example Delwyn would not become part of the "spaghetti soiree" circuit as a means of enhancing her husband's career; instead she advanced her own education. This kind of choice can partly be ascribed to the influence of the ideas of the women's movement in New Zealand society, but it was also part of a growing expression of individualism and selffulfilment that was affecting both men and women.

\section{WORK: - INDEPENDENCE - FULFILMENT - AND AN END IN ITSELF}

Giving up an income and being totally financially dependent on a husband, or in the case of Penny and Carolyn, on the State, created feelings of financial insecurity. There was no immediate sense of security in being supported by a breadwinner or by a benefit. For most of the women this total dependence was not for long, and for the two women who had had no paid employment since marriage, there was eventually a rationalisation that made the situation manageable. Nevertheless, the shock to begin with was profound and Adrienne's statement summed up the common feeling. I can remember when I first stopped work. It was horrible. I hated that. Not having any money. Never having had to ask for it before. It was awful, Adrienne's husband eventually gave her his wages which she organised; for others, a joint account or a personal allowance, gave access to money. But still some of the women had no money unless they earned it, or asked for it, item by item.

Paid employment, however, was not just about gaining financial independence or self-fulfilment. For most it was also a case of financial necessity in order to buy a home, pay the bills and support the children. And for middle class couples there was pressure to gain a double income in order to maintain the trappings of a middle class life style. Three women who had no independent income were married to men with high incomes. The rest had lived on one income for short periods only. There was an ideal that work ought to be satisfying or a career. For a few of the women this did happen, but more often the kinds of work the women were doing was of lesser status than before they left to have children, and had less career 
possibilities in that it was casual or part-time work fitted around other commitments (Beauchamp 1978).

\title{
SHARON: "There is always someone you don't get on with or who picks on you"
}

Sharon's work experiences had not been particularly pleasant and she was relieved to take a break to have children. For the first time she felt good at something, even though she found the years of mothering preschoolers endless. Sharon's husband worked for the airforce where there was a practice of giving the wives a proportion of their husband's wage:

When we first got married it was $\$ 70$ which was quite a bit. I used to bank that and I had a lot left over by managing on less. But then it got less and less left over. Then it barely covered the groceries.

Sharon got a job as a spot welder:
I loved working as a spot welder but we were always slack. There wasn't enough work. It was cold and very heavy work and you had to be strong. But best of all I liked the money and I didn't have to ask $T$ _ about money. $T$ _ is very good and would never say no but the $\overline{\text { fact }}$ is you keep coming back and back and back.

This job ended as the work ran out and later Sharon got a job at nights in the Base canteen. She enjoyed the break away from home and it was convenient. The job ended as her husband was transferred. Wives of servicemen considered themselves fortunate if they could find this kind of work, as there was little opportunity for them to establish anything more permanent. When both of her children were at school and it appeared that her husband would remain in one town for while, Sharon found the "ideal" part-time job working as a library assistant in a nearby school. She found the environment stimulating, and the part-time hours and school holidays allowed her to manage her childcare and domestic responsibilities. Sharon still saw her husband as the breadwinner, but was beginning to look at her job as meaning more to her than extra money and company. She wondered whether to get qualifications because there were no promotion prospects. For the time being, however, Sharon was feeling that she has got her life reasonably balanced. Seeking qualifications or working full-time would create tensions she did not want:

\begin{abstract}
My job is to keep everyone going without too much explosion. Like in the morning to get everyone out without too much trouble. It stretches you to the limit sometimes. Sometimes it doesn't work but I really try to keep everyone happy. That is important to me.
\end{abstract}

\footnotetext{
ADRIENNE: " I always knew that I would not be just a housewife and a mother".

Adrienne suspects that her mother was disappointed when she moved into marriage and children so rapidly. She had by then completed a degree, but her proposed career as a social worker had hardly begun when she abruptly switched to train as a teacher and then got pregnant before starting teaching. It had always been expected that Adrienne would have a career and would travel :
} 
They were quite shattered at the time of being told...because I think now that I hadn't fulfilled all the ideals they had of me. I think perhaps that in some ways that I was letting myself down because I hadn't done the things I had set out to.

Adrienne had been influenced by feminist ideas, but was to find herself married to a man from a European culture in which women looked after men. This caused arguments at times:

I used to blow up occasionally and I still do. I used to do a big rave. But I kept thinking that I had known him for years and years and knew what he was like and therefore it was stupid of me to think that I could change him.

Adrienne, like most of the other women in this study, had a strong perception that men could not or would not change. More specifically it was an awareness that the women would have to inititiate changes; that changes would not come from men; and that it was easier to assume that the men would remain the same rather than to go through the process of causing conflict that might threaten their security they had invested in their men. Yet it was apparent that all of the men did, to some extent, accommodate to change which gave each woman more independence. The problem was that the extent and pace of male accommodation was not in accord with what the women would have liked. Insofar as Adrienne was concerned, there was a realisation that if she found employment she would still have all the domestic and childrearing responsibilities. Yet Adrienne still regarded her sojourn at home with the children as temporary and thought that one day she would establish the career she had begun. After the birth of each of her three children Adrienne would pen a letter to the Department of Education asking for her teaching bond to be deferred as she had left without completing her teaching requirements ${ }^{11}$ :

I can remember once writing and saying that there was no possibility of me returning to teaching because childcare services were totally inadequate. There was nowhere I could find somewhere suitable to leave my children. I had obviously had this noble idea that by the time I had my children there would be childcare centres attached to schools where teachers could leave their children. It hasn't happened.

Adrienne's career got caught amidst a period of change in the teaching service. She began her training at a time of teacher shortages, but within the space of a few years there was an over supply. In the meantime Adrienne became involved in playcentre. She made a little money by making handcrafts and did some night catering. Her husband worked as a mechanic and it was only by being very careful that they just managed financially.

When Adrienne's youngest child was a toddler, she got a job working in a childcare centre. This gave her the opportunity to use her playcentre and teaching qualifications, as well as to practise her social work skills. Childcare work may not have had the status or remuneration of teaching, but Adrienne found that, not only did it provide the family with extra money but also that it was something she enjoyed. Adrienne's return to the workforce

11 In return for a salary paid during training teachers had to pay this back with an equivalent number of years in teaching service. During the 1970's however, as the teaching shortage turned into an over supply, bonds were ignored. 
had been gradual, and it was not until her youngest child was at school that she took on a fultime job which she now saw as a career. This had just happened before the interview and Adrienne had resolved to pay somebody to help with housework and childcare. Adrienne felt that doing things gradually had lessened the conflict there might have been in her marriage. She had, however, learnt to be more assertive in getting time for herself and more help with the children. Her husband was helping more, and as their salaries were similar they were starting to see themselves as dual breadwinners.

\section{PAULINE "I would be frightened to go back into the workforce".}

Pauline and her husband married with the shared ambition to build a business. Fifteen years later they were affluent, but this had taken nine years of sacrifice and hard work.

We worked seven days a week and when the shop was closed we still worked. We did it faster because I worked in the business. Also the fact that we flatted above the shop. I perhaps put up with things that other people would not have put up with.

Getting pregnant was an accident. Pauline was not ready to give up work in the business and arranged childcare:

I looked at two. There was one place that I went in and wasn't happy with what I felt. It smelt of urine and it just didn't have the right feeling. So then I went to the next one and I still don't know if I chose right. That one was very military. Everything was done at the right time and it was very clean. She was quite haughty but I put him in there. It upset me at first because he didn't like it and he didn't settle. He did eventually but I have always remembered that little face with waxy eyes, nose and cheeks.

Pauline felt she had little option because their living conditions were not suitable for a child, and she arranged for her mother to have him on Saturdays. Such hard work was stressful:

I got tired, very tired...I worked from 6 o'clock 'til night time and sometimes never stopped until $12 o^{\prime}$ clock. Then I would have to drive six miles there and six miles back and then go and pick him up at night time. Another twelve miles. The driving was also a big stress to me.

This pattern continued until Pauline had her second child after a seven year gap. By then the business was established and Pauline stopped work. She would have liked to have gone back into the business and again put the baby in childcare, but this did not seem so acceptable because financially she did not have to work. Instead, when the child was three she got a place in a preschool attached to a prestigious private school. This was acceptable, even though it actually would have had less staff than any childcare centre (Cook 1985d).

Pauline knew that her work had helped build the business. She saw it as an investment in her future security, but now her life felt empty. She held directorships in two companies, but these did not involve any work. Financially Pauline did not need to work, but she was feeling the distance growing between herself and her husband as he continued to expand a business that she helped begin, whereas her role was in the home. In the meantime, 
the focus of the business had shifted from selling jewellery, about which she was knowledgeable, to computer software. She now felt alienated and lacking in knowledge.

DENISE: " When I had a child in 1971 there wasn't much choice. You either stayed with them or didn't have them".

Denise's mother had been in full-time employment during her childhood, and Denise did not want to leave her children alone at home, as she had been. Again there was a sense of trying not to be like her mother, but unlike most of the women in this study, the roles were reversed as Denise. wanted to stay at home rather than go to work. Denise perceived this shift in terms of class. Her parents had both been factory workers, but had later bought a house in a middle class suburb where Denise met her husband. She had strong perception of not needing to work because her husband could support her. Denise expected her husband to be the breadwinner and she expected to have children and stay home to care for them. It was very straightforward, but there were still some adjustments to make when Denise gave up her office job:

Well to be out working and being independent and then to have a baby and to be totally dependent on your husband. That was a big change, but then you adjust. I did. I just thought, well this is what I am doing and I just did it best I could and got on with it really.

Denise saw her husband as a good provider as he worked his way up to to be manager of a retail chain store. Denise was firmly of the view that it was not possible to have a career and a family, and that women had to make a choice:

I looked at it this way - you can't do both. It has to be one or the other. $O K$ if I was chasing up a career I couldn't have children and I would have done that. But I chose to have a baby and I didn't have any wish to go to work and have some one else look after it. I couldn't have done that. I was happy to stay home and look after the baby really. That is probably quite old fashioned isn't it? But I would have been worrying myself sick all the time.

Denise found that the freedom to organise her time was much more fulfilling than the kind of regimentation she had experienced as an office worker. This may have given her financial independence, but Denise expressed more fulfilment in being a mother and a wife. It is the best thing I ever did. Denise did find sometimes things were difficult, particularly when her husband shifted towns to get promotion:

Mum said, "It is his job and you have to go and that is all there is to it because he is bringing in the income". Well I just had to get on with it because it was $A$ 's job and there was no point in going around saying I don't like it here.

Denise's decision not to work, even though all her children were now at school, was motivated partly because her husband was earning enough and she had access to money through a joint account, but also because of a conscious rationalisation that a job would make complications in a houschold that was working smoothly: 
Jobs are hard to come by that don't mess up your family arrangements. If you want both worlds of a career and children you would have to earn enough to have a nanny or be able to afford childcare.

Denise knew she could never earn that kind of money. She had friends who worked at night time, but that was the only time. of day she got to spend with her husband. Denise could not see sufficient reason to justify herself going out to work, yet she was feeling guilty. Her husband had no expectations of her working, but she felt it from friends and was fecling in something of a quandary as if she had to be seen to do something:

I don't want to rush things but it is the big million dollar question right now. At the moment I am quite busy though as I have my Silhouette classes $^{12}$ that I go to three times a week. I would like to do something completely different like being a nurse aide or something but those jobs are difficult to get. I don't want anything too mentally demanding like balancing books, or cleaning as I feel I have done my dash of that. And I wouldn't want to get behind in my work at home. But once $A$ settled in school I might go and look for something but whether or not I find it is another story.

Denise's story seemed to typify the experience of women who saw the financial independence of the workforce as neither fulfilling as nor as secure as the their role at home as a wife and mother. Her assessment that you had to choose between motherhood and paid work, in many ways accurately reflected the constraints upon women who tried to manage both. Denise had avoided such conflicts by choosing to stay at home, although the future was beginning to be a worry. She was aware that her decision was regarded as a little old fashioned and she was thinking of some way of assuring herself an identity and an interest apart from being wife of A__ and mother of her three children. Denise knew that this would not be easy.

\section{SHEILA: "At least there was someone else to say hallo to each day"}

Sheila had married at sixteen, was pregnant at seventeen and thus had little opportunity to achieve much in the workforce. She had worked as a waitress and then as a receptionist in a small town. Sheila's short working life had brought little independence:

I thought I was in a world where I didn't deserve to be recognized. I was a nobody and everybody older than me had to be respected and I was at their beck and call. I was in the workforce only to get money to live. That was all. There was no sense of individuality. It was Mr $\mathrm{C}_{\text {__ 's }}$ daughter or $G \_$_s wife.

Before she left home Sheila's money went to her mother to help support a family trying to manage on a sickness benefit and when she married it went on food. There was no sense of any of it ever belonging to her. When Sheila had her first child her life centred on the home:

I was Mrs _the housewife and I was stuck at home and I was in a situation where your husband came home and he had been out in the world and broken the monotony. I didn't have the same confidence to get out and be a person. I didn't feel that I was allowed to go out and do things.

\footnotetext{
12 Fitness and dancing class.
} 
Sheila's husband controlled all the money and such money she was given hardly covered housekeeping expenses. He would buy her clothes occasionally as a gift and Sheila had to make do, or wait for such occasions to arise. Being alone in a new city and not knowing anybody. Sheila decided in desperation to try childminding. It would bring in some extra money and get her out of the house, and she had experience with looking after her younger siblings. Sheila registered with a Nanny Bureau and within a week had an afternoon job looking after two preschoolers. Sheila stayed in this job for some years, continuing even when she had another child. Sheila gradually started to feel as if she was "somebody":

I started to come out of myself. I was breaking the monotony and I had someone to talk to and we desperately needed the money at that time.

Sheila was never sure where her husband spent his money. He had a small car-painting business Her money, however, gave her some independence if only to buy clothes for herself and the children, although it often went on buying food and essentials. Later Sheila set up a secret Post Office account that would help tide her over on the occasions when she left her husband to go into a Women's Refuge. Sheila's husband thought women should be at home looking after their men and children, but he was never opposed to her working as long as it was only childminding. This was in realm of the domestic and not really out of the home:

He didn't really mind. You see it wasn't a world where I was doo-daahed up or where there were men so there was no sexual threat. And we desperately needed some extra money. He never felt threatened in positions where I was childminding.

On one occasion, after she returned from the Refuge, Sheila got a job as a receptionist and put the youngest child into childcare centre, but it did not work out. Her husband found this kind of independence too threatening and it was difficult for Sheila to manage unless she had some help from her husband. She also found it hard to justify working when her wages nearly all went on paying the childcare fees, so she again returned to child minding. Sheila's work was not unionised and she was sometimes exploited by women who themselves were wanting to work. She was at the bottom of the ladder. Because childminding was a job mothers did for nothing, it was hard persuading people that it ought to be well paid (Cook 1984), but Sheila was learning to be more assertive about her working conditions and was beginning to be conscious of the fact that, with the increasing demand for childcare, she was perhaps a valuable commodity. Unlike her early experiences of work when she felt that she was a "nobody", Sheila now felt some pride in herself and her work.

The ideal of managing paid work and children, let alone seeking equality in the Workplace for women with children, was a distant ideal. It was only women like Adrienne who had a good education, who could afford the luxury of seeing childrearing as an interlude in a career. And even then her children had been a priority ahead of establishing a career. For some women it was childrearing that provided more freedom and identity than the workplace had ever given. The return to work was a dilemma. It had to be fitted around family commitments or 
entailed a complex rearrangement of childcare and domestic responsibilities. Invariably though, the women felt positive about working after being at home. It provided some kind of financial independence and there was a growing consciousness that women should have some identity other than just as a wife and a mother. Unlike the older women, where going to work was seen as more of a stop-gap to help one's husband in his breadwinning role, there was now a sense that women worked for their own benefit. Work did not need to be justified within such a narrow criteria as before. All the younger women expressed the belief that there should be equality in the workforce but there was also a pragmatic acceptance that having children required compromises. The fact that there was such a gap between the realities of women's lives, and the realities of the workplace, placed an onus on women to make choices. It was not always possible.

\section{WORKING AT MOTHERHOOD}

These women were rearing children amidst conflicting ideas concerning the role of women in relation to their children. There was the view that mothers should organise their lives around the needs of their children, and in an age of permissive childrearing these needs became even more demanding. But there was also a newer view that women had a right to pursue their own interests, apart from her responsibilities to children (McKinlay 1983). This was a time when the popular maxim of "Girls Can Do Anything" was also coming to mean that mothers could do anything too. The reality though was that there were few support services to help relieve mothers of their childrearing and domestic responsibilities. Women were caught between trying to do the best for their children in an era of ever increasing expectations of childrearing, and trying to manage time to work, pursue a career, or just to find time for self, apart from children.

\section{Problem children - problem mothers}

The view that women could manage the responsibilities of work and children took no account of the fact that there were still children whose needs or disabilities demanded extra time and commitment. Like the women in the older generation this extra responsibility fell on mothers. While there were more support services for children with problems, the younger women still felt that they were managing alone because the difficulties their children had were often not officially identified as "problems" by mainstream educational and medical agencies. The mothers felt guilty and the practice of blaming the mother was akin to "blaming the victim" (Margolis 1984). The three following case studies show the kinds of struggles women had to get help, and recognition that there was a problem not of their own making.

Beverly's first child did everything by the book but her second child was sickly:

He didn't put on weight and he didn't thrive. He was always sleepy. I wasn't ever up with a screaming baby but he just didn't thrive. The 
Plunket Nurse then suggested I wean him as my milk was probably no good. But then he lost even more weight and so I feel sad now as I think that if I had kept on feeding him it might have helped as he was allergic to all the milk powders. He had giant allergies.

Beverly knew that there was something wrong with the child but could get no support in this view from the medical profession:

Finally at six months after my screaming for something to be done in the sense that this was not my first baby. This is my second baby and I know what I am talking about. I am not an hysterical mother trying to make an issue out of nothing.

The child was eventually put into hospital for tests. This was a relief in the sense that something was at last being done but this proved to be a traumatic experience. It was 1973 and the hospital still viewed mothers as a nuisance:

I wished I had been more assertive. We handed him over in the foyer. They whipped him away and they came back with his clothes and told us not to visit him for a week. And we didn't - and of course we still feel terrible about it. He rejected us. He wouldn't look at us - nothing. It was absolutely mind boggling and it took about four years to build up that trust again. We visited then day after day but he wouldn't respond.

A rare disease was suspected that caused mild retardation. Rearing the child was difficult as he had unpleasant bowel problems and allergies. He was not a nice child to be near and he always smelt. Because his retardation was mild, the general view of friends and family was that he was just a naughty child and needed a jolly good hiding to fix him. Beverly often felt that she was not a good mother. She felt unsupported by the medical profession, family and friends. It was not until she started going to playcentre that she started to feel support for herself as a mother. The knowledge of child development gave her skills to diagnose her son's development and made her more assertive with the medical profession. Most of all there was support from other mothers who would help clean up D__ 's dirty pants and give her a break.

Annette had looked forward to motherhood but once the child was born there was a feeding problem which was later attributed to the pethidine pain killer she had been given during childbirth:

The main problem with the feeding was that it was nothing that the doctors or medical people recognised. They couldn't understand what I was talking about because they couldn't put a name to it. We couldn't say, "Such and such is wrong".The child was putting on weight and doing all the right things. But they had no understanding of the difficulties at home and the hours spent trying to feed a child. I eventually kept a diary and discovered that I was spending up to eight hours a day just feeding him. It wasn't until I presented this to the doctor when the child was six months of age that anyone accepted that there might be a problem and by then it was resolving itself.

Annette talked about being unprepared for the fight she had to get recognition of the problem.

At this stage Annette went into a state of depression:

Before I had been too busy to even think of myself. I was just so exhausted, but when the child got better I didn't have the incentive to do 
very much...I would have been seen by others to be coping but it seemed to take me much longer to things. I would burst into tears very easily and just have a general state of unhappiness. It was affecting my marriage. My husband knew there was something wrong but he couldn't understand it. He could understand the feeding problem, but he couldn't see what was wrong with me and I couldn't tell him. I just knew that I wanted to cry for most of the day.

Then at ten months the child developed a sleeping problem. Coping with this somehow cured Annette's depression. The problem began when the child was sick, and from then on he screamed hysterically when put to bed and it took almost a year to resolve. They tried every solution from walking away and leaving him screaming to heavy sedatives:

Nothing worked. My husband and I would take it in turns with him. We had various measures. One of the measures prescribed by the doctors was to let him cry and over a fortnight the child would get the message. Well it didn't happen. He got more and more hysterical and upset to point of vomiting. It was sheer hell.

During the day time the child was loving and amenable and nobody understood the night traumas. Annette and her husband lived like zombies through the lack of sleep, and Annette could not but help feel at times that it must be her fault even though she knew the causes:

There were many times when I really questioned whether it was me and I was very anxious. I wondered whether he picked up my anxiety. But then I knew that I was only anxious because of the situation. The anxiety of whether I was a bad mother was not in the fact of the sleeping or the feeding but more in the discipline. I felt bad about the measures I had to take to correct them

The idea of having a second child was approached with some caution but this child had none of the early difficulties experienced with the first, and Annette's confidence as a mother was restored considerably.

Delwyn had two boys who appeared normal throughout their early childhood years, but upon beginning school they were to have academic and behavioural problems. They were eventually diagnosed as dyslexic, but before this diagnosis, the oldest boy in particular was considered a troublemaker. While Delwyn was believed, the school saw her as a pushy, overprotective and sometimes a neurotic mother. But it took assertive behaviour to protect her children from the discipline and educational failure of school, as well as getting recognition that there was a problem beyond the boys disaffection or her own abrasiveness. With the oldest child the pattern was that he would get into trouble at school, the school would ring home and the child would then be in trouble at home and at school. Eventually Delwyn and her husband took some action:

We decided to send him to boarding school. We were just getting too much flak and they would not listen to me that I thought he was dyslexic. I knew it and so I felt that he had to get right away and we had to look for alternatives. We were also worried at the bad effect we as a family were having on him. I thought that if he got completely out we could perhaps sort out the problem. The upshot was that he was 
dyslexic. The school got in the "psych" services and a neurologist and just confirmed what I had already known.

Sending an eight year old to boarding school was not an acceptable move among friends and family, and Delwyn again had to face criticism of being an uncaring mother. Delwyn felt guilty but could see no alternative to resolve the situation which had arisen. After four years at boarding school her son had returned home. In the meantime the younger child was also diagnosed as dyslexic, but this time the school was more supportive. Both children were having tuition through SPELD ${ }^{13}$, but Delwyn found that coping with this required a great deal of home support and much discipline:

I have done what I can in every single solitary way and I think at considerable cost and emotion too. I don't know what else to do.. We have got to the stage where we can invest financially and emotionally but just won't get a return. We are beginning to put up protective shutters.

\section{Good mothers breastfeed}

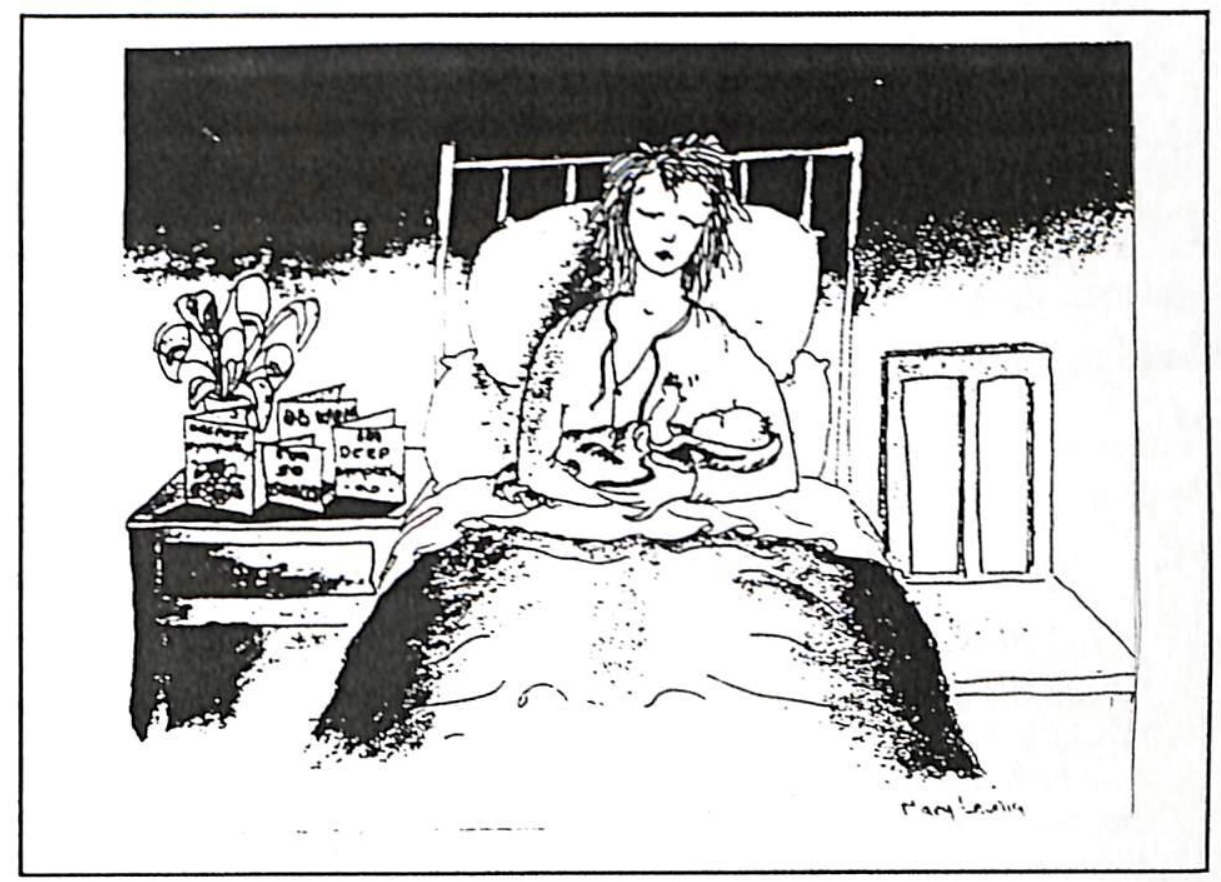

During the years after the World War Two there was a steady decline in breastfeeding amongst mothers ${ }^{14}$. This was noticeable even between the two groups of women interviewed. All the older women breastfed their babies, although it was not always easy. Not all the younger women breastfed, and if they did it was generally for less time than the older women. The reasons were varied but it was apparent that rigid hospital management of childbirth and

13 A society which worked with children with specific learning difficulties that were not always given help within the education system.

${ }^{14}$ In $194580 \%$ of babies were breastfed. By 1968 this had dropped to 47\%. During the 1970's there was a dramatic rise so that by the end of the decade figures were almost comparable with the early postwar years (Donley 1986). 
the lack of support for mothers were important reasons. During the 1970's there was an upsurge in breastfeeding. Organisations like La Leche became powerful advocates of natural feeding and provided support for mothers having problems. Many more hospitals had rooming-in practices and demand feeding was in vogue. Different strands, from the women's movement, alternative lifestylers, childrearing experts, mother's groups and health institutions, converged in supporting the idea that breastfeeding was natural and best. Thus the first test of being a good mother in the 1970's was someone who breastfed, and most women endeavoured to leave the hospital at least, still feeding. In such a short space of years there had been a considerable shift in attitudes and the new ideal had become so strong that women who failed to breastfeed, or had problems, were to feel a strong sense of failure. Half of the women told of the problems they had with breastfeeding and the sense of guilt when they gave up.

Elizabeth had every intention of breastfeeding her first child, born in 1977. She felt she had prepared herself well, but Elizabeth had a difficult labour. She was shunted around various medical teams of Auckland Women's Hospital and eventually had a caesarian birth. None of this was conducive to establishing breastfeeding. Elizabeth tried, but it did not work:

There was this disillusionment of not being able to breastfeed and finding out that it was not a natural thing that anyone can do. I had to bottle feed her. That was a big hurdle for me. I felt very guilty about that. I found it very hard to accept. She was a hungry baby and became a very big baby and I felt very guilty about that...

Elizabeth had a second child by the time of her interview. Again she had a caesarian but had been a lot more assertive about the conditions of her stay in hospital. This time breastfeeding worked well.

Sharon had been anxious about the birth of her first baby after marriage as she had given birth to a stillborn baby as a teenager, and had never found out what had gone wrong. The birth, however, went smoothly but when Sharon tried to breastfeed she struck trouble:

I didn't find breastfeeding the most wonderful thing like some people did. I found it very sore and it hurt my neck and made me feel low all the time. I told the doctor and he said, "Oh don't worry, sit with your breasts exposed to the sun". Well what else did he think I had to do. You can't sit out there airing your nipples in the sun at an Airforce Base. I'd get arrested. I went to the Plunket nurse and she said, "Oh persevere Mrs M__. Well one day there was a relieving Plunket nurse and she said to try one meal on the bottle and that was it - bang! I just stopped and all meals went on the bottle. Probably not a good thing for the baby, but it certainly made me feel happier about feeding him.

For the next child Sharon breastfed while in hospital, but quickly put the child on the bottle when she got home. She felt more confidence in suiting herself.

The idea was that because breastfeeding was natural, it must be easy. While some of the women certainly found this true, not all did. Some of the women who had difficulties first time around were more successful with the next attempt, but others decided that despite the guilt, life was complicated enough without adding extra problems. The women in this study had their babies at the height of a breastfeeding campaign, a campaign that was at times 
intolerant when physical disability, lack of support or kind of lifestyle, made breastfeeding impossible. This was again symptomatic of how new definitions of what was good childrearing placed increasing demands upon women.

\section{Good mothers send their children to preschool}

Throughout the postwar years, the demand for early childhood education could hardly keep pace with provision. The demand came in part from the childcare support it gave mothers, combined with the attitude that as long as the child was over three and the session was only half a day, then preschool experiences were a good things for children. By 1970 it was estimated that a third of children reaching school had had some preschool experience (Hill Report 1971). As fertility declined during the 1970's, the services were able to cope with the demand and by 1982 it was estimated that $78 \%$ of four year olds had attended a preschool before their entry into school (Department of Education 1984). "Good mothers" ensured that their children went to preschool as a place providing play experiences in which children learnt social skills, and certain academic skills, as a good preparation for school education. Like the shift in attitude over breastfeeding, early childhood education became a new measure for separating well reared children from badly reared ones. Sharon was very sensitive because she had not sent her second child to kindergarten. She had not enrolled her at age two ${ }^{15}$ :

They sent me an enrolment form but I lost it. I think I sent for another one but it never came. I felt so embarrassed about it all. But she was quite happy at home. We used to go to things together. When she went to school I asked what she was like in comparison with the other children and the teacher said said she was fine. So it didn't hurt but I thought that I was doing the wrong thing. I was letting her down somehow.

Early childhood services provided much support for mothers and several of the women paid tribute to this. Adrienne initially became involved in the local playcentre ${ }^{16}$ because it offered playgroups for children under the age of two and there were waiting lists at the kindergarten. She became involved in setting up a new playgroup, began her own playcentre training, and eventually became the supervisor of the playcentre. Adrienne felt that there had been many benefits for herself in this experience, but most of all friendship:

Without a doubt the companionship. And you had to learn to think about other people's ideas and feelings. I enjoyed it and I made friends and my children did too.

\footnotetext{
15 Children were enrolled at aged two and called up for a place sometime after the age of three. In many areas during the 1970's this would not happen until aged four. Research showed that one of the reasons lower economic groups and some ethnic groups were not sending their children to preschool was because they had not enrolled their children at the right time (Dept of Education 1984).

16 Unlike the kindergarten which received government funding to pay the salary of teachers, the playcentre was run by parents themselves. The philosophy was that parents and not the teachers were the experts on their children.
} 
Annette chose playcentre because she could take the baby and did not have a car to get her child to the kindergarten. But she found the commitment a strain:

I appreciate the philosophy and tend to go along...I noticed other mothers who found it very difficult to fit in their duties at playcentre plus care for younger children. A lot of women left playcentre to go to kindergarten because of the sheer commitment. They just didn't have it...But I realise that I did make a lot of friends there.

Elizabeth was an advocate of the idea of early childhood education, but with a view that she wanted it as a break for herself too. She sent her children to kindergarten on the basis that it gave her time away from mothering and required a minimal involvement:

I don't think children are my whole life. I will never go as far as that. I always like to have something extra that is mine. There is another self that is partly postponed.

Elizabeth saw this as a compromise. She had earlier worked while she had a preschooler, but now she would soon have three children she could not manage work. Sending her children to kindergarten fitted within the boundaries of being a good mother even though she she regarded the time as selfishly being her own.

Early childhood organisations were powerful in prescribing codes of acceptable and unacceptable roles for women, in addition to friendship, support, relief and opportunities for women. But not all the women fitted their prescription of being a good mother. Organisations like playcentre, Plunket, Parent Centre and kindergarten assumed that mothers were at home with their preschoolers and were available for fundraising, help and/or supervision. Moreover, they were strong advocates of mothers not working and often reluctant to see their services used by working mothers. For example Delwyn found it difficult when she left the local playcentre to put her child into childcare so that she could study:

Again with the influence of the Parents Centre ${ }^{17}$ group I felt guilty. That Parents Centre has a lot to answer for as they are really for the traditional mother. $P$ _ went to playcentre and they rounded on me too. Parents Centre and playcentre go hand in hand. They told me what a rotten mother I was and made me feel guilty. The ironical thing now is that so many of them are out working whereas I am at home. They tried to make me feel guilty and they did make me feel guilty but I carried on regardless.

In fact, seven out of the thirteen women used childcare services at some point so that they could work, study, or in the case of Beverly, as an emergency when she was in hospital ill. For some of the women this was the only early childhood education their children received and they argued that childcare was a support to their family and in no way harmful. The growing support for childcare during the 1970's, the increasing use of it by middle class women to pursue careers, and the gradual improvements in quality of childcare services, were to make it more acceptable than it had been in earlier years. But still, women who used childcare felt guilty initially, and like mothers who had not sent their children to kindergarten or playcentre

${ }^{17}$ An organisation giving support to parents that had strong connections with playcentre. 
felt they had to justify their actions and prove that their children had not been harmed. By the mid 1980's, however, the relationships between the early childhood services was changing. The 1984 Labour Government had a policy of equity between the services and promised funding support to childcare, to make it affordable to parents and to improve the quality. There was also government support for childcare as part of the policy for encouraging equal opportunities for women in the workplace. There was for the first time a shift in political rhetoric, if not actual policies, that early childhood services should not only service the needs of children but of families as a whole. It was being argued that Government policy on early childhood should not be used, as it had in the past, to constrain the options of women but to enhance them (Cook 1985d). Both kindergarten and playcentre were tentatively looking towards ways to restructure their services so that they could accommodate the needs of working mothers. Between 1975 and 1985 playcentre attenidance had dropped from 22,000 to 14,000 as fewer women were prepared to make the commitment it demanded. Instead more women looked to investing that energy in the workplace and in themselves, rather than their children.

\section{WORKING FOR CHANGE}

During this period there was a plethora of organisations and activities calling for involvement from women and working on behalf of women. Some arose under the framework of feminist activism; many were formed around specific issues like abortion or childcare; while established political organisations also saw an increased involvement by women. The activities of the younger group of women spread across all of these, but like the older women there were some who had no involvement: like Raewyn where farm and family responsibilities allowed no time; or Sheila who needed all her energy to cope with her own life; or Elizabeth and Denise who avoided committees or clubs and preferred their time away from children to be for themselves. As with the generation earlier, there was again an emphasis on the causes of "reasonable feminism" (Wilson 1980). Only two of the women became involved in feminist groups that were explicitly working for radical change: Penny who had always been active in radical politics, and Carolyn, who never married and was to gradually identify herself with feminist issues in working women's organisations. There was often sympathy for feminist issues, but for most of the women, activism was in organisations like kindergarten, Plunket, playcentre, childcare, Parent's Centre, and school committees. These were relevant and essential to their lives at the time, and they were seen as acceptable in that they were not seen as threatening the status quo. Yet such activism did politicise women by making them more conscious of the oppression of women at home and outside of it. As Zillah Eisenstein (1981) has argued, the cause of liberal politics can serve radical politics. With the younger women there was more evidence of a commitment that would not be dropped so easily under pressure from family demands, and for Penny, Adrienne, Annette and Beverly this commitment at 
times had the priority of a paid job. The final three case studies look at three different strategies of political and personal change showing the interwoven strands between the personal and political in relation to social change.

\title{
$\underline{\text { Radical Politics }}$
}

Penny's involvement with radical politics had begun in the 1960's with the left wing Progressive Youth Movement (PYM). But the experience of childrearing was to shift the focus of Penny's activism towards issues affecting women with children. Penny also became involved in mainstream organisations while retaining her radical perspective and radical brief for revolution. This required political and personal accommodation in order to be accepted and credible by both her radical and more mainstream associates. The process began when women's liberation arrived in New Zealand:

\begin{abstract}
It very quickly had a dramatic impact on the PYM...The men in PYM, the young men were forced by the women to look at their sexism... When it was asked to put up speakers of mobilisation, women were put up and women were in chairing positions...The women got together so that if any man was taking advantage of a woman there was a reporting system. The men weren't allowed to make any sexist jokes and the responsibility for change was laid on them.
\end{abstract}

When Penny had her first child she already had a philosophical commitment to the idea of group experiences being good for children, and placed her one year old in childcare so that she could work as a postie. She was influenced by marxist writings on the family and it seemed a natural transition to become involved in the early childcare campaigns of the 1970's:

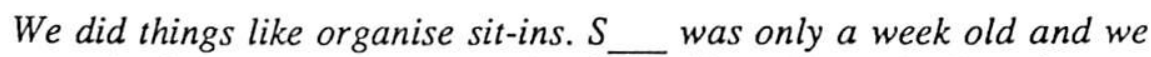
organised this sit-in at the Auckland $\overline{C i t y}$ Council. We leafletted areas on childcare. We held demonstrations relating to childcare.

This kind of activism was linked also to concerns about women's employment and particularly equal pay:

Equal pay highlighted the unpaid work that women did. We were very into the unpaid work that women did. The ways of showing that were in the employment struggle and in the childcare struggle.

Penny was looking towards a revolution for women and for society but was also pragmatic:

I remember feeling that we weren't in a revolutionary stage and that the general community was not in a heightened state of awareness...My analysis at that stage was that it was going to be many years before there was a revolutionary situation. I was far more intensely aware of the power of the state than a lot of them were...I decided that given the time and energy that you should first of all work with ordinary people involved in established groups. To at least exhaust their possibilities as that is where the bulk of the people are at.

Her first move in this direction was to become involved in the local playcentre:

I had a very political idea of getting involved, but I also had needs to get to know people, to have friends. I really did need friends and the friends I made then are still close friends. We write.

Helen: Politically they would have been quite different to you? 
Completely different, but I used to analyse what was happening. I think my political thing gave me tools for analysing practical situations. I saw Playcentre Education Officer as the thing I wanted to be as you ran and organised the discussion groups and I saw that as potentially the most radical thing to do.

Penny saw radical politics as enabling people to make changes in their own lives:

I have never felt that I know what sort of change. I am quite happy with people making small advances as far as their understanding is. What it did mean was that within the group we set up a lot of things for our mutual support which I didn't really see as politically radical. Baby sitting clubs, a food co-op. We set up a solo parents club. I saw the culture thing too as very political. There were problems in the Centre that were really racist in origin.

An involvement in playcentre after the Progressive Youth Movement was a kind of an accommodation to the realities of living in the suburbs with three young children and no transport, but Penny became conscious that interpersonal relationships between men and women were probably the most explosive issue politically:

I daren't touch their relationships at that stage with their husbands because it was too sensitive and they weren't ready for it. I found out later when I became involved in parent groups that very quickly women wanted to look at their own relationship. That was political and they all very quickly left their husbands. Potentially "parenting" is a very radical thing... You are looking at a family relationship and that is dynamite.

From an involvement with groups working towards revolution, Penny had come to believe that it was the personal that was the most political and that women had to make changes in their relationships before any real liberation was possible. This was also an arena in which she could mesh her own domestic responsibilities and needs with her tools of political analysis and activism.

\section{Playcentre as a process of education}

Beverly still felt a lingering sense of failure in not passing her School Certificate $e^{e x a m s}{ }^{18}$. Beverly started attending playcentre when her first child was two and was selfconscious about her own ability amidst a group of middle class women who appeared to be so confident. This child was fifteen at the time of Beverly's first interview and she was contemplating moving into paid employment for the first time since her marriage. At a second interview two years later, Beverly had just been appointed to a high status communications position, and as she said To think that I haven't even got my School Certificate. The process of this change came through her involvement with the playcentre movement. Beverly felt that she struck playcentre at a good time:

There were no expectations of me..There were no demands that you must do training because the place is going to the pack. So it was really good...I actually hid a lot. Several times the supervisor said to me, "You're a natural".

\footnotetext{
${ }^{18}$ Examinations sat in the fifth form year.
} 
It was concern over a mildly retarded son that really got Beverly interested. She learnt skills which helped her identify his retardation and helped her as a parent handle his behaviour difficulties. Her first training certificate was a family occasion which also involved her husband:

He came to the graduation with me. He thought it was going to be like a school prize giving - boring, but it was absolutely fantastic. A really big do. He was really impressed but then he got to the stage that if anything went wrong with the kids he'd say, "You've done this training, you should know what to do".

Beverly continued with her training and became more positive about herself and aware that she had special skills:

I started to think that maybe I could do something, but then I would think, "What have I got to offer"...Then I started to realise that I was a person of worth and it wasn't until then that I did. I was accepted for what I could do. Not for School Cert or UE ${ }^{19}$, or whether I was nice looking or had good clothes. It was me and I could do it and it was just lovely...When I heard one or two things back like $B$ _ is a fantastic supervisor I was a bit frightened because I had never thought that anyone might think that I was special.

All the years in which Beverly was taking her children to playcentre and even after her third child had started school, Beverly resisted going into paid employment. Her husband was on a low wage , and managing a family of three required sacrifice:

We don't have lot of things. The kids don't have a lot of clothes. They have one clean and one in the wash. We live very much like that. Clothes that other people give us...We have plain simple meals and we don't go out at all. We go and visit mums. We don't have expensive things in the home.

Part of this decision was because of her commitment to playcentre and to give to others what she had beeri given, but there was also a commitment to her marriage:

Once I got into this playcentre thing and taking positions of
responsibility I did a lot of soul searching of my life about where I was
going, my marriage and my children. And I can remember making the
decision. I was scared that I would outgrow J and the kids I suppose.
It was exciting growing and seeing things in myself...but I thought that
my marriage was so important that I would give up against all else if I
felt it was pulling. That sounds dreadfully self-sacrificing. I can
remember all the things I was learning at human relationship and
leadership courses and I would come home and tentatively share them
with J_and he would think I was mad. This process of change was, as Penny earlier described, the most politically delicate and explosive, and Beverly was wary of widening the potential conflict she could see and feel. A personal crisis came when she was offered an important position in playcentre. She accepted the position, but reaffirmed her commitment to the marriage:

I don't have meetings here. This is his home and his castle too. I was getting all I wanted so I made the decision to divorce the two. I realised

${ }^{19}$ University Entrance exam sat or accredited in the sixth form year. 


$$
\begin{aligned}
& \text { that J couldn't cope with all that other although he was very } \\
& \text { supportive of me but always in the background. I don't try to change } \\
& \text { hm. I love my home too much yet I was scared that he couldn't cope } \\
& \text { whth my new self. }
\end{aligned}
$$

Beverly's new self brought her into contact with the ideas of the women's movement and lesbian feminist women. This created ambivalent feelings, of supporting many of the ideas, of

but fecling the threat of it personally:

Now that really frightened me. This was all part of the struggling
within, but to me the most important part still was my marriage and my
children, and yet I could see that perhaps I really had a future elsewhere.

This took time and anguish to resolve; of accepting that it was really a women's movement which had changed her, but that she could also be comfortable with choices in her personal life that may appear contrary to the feminist ideal. Like Penny, Beverly had become aware of the power of being an Education: Officer in playcentre. They worry me sick at what I am doing because women say, "Oh gosh it has changed my life". Oh good heavens!.

When Beverly began her new job, her pay was double that of her husband, but again she had adopted the philosophy of keeping home and work separate and of ensuring that her marriage and children were still paramount. The immediate change in their lifestyle had been in persuading her husband that he need not work overtime. This caused tension because he was unused to evenings of leisure at home, but then he had started cooking the evening meal. Throughout these personal and eonomic changes, Beverly consciously avoided allowing personal change to translate into a reordering of priorities or political activism, although she was very conscious of its power to do so.

\section{A New Outlook}

A popular course at New Zealand Polytechnic Institutes for women who were looking towards new options when their children were at school or left school, was "New Outlook". The following insights came from women on two such courses. All had had a long break from the workplace and had made a priority commitment to home, husband and family. Few had skills that could be immediately transferred into employment, and most had married men who had moved ahead in their careers. There were also women who were on the Domestic Purposes Benefit and were worried about what was to happen when their youngest child was sixteen and they would have to join the workforce. In the New Outlook course these women were sharing their concerns and examining their options, a process as, Delwyn and Penny found, was very political. The following comments show women in the process of manouevering towards a more independent identity apart from their home, children and husband and making decisions that would trigger off a ripple of changes in their family relationships:

Vicky : $\quad$ arrange meals. There is always something on the table. Breakfast,
morning tea, lunch, afternoon tea, dinner. If I have to go out I would
leave it all set out for him. I used to love the days he went away and I
could have the day to myself. I'm not going to do that now. If he wants 
a cup of tea he can get it for himself and I will get my own when I want it too.

Suzanne: $\quad$ I joined this course because I was feeling rebellious with my husband. "Hello Dear how was your day? What did you do today?" You are so busy asking what he has done all day because he has been out in the world. But now I am bringing home all these ideas and you have never got him to discuss them before. The trouble is they are always the radical bits. He is so used to bringing the news home.

Raeline: I was carrying heaps of guilt about the marriage even though I had lived very much on my own because my husband would only pop home for a meal and naughty when it suited him. I ran off with another man but I really copped a lot of flack. The scarlet woman and all that. I started drinking....T_ was against me going out to work because he is the breadwinner and so I came to this course. When I told him he said "But what about the kids?". We had a flaming row and I said "Well what about the fucking kids?"...Coming to the course and by coming out and saying my problems and finding they all felt the same. Things have started looking up...I am thinking of taking a job as a supervisor of a

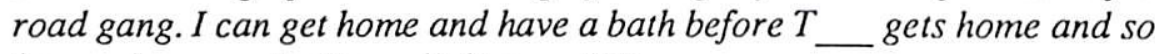
he won't see me looking all dirty and like a man.

Linda: $\quad$ I felt unsettled. The children are growing up and want to get a job but they are hard to get. I don't just want any old job. I want it to be my hours and I don't want a cleaning job as I have already done enough of that. I want to use my brains. I want something stimulating. Financially there is no reason but then there is that feeling of wanting some money in hand. Since I came on the course my husband and I have worked out our finances so that we both have some separate pocket money.

Kay was more pessimistic and could clearly see herself as being caught between the constraints of two codes: one of independence and one of security:

I don't know what to do. If I am a good wife and look after my children I lose my other skills. That is all very well but what if $H$ _ leaves me for another woman. That puts me in a very different situation. It's too hard for a woman to try and keep a job and look after her husband and family. The system works against it, but women need this as a safeguard in case their men leave. It is not nice being in this situation of being dependent on a man that way. You worry about the future.

All the women in this study had to confront this dilemma in some way, whereas the older women vested their security more clearly in men because there were few other ways of achieving it if a woman had children. Rosemary summed up the attitude that was changing the consciousness of the younger generation of women:

We aren't anybody's trailers. As I have got older I have started to realise that. I used to think that it wasn't important as I wanted to be a good mother and a good wife and all the usual things. Now I feel a lot more self-centred. Much more concerned about myself and realise that I have to look out for me. Can't rely on other people.

There was now a realisation that security through dependence upon men was potentially insecure, but the dilemma facing these women was that independence from men caused social and economic vulnerability, led to marital conflict, and caused work overload unless men made 
some accommodation. Apart from Penny, the other women in this study saw the men's accommodation to change as being either cautious or strongly resistant. 


\section{CHAPTER THIRTEEN}

\section{CONCLUDING OVERVIEW}

When I ask what independence means to women I imagine it...as the ways and means of transforming some of the stubborn realities of everyday life, and of creating new possibilities for ourselves (Heron 1986:5).

The period of this study covers two generations of New Zealand social history and has been concerned with tracing the changing context of life for a group of Pakeha women during their childrearing years. The changes between generations have been both cumulative and variable among different groups of women. In this study the women of both generational groups also had much in common, in the sense that they all had the primary responsibility for childrearing and were all economically dependent on their men or a Domestic Purposes Benefit for periods of time. The continuity of experiences between the two generations outweighed the discontinuity. However, alongside the common experiences between the two groups of women there were identifiable differences in the context and meaning ascribed to their experiences. Anthropologist Katherine Newman (1986) has addressed the question of there being distinctive symbolic dialects between generations. In her analysis of divorced American women from two generations, she concluded that their different cultural frameworks were in part "generational phenomena" (1986:231). There are interesting comparisons as the women in both Newman's and this study were of a similar age.

Firstly, like myself, Newman found that the older women's experiences of the depression years and the Second World War had created a consciousness of scarcity. This was irrespective of economic class or their actual experience of deprivation during these years. In my study the women expressed this in terms of their self-sacrifice, acceptance, managing and making do. Even though the older women in my study experienced considerable improvement in their standard of living and/or upward mobility in the postwar years, they did not lose their "scrimping" consciousness and skills. In both studies it was apparent too, that home ownership, careful saving, acquisition of consumer goods, and investing resources into their husband's breadwinning ability were seen by the women as security safeguards. This view of security embodied a particular arrangement of gender roles and responsibilities which were intended to protect them against social and economic vulnerability. In contrast, in both studies the younger women were reared during a period of economic growth and although their experiences varied, there was little impetus to acquire the kinds of survival skills possessed by the older women. Newman found that the key concepts for the younger women were ones of autonomy, independence and self-determination, and when faced with divorce, which was the particular focus of her study, the younger women were concerned to find a plan of "liberation" (1986:238), so that they would escape their dependence. This was in contrast to the older divorced women who felt they were owed the on-going support of men. In both Newman's and 
my own study, it is evident that the concept of security for the younger women was more ambivalent in relation to the assumption of economic and social dependence on men as part of the gender relationship.

Secondly, in relation to this study, a shift in meaning can be seen when comparing the older women's views of motherhood with that of the younger women. Apart from Dulcie who was in full-time employment throughout her childrearing years, the older women viewed motherhood as a full-time task. For some this task was a "career", in the sense that it was seen by the women as replacing the "career" they might have once had. This perception of motherhood as a full-time vocation existed irrespective of the kinds of part-time paid work the women were also doing. In contrast, the younger women saw motherhood as one of a number of things things they were doing with their lives, even though in most cases, all of the younger women spent some time as a full-time mother. Staying at home to care full-time for children was justified as a necessary arrangement at the time, but one that would invariably have to end. Even the women who had not returned to work and whose children were all at school, had a consciousness that motherhood was not seen as a full-time task by expressing guilt that they had not yet made plans for the future. While the younger women often expressed enjoyment in motherhood there was less sense of vocation in the role, a view that reinforces the findings of both, McKinlay's (1983) study of New Zealand motherhood, and Wearing's (1984) study of the ideology of motherhood in Australia. Both of these studies identified a more recent view that motherhood was one of various options for women. During the postwar period that this study covers, there was a demonstrable shift in the balance of power between men and women. In her study of motherhood in eigthteenth century France, Badinter (1980) suggests that such shifts in power are invariably accompanied by shifting responsibilities and rights over children. In early postwar New Zealand, married women saw the role of full-time mother and wife as bringing economic security and political support for the needs of women and children. The later generation of women as mothers in this study, felt more ambivalent about this earlier view. They were to realise that the achievement of economic security and political power for themselves meant that such a full-time commitment to motherhood was almost impossible.

Thirdly, there was a shift in meaning in the perception of paid work for women in this study. Once the older women were married or had children, their paid work was either hidden, in the sense that few people would have realised that they were in paid work, or it was neatly fitted around the needs of the family so as not to cause conflict. Dulcie was again an exception, but she came from a tradition where working class women worked and she resisted the bourgeios ethic of wives staying at home to be supported by their husbands. Even though the other women sometimes enjoyed their employment, or enjoyed the increased financial independence it gave, their employment was justified mainly through the context of their giving support to the male breadwinner. In contrast for the younger women, paid work during their childrearing years was more visible and more clearly linked to their own identity as a 
person. However, these women still tried to minimise the conflict their paid work might cause, and the additional money was invariably used to support the well-being of the family.

The existence of a symbolic dialect that both defines and reflects meaning in any particular generation is a useful concept, and in my study this shift in meaning was also evident in the older women's perceptions of the lifestyle of their daughters or other women of the younger generation. Conversely, it was also apparent when the younger women appraised their mother's lives or women of the older generation. Their respective ordering of priorities was clearly different. For example, while the older women welcomed and were even envious of the opportunities of their daughters, there was also a sense of ambivalence. For some of the older women this was expressed as a kind of anger that their daughters had not always availed themselves of opportunities which they, in their youth, would have given anything to have had. Their daughters had left school or got pregnant too young, married too soon, had left a husband who seemed to be a "good provider", or had not pursued the opportunities which the older women felt they had sacrificed themselves to provide. On the other hand when the younger women had, for example, moved back into the workforce, it was not unusual for the older women to express concern about the effects of their actions on the children or husband. The potential conflict of interest between family members that this posed, was something the older women felt uncomfortable about, as they interpreted such an action as perhaps upsetting the balance of gender roles and responsibilities in which they themselves had invested for security. The older women could accept that their daughters should have a right to some life of their own, but would cite their own self-sacrifice in placing the interests of children and husbands before their own needs. Several of the older women, however, believed in retrospect that they had been foolish to do so to such an extent and admired their daughter's comparative independence. But they would still express concern that their daughter was taking risks and pursuing ends that they thought were not in the interests of the family as a whole.

From the younger women in this study there was a consistent view that they were not prepared always to place the interests of other family members before their own, as their mothers had appeared to do. They were more ambivalent about this kind of investment in men and even children, and did not see it in their own best interests in terms of future security or well-being. All of these women still measured the differences between their mother's situation against their own in terms of autonomy, in the sense that younger women might have more access to money, the use of a car, or a husband who could cook or help look after the children. Even for those women whose lives were still arranged around the traditional breadwinner homemaker roles, there was concern that such an attitude might be "old fashioned" although they would justify their choice of action by arguing that any other arrangement would create stress and conflict. In appearance, however, there was still a strong continuity between the younger women's and older women's lives in the sense that all the women had had the primary responsibility for childrearing. Although the sample of younger women may be selective and 
small, all except one woman still regarded some economic and social security within a heterosexual relationship as being necessary. The differences however were that the younger women saw other options in the long term which could be achieved by some. In contrast, the older women showed less consciousness of possible alternatives. Such alternatives did not appear to exist for these women, or if they dreamed about the possibility of alternatives, as Meg did when she thought about a career for herself and daycare for her children, the reality was that it was impossible to achieve. For the younger women, both views of security in relation to gender roles and responsibility were powerful, but they were caught between the two in the sense that, in their ideal forms, both views were only possible for a very few women.

It was evident with both groups of women that the older view of security, which was so pervasive in the early postwar years, was seen as more acceptable and correct, and that the changing perspective of the younger women was less acceptable. This retrospective aura of normality surrounding, in particular, the decade of the 1950's is understandable when viewed in its historical context. But it is also misleading. Set between a decade of war and reconstruction and the decade of the 1960's when many values were challenged, it has been tempting for the present generation to see the apparent order and consensus of the 1950's as a measure of being acceptable or unacceptable. The years before and after the 1950's have appear by comparison as more uncertain. To many people the apparent social changes of recent years appear to diverge from the acceptable and to be creating a sense of uncertainty, although to others they are evidence of the real diversity in New Zealand lifestyles and values. The argument of this study is that such aberrations and/or diversification in lifestyles were not just a post 1960's phenomena, but had in fact taken root much earlier. New Zealand society in the early postwar years was structured in such a way as to cover up firstly,the changing social patterns in terms of demographic changes and inequality, and secondly, the diversity in terms of cultural and changing lifestyles that were already present. In the context of America, for example, Andrew Cherlin (1983:158) has argued that demographic patterns of the 1950's should be seen as "distinctive" in that they were at odds with the decades preceding or following. Cherlin found that the patterns of fertility, divorce, age of marriage, and roles of men and women evident later during the 1980's were more in accord with trends that had begun earlier in the century. In this context it can be argued that the 1950's were anomalous,and created mainly by the impact of the extraordinary circumstances of a depression and war. In New Zealand, as in most Western countries, the war encouraged economic growth, and the cumulative psychological effect of a depression and a war encouraged an ideological climate that was fertile ground for idealism and utopian views. This combination facilitated the chance for more people to live according to a middle class, European bourgeois ideal of separate spheres for men and women, which had become prevalent in the late nineteenth century. By the postwar period these ideals had become the criteria against which normality in the arrangement of family lifestyles could be measured for all economic classes. Applying Cherlin's argument to New Zealand, where there are close 
similarities to American demographic patterns, it can be suggested that this criteria of acceptablity which has come to characterise memories of the 1950's, has overshadowed the growing diversity of lifestyles. Furthermore, this "invisible" diversity was in fact "normal" in relation to longitudinal trends, and that the "visible" criteria of order that was strongly expressed in the 1950's was in Cherlin's terms, "distinctive" or abnormal. This contradiction between ideology and reality was evident in many dimensions of family life. So for example, while women at home were being glorified as symbolic of the order of how good families should operate, they were in fact quietly taking paid employment to support the children and a family life style which women at home were supposed to be servicing full-time. However, the apparent ideological unity surrounding separate spheres for men and women was pervasive, and has in retrospect become a dominant paradigm because both men and women had vested econcmic, social and political interests in preserving its appearance. By the 1970's, the belief in this investment was neither as powerful as it had been, nor were women quite so dependent on it. The values and economic structures upon which the ideology of separate spheres was constructed were being challenged and were changing. A diversity of family life styles began to appear as inevitable, more widespread and more acceptable - although never totally acceptable.

The movement towards the recognition of New Zealand as a society with a variety of family lifestyles can be linked with the tendency of women to negotiate more independence within families, although this has been seen by some as disruptive to the assumed unity of interests of men, women and children. Yet so much has happened in terms of new educational and work opportunities, the ability of women to control their fertility more, and legislative support for women's equality, that it has often been assumed that women have gained independence. For example, after the advent of women's suffrage in the late nineteenth century, it was asserted that women had an equal voice in social and political affairs with men. Later, in the postwar years, it was asserted that women had equality in difference through separate spheres, and it was up to women to choose between a career and marriage. Then in the 1970's, it was said that women had equal rights - and it was up to women to achieve them. These assumptions, however, supressed the difficulties and conflicts surrounding the movement towards independence from, and equality with, men. There is a difference, for example, between the theoretical acquisition of rights for women during the 1970-80's, and the extent to which women could pursue them. It can be argued that by 1985 women had more choices, and the evidence for this can be measured on a generational basis as has been done in this thesis. Real choice, however, has bees differentially available to women in terms of their class and educational background, and it is probably a more useful perspective to record that today some women have fewer constraints and exclusions than previously, and that changing attitudes have made it easier for some women to make choices. The recent media myth, however, has been that all women have choices because they now have equal opportunities with men, but such assumptions do not take account of the fact that, for example, married women, and women 
with children often have to make choices which makes the pursuit of this equality impossible. As this study has shown, unless a women has superwoman qualities, or is economically privileged, it is very difficult to combine childrearing and a full-time job.

The lessening of some of the constraints surrounding women's lives during the present century has on the one hand given women more room to manoeuvre, but on the other hand the basic conflicts underlying this quest have changed little. Women who are mothers are still torn between their childrearing responsibilities in the home, and the economic dependence upon men that this entails, and between their self-identity and independence as a person in a wider world outside the home. This conflict has created feelings of ambivalence and confusion for women as they have attempted to reconcile the needs of others, as well as the needs of self, the needs of economic and emotional security with the need for self-fulfilment and independence. These basic conflicts, however, have been expressed in different ways as the context of meaning of "independence" for women has shifted. The lives of the two groups of women as mothers in this study span a forty year period. But it is relevant also to look briefly at some earlier expressions of this conflict as a means of understanding the changing views of independence for women in recent years.

The 1970's women's movement held out the idealistic promise of independence in which it was argued that women should not only have economic and sexual independence from men, but also that the bearing and rearing children should place no constraint upon selffulfilment. This was a challenge to the particular construction of femininity which located women's childbearing and rearing functions within marriage, in which the gender ranking and division of the labour was arranged around women's dependence as a homemaker and men's role as a breadwinner. This kind of order had been championed a century earlier in what Olssen and Levesque (1978) described as the new "cult of domesticity", which would bring a new order to family life based on middle class values and economic expectations. Throughout the following century this ideal for family life was strongly espoused and supported by policy makers in most Western nation states, but even during the 1950's, when the gap between the ideal and reality was the narrowest, the economic and social situations made this ideal impossible to achieve.

During the late nineteenth century the women's suffrage movement had espoused independence for women as a right to exercise an independent voice on political matters, and later the rights of girls and women to gain access to the kinds of education once available only to boys and men. Underlying this quest was the view that women would be able to achieve economic independence by way of the new professions opening up for them and that equality of education was the key to this independence. These again were middle class aspirations that sought in particular to redress the dependence of unmarried women on their families; working class women had few such choices, economic survival being the priority. During this period the view of independence which sought a voice for women in the world beyond the home, sat somewhat uncomfortably alongside the views embodied in the "cult of domesticity", which 
sought to restrict the boundaries of women's lives within the home. This conflict was partly "managed" by the distinction between married and unmarried women, in that if a woman "chose" to marry she was accepting that her primary responsibilities were towards her husband and children.

One of the important, but since much maligned, thrusts of feminism at this time was the redefinition of spinsterhood as a positive choice for women (Jeffreys 1985). These were middle class women, with independent means or professional qualification, who made such a choice, either because they wanted to pursue a way of life that would not be possible if they married, or they were lesbian and/or, because they regarded marriage as a kind of sexual slavery. Unlike later heterosexual feminists, who sought to redefine the nature of marriage itself, these women saw little possibility of men changing. In such views a conflict of interest was seen between men and women, and separation from men was seen as the only means of attaining independence. This meant that there was also a conflict of interest between women and children in the sense that having children necessitated sexual and economic dependence upon men, as there were no acceptable frameworks for unmarried women to bear and rear children. In New Zealand, for example, the Women's Christian Temperance Union (WCTU), which organised the campaign for the vote, led a crusade for social purity which demanded not only a total prohibition on alcohol, but also an end to the double standards of sexuality for men and women. The WCTU perceived male sexuality as a major problem for women, and the organisation campaigned against all forms of sexual activity except for the purposes of reproduction, because they believed that sex degraded women (Bunkle 1980:62-3). The situation for married women in this view, was somewhat ambivalent. Married women were the partners of male sexuality, although motherhood itself was viewed also as a pure state.

In the years following World War One, feminist concerns in New Zealand, Britain and America shifted towards an accommodation with the"cult of domesticity", and its glorification of motherhood. The mainstream femininst focus shifted away from explicitly seeking separation from, and independence from men, to issues such as birth control, and family support and protection. Marriage, with separate spheres for men and women, was reaffirmed strongly as the norm, and the concern was to improve the situation of women within marriage, but without challenging the gender roles embodied in separate spheres. Olive Bank's analysis of the Faces of Feminism (1981) in America and Britain termed the shift as "welfare feminism", in that it acknowledged that women were first and foremost mothers. Within this context, however, feminist activism was still radical and, for example during the 1930-40's in New Zealand, can be seen in the Sex and Hygiene Society's work to promote family planning (Fenwick 1977). This new feminist perspective did not embody the earlier ideals of sexual and/or economic independence from men, but sought to give women more autonomy within the marriage relationship. It was assumed that firstly, economic security for all women could be attained through co-option, rather than separation from men; for example, a breadwinner's 
wage was seen as crucial. as was a motherhood allowance. Secondly, there was the assumptuon that the unterests of women and men, or women and their children were synonomous and not un conflict, as was apparent in the earlier view.

The perrod for this - study from 1945 onwards - is of interest as a period of transition in that there was an attempt by women to reconcile and reformulate these earlier feminist perspectuves. One sought independence for women apart from men, but this assumed celibacy and childessness, and another sought to improve the situation for women and children within the marriage relationship. In the early postwar years, the view was that women would still have to choose between a career in the workforce or a dedication to marriage and motherhood. The reality was heavily weighted towards the latter. However, there was a growing view that married women should be allowed more independence to pursue their own interests, to work voluntarily in the community or part-time in the workforce. But by the 1970-80's the new expression of feminism in the women's movement was that childrearing and relationships with men should not be a barrier to economic independence for women, and sexuality for women should not entail dependence on men as it had usually done in the past. There was a much clearer articulation of the conflict in interests between women and men and women and children, and as Hartmann argued the family became the "locus of a struggle" (1981:368). As the constraints against some women lessened, the contradictions surrounding women's lives was more openly acknowledged. But while there was more conflict, there were also new opportunities that attempted to reconcile it. So for example if a woman "chose" to continue work during the early childrearing years, there was conflict between the interests of herself and her children. But at the same time there were more childcare options available than in the early postwar years, and less antagonism by society to those women who used childcare. The existence of childcare did not totally reconcile the conflict, but eased it and for some women made the conflict manageable. Where women chose not to reconcile the conflict, and for example, attempted to combine sexual independence and motherhood by being a single mother, they faced economic, emotional and social vulnerability. To avoid such vulnerability it was still in the interests of most women to reconcile conflict. For some women in this study, this meant reaffirming the established gender ranking and responsibilities, and from the mid 1970's new groups emerged which articulated a reformulation of more conservative views in which the interests of men and women were again deemed to be complementary rather that contradictory. For most of the women, however, the existence of conflict meant making compromises and acknowledging that women with children cannot gain total independence As Liz Heron (1986:35) has written about women in Britain during the 1980's, "The patterns of female experience at their most familiar have a common thread - that one set of satisfactions involves the loss of another, that one kind of happiness rules out another". The difference between the $1970-80$ 's and the 1940-50's would be that women in the later period theoretically have had more choice in how to determine and balance the "satisfactions". 
Economic changes have been just as potent in their affect on family lifestyles during the period of this study. The shifts for women from total dependence towards independence have been inextricably bound within an economic order which demanded a more educated and skilled workforce and which incorporated more and more working class women into the labour force. Although women still do not necessarily define themselves as breadwinners, and there is still gross inequality in the workforce between men and women, the monetary contribution of women to the family has in most cases become essential for the economic survival of the family as a unit. There is however a class difference in this incorporation. Working class women have always worked, although not necessarily visible in the formal economy, and their contribution has been an essential part of the household's survival. Middle class families, however, have had to secure more directly through the workplace the extra income to maintain their lifestyle and acquisitions. On the one hand the growing economic independence of women has revealed the emerging conflict of interest between family members, but it has also mediated the conflict because women have generally ploughed their new economic resources back into the support of the family. Such economic independence has usually been a matter of the power to influence family spending patterns, or in the potential rather than the actual independence it signifies for options outside of the family. A growing consumerism too, has altered the focus and arrangement of family life. In the time span of this study alone, the acquisition of consumer appliances to lessen the domestic load has snowballed, and the younger women were purchasing more items like ready-made food and clothing, and services such as childcare and entertainment, rather than provide these themselves as the older women tried to. In the generation before this study there was still a servant class in New Zealand to provide domestic services for some women, but this had all but disappeared by 1945 and during the early postwar years women from all economic classes provided such services for their families. Ernest Gellner has argued that the old stabilities and inequities vested in social roles are incompatible with the rapid economic changes which have accompanied the growth-orientated industrial societies, and that a consequence of the social mobility in this kind of society is "a certain kind of egalitarianism" (1983:24). From the perspective of New Zealand society one can argue that the earlier rigidity of the sexual division of labour in the workplace and in the home, has become more flexible and this has advantaged women. But by 1985 the advantages were still selective, and more flexibility had still not altered the basic arrangements and privileges of the sexual division of labour. Thus, the quest towards equality for women may have encouraged by economic changes but it has not been a hand in glove experience.

Another factor underpinning the changing aspirations of women can be seen in the shift from an ideal of self-sacrifice in women towards one of self-fulfilment. This has been linked to the growth of individualism which again undermined the assumption that the interests of all family members were synonomous. The code of self-sacrifice which had earlier made possible the appearance of synonomous interests between women and men and women and 
children, has become less potent. In a postwar era where self-fulfilment has become a more fashionable code, the conflict of interests between family members has become more visible. It has not only been that women have sought more political power, economic resources and time apart from domestic responisbilities to pursue personal fulfilment, but also, as Ehrenreich's (1983) analysis has shown, men too have sought to escape from the economic responsibilities of supporting women and children. Also in the world of childhood, the criteria for childrearing have become more complex, requiring considerably more parental input than in earlier years, and the cost of supporting children in time and money has competed with the expanding consumerism of adult lifestyles. The conflict thus operated in all contexts. The growth of individualism was accompanied by the emergence of the bourgeois family (Berger and Berger 1984), but individualism has in the past been balanced by strong codes of social and moral responsibility. The precariousness of such a balance was always present, but reconciled insofar as women were concerned by a code of self-sacrifice, which made it more possible to mediate conflict. It can be argued that the old balance is tipping towards individualism, thus altering the structures within which the bourgeois family has prospered. The growing debate and conflict over "whose responsibility are children", in the sense of the state versus the family, and more recently women versus men, are pertinent examples of the shifting balance of opinion. In New Zealand, as in other industrialised societies, the individualistic quest for self-fulfilment has also been symptomatic of a society which has, in the last fifty years, shifted from a national vision of collective security in terms of politics and family life, to one which emphasises individual opportunity often beyond local or even national interests. So for example, whereas the marriage relationship was seen in the early postwar years as providing emotional and economic security for women and children, this view was not so persuasive by the 1970's-80's. More women with children were seeking new kinds of economic safeguards, or for a few, economic and political power that were located outside of the home, although even by 1985 the security of the workplace, or the state was just as precarious as the security of the home. Women have been caught between establishing a foothold in both worlds. Another example of the shifting climate of opinion towards individualism is that the State's earlier claim that bearing children was for the good of the nation, which was still powerful during the early postwar years, has declined. Children are now something couples may choose to have for their own well-being, although ironically the State is being called to take more and more responsibility for supporting the cost and time of childrearing.

In accepting that the family has become a "locus of struggle" as family members seek more self-fulfilment, this study has sought to show how women have attempted to redefine the boundaries of their responsibilities and spheres of interest to allow this to happen. This process has revealed the conflict of interest for women with children between self -- in terms of seeking autonomy, and others -- in terms of dependence upon their men and responsibility to their children. Prior to this process of redefinition, conflict for example over "who minds the 
children" was not so evident as women accepted that all childrearing responsibilities were theirs. This study has explored the context of this redefinition for women with children within three interconnected spheres of the family - motherhood, relationships with their men and work, and over the forty year period of this study it has been possible to identify shifts in the construction of what is acceptable and possible, as women as mothers, individually in the home and collectively outside of it, have renegotiated and extended the boundaries and the criteria they use to define femininity. The findings from the sample of women in this study show again that this process has been experienced differently by both groups of women. With the older women such a redefinition was less explicit in the sense that the women saw little option and indeed often wanted to fit into a pattern in which their role was defined by separate spheres. In the early years after the World War Two it was, as Jane described, a yearning for the appearance of stability and normality that channelled the options for women. However, within such a framework these women were redefining the boundaries of femininity without challenging the ideal of separate spheres. Each of the older women slowly negotiated more independence that served to broaden their role as a married woman with children. This renegotiation and redefinition inevitably revealed new conflicts. And as Margolis (1984:271) argued, in her analysis of white middle class American women, .... the growing "disjuncture" between the ideology and the reality of women's lives during this period created the discontent which caused the later women's movement. The process of redefinintion for the younger women was somewhat different. There was by then a new collective consciousness challenging the definitions of femininity which their mothers had arranged their lives around. There was a new set of rules around which choices could be justified. Those women whose lives were still arranged around the spheres of breadwinner and homemaker felt they had to justify why they did not work, and why they did not feel oppressed. However, as this study has shown, such shifts away from the older framework were cautious and there was still a strong view that although it was advisable and/or necessary to earn, it was still the responsibility of men, or the state, to support women and their children on the occasions when earning was not possible. In all cases the women in this study depended upon this support for periods of time. It was not so much that the women were adopting a new code, although Penny came to closest to it, but that they were tentatively adapting an older code by selectively using some of the ideological rationales of the women's movement. Women, like Jane and Meg among the older women and Penny among the younger women, who all tried at times to live by a newer code had an important part in the redefinition of femininity for their respective generations. Although none could successfully match any of the new codes with the reality of their lives, each woman was able, on occasions, to push beyond the boundaries of the old codes. As Wearing (1984:204) argued in the context of her Australian study of motherhood, it was only those women who had contact with "feminist utopian ideas" who were able to construct any kind of workable 
alternative. And also, as in the case of Jane, Meg and Penny, access to to educational and/or material resources was a crucial factor in overcoming constraints.

This analysis can only be limited in its appraisal of this redefinition, in that it focusses on a very small group of women. Although these women had a wide range of experiences it is a task for future researchers to test these general ideas against more specifically selected groups of women with children: for example, an analysis of women with children who never married, or who separated, or lesbian mothers. Each of these perspectives would bring the richness of variety of experiences that this study can only begin to glimpse at. I hope, however, that this study can give some general frameworks for others to contradict or build upon. Of particular interest also would be following through the lives of the older women beyond their childrearing years. This study cuts out the years of their lives in which they were faceci with finding an identity beyond that of a mother. This was not easy. And the question that kept recurring throughout all of this analysis was - What about the men? It was hard at times to hold back from interviewing the men that these women were associated with during their childrearing years. The men were absent from the analysis, but the women talked such a lot about them. 


\section{REFERENCES FOR GRAPHICS AND CARTOONS}

Page 3

Page 54

Page 55

Page 62

Page 64

Page 69

Page 73

Page 74

Page 76

Page 85

Page 90

Page 93

Page 95

Page 96

Page 100

Page 101

Page 109

Page 115

Page 116

Page 120

Page 123

Page 124

Page 131

Page 154
My family in Oamaru in 1957.

Republished in Ebbett (1981:163).

1938 election poster. Published source unknown to author ${ }^{1}$.

Top to bottom: Advertisement used in the Woman's Weekly during the war years. Republished in Ebbett (1984:103). Common advertisement in the Woman's Weekly towards the end of the war years.

Advertisement republished in Ebbett (1984: 184).

Listener November 11946.

Top to bottom: Listener_October 23 1954; Woman's Weekly November 11 1954; Woman's Weekly November 41954.

Common advertisement in the Woman's Weekly in 1949-47.

Woman's Weekly September 51946.

The Child and his Family. Bulletin No 337, 1951. Wellington: N.Z. Department of Agriculture.

Top: Listener October 14 1955. Left to right: Listener August 8 1958; Listener January 41957.

Listener January 41946.

Source unknown.

Listener August 181944.

Woman's Weekly August 221946.

Top to bottom: Listener June 22 1945; Listener October 261945.

Common advertisment in the Woman's Weekly in the early 1950's.

Woman's Weekly May 171951.

Common advertisement in the Woman's Weekly in the late 1940's.

Listener October 101947.

Listener November 201959.

Woman's Weekly February 161959.

Listener September 111953.

Common advertisements in the Woman's Weekly throughout the late 1940's and early 1950's.

${ }^{1}$ A number of the graphics and cartoons have been passed to the author over a number of years, and it has sometimes been difficult to trace all their origins as some were not originally passed to me in connection with this work. 
Page 195

Page 197

Page 199

Page 200

Page 204

Page 206

Page 209

Page 214

Page 215

Page 219

Page 226

Page 228

Page 235

Page 244

Page 245

Page 248

Page 252

Page 253

Page 254

Page 257

Page 260

Page 261

Page 262

Page 264

Page 266

Page 268

Page 270
Cartoon by Les Gibbard, in Mitchell (1969:135).

Rosemary Seymour collection, Waikato University.

Posters reprinted in Shadbolt (1971).

1970 Simplicity sewing pattern advertised in the Woman's Weekly.

Cartoon by Paula Youens, in Lone thoughts from Abroad. London: The Women's Press Ltd, 1981.

Source unknown.

Drawing by Mary Leunig, There's no place like home. Australia: Penguin, 1982.

Cartoon by Christine Roche, source unknown.

Rosemary Seymour collection, Waikato University.

Cartoon published in Pork Roast: 250 Femininst Cartoons. (Ed) Avis Lang Rosenberg, Vancouver. UBC Fine Arts Gallery, 1981.

Rosemary Seymour collection, Waikato University.

Drawing by Vanya Lowry, in Phillips (1986:144).

Cartoon by Etta Hulme, in Pulling Our Own Strings (Ed) G. Kaufman and M. K. Blakely. Bloomington : Indian University, 1980.

Cartoon by Christine Roche, in Sourcream. (Ed) J. Nesbitt, L. Ruda, L Mackie, C. Roche, London: Sheba Femininst Publishing, 1980.

Cartoon published in Pork Roast: 250 Femininst Cartoons. (Ed) Avis Lang Rosenberg, Vancouver. UBC Fine Arts Gallery, 1981.

Drawing by Ellen Blander, in At your age having a what? by Rita Abrams, California: Whatever Publishing Inc, 1983.

Rosemary Seymour collection, Waikato University.

Source unknown.

Source unknown.

Cartoon published in Pork Roast: 250 Femininst Cartoons. (Ed) Avis Lang Rosenberg, Vancouver: UBC Fine Arts Gallery, 1981.

Drawing by Rosemary McLeod. Presumably from her articles in the Listener during the mid 1970's to the early 1980's. Have been unsuccessful in locating the original.

Source unknown

Drawing published in Women Workers in New Zealand 1977. (Ed) Mary Sinclair.Wellington: New Zealand Working Women's Council.

Source unknown.

Rosemary Seymour collection, Waikato University.

Rosemary Seymour collection, Waikato University.

Rosemary Seymour collection, Waikato University. 


\section{BIBLIOGRAPHY}

Abigail, Jill. (1983) Secondary School Influences on the Training and Career Aspirations of Girls. Wellington: Vocational Training Council.

Alcock, Peter. (1970) Eros Marooned: Ambivalence in Eden: The Family in New Zealand Literature. (Ed) S. Houston, Marriage and Family in New Zealand. Wellington: Street and Maxwell. Pp 243-275.

Althusser, Louis. (1971) Ideology and Ideological State Apparatuses. Lenin and Philosophy and other Essays. London: New Left Books. Pp. 123-173.

Anderson, Karen. (1981) War Time Women. West Point, Connecticut: Greenwood Press.

Andreski, I. (1970) Old Wives Tales. New York: Schocken Books.

Anyon, Jean. (1983) Intersections of Gender and Class: Accommodation and Resistance by Working-Class and Affluent Females to Coniradictory Sex-Role Ideologies. (Eds)

S. Walker and L. Barton, Gender Class and Education. Barcombe: Falmer. Pp. 19-37.

Ashton-Warner, Sylvia. (1963) Teacher. Harmondsworth: Penguin.

Awatere, Donna. (1980) Korero-tia-wahina ma! Broadsheet 84, pp.10-14.

Badinter, Elizabeth. (1980) Mother Love:Myth and Reality. New York: MacMillan Co. Inc.

Banks, Olive. (1981) Faces of Feminism. Martin Robertson: Oxford.

Bassett, Michael. (1972) Confrontation' 51. The 1951 Waterfront Dispute. Wellington: A.H.\& A.W. Reed.

Bernard, Jessie. (1975) Women Wives and Mothers: Values and Options. Chicago: Aldine Publishing Co.

Barnes, Hazel. (1981) Women Night Cleaners. Wellington: Department of Labour.

Barrington, Rosemary. (1982) Women's Work. (Ed) H. Haines, Women's Studies Assocation Conference Papers '81. Women's Studies Association Inc. Pp. 21-32.

Barrington, R. and Gray, A. (1981) The Smith Women. Wellington: Reed.

Barthes, Roland. (1967) Mythologies. Hertsfordshire: Paladin.

Beauchamp, Hazel. (1978) Job Selection of Re-Entry Women. (Ed) R. Seymour, Research Papers. Women's Studies Association Inc. Pp. 1-5.

Beeby, C.E. (1986) The Place of Myth in Educational Change. N.Z. Listener November 8, pp. 53-55.

Begg, Neil. (1970) The New Zealand Child and His Family. Christchurch: Whitcombe and Tombes for the New Zealand Plunket Society.

Benston, Margaret. (1969) The Political Economy of Women's Liberation. Monthly Review September, pp.13-25.

Berger, P. and Luckman, T. (1966) The Social Construction of Reality. Allen Lane: Penguin Press. 
Berger, Brigitte and Peter. (1984) The War Over the Family: Capturing the Middle Ground. London: Hutchinson.

Bett heim, Bruno. (1956) Fathers Shouldn't Try to be Mothers. Parents Magazine New York. October, pp. 126-129.

(1962) Growing Up Female. Harpers Magazine October, pp121-123.

Birch, Kate. (1984) Positive Parenting. New Zealand: Methuen.

Birmingham Feminist History Group. (1979) Feminism as Femininity in the 1950's. Feminist Review No.3, pp. 48-65.

Boston Women's Health Collective. (1979 rev ed) Our Bodies Ourselves. New York: Simon and Schuster.

Boulton, M. G. (1983) On Being a Mother. London: Tavistock Publishing.

Bourdieu, Pierre. (1974) The School as a Conservative Force. Scholastic and Cultural Inequality. (Ed) J. Eggleston, Contemporary Research in the Sociology of Education. London: Methuen. Pp. 110-117.

(1977) Outline of a Theory of Practice. Cambridge: Cambridge University Press.

Bourguignon, Erika. (1980) A World of Women: Anthropological Studies of Women in Societies of the World. Praeger: New York.

Bowlby, John. (1952) Maternal Health and Mental Health. Geneva: World Health Organisation Monograph.

Bowles, G. and Klein, D. (1983) Theories of Women's Studies. London: Routledge and Kegan Paul.

Brazer-Rush, Andrea. (1982) What's in a "Kiwi" Dad? Parents Centre Bulletin 192, pp9-11.

Brew, Helen. (1954) Maternal Care and the Family. Parents Centre Bulletin Vol. 3, No. 7, p.7.

Brookes, B. MacDonald, C. and Tennant, M. (eds) (1986) Women in History. Essays on European Women in New Zealand. Wellington: Allen and Unwin - Port Nicholson.

Brookes, Barbara. (1986) Reproductive Rights. (Eds) B. Brookes et al, Women in History. Essays on European Women in New Zealand. Wellington: Allen and Unwin Port Nicholson. Pp. 119-136.

Brown, Helen. (1981) Don't Let Me Put You Off. How to Survive in New Zealand Suburbia. New Zealand: Whitcoulls.

(1983) Confessions of a Bride Doll. Wellington: A.H. and A.W. Reed.

Bryant, Anita (1976) Bless This House. New York: Bantam Books.

Bunkle, Phillida. (1979-80) A History of the Women's Movement.

Broadsheet. September 1979, pp. 24-28; October 1979, pp. 26-28; November 1979, pp.26-28; December 1979, pp. 28-32; January/February 1980, pp. 30-35. 
Bunkle, Phillida. (1980) Origins of the Women's Movement in New Zealand. The Women's Christian Temperance Union 1885-1895. (Eds) P. Bunkle and B. Hughes Women in New Zealand Society. Auckland: Allen and Unwin. Pp. 52-76.

Bunkle, P. and Hughes, B. (eds) (1980) Women in New Zealand Society. Auckland: Allen and Unwin.

Burke, E. (1958) Children of the Employed Mother. Unpublished M.A. Thesis Canterbury College, University of New Zealand.

Calvert, Sarah. (1979) Women and Mental Health in New Zealand (abstract). (Ed) R. Seymour, Women's Studies Association Research Papers '78. Women's Studies Association Inc. P. 97.

(1982) Healthy Women. Auckland: New Women's Press.

Cameron, J. Mudrovich, J. Shadbolt, T. (eds) (1980) In Defense of Children. Martinborough: Alister Taylor.

Campbell, G. (1982) Women in the Workforce. N.Z. Listener May 22, pp. 11-12, 22.

Carlson, E. ( 1974) Autobiographies of Three Pamo Women. Berkeley Archeological Research Facilities, Department of Anthropology, University of California.

Cameron, Jan. (1984) Teenagers and Sexuality. (Ed) P. Ramsey, Family School and Commuity. Sydney: George Allen and Unwin. Pp. 288-298.

Cass, Bettina. (1982) Family Policies in Australia. Social Welfare Research Centre, University of New South Wales. Reports and Proceedings No. 21.

Chapple, Geoff. (1980), Rewi Alley of China. New Zealand: Hodder and Stoughton.

Chapman, Robert. (1953) Fiction and the Social Pattern. Landfall Vol.7, No. 1, pp. 26-58.

(1981) From Labour to National. (Ed) W.H. Oliver, The Oxford History of New Zealand. Oxford University Press. Pp. 333-368.

Cherlin, Andrew. (1983) Changing Family and Household: Contemporary Lessons from Historical Research. Annual Review of Sociology Vol. 9, 1983, pp. 51-56.

Chetwynd, J. Calvert, S. and Ross, V. (1985) Caring and Coping: Life for Mothers of Intellectually Handicapped Children. N. Z. Women's Studies Journal Vol. 1, No. 2, pp. 7-20.

Chetwynd, J. and Fenwick, P. (1977) Guilt and Sex Role Expectations. Paper presented to N.Z. Sociologial Conference. Christchurch.

Christchurch City Council. (1976) Report of the Steering Committee on a Bill of Rights for Children.

Chodorow, Nancy. (1978) The Reproduction of Mothering: Psychoanalysis and Sociology of Gender. Berkeley: University of California Press.

Church, John. (1978) How to Get Out of Your Marriage Alive. Christchurch: J. Church.

Clarke, Alison. (1986) Part Time Work in New Zealand. Wellington: N. Z. Planning Council.

Clarke, A. and Clarke A.D.B. (1976) Early Experience: Myth and Reality. London: Open Books. 
Clark, Margaret. (ed) (1986) Beyond Expectations. New Zealand: Allen and Unwin - Port Nicholson.

Clements, Kevin. (1981) Politics. (Eds) P. Spoonley, D. Pearson, I. Shirley, New Zealand Sociological Perspectives. Palmerson North: Dunmore. Pp. 143-168.

Cleveland, Les. (1972) Anatomy of Influence: Pressure Groups and Politics in New Zealand. Wellington: Hick Smith and Sons.

(1979) The Politics of Utopia. New Zealand: Methuen.

Cole, Christine. (1960) Trouble in the Maternity Wards. N.Z. Parent and Child January/February, pp. 12-15.

Colgan, A. and McGregor, J. (1981) Sexual Secrets. Martinborough: Alister Taylor.

Comfort, A. (1972) The Joy of Sex: A Cordon Bleu Guide to Lovemaking. New York: Crown.

Committee on Women, (1976) Repor: of the Conference on Women in Social and Economic Development. Wellington.

Coney, Sandra. (1986) Every Girl: A Social History of Women and the YWCA in Auckland. Auckland: YWCA.

Conran, Shirley. (1977, NZ edition) Superwoman in Action. Harmondsworth: Penguin Books.

Cook, Enid. (1945) Towards Readjustment: The Woman's Part. Christchurch: Lighthouse Series No. 4.

(1946) The Psychology of Childbirth. (Publisher unknown).

Cook, Frank. (undated) Ex-Servicemen Talk it Over. Christchurch: Lighthouse Series No. 7.

Cook, Helen May. (1983) The Politics of Childcare: An Analysis of Growth and Constraint. Unpublished M.A. Thesis, Victoria University Wellington.

(1984) Childcare Workers' (Under)paid as Surrogate Mothers. N.Z. Women's Studies Journal Vol.1, No.1, pp. 26-35.

(1985a) Images, Illusions of Harmony: the 1950's Wife and Mother. N.Z. Women's Studies Journal Vol. 1, No. 2, pp. 86-92.

(1985b) The Art of Marriage as Career for the 1950's. N.Z. Women's Studies Journal Vol. 2, No. 1, pp. 50-67.

(1985c) The Contradiction of Postwar Reconstruction: The Aspirations and Realities of a Postwar Generation of Wives and Mothers. (Ed) C. Philipson,Women's Studies Association Conference Papers '84. Women's Studies Association Inc. Pp. 46-76.

(1985d) Mind That Child. Childcare as a Political and Social Issue in New Zealand. BlackBerry Press.

(1986) The "Lady Juggler": Workers, Wives, Mothers and Managers: A 1950's View of Women and Work. (Ed) C. Philipson, Women's Studies Association Conference Papers 1985. Women's Studies Association Inc. Pp. 1-27.

Council for the Single Mother and her Child. (1978 ed) Everything a Single Parent Needs to Know. Auckland. 
Crowther, D. M. (ed) (1957) Street Society in Christchurch. Psychology Department, Canterbury University College.

Cumberland, K. (1970) To the North to the Cities. New Zealand in the Sixties. N.Z. Listener January 9, p. 10.

Dally, Ann. (1982) Inventing Motherhood: The Consequences of an Ideal. London: Burkett Books Ltd.

Daly-Peoples, Linda. (1977) The Politics of Childbirth: The Characteristics of Institutionalised Childbirth. Broadsheet April, pp. 14-17.

Dann, Christine. (1985a) From the Myth of the Vaginal Orgasm to the Myth of Self Sufficient Sexuality: The Beginnings of a Critique of Modern Theories of Female Sexuality. (Ed) C. Phillipson, Women's Studies Association Conference Papers ' 84.. Women's Studies Association Inc. Pp. 77-95.

(1985b) Up From Under. Women and Liberation in New Zealand 1970-1985. New Zealand: Allen and Unwin - Port Nicholson Press.

Davey, J. and Koopman-Boyden, P. (1983) Issues in Equity. Wellington: N.Z. Planning
Council.

Davidson, Paul. (1985) Marriage in Crisis. Wellington: Mallinson Rendel Publishing Co. Davies, Sonja. (1984) Bread and Roses. Australia and New Zealand Book Co. Pty. Ltd. with
Fraser Books.

Deem, H. and Fitzgibbon, N. $(1948,1953)$ Modern Motherhood. Dunedin: Royal New Zealand Society for the Health of Women and Children Inc.

Deem, Rosemary. (1978) Women and Schooling. London: Routledge and Kegan Paul.

Densom, Ailsa. (1980) The Playcentre Way. Auckland: N.Z. Playcentre Federation.

Department of Education. (1947) Report of the Consultative Committee on Preschool Education. (Bailey Report) Wellington.

(1962) Report of the Commission on Education in New Zealand. (Currie (1971) Report of the Committee of Inquiry on Pre-School Education. (Hill
Report) Wellington. (1975) Report of the Conference on Education and the Equality of the Sexes.
Wellington.

(1977) Growing Sharing and Learning. The Report of the Committee on Health and Social Education. (Johnson Report) Wellington.

(1980) The Promotion of Women in the Primary Teaching Service. Wellington.

(1984) Attendance at Preschool. Wellington.

(1985) The Position of Women in Education. Wellington.

Department of Health. (1955a) Sex and the Adolescent Girl. Wellington.

(1955b) Sex and the Adolescent Boy. Wellington. 
Department of Justice (1987) Report of the Committee of Inquiry into Violence. (Roper Report). Wellington.

Department of Labour (1980) Women in the Workforce: Facts and Figures. Wellington.

Department of Social Welfare. (1972) Report on Child Abuse. Wellington.

(1977) Report of the Domestic Purposes Review Committee. Wellington.

(1977) Policy Statement on Childcare to the International Labour Organisation.

Department of Statistics. (1977) Social Trends in New Zealand. Wellington.

(1978) Report on Family Statistics in New Zealand. Wellington.

(1986) Demographic Trends. Wellington.

Dick-Read, Grantley. (1947) Revelations of Natural Childbirth. London: Heinemann.

Dominy, Michelle. (1985) Gender Complementarity, Aging and Repsoduction among New Zealand Pakeha Women. (Eds) Dorothy, and D. R Counts, Aging and Its Transformation: Moving Towards Death in Pacific Societies. A.S.A. Mongraph 10. New York: University Press of America. Pp. 47-62.

Donley, Joan. (1986) Save the Midwife. Auckland: New Women's Press.

Donnelly, Felix. (1977) Big Boys Don't Cry. Auckland: Cassell.

Dowrick, S. and Grundberg, S. (1980) Why Children? London: The Women's Press Ltd.

Driver, S. and Robinson, D. (1986) Voluntary Social Services: A Review of Funding. Wellington: N.Z. Planning Council Paper No. 28.

Duckworth, Marilyn. (1984) Disorderly Conduct. Auckland: Hodder and Stoughton.

duFresne, Karl. (1979) Power to the Children. N.Z. Listener June 30, p. 15.

Dumont, Louis. (1986) Essays on Individualism: Modern Ideology in Anthropological Perspective. University of Chicago Press.

Dunstall, S. (1981) The Social Pattern. (Ed) W.H. Oliver,Oxford History of New Zealand. Wellington: Oxford University Press. Pp. 369-429.

Dworkin, Andrea. (1983) Right Wing Women:Politics of the Domesticated Female. London: The Women's Press Ltd.

Dwyer, Marie. (1980) Women on the Dole. Broadsheet June, pp. 22-23.

Easton, Brian. (1972) The Mothers Benefit. Paper presented to the National Conference of Parents Centres.

(1979) The Family Costs of Children. Paper presented to the Annual Conference of the New Zealand Demographic Society.

(1980) Social Policy and the Welfare State. Auckland: George Allen and Unwin.

Ebbett, Eve. (1981) Victoria's Daughters: New Zealand Women of the Thirties. Wellington: A. H. and A. W. Reed.

(1984) When the Boys Were Away: New Zealand Women in World War Two. Wellington: A. H. and A. W. Reed. 
Edmond, Lauris (ed) (1986) Women in Wartime: New Zealand Women Tell their Story. Wellington: N. Z. Government Printing Office.

Ehrenreich, Barbara. (1983) The Hearts of Men. London: Pluto Press.

Eisenstein, Zillah. (1981) The Radical Future of Liberal Feminism. New York: Longman.

(1982) The Sexual Politics of the New Right: Understanding the "Crisis of Liberalism" for the 1980's. (Eds) N. Keohane, M. Z. Rosaldo, B. C. Gelpi, Feminist Theory: A Critique of Ideology. Chicago: Harvester. Pp. 77-112.

Else, Anne.(1979) Can Marriage Survive Feminism? Broadsheet May, pp. 18-20. (1986) Edmonds Cookery and Bernadine. N.Z. Women's Studies Journal Vol. 2,
No. 2, 70-78.

Elley, W. and Irving, J. (1977) Socio-Economic Index of the Female Labour Force in New Zealand. N.Z. Journal of Educational Studies. Vol. 12, No. 2, pp. 154-163.

Erikson, Erik H. (1950) Childhood and Society. Harmondsworth: Penguin.

Fenwick, Penny. (1977) N.Z. Family Planning Association, its Growth and Development.
Unpublished M.A. Thesis, University of Canterbury.

(1980) Fertility Sexuality and Social Control. (Eds) P. Bunkle, and B. Hughes, Women in New Zealand Society. Auckland: George Allen and Unwin. Pp. 77-98.

Finch, Janet. (1983) Married to the Job: Wives Incorporation in Men's Work. London: George
Allen and Unwin.

Findlay, Mary. (1974) Tooth and Nail. Wellington: A. H. and A. W. Reed.

Firestone, Shulamith. (1971) The Dialectic of Sex. London: Paladin. Fletcher, Garth. (1978) Division of Labour in the New Zealand Nuclear Family. N.Z.
Psychologist Vol. 7, No. 2. November, pp. 33-40. Fletcher, R.M. (1949) Women in the N.Z. Labour Force, Unpublished M.A. Thesis. Victoria
University College of New Zealand.

Foucault, M. (ed) (1978) Pierre Riviére, having slaughtered my mother, my sister and my
brother... Harmondsworth: Penguin.

Frame, Janet.(1958) Owls Do Cry. Christchurch: Pegasus.

(1983) To the Is-land. The Women's Press: Hutchinson Group NZ Ltd.

(1984) An Angel on my Table. New Zealand: Hutchinson.

Freire, Paulo. (1972) Pedagogy of the Oppressed. Harmondsworth: Penguin.

Friedan, Betty. (1963) The Feminine Mystique. Harmondsworth: Penguin.

Friedl, Ernestine. (1975) Women and Men: An Anthropological View. New York: Holt
Reinhart and Winston.

Fry, Ruth. (1985) It's Different for Daughters. Wellington: N.Z. Council for Educational
Research.

Gamble W.A. (1952) Caravan Colony. N.Z. Listener January 17, pp. 12-13. 
Game, A. and Pringle, R. (1979) Sexuality and the Suburban Dream. Australia and New Zealand Journal of Sociology Vol. 15, No. 2, pp. 4-15.

Gardiner, Jean. (1976) Political Economy of Domestic Labour in Capitalist Society. (Eds) D. Berber and S. Allen, Dependence and Exploitation in Work and Marriage. London: Longman. Pp. 109-120.

Geddis, D.C. (ed) (1979) Child Abuse: Report of National Symposium. Auckland: National Children's Health Foundation.

Gee, Maurice. (1977) Our Mabel. Wellington: Millwood Press.

Geiringer Eric. (1978) Spuc Em All: Abortion Politics '78. Martinborough: Alister Taylor.

Gellner, Ernest. (1983)Nations and Nationalism. England: Basil Blackwell.

(1987) Culture, Identity and Politics. Cambridge: Cambridge University Press.

Giddens, Anthony. (1979) Central Problems in Social Theory: Action, Structure and Contradiction in Social Analysis. London: MacMillan.

Gidlow, Bob. (1982) Deviance. (Eds) P. Spoonley, D. Pearson, I. Shirley, New Zealand Sociological Perspectives. Palmerston North: Dunmore. Pp. 325-352.

Gilling, M.L. (1985) Parenting: Concept and Praxis. Unpublished Ph.D. Thesis, Monash University.

Gillespie, Christine. (1980), The Road Ahead for the Women's Movement. (Eds) P. Bunkle and B. Hughes, Women in New Zealand Society. Auckland: George Allen and Unwin. Pp. 99-117.

Gluck, Shema. (1977) What's So Special About Women? Women's Oral History. Frontiers: A Journal of Women's Studies Vol. 11, No. 2. Special Issue on Women's Oral History. (Pages unknown.)

Goodger, Kay. (1974) A Strategy for Women's Liberation. Auckland: Pilot Books.

Gordon, Doris. (1955) Back-Blocks Baby Doctor. London: Faber and Faber.

(1957) Doctor Down Under. London: Faber and Faber.

Gottleib, David. (1973) Children's Liberation. Englewood Cliffs, New Jersey Prentice-Hall Inc.

Grant, David. (1986) Out in the Cold. Pacifists and Conscientious Objectors in New Zealand During World War Two. Auckland: Reed-Methuen.

Gray, Alison, (1979) The Marriage Maze. Whatamongo Bay: Cape Catley Ltd.

(1984) The Jones Men. Wellington: A.H. and A.W Reed.

(1985) Expressions of Sexuality. Auckland: Reed-Methuen.

Greer, Germaine. (1971) The Female Eunuch. London: Paladin.

Gribbens, Trish. (1979) Pyjamas Don't Matter. Auckland: Heinemann Educational Books.

Griffen, A. and Griffen, B. (1985) Women Hunters: The Implications for Pleistocene Prehistory and Contemporary Ethnography. (Ed) M.J. Goodman, Women in Asic and the Pacific: Towards an East West Dialogue. University of Hawaii Foundation. Pp. 61-81. 
Guy, Christina. (1943) Women on the Home Front. Wellington: Progressive Publishing
Company.

Hadfield, Claire. (1981) Childcare in Newtown: A Study of Working Mothers and their Families. Occasional Papers, Sociology and Social Work No. 3, Victoria
University, Wellington.

Haines, Hillary. (1987) Mental Health for Women. Auckland: Reed - Methuen.

Hall, Leslie. M. (1958) Women and Men in New Zealand. Landfall 45, pp. 47-57. Hancock, Mary. (1981) It just Doesn't Seem to Matter What Happens to Women. Wellington:
Working Women's Council.

(1983) Invisible Workers: Women, Redundancy and Unemployment. (Ed) H. Haines, Women's Studies Association Conference Papers '82. Women's Studies
Association Inc. Pp. 38-47.

Hansen, S. and Jensen, J. (1972) The Little Red School Book. Wellington: Alister Taylor.

Hardyment, Christina. (1983) Dream Babies: Childcare From Locke to Spock. London:
Johnathon Cape.

Harper, J. and Richards, L. (1979) Mothers and Working Mothers. Harmondsworth - Penguin
Books.

Hartmann, Heidi. (1981) The Family as the Locus of Gender, Class, and Political Struggle: The Example of Housework. Signs Vol. 6, No. 3. Spring, pp. 366-394. Hartmann, Susan. (1982) American Women in the 1940's: the Home Front and Beyond.
Boston: Twayne Publishers.

Havighurst, G. (1953) Human Development and Education. New York: Longman's Green. Hayman, M and Roberts, B. (1983) Mothers, Homemakers and Paid Workers. Some Issues in
Childcare and Women's Employment. Paper presented to the N.Z.A.R.E
. Conference Christchurch. . Conference Christchurch. Haworth, R. M. (1975) Social Class and Feminine Role in New Zealand Women's Magazines.
Unpublished M.A. Thesis, University of Otago. Hercus, C.E. (1940) Women and National Survival. Canterbury University, Wilding Memorial
Lecture, Christchurch: Whitcombe and Tombes Ltd.

Heron, Liz. (ed) (1985) Truth, Dare or Promise: Girls Growing up in the Fifties. London:
Virago. (1986) Changes of Heart: Reflections on Women's Independence. London and
New York: Pandora.

Hill, Roberta. (1979) Capitalist Crisis and the Reserve Army of Labour. Unpublished M.A.
Thesis,University of Canterbury.

Hite, Sheer. (1976) The Hite Report: a Nationwide Study on Female Sexuality. New York:
Macmillan.

Holland, Norah. (1950), Some Aspects of Homemaking. Unpublished Master of Home Science Thesis, Otago University College.

Holt, John. (1965) How Children Fail. Harmondsworth: Penguin.. 
Holt, Barbara. (1982). Women in Public Administration. (Ed) H. Haines, Women's Studies Conference Papers '81. Women's Studies Association Inc. Pp. 49-54.

Hughes, Beryl. (1981) Early Professional Women. (Ed) R. Seymour, Women's Studies Association Conference Papers '80. Women's Studies Association Inc. Pp. 1-5.

Houston, S. (ed), (1970) Marriage and Family in New Zealand. Wellington: Street and Maxwell.

Hyde, Robyn. (1938, repub 1986) Nor the Years Condemn. Auckland: New Women's Classics.

Hyman, P. J. and Clark, C. (1987) Equal Pay Study: Phase One Report. Wellington: Department of Labour.

Illich, Ivan. (1971) Deschooling Society. London: Calder and Bayers.

Ingham, Mary. (1981) Now We are Thirty. London: Methuen.

(1984) Men The Male Myth Exposed. London: Century Publishing.

Isaacs, Susan. (no date) The Psychological Aspects of Child Development. University of London Institute of Education.

Jagger, A. and Struhl, S. (1978) Feminist Frameworks. New York: McGraw-Hill Book Co.

Jeffries, Sheila. (1985). The Spinster and Her Enemies. London: Pandora Press.

Johnson, Leslie (no date) The Teenage Girl. The Social Definition of Growing up for Young Australian Women 1950-65. Unpublished Paper, University of Melbourne.

Jones, A. (1975) A Hard Won Freedon: Alternative Communities in New Zealand. Auckland: Hodder and Stoughton.

Jones, Alison (1985) Which Girls are "leaming to Lose"? Gender, Class, and Race in the Classroom. N.Z. Women's Studies Journal Vol. 2. No. 1, pp.15-27.

Joyce, P. and Rosier, P. (1985). Motherhood: Hating it and Loving it. Broadsheet December, pp. 18-23.

Kaledin, Eugenia. (1984) American Women in the 50's: Mothers and More. Boston: Twayne Publishers.

Kane, M.A. (1972) A Study of Equal Pay in New Zealand. A study of changing attitudes towards women and the associated part played by the Public Service Association in the acquisition of equal pay. Unpublished M.A. Thesis, University of Auckland.

Kedgley, Susan. (1971). What 1971 Meant to Me. N.Z. Listener December 27, p. 12.

(1985) The Sexual Wilderness. Auckland: Reed-Methuen.

Kedgley, S. and Cederman, S. (1972) Sexist Society. Wellington: Alister Taylor.

Kessler, Evelyn. (1976) Women: An Anthropological View. New York: Holt, Reinhart Winston.

Kidman, Fiona. (1979) A Breed of Women. Melbourne: Sun Books.

(1981) Mandarin Summer. Auckland: Heinemann.

(1982) Paddy's Puzzle. Auckland: Heinemann. 
Kinsey, A. et al. (1948) Sexual Behaviour in the Human Male. Indiana University, Philadelphia: Saunders.

Kinsey, A. et al. (1953) Sexual Behaviour and the Human Female. Indiana University, Philadelphia: Saunders.

Kitzinger, Sheila. (1978) Women as Mothers. London: Fontana - Collins.

Klein, Duelia. (1983) How to do what we want to do: thoughts about feminist methodology. (Eds) G, Bowles. and D, Klein. Theories of Women's Studies. London: Routledge and Kegan Paul. Pp. 88-104.

Koedt, Anne. (1973) The Myth of the Vaginal Orgasm. (Ed) A. Koedt, E. Levine, A. Rapone. Radical Feminism. New York: Quadrangle Books. Pp198-207.

Koopman- Boyden, P. (ed) (1978) Families in New Zealand Society. Wellington: Methuen.

Koopman-Boyden P. and Scott, C. (1984) The Family and Government Policy in New Zealand. Sydney: George Allen and Unwin.

Kuhn, A. and Wolpe, A (1978) Feminism and Materialism: Women and Modes of Production. London: Routledge and Kegan Paul.

Laing, R.D. (1967) The Politics of Experience. Harmondsworth: Penguin. Laing, R.D. and Esteren, A. (1964) Sanity, Madness and the Family. Harmondsworth:
Penguin. Langness, L. and Frank, G. (1981) Lives: An Anthropological Approach to Biography. Novata
California: Chandler and Sharp Publishers. La Rossa, M. and La Rossa, R. (1981) Transition to Parenthood. How Infants Change
Families. Beverly Hills: Sage Publication.

Lazarre, Jane. (1976) The Mother Knot. McGraw Hall: New York.

Leach, Edmund. (1967a) A Runaway World. The Reith Lectures. Oxford University Press. (1967b) The Structural Study of Myth and Totemism. A.S.A. Monographs,
London: Tavistock Publications.

Lee, M. (1949) Are You Hoping For a House? Here and Now November, pp. 8-10.

Lévesque, Andrée. (1986) Prescribers and Rebels: Attitudes to European Women's Sexuality in New Zealand 1869-1916. (Eds) D. Brookes, C. MacDonald, M. Tennant, Women in History: Essays on European Women in New Zealand. New Zealand: Allen
and Unwin - Port Nicholson. Pp. 1-12.

Lévi-Strauss, Claude. (1968) Structural Anthropology. London: Allen Lane. List, D. and Taylor, A. (1975) The Second New Zealand Whole Earth Catalogue.
Martinborough: Alister Taylor.

Locke, Elsie. (1981) Student at the Gate. Christchurch: Whitcoulls.

Mahar, Cheleen, (1984) Government Housing Policy: The Impact on Consumers. (Eds) C.Wilkes, I. Shirley, In the Public Interest. Auckland: Benton Ross. Pp. 254-
279.

Maharey, Steve and Maggie. (1979) Childless by Choice. N.Z. Listener November 10, pp. 9-
10. 
Maharey, S. (1985) Filling the Hole: An Approach to Cultural Studies. Sites Issue 10, Autumn, pp. 44-59.

Malcolm, Margaret. (1978) The Almost Invisible Woman. N.Z. Council of Educational Research, Set 78, No. 2.

Manning, A. E. (1958) The Bodgie: A Study on Abnormal Psychology. Wellington: A.H. \& A.W. Reed.

Marcus, G. and Cushman, D. (1982) Ethnographies as Texts. Annual Review of Anthropology Vol. 11, pp. 25-69.

Margolis, Maxine. (1984) Mothers and Such. Berkley: University of California Press.

Mason, Diana. (1986) The Force of Life. (Ed) Margaret Clark, Beyond Expectations. New Zealand: Allen and Unwin - Port Nicholson Press. Pp. 31-36.

Masters, W and Johnson, V. (1966) Human Sexual Response. Boston: Little Brown.

Matthews, Jill Julius. (1984) Good and Mad Women. The Historical Construction of Femininity in Twentieth Century Australia. Sydney: George Allen and Unwin.

Marcuse, H. (1961) Eros and Civilization: A Philosophical Inquiry into Freud. New York: Vintage Books.

May (Cook), Helen. (1988) Motherhood in the Fifties: An Experience of Contradiction. (Ed) S. Middleton, Women, and Education in Aotearoa. New Zealand: Allen and Unwin Port Nicholson. Pp. 57-71.

McCauley, Sue. (1982) Other Halves. Auckland: Hodder and Stoughton.

McDonald, Dugald. (1978) Children and Young Persons. (Ed) P. Koopman-Boyden, Families in New Zealand Society. Methuen. Pp. 44-56.

McDonald, Geraldine. (1974) Educational Innovation: the Case of the New Zealand Playcentre. N.Z. Journal of Educational Studies Vol. 9, No. 2, pp 153-165.

(1977) Maternal Deprivation: Fact or Fallacy. N.Z. Council of Educational Research Set 77, Item 3.

(1978) The Politics of Childcare. (Ed) R. Seymour, Research Papers '78. Women's Studies Association Inc. Pp. 70-75.

McGraw, David. (1981) Reluctant Ally: New Zealand's Entry into the Vietnam War. N.Z. Journal of History Vol. 15, No. 1. April, pp. 49-60.

McLauchlan, Gordon. (1976) The Passionless People. New Zealanders in the 1970's. New Zealand: Cassell.

McLeod, John. (1986) Myth and Reality: New Zealand Soldier in World War Two. Auckland: Reed-Methuen.

McLeod, Rosemary. (1978) A Girl Like I. Dunedin: J McIndoe.

McKinlay, Robin. (1981) Madonnas or Heroes? A Reappraisal of the Mythic Models of Motherhood. Mothers. Wellington: The Women's Gallery. Pp. 22-26.

(1983) Mothers, Where Would We Be Without Them? Motherhood and Self Definition in New Zealand. Unpublished PH.D Thesis, Victoria University. 
MacCormack, C. Strathern, M. (1980) Nature and Culture and Gender. Gmbridge: Cambridge University Press.

Mead, Margaret. (1950) Male and Female: A Study of the Sexes in a Changing World. Harmondsworth: Penguin.

(1951) Of Myths and Men. N.Z. Listener August 31, p. 7.

(1959) Job of the Children's Mother's Husband. New York Times Magazine May 10, pp. 7-9.

Meade, A. Rosemergy, M. Johnston, R. (1985) The Effects of Children on Family Style. N.Z.Women's Studies Journal Vol. 1, No. 2, pp. 21-34.

Mein Smith, Philippa. (1986) Maternity in Dispute. Wellington: Government Printer.

Michaels, Joanne. (1982) Living Contradictions, Women of the Baby Boom Coming of Age. New York: Simon and Schuster.

Middleton, Sue. (1985a) Feminism and Education in Post-War New Zealand: An Oral History Approach. Draft Paper for publication in Perspectives in the History of New Zealand Education. (Eds) D. McKenzie and R. Openshaw, Wellington: N.Z.C.E.R.

(1985b), Feminism and Education in Postwar New Zealand: A Sociological Analysis. Unpublished Ph.D Thesis, Waikato University.

Ministry of Housing. (1957) Home Ownership - How to Achieve it.Wellington.

Millet, Kate.(1970) Sexual Politics. Garden City, New York: Doubleday.

Mitchell, Austin. (1969) The Half Gallon Quarter Acre Pavlova Paradise. Christchurch: Whitcombe and Tombes Ltd.

Mitchell, Juliet. (1971) Women's Estate. Harmondsworth: Penguin.

Moorsom, Sasha. (1976) Children and a Job. How Women Manage Both. Education Vol. 25, No. 1, pp. 16-17.

Morgan, Marabel. (1973) The Total Woman. London: Hodder and Stoughton.

Morris, Beverley. (1971) The Isolated Housewife. N.Z. Listener February 22, pp. 8-9.

Munroe, D. H. (1955) Juvenile Delinquency and Divorce. Landfall Vol. 9, No. 1, pp. 76-82.

Munroe, J. F. (1977) New Zealand at the Crisis Point. Private Publication.

Nash, Walter. (1943) New Zealand A Working Democracy. London: J. M. Dent and Sons Ltd.

National Advisory Committee on the Employment of Women (1969) A Study of the Education of Girls in New Zealand. Wellington.

National Council of Women. (1974) What Price Equality? Women and Work in New Zealand. Wellington.

(1985) Women and Change. A Study of New Zealand Women. Wellington.

National Organisation of Women (1975) M.P.'s Attitudes to Women's Issues. Wellington: Herstory Press.

Neal, Sue. (1981) Motherhood and Feminism. Broadsheet December, pp. 11-12. 
Newman, Katherine. (1986) Symbolic Dialects and Generations of Women: Variations in the Meaning of Post-Divorce Downward Mobility. American Ethnologist Vol. 13, No. 2, May, pp. 230-251.

New Zealand Army (1943a) Our Population Problem. N.Z. Army Current Affairs Bulletin vol. 1, No. 1.

(1943b) Women and the War. N.Z. Army Current Affairs Bulletin Vol. 1, No. 15 .

New Zealand Federation of University Women. (1968) Women at Work. Wellington Branch.

(1976) Women at Home.

New Zealand Government. (1954) Report on Moral Delinquency in Children and Adolescents. (Mazengarb Report) Wellington: Government Printer.

(1971) Commission of Inquiry into Housing. Wellington: Government Printer.

(1971) Royal Commission of Inquiry into Equal Pay. Wellington: Government Printer.

(1972) Report of the Royal Commission of Inquiry into Social Security. Wellington: Government Printer.

(1975) Report of the Select Committee on Women's Rights: The Role of Women in New Zealand Society. Wellington: Government Printer.

New Zealand Labour Party (1981) Getting New Zealand Working Again. 1981 Manifesto.

New Zealand National Party. 1978 General Election Policy. We Are Keeping Our Word.

This is Your Future. 1981 Election Manifesto.

New Zealand Organsiation of National Development. (1944) Interim Report on Postwar Reconstruction and National Development.

New Zealand Planning Council. (1977) A Moment of Truth. Wellington.

(1978) Planning Perpectives 1978-1983. Wellington.

(1979) The Welfare State? Social Policy in the 1980's. Wellington.

(1981) Directions. Wellington.

New Zealand Rehabilitation Department. (1945) Training for a Job. Wellington.

New Zealand Values Party. (1972) Blueprint for New Zealand; An Alternative Future.

(1975) Beyond Tomorrow.

(1978) Critical Issues.

Novitz, Rosemary. (1976) The Priority of the Mother Role: An Investigation of the Importance Women Give to their Role as Mothers and its Relationship to their Employment Behaviour. Unpublished M.A. Thesis, Canterbury University.

(1979) Male Dominance - The Polemic in Anthropology. (Ed) R. Seymour, Women's Studies Association Research Papers '79. Women's Studies Association Inc. Pp. 1-13. 
(1982) Feminism. (Eds) P. Spoonley, D. Pearson, I Shirley, New Zealand Sociological Perspectives. Palmerston North: Dunmore Pp. 293-324.

(1984) Domestic Labour and the Informal Economy. (Unpublished Paper).

Norton, M. B. (1979) The Paradox of "Women's Sphere". (Eds) C. R. Berkin and M. B. Norton, Women of America: A History. Boston: Houghton, Mifflin Co. Pp. 139-149.

Oakes, Les. (1986) Inside Centrepoint. Auckland: Benton Ross Publishers.

Oakley, Ann. (1974) The Sociology of Housework. London: Robertson

(1979) Becoming a Mother. London: Martin Robertson and Co. Ltd.

(1981) Interviewing Women: A Contradiction in Terms. (Ed) H. Roberts, Doing Feminist Research. London: Routledge and Kegan Paul. Pp. 30-61.

O'Brien, Denise. (1984) "Women Never Hunt": The Portrayal of Women in Melanesian Ethnography. (Eds) D. O'Brien and S. Tiffany, Rethinking Women's Roles. University of California Press. Pp. 53-70.

O'Brien, Mary. (1981) The Politics of Reproduction. London: Routledge and Kegan Paul.

O'Donnell, Lydia. (1985) The Unheralded Majority: Contemporary Women as Mothers. New York: Lexington Books.

Oliver, W.H. (1981) The Awakening Imagination. (Ed) W.H. Oliver, The Oxford History of New Zealand. Wellington: Oxford University Press. Pp. 430-462.

(1983) James K Baxter: A Portrait. Wellington: The Port Nicholson Press.

Olssen, E. and Lévseque, A. (1978) Towards a History of the European Family in New Zealand. (Ed) P. Koopman-Boyden, Families in New Zealand Society. Wellington: Methuen. Pp. 1-26.

Ohu Advisory Committee. (1975) Alternative Life Style Communities. Wellington: Government Printer.

O'Neill, C. James. (1980) Changing Trends in New Zealand Family Life: Fact and Myth. Hamilton: Population Studies Centre, University of Waikato.

O'Neill, C. J. and Warwick-Neville, R.J. (eds) (1979) The Population of New Zealand: Interdisciplinary Perspectives. Auckland: Longman Paul.

Openshaw, Roger. (1983) Saving Femininity From the Feminists. Some Underlying Values of a New Zealand Back to Basics Pressure group. Discourse Vol. 4, No. 1, pp.32-
48 .

O'Rourke, B. and Clough, J. (1978) Early Childhood in New Zealand. New Zealand: Heineman Educational Books.

O'Rourke, Maris. (1981) Quality Childcare. Unity and Diversity. Address to the N.Z. Childcare Association Annual Conference, Auckland.

Ortner, S.B. and Whitehead, H. (eds) (1981) Sexual Meanings: The Cultural Construction of Gender. Cambridge University Press. 
Park, Julic. (1982) Doing Well: An Ethnology of Coping. Working Papers in Anthropology, Archeology, Linguistics and Maori Studies. University of Auckland, Department of Anthropology.

Paske, Helen. (1978) Wives Out of Work. N.Z. Listener April 22, pp. 16-19.

Parsons, T. and Bales, R.F. (1955) The Family:Socialization and Interaction Process. New York: Free Press.

Payne, Karen. (ed) (1983) Between Ourselves: Letters Between Mothers and Daughters. Boston: Houghton Mifflin Co.

Pearson, Bill. (1952) Frefful Sleepers: a Sketch of New Zealand Behaviour and its Implications for the Artist. Landfall Vol. 6, No. 3, pp. 201-230.

Penman, R. and Stolk, Y. (1983) Not the Marrying Kind. Harmondsworth: Penguin Books.

Phillips, Jenny. (1983) Mother s Matter Too. Wellington: A.H. and A. W. Reed.

(1986) The Mother Manual. Wellington: A.H. and A. W. Reed.

Phillips, Jock. (1980) Pakeha Men as Mummy's Boys, (Eds) P. Bunkle and B. Hughes, Women in New Zealand Society. Auckland: George Allen and Unwin. Pp. 217243.

(1987) A Man's Country? The Images of the Pakeha Male. Auckland: Penguin Books.

Phillips, Roderick. (1981) Divorce in New Zealand. A Social History. Auckland: Oxford University Press.

Phillipson, Irene. (1982). Narcissism and Mothering: the 1950's Reconsidered. Women's Studies International Forum Vol. 5, No. 1, pp. 29-39.

Phipps, Grace (1955) Marriage With Eve. Wellington: A. H. and A. W. Reed.

(1956) The Women in the Family. Wellington: A.H. and A.W. Reed.

Place, Helen. (1981) Women and Management. Takapuna: Motivation Inc.

Plummer, K. (1983) Documents of Life. London: Allen and Unwin.

Pool, I. and Sceats, J. (1981) Fertility and Family Formation. Waikato University - Ministry of Works and Development.

Pryor, Marilyn. (1985) A Funny Thing Happened on the Way to the 1984 Forum. Private Publication.

Ramsay, Peter. (ed) (1975) The Family and the School in New Zealand Society. Melbourne: Pitman.

Ray, Pauline. (1978) Child Abuse:the Tangled Web. N.Z. Listener June 3, pp. 8-11.

Reich, Wilhelm. (1962) The Sexual Revolution. New York: Noon Day Press.

Reiner, Everett. (1971) The School is Dead. Harmondsworth: Penguin Educational Specials. 
Reinharz, Sheila. (1979) On Becoming a Social Scientist. San Fransisco: Jossey-Bass.

(1983) Experiential Analysis: A Contribution to Feminist Rescarch. (Eds) G. Bowles and D. Klein, Theories of Women's Studies. London: Routledge and Kegan Paul. Pp. 162-191.

Reiter, Rayna. (ed) (1975) Towards an Anthropology of Women. New York: Monthly Review Press.

Rendall, Duilia. (1987) Childcare Activism in the Seventies. Childcare Quarterly Vol.7, No.2, pp. 22-31.

Report of the Taskforce on Economic and Social Planning. (1976) New Zealand at the Turning Point. Wellington.

Rich, Adrienne. (1977) Of Women Born. New York: Barton Paperbacks.

(1980) Compulsory Heterosexuality and Lesbian Existence. Signs Vol. 5, No. 4, pp. 631-660.

Riley, Denise. (1983) War in the Nursery. London: Virago.

Ritchie, Jane and James. (1970) Childrearing Patterns in New Zealand. London: Allen and Unwin.

(1978) Growing Up in New Zealand. Auckland: Allen and Unwin.

(1981) Spare the Rod. Sydney: George Allen and Unwin.

Ritchie, Jane. (1979) Childrearing Patterns: Further Studies. (Ed) R. Seymour,Women's Studies Research Papers '79. Women's Studies Association Inc. Pp. 117-125.

Ritchie, Helen. (1982) Women and Regional Government. (Ed) H. Haines, Women's Studies Assocation Conference Papers. '81. Women's Studies Association Inc. Pp. 191-
192.

Roberts, John. (1987), Interview on Morning Report National Radio Network. April 311987.

Rogers, Maggie. (1982) Where do All the Children Go? An Investigation into the School Holiday Problem. University of Auckland.

Rohrlich-Leavitt, R. (ed) (1975) Women Cross Culturally: Change and Challenge. The Hague: Paris: Mouton Publishers.

Rosak, Theodore (1972) The Making of a Counter Culture. London: Faber and Faber.

Rosaldo, M. Z. and Lamphere, L (eds) (1974) Women, Culture and Society. Stanford: Stanford University Press.

Rosaldo, M. Z. (1974) Society and Culture:a Theoretical Overview. (Eds) M. Z, Rosaldo and L, Lamphere, Women, Culture and Society. Stanford: Stanford University Press.
Pp. 17-42.

Roth, Margot. (1980) New Zealand Family: Cornerstone of Colonization. Unpublished M.A. Thesis, University of Auckland.

Royal New Zealand Society for the Health of Women and Children Inc. (1974) Submission to the Select Committee on Women's Rights.

Rowbotham, Sheila. (1973) Women's Consciousness, Man's World. Harmondsworth: Penguin. 
Rubin, Nancy. (1982) The New Suburban Woman. Beyond Myth and Motherhood. New York: Coward, McCann and Geoghegan.

(1984) The Mother Mirror. New York: G.P. Putnam's Sons.

Rubin, Gayle. (1975) The Traffic in Women: Notes on the "Political Economy" of Sex. (Ed) R. Reiter, Towards and Anthropology of Women. New York: Monthly Review Press. Pp. 157-210.

Rutter, Michael. (1972) Maternal Deprivation Reasessed. Harmondsworth: Penguin.

Ryan, Allanah. (1984) Constructing Stable Happy Families: Contraception, Sterilization and Abortion in New Zealand. Draft copy for,Working Papers on the State Vol. 2, Massey University.

Salmond, Ann. (1976) Amiria: The Life Story of a Maori Woman. Wellington: Reed.

(1980) Eruera: The Teachings of a Maori Elder. Wellington: Oxford University Press.

Saphira, Miriam. (1981) The Sexual Abuse of Children. Auckland: Miriam Saphira.

(1984) Amazon Mothers. Auckland: Papers Inc.

Sarr, Patricia. (1981) Think Big: Less than Nothing for Women. Witches Bitches and Dykes November.(Pages unknown)

Schafly, Phyliss. (1977) The Power of the Positive Woman. New Rochelle, New York: Arlington House Publishers.

Schlegel, Alice (ed). (1977) Sexual Stratification. New York: Columbia University Press.

Scott, Mary. (1944) Life With Barbara. Wellington: A.H. and A. W. Reed.

Scott, Tom. (1977) Tom Scott's Life and Times. Dunedin: J. McIndoe.

Second New Zealand Expeditionary Force Education Rehabilitation Service. (1944) Serviceman to Civilian.

Sedgewick, Charles. (1983) The Life History Method: a Method with Issues, Troubles and a Future. Department of Sociology, University of Canterbury.

Segal, Lyn. (1983) What's to be Done About the Family? Crisis in the Eighties. Harmondsworth: Penguin.

Seymour, Rosemary. (1977) The Myth of the Male Breadwinner. Submission to the Cabinet Committee on Family Affairs.

Shadbolt, Tim. (1971) Bullshit and Jellybeans. Wellington: Alister Taylor Publishing.

Shallcrass, Jack. (1980) Kid's Rights. N.Z. Listener, February 14, p. 18.

Sheehy, Gail. (1977) Passages. Toronto: Bantam.

Sheridan, M. and Saloff, D. (eds) (1984) Lives. Bloomington: Indiana University Press.

Shipley, Susan. (1983) Women's Employment and Unemployment: A Research Report. Department of Sociology, Massey University.

(1984) Doing Feminist Research: its Politics and Practice. (Ed) H. Haines, Women's Studies Association Conference Papers '84. Women's Studies Association Inc. Pp. 15-20. 
Shostak, Marjorie. (1981) Nisa: The Life and Words of a !Kung Woman. Cambridge Massachussets: Harvard University Press.

Shuker, Roy. (1983) Security in Equality. The Utopian Impulse and New Zealand Society, N.Z. Cultural Studies Working Group Journal No. 7. Spring, pp. 17-27.

Simpson, Tony. (1974) The Sugar Bag Years. Wellington: Alister Taylor Publishing.

(1976) The Road to Erewhon. Auckland: Beaux Arts Ltd.

Sinclair, Keith.(1959) A History of New Zealand. Harmondsworth: Penguin.

Sissons, Linda. (1982) Women's Studies Programmes. (Ed) H. Haines, Women's Studies Conference Papers '81. Women's Studies Association Inc. Pp. 121-128.

Social Advisory Council. (1985) Childcare Services; Impact and Opportunities. Wellington.

Social Development Council. (1977a) Housework and Caring Work - Can Men Do Better? Wellington.

(1977b) Bringing up Children - Can We Do Better?Wellington.

(1978-9) Families in Special Circumstances Report Series. Wellington.

(1980) Families and Violence. Wellington.

(1981) Families First. Aspects of Family Policy. Wellington.

Society for Research on Women. (1970) The Unmarried Mother. Problems Involved in Keeping her Baby. Lower Hutt Wellington, National Publications Committee.

(1972 rev 1981) Urban Women. Wellington.

(1973) Employers Attitudes: Work and Opportunities for Women. Wellington.

(1974) Retraining: Some Facts and Assessments of the Problem of Women ReEntering the Labour Market. Wellington.

(1975) Solo Mothers. Christchurch Branch with Angela Sears.

(1981) Women and Money: A Study of Financial Management in New Zealand Households. Johnsonville-SROW inc.

(1984) Jobs, Chores and Women. Christchurch Branch-SROW inc.

(1985) Bibliograpy 1966-1983. Wellington: SROW Inc.

Spender, Dale. (1981) Men's Studies Modified: the Impact of Feminism on the Academic Desiplines. Oxford: Pergamon Press.

Spender, D. and Sarah, E. (eds) (1980) Learning to Lose: Sexism and Education. London: The Women's Press.

Spock, Benjamin. (1946) The Commonsense Book of Baby and Child Care. New York: Duell, Sloan and Pearce.

Spoonley, P. Pearson, D. and Shirley, I. (eds) (1982) New Zealand Sociological Perspectives. Palmerston North: Dunmore.

Spring-Rice, Marjery. (1939 repub 1981) Working Class Wives. London: Virago.

Squire, Jillian. (1954) Family Daze. Wellington: A.H. and A.W. Reed. 
Stanley, L and Wise, S. (1983) Breaking Out: Feminist Consciousness and Feminist Research. London: Routledge and Kegan Paul.

State Services Commission Report on Early Childhood Care and Education (1980). Wellington: Government Printer.

Statements by the Prime Minister and the Leader of the Opposition on Compulsory Military Training. (1949) Wellington.

Steadman, Carolyn. (1986) Landscape for a Good Woman: A Story of Two Lives. London: Virago.

Strathern, Marilyn. (1981) Culture in a Netbag: The Manufacture of a Sub-discipline in Anthropology. Man Vol.16, No. 4. December, pp. 665-688.

Sutch, W.B. (1966) The Quest for Security in New Zealand 1840-1966. Wellington: Oxford University Press.

(1973) Women With a Cause. Wellington: Price Milburn.

Swain, David. (1980) New Zealand is Great Place for Kids and Other Myths. Parents Centre Bulletin 81, pp. 7-10.

(1983) Families Changing: Changing Families. 1983 Third Early Childhood Convention Papers. Pp. 124-137.

(1984) Nitpicking and Heresy. (Ed) P. Ramsey, Family, School and Community. Sydney: George Allen and Unwin. Pp. 28-47.

Tapp, Pauline. (1982) Domestic Violence: The Domestic Protection Bill 1982. Auckland Legal Research Foundation.

Taylor, Alister. (1972) First New Zealand Whole Earth Catalogue. Wellington: Alister Taylor.

Taylor, Nan. (1986) The People at War: The Home Front. (Volumes One and Two) Wellington: Government Publishing.

Tennant, Margaret. (1984) "Brazen Faced Beggars and the Female Sex": Women in the Charitable Aid System in the Late Nineteenth Century. (Ed) H. Haines, Women's Studies Conference Papers '83. Women's Studies Association Inc. Pp. 32-41.

(1985) Maternity and Morality: Homes for Single Mothers 1890-1930. N.Z. Women's Studies Journal Vol. 2, No. 1, pp. 28-49.

Thompson, Julie. (1977) Marriage for Women, Not a Healthy Business. Women and Health Conference, Wellington: Comittee on Women.

Vocational Training Council. (1977) Women Back to Work. Wellington: Women's Advisory Committee.

Vosborough, (Gilson) Miriam. (1978) The New Zealand Family and Social Change: A Trend Analysis. Occasional Papers in Sociology and Social Work No. 1. Victoria University.

Waring, Marilyn. (1978) What's Been Done. Wellington: Committee on Women.

Wearing, Betsy. (1984) The Ideology of Motherhood. Sydney: George Allen and Unwin.

Weeks, Jeffrey. (1985) Sexuality and its Discontents. London: Routledge and Kegan Paul. 
Westcott, M. (1979) Feminist Criticism in the Social Sciences. Harvard Educational Review Vol. 49, No. 4.

Women's Electoral Lobby. (1978) A New Look: A W.E.L. View of Somes Changes for New Zealand. Wellington: Women's Electoral Lobby.

Winnicott. D.W. (1949) The Ordinary Devoted Mother and Her Baby. London: Published by Author.

Winship, Janice. (1978) A Woman's World: "Woman" an Ideology of Femininity. Women Take Issue. Birmingham Centre for Research in Cultural Studies / Hutchinson and Co. Pp. 134-154.

(1981) Woman Becomes an "Individual" - Femininity and Consumption in Women's Magazines 1954-69. Birmingham Centre for Contemporary Cultural Studies. Occasional Paper. Women Series: SP. No. 65.

Wilson, Elizabeth. (1977) Women and the Welfare State. London: Tavistock Publications.

(1981) Only Halfway to Paradise. London: Tavistock Publications.

Wilson, Margaret. (1986) Report of the Status of Academic Women in New Zealand. Wellington: Association of University Teachers.

Whitcombe, Judy. (1980) The Promotion of Women in the Primary Teaching Service. Wellington: Department of Education.

White, Helen. (1985) Roles for Women in New Zealand Drama. (Ed) C. Philipson, Women's Studies Association Conference Papers '84. Women's Studies Association Inc. Pp. 259-271.

Women's Division of Federated Farmers. (1976) The Rural Women of New Zealand: A National Survey 1975. University of Canterbury.

Working Women's Council. (1978) The Working Women's Charter.

Working Women's Council Inc. (no date) Why the Working Women's Council is a Dangerous Document.

(no date) Why You Must Say NO to the Working Women's Charter.

Wright-Mills, C. (1959) The Sociological Imagination. New York: Oxford University Press.

Wylie, Cathy. (1980) Factors Affecting the Participation in the Workforce of Female Heads of One Parent Families. Wellington: Department of Social Welfare.

Young, Michael. (1983) Our name is woman, we are bought with limetsicks and limepots: an analysis of the autobiographical narrative of a Kalauna woman. Man Vol. 18, No. 3, pp. 478-501. 



\section{REFERENCE ONLY}

NOT TO BE REMOVED FROM LIBRARY

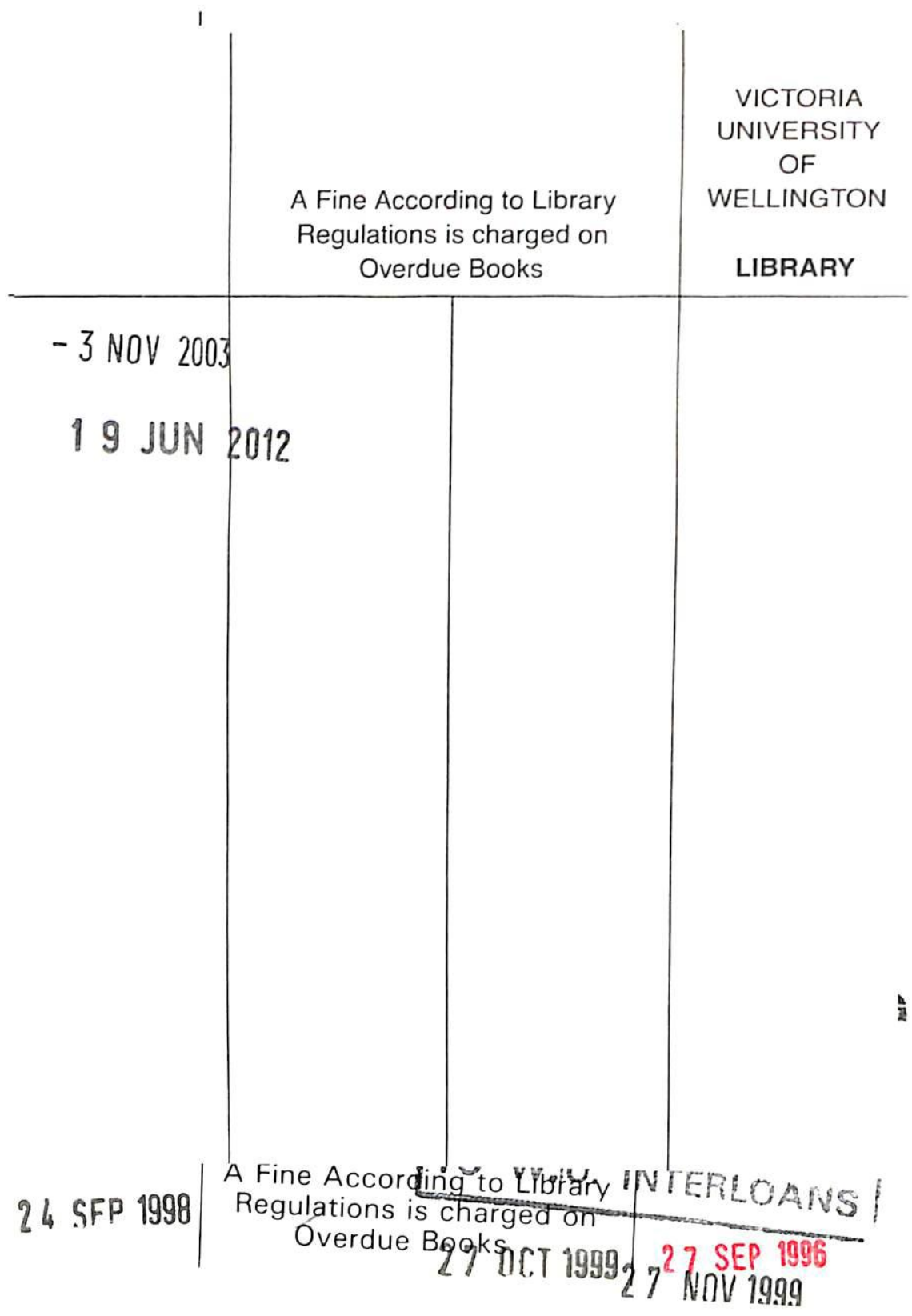

is 
h

AS 741

VUW

PhD

TAnt

6
May, Helen

Postwar women 1945-1960 and

their daughters

1970-1985 


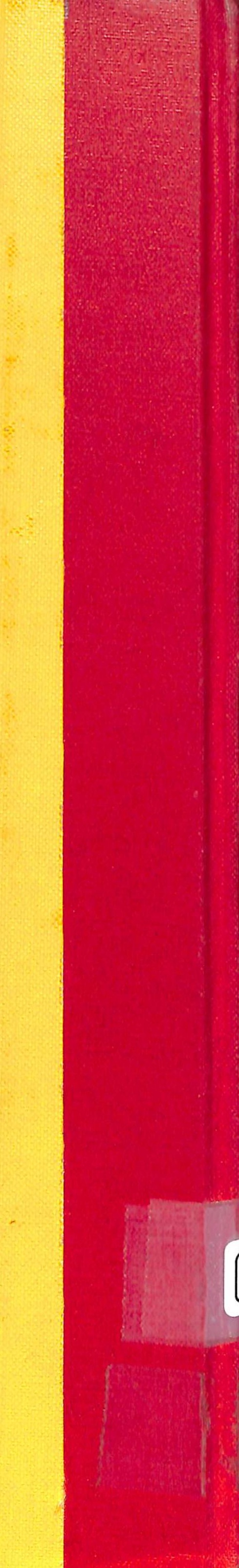

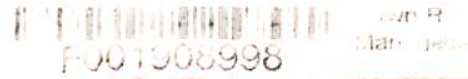

